\title{
PENSAMIENTO SOCIAL ESPAÑOL SOBRE AMÉRICA LATINA
}

\section{Juan Jesús Morales Martín}

(Editor)

Francisco Ayala | José Medina Echavarría Juan Francisco Marsal | Ignacio Sotelo Manuel Lizcano | Juan Maestre Alfonso José Luis Rubio | Joan Garcés Manuel Castells | Xabier Gorostiaga Ignacio Ellacuría | Pedro Casaldáliga Jon Sobrino | Manuel Alcántara Ludolfo Paramio | Marisa Revilla Blanco Juan Carlos Monedero | Enrique V. Iglesias Marcos Roitman | Jesús Martín Barbero

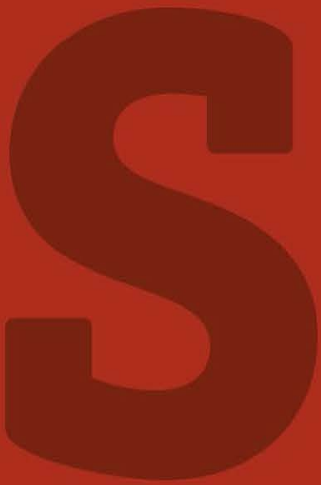




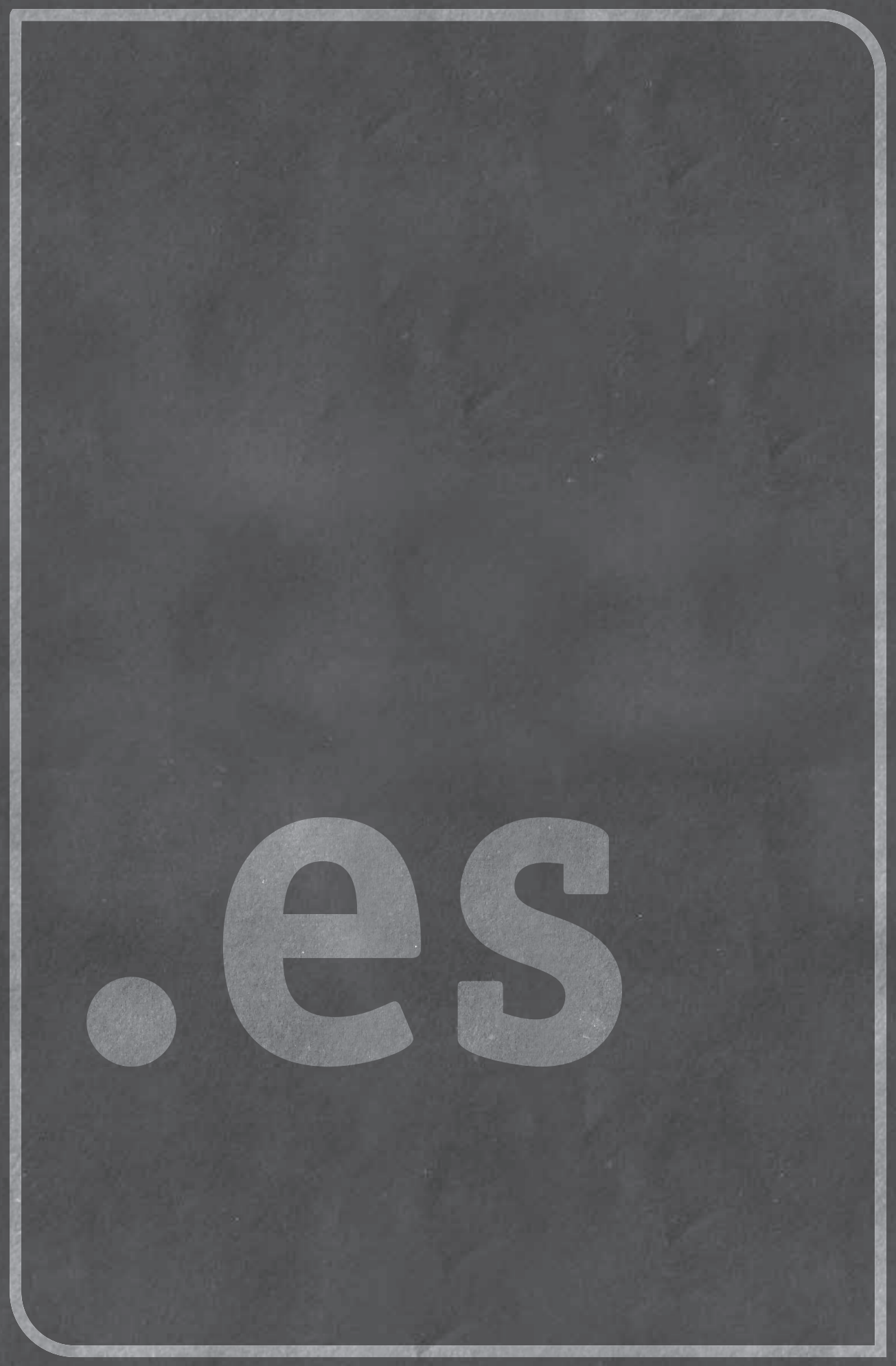


5 


\section{Pensamiento social}

español sobre

América Latina

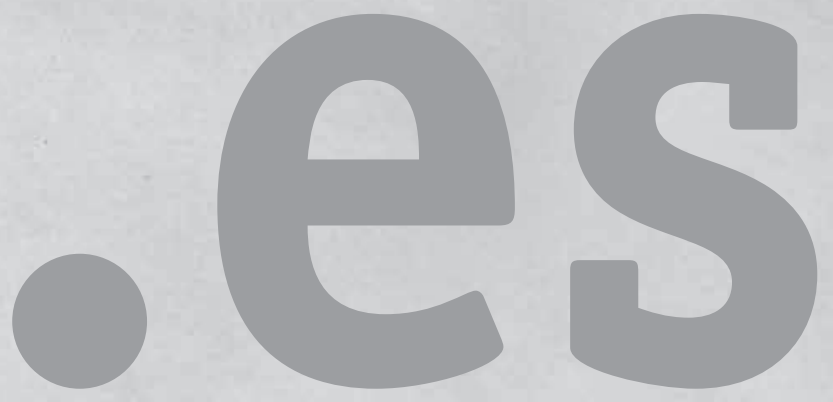


Pensamiento social español sobre América Latina / Juan Jesús Morales Martín... [et al.]; compilado por Juan Jesús Morales Martín - 1a ed. - Ciudad Autónoma de Buenos Aires: CLACSO, 2017. Libro digital, PDF

Archivo Digital: descarga y online ISBN 978-987-722-241-8

1. Pensamiento Social. 2. Exilio. 3. Emigración. I. Morales Martín, Juan Jesús II. Morales Martín, Juan Jesús, comp. $\operatorname{CDD} 304.8$

Otros descriptores asignados por CLACSO:

Pensamiento Social / Pensamiento Contemporáneo / Pensamiento Crítico / América Latina / España 


\section{Pensamiento social español sobre América Latina}

\section{Editor}

\section{Juan Jesús Morales Martín}

Francisco Ayala | José Medina Echavarría Juan Francisco Marsal | Ignacio Sotelo | Manuel Lizcano Juan Maestre Alfonso | José Luis Rubio | Joan Garcés Manuel Castells | Xabier Gorostiaga | Ignacio Ellacuría Pedro Casaldáliga | Jon Sobrino | Manuel Alcántara Ludolfo Paramio | Marisa Revilla Blanco Juan Carlos Monedero | Enrique V. Iglesias Marcos Roitman | Jesús Martín Barbero

Colección Antologías del Pensamiento Social Latinoamericano y Caribeño Serie Miradas Lejanas 


\section{CLACSO 50 AÑOS}

Consejo Latinoamericano de Ciencias Sociales

\section{Antologías del Pensamiento Social Latinoamericano y Caribeño \\ Serie Miradas Lejanas}

Dirección de la Colección Pablo Gentili

Coordinación Editorial Fernanda Saforcada y Lucas Sablich

Diseño de Colección Marcelo Giardino

Producción Santiago Basso

\section{Primera edición}

Pensamiento social español sobre América Latina (Buenos Aires: CLACSO, mayo de 2017)

ISBN 978-987-722-241-8

(C) Consejo Latinoamericano de Ciencias Sociales

Queda hecho el depósito que establece la Ley 11.723.

\section{CLACSO}

Consejo Latinoamericano de Ciencias Sociales - Conselho Latino-americano de Ciências Sociais Estados Unidos 1168 I C1101AAX Ciudad de Buenos Aires, Argentina

Tel. [54 11] 43049145 I Fax [54 11] 43050875 I <clacsoinst@clacso.edu.ar> I <www.clacso.org>

Patrocinado por la Agencia Sueca de Desarrollo Internacional

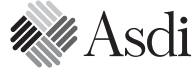

Este libro está disponible en texto completo en la Red de Bibliotecas Virtuales de CLACSO www.biblioteca.clacso.edu.ar

No se permite la reproducción total o parcial de este libro, ni su almacenamiento en un sistema informático, ni su transmisión en cualquier forma o por cualquier medio electrónico, mecánico, fotocopia u otros métodos, sin el permiso previo del editor. 


\section{ÍNDICE}

Juan Jesús Morales Martín

Cruces y contrapuntos: A modo de Introducción

\section{LOS SOCIÓLOGOS DEL EXILIO Y DE LA EMIGRACIÓN}

\section{Francisco Ayala}

La integración social en Indoamérica

(en La integración social en América, 1958)

José Medina Echavarría

Las relaciones entre las instituciones sociales y las económicas.

Un modelo teórico para América Latina

(en Boletín Económico de América Latina, 1961)

\section{Juan Francisco Marsal}

La sociología en América Latina. Algunas características

de la literatura sobre cambio social

(en Revista Latinoamericana de Sociología, 1966)

\section{Ignacio Sotelo}

Marginalidad y dependencia (en Sociología de América Latina, 1975) ～～ 101 


\section{PENSANDO BAJO EL FRANQUISMO}

\section{Manuel Lizcano}

Sociología del cambio estructural y metodología analéctica

(en La estructura social de Iberoamérica y España, 1965)

\section{Juan Maestre Alfonso}

La revolución del 20 de octubre

(en Guatemala: subdesarrollo y violencia, 1969)

\section{José Luis Rubio}

La destrucción de las causas últimas: la sociedad autogestionada

(en Aproximación a la revolución peruana, 1974)

\section{SABER Y POLÍTICA EN LOS LABORATORIOS SOCIALES LATINOAMERICANOS}

\section{Joan Garcés}

Estado burgués y gobierno popular (en Chile: el camino

político hacia el socialismo, 1972)

Manuel Castells

Para leer este libro con los puños cerrados

(en La lucha de clases en Chile, 1974)

\section{Xabier Gorostiaga}

Los dilemas de la revolución sandinista a tres años del triunfo

(en Revista Envío, 1982)

\section{LA OPCIÓN POR LOS POBRES Y LA TEOLOGÍA DE LA LIBERACIÓN}

\section{Ignacio Ellacuría}

La teología de la liberación frente al cambio sociohistórico

de América Latina (en Revista Latinoamericana de Teología, 1987)

\section{Pedro Casaldáliga}

Opción por los pobres, inculturación y comunitaridad

(en Iglesia Viva: Revista de Pensamiento Cristiano, 1992)

Jon Sobrino

¿Qué queda de la teología de la liberación? (en Éxodo, 1997) 


\section{DE LAS TRANSICIONES DEMOCRÁTICAS A LAS NUEVAS EXPERIENCIAS POLÍTICAS}

\section{Manuel Alcántara}

De la democracia en América Latina al comenzar el siglo XXI

(en Quórum: Revista de Pensamiento Iberoamericano, 2003)

\section{Ludolfo Paramio}

La izquierda en América Latina (en Quórum: Revista de Pensamiento

Iberoamericano, 2008)

\section{Marisa Revilla Blanco}

América Latina y los movimientos sociales: el presente de la rebelión del coro (en Nueva Sociedad, 2010)

\section{Juan Carlos Monedero}

Democracia y Estado en América Latina: por una imprudente reinvención de la política (en Documentos de Política, 2011)

\section{CAMINOS DE IDA Y VUELTA}

\section{Enrique V. Iglesias}

El papel del Estado y los paradigmas económicos en

América Latina (en Revista de la CEPAL, 2006)

\section{Marcos Roitman}

Las maldiciones de pensar América Latina (en Pensar América

Latina. El desarrollo de la sociología latinoamericana, 2008)

\section{Jesús Martín Barbero}

Pensar la comunicación en Latinoamérica (en Redes.com:

Revista de Estudios para el Desarrollo Social de la Comunicación, 2014)

Sobre los autores 



\title{
CRUCES Y CONTRAPUNTOS: A MODO DE INTRODUCCIÓN
}

\author{
Juan Jesús Morales Martín
}

LA ANTOLOGÍA Pensamiento social español sobre América Latina tiene el objetivo principal de acercar al público académico y general la rica y diversa tradición de ideas, autores y escuelas españolas que han pensado América Latina y que, también, han influido en el propio desarrollo de las ciencias sociales latinoamericanas como impactaron, igualmente, en los ámbitos académico, cultural y político de uno y otro lado del Atlántico. Pues el desarrollo de las ciencias sociales, tanto en España como en América Latina, ha seguido historias con bastantes entrecruzamientos, algunos elementos comunes y con importantes redes intelectuales de intercambio que han establecido un contrapunto dialéctico. Pues si las circunstancias y la gestación de la propia idea de ciencias sociales y de "sociología latinoamericana" fueron fundadas como tal a mediados del siglo XX como un campo de investigación regional y como un proceso endógeno de producción de ideas, de categorías y de teorías, no solo tiene un valor anecdótico el señalar, entonces, la particular participación de pensadores españoles en ese movimiento. Por tal motivo, ese interés sobresaliente por América Latina lo concebimos en este volumen como un puente tendido entre dos orillas y como un diálogo franco y plural.

Además, muchos de esos cruces y contrapuntos estuvieron motivados por experiencias traumáticas como los exilios y las migraciones 
cuyos efectos, en un plano intelectual, hacen del todo problemático pensar en un pensamiento social español enfocado a América Latina puramente homogéneo. Pues muchos de los autores recogidos en esta antología padecieron el exilio o vivieron la migración en América Latina, insertándose en sus países y, por tanto, pensando la región, sus desafíos y problemas desde dentro de su objeto de estudio. En todo caso, y más allá de esa cuestión epistemológica fundamental, la selección de textos de esta antología está enfocada desde la historia intelectual, la historia de las ciencias sociales y la sociología histórica para así relacionar la evolución del pensamiento social español sobre y desde América Latina con la propia historia política de España y de América Latina. Además se ha seguido un criterio representativo y multigeneracional para abarcar diferentes períodos y, sobre todo, atender grandes líneas temáticas como la modernización, la integración, el subdesarrollo económico, la dependencia, la democracia o las nuevas experiencias políticas latinoamericanas ${ }^{1}$.

Escribir, como decíamos, sobre el pensamiento social español dedicado a América Latina es escribir teniendo como obligada referencia la particular historia de las ciencias sociales españolas. Por tal motivo, tendremos en cuenta sus quiebres y sus rupturas, siendo la Guerra Civil el más importante hecho histórico del siglo XX español, por sus duraderas consecuencias económicas, sociales y políticas, que condicionaron, sin duda alguna, la posterior institucionalización y profesionalización de las disciplinas sociales (Lamo de Espinosa, 1990; Morente, 2000; Rodríguez Ibáñez, 2004)². Además las repercusiones biográficas e intelectuales de esta contienda bélica, como fueron los exilios, las migraciones o el pensar bajo el franquismo, condicionaron la trayectoria de varios autores de este volumen. Pero no solamente queremos fijarnos en los traumas y en las discordias, sino que también, desde una narrativa abierta, pretendemos ofrecer una línea de continuidad del pensamiento español dedicado a América Latina (Ribes, 2011). Ello tiene que ver con los constantes y prolonga-

1 Ha sido complicado, sin embargo, encontrar el nombre de mujeres que, desde la sociología o desde ciencias sociales afines, hayan abordado el estudio sistemático de América Latina. En todo caso reconocemos aquí a mujeres como Enriqueta Vila Vilar, Ascensión Martínez Riaza, Manuela Mesa Peinado, Anna Ayuso, Esther del Campo, Nieves Pinillos Iglesias o la recientemente fallecida Carmen Ninou, quienes han investigado y estudiado seriamente la realidad latinoamericana desde disciplinas como la historia, la educación, el derecho internacional, las migraciones o las relaciones internacionales.

2 Para tener un panorama más completo sobre la historia de la sociología española véase Del Campo (2001), Giner y Moreno (1990), y el volumen colectivo de Política y Sociedad sobre la sociología española posterior a la Guerra Civil (2004, Vol. 41, n 2). 
dos intercambios intelectuales y profesionales entre una y otra orilla del Atlántico, motivados, la mayoría de las veces, por sus variadas y ricas redes académicas, científicas y universitarias de colaboración, con sus asociaciones, programas de becas, congresos, seminarios y publicaciones. Pero también es producto de la importante circulación de autores y de ideas a partir de libros, revistas y editoriales, como de la labor de otros medios de comunicación y otros canales de cooperación, ligados a partidos políticos, sindicatos, instituciones religiosas, fundaciones filantrópicas, organizaciones no gubernamentales, u organismos internacionales y regionales.

Hay además, por supuesto, otros elementos claves para explicar la fijación por América Latina desde el pensamiento social español como fueron la solidaridad de sus países a la hora de recibir a los exiliados republicanos y a los migrantes políticos; la posibilidad de los científicos sociales de intervenir en sus laboratorios sociales y experimentar importantes procesos históricos de cambio social; y, más recientemente por ejemplo, las oportunidades profesionales que conceden estos países a numerosas científicas y científicos sociales que se ven obligados a emigrar. Sea por condicionantes históricos, inclinaciones políticas, crisis económicas o motivos personales, es evidente, como se puede percibir, que América Latina ha ocupado históricamente en el imaginario del pensamiento social español un lugar privilegiado. Son consecuencias y productos relativos, claro está, de un diálogo continuo, constante y de largo aliento, y de una movilidad permanente que han generado consecuentemente un espacio común de posibilidades y una tradición compartida de inquietudes y de reflexiones. Además, podemos decir hoy día, que este interés por América Latina alude ya a cuestiones propias de la identidad de las ciencias sociales y de sus practicantes, por lo menos para los pensadores españoles que, gracias a sus experiencias biográficas, intelectuales, profesionales y políticas en América Latina, se han "latinoamericanizado" y miran con menos prejuicios y con menos inclinaciones intuitivas la realidad social de esta región, a sus gentes y a sus procesos económicos, sociales y políticos (Morales, 2009). La "cuestión latinoamericana" en el pensamiento social español no solo se debe, por tanto, a la institucionalización de los estudios latinoamericanos en España, sino que mucho antes fue deudora de aprendizajes y experiencias vividas en primera persona.

Muchos de los textos aquí seleccionados están surcados, justamente, por los modos personales y biográficos que tuvieron sus autores de acercarse y aproximarse a América Latina, a su sociología, a sus ciencias sociales y a sus pensadores. Incluso algunos de los intelectuales que componen esta obra han participado activamente con aportes teóricos, conceptuales, metodológicos y temáticos en la evolución del 
mismo pensamiento social latinoamericano. Se implicaron, si cabe, en la elaboración de tradiciones académicas propias de la región como la sociología científica, la sociología de la modernización, los análisis de la dependencia, la teología de la liberación, el colonialismo interno, la democratización y las sociedades en transición y, más recientemente, el colonialismo del poder y del conocimiento y las alternativas epistemológicas y políticas del Sur. Pues bien, todas esas corrientes que emergieron en medio de tradiciones locales interdisciplinarias (como el enfoque centro-periferia y el estructuralismo de la CEPAL) y la recepción crítica de las tradiciones occidentales como el marxismo clásico, el funcionalismo norteamericano, el estructuralismo francés o la sociología comprensiva alemana, sumados al alto nivel de desarrollo institucional y a la libertad intelectual de la región, y a los propios "laboratorios sociales" latinoamericanos, con sus procesos políticos e históricos parejos, están recogidos de forma sucinta en esta antología que el lector tiene en sus manos.

\section{LOS SOCIÓLOGOS DEL EXILIO Y DE LA EMIGRACIÓN}

De forma específica, los autores seleccionados en el primer capítulo son, por un lado, dos sociólogos del exilio español de 1939 - también conocidos como "sociólogos sin sociedad propia" (Gómez Arboleya, 1958: 70)_ como Francisco Ayala y José Medina Echavarría y, por otro lado, dos sociólogos de la emigración española de mediados de los años sesenta como Juan Francisco Marsal e Ignacio Sotelo ${ }^{3}$. Estos cuatro autores son representantes del pensamiento social español sobre América Latina escrito en la propia región. Para empezar, es necesario recordar aquí que la Guerra Civil supuso una quiebra enorme para la sociedad española y también para la emergente sociología. Lo que tenía que haber sido en condiciones históricas y democráticas normales el proceso definitivo de institucionalización de las ciencias sociales bajo el nombre de Ayala o Medina Echavarría se pasó, bajo el contexto autoritario del franquismo, a un letargo de varias décadas

3 La etiqueta de "sociólogos sin sociedad propia" fue acuñada por Enrique Gómez Arboleya para referirse, bajo el contexto del franquismo, a Francisco Ayala, José Medina Echavarría y Luis Recasens Siches, los sociólogos del exilio republicano de 1939. La atención hacia las voces del exilio sociológico fue difícil y dolorosa por parte de esta voz del interior (Morales, 2014). Aclarar aquí que decidimos no incluir a Recasens Siches en esta antología al derivar hacia la filosofía sus preocupaciones intelectuales de los años cincuenta y sesenta. Por lo que respecta a Gómez Arboleya, debemos reconocer que él fue el nexo de unión entre los sociólogos sin sociedad, los sociólogos de la guerra y la nueva sociología española, aportando una visión de esta disciplina desde una clara fundamentación empírica y funcionalista, aunque de clara vocación modernizadora (Morente, 1998; Rodríguez Ibáñez, 2008). 
que afectó a la generación posterior de Marsal y Sotelo. Ayala y Medina Echavarría tomaron el camino del exilio latinoamericano protagonizando notables iniciativas docentes, editoriales e investigadoras en Argentina, Brasil, México, Chile o Puerto Rico.

Francisco Ayala, por ejemplo, se ganó la vida como traductor para la editorial Losada, dirigiendo su colección "Biblioteca de Sociología" desde 1941, y también colaborando con la editorial Sudamericana. Fue catedrático de ciencias sociales en la Universidad Nacional del Litoral y miembro en los años cuarenta del Instituto de Sociología de la Facultad de Filosofía y Letras de la Universidad de Buenos Aires. En 1945 se trasladó a Brasil para impartir un curso de Sociología para altos funcionarios en Río de Janeiro. Regresó a Buenos Aires en 1946. Dictó un curso de Sociología en el Colegio Libre de Estudios Superiores y en 1947 publicó su célebre Tratado de Sociología. Después, a principios de los años cincuenta, ejercería como catedrático de Ciencias Sociales en la Universidad de Puerto Rico. A partir de 1955 comenzó su periplo norteamericano en Princeton, ocupando diversos cargos académicos en varias universidades hasta su jubilación como catedrático en el Brooklyn College de la City University of New York. Precisamente el texto que recogemos en esta antología se circunscribe a su etapa norteamericana, ofreciendo en él una perspectiva cultural e histórica sobre las relaciones entre ambas Américas y dejándonos, además, su particular mirada a lo que llamó, en un ámbito macrosociológico, la "ley de unificación del mundo" (Ribes, 2002)4.

José Medina Echavarría se dedicó con decisión a los estudios sociológicos al punto de ser reconocido como uno de los grandes autores y promotores de la sociología científica en la América Latina posterior a la Segunda Guerra Mundial (Germani, 1956 y 1959; Franco, 1974; Morcillo 2010). Por ejemplo, impartió clases de Sociología en la Universidad Nacional Autónoma de México y fue el primer encargado de la Sección de Sociología del Fondo de Cultura Económica, donde publicó su célebre obra Sociología: teoría y técnica, de 1941, y se traduciría la titánica Economía y sociedad, de Max Weber (Moya, 2007; Morales, 2015). En 1943 fue nombrado director del Centro de Estudios Sociales de El Colegio de México, donde puso en marcha el primer Diplomado de Ciencias Sociales de América Latina. Además creó y dirigió entre 1943 y 1946 la revista Jornadas, publicación que trató de fomentar un debate académico entre los científicos sociales

4 Para indagar en la figura de Francisco Ayala y su faceta como destacado sociólogo se deben recurrir a los importantes trabajos de Ribes $(2004 ; 2007)$. Por lo que respecta a la experiencia académica e investigadora de este autor en la Universidad Nacional del Litoral, ésta ha sido descrita al detalle por Escobar (2011). 
hispanoamericanos. En 1946 se marchó a la Universidad de Puerto Rico como profesor de Sociología. Allí permaneció hasta 1952, momento en el que se incorporó a la CEPAL de Santiago de Chile. Desde allí fue el primero en hablar en la región de los "aspectos sociales del desarrollo económico", en un libro homónimo publicado en 1959. El texto que recuperamos en esta antología ilustra, en concreto, las preocupaciones de este autor en relación a la problemática del desarrollo económico y social en América Latina, y, sobre todo, su inclinación personal de formular un marco teórico, sólido y responsable, que asiente esas aspiraciones individuales de mejora social junto con el reconocimiento político y la convivencia democrática. Ese modelo teórico para el desarrollo económico regional quedaría contenido después en obras tales como El desarrollo social de América Latina en la postguerra, de 1963, o Consideraciones sociológicas sobre el desarrollo económico, del año 1964.

Pero también es necesario reconocer aquí el papel destacado que tuvo Medina Echavarría en la promoción e institucionalización de los estudios sociales en América Latina. Fue el director, entre 1957 y 1959, de la primera Escuela Latinoamericana de Sociología de FLACSO y participó después en los primeros pasos de CLACSO. Además se interesó para que la sociología tuviera un peso específico en el ILPES, creado en Santiago de Chile en 1962 bajo la égida de las Naciones Unidas. En ese Instituto asumió la dirección de la División de Planificación Social en 1963. Allí formó un nutrido grupo de investigación en el que destacaron, entre otros nombres, el chileno Enzo Faletto y el brasileño Fernando H. Cardoso (Morales, 2010). Después, en los años setenta, en una época dura y gris para la región, reflexionó de forma crítica y abierta sobre los límites, equívocos y posibilidades de la democracia en América Latina y en las sociedades occidentales, destacando en ese tiempo su libro Discurso sobre política y planeación, de 1972. Este es sin duda su mayor mérito como intelectual, como sociólogo y como teórico del desarrollo: fue capaz de que muchos economistas y científicos sociales latinoamericanos empezasen a tomar con seriedad a la democracia como un elemento indispensable para la modernización económica y social (Gurrieri, 1980; Cardoso, 1982; Furtado, 1988; Graciarena, 1988).

El alto grado de institucionalización y de desarrollo de las ciencias sociales latinoamericanas, forjado por autores como Medina Echavarría, sumado a la dificultad de pensar sociológicamente bajo el franquismo, explica la emigración voluntaria y la decisión de formarse y hacer carrera en América Latina de Juan Francisco Marsal e Ignacio Sotelo. Estos autores se harán sociólogos en la región. Incluso Marsal en alguna ocasión llegó a afirmar que "como sociólogo era 
un americano" (Marsal, 1977: 15). Este autor, graduado en Derecho y Ciencias Políticas en Barcelona, había emigrado a Argentina en 1954 ante la presión cultural e intelectual del franquismo. Allí trabajaría en la Universidad de Buenos Aires junto a Gino Germani durante los años sesenta (Blanco, 2010). Muy influido por este gran sociólogo, Marsal se interesaría por temas tales como las migraciones, la adaptación individual a un nuevo medio social o la importancia de la idea de retorno en los inmigrantes. Estas preocupaciones serían recogidas en su clásico libro Hacer la América, del año 1969.

El tinte biográfico será característico de su obra, reflexionando constantemente sobre su condición de emigrado y sobre su rol de intelectual en una sociedad ajena, lo que le valdrá para realizar valiosas aportaciones en América Latina sobre el método biográfico y sobre la sociología de los intelectuales (Sotelo, 1979; Morales y Rodríguez, 2009). Ahí nos dejó importantes libros como El intelectual latinoamericano, de 1970, Los intelectuales políticos, de 1971, y, sobre todo, La sombra del poder, de 1975. Pero Marsal también se comprometió seriamente con los derroteros de las sociologías argentina y latinoamericana a partir de una serie de iniciativas institucionales y académicas. Por ejemplo, llegó a ser director entre 1966 y 1970 del Centro de Investigaciones Sociales del Instituto Torcuato di Tella y de la Revista Latinoamericana de Sociología. También tendría una participación activa en los Grupos de Trabajo de CLACSO. Y, después de su vuelta a la Universidad Autónoma de Barcelona, divulgaría en el medio español buena parte de los debates contemporáneos de la sociología latinoamericana en obras como Teoría y críticas sociológicas, de 1977, y su obra póstuma, Dependencia e independencia. Las alternativas de la sociología latinoamericana en el siglo XX, de 1979. Aquí recuperamos un escrito suyo de 1966 en el que hace referencia a los debates teóricos de esa época, a las grandes líneas de pensamiento y, sobre todo, el texto evidencia el proceso de articulación, autonomía y consolidación de las ciencias sociales latinoamericanas.

Ignacio Sotelo ejemplifica también cómo el interés por América Latina del pensamiento español surgió, la mayoría de las veces, fuera del sistema extraacadémico durante la época del franquismo. Procesado por asociación ilegal por el régimen dictatorial en 1957, este autor decide salir clandestinamente en 1959 de España. En 1960 llega a la República Federal de Alemania, doctorándose en Filosofía en 1965 por la Universidad de Colonia. Después sería profesor en Ecuador, México y Perú hasta el año 1973, momento en que se incorpora al Instituto de Estudios Latinoamericanos de la Universidad Libre de Berlín. Desde allí se encargaría de difundir en el ámbito español y europeo el pensamiento social latinoamericano. Por ejemplo, organi- 
zó en noviembre de 1973 un destacado congreso sobre la teoría de la dependencia y el desarrollo latinoamericano que acercó a científicos sociales de uno y otro lado del Atlántico ${ }^{5}$. Además Sotelo, entre mediados de los años setenta y principios de los años ochenta, publicó en España importantes artículos y libros sobre sociología latinoamerica$n^{6}$. De esa producción destacan su obra Sociología de América Latina, de 1975 - de la que incluimos algunos fragmentos en este volumen-, y América Latina. Un ensayo de interpretación, de 1980. Sociología de América Latina, en particular, es un libro hecho en Berlín, pero ciertamente expresivo de cómo Sotelo abordó su experiencia personal durante su emigración latinoamericana, inmiscuyéndose en su sociología, recogiendo sus debates y tensiones, y, sobre todo, dialogando con la incipiente teoría de la dependencia y con el pensamiento marxista. En ese sentido, el libro surca desde un enfoque crítico las formas históricas del capitalismo latinoamericano, los modelos de acumulación, la cuestión de la dependencia y el fracaso del funcionalismo norteamericano a la hora de descifrar una región tan peculiar y diversa.

\section{PENSANDO BAJO EL FRANQUISMO}

El segundo capítulo de esta antología lo conforman tres autores que pensaron América Latina bajo el clima intelectual del franquismo de los años sesenta y principios de los setenta, y alejados también de la retórica oficialista del Instituto de Cultura Hispánica. Nos referimos a Manuel Lizcano, a Juan Maestre Alfonso y a José Luis Rubio, quienes, frente a una sociología institucionalizada de corte empírico y funcionalista (De Miguel, 1975; Lamo de Espinosa, 1992) y frente a unas ciencias sociales de familias y grupos reducidos, buscaron fuera del sistema universitario y académico oficial un espacio en el que

5 El "Seminario de Sociología del Desarrollo: Dependencia y Estructuras del Poder" se celebró entre el 4 y 11 de noviembre de 1973 en la Universidad Libre de Berlín. Contó con auspicio de la Fundación Alemana para el Desarrollo Internacional, el Consejo Europeo de Investigaciones Sociales sobre América Latina (CEISAL) y el mismo CLACSO (Durand Ponte, 1973: 23). Entre los asistentes destacan algunos autores clave de las ciencias sociales latinoamericanas como Manuel Antonio Garretón, Rolando Franco, Edmundo Fuenzalida, Osvaldo Sunkel, Fernando H. Cardoso, Edelberto Torres-Rivas, Celso Furtado, o André Gunder Frank (Franco, 2007: 164). También asistió Juan Francisco Marsal.

6 Por ejemplo, Ignacio Sotelo publicó en 1975 en la revista Sistema el artículo "Subdesarrollo y dependencia: notas para una evaluación de la categoría de la dependencia en el análisis del subdesarrollo" ( ${ }^{\circ} 10$, pp. 41-50), y en Papers. Revista de Sociología, fundada por Juan Francisco Marsal después de regresar de Argentina, aparecieron sus trabajos "Los militares en el Perú: continuidad y cambio de su función política”, de 1974 ( $\mathrm{N}^{\circ}$ 2, pp. 79-114) y "Modelos de explicación del militarismo latinoamericano: una explicación histórica”, de 1977 ( ${ }^{\circ}$ 7, pp. 65-89). 
fomentar la investigación crítica y comprometida. A los tres les une, en consecuencia, haber sido miembros fundadores y profesores de la Escuela Ibérica de Sociología y Desarrollo, abierta en Madrid en 1966 y que posteriormente pasó a llamarse Instituto de Sociología y Desarrollo del Área Ibérica (ISDIBER). Para entender bien la aventura académica y la vocación latinoamericana del ISDIBER debemos tener en cuenta, principalmente, la trayectoria y las iniciativas institucionales de Manuel Lizcano, aparte de las características de las ciencias sociales españolas de esos años.

Lizcano, antiguo profesor de Sociología en la Facultad de Ciencias Políticas de la Universidad de Madrid, había comenzado a establecer a partir de 1962 una red académica hispanoamericana desde la dirección del Centro de Prospección Social y Asociativa del Instituto de Estudios Sindicales, Sociales y Cooperativos (Lizcano Pellón, 20052006: 61). Muy importante para el establecimiento de estos contactos fueron, claro está, los constantes viajes a América Latina del propio Lizcano y también de Juan Maestre Alfonso y José Luis Rubio, los cuales les permitieron conocer, dialogar y entablar relaciones académicas y profesionales con destacados científicos sociales de la región. Muchos de esos intercambios se vehicularon entonces a partir de sendas publicaciones promovidas por Lizcano. Nos referimos a la revista Comunidades, fundada en 1965 y que vio luz hasta 1970, y al Anuario de Sociología de los Pueblos Ibéricos, que tuvo una efímera vida de dos años (1967 y 1969). Precisamente el Anuario de Sociología de los Pueblos Ibéricos fue el órgano de la Asociación de Sociólogos en Lengua Española y Portuguesa (ASLEP), constituida en Madrid, por iniciativa de Lizcano, entre el 19 y el 24 de junio de 1967. Entre los primeros sociólogos fundadores de la Asociación se encontraban Orlando Fals Borda, Josué de Castro, Isaac Ganón, Lucio Mendieta y Núñez, Orlando Sepúlveda, José Luis de Imaz, Manuel Diegues Junior, Gustavo Pérez, Alfonso Trujillo, y el ya estudiado José Medina Echavarría, hecho que nos confirma las relaciones latinoamericanas entre la sociología del interior y la sociología del exilio español (ASLEP, 1967a: 293-295).

Esta Asociación de Sociólogos en Lengua Española y Portuguesa destacó por promover la creación e institucionalización en 1966 de la citada Escuela Ibérica de Sociología y Desarrollo, auspiciada bajo el patrocinio del Instituto de Cultura Hispánica y el Instituto de Estudios Sindicales, Sociales y Cooperativos (ASLEP, 1967b: 296-301). En 1968 este centro superior de enseñanza pasó a llamarse Instituto de Sociología y Desarrollo del Área Ibérica (ISDIBER). El Instituto dio más importancia, si cabe, a la formación de especialistas en materia de desarrollo social y económico. Manuel Lizcano continuó en sus labores de dirección y Juan Maestre Alfonso y José Luis Rubio ense- 
ñaron estudios antropológicos y sociológicos a partir de sus experiencias en América Latina. El ISDIBER ofreció un "Diploma básico" de Sociología y Desarrollo cuya duración era de tres años académicos. El programa del diploma destacaba por la enseñanza de distintas áreas temáticas como la estructura social, la economía, la política, la cultura o la cooperación iberoamericanas. Asimismo se profundizaba en la investigación sociológica aplicada y en la realización de investigaciones en diversos campos económicos y sociales, cuyos aportes fueron fundamentales para el conocimiento de la realidad latinoamericana (ASLEP, 1968: 277-311). La primera etapa del ISDIBER duró hasta 1983 en la que se graduaron unos 300 alumnos (Lizcano Pellón, 20052006: 60$)^{7}$. Posteriormente el Instituto sería refundado en 2002, pero ya en el seno del Instituto Español de Estudios Estratégicos.

Si nos hemos detenido en esta aventura académica del ISDIBER es porque ha estado fuera de los manuales de historia de las ciencias sociales españolas al alejarse, en su momento, de la oficialidad del régimen y de la por entonces hegemónica sociología funcionalista de orientación norteamericana (Moya, 1970). Hemos querido destacar, por tanto, la importancia de esta isla de pensamiento libre dedicada a establecer puentes duraderos con América Latina y en formar a científicos sociales españoles y latinoamericanos, sensibilizados por problemáticas comunes como el tratamiento del desarrollo social y económico en contextos políticos autoritarios (Maestre Alfonso, 1991: 14). De hecho, la vocación de Lizcano, Maestre Alfonso y Rubio fue la investigación en el terreno de las experiencias comunales, cooperativas y comunitarias en países de América Latina con tal de trasladar ese conocimiento aprendido a la realidad española bajo un objetivo claro de cambio social y de crítica activa al régimen franquista.

Precisamente los textos aquí seleccionados de Manuel Lizcano, Juan Maestre Alfonso y José Luis Rubio reflejan el interés que hubo en ambientes independientes dentro de la España franquista por las experiencias políticas y sociales de América Latina. De esta forma, el texto de Lizcano, tomado de su libro La estructura social de Iberoamérica y España, se preocupa, principalmente, por las situaciones de cambios sociales de las sociedades española y latinoamericana, especialmente los procesos de urbanización, migratorios y de transformación impulsada por el movimiento obrero. La perspectiva de este autor estuvo basada en estudiar la estructura comunal ibérica y el estudio de los pueblos iberoamericanos a partir de las experiencias comunales, cooperativas y comunitarias. Esta orientación se debe a la militancia obre-

7 El ISDIBER además organizó los primeros Foros Iberoamericanos (Bogotá, 1973; La Rábida, 1975), que son precursores de las actuales Cumbres Iberoamericanas. 
ra católica de Lizcano durante los años más duros del franquismo. Pero el interés intelectual y personal de Lizcano estaba puesto, además, en promover un pensamiento libertario para los pueblos iberoamericanos. Estas aspiraciones las recogió en numerosos artículos y en libros clave de su pensamiento como El nuevo proyecto español: quince tesis sobre la sociedad ibérico-americana y su identidad cultural, de 1977, y La revolución comunal: hacia una nueva comunidad iberoamericana, de 1979.

Esa misma perspectiva "hispánica", crítica y heterodoxa es la que descuella de los textos aquí seleccionados de Maestre Alfonso y Rubio, los cuales se interesaron por las experiencias guerrilleras y revolucionarias de la América Latina de los años sesenta y setenta. En el caso del primero, seleccionamos fragmentos de su libro Guatemala: subdesarrollo y violencia, de 1965. Esta obra, de hecho, inicia el compromiso militante de Maestre Alfonso con los movimientos latinoamericanos de izquierda y su interés intelectual por comprender los conflictos políticos y los procesos revolucionarios y populares en la región. A esos temas les dedicó después toda una serie de importantes libros, como, por ejemplo, Chile: revolución y contrarrevolución, de 1973, Bolivia, victoria o muerte, de 1975, Brasil: de situación colonial a Estado gendarme, de 1976, o El Che y Latinoamérica, del año 1979. Además Juan Maestre Alfonso dejó un significativo libro sobre técnicas cualitativas, La investigación en antropología social, de 1974, fruto de sus experiencias biográficas e investigaciones de campo en América Latina ${ }^{8}$.

Por lo que respecta a José Luis Rubio, este autor pensó también en las posibilidades de una España integrada en la dinámica revolucionaria de Iberoamérica. Así dejó en libros como La rebelión mestiza, de 1966, Las internacionales obreras en América, de 1971, o el que incluimos en este volumen, Aproximación a la revolución peruana, de 1974, su inclinación por una Iberoamérica que materializase una sociedad socialista, inspirada por un cristianismo revolucionario, y superadora del antagonismo entre capitalismo y estalinismo. Pensemos que eran los tiempos de la Guerra Fría y, desde el interior de la sociedad franquista, se buscaron aspiraciones y fuerzas históricas alternativas al autoritarismo y a la incipiente lógica del mercado. Para

8 Después este autor se hizo cargo en 1991 de una destacada colección de "Pensamiento político, social y económico español sobre América Latina”, patrocinada por Ediciones de Cultura Hispánica, la cual divulgó en el medio hispanoamericano, hasta hace unos años, la tradición del pensamiento español dedicado a la región. Valga aquí el reconocimiento por parte del autor de estas líneas a Juan Maestre Alfonso por la oportunidad que me dio de participar en esa colección editando, junto a María del Carmen Rodríguez, las antologías dedicadas a Juan Francisco Marsal (Ediciones de Cultura Hispánica, N ${ }^{\circ}$ XI, AECID, Madrid, 2009) y a Américo Castro (Ediciones de Cultura Hispánica, No XVII, AECID, Madrid, 2012). 
estos autores, por tanto, América Latina y sus movimientos sociales que luchaban por la liberación del imperialismo y del capitalismo fueron una auténtica inspiración intelectual y política.

\section{SABER Y POLÍTICA EN LOS LABORATORIOS SOCIALES LATINOAMERICANOS}

Esa idea de vivenciar y experimentar en primera persona los procesos históricos, sociales y políticos latinoamericanos que tuvieron los científicos sociales españoles distingue la selección de autores y textos del tercer apartado de esta antología. De esta forma, las trayectorias de Joan Garcés, Manuel Castells y Xabier Gorostiaga tienen esto en común: se sintieron atraídos por el "laboratorio social" de América Latina. Pues esta región ha destacado por ser un poderoso "laboratorio" de desarrollo, producción y aplicación de conocimiento al estar estrechamente condicionada por la coyuntura internacional, los contextos históricos y por las cambiantes condiciones sociales. El deseo de intervenir en la realidad social y política por parte de los intelectuales, científicos sociales y productores de pensamiento ha sido uno de sus rasgos más distintivos (Graciarena, 1978). Esto, justamente, motivó el interés intelectual y la participación política de Garcés por la vía chilena al socialismo encabezada por Salvador Allende y la Unidad Popular. También Castells residiría en el Chile de principios de los años setenta, y asimismo tuvo experiencias académicas y docentes en Brasil y México, interesado en aquel tiempo en temas relacionados con el urbanismo, la planificación social o las clases sociales.

Efectivamente, la experiencia chilena fue muy importante para la biografía de Garcés y de Castells, como lo fue igualmente para tantos otros científicos latinoamericanos, europeos y extranjeros durante la década de los sesenta y setenta. Esos años fueron sinónimo de formación, de estudio, de investigación, pero también de militancia y de compromiso social y político. Esta atracción por Chile, por sus ciencias sociales y por sus procesos políticos no fue casual. Este país, de hecho, fue centro de la sociología y de las ciencias sociales latinoamericanas, como vimos anteriormente con Medina Echavarría, desde la creación en 1948 de la CEPAL hasta el golpe de Estado del 11 de septiembre de 1973. Más específicamente, Santiago de Chile fue sede de organismos regionales e internacionales, como la FLACSO, el ILPES, el CELADE, DESAL, Escolatina o ILADES, que institucionalizaron y estimularon los estudios económicos, sociales, históricos y políticos de la región y, con el tiempo, se convirtieron en relevantes actores de la política nacional y regional al alentar la ideología desarrollista y, sobre todo, promover la intervención del científico social en los asuntos públicos (Garretón, 1989; Franco, 2007; Pérez Brignoli, 2008; Beigel, 2009). 
Santiago de Chile se convirtió, de hecho, en un punto de encuentro que ayudó a forjar una "perspectiva latinoamericana" para toda una generación de científicos sociales. Esos organismos regionales e internacionales asumieron la tarea de promover la docencia y la investigación social, sustituyendo inicialmente la función que le correspondía a las universidades. Pero también ayudaron a hacer circular a los científicos sociales y a sus ideas, al haber acogido y resguardado a un buen número de exiliados que escapaban de los golpes de Estado de Brasil (1964) y de Argentina (1966). Estos científicos sociales exiliados portaban experiencias políticas y teorías sociológicas que se expandieron después por toda la región (Beigel, 2009: 346; Beigel, 2010). Así sucedió, por ejemplo, con la teoría de la dependencia y sus diferentes corrientes, atravesadas por la economía, la historia, la sociología o la ciencia política (Cardoso y Faletto, 1969; Ianni, 1971; Casas Gragea, 2006). Nacida entonces como una crítica al paradigma estructuralista, reformista y desarrollista de la CEPAL, tuvo un gran apogeo en la región hasta mediados de los años setenta. El marxismo y el programa de investigación sociológica del materialismo histórico fueron su sustento teórico. Mientras que la originalidad de la dependencia estuvo a la hora de proponer alternativas al desarrollo capitalista y al hecho de haberse constituido en un movimiento de ideas capaz de generar experiencias políticas y compromisos con las inquietudes, necesidades y esperanzas de las clases sociales más necesitadas (Weffort, 1970).

Precisamente a partir del triunfo de Salvador Allende en las elecciones presidenciales de 1970 se produjo en Chile una imbricación mutua entre el enfoque dependentista, la capacidad de intervenir en la realidad del científico social y la aspiración de alcanzar por vía pacífica una sociedad socialista (Faletto, 1999a; Cueva, 2008). Fue un momento histórico en el que se dio una suerte de fusión entre el científico social y su objeto de estudio. El sociólogo, el científico social o el economista sintieron que podían cambiar y transformar esa misma realidad social. Ante la flagrante desigualdad y marginalidad social, se radicalizaron y se comprometieron en pensar las sociedades chilena y latinoamericana como un laboratorio de cambios y de necesarias transformaciones económicas y sociales. Estas aspiraciones e inquietudes son, justamente, las que sobrevuelan y descuellan en los textos aquí seleccionados de Joan Garcés y Manuel Castells. El primer autor fue asesor y acompañante hasta el último momento de Allende en aquel fatídico 11 de septiembre de 1973, y el segundo trabajó como profesor de la Universidad Católica de Chile y de la FLACSO.

De Garcés reproducimos fragmentos de su clásico libro Chile: el camino político hacia el socialismo, del año 1971. Este autor acopiaría después en obras como, El Estado y los problemas tácticos en 
el gobierno de Allende, de 1974, o Allende y la experiencia chilena. Las armas de la política, de 1976, sus reflexiones y análisis más detallados de aquel singular periodo histórico ${ }^{9}$. Por parte de Castells, dedicado entonces desde una perspectiva crítica y marxista a los temas de la sociología urbana, rescatamos pasajes de su libro La lucha de clases en Chile, de 1974, en el que repasa el conflicto social y las estructuras económicas, sociales y políticas en una sociedad en transición. Ambos textos son, sin duda alguna, evocación de una época clave de la historia latinoamericana y revelan, además, el significado del proyecto cultural, democrático y político que representó el gobierno de la Unidad Popular. También, por supuesto, ofrecen claves intelectuales y sociológicas de uno de los procesos políticos que más influyó en las izquierdas de todo el mundo.

El golpe de Estado en Chile representó, por cierto, varias cosas para América Latina: por un lado, inauguró un "nuevo" modelo de desarrollo y, por el otro, generó un cambio en el eje del circuito de las ciencias sociales regionales ante otra ola de exiliados académicos. En primer lugar, el capitalismo y su racionalidad tecnocrática y neoliberal se instalaron en la región a través del autoritarismo, la violencia y la represión (Faletto, 1999b; Devés, 2003; Urquidi, 2005). El modelo económico impuesto en Chile constituyó la aplicación más extrema de la ortodoxia monetarista y librecambista de la Escuela de Chicago que fue seguida más tarde por otros países y que se consolidó en América Latina durante los años ochenta (Vergara, 1985). Y, en segundo lugar, se produjo un "parteaguas" en las ciencias sociales latinoamericanas, como así lo definió Agustín Cueva (1988), al separarse las preocupaciones de los científicos sociales residentes en México y en América Central de los sociólogos, politólogos y economistas del Sur. Efectivamente, si el Chile de Allende fue estandarte del socialismo democrático en la región y se convirtió en un país líder del tercermundismo, la revolución de la Nicaragua sandinista, por su parte, gozó de amplios apoyos y reactivó el trabajo crítico de numerosos pensadores y científicos sociales al ser vista como una respuesta factible a la hora de escapar de la dominación estadounidense en la región.

La implicación del científico social con los problemas inmediatos de la realidad explica, en concreto, el compromiso del padre jesuita Xabier Gorostiaga (1937-2003) con Centroamérica y, más específicamente, con Nicaragua y su revolución sandinista de 1979. De vasta experiencia en América Latina, pues había llegado a Cuba en 1958,

9 De hecho el compromiso de Garcés con Chile continuaría después encabezando y dirigiendo el proceso judicial contra el dictador Augusto Pinochet por crímenes de lesa humanidad y terrorismo de Estado. 
este economista fue asesor del gobierno de Panamá durante las negociaciones con Estados Unidos sobre el canal. Después se implicó en el proceso revolucionario nicaragüense hasta el punto de ser consultor del gobierno sandinista y desempeñándose también como Director General de Planificación. Gorostiaga comandó, además, diferentes iniciativas académicas para promover el estudio de las ciencias sociales en Centroamérica. Por ejemplo, fundó el Centro de Estudios y Acción Social y la revista Diálogo social en Panamá, fue director del Instituto Nacional de Investigaciones Económicas y Sociales (INIES) en la Universidad Nacional Autónoma de Nicaragua, y fue rector, asimismo, de la Universidad Centroamericana (UCA) en su sede de Managua. También dirigió la Coordinadora Regional de Investigaciones Económicas y Sociales (CRIES), institución que agrupa a centros de investigación de la región centroamericana y del Caribe. Gorostiaga dejó numerosos trabajos sobre Centroamérica, su economía, sus problemas sociales y políticos, su educación y desarrollo, en los que trató de abrir nuevas rutas de pensamiento propio y de acción colectiva. Aquí incluimos, en todo caso, un texto suyo dedicado a la revolución sandinista en el que realiza un balance crítico y personal a aquel proceso político.

\section{LA OPCIÓN POR LOS POBRES Y LA TEOLOGÍA DE LA LIBERACIÓN}

En el cuarto apartado de esta antología recogemos a tres autores que, siguiendo el caso de Xabier Gorostiaga, continúan con el hilo conductor de las redes vinculadas al compromiso católico con el desarrollo económico, social y político de América Latina. Nos referimos a Ignacio Ellacuría, Pedro Casaldáliga y Jon Sobrino, concienciados e implicados con las realidades de varios países latinoamericanos a la vez que destacaron por ser importantes teóricos y representantes de la teología de la liberación. En buena medida estos tres autores vivieron intensos procesos de "latinoamericanización", trocando la visión eurocéntrica del pensamiento cristiano por una mirada desde la periferia al centro y en la que destaca una decidida opción por los pobres y una crítica a la desigualdad económica y a todo pensamiento censor y autoritario.

Para comprender el compromiso apremiante de estos autores españoles con la realidad social de la región, debemos tener en cuenta, sin duda, el caminar de la Iglesia latinoamericana y su opción preferencial por los pobres desde que trazó este rumbo en la Conferencia General del Episcopado Latinoamericano, realizada en Medellín en 1968. Ese camino fue confirmado después en Puebla en 1976. Durante esos años tomó cuerpo teórico y sustento político la teología de la liberación, destacando los aportes intelectuales y las posturas críticas de sus primeros fundadores, caso, por ejemplo, de Gustavo Gutiérrez 
y Leonardo Boff (Cuda, 2013). Podemos decir, en apretada síntesis, que ese conjunto intelectual nació de una praxis previa de comienzos de los sesenta: fue la expresión de un movimiento social que abarcó a distintos actores de la Iglesia latinoamericana que apreciaron como indispensable dentro de su labor pastoral relacionarse, sentir y acompañar al pueblo en sus padecimientos, miserias y sufrimientos por un modelo de desarrollo injusto y desintegrador. La teología de la liberación estuvo muy influida por el marxismo y la sociología crítica, siendo estas aplicadas como herramientas analíticas y teóricas para poder entender y comprender en los países de América Latina las causas de la pobreza y la marginalidad social, las contradicciones del capitalismo y las formas de la lucha de clases (Lowy, 1999: 51). En consecuencia, la experiencia de vida y la sensibilidad de los teólogos de la liberación es la que les llevó a acercar a la Iglesia católica a los asuntos y problemas cotidianos de la gente.

Las diferentes corrientes de la teología de la liberación se propusieron, entonces, una "misión paradigmática" para cambiar las estructuras eclesiales, pero también, por supuesto, que esta tuviera efectos en las estructuras económicas, sociales y políticas. A esto se le llamó "misionariedad" (Cervera y Milanesi, 2008). De esta forma, muchos teólogos y sacerdotes sintieron que no podían estar lejos de la realidad social y, por tal motivo, su vocación estuvo en evangelizar a los pueblos pobres para que estos tengan vida, reconocimiento, dignidad y la tengan en abundancia. Precisamente esta "misionariedad" es la que sintieron los jesuitas Ignacio Ellacuría y Jon Sobrino respecto a El Salvador. Este país, al igual que Nicaragua y Guatemala, fue golpeado dura y dramáticamente por la guerra civil. Aunque la violencia venía de lejos, se desbordó durante los años ochenta (Ansaldi y Giordano, 2012). Ante un panorama crítico, de pobreza, de lacerantes desigualdades y de apatía ante esta realidad por parte de las oligarquías nacionales, aliadas históricas de Estados Unidos, estos autores, junto con muchos otros, protagonizaron labores de enseñanza e investigación en la Universidad Centroamericana (UCA) de El Salvador. Esas actividades también estuvieron acompañadas por una llamada a la acción y por la "promoción popular". Esto es: hubo una reiterada apelación por parte de Ellacuría y de Sobrino de intervenir en la realidad buscando la justicia social.

Estos teólogos actuaron defendiendo a los más necesitados y denunciando la extrema violencia y la violación de los derechos humanos por parte del ejército salvadoreño en la guerra civil de ese país. Quedaron muy atraídos, biográfica e intelectualmente, por el compromiso liberador del mártir Monseñor Romero, asesinado en 1980. Ignacio Ellacuría, de hecho, trabajó buscando la paz y se erigió en un 
puente de diálogo y de acercamiento entre los militares y las Fuerzas Populares de Liberación Farabundo Martí. Sin embargo, el 16 de noviembre de 1989 un batallón militar lo asesinó en las dependencias de la UCA junto a otros cinco sacerdotes jesuitas y dos empleadas ${ }^{10}$. Jon Sobrino se encontraba de viaje y por esa razón salvó su vida. En ese momento Ellacuría era rector de la UCA y había logrado convertir a esa casa de estudios en una de las instituciones universitarias latinoamericanas más destacadas en la difusión de la teología de la liberación. Precisamente en esta antología recuperamos un artículo suyo en el que articula categorías sociológicas y teológicas en un discurso incluso político, apuntando la necesidad de transformación radical de la sociedad latinoamericana en su conjunto ${ }^{11}$.

El texto de Sobrino, por su parte, se pregunta sobre el derrotero y vigencia de la teología de la liberación a finales de los años noventa. En esos años, ante el "triunfo" en la región de las políticas macroeconómicas y sociales del Consenso de Washington, se decretó la defunción de este pensamiento y también se puso en entredicho el aporte de otras escuelas críticas como la sociología marxista, la teoría de la dependencia y sus distintos enfoques (Roitman, 2008; Beigel 2010; Dos Santos, 2011). Se cuestionó y se miró con descrédito a todo ese pensamiento latinoamericano por ser "tercermundista". Sin embargo, Sobrino aborda un conjunto de problemas que, vistos hoy con la distancia del tiempo, siguen siendo, lamentablemente, vigentes en América Latina. Sobre todo si los observamos desde la lupa propia de las ciencias sociales: la globalización económica sigue marginando y excluyendo. Temas que, justamente, han seguido ocupando a Sobrino en obras como América Latina: el evangelio de Jesús frente a la lógica del capital y de los imperios, del año 2011.

10 Ignacio Martín-Baró y Segundo Montes, dos jesuitas y científicos sociales españoles, fueron asesinados junto a Ignacio Ellacuría. Martín-Baró, psicólogo social, era director del Instituto de Opinión Pública de la UCA (IUDOP) y dejó una extensa obra en la que sobresale su Psicología de la liberación, libro publicado póstumamente en 1998. Por su parte, Segundo Montes, filósofo y sociólogo, dirigió el Departamento de Sociología de la UCA y dejó varias obras sobre el compadrazgo y la estratificación social de El Salvador.

11 Ignacio Ellacuría legó una importante obra de pensamiento teológico, político y social que se ha venido editando después de su muerte. Destacan, por ejemplo, su libro póstumo editado junto a Jon Sobrino, Conceptos fundamentales de la teología de la liberación, del año 1990, en el que escriben algunos de los teóricos y filósofos liberacionistas más importantes, como Leonardo Boff, Gustavo Gutiérrez o Enrique Dussel; y los tres volúmenes aparecidos en 1991 titulados Escritos políticos, en donde se incluyen trabajos suyos dedicados a Centroamérica, a El Salvador, al papel social de la universidad, a la filosofía política y a la teología de la liberación latinoamericana. 
Esas mismas inquietudes son las que han inspirado durante décadas el trabajo en tierras brasileñas de Pedro Casaldáliga y buena parte de sus reflexiones académicas más maduras, recogidas en libros como Cartas de Brasil, de 1989 o Espiritualidad de la liberación, de 1992. Este religioso español, vinculado a la teología de la liberación, tomó partido por los más pobres, por los marginados, los jóvenes, las mujeres y los indígenas. Al igual que otros compañeros de esta corriente de pensamiento, Casaldáliga considera que el Evangelio cristiano exige la opción preferencial por los más necesitados, por los desheredados y por los excluidos de la sociedad. Por tal motivo, y valiéndose de las ciencias humanas y sociales, este misionero ha cuestionado profundamente las violentas y eternas desigualdades sociales y económicas brasileñas y latinoamericanas, apostando por una civilización de la pobreza superadora de la civilización del capital.

Preocupado por la promoción popular de los violentados, de los desplazados y de los pobres, Casaldáliga no solamente se quedó en el lado de la reflexión teórica, sino que además protagonizó importantes acciones como la creación de la Comisión Indigenista Misionera para proteger a los pueblos indígenas de Brasil o la Comisión Pastoral de la Tierra para defender los derechos humanos de los campesinos sin tierra. Buena parte de estas iniciativas han estado fundamentadas en su visión pastoral, del todo política, de fomentar la autonomía de los pueblos indígenas y del pueblo negro, de favorecer el proceso de integración latinoamericana y de crear comunidades de base. Esta visión utópica es la que recoge el texto aquí seleccionado de este autor. Vale la pena añadir que su perspectiva es valiosa por la vigencia de esos problemas aún abiertos.

\section{DE LAS TRANSICIONES DEMOCRÁTICAS}

\section{A LAS NUEVAS EXPERIENCIAS POLÍTICAS}

En el quinto apartado de la antología, y siguiendo ese puente que constituyen los laboratorios sociales de América Latina, destacamos el aporte de cuatro autores que se han ocupado de las transiciones democráticas en la región, los movimientos sociales y las nuevas experiencias políticas. De esta forma, con Manuel Alcántara, Ludolfo Paramio, Marisa Revilla Blanco y Juan Carlos Monedero pretendemos ver cómo desde la recuperación democrática en España se han venido institucionalizando los estudios latinoamericanos en sus organismos científicos y en sus universidades públicas al tiempo que se ha mantenido intacto el interés y el compromiso por la región.

Así, por ejemplo, Manuel Alcántara ha sido una figura clave al impulsar la creación del Instituto de Iberoamérica de la Universidad de Salamanca. Este autor destaca por estudiar las élites parlamenta- 
rias, los sistemas y los partidos políticos de América Latina. Entre sus numerosas publicaciones destacan los libros, Gobernabilidad, crisis, y cambio, de 1995, Sistemas políticos de América Latina, de 1999, Políticos y política de América Latina, de 2008 o El oficio del político, de 2012. Por su parte, Ludolfo Paramio viene reflexionando desde el Consejo Superior de Investigaciones Científicas sobre el devenir del pensamiento crítico y de la izquierda en la América Latina de los últimos 30 años. También ha incursionado en el estudio de la consolidación y la estabilidad democrática en la región en obras como, Democracia y desigualdad en América Latina, de 1999, Clases medias y gobernabilidad en América Latina, de 2010 o Clases medias y procesos electorales en América Latina (2009-2010), del año 2012.

Por su parte, Marisa Revilla Blanco y Juan Carlos Monedero, docentes de la Universidad Complutense de Madrid, representan una nueva generación de pensadores sociales españoles sensibilizados con los acontecimientos de la región e implicados en sus más recientes experiencias políticas. Revilla Blanco se ha ocupado de estudiar la ciudadanía, la acción colectiva y los movimientos sociales en América Latina, destacando su libro del año 2001 ¿Y todo lo que nos mueve nos une?; mientras que Monedero se ha implicado, desde las ideas y la acción, en los destinos de varios gobiernos latinoamericanos. Por ejemplo, fue asesor del gobierno de Venezuela entre 2005 y 2010, como también ha sido observador del PNUD en los procesos regionales de integración de UNASUR y ALBA. Además ha desarrollado en los últimos años una intensa actividad académica en universidades latinoamericanas y ha participado activamente en varias iniciativas de CLACSO. Como teórico del Estado y la democracia, ha dejado en algunos libros, como Disfraces del Leviatán: El papel del Estado en la globalización neoliberal o Claves para un mundo en transición. Crítica y reconstrucción de la política, ambos de 2009, agudos análisis sobre la necesidad que tiene la actual izquierda de construir un nuevo sujeto político y un nuevo marco ideológico en el actual contexto de globalización.

Estos cuatro autores han ofrecido, cada uno a su manera, respuestas e interpretaciones a la reconfiguración del escenario económico, social y político de América Latina a principios del siglo XXI (Ferrer, 2008). A la luz de este proceso hubo, por supuesto, un atento acompañamiento académico y también político por parte del pensamiento social español. Recordemos que se abrió entonces un nuevo contexto histórico que revitalizó el imaginario intelectual crítico al compás del cambio de signo de los gobiernos de la región. De esta forma, si la década del noventa había comenzado para América Latina con un mayúsculo desafío (consolidar los recientes regímenes democráticos a partir del desempeño económico y después de los costos 
sociales de la "década perdida" de los años ochenta), el siglo XXI abrió una época de crecimiento económico y prosperidad al tiempo que se destaparon también añejas demandas sociales en materias tales como educación, salud, vivienda, derechos laborales o derechos humanos (Ocampo, 2012).

Precisamente el arco temporal de los textos seleccionados en este volumen coincide con el dilema que enfrentaron los gobiernos progresistas de América Latina entre 2003 y 2015: cómo profundizar la democracia al tiempo de generar un proceso de desarrollo económico y social que ampliase las oportunidades de participación de la gente en ese mismo proceso. En consecuencia, estos gobiernos, críticos del Consenso de Washington, y cercanos a los ciudadanos, llevaron adelante políticas económicas expansivas para mejorar los niveles de consumo de las clases medias y de los sectores más desfavorecidos. Consiguieron además reducir la pobreza y fueron recompensados con un alto apoyo popular. Frente a los ajustes estructurales de la tecnocracia neoliberal de las décadas anteriores (Ferrer, 1998), recuperaron la capacidad del Estado de intervenir políticamente en los asuntos económicos y sociales, como al mismo tiempo intentaron atender y canalizar las demandas de los movimientos sociales en cuestiones identitarias, de justicia social o defensa del medio ambiente. Estos gobiernos progresistas de Argentina, Ecuador, Brasil, Bolivia, Uruguay y Venezuela pusieron en marcha una estrategia de integración regional, como es UNASUR, que consolidó una forma de insertarse internacionalmente en bloque, como también trató de representar un modelo de acumulación diferente del neoliberal y extractivista.

Sin embargo, el actual horizonte político es, a simple vista, menos esperanzador y optimista para América Latina de lo que fue durante los primeros años del siglo XXI. La dramática caída del precio de las materias primas - principal sostén de las políticas distributivas de los gobiernos progresistas-y la crisis financiera global iniciada en el año 2008 redujeron la actividad económica de los países de la región (Morales, 2016). En consecuencia, aumentó la inflación y se elevó el descontento ciudadano que motivó un giro electoral hacia gobiernos conservadores y de derecha. Con tales antecedentes, los textos de Manuel Alcántara, Ludolfo Paramio, Marisa Revilla Blanco y Juan Carlos Monedero deben ser leídos en el contexto de un ciclo reciente que prácticamente tocó su fin. Aunque, por supuesto, dejan importantes lecciones en cuanto a pensar cómo se procesan en América Latina los proyectos desarrollistas. Tal vez el aprendizaje para futuras y próximas experiencias esté puesto en que, frente a las políticas más austeras y restrictivas recomendadas por los expertos y las tecnocracias internacionales, es conveniente, de vez en cuando, dejar de lado la receta 
milagrosa del crecimiento económico y que, en cambio, lo importante es alentar la construcción de auténticas sociedades democráticas.

\section{CAMINOS DE IDA Y VUELTA}

En el sexto y último capítulo de esta antología rescatamos a tres autores que representan con sus propias trayectorias estos caminos de ida y vuelta entre América Latina y España. Son unos autores marcados por los exilios y las migraciones y que han recorrido, si cabe, unos caminos transatlánticos de aprendizajes, experiencias, intercambios y diálogos. Así Marcos Roitman, nacido en Chile pero exiliado en España, o Enrique V. Iglesias y Jesús Martín Barbero, nacidos en España pero emigrados a Uruguay y a Colombia respectivamente, representan esos fructíferos entrecruzamientos. Con la selección de estas voces pretendemos, fundamentalmente, dar cuenta de la riqueza de las ciencias sociales latinoamericanas y la variedad de escuelas, saberes culturales, históricos, sociales y económicos sobre la región.

Precisamente el texto de Marcos Roitman descuella por su particular y personal forma de entender la evolución de las ciencias sociales latinoamericanas, ligándolas a los procesos económicos, históricos y políticos de la región. Este autor, de hecho, ha venido desarrollando esta perspectiva en libros como Pensamiento sociológico y realidad nacional en América Latina, del año 2002, y Pensar América Latina: El desarrollo de la sociología latinoamericana, publicado en $2008^{12}$. Pues, sin duda alguna, un rasgo característico de estas disciplinas ha sido su integración en los procesos de cambio, lo que las ha permitido combinar el conocimiento científico con la inclinación política. De esta forma, las ciencias sociales han sido históricamente entendidas como un instrumento desenmascarador de numerosos problemas sociales, donde la praxis y la militancia jugaron un rol significativo a la hora de promover proyectos alternativos de sociedad para América Latina (Marsal, 1979). Sin embargo, Roitman advierte en el texto aquí seleccionado que las nuevas generaciones de científicos sociales latinoamericanos acusan en la actualidad la ausencia de capacidad crítica para pensar, razonar y elaborar auténticas teorías sociales. Su postura hay que entenderla como una llamada de atención respecto al ajuste de modelos teóricos pensados fuera de la región y a la crisis general de paradigmas y teorías. Su solución, en cambio, es ofrecer una relectura de los fundadores, de las tradiciones y de las escuelas de pensamiento social latinoamericano más destacadas, como el estructuralismo

12 Otro importante trabajo de Marcos Roitman que no queremos dejar la oportunidad de señalar es el que escribió, junto a Pablo González Casanova, La democracia en América Latina. Actualidad y perspectivas, del año 1992. 
cepalino, el dependentismo y otras corrientes de la sociología crítica. Pues este ejercicio, también político, nos suministra abundantes ejemplos de autonomía académica, independencia de pensamiento, categorías propias, y, en fin, nos proporciona menos ataduras intelectuales respecto a la dependencia exterior.

Justo en esa línea de reabrir el estudio de las escuelas y corrientes de pensamiento social latinoamericano se entiende la selección del texto de Enrique V. Iglesias. Este autor destaca por haber sido miembro de esa importante escuela de teoría económica, social y política que ha sido la CEPAL de Santiago de Chile (Rodríguez, 1988; Faletto, 1996; Di Filippo, 2007). Además él ha sido un practicante privilegiado de la política regional a la hora de aunar la reflexión académica y la praxis en lo que concierne a las políticas de desarrollo de gran número de países de América Latina. Su trayectoria es ejemplo de esa relación específica entre conocimiento especializado y capital político. Por ejemplo, Iglesias fue un actor destacado de los procesos económicos y políticos uruguayos de la década del sesenta a partir de la Comisión de Inversiones y Desarrollo Económico (CIDE), para asumir después un protagonismo regional mayor como Secretario Ejecutivo de la CEPAL, como Presidente del Banco Interamericano (BID) y, más recientemente, como el primer Secretario General Iberoamericano. Todo ese entronque le ha permitido hilar, en numerosos escritos, una visión panorámica sobre la forma que tiene de operar el capitalismo regional en los márgenes del sistema económico y financiero mundial. Aquí rescatamos, en ese sentido, un texto en el que sobresalen algunos rasgos del pensamiento heterodoxo de la CEPAL. Su lectura es del todo actual, pues Iglesias nos recuerda que, frente a la visión ortodoxa y tecnocrática dominante que considera al mercado el único camino capaz de garantizar un crecimiento económico elevado, se impone, en cambio, fortalecer al Estado como actor clave para crear las condiciones necesarias que erradiquen definitivamente la pobreza y promuevan, a su vez, el desarrollo económico y social en la región.

Desde otra perspectiva y para cerrar la antología, se incluye un texto de Jesús Martín Barbero dedicado a las cartografías culturales y comunicativas de América Latina. Este autor cuenta con una extensa y dilatada trayectoria en la región desde que a mitad de los años setenta llegase a Colombia para fundar el Departamento de Ciencias de la Comunicación de la Universidad del Valle. Después protagonizó importantes actividades académicas e investigadoras relacionadas con las áreas de la comunicación, la cultura, la gestión cultural o las industrias culturales en otras universidades colombianas y mexicanas. Todos sus aportes, sintetizados en su clásico libro De los medios a las mediaciones. Comunicación, cultura y hegemonía, del año 1987, le 
han valido para ser reconocido como uno de los mejores exponentes de los estudios culturales, la sociología de la cultura y de los medios de comunicación del actual pensamiento social latinoamericano. Precisamente aquí recuperamos un texto más contemporáneo que recoge, en líneas generales, la matriz de su pensamiento alrededor del poder de la audiencia y de su papel político en la configuración de su propio mundo. Pues las preocupaciones más recientes de Martín Barbero giran, precisamente, en repotenciar algo que los intelectuales y los teóricos de las ciencias sociales creían como muerto: la muchedumbre de la calle, sus nuevos lazos sociales, sus creatividades y sus nuevas formas de hacer política, cada vez más mediadas por las tecnologías de la información y las redes sociales. No hay mejor forma, en fin, de concluir esta antología con un texto que señale la potencialidad de lo social; un rasgo, sin duda, muy distintivo de América Latina, de su política y de sus pueblos.

\section{PALABRAS FINALES}

El anterior repaso pormenorizado de los autores y los textos seleccionados que componen esta antología dedicada al pensamiento social español desde y sobre América Latina ha permitido comprender un poco más la historia cruzada de las ciencias sociales a ambas orillas del Atlántico. Por un lado, la apuesta por una perspectiva intelectual crítica, histórica e inclusiva ha hecho posible trazar una línea continua y, sobre todo, ha permitido reconocer el papel fundamental de los sociólogos del exilio, los sociólogos emigrados y los científicos sociales periféricos y marginales al interior de la España franquista por seguir la evolución del pensamiento social latinoamericano. Unos eslabones que se consolidaron y se reconocieron con la vuelta a la democracia. Por otro lado, se apostó al mismo tiempo por una mirada que privilegiase los puentes y las conexiones entre los dos mundos académicos y culturales. De esta forma, se ha querido demostrar cómo el pensamiento social español evolucionó en relación al laboratorio social y político de América Latina. De hecho, para muchos de los pensadores recogidos en este volumen fue importantísima en su trayectoria biográfica y profesional su experiencia de vida en la región, participando en sus procesos de cambio y combinando a la vez reflexión intelectual y compromiso político. Con ellos logramos entender que los problemas latinoamericanos son también parte de nuestros problemas españoles, europeos y occidentales, sobre todo cuando hoy día compartimos las ataduras a la democracia por parte de las fuerzas económicas y financieras.

Con esta antología, además, se pretende poner en valor el legado crítico de las ciencias sociales en español. En el contexto actual mar- 
cado por la tensión permanente entre la autonomía y la dependencia académica e intelectual, el análisis serio y riguroso de estos clásicos y contemporáneos merece un espacio en los debates académicos y públicos. Ese fue y sigue siendo hoy día también el mismo empeño de varios de los autores aquí recogidos, quienes pensaron y siguen pensando lo social latinoamericano - y también lo social españolprocurando no dejarse arrastrar completamente por la fuerza del embate académico de los países centrales. En las páginas que siguen se encontrarán, en ese sentido, abundantes ejemplos por forjar un pensamiento colectivo caracterizado por importantes hallazgos teóricos, por una fina sensibilidad hacia los problemas sociales y por un especial sentido histórico. Por supuesto, en todos los textos descuella una aspiración común de mejora y suministran abundantes ejemplos de pensar libremente las ciencias sociales.

Toda obra, por supuesto, es responsabilidad de su autor. Por tal motivo, espero que los textos seleccionados colmen las expectativas de ofrecer una panorámica visión de cómo el pensamiento social español ha analizado, ha pensado y ha vivido América Latina. Seguramente se echarán en falta algunos nombres, pues toda selección, por desgracia, es caprichosa. La tarea de editor involucró, justamente, cuestiones personales, académicas e intelectuales, donde tomar distancia siempre es difícil. En todo caso se ha procurado abarcar, de forma honesta, las escuelas, las corrientes y los aportes de quienes tuvieron y siguen teniendo un papel relevante en la construcción de esta área académica. El atractivo de este volumen, en última instancia, permite traer a la memoria el variado, rico y fructífero pensamiento social español desde y sobre América Latina escrito durante las últimas décadas. Naturalmente, queda en manos del lector ponderar si este esfuerzo generalizador, pese a sus inevitables injusticias, consiguió sus propósitos.

Para ir concluyendo, quiero agradecer a CLACSO la confianza entregada para hacerme responsable de la edición de esta antología. Me acuerdo también de Juan Luis Recio Adrados y Leoncio López Ocón por las observaciones ofrecidas y los consejos que me entregaron para afinar la selección de autores. Agradezco a Fernanda Beigel, a Paola Bayle y a Juan José Navarro el haberme aportado las claves necesarias para conocer e interpretar la historia de la sociología y de las ciencias sociales latinoamericanas. Ha sido muy importante, igualmente, el diálogo permanente con Alberto J. Ribes y María del Carmen Rodríguez para entender la historia de la sociología española del siglo $\mathrm{XX}$. No quiero olvidarme, tampoco, del buen recibimiento recibido por parte de mis nuevos colegas de la Escuela de Sociología de la Universidad Católica Silva Henríquez. Por último, me alegra especialmente poder agradecer a José Enrique Rodríguez Ibáñez sus valiosos 
comentarios y sus sugerencias de siempre. Junto a él me encaminé, en el Grupo de Investigación de la Universidad Complutense de Madrid "Sociología en Lengua castellana: perspectiva histórica", al estudio de la historia de la sociología española e hispanoamericana. Como gratitud de ese aprendizaje, a él va dedicado este trabajo.

\section{BIBLIOGRAFÍA}

Ansaldi, Waldo; Giordano, Verónica 2012 América Latina. La construcción del orden, Tomo 2 (Buenos Aires: Ariel).

ASLEP 1967a "Constitución de la Asociación de Sociólogos en Lengua Española y Portuguesa (ASLEP)" en Anuario de Sociología de los Pueblos Ibéricos, Vol. III (Madrid) pp. 293-295.

ASLEP 1967b "Escuela Ibérica de Sociología y Desarrollo" en Anuario de Sociología de los Pueblos Ibéricos, Vol. III (Madrid) pp. 296-301.

ASLEP 1968 "Instituto de Sociología y Desarrollo del Área Ibérica" en Anuario de Sociología de los Pueblos Ibéricos, Vol. IV (Madrid) pp. 277-311.

Beigel, Fernanda (dir.) 2010 Autonomía y Dependencia Académica. Universidad e investigación científica en un circuito periférico: Chile y Argentina (1950-1980) (Buenos Aires: Biblos).

Beigel, Fernanda 2009 "La FLACSO chilena y la regionalización de las ciencias sociales en América Latina (1957-1973)" en Revista Mexicana de Sociología, N 2, pp. 319-349.

Cardoso, Fernando H. y Faletto, Enzo 1969 Dependencia y desarrollo en América Latina (México DF: Siglo XXI).

Cardoso, Fernando H. y otros 1982 Medina Echavarría y la sociología latinoamericana (Madrid: Ediciones de Cultura Hispánica).

Casas Gragea, Ángel María (ed.) 2006 La teoría de la dependencia (Madrid: Ediciones de Cultura Hispánica).

Cervera, Joaquim M. y Milanesi, Giancarlo 2008 Sociología de la religión (Madrid: Editorial CSS).

Cuda, Emilce 2013 "Teología y política en el discurso del papa Francisco ¿Dónde está el pueblo?” en Nueva Sociedad, N 248 , pp. 11-26.

Cueva, Agustín 1988 "Sobre exilios y reinos. (Notas) Críticas sobre la evolución de la sociología sudamericana" en Estudios Latinoamericanos (México DF: CELA-UNAM).

Cueva, Agustín 2008 "Análisis "posmarxista" del Estado latinoamericano" en Cuadernos del Pensamiento Crítico Latinoamericano (Buenos Aires: CLACSO) No 2, pp. 17-24. 
De Miguel, Amando, 1975 Sociología del franquismo (Madrid: Editorial Euros).

Del Campo, Salustiano (dir.) 2001 Historia de la sociología española (Barcelona: Ariel).

Devés, Eduardo 2003 El pensamiento latinoamericano en el siglo XX. Desde la CEPAL al neoliberalismo 1950-1990, Tomo II (Buenos Aires: Editorial Biblos).

Di Filippo, Armando 2007 "La Escuela Latinoamericana del Desarrollo" en Cinta de Moebio, No 29, pp. 124-154.

Dos Santos, Theotonio 2011 Imperialismo y Dependencia (Caracas: Biblioteca Ayacucho de Clásicos Políticos da América Latina / Banco Central de Venezuela).

Durand Ponte, Víctor 1973 "Informe sobre el Seminario Sociología del Desarrollo y Desarrollo: Dependencia y Estructuras de Poder" en Boletín CLACSO, Año V, No 20-21, pp. 20-23.

Escobar, Luis Alberto 2011 Francisco Ayala y la Universidad Nacional del Litoral. La construcción de una tradición sociológica (Granada: Fundación Francisco Ayala / Universidad de Granada).

Faletto, Enzo 1996 "La CEPAL y la sociología del desarrollo" en Revista de la CEPAL, N 58, pp. 191204.

Faletto, Enzo 1999a "Los años sesenta y el tema de la dependencia" en Revista de Sociología, ํ13, pp. 119-126.

Faletto, Enzo 1999b "De la teoría de la dependencia al proyecto neoliberal: el caso chileno" en Revista de Sociología, $\mathrm{N}^{\circ} 13$, pp. 127-140.

Ferrer, Aldo 1998 “América Latina y la globalización” en Revista de la CEPAL, número extraordinario, pp. 155-168.

Ferrer, Aldo 2008 "Globalización, desarrollo y densidad nacional" en Cuadernos del Pensamiento Crítico Latinoamericano (Buenos Aires: CLACSO) $\mathrm{N}^{\mathrm{o}} 4$, pp. 43-48.

Franco, Rolando 1974 "Veinticinco años de sociología latinoamericana. Un balance" en Revista Paraguaya de Sociología, $\mathrm{N}^{\circ} 30$, pp. 57-92.

Franco, Rolando 2007 La FLACSO clásica (1957-1973). Vicisitudes de las Ciencias Sociales latinoamericanas (Santiago de Chile: Catalonia / FLACSO-Chile).

Furtado, Celso 1988 La fantasía organizada (Buenos Aires: Eudeba).

Garretón, Manuel Antonio 1989 "La evolución de las ciencias sociales en Chile y su internacionalización. Una síntesis" en Documento de trabajo. Programa FLACSO-Chile, $\mathrm{N}^{\circ} 432$. 
Germani, Gino 1956 La sociología científica (México DF: Universidad Nacional Autónoma de México).

Germani, Gino 1959 "Desarrollo y estado actual de la sociología latinoamericana" en Boletín del Instituto de Sociología, N $\mathrm{N}^{\circ}$ 17, pp. 423-454.

Giner, Salvador; Moreno, Luis (eds.) 1990 Sociología en España (Madrid: Consejo Superior de Investigaciones Científicas).

Gómez Arboleya, Enrique 1958 "Sociología en España” en Revista de Estudios Políticos, $\mathrm{N}^{\circ}$ 98, pp. 47-83.

Graciarena, Jorge 1978 “Entre realidad y utopía. La dialéctica de las ciencias sociales latinoamericanas" en Revista de la CEPAL, $\mathrm{N}^{\circ} 5$, pp. 35-63.

Graciarena, Jorge 1988 "Una esperanzada visión de la democracia" en Revista de la CEPAL, $\mathrm{N}^{\circ} 35$, pp. 83-92.

Gurrieri, Adolfo (ed.) 1980 La obra sociológica de José Medina Echavarría (Madrid: Ediciones de Cultura Hispánica).

Ianni, Octavio 1971 "La sociología de la dependencia en América Latina” en Revista Paraguaya de Sociología, No 21, pp. 18-29.

Lamo de Espinosa, Emilio 1990 “Teoría sociológica” en Giner, Salvador y Moreno, Luis (eds.) Sociología en España (Madrid: Consejo Superior de Investigaciones Científicas) pp. 71-103.

Lizcano Pellón, Manuel 2005-2006 "Epílogo autorreflexivo" en Revista Iberoamericana de Autogestión y Acción Comunal, $\mathrm{N}^{\circ} 45-$ 47, pp. 17-74.

Löwy, Michel 1999 Guerra de dioses. Religión y política en América Latina (México DF: Siglo XXI).

Maestre Alfonso, Juan 1991 "Introducción” en Maestre Alfonso, Juan (ed.) José Medina Echavarría (Madrid: Ediciones de Cultura Hispánica) pp. 11-21.

Marsal, Juan Francisco 1977 Teoría y crítica sociológicas (Madrid: Biblioteca Universitaria Guadiana).

Marsal, Juan Francisco 1979 Dependencia e independencia. Las alternativas de la sociología latinoamericana en el siglo XX (Madrid: Centro de Investigaciones Sociológicas).

Morales, Juan Jesús 2009 “Hacer la América: Una estrategia alternativa al proceso de inserción académica en la sociología española" en Nómadas. Revista Crítica de Ciencias Sociales y Jurídicas, $\mathrm{N}^{\circ} 24$, pp. 159-172.

Morales, Juan Jesús 2010 "José Medina Echavarría y la sociología del desarrollo" en Íconos: Revista de Ciencias Sociales, $\mathrm{N}^{\circ} 36$, pp. 133-146. 
Morales, Juan Jesús 2014 “Algunos elementos sobre el intento de institucionalizar una tradición sociológica científica y reformista en España 1931-1936)" en Nómadas. Revista Crítica de Ciencias Sociales y Jurídicas, $\mathrm{N}^{\circ} 43$, pp. 35-51.

Morales, Juan Jesús 2015 "Max Weber en el Cono Sur" en Morcillo, Álvaro y Weisz, Eduardo (eds.) Max Weber: una mirada iberoamericana (México DF: Fondo de Cultura Económica / CIDE) pp. 601-626.

Morales, Juan Jesús 2016 "La sociología del desarrollo en América Latina: una tensión permanente entre democracia y crecimiento económico" en Espacio Abierto: Cuaderno Venezolano de Sociología, Vol. 25, ํ3, pp. 171-182.

Morales, Juan Jesús y Rodríguez, María del Carmen 2009 "Marsal y la emigración en América: biografía, historia y sociedad" en Morales, Juan Jesús y Rodríguez, María del Carmen (eds.) Juan Francisco Marsal (Madrid: Ediciones de Cultura Hispánica) pp. 13-41.

Morcillo, Álvaro 2010 "El forastero que se queda: José Medina Echavarría y la sociología latinoamericana" en González Navarro, Moisés (ed.) José Medina Echavarría y México. José Medina Echavarría: correspondencia (México DF: El Colegio de México) pp. 343-372.

Morente, Felipe 1998 “Enrique Gómez Arboleya. Un clásico joven de la sociología española" en Revista Española de Investigaciones Sociológicas, $\mathrm{N}^{\circ} 83$, pp. 291-301.

Morente, Felipe 2000 "Sociología en España. Una aproximación sintética" en Revista de Estudios Políticos, N 108, pp. 271-292.

Moya, Carlos 1970 Sociólogos y sociología (Madrid: Siglo XXI).

Moya, Laura Angélica 2007 "José Medina Echavarría y la colección de Sociología del Fondo de Cultura Económica, 1939-1959” en Estudios Sociológicos, N ${ }^{\circ} 75$, pp. 765-803.

Ocampo, José Antonio 2012 La historia y los retos del desarrollo latinoamericano (Santiago de Chile: CEPAL).

Pérez Brignoli, Héctor 2008 Los 50 años de la FLACSO y el desarrollo de las Ciencias Sociales en América Latina (San José de Costa Rica: Editorial Juricentro).

Ribes, Alberto 2002 "Introducción a la sociología de Francisca Ayala: Reflexiones en torno a la 'Ley de unificación del mundo"' en Sistema: Revista de Ciencias Sociales, No 166, pp. 101-111.

Ribes, Alberto 2004 "Sociología y literatura en Francisco Ayala" en Política y sociedad, Vol. 41, $\mathrm{N}^{\circ}$ 2, pp. 53-73. 
Ribes, Alberto 2007 Paisajes del siglo XX: sociología y literatura en Francisco Ayala (Madrid: Biblioteca Nueva).

Ribes, Alberto 2011 "Visiones sobre la sociología española: hacia las narrativas abiertas y sacerdotales" en Nómadas. Revista Crítica de Ciencias Sociales y Jurídicas, № 32, pp. 545-558.

Rodríguez Ibáñez, José Enrique (ed.) 2008 Enrique Gómez Arboleya. Obra póstuma (Madrid: Centro de Investigaciones Sociológicas).

Rodríguez Ibáñez, José Enrique 2004 “Epílogo” en Política y Sociedad, Vol. 41, $\mathrm{N}^{\circ}$ 2, pp. 199-201.

Rodríguez, Octavio 1988 La teoría del subdesarrollo de la CEPAL (México DF: Siglo XXI).

Roitman, Marcos 2008 Pensar América Latina. El desarrollo de la sociología latinoamericana (Buenos Aires: CLACSO).

Sotelo, Ignacio, 1979 "A manera de prólogo: Juan Francisco Marsal, el sociólogo de la emigración" en Marsal, Juan Francisco (ed.) Dependencia e independencia. Las alternativas de la sociología latinoamericana en el siglo XX (Madrid: Centro de Investigaciones Sociológicas).

Urquidi, Víctor 2005 Otro siglo perdido. Las políticas de desarrollo en América Latina 1930-2005) (México DF: El Colegio de México / Fondo de Cultura Económica).

Vergara, Pilar 1985 Auge y caída del neoliberalismo en Chile (Santiago de Chile: FLACSO).

Weffort, Francisco 1970 "Notas sobre la "teoría de la dependencia": ¿teoría de clase o ideología nacional?" en Revista Latinoamericana de Ciencia Política, N 3, pp. 389-414. 



\section{Los sociólogos del exilio y de la emigración}





\section{Francisco Ayala}

\section{LA INTEGRACIÓN SOCIAL EN INDOAMÉRICA*}

NO HACE MUCHO TIEMPO se celebró en Guatemala un Seminario de Integración Social con la finalidad de estudiar la realidad de la estructura sociológica de aquel país y sus problemas básicos. Participaron en el foro sociólogos, etnólogos y economistas de todo el continente americano, inclusive varios españoles radicados en América; y aunque, de acuerdo con el programa, se desarrolló en forma controversial, las discusiones estuvieron ceñidas en todo momento a las exigencias del planteamiento científico, sin que jamás prevalecieran otras intenciones de orden más inmediato.

La intervención de los norteamericanos fue muy notable, y merece subrayarse como significativa en diversos aspectos. Por su buena fe, voluntad de servicio y espíritu objetivo, redime el nombre de su país la antipatía que le concitan a veces intervenciones de otro tipo, obra esta de la actuación desaforada de negociantes y políticos. Los hombres de ciencia allí reunidos (varios de los cuales están familiarizados con el mundo hispánico a través de años de dedicación profesional al desarrollo de Puerto Rico, y todos ellos conocedores y estudiosos de Latinoamérica) dieron una nota muy alta, de seriedad, interés y competencia, en el análisis y discusión de las realidades sociales guatemaltecas.

* Ayala, Francisco 1958 "La integración social en Indoamérica" en La integración social en América (Buenos Aires: Nova) pp. 9-20. 
En cuanto a estas realidades (semejantes, si no idénticas en lo fundamental, a las de la mayoría de los países hispanoamericanos con base de población indígena) son lo bastante distintas, en cambio, de las que caracterizan al Río de la Plata como para que valga la pena presentar aquí un ligero esbozo, que a muchos lectores les traerá, sin duda, algo de novedad. Todos han oído hablar, desde luego, del problema indio: pero no todos saben ni aproximadamente en qué consiste y cómo se plantea ese problema; desconocen, por ejemplo, que en Guatemala, como en muchos otros países de nuestra América, subsiste todavía una doble estructura que se compone de una sociedad a la que se ha venido llamando "nacional" en el Seminario de referencia, instalada sobre comunidades indígenas inasimiladas, las cuales perviven hasta la fecha dentro de formas culturales aborígenes. Poco más o menos la mitad de población de Guatemala está formada todavía en la actualidad por estos indios que, agrupados en sus propios cuadros sociales, ignoran la lengua española y participan escasamente en la vida pública del país. Las comunidades indígenas — que, por otra parte, son independientes entre sí, hablan distintos idiomas y no constituyen unidad sino vistas desde fuera, pues ellas mismas son cerradas las unas frente a las otras- en su conjunto estás separadas, como una casta, de los llamados "ladinos", es decir, de los guatemaltecos latinizados e incorporados a la civilización general del Occidente cristiano, esa otra mitad de la población total guatemalteca que - estratificada horizontalmente en clases- se le superpone, y en la cual se funda la existencia del país como nación.

Resulta obvio, y las leves indicaciones que preceden bastan para evidenciarlo, que estamos con esto en presencia de un proceso de transculturación incompleto, y que se encuentra todavía a medio cumplir hasta la fecha, sobre una gran parte del suelo americano la obra de incorporación iniciada, a raíz del descubrimiento, mediante la conquista y dominación española. La separación de indios y ladinos en dos planos sociales marca la línea divisoria neta de una estructura de dominación, que no es otra sino la creada en un comienzo por el hecho de la conquista, y que es independiente de las tensiones y más o menos inestables equilibrios de poder que se dan en el seno de la sociedad superpuesta, y que ocasionan ahora las alternativas y avatares de la política nacional guatemalteca, como antes los conflictos sociales y personales entre las diferentes autoridades de la colonia. Por debajo de esa línea divisoria están situadas las diversas comunidades indígenas, remanente de culturas precolombinas en vías de incorporación a la civilización occidental, de la cual permanecen todavía al margen; por encima de ella, la sociedad "ladina", escalonada en clases, y a la que se van agregando paulatinamente, pero sin cesar, nue- 
vos elementos procedentes de esa especie de zócalo o subsuelo social constituido por la casta aborigen; con lo cual — dicho sea de paso-el proceso de transculturación prosigue.

Es interesante observar que esta realidad básica apenas ha sido considerada y tomada en cuenta antes de ahora desde los días de la independencia; se prefería omitirla, ignorarla, pues su perduración contradecía de manera escandalosa los principios fundamentales de la ideología nacionalista y liberal en que se inspiraron los llamados movimientos emancipadores, y era un desmentido flagrante a muchas de las soflamas empleadas para calentar los nuevos patriotismos. De otra parte, la cristianización precipitada y en masa, pero muy efectiva sin embargo, que habían operado los conquistadores ayudaba a ocultar el hecho de las diferencias culturales subsistentes. ¿No eran acaso católicos, y de una fe inconmovible y cándida, los campesinos indios? Su tozuda adhesión a costumbres y prácticas tradicionales en ellos debía tomarse, pues, como una manifestación de estupidez rústica, y nada más. Ni siquiera resultaban demasiado perturbadoras esas diferencias culturales para la explotación señorial. Desde la conquista hasta la revolución tecnológica de nuestros días los métodos de cultivo siguieron siendo hasta cierto punto elementales, y en la etapa agrícola de la civilización poco significan tales diferencias para un trabajo y una producción tan ligados al orden de la naturaleza. Por eso mismo, tampoco fue rápido, sino más bien quedó estancado, el proceso de transculturación. Después de la forzada y veloz adopción del cristianismo por las poblaciones sometidas, la asimilación cultural de ellas se hizo lenta en grado sumo. $\mathrm{Ni}$ aun en el aspecto religioso puede considerarse todavía completa. Los sociólogos que han actuado al indígena actual descubren un fuerte sincretismo entre las creencias católicas y las aborígenes, insertadas en el marco de aquellas, así como una relación de los fieles con la iglesia, no directa, sino mediatizada por las jerarquías de cada comunidad india y cumplida a través de ella. Con eso y todo, el paso fundamental para la transculturación está dado; lo dieron desde un principio los conquistadores; y al cumplirse quedaron ya privadas de vitalidad para siempre, y como desmeduladas las viejas culturas. Quienes no han salido de su seno tienen que llevar, por insoslayable destino, solo una vida letárgica, apagada y disminuida, a la espera de su activa incorporación a la corriente de la historia dentro del orden de los marcos sociales occidentales —una incorporación que, por lo demás, escasamente desean.

En conjunto, el panorama cultural de Guatemala presenta a primera vista el cuadro de una sociedad compuesta por dos sectores culturalmente heterogéneos (con las correspondientes subdivisiones dentro de cada uno de ellos), y entre los cuales se está cumpliendo 
un proceso de transculturación; en seguida, una formación nacionalista que, sostenida en el sector dominante, opera dentro del orden del Estado y a través de él; y, en fin, el fenómeno de una transformación social de profundo calado, económico-tecnológica en sus bases, y servida en su instrumentación por movimientos políticos de diversa fisonomía.

En cuanto al primer aspecto, ya quedó bosquejado en sus rasgos formales. Por lo que respecta al contenido, bastará recordar que la cultura superpuesta y dominante es, desde luego, la cristiana occidental, precisando además — pues es importante recalcarlo- que se trata de la versión española de esta cultura, con modalidades que son, para bien o para mal, muy definidas y persistentes en toda Hispanoamérica. Alguno de los sociólogos que han estudiado a Guatemala y han aportado al referido seminario el fruto de esos estudios, ofreció una caracterización de ellas, en términos de actitudes típicas, que yo encuentro bastante satisfactoria y por lo general acertada. Pero es digno de notarse - como allí se observó- que esa caracterización, formulada con vistas a Guatemala, resulta aplicable por igual a cualquier otro país de la América hispana y a España misma. En verdad, contemplado desde el ángulo de los trazos culturales típicos, todo el mundo hispánico forma unidad, sin perjuicio de las diferencias muy acentuadas que, por debajo de ella, ofrecen sus distintos países y regiones.

Esas diferencias se han intensificado todavía con cierta deliberación, a partir de las guerras de independencia, como resultado del concepto nacionalista, bajo cuya ideología se organizaron los numerosos Estados políticos salidos del viejo Imperio español. Y este es el segundo elemento de importancia mayor que se descubre en la presente realidad guatemalteca, igual que en la de los restantes países hispanoamericanos. Actúa en ellos un complejo ideológico asumido como instrumento de esa vida nacional independiente que constituyó la perspectiva política del siglo XIX y mitad del actual, en el que se inspiraron los programas de los patricios liberales en un principio, y luego de las clases medias empeñadas en afirmarse, consolidarse y prevalecer.

No hay duda de que muchos de los trastornos sufridos por las modernas "naciones" de original acuñación española, empezando por España misma, desde comienzos del siglo pasado, provienen de la incongruencia entre estos principios modernos y aquella acuñación original en valores culturales que ya no corresponden a la situación efectiva, pero que pueden agarrarse a las viejas instancias de la propiedad y economía, y perdurar, y hasta imponerse con demasiada frecuencia al amparo de ciertas instituciones tradicionales.

Lo que sí aparece ahora como un fenómeno nuevo, y preludia una transformación completa del ambiente hispanoamericano, es la revo- 
lución tecnológica que, aquí como en todas partes, está dejando sentir hoy sus efectos más poderosos. Claro está, que esos efectos son, en gran parte, mediatos, dando lugar a fenómenos político-sociales, cuyo revestimiento ideológico, bastante inadecuado a veces, ilustra poco acerca de su verdadero alcance. Valga de ejemplo el movimiento político establecido en Bolivia, y cuyas formulaciones teóricas, donde se combina el marxismo con un nacionalismo exacerbado de tono fascista, le han acarreado prevenciones y antipatías automáticas, de las que se hubiera visto libre en el caso de poder expresarse a sí mismo sin tales apoyaturas intelectuales extraídas del inmediato pasado europeo. Pero, en general, las clases medias, nutridas en los dogmas oficiales del nacionalismo y seducidas por las postulaciones de justicia social que corresponden a las tendencias internas del desarrollo económico a que van unidas sus aspiraciones de ascenso, no tienen a su alcance otro arsenal de ideas, y necesitan echar mano de esos residuos maltrechos para componer algún programa con sus contradictorios retazos. Armadas de ellos, se dirigen, en los países donde la sociedad está montada sobre una casta de comunidades indígenas, a estos dormidos remanentes de las culturas precolombinas, sacudiéndolos, tratando de activarlos, de sumarlos a su causa, de utilizarlos para sus fines. De las ponencias presentadas al seminario de Guatemala y de otros documentos se desprende con toda claridad este hecho, en virtud del cual las viejas comunidades tradicionales fueron literalmente invadidas y forzadas por los partidos revolucionarios de clase media, con el designio de romperlas e incorporar sus miembros a la política nacional; lo que significa, en definitiva, tanto como asimilarlos, transculturarlos y completar con enérgico impulso y no menos recelo redentorista, la obra que los conquistadores españoles habían iniciado mediante las conversiones en masa al catolicismo, mientras que hasta ahora, en los siglos de la colonia e independencia, cuando el poder político estuvo basado principalmente sobre la explotación de la tierra, desinteresados y aun opuestos sus propietarios a toda evolución cultural de los indígenas, la incorporación de estos a la sociedad occidental se había venido procesando por las vías lentas de la espontaneidad, en los individuos marginales, o en situaciones de excepción.

Distinto es el caso ahora, cuando el proceso económico mundial empuja hacia la industrialización y abre con ella oportunidades crecientes de dirección social a la clase media. Controlada o ejercida por esta, la política del Estado se centra en el propósito de "modernizar" al país, con afirmaciones a un tiempo mismo nacionalistas y sociales, para romper los viejos dispositivos de poder fundados en la propiedad del suelo y para hacer frente a la explotación "imperialista" del exterior, que fue, precisamente, el agente principal del desarrollo hacia la 
industrialización, pero que la industrialización, una vez consumada, habrá de eliminar.

No aparece arriesgado el pronóstico, dadas las corrientes generales de la época, de que la modernización de Guatemala, como la de los demás países que, en todo el mundo, se llaman con burocrático eufemismo "subdesarrollados", tendrá efecto rápidamente. Pero tal modernización impone alteraciones muy sustanciales en la conducta social, introducción de nuevas pautas y abandono de las antiguas, transformación, en fin, de los modos comunes de vida, tanto como una modificación bastante amplia y bastante profunda de la estructura social. Pues los aspectos tecnológico, social y moral no pueden separarse por completo, aunque tampoco sea lícito colocarlos en una escala de determinaciones unilaterales. El empleo de máquinas en el trabajo, en las comunicaciones, en el hogar, trae como consecuencia ineludible la acomodación de la gente a las exigencias implícitas en su uso y la formación de una mentalidad concorde, con modos de conducta y valoraciones sociales adaptados a ella; aun cuando, por otra parte, los modos de conducta y las valoraciones sociales que son tradicionales en un pueblo influirán quizás en la mayor o menor acogida que este quiera prestar al maquinismo y, desde luego, en el estilo de la adaptación que haya de producir para ajustarse a sus requerimientos, que son impersonales y compulsivos.

Todo esto es demasiado evidente; pero cuando la situación, ya de por sí difícil en el supuesto normal de una sociedad homogénea transformándose a resultas de la revolución tecnológica, se complica con un proceso de transculturación, como en los países donde subsiste una casta indígena inasimilada, los problemas se multiplican hasta lo indecible. Pensemos que en aquel caso normal, que puede ser el de las viejas naciones europeas, se hace siempre cuestión, y cuestión seria, de la conservación o abandono - en qué medida lo uno y lo otro- de las actitudes y valores sociales tenidos por característicos de la comunidad nacional. En todas partes se habla, en efecto, desde que se inició dicha revolución, de "americanización" de las costumbres; y por cierto, no son los Estados Unidos el país que menos ha cambiado respecto de su inmediato pretérito, en vías de esta llamada "americanización", que supone la eliminación de elementos muy superficiales o meramente pintorescos, pero también, sin duda, la pérdida de virtudes y disposiciones morales, sustituidas por criterios de pura funcionalidad práctica, por los que se supedita el hombre al colosal mecanismo de la vida colectiva, bien sea reduciendo su personalidad y borrando su carácter individual, bien sea sometiéndole a una existencia de infecunda disconformidad.

Por otro lado, no es menos cierto que, pese a todo el poder conformador que ejerce sobre los hombres, la tecnología es, sin embargo, 
neutra en cuanto a los principios orientadores de la vida; de manera que si la adopción de una técnica y unos modos de trabajo determinados obliga a abandonar cierto tipo de actitudes y conductas no obliga en cambio a sustituirlas por los criterios impersonales de una eficiencia sin fines últimos; antes bien, aconseja revisar el núcleo de los valores comunitarios, para articularlos de manera que, sin renunciar a las ventajas de la máquina, los ponga más bien al servicio de una existencia humana digna y cargada de sentido. El riesgo de semejante conversión y las preocupaciones que debe ocasionar, nunca serán demasiado ponderados.

Y si tal ocurre en sociedades culturalmente homogéneas, ¿qué no decir de aquellas donde la revolución tecnológica es, al mismo tiempo, el instrumento que realiza o acelera un proceso de transculturación? La "modernización" de Guatemala, como la de todos los países hispanoamericanos de análogas condiciones, incorporará con celeridad suma, casi de súbito, las masas indias a la vida "civilizada" de una sociedad que, ella misma, está experimentando una honda crisis, la crisis de esas actitudes hispánicas que los antropólogos caracterizan con bastante precisión, y que han constituido hasta ahora su ethos. Y es legítimo preguntarse, en estas circunstancias, si esas masas indias ingresarán a la modalidad hispana de la cultura occidental o se incorporarán más bien a una civilización técnica desprovista de otros principios que los de pura eficiencia implícitos en la maquinaria misma; si, al irrumpir en la sociedad ahora dominante, no contribuirán a impedir que supere la crisis en términos positivos.

En todo caso, lo seguro es que el proceso ya no puede detenerse; y a este respecto no deja de ser significativa la celebración del Seminario de Integración Social de Guatemala bajo los auspicios de un gobierno cuyos orígenes no prometían iniciativas de ese género. Es que el proceso desencadenado con el derrocamiento de la dictadura de Ubico en 1944 no se ha interrumpido, ni puede interrumpirse ya, cualquiera sea la orientación política de los gobiernos, quienes, quizás acelerándolo, quizás tratando de frenarlo, necesitan de cualquier manera aceptar su manera de ineluctable. 



\title{
José Medina Echavarría
}

\section{LAS RELACIONES ENTRE LAS INSTITUCIONES SOCIALES Y LAS ECONÓMICAS}

\author{
UN MODELO TEÓRICO \\ PARA AMÉRICA LATINA*
}

\section{CUESTIONES TEÓRICAS GENERALES}

Las cuestiones metodológicas y de principio suelen parecer digresión enojosa que no hacen sino retardar el instante de encarar de modo directo los problemas que realmente importan. Tienen por eso un público escaso y siempre conviene manejarlas con mesura. Son, sin embargo, indispensables, cuando se quiere obtener la máxima claridad en los planteamientos. Es decir, para saber, por una parte, qué es lo que puede preguntarse con sentido y, por otra, qué es lo que puede esperarse de la respuesta. Tal como se enuncia en su título, el tema de este trabajo lleva implícitas dos cuestiones, dos supuestos inexpresos, que es necesario considerar previamente. Alude, en efecto, por un lado a las posibilidades de construcción de un modelo del desarrollo económico y social de los países latinoamericanos, modelo en que se muestren además, o se tengan en cuenta, las conexiones recíprocas entre las distintas instituciones. Y, por otro, parece atribuir la tarea de semejante construcción a la especialidad o peculiar punto de vista que supone la sociología. Esas dos cuestiones pueden en consecuencia formularse en la forma de las siguientes preguntas: ¿Qué es lo que

* Medina Echavarría, José 1961 "Las relaciones entre las instituciones sociales y las económicas. Un modelo teórico para América Latina” en Boletín Económico de América Latina (Santiago de Chile) Vol. VI, N ${ }^{\circ}$, pp. 27-39. 
cabe esperar del análisis sociológico en las tareas del desarrollo? ¿Qué significa propiamente la palabra "modelo"?

En otro lugar se examinaron con algún detenimiento las cuestiones más generales que se refieren al papel del sociólogo en las tareas del desarrollo; huelga por eso su reiteración en estos momentos. Conviene, sin embargo, recordar que el alcance de ese papel varía según la amplitud que se asigne a la responsabilidad intelectual de la sociología. Puede considerarse al sociólogo como simple colaborador, entre ciertos límites, en las labores más esenciales del economista; puede concedérsele un campo específico en determinados sectores de la investigación y de la doctrina; o cabe, por último, admitir que en su tarea puede llegar hasta las últimas posiciones crítico culturales y ser por tanto partícipe en las orientaciones generales -incluso políticas- del desarrollo económico.

Pero aquí interesa enfocar la cuestión del valor de la sociología en las tareas del desarrollo en forma distinta. Se exige examinar, por una parte, las relaciones de la sociología con la acción práctica, y, por otra, las conexiones de la construcción teórica con la investigación empírica. Se entiende dentro estrictamente de nuestro tema.

No habría razón alguna para plantear la primera de las cuestiones indicadas si la labor sociológica quedase meramente reducida al ámbito académico del análisis teórico. Pero sucede hoy -no siempre sin peligros- que un vasto público más o menos lego demanda de la tarea sociológica aplicaciones inmediatas de carácter práctico análogas a las que se exigen a otras disciplinas sociales, y a la ciencia económica muy en particular. Demandas de las que participan además organismos de toda índole, públicos y privados. Conviene por eso despejar rigurosamente el terreno, y señalar las distintas pretensiones ofrecidas hasta hoy por la sociología en sus relaciones con la praxis. Claro es que solo se hace aquí en rápido esbozo.

Para una primera concepción de las mencionadas relaciones todavía hoy vigente - la actividad del sociólogo significa una postura crítica de carácter total de la sociedad en que vive y con que se enfrenta; crítica que se apoya por eso de modo necesario en un momento ideológico o de concepción del mundo y que ofrece como resultado la propuesta de una remodelación completa de esa sociedad, en una u otra dirección, de izquierda o derecha.

Para una segunda posición, la pretensión no es tan amplia, pero no por eso menos ambiciosa. Al momento ideológico de la postura anterior sustituye ahora uno de riguroso carácter científico. La sociología se proyecta como una disciplina de naturaleza funcional capaz de desprender, al igual que otras de esa misma clase, orientaciones precisas para la conducta práctica. La praxis derivada del análisis 
sociológico no pretende la reforma o transformación completa de la estructura social, sino la eficaz actuación sobre uno u otro de los componentes de la misma, quizá de acuerdo con metas que le han sido fijadas de antemano. La sociología acentúa en este sentido su significación "operativa” y aspira a ofrecer como otras ciencias un repertorio de afinados instrumentos. Hasta qué punto haya alcanzado la sociología semejante grado de madurez es cosa que no corresponde examinar aquí y ha de quedar por lo menos como cuestión problemática.

En una tercera posición, por último, las relaciones entre teoría y praxis se presentan menos comprometidas, pues no se trata en ella de formular predicciones de estricta precisión científica - aunque sean limitadas - análogas a las del conocimiento de las disciplinas naturales, sino de "comprender" una situación social de carácter histórico. Aspira, por consiguiente, a un tipo de análisis en que se muestre la estructura y las tendencias dinámicas de esa situación, proyectando hasta donde sea posible las diversas probabilidades en ella contenidas. La sociología destaca aquí su valor de "diagnóstico". Y este, una vez realizado, deja a las responsabilidades de la acción y al influjo de otros puntos de vista la elección entre las alternativas posibles. Esta es la postura, importa declararlo, aceptada en este trabajo.

También interesa fijar con igual claridad, y aunque parezca de pasada, el otro punto referente a las relaciones actuales entre la teoría y la investigación empírica. Es muy posible que nos encontremos con una situación - y pudiera quizá probarse con calma- en que existe ya un relativo consenso respecto a los planteamientos generales teóricos en la sociología del desarrollo económico. Al menos puede contarse con cierto número de hipótesis de trabajo que mantienen su validez hasta ahora. No se afirma con ello en modo alguno que hayan perdido todo su interés e importancia tanto la elaboración cuidadosa de la teoría general, como la busca y afinamiento de las categorías e instrumentos conceptuales que se consideren más adecuados.

Con respecto a América Latina parece evidente que las mayores lagunas y fallas no tanto se encuentran en los planteamientos teóricos como en la carencia de las aportaciones concretas de la investigación empírica. Esas investigaciones, aparte el saber que puedan significar por sí mismas, sirven para confirmar o desechar hipótesis generalmente admitidas pero que provienen de otros medios sociales. Podría sostenerse por eso que, en la fase actual del esfuerzo por conocer los aspectos sociales del desarrollo económico, el centro de atención se desplaza y debe desplazarse al acopio de esas investigaciones empíricas de base. En efecto, es necesario reconocer que respecto de un número considerable de problemas carecemos todavía de las descripciones empíricas más elementales. 
Ahora bien, reconocida esa necesidad, deben asimismo encararse de frente algunas de sus dificultades y peligros. Solo cabe esbozarlos en forma apresurada. Como es de todos sabido, las dificultades mayores radican en la escasez $-\mathrm{y}$ a veces total ausencia- de personal competente, en la pobreza de los medios instrumentales y financieros, y en la exigüidad de los centros u organizaciones capaces de coordinar unos y otros.

De otro lado, los peligros provienen en parte del entusiasmo con que se acoge hoy la denominada "investigación científica". Y consisten más que nada en lo que podría llamarse un afán imitativo, innecesariamente perfeccionista, que puede malograr no ya los resultados, sino el simple planteamiento de muchas investigaciones. Es urgente desde luego poseer un cuadro que ponga en orden preciso y sistemático las que son más indispensables, pero no menos importa una conciencia clara de los límites en que deben realizarse. Dada la situación de América Latina se requiere plantear investigaciones que no pretendan llenar el máximo de la aspiración científica, sino que en forma modesta en determinadas ocasiones ofrezcan los primeros pasos en el conocimiento de la realidad.

Siempre y en todas partes el avance de la ciencia social $-\mathrm{y}$ de la sociología muy en particular - se ha realizado en torno de algunos temas que, distintos según los momentos, polarizaban la atención no solo de científicos y políticos, sino del público en general. El "tema del desarrollo económico" en América Latina tiene esa significación capital en estos momentos. Conviene por eso hacerlo explícito, para que desde su perspectiva - como centro de convergencia y orientación teóricas- se analicen no solo las cuestiones estrictamente económicas, sino todas las relacionadas con ellas en forma muy estrecha, como son las sociales, políticas, educativas, etcétera.

\section{EL “TIPO IDEAL” DEL DESARROLLO EN LA HISTORIA OCCIDENTAL WEBER Y LAS CONDICIONES SOCIALES DE LA ECONOMÍA LIBERAL}

Cuando se trata de construir un modelo del desarrollo económico suelen seguirse dos caminos: o se acude al historiador o se invoca al economista. Quizá lo más fecundo sería no separar en momento alguno ambas perspectivas, pero son escasas las figuras y los libros en que se da semejante compenetración. Por eso nada tiene de extraño la frecuencia con que se acude en nuestros días a la obra de Max Weber en busca de inspiración y enseñanza. En efecto, cuando desde una perspectiva histórica se quiere entender lo ocurrido en el desarrollo económico de occidente - de elaborar por tanto el tipo ideal de su trayectoria- no puede eludirse un primer contacto a fondo con la inter- 
pretación del sociólogo alemán. Sin embargo, a pesar de la reiterada apelación a sus teorías en el momento actual, no siempre se muestra con claridad la doble contribución que su obra representa, pues si, por un lado, es el intento hasta ahora más plausible de interpretar el origen y la formación de la moderna economía occidental, por otro, ofrece quizá también la construcción más acabada del "modelo" o paradigma de la estructura liberal-capitalista de una sociedad. Conviene recordar sucesivamente y en forma sumaria estos dos momentos.

Sabido es que el esquema weberiano del origen histórico del capitalismo — del moderno sistema industrial — trata de responder a una pregunta incisiva sobre cuál sea la peculiaridad más significativa de la cultura occidental. Es decir, intenta encontrar las razones de este hecho: que el capitalismo solo se haya producido en Europa con las notas que hoy se aceptan como típicas de su forma industrial, aunque antes y en otras partes del mundo se diera con diversas características. A tenor de la aguada versión de los manuales, la ética religiosa del protestantismo - del calvinismo en particular - vendría a ser algo así como la causa del capitalismo moderno. Sería impertinente ahora ni siquiera insinuar el carácter simplista de semejante y vulgarizada versión; como tampoco es cosa de considerar, ni aun en forma alusiva, la polémica desencadenada por la auténtica tesis weberiana. Es de suyo evidente, y bastaba para comprobarlo en caso de duda con una rápida ojeada a su Historia económica general, que Weber conocía toda la complejidad del problema y que en modo alguno se desentendió de los factores externos que favorecieron la formación del capitalismo europeo.

Pero para lo que ahora importa - los fines que presiden este trabajo- es posible prescindir de todo lo que no sean dos elementos esenciales. El primero se refiere a la formación de lo que más tarde denominaremos disposición económica general; el segundo guarda relación con las condiciones que hicieron posible el despliegue efectivo de la mencionada disposición. En palabras de Weber, se trataba en primer lugar de explicar la aparición de un determinado ethos profesional, o si se quiere en términos psicológicos y más actuales, de los hábitos de trabajo de la sociedad industrial. ¿Cómo se ha formado la actitud racional, sobria y disciplinada que había de ser el sostén psicológico de la vida económica moderna? ¿Cómo surge la "racionalidad económica" y qué relación mantiene con el proceso general de racionalización de la cultura entera de occidente? La respuesta es bien conocida. Pero no debe olvidarse que la influencia en este punto del protestantismo - a través de la ética religiosa alimentada por peculiares soluciones al problema de la salvación- no hacía sino acentuar o llevar a plena forma en todo caso, tendencias permanentes de la 
cultura occidental, manifiestas al mismo tiempo en campos distintos, y muy en particular, el de la ciencia que tuvo su origen precisamente en países católicos.

Ahora bien, a la consideración parcial de la obra weberiana se debe que no se haya prestado la debida atención al segundo elemento antes indicado, pues supuesta la formación del ethos profesional moderno, y de los hábitos de trabajo que lleva consigo - de determinados economic commitments como se dice ahora- ¿cómo pudo desplegarse y funcionar de modo efectivo semejante racionalidad económica? La respuesta - menos reiterada o vulgarizada que la anterior - se encuentra en la historia del derecho y de la administración de los países occidentales, que tienen orígenes - políticos, profesionales e ideológicos- en buena parte independientes de toda condicionalidad económica. Sin la seguridad otorgada por los sistemas jurídicos continentales o del "common law", sin la previsibilidad del futuro garantizada por la "burocracia" profesional, hubiera sido imposible el cálculo y la estabilidad en las expectativas que exige la racionalidad económica, hubiera sido irrealizable la maduración social de las más sobrias actitudes de trabajo y disciplina. A la luz de esa singular experiencia histórica, lo ocurrido en sistemas económicos muy distintos o a través de procesos históricos muy diferentes, lleva sin embargo a la misma pregunta: ¿cómo ha surgido y se ha mantenido en ellos la necesaria "racionalidad económica"? ¿En el Japón por ejemplo, o la Unión Soviética? ¿Cómo puede conformarse en los países poco desarrollados?

Pero, como antes se dijo, el significado de la aportación weberiana no solo radica en ser una interpretación inteligible - pues no pretende otra cosa- de la configuración originaria del industrialismo moderno, sino de haber formulado con análoga brillantez el paradigma — como hoy se diría- de las "condiciones sociales" de la "economía liberal". De suerte que cuando se examina la bibliografía contemporánea sobre el tema nos topamos una y otra vez con los elementos conceptuales de aquel paradigma. Dado que la idea básica en que se apoya es la de la "racionalidad formal", su fórmula más concentrada pudiera ser esta: los supuestos sociales de la "economía liberal" son los que hacen posible y fundamentan el ejercicio de semejante racionalidad. En principio, esos supuestos pueden reducirse a los que gobiernan estos tres campos: el mercado, las relaciones de propiedad y de trabajo, y la organización política económica.

Un sistema económico funciona con arreglo a las exigencias de la idea de racionalidad formal: primero, cuando, sobre el supuesto de una determinada demanda efectiva, existe competencia plena entre entidades autónomas y riguroso cálculo de capital; segundo, cuando en las relaciones de la propiedad se da además la completa apropiación 
por parte de la empresa de los medios materiales de producción, y en la relación de trabajo domina el contrato formalmente libre; lo que va acompañado, en tercer lugar, por un Estado que se limita a mantener un sistema monetario racional, un derecho y una administración del mismo tipo, y en todo lo demás abandona a su propio juego el funcionamiento de la vida económica. Dicho de otra forma, la racionalidad formal de la economía tiene su más exacta traducción en el cálculo de capital, lo que a su vez requiere - $\mathrm{y}$ volvemos a encontrarnos algunas de las condiciones señaladas- libertad rigurosa de mercado, estabilidad disciplinaria de la empresa y relaciones estables de apropiación. Ahora bien, los mencionados elementos del paradigma weberiano son los que se encuentran implícitos o explícitos, articulados de una u otra manera y con meras diferencias terminológicas, en la bibliografía reciente (Parsons, Lewis) dedicada a examinar el tema de los aspectos sociales del desarrollo. Y de ese esquema se derivan y suelen derivarse, por añadidura, orientaciones de política económica y social.

\section{LA INVALIDACIÓN HISTÓRICA DEL PARADIGMA WEBERIANO}

Sucede, sin embargo, lo siguiente: ese paradigma constituye, a no dudarlo, la expresión más acabada de una interpretación sociológica de las condiciones sociales de la economía liberal, o sea, sigue valiendo en ese sentido en su papel teórico, pero en cambio parece incuestionable que hoy no encarna por completo la situación actual de las sociedades industriales más maduras. Dicho en otra forma todo lo ocurrido hasta aquí en el proceso real de las economías occidentales durante las últimas décadas supone en definitiva la invalidación, al menos parcial, del referido paradigma. Ello llevaría a examinar lo que esa invalidación significa tanto por sí misma como por lo que representa para los países en vías de desarrollo. Las alteraciones ocurridas en el conjunto de las condiciones sociales del capitalismo liberal son de muy varia índole, y se exigiría examinarlas una a una, al hilo de su enumeración anterior. Pero quizá baste decir, por lo pronto, que esa invalidación ha consistido en su esencia en el mayor o menor abandono del principio de la racionalidad formal y su sustitución en todo o en parte por principios de racionalidad material o funcional.

Como es bien sabido, las transformaciones económicas han consistido primero en el deterioro de las relaciones de libertad rigurosa de mercado o, como se formula hoy, de las situaciones de competencia perfecta. Segundo, en la mutación de las relaciones de trabajo, establecidas en teoría aún por libre contrato pero que de hecho escapan a la situación disciplinaria típica de la empresa de los primeros tiempos, sea por la acción de las organizaciones colectivas o por el influjo de las tendencias inexpresas a la estabilización o apropiación de los 
puestos de trabajo. Y tercero, muy en particular, por el abandono en todas partes de la posición rigurosamente neutral del Estado frente a los asuntos económicos, y su intervención mayor o menor en su regulación o en la actividad económica misma.

En los países de mayor madurez económica esos cambios se han visto acompañados por transformaciones de gran alcance en la estructura social que no es posible examinar en detalle, pero que se traducen en su último extremo en una mayor equiparación del nivel de ingresos y de vida, y en una atenuación -no eliminación, naturalmente- de los conflictos entre las clases. Lo reseñado de esta suerte, y que se ha resumido de acuerdo con la terminología weberiana en la frase, críptica al parecer- de la sustitución de la racionalidad material por la formal antes vigente, es cosa que describen hoy con la más varia terminología y desde diferentes puntos de vista tanto los sociólogos como los economistas y los teóricos de la política. Unos desde la perspectiva del mercado: el paso del mercado de competencia perfecta hasta los mercados de competencia imperfecta en sus varias formas. Otros esforzándose por encontrar la nota definitoria de la distinta estructura social: el predominio de la "organización", por ejemplo. Otros más, en fin, describiendo o formulando la teoría del welfare state y los problemas que trae consigo, constitucionales y administrativos.

Ahora bien, desde el ángulo de nuestra actual preocupación —la de los países en vías de desarrollo- el hecho decisivo que importa fijar es que la imagen real, el modelo efectivo que tienen hoy ante sí esos países y que atrae ante todo su atención —manifestación del famoso demonstration effect-, no es la condensada en el histórico paradigma, sino la que es producto vivo de su transformación. Por tanto, las orientaciones derivadas del clásico esquema, y que una y otra vez se proponen para esos países, contradicen su auténtica experiencia del mundo contemporáneo. En este sentido la tarea del pensamiento actual - y existen algunas manifestaciones - no es tanto reiterar con insistencia académica - inocente si no fuera a veces peligrosa- las notas del paradigma weberiano, como si todavía fueron aplicables a las condiciones del mundo económico contemporáneo, sino la de construir el nuevo "modelo" de las condiciones sociales que hacen realmente posible la continuación del capitalismo en su forma actual.

La contradicción entre la imagen teórica y la imagen realmente vivida viene a complicarse más todavía en los países en vías de desarrollo por la presencia del "modelo" soviético que, claro está, tiene supuestos distintos de los tradicionales, tanto en lo que se refiere al tipo de las "vigencias" racionales de sus agentes, como a lo relativo a las condiciones sociales y políticas de su organización. 


\section{EL CONCEPTO DE MODELO EN EL PENSAMIENTO ACTUAL HISTORIA Y TEORÍA DEL MODELO}

En la sección anterior se ha cometido una infidelidad que es necesario salvar ahora como punto de partida de la que aquí se inicia, pues en la aceptación de la interpretación weberiana de los orígenes del capitalismo se han empleado para designarla, con evidente flotación terminológica, denominaciones que no hubiera aceptado su propio autor. Se ha estado hablando de modelo y paradigma para designar lo que en la propia teoría metodológica de Max Weber se define con precisión como "tipo ideal". De esta manera nos encontramos de lleno frente a un problema aparentemente menor, pero que no deja de ser grave en el estado actual de las ciencias sociales: la continuada creación de nuevos términos, el empleo de los ya conocidos con nuevo significado y, en general, el deterioro sufrido en las distintas rachas de la moda intelectual por conceptos que siempre deberían tener un empleo muy riguroso.

Tal es lo que ahora ocurre con el término "modelo", empleado con los más diversos significados en todas y cada una de las varias disciplinas de la ciencia social: economía, sociología, psicología, ciencia política, etc. La narración de lo ocurrido con este término en nuestros días está por escribir, y en estos instantes solo parece oportuno señalar sus líneas más generales. Las cuales se tienden entre los dos extremos de una interpretación de ese modelo históricamente saturada y una concepción rigurosamente matemática del mismo.

Sin que sea ahora posible llegar a mayores precisiones, cabe imputar el origen del uso del "modelo" al concepto de tipo ideal en la metodología de Max Weber, que a su vez tiene sus propias fuentes de inspiración. Ahora bien, el tipo ideal como construcción interpretativa tiene en Weber el significado riguroso de ser una elaboración acentuada de ciertos rasgos existentes en un determinado fenómeno real; acentuación o exageración necesarias para facilitar su mejor comprensión. El tipo ideal así construido es solo un instrumento heurístico para constatar si lo ofrecido por la realidad se acerca o distancia de lo articulado con la mayor plenitud lógica en el concepto. Es esencial, sin embargo, que su elaboración se apoye en los datos empíricamente ofrecidos por los hechos históricos mismos. Pero sin abandonar ese su contenido histórico, una posición posterior ha tratado de eliminar todo lo que puede considerarse artificioso en la metodología weberiana relativa al "tipo ideal", proponiendo la construcción de "tipos reales". Esa posición está representada en su forma más cabal por los modelos que formularon Eucken y el grupo de economistas franceses contemporáneos que siguen la teoría de los sistemas y de las estructuras económicas. 
Una significación muy distinta tiene el modelo en otras direcciones de la teoría económica contemporánea. Aquellos más conocidos, y sobre todo los que se ofrecen en la teoría del desarrollo económico, son, por su naturaleza o contextura lógica, verdaderas teorías cuantificadas o - para expresarlo con mayor rigor- series de hipótesis cuantificadas. Por último, el modelo aparece algunas veces en la ciencia social con el carácter que posee en las disciplinas físico-matemáticas, es decir, con la pretensión de ser una formalización de relaciones isomórficas. Basta esta rápida referencia a los principales tipos de modelos ofrecidos por la ciencia social actual para plantear con algún rigor la relación del modelo económico y del modelo social en la teoría del desarrollo económico.

Dado que el modelo más frecuente de la teoría económica constituye, según acaba de señalarse, una teoría cuantificada o un conjunto cuantificado de hipótesis, se destaca como supuesto esencial de esa cuantificación la posibilidad de medida, exigiéndose - como siempre ocurre en toda teoría económica- que la cuantificación se traduzca en relaciones causales. No corresponde a este instante la crítica del modelo económico así concebido, sea por la naturaleza de su validez o por su alcance metodológico, ni tampoco determinar si puede aceptarse por completo en lo que tiene de pretensión teórica o si solo cabe hacerlo por su valor instrumental, y cuáles son los límites en la construcción del mismo. El punto de vista crítico de la perspectiva del sociólogo solo aparece propiamente cuando se trata del funcionamiento de modelo.

Lo que importa ahora es examinar hasta qué punto es o no posible ampliar el contenido de este modelo económico, tratando de insertar en él determinadas variables de carácter social. La aplicación de ese modelo a las cuestiones sociológicas puede tener en algunos casos, y por lo pronto lo tiene, un simple valor metafórico, como ocurre con la tendencia reciente de manejar, tanto en la sociología como en ciencia política, la terminología y el esquema del análisis económico del insumo-producto. Mas semejante uso, como sucede por lo general en estas transposiciones analógicas, no deja de ser peligroso si induce a la confusión de que se está ante proposiciones de idéntica precisión en unas y otras disciplinas. Ahora bien, este uso o empleo metafórico - es decir, la transferencia del modelo económico como teoría cuantificada del campo mensurable de los fenómenos económicos a los más complicados y menos sujetos a medida de otras ciencias sociales- permite descubrir cabalmente los puntos débiles de este y otros ensayos semejantes. En la producción intelectual acuciada por los problemas del desarrollo económico, la teoría de Rostow ha sido, como se sabe, un intento de incluir en el modelo económico variables 
de carácter social; pero las "propensiones" con que trata de apresar esas variables sociales - por ejemplo, la denominada propensión a la procreación, o la propensión a la innovación o la que tiende a la mejora material - no pueden equipararse en su precisión cuantitativa a las variables estrictamente económicas. Por eso se ha dicho con razón que si desde el punto de vista económico es escasa su utilidad, tampoco es satisfactoria desde el punto de vista sociológico.

En el ensayo de Rostow se ha puesto claramente de manifiesto dónde está la falla de la aplicación del modelo económico, en estricto sentido, a factores sociales; su carácter problemático reside en el doble hecho de la complejidad y multiplicidad de esos factores o variables y en las resistencias que los mismos ofrecen a la requerida cuantificación. Quizás pueda llevarse a cabo algún día, pero no parece viable por ahora la construcción de hipótesis cuantificadas con variables de muy distinta naturaleza, ni existe la posibilidad de actuar operativamente por el encadenamiento causal de una y otras.

Es más, aun en el caso de modelos de distinta naturaleza como son los construidos por el análisis histórico-estadístico, es decir, estrictamente inductivos, no puede precisarse con todo rigor el grado de interdependencia de los fenómenos puestos en correlación, reconociéndose que varía y depende de factores no económicos: por ejemplo, la estructura social, el cuadro político o el medio cultural. Así lo declara Kuznets.

Esta referencia basta para plantear la cuestión de hasta qué punto sea posible para el sociólogo la construcción de modelos equiparables a los económicos en estricto sentido por lo que respecta a su rigurosa significación causal. Pues bien, no cabe duda de que el sociólogo podría construir un modelo semejante si contase con una completa teoría funcional de la sociedad, plenamente comprobada.

Como es sabido, en los últimos años predominó en sociología el intento de formular esa teoría; y existen, a no dudarlo, resultados valiosos aunque solo tengan, precisa reconocerlo, una significación instrumental o heurística.

Más la teoría funcional, como tal teoría - es decir, como el intento de formular el sistema de los componentes institucionales de una sociedad - falla en lo que ahora más importa, en el conocimiento exacto - predecible - de las relaciones tanto de interdependencia como de equilibrio entre tales elementos. El sociólogo podría construir el modelo buscado, análogo en su naturaleza al económico, si dispusiera de un sistema de hipótesis precisas sobre los mecanismos que hacen posibles las mencionadas relaciones de interdependencia y sobre los mecanismos que tienden — según se afirma- a producir asimismo relaciones de equilibrio. En tales circunstancias las variables 
conjugadas en el modelo podrían manejarse en auténticas "funciones", haciendo viable, junto con la predicción rigurosa, la posibilidad de operar prácticamente partiendo de cualquiera de ellas.

Sin embargo, y sin ánimo alguno de polémica, se impone confesar que no se posee por el momento un saber semejante y que la precisión conceptual que a veces presentan las teorías sociológicas de carácter funcional se debe a una tautología subyacente.

La plena validez del "modelo" solo se ofrece en sus puras formas matemáticas allí donde es posible traducir con exactitud en un determinado lenguaje lo formulado en otro diferente, y de que es ejemplo ilustre la geometría analítica. Pero esa equivalencia punto por punto de los elementos de dos ámbitos distintos -el completo isomorfismo- difícilmente puede encontrarse entre distintas instituciones sociales. Sin embargo, la atracción metodológica de ese ideal científico puede a veces manifestarse inexpresa, como ocurre en los rigurosos paralelismos categoriales de algunos esquemas de Parsons. Claro que entonces en puro juego conceptual funcionan, a no dudarlo, las equivalencias de los componentes institucionales y por tanto su acción e influencia recíprocas.

Todo lo anterior, que no va más allá de lo meramente alusivo, no pretende criticar el denominado funcionalismo — crítica que mejor se haría desde otros puntos de vista- sino tan solo señalar lo problemático de la pretensión de que el sociólogo pueda ofrecer en el campo del desarrollo económico modelos "funcionales" equivalentes a los manejados por el economista, es decir, de análoga seguridad operativa. Para evitar equívocos, se impone advertir que no solo los mayores sociólogos sino todos los cultivadores de la ciencia social han sido y son funcionalistas en su amplio sentido, pues siempre han concebido a la sociedad como una totalidad dinámica de diversas partes entrelazadas -instituciones, fuerzas sociales, grupos, tendencias, etc.-, cada una de las cuales influye con sus alteraciones en la contextura de las demás y del conjunto. Esa concepción es el punto de partida de todo intento de comprender históricamente la realidad social y el supuesto de cualquier tipo o modelo. Solo varía la pretensión de exactitud.

\section{LOS COMPONENTES SOCIALES DEL MODELO ECONÓMICO}

En esa aspiración a entender la sociedad como complejo de instituciones y estructuras, las distinciones fundamentales que hoy día se reiteran cuando se analizan los aspectos sociales del desarrollo económico tienen asimismo una inmediata filiación weberiana, es decir, la distinción de base entre instituciones económicas e instituciones "económicamente relevantes". Es cierto que las páginas de su Economía y sociedad en que aparece esa distinción no tratan de las institu- 
ciones, sino de las comunidades económicas, pero desde luego valen para unas u otras. Las comunidades económicas en estricto sentido son las que despliegan una actividad de ese tipo - para el logro de un beneficio o para la cobertura de sus necesidades- como finalidad propia o primaria. En cambio, las comunidades "económicamente relevantes" son aquellas en que su actividad peculiar, sin ser económica, puede representar un "momento causal" en el proceso de una actividad económica. Entre ellas destacan las comunidades reguladoras de la economía. Distinciones que valen, como antes se dijo, si en vez de comunidades se utiliza el concepto de instituciones. Weber, en esas mismas páginas, ataca precisamente como prejuicio histórico la "conexión funcional" de la economía con otras estructuras sociales, si por tal se entiende una "inequívoca" condicionalidad recíproca. Pero es significativo al mismo tiempo que se postule en ellas el valor de ese funcionalismo en forma más moderada. En efecto, es posible afirmar en principio que existe una "afinidad electiva" entre determinadas estructuras económicas y ciertas estructuras sociales, o sea, que es posible decir en qué medida son "adecuadas o inadecuadas" entre sí, cómo y en qué grado se favorecen, impiden o excluyen recíprocamente. Esta posición, que en definitiva es la clásica en la tradición sociológica, puede parecer insuficiente a algunos. Sin embargo, dentro de sus límites, permite diagnosticar con alguna eficacia en la complejidad de las situaciones históricas, entre los dos extremos de la fe exagerada en el valor de la absoluta predicción científica - cuantificable- y el desaliento que provoca el abandono a la marcha ciega.

Las referidas distinciones, aunque no siempre aparezcan articuladas de igual manera, constituyen el esquema fundamental de todo tipo o modelo del desarrollo económico desde la perspectiva del sociólogo. Las encontramos por eso necesariamente de una u otra forma en el pensamiento posterior, y así ha sido en una de las más finas y adecuadas presentaciones recientes, la de W. E. Moore. Conviene por eso recordar muy rápidamente su distinción entre los requisitos primarios (first-order requirements) y los secundarios (second-order requirements), paralelos a la separación entre instituciones económicas e instituciones económicamente relevantes cuando se trata del cuadro institucional. Es cierto que al lado de este sitúa Moore el cuadro constituido por la organización y el cuadro —en su primera formulación - de las motivaciones y actitudes. Sin embargo, lo que interesa observar ahora es que en el cuadro institucional señala entre los requisitos de primer orden a la propiedad, a la mano de obra y a las relaciones de cambio o de mercado, y entre los de segundo orden al régimen político, a la ciencia y la técnica y a las formas de estratificación. Es decir, la fidelidad del autor al esquema tradicional se 
muestra en el carácter secundario - regulador- que otorga al orden político, lo que permite plantear una cuestión respecto a la universalidad del esquema, si se atiende a la posibilidad — históricamente realizada- de que ese orden político tenga un papel y significación diferente. Con todo, el esquema es válido dentro de la tradición occidental aun dentro de sus posibles variantes.

En este momento -y solo a título ilustrativo, pues en modo alguno se pretende agotar el tema-conviene señalar la presencia en la bibliografía más reciente de otros esquemas en los que sin embargo siempre juegan los mismos elementos. Así ocurre con el grupo de economistas franceses que destaca la significación de los conceptos de estructura y de sistemas sociales para la teoría económica. En este sentido, A. Marchal concede considerable atención, entre las estructuras que integran los regímenes económicos —aparte las demográficas, físicas y económicas en estricto sentido- a las que denomina estructuras de encuadramiento, o sea las de carácter social y psicológico. Semejantes estructuras comprenden las "instituciones" (sean instituciones-cosa o instituciones-grupo), las estructuras sociales y las estructuras mentales o psicológicas. Basta su enumeración para subrayar el consenso existente hoy sobre este punto. Con el nombre de instituciones-cosa (nombre poco feliz derivado de las tradiciones del institucionalismo francés), considera al derecho de propiedad y al contrato, y entre las instituciones-grupo, al Estado y a los sindicatos. Entre las estructuras socia es señala la morfología social, las relaciones entre los diversos grupos y la movilidad. Y entre las estructuras mentales trata, entre otras, de la actitud respecto del trabajo, del espíritu de riesgo y de competencia y del culto al progreso.

El elemento dinámico que en la elaboración de Moore tienen los motivos está representado en la teoría de Marchal por lo que califica de "fuerzas autónomas", y que son el progreso técnico, la población y el movimiento de las ideas. Sin embargo, estas proposiciones de A. Marchal solo adquieren su pleno significado dentro de la teoría más amplia de los sistemas económicos y de su peculiar plasticidad y dinamismo, lo que abre ya desde su punto de partida horizontes muy amplios al análisis sociológico.

Con la declarada intención de formular un modelo del desarrollo económico, cabe citar por último la articulación contenida en el libro reciente de S. Klatt, de considerables pretensiones teóricas. En el modelo de Klatt se distinguen con este nombre los elementos reguladores y dinámicos del proceso industrial, destacándose entre los elementos reguladores activos las agrupaciones sociales —el Estado muy en particular - y las denominadas fuerzas sociales, que son la religión, el derecho y la educación. Entre los elementos activos o impulsos se 
cuentan el crecimiento demográfico, el progreso técnico y la actividad del empresario, sea este público o privado.

El esquema de Klatt representa uno de los más acusados intentos actuales de integrar en el modelo de crecimiento económico - para ser más precisos, del desarrollo industrial - los aspectos o factores sociales más importantes. Pero como ocurre en otros modelos estrictamente económicos, semejantes factores dejan de figurar pronto de manera decisiva en los análisis del libro.

No sobra recordar que, las más de las veces, en algunos modelos histórico-económicos del desarrollo se encuentra implícito un contenido social. Tal ocurre con las grandes líneas de las teorías de Clark o Fourastié, que suponen en sus etapas principales una diversa estructura social. Y lo mismo con las categorías históricas de las cinco fases del desarrollo económico, de Rostow, en cada una de las cuales —se presume- existen condiciones político-sociales de diversa naturaleza.

\section{ESQUEMA DE LOS FACTORES SOCIALES ESTRATÉGICOS EN EL DESARROLLO ECONÓMICO}

Con holgura de espacio y tiempo por delante, la tarea inmediata hubiera consistido en aplicar el esquema fundamental antes bosquejado - y en cualquiera de sus posibles articulaciones - a la realidad social latinoamericana, de manera que el "modelo" de las condiciones de su desarrollo bajara del plano abstracto a la situación concreta en que ha de funcionar aquí y ahora. La extensión que tomaría aun el ensayo menos ambicioso aconseja renunciar a él en este momento. Por otra parte, sustituir ese tema por el examen en el plano teórico, en forma concentrada, de las principales cuestiones contenidas en el de los aspectos sociales del desarrollo, parece asimismo inconveniente por haberse realizado ya en diversas ocasiones.

Por fortuna, la perspectiva en que está situado este escrito y el impulso intelectual que lo sostiene permiten ceñir la tarea a unos cuantos puntos centrales, pues lo que interesa en estos momentos es la posibilidad de señalar algunos factores o elementos de valor estratégico sobre los que sea posible actuar de alguna forma para acelerar el proceso del desarrollo. Ahora bien, esos elementos o factores son los destacados por unos y otros autores, como se vio en la sección anterior, por su carácter dinámico.

Por otro lado, cabría sostener con abundantes razones que la sociología económica — esa disciplina todavía por hacer de manera sistemática- tiene en definitiva que construirse sobre tres elementos fundamentales: la propiedad, el trabajo y la empresa. En lo que sigue, sin embargo, se prescinde del elemento de propiedad por dos razones. Primero, porque sus características deben admitirse como un supues- 
to conocido dentro de las economías de tipo occidental y su examen exigiría además considerar todo el cuadro del sistema jurídico actual. Y segundo, porque desde el punto de vista sociológico únicamente importa en realidad una sola cosa: la claridad y estabilidad en los poderes de disposición cualesquiera que sean las formas de esa propiedad. Claro es que tratándose de los países latinoamericanos existe el hecho de la organización defectuosa en muchos de ellos de la propiedad agraria como obstáculo mayor al dinamismo de su desarrollo. Pero se trata de un tema especial que no incumbe examinar ahora. El problema de las modificaciones estructurales requeridas se reconoce por todos, aunque difieran las medidas propuestas para solucionarlo.

\section{LA DISPOSICIÓN ECONÓMICA GENERAL}

Hay además un componente fundamental en la sociología económica de una decisiva significación estratégica, que ya fue aludido sin mayores perfiles en anteriores páginas: el que pudiera denominarse, a falta de otros términos, disposición económica general. Toda la historia económica de Occidente puede trazarse al hilo de la formación trabajosa y lenta de esa disposición o actitud económica; y los problemas más urgentes que ha planteado el desarrollo de los países más atrasados derivan, o han derivado, de la necesidad de crear, conformar o estimular esa disposición económica general. Sin embargo, lo que con este término se indica comprende en realidad dos cosas distintas: las aspiraciones económicas y el sentido de la responsabilidad personal y colectiva.

Es muy posible que la más penosa dificultad de nuestro tiempo estribe en el hecho de que las creencias económicas fundamentales están muy lejos de ser homogéneas. Hay por todas partes una dilatación de las aspiraciones económicas que se confunde con esa ampliación de los horizontes de vida que preside toda gran transformación histórica; hay en todos sitios la misma aspiración a elevar el nivel de vida, e idéntico afán por mejorar la capacidad de consumo, que muchos juzgan simple resultado del tan citado fenómeno del demonstration effect. Pero esa dilatación del horizonte vital y económico y ese deseo de satisfacer mayores necesidades no se apoyan en modo alguno en una "creencia económica" igualmente compartida por todos, letrados e iletrados. En cambio, en la historia del desarrollo económico europeo, la creencia económica del hombre de la calle venía a coincidir, supiéralo o no, con las ideas científicas del economista. Ese estado de "efervescencia" o de desorientación en las creencias económicas del momento actual podría conocerse con toda exactitud si dispusiéramos de investigaciones sobre la situación de la juventud contemporánea - como ha visto el economista Raúl Prébisch-, o sobre la posición de los intelectuales, que la traducen en forma dramática. 
La contradicción más notoria en el seno de esas creencias consiste, por una parte, en que la aspiración a la mejora del nivel de vida o de la capacidad de consumo puede no estar acompañada del impulso paralelo a realizar el esfuerzo necesario para conseguirlo; y en segundo lugar - simple faceta quizá de la anterior- en que la aspiración individual a esa acentuación en el goce no esté frenada por el necesario sentido de responsabilidad individual y colectiva. En esencia, como debiera saberse, el desarrollo económico, en cualquier circunstancia, es posible únicamente a costa de sacrificios de parte considerable de la población, que solo hay dos medios de canalizar: el indirecto del beneficio en un sistema, o el directo de la carga impositiva del Estado en el sistema opuesto. Pero en ambos casos, ese sacrificio no deja de ser humana y socialmente semejante, cualquiera que sea el criterio con que se le mida. Ahora bien, las vacilaciones en las creencias de nuestro tiempo tienen su origen en la ocultación de ese hecho fundamental, y en la dificultad, por tanto, de que se llegue a una decisión por motivos racionales en favor de una u otra de las fórmulas posibles. ¿Cuál es el estado de esas creencias en nuestros países? ¿Qué es lo que cabe hacer para impulsar y generalizar en ellos la formación que resulte más adecuada de la requerida disposición económica?

Supuesta, desde luego, la persistencia de los regímenes democráticos, no deja de darse en ellos la posibilidad de una acción enérgica en este campo. Por lo pronto - y no será esta la última vez que aparezca en estas páginas- el sistema educativo ofrece el instrumento más flexible para actuar con continuidad y eficacia. Pero además la acción pública del Estado puede utilizar los denominados "medios de comunicación de masa", siempre que se salven con tacto los escollos de las reacciones negativas que provoca la insistencia prolongada de toda propaganda. Y junto con el Estado pueden actuar en el mismo sentido otras fuerzas sociales como la prensa, los partidos políticos y los sindicatos.

Sin embargo, toda esa acción quedaría trunca a la larga si la sociedad no ofrece en la conducta de sus grupos dirigentes el modelo real de lo que debe ser imitado. Es problemático que una sociedad industrial avanzada - estimulada por el aumento constante del consumo- pueda ser compatible con principios de ascetismo. Pero no cabe duda que todas las sociedades industriales han exigido en las primeras fases de su expansión - cualquiera que haya sido el modo como esta se haya realizado- una fuerte dosis de capacidad ascética en sus élites dirigentes, económicas o políticas. En los momentos actuales ocurre en más de algún lugar que la atonía o desorientación de las masas está producida por la ausencia de las necesarias conductas ejemplares en la minoría dirigente. La presencia de esa conducta ejemplar puede 
ser decisiva ante el dilema que supone la elección entre una u otra forma de aceptar el inevitable sacrificio: por el camino indirecto del beneficio de la gestión privada o por el directo del sistema impositivo del Estado controlado por un grupo político. La capacidad de atracción de la primera fórmula solo reside en que la minoría dirigente, beneficiaría temporal del esfuerzo de los demás, sea la primera en actuar con la debida responsabilidad; dicho en términos económicos: que el beneficio sea el instrumento visible de una rápida capitalización y no el medio inmoral del gasto ostensorio.

Sobre el suelo de una disposición económica general favorable ya exista enérgica o más o menos atenuada- no solo el crecimiento, sino la simple continuidad y persistencia de la actividad económica depende - cualquiera que sea el sistema en que se inserte- de dos capacidades no siempre fáciles de adjetivar: la capacidad de ejecución o de realización, es decir, la capacidad de trabajo en su más amplio sentido, y la capacidad directiva o de gestión, denominada hasta hoy con el término equívoco de empresa.

\section{LA CAPACIDAD EJECUTIVA}

Los problemas sociológicos del trabajo, mano de obra o - dicho en su forma más abstracta - capacidad ejecutiva son, como es sabido, estos tres: a) el de la diligencia o impulso al esfuerzo, con los atributos que lo conforman y que permiten hablar de la moral o ethos del trabajo; $b$ ) el de la adaptación técnica en el trabajo, y $c$ ) el de la responsabilidad social del trabajo como expresión de la conciencia de su propia función en el conjunto de la sociedad. En estas rapidísimas notas alusivas a que obliga la contextura de este escrito solo cabe decir lo siguiente como simple recordatorio: nada ha habido más lento y más difícil que la formación del impulso al trabajo de las que hoy parecen laboriosas masas en los países económicamente más avanzados. Historia morosa en Occidente, volcánica en el mundo soviético, ha consistido en la imposición de una disciplina contraria siempre a las tendencias instintivas; pero en los países más maduros el triunfo de esa historia se expresa en el cambio fundamental de los estímulos, desde el inhumano y fisiológico del hambre al ya socializado de la aspiración a la mejora gradual en los niveles de vida.

Más breve, aunque a veces no menos dramática, ha sido en cambio la historia de la adaptación del trabajador a su medio laboral, que comprende no solo el ajuste del hombre a la máquina — cosa en la que primero se piensa-, sino en la adaptación mucho más complicada del obrero industrial a las condiciones sociales y psicológicas impuestas por la moderna industria en sus tres peculiares dimensiones del espacio, el tiempo y la jerarquía. En los países más avanzados esa adap- 
tación no ofrece hoy en principio dificultades insuperables, aunque subsistan conflictos y se ofrezcan nuevos problemas- el de ocio por ejemplo- que no viene al caso examinar.

Por último, en lo relativo a la participación del trabajo en el todo social y a la conciencia de responsabilidad que de ella se deriva, cabe decir en apretada expresión que su historia se confunde con la de la organización obrera. En todas las sociedades industriales maduras el obrero participa de una u otra forma, a través de sus propios cuadros, en la organización económica y en el destino político de las mismas.

¿Cuál es en este punto la situación de América Latina? ¿Cómo manejar adecuadamente dentro de ella este factor estratégico? La ausencia en general de algunas investigaciones que son indispensables y que fueron formuladas en otras ocasiones, quizá no permitan contestar estas preguntas con el rigor debido. Pero los conocimientos parciales de que se dispone y la visión impresionista — si así quiere llamarse- del problema, hacen posible formular las siguientes aseveraciones: a) la propia historia económica de América Latina es la mejor prueba de la existencia en ella del impulso al trabajo, sin la que no hubiera sido posible; $b$ ) la marcha de su formación - aún incompleta - ha sido también paralela en su lentitud y dificultades a la ofrecida en los distintos países europeos; $c$ ) es problemático que las incrustaciones de arcaísmo que todavía contiene su región - los grupos indígenas más atrasados - sean un factor absolutamente negativo en la formación de los impulsos al trabajo y mucho induce a pensar en su rápido despliegue cuando se ofrezcan los estímulos económicos y educativos a la par necesarios; d) no parece ofrecer la mano de obra ningún impedimento congénito y esencial en la adaptación del hombre a la técnica ni en la aceptación de las disciplinas de la organización industrial, aunque sea evidente que el mayor problema latinoamericano a este respecto es la pobreza o escasez en capacidades calificadas; $e$ ) en cambio, y en oposición a los puntos anteriores, es muy posible que la falla mayor en el campo del trabajo se encuentre por el momento en el hecho de la escasa participación del mismo en el ámbito nacional, debido a influencias de carácter político que han impedido la adecuada formación de las organizaciones obreras. Nada tiene de extraño que la organización sindical se ofrezca las más de las veces con una marcada acentuación de sus tendencias reivindicatorias, frente a las que inclinan a la participación y a la corresponsabilidad. En todos los aspectos señalados es posible actuar con resultados positivos en la aceleración del desarrollo, aparte de otros fines puramente humanos y de justicia social. Cómo llevarlo a efecto es precisamente el tema de otro trabajo especial. 


\section{LA CAPACIDAD DIRECTIVA}

Con la afirmación de que por todas partes el desarrollo económico ha sido obra de la empresa no se incurre en forma alguna de determinismo, ni supone cántico o apología, ni menos implica la adscripción sin restricciones a la escuela schumpeteriana. Como la palabra empresa es equívoca, la frase anterior o apenas dice nada o solo enuncia un principio de la sociología formal de la cultura. En un sentido equivale a decir que el progreso económico es resultado de la innovación o creación económica, pero por otro indica el papel que en el ámbito cultural de la economía desempeña un tipo humano semejante por su naturaleza al que se ofrece asimismo en otras regiones culturales, el profeta o el gran científico por ejemplo. Tampoco es posible en este momento sino recordar ciertos elementos esenciales. El primero y fundamental, ya aludido, es el de la significación histórica del empresario, si por tal se entiende, sin otras especificaciones, que se trata del gestor e innovador económico. No menos conocida es la evolución histórica de la empresa, es decir, la transformación de los distintos tipos sucesivos de la gestión económica y de las diferentes ideologías que la han mantenido, prestándole la necesaria legitimidad. Por último, apenas cabe sino señalar que en los últimos decenios comienza a destacar un nuevo tipo de gestor económico - tanto en las economías planificadas como en las más maduras de carácter mixto- que a falta de término reconocido denominaremos por el momento "gerente público".

Pues bien, a pesar de la insistencia con que desde hace algunos años se ha señalado la necesidad de iniciar investigaciones sobre la empresa latinoamericana, no contamos todavía con las monografías -históricas y contemporáneas- necesarias para hablar con rigurosa competencia, tanto de sus formas de actividad como de sus justificaciones ideológicas y sociales. Pero al igual que en el caso del factor trabajo, parece posible hacer aquí una pequeña serie de afirmaciones, que al menos cabe formular como hipótesis:

1. El siglo XIX ofrece en la mayoría de los países de América Latina la prueba de la existencia de hombres de empresa eficaces y de amplia visión; en las últimas décadas y entre sus países más avanzados no puede negarse la presencia de la capacidad empresaria en constelaciones de gran empuje;

2. Sin embargo, ha predominado en la mayoría de sus países la empresa comercial frente a la industrial en estricto sentido y, sobre todo, el tipo de empresario político o de coyuntura, al amparo de las alternativas del poder;

3. Podría señalarse en unos y otros países la aparición del tipo de empresario que hemos denominado "gerente público", sin que 
sus perfiles estén todavía bien definidos. Para resumir, desde cualquier aspecto que se considere parece incuestionable que una de las claves del porvenir económico de América Latina esté en la posibilidad de que se ofrezca a tiempo la adecuada constelación de gestores económicos públicos y privados capaces de crear los polos de desarrollo - para emplear terminología francesa- de que depende su destino. ¿Cómo manejar este factor estratégico? ¿Cómo estimular la capacidad de empresa, es decir, de innovación y de organización? Los dos únicos caminos - señalados con acierto por un psicólogo contemporáneo cuya teoría del achievement motive no es cosa de examinar aquí- consisten o en la rígida imposición en toda la sociedad de orientaciones mantenidas por los supuestos psicológicos de la empresa, como ha ocurrido en el mundo soviético, o por la "profesionalización" de la gestión económica, de la gerencia, como ya se inicia dentro del mundo occidental. En este caso incumbe al espíritu universitario el llevar a cabo esta tarea, con la colaboración desde luego de la experiencia adquirida por el medio empresarial. Y lo mismo si se trata del empresario privado como del gerente público en formación.

Con relación a este último no puede olvidarse, sin embargo, el problema que presentan los países menos avanzados — tan escasos en sus clases medias- de equilibrar sus limitados recursos humanos, de suerte que la absorción por las tareas públicas no malogre el caudal de las energías necesarias en el campo de la empresa privada.

\section{LA MOVILIDAD SOCIAL}

Suele ocurrir con frecuencia en consideraciones semejantes a las de este escrito que, después de señalar en una u otra forma los elementos estratégicos de que se ha hecho mención - disposiciones económicas y capacidades ejecutivas y de gestión-, se trate de la denominada movilidad social. Pero es dudoso que pueda situarse este elemento en el mismo plano que los anteriores, es decir, con una significación equivalente como factor estratégico. Los estudios sobre movilidad han estado de moda en estos últimos años y se han publicado y realizado numerosas investigaciones. Sin embargo, dejando aparte el valor intrínseco de semejantes trabajos, el examen de conjunto de los mismos no deja de mostrar el carácter problemático de aseveraciones repetidas sobre las relaciones entre desarrollo económico y movilidad social. Se afirmaba, en efecto, que la movilidad social — como confirma la historia de los países industriales- es "condición" indispensable del desarrollo económico. Y, en consecuencia, que una de las maneras 
eficaces de acelerarlo era provocar de alguna manera la mayor rapidez de esa "movilidad". Ahora bien, los estudios antes referidos permiten formular una serie de dudas frente a las ideas habituales. Primero, surge la sospecha de que los estudios de movilidad al uso - como asimismo los denominados de estratificación- no hacen sino describir por medio de sus índices el fenómeno mismo del desarrollo ya realizado. O sea, movilidad social y desarrollo económico son las dos caras de una misma realidad, lo que encierra teóricamente - no en su valor empírico-descriptivo- un elemento tautológico. Segundo, como ha visto acertadamente Aron, se duda de que los resultados de esos análisis de movilidad puedan descubrir por sí mismos la existencia de un factor sociológico independiente. Los análisis intergeneracionales, el paso del hijo a una posición superior a la del padre - de trabajos manuales a otros no manuales en particular- solo traducen los cambios ocurridos en la nueva distribución de la mano de obra como resultado del desarrollo. Frente a esta movilidad bruta sería necesario obtener el concepto operativo de la movilidad neta para descubrir la existencia de factores independientes de los económicos. Tercero, se vuelve hoy a pensar que la movilidad social se ha dado siempre en todo tipo de sociedad y con configuraciones semejantes en todas ellas. Cuarto, se ha puesto en duda la creencia existente acerca de la mayor movilidad social de los Estados Unidos frente a otros países europeos. Y, quinto, algunas investigaciones han puesto en duda la convicción de que podía actuarse con la eficacia deseada sobre la movilidad por medio del sistema educativo. Otras investigaciones contradicen, es necesario consignarlo, los resultados de las anteriores.

Parece, en definitiva, que no puede hablarse de la movilidad social como un factor estratégico por sí mismo, y que hay que buscar por debajo de ella los verdaderos elementos dinámicos. Asimismo, desde el punto de vista del desarrollo económico, los estudios expost - descriptivos nada más de lo ocurrido- ofrecen menor interés que los de carácter proyectivo respecto de las nuevas funciones, ocupaciones y papeles sociales que han de ser previstas dadas ciertas metas económicas.

Sin embargo, a pesar de las dudas indicadas, sigue en pie el valor instrumental del sistema educativo como estimulante de una mayor movilidad, pues de la educación depende en definitiva el grado mayor o menor en que se ofrezcan dos elementos dinámicos indiscutibles constituidos por el nivel de aspiración y por la existencia de las capacidades requeridas para el ascenso social.

Las reiteradas veces en que se ha presentado en esta sección del trabajo el valor de la educación - en sus diversas formas- como instrumento indispensable en la actuación sobre los distintos factores 
sociales estratégicos del desarrollo, confirman la decisiva importancia que tiene para América Latina - y para todos los países en cualquier grado de desarrollo- el enfrentarse enérgicamente con el problema de las nuevas tareas de la educación en las sociedades industriales.

\section{EL ELEMENTO EXTERNO FUNDAMENTAL DEL MODELO ECONÓMICO}

Ninguna de las posibles actuaciones antes consignadas sobre algunos de los factores estratégicos de naturaleza social en el proceso del desarrollo económico, puede llevarse a cabo si no tienen como base un programa claramente definido de expansión. Y casi huelga decir que semejante programa y aquellas actividades reclaman la presencia de un agente determinado. Es decir, carece evidentemente de sentido plantearse el problema de cuáles son los elementos sociales de carácter dinámico sobre los que convenga o se imponga operar, si al mismo tiempo no se considera quién va a actuar sobre ellos y cuál sea la forma de hacerlo.

Frente a las cuestiones planteadas no hay pues manera de eludir otra que es de suyo básica o fundante: la de la naturaleza del poder político portador necesario de todas las mencionadas actividades. En el tipo ideal de desarrollo asignado por la coyuntura histórica a los países latinoamericanos, es imposible omitir en consecuencia el papel decisivo de la acción del Estado y de los procesos políticos que lo constituyen. Se trate tanto de un modelo económico en estricto sentido como de un modelo más amplio en que intervengan estos o los otros componentes del cuadro social, el soporte externo de los mismos, las condiciones de la posibilidad de su realización se encuentran en la estructura del poder político y en la naturaleza de sus relaciones con la organización económica. Por consiguiente, destacar el papel del Estado en las tareas del desarrollo económico en América Latina no es preferencia temperamental alguna, ni disquisición académica, ni fugaz manifestación del contagio ideológico.

\section{RACIONALIDAD ECONÓMICA Y POLÍTICA}

En el plano teórico - que no solo tolera sino que parece ineludible en un trabajo de este tipo- el punto de partida de toda consideración se formula, y necesariamente en términos abstractos, como el de las relaciones entre la racionalidad económica y la racionalidad política; es decir, en qué forma y medida se exigen o repelen mutuamente sistemas económicos y sistemas políticos por virtud de la naturaleza y grado de su racionalidad. Este planteamiento tiene dos supuestos quizá problemáticos: $a$ ) que la actividad económica encarna siempre un máximo de racionalidad, y b) que en todo caso la actividad política puede acercarse en su grado de racionalidad al que exige la economía. 
Ahora bien, ese problematismo se atenúa si se tienen en cuenta dos cosas. Primero, que en la realidad histórica no se encuentran ni cabe buscar sistemas puros, sino que siempre se trata de regímenes concretos, saturados de imperfecciones y distendidos por tendencias contradictorias, que solo encarnan por tanto más o menos las líneas ideales de un sistema. Segundo, que el paralelismo entre los regímenes políticos y los económicos no supone una equivalencia permanente y siempre constante entre los elementos de unos y otros, de tal manera que sea posible declarar en todo momento que a una determinada forma política "corresponda" por necesidad otra determinada forma económica. Se trata más bien de "afinidades electivas", como antes se deslizó en la frase weberiana. Afinidades o parentescos compatibles con las experiencias más patentes de estos últimos años, que confirman el carácter plástico de las estructuras políticas y sociales y el hecho de que un mismo sistema se ofrezca con variantes considerables tanto en el tiempo como en el espacio.

Solventadas las anteriores reservas, se exige volver al punto de partida. De suerte que al hilo de la relación postulada en su planteamiento sea posible formular algunas hipótesis confirmadas, según se cree, por la evolución histórica misma. En este sentido, parece por lo menos plausible afirmar que al momento de la economía liberal, caracterizada por el predominio de la racionalidad formal, correspondió en la política el imperio de la típica "democracia representativa", que pudo funcionar en muchas partes con eficacia y sin tropiezos a lo largo del siglo XIX. En esta fase la economía queda abandonada a su propio juego y el Estado solo interviene para mantener los mecanismos formales que la misma necesita, muy en particular el cuadro jurídico y administrativo de que depende la seguridad y carácter previsible de su funcionamiento. Sería inoportuno entrar en mayores detalles - conocidos por lo demás-, pero no puede menos de aludirse a lo que representó entonces el parlamento en el proceso político de ese tipo de Estado. En efecto, su estricto carácter representativo, su naturaleza como foro de "discusión" nacional y órgano supremo de defensa de las garantías jurídicopolíticas constitucionalmente otorgadas, correspondían a una sociedad en que predominaba la acción individual en todos los aspectos de la vida, incluyendo ante todos los económicos. Se ha dicho con acierto a este respecto que la estructura social y la estructura del mercado venían a ser una y la misma cosa. Por lo tanto, la conexión entre las dos clases de racionalidad pudo realizarse de una manera relativamente sencilla: por la subordinación de la razón política a la razón económica, que solo obedecía al mecanismo de sus principios formales.

Pero coincidiendo con el nuevo siglo empieza a manifestarse la alteración profunda ocurrida en todas esas condiciones. En los países 
industriales más avanzados el Estado abandona su tradicional posición de neutralidad y comienza a intervenir en la vida económica y social, impulsado por tres exigencias fundamentales: $a$ ) la necesidad de hacer frente a los problemas ofrecidos por la coyuntura internacional, día a día más graves y complicados; $b$ ) la necesidad de tener en cuenta las transformaciones ocurridas en la estructura interna de las diversas economías y c) la necesidad de realizar una política social, dentro de una sociedad modificada también en su contextura tradicional. No es cosa desde luego de trazar aquí con detalle cada una de esas tendencias, pero sí parece conveniente reseñar algunas de sus más características manifestaciones. En lo económico, la aparición de las diversas formas de mercado de competencia imperfecta, que tienen su soporte en la gran organización en vez de la pequeña empresa individual. En lo social, la formación de poderosos grupos de intereses —empezando por las organizaciones obreras- que se oponen entre sí. En lo político, la mayor importancia del ejecutivo frente a una sustancial modificación interna de la vida parlamentaria. Claro está que no es fácil caracterizar en una sola frase toda esa transformación. Para algunos se trata del paso de la democracia liberal-representativa a la democracia radical-igualitaria del estado de partidos. Para otros es la historia de la formación del moderno welfare state. Se expresa también con la fórmula de la denominada democracia pluralista, que quizá sea la más expresiva para la perspectiva sociológica de este trabajo, pues la estructura social en los países industriales más avanzados es, en efecto, un complejo de grupos y "organizaciones" que cubren casi todo el campo de las actividades humanas. En ese tipo de sociedad el Estado toma necesariamente un papel de árbitro entre los intereses en conflicto y procura equilibrar las pretensiones de unos y otros. A la fase mixta de la economía corresponde así en lo político la democracia de grupos o pluralista, de manera que la conexión entre las dos formas de racionalidad - la política y la economía - tiene que ser el resultado del perseverante esfuerzo por encontrar en cada caso un compromiso temporal. La racionalidad más que formal toma en este uso un carácter "funcional".

Si abandonamos por un momento el ámbito de la tradición occidental, en la planeación totalitaria se ofrece una nueva manera, muy distinta como es natural, de realizar la conexión entre la racionalidad política y la económica y que indudablemente ha podido operar con eficacia. Es una paradoja histórica que el sistema que declara como supuesto doctrinal el imperio decisivo del factor económico como motor de cambio, represente en la práctica el predominio del factor político. De suerte que así como en la economía liberal representativa, el predominio de la racionalidad formal económica garantizaba su ejercicio paralelo en el campo político, en los sistemas totalitarios 
rigurosos, al contrario, es el imperio de la racionalidad política la que asegura las posibilidades de su realización en la esfera económica.

Todo lo que se ha tratado antes de exponer en concentradas fórmulas no tiene más que esta finalidad: desprender la tesis de que el óptimo o máximo en la necesaria conexión entre la racionalidad política y la económica solo se ha realizado en la historia de una u otra de las maneras indicadas. Ahora bien, reconocida la dificultad — si no imposibilidad- de encarnar en las actuales circunstancias la economía liberal en su forma pura, resulta que en el plano teórico solo existen dos formas que permiten en nuestros días aproximarse al equilibrio entre racionalidad política y económica: la democracia pluralista o el Estado totalitario.

A semejante conclusión puede llegarse también por un camino inverso, mostrando cuáles son las formas de actividad política que hacen difícil o imposible el necesario paralelismo entre las dos racionalidades, o dicho de otra manera, que son irracionales desde la perspectiva del desarrollo económico. Tales son, por un lado, el autoritarismo tradicional y, por otro, las "dictaduras populistas" o "cesarismos democráticos" - la terminología es imprecisa-, que se caracterizan por la ausencia en ellas de ideologías rigurosamente racionalizadas y de un aparato político del mismo carácter. En el autoritarismo tradicional parece ser lo típico la desatención a los problemas del desarrollo, o en el caso más favorable el hecho de que ese desarrollo quede frenado en una u otra forma cuando las consecuencias político-sociales del mismo amagan peligrosamente la duración del régimen autoritario. En los "cesarismos democráticos" puede existir, y se da las más de las veces, un interés por el crecimiento económico, pero se traduce por lo común en impulsos irracionales y de carácter explosivo. Como semejantes regímenes carecen de la rigurosa disciplina existente en los de carácter totalitario, están expuestos no solo a la confusión ideológica, sino a la corrupción permanente de sus engranajes administrativos. Allí donde se ofrecen tendencias políticas de ese tipo el desarrollo económico pierde continuidad y se realiza en el caso mejor con enormes e irregulares altibajos.

Lo que se ha dicho hasta aquí de manera demasiado abstracta y poco atractiva en consecuencia, cabría quizá formularlo en lenguaje más plástico y expresivo; pero la busca de un apoyo en ese sentido en la bibliografía científico-política de nuestros días pudiera ser decepcionante. Basten algunos ejemplos entre los más recientes. Un grupo de estudiosos de los sistemas políticos en los países poco desarrollados - más que nada asiáticos y africanos- propone estos tres modelos fundamentales: el sistema de movilización, el sistema consociational y el sistema de la autocracia modernizadora, términos ya de 
suyo difíciles de traducir adecuadamente. Y no menor complicación expresiva se ofrece para otro equipo que trata de aplicar al análisis de los procesos políticos las categorías de la teoría sociológica de la acción social, y con ellas examinar la situación de los países, nuevos y viejos, en vías de desarrollo. Queda, sin embargo, para el momento oportuno el examen de las ventajas e inconvenientes de tanta innovación terminológica.

A pesar de todo, sea cual fuere la que se emplee -innovada o tradicional-, el núcleo del problema es siempre el mismo: lograr la necesaria coherencia entre la actividad económica y el proceso político. No es posible querer - y menos llevar a cabo- propósitos incompatibles, ni utilizar instrumentos en desacuerdo con los fines propuestos. Y siempre son también los mismos al alcance y los límites del análisis científico puesto al servicio de la acción práctica: mostrar la armonía entre las metas, la adecuación de los medios elegidos para alcanzarlas y la repercusión previsible de los objetivos propuestos, en la medida en que pudiera ser adversa o negativa por una u otra razón.

Por lo que al desarrollo económico respecta, todo ello se resume en la afirmación, no menos cierta por más reiterada, de que en las circunstancias actuales no es posible alcanzarlo si no se tiene un programa claramente formulado y si ese progreso económico no funciona dentro del marco político apropiado. Las mayores diferencias entre los países latinoamericanos no están tanto en lo económico como en su infraestructura social y en los procesos políticos que esta permite. Sin embargo, puede sostenerse que los más avanzados de entre ellos están ya en situación de hacer viable su expansión económica dentro de una "democracia pluralista", aunque no sea punto por punto de igual manera que los países más avanzados de Europa o Norteamérica. Por el influjo de sus comunes tradiciones occidentales, sus formas políticas dibujan también un "Estado benefactor", pero aquí importa subrayar enérgicamente las diferencias del welfare state entre los países industriales maduros y los menos desarrollados, como Myrdal ha indicado con acierto. Las funciones de la intervención estatal en los primeros son sobre todo de arbitraje y de nivelación; en los segundos han de ser antes que nada de orientación y programación.

\section{EFECTOS POLÍTICOS DEL DESARROLLO}

Este tema quedaría incompleto si no se rozara - aun a igual paso apresurado que los anteriores-, otro problema de interés: el de los efectos políticos del desarrollo económico. Son evidentes - y no hay por eso que tratarlos- los del estancamiento y la pobreza.

En la actualidad la aplicación de las técnicas de la llamada sociología electoral ha permitido a algunos investigadores trazar correla- 
ciones entre el grado de madurez económica y el grado de madurez política, se entiende dentro de las tradiciones e ideales occidentales. Esas correlaciones parecen mostrar que en los países más avanzados la democracia funciona con "relativa" contabilidad por la eliminación -mejor atenuación- de los extremismos políticos. Es cierto que esas correlaciones pecan a veces de ingenuas y que pueden ser objeto de críticas severas, pero a la larga es innegable que traducen con corrección resultados visibles del proceso histórico. Esos resultados no han sido cosa de un día ciertamente y vienen precedidos de una historia empeñosa de luchas y conflictos; más el hecho actual en los países económicamente más adelantados es que las transformaciones en la estructura social derivadas de su mayor riqueza han atenuado - no suprimido - las tensiones sociales más graves y que, por consiguiente, la política puede reducirse al enfrentamiento sobre restringidas cuestiones de carácter objetivo —en el campo económico muy en particular - sobre las que cabe llegar las más de las veces a un compromiso provisional. Sin embargo, en las economías menos ricas y en trance de desarrollo casi parece imposible evitar que por obra de este mismo - sobre todo en sus fases de aceleración- surjan condiciones de desajuste en la estructura social favorables a la formación de situaciones de masa, que inclinan a uno u otro tipo de política extremista. Semejantes situaciones derivan de una u otra de las siguientes causas: primero, del desarraigo súbito de un gran número de gentes - de origen sobre todo campesino- envuelto en el crecimiento rápido tanto industrial como urbano - no necesariamente coincidentes - y que no puede adaptarse con facilidad por razón de esa rapidez a las nuevas condiciones. Segundo, de las desigualdades producidas entre los distintos sectores de la vida nacional, desniveles graves entre regiones avanzadas y retrasadas, u otros fenómenos semejantes dentro de las distintas industrias. Y tercero, de la ascensión rápida a la "sociedad de consumidores" — típica de los países ricosde grandes masas sin las "reservas morales" necesarias para atemperarlas en sus goces y deseos.

\section{LA CONSTELACIÓN ORIGINARIA Y LAS PARADOJAS DE LA HISTORIA LATINOAMERICANA}

Poco a poco de las páginas anteriores se han ido desprendiendo los elementos fundamentales para la construcción de un modelo del desarrollo de América Latina. Se perfila la imagen de una tarea que desde luego no es sencilla ni puede pretenderlo ser, pues requiere un esfuerzo paralelo en los campos económico y social, sujetos ambos a un mismo programa claramente formulado, y, por otra parte, exige el propósito de mantener una relación equilibrada entre la voluntad 
enérgica del Estado y la espontaneidad social. Pero esta es la tarea que viene impuesta por la confluencia de la historia entera de América Latina con la coyuntura internacional de nuestros días. Toda consideración sociológica culmina - cuando no lo precede- en el estudio de la constelación universal desde el centro de una historia singular, y de él depende en definitiva el sentido que pueda tener cualquier análisis particular por importante que parezca en sí mismo. Pero excede de lo discreto pretender encarar en estas páginas semejante tema y solo parece aconsejable bosquejar unas rápidas notas de interpretación histórica que sirvan para prestar algún significado de conjunto a todo lo dicho anteriormente.

La historia económico-social de América Latina está todavía por hacerse de manera completa y satisfactoria. Y esto se debe a razones por lo demás conocidas; primero, a causa del tardío interés que esa historia despierta frente a la tradicional puramente política; segundo, por el carácter fragmentario que adquiere en las diversas historias nacionales, y que malogra la visión de conjunto de los grandes movimientos semejantes en toda la región. Pero sin tener bien en cuenta esa historia común no pueden entenderse cabalmente los problemas del desarrollo en la hora actual, lo mismo por propios que por extraños.

El hecho fundamental que se olvida o no se tiene en cuenta por unos y otros - no siempre más por los otros- es que América Latina, si así se la quiere llamar, es un fragmento por derecho propio de la civilización y del cuerpo de Occidente, aunque dentro de ellos haya mantenido más o menos hasta hoy la misma fisonomía en cierto sentido marginal de los viejos países metropolitanos. Cuáles sean las notas de esa peculiaridad no es cosa que interesa en este punto; importa por el contrario subrayar con alguna fuerza que frente a aquellos viejos países la historia cultural y política de América Latina se destaca acusadamente por dos características esenciales de su constelación originaria: $a$ ) por haber sido "tierra nueva" y haber vivido, en consecuencia, una "cultura colonial", y $b$ ) por haber forjado su independencia con la bandera del ideario liberal más exaltado y puro.

No se sabe cuál de esas notas ha sido más decisiva en la historia posterior y son de por sí y por sus consecuencias demasiado complejas para que ahora se intente su examen. Mas la segunda interesa de un modo singular, pues de ella deriva la primera gran paradoja fundamental de la historia latinoamericana. El hecho de que por un largo número de décadas la persistencia de esa mentalidad liberal se mantuviera en contradicción patente con la estructura social real — de naturaleza agraria - heredada del virreinato. Desde la perspectiva de hoy la perduración de esa aspiración liberal, siempre intacta, convierte casi en anécdota el hecho desventurado de las dictaduras y los cuartelazos. 
A la historia del XIX, enfocada sobre todo —en vago conjuntopor sus lados deprimentes, se debe el injusto olvido en que se tiene al enorme esfuerzo realizado en la mayoría de los países a partir de la segunda mitad de ese siglo. En los momentos actuales la impregnación atmosférica por la idea del subdesarrollo, que tiende a hacer gatos pardos de todos los pueblos comprendidos en el denominado "tercer mundo" ha producido - en la sabrosa fórmula popular derivada del demonstration effect de la ciencia - un complejo de timidez e inferioridad, que por su interés va más allá de ser un tema académico de la sociología cultural. Por un lado, ciega para apreciar con exactitud el considerable esfuerzo realizado en todos los terrenos durante los últimos cincuenta años. Por otro, deprime más de lo necesario el estado de ánimo de las nuevas generaciones, destinadas a llevar a cabo en circunstancias distintas lo que en buena parte hicieron las anteriores.

Dos cosas sobre todo quedan opacadas en esa injusta apreciación del pasado inmediato. En primer lugar suele olvidarse que en la mayoría de los países existieron elementos de las minorías dirigentes que tuvieron en su día visiones adecuadas - políticas y económicas- de la realidad, y que supieron crear en condiciones adversas, y a pesar de todo, la "infraestructura económica" de que hoy se goza y de la que hay que partir con mayores ventajas. El hecho de que esas minorías dirigentes no hayan tenido por lo común el sentido de la renovación oportuna, justificando el ataque posterior a su "dominación oligárquica”, no debiera impedir el reconocimiento de sus realizaciones económicas y de su, en ocasiones innegable, capacidad política.

Pero, en segundo lugar, no se concede tampoco la debida importancia al hecho de la profunda transformación social ocurrida en esos años y a la aparición, en el grupo más importante de los países latinoamericanos, de nuevas capas sociales con fuerte impulso ascensional, que se extienden — con diferencias claro es, entre unas y otras- desde las clases medias al proletariado organizado, y que algunas veces solo esperan los cuadros políticos necesarios para su completa incorporación a la vida nacional. Por lo demás, es un lugar común —correcto en este caso-que todas las dificultades de los últimos años no son sino expresión del choque de esas nuevas capas con las "oligarquías" establecidas.

Ahora bien, la segunda gran paradoja de la historia latinoamericana — secuela sin duda de la anterior — es que la coyuntura histórica e internacional es hoy el mayor impedimento para la plena realización de la "estructura liberal" que fue la meta de su más tenaz aspiración centenaria. Supuesta la continuación de su vida en un vacío histórico, y tiempo largo por delante, América Latina podría "ahora" madurar la sociedad liberal del viejo tipo. Pero en la era de lo "colectivo", y ante 
la urgencia de adaptación que exigen los rápidos procesos del mundo, las recetas de los viejos manuales suenan a cantinelas inoperantes. El desafío presentado por las circunstancias actuales a la capacidad creadora de Hispanoamérica - mantener con vigor en la era de la organización, incorporándolos eficazmente, los impulsos de su "añeja" tradición liberal- es más que considerable, pero no deja de estar en definitiva a la altura de su propia historia.

La tercera gran paradoja en la historia de América Latina es el hecho de la necesidad en que se encuentra de realizar urgentes integraciones supranacionales cuando la integración nacional de muchos de sus países solo ahora comienza a estar completa y acabada.

En realidad la historia de los países desunidos de América está asimismo por hacer desde esta perspectiva. A partir de la Independencia y sobre el fondo homogéneo de su constelación originaria —es decir de sus notas esenciales- todos y cada uno de los países han tenido que llevar a cabo su integración nacional en procesos de extraordinaria lentitud, cuyos últimos actos - revolucionarios a veces y paradójicos otros- vienen tardíamente a producirse en nuestro siglo. Y no cabe duda de que existen marcados desniveles entre unos y otros. No es cosa de entrar en pormenores. Lo importante es destacar que es en este mismo siglo cuando viene a abrirse paso por el camino de la economía y de la técnica y ante las exigencias de la coyuntura internacional una nueva integración de otro tipo - de carácter supranacional- más acá de las herencias históricas comunes y de los ideales bolivarianos siempre vivos y en el momento en que apenas acaban de cuajar las integraciones nacionales. De cómo se plantea y comienza a realizarse en nuestros días la integración supranacional de nacionalidades apenas recién nacidas, es ya una muestra la tarea en marcha en Centroamérica y la aceptación por unos y por otros de las metas inmediatas del mercado común, de que es primera manifestación la creación reciente de la Zona de Libre Comercio por el Tratado de Montevideo.

El cuadro constituido por estas pocas notas esenciales y generales de la historia de América Latina, aunque ofrezca su último sentido unitario a todas las tareas parciales de su desarrollo económico - y de las que se ha tratado en estas líneas apresuradas- no puede manejarse con alcance práctico si no se tiene presente toda la gama de las diferencias. Por ello es necesario contar con una tipología bien elaborada de la realidad socioeconómica de los distintos países latinoamericanos, que será necesario renovar de cuando en cuando —es de esperar- de acuerdo con las modificaciones de sus índices. 



\title{
Juan Francisco Marsal
}

\section{LA SOCIOLOGÍA EN AMÉRICA LATINA}

\author{
ALGUNAS CARACTERÍSTICAS DE LA \\ LITERATURA SOBRE CAMBIO SOCIAL*
}

\section{OBJETO Y LÍMITES}

A fin de delimitar inicialmente el campo a que se refiere este trabajo creo que procede hacer las siguientes especificaciones respecto a lo que en él se pretende: no se trata de ofrecer un panorama general de los estudios sobre Latinoamérica sino solo de aquellos que sean relevantes para los problemas del cambio social.

Su objeto son las teorías de cambio que se refieren a las sociedades globales de América Latina. No se estudian aquí procesos de cambio que solo traten de sectores, instituciones o subsistemas sociales (Cfr. Etzioni, 1964: 77 y 404).

Como consecuencia de la perspectiva adoptada se dejan de considerar estudios que como los demográficos, económicos, ecológicos, etc., se refieren únicamente a aspectos particulares de la sociedad latinoamericana. También se excluyen los ideográficos como lo en su mayor parte los históricos.

Los estudios que se examinan en este trabajo son en su inmensa mayoría de carácter sociológico o antropológico más el ensayismo

* Marsal, Juan Francisco 1966 "La sociología en América Latina. Algunas características de la literatura sobre cambio social" en Revista Latinoamericana de Sociología, Vol. II, N 2, pp. 237-253. 
parasociológico intelectual. La teoría social científicamente enmarcada tiene en Latinoamérica fecha muy reciente. Sería por tanto muy desigual comparar lo producido por la ciencia social mundial y particularmente la de los Estados Unidos en medio siglo con los actuales resultados de las noveles disciplinas latinoamericanas. Las últimas tienen detrás, sin embargo, un rico pasado de ensayismo parasociológico que no puede ser desechado. Pues, como ha dicho Edward Shils, el análisis sociológico no es más que una continuación en idioma contemporáneo de los grandes esfuerzos de la mente humana para juzgar las vicisitudes del hombre sobre la tierra.

Debe tenerse en cuenta, además, que este trabajo está escrito teniendo como marco de referencia a Latinoamérica. Porque hay teorías de cambio social que en lo que atañe a factores, dirección y otras básicas cuestiones del cambio pueden interpretarse de una manera para un área o unidad determinada y de forma distinta y aún opuesta si la unidad o área considerada es otra. Así por ejemplo algunas teorías de cambio social de fines de la pasada centuria y comienzos de la actual adoptaron una posición progresista respecto a la dirección de cambio de la cultura occidental o de la humanidad como un todo que, sin embargo, se tornaba en regresiva cuando la unidad considerada eran las sociedades o culturas no occidentales.

Este artículo pertenece a lo que en habla inglesa se llama library research, es decir, se basa en material publicado sobre el asunto. Quien esto escribe desea ya dejar bien establecido que no se trata de un trabajo sobre el cambio social en América Latina sino sobre cómo el cambio social en Latinoamérica aparece en ciertos estudios que se han destacado por su significación e influencia disciplinaria. Toda pretensión exhaustiva ha sido también desechada.

\section{TIPOLOGÍA DE LAS TEORÍAS SOBRE CAMBIO SOCIAL EN AMÉRICA LATINA}

A continuación se esboza una tipología de las teorías de cambio social en América Latina utilizando como fundamentum divisionis la posición tomada por ellas respecto a factores y dirección de cambio. La razón para la selección de este criterio es la siguiente. La multitud de problemas que conciernen al problema de cambio social pueden agruparse en torno a cinco temas fundamentales - unidad, magnitud, fuentes, orden y dirección-que responden a las preguntas sobre qué es lo que cambia, cuánto, porqué, en qué orden y hacia dónde se produce el cambio ${ }^{1}$. Sin embargo, aunque esas son cuestiones indispen-

1 Estas preguntas se basan principalmente en las sugeridas por W. E. Moore (1963 y 1964) y por Bottomore (1963: 285-288). 
sables para el estudio del cambio social no todas son abordadas en la literatura que se examina en este artículo.

El primer problema, unidad de cambio, queda reducido al estudio de la sociedad como un todo. Incluso los estudios de comunidades que se basan metodológicamente en unidades menores tienden a generalizar sus resultados a la sociedad que las engloba. Por otra parte el objeto de este artículo y la tendencia totalista de las obras seleccionadas convierten aquí este problema en una petición de principio.

Las cuestiones que tratan sobre magnitud, significación y secuencia del cambio son demasiado complejas para la mayor parte de la literatura estudiada que generalmente no las aborda. Quedan solo, pues, cuestiones referentes a las fuentes y dirección de cambio que son tratadas en todas las obras sobre cambio social, y que fueron también "los dos grandes problemas" que preocuparon a los clásicos en la sociología del cambio social (Cfr. Mac Iver y Page, 1949: 518 y passim, Sorokin, 1939-1941; Sorokin, 1947: Caps. 44 a 46; Moore, 1960).

\section{TEORÍAS DE CAMBIO SOCIAL SEGÚN LOS FACTORES PREDOMINANTES DE CAMBIO}

Las teorías de cambio social pueden ser clasificadas de acuerdo a los factores a los que en ellas se les da el rol principal, usándose aquí el término factor como un sinónimo por los de "causa" o "fuente" (Cfr. Mac Iver y Page, 1949: 512). El uso del término "predominante" tampoco es casual pues significa que no se hace aquí distinción entre teorías monistas, que sostienen teóricamente una explicación unifactual pero que en realidad trabajan con varios factores, y las que en teoría se adhieren a una interpretación basada en la interdependencia de factores pero que en realidad se apoyan en el predominio de un factor sobre los otros.

Hay también que hacer notar dos aspectos adicionales. En primer lugar, que la perspectiva multifactorial adoptada casi unánimemente por la sociología contemporánea ha sido utilizada con éxito en el estudio de los procesos sociales pero no en el estudio de la sociedad como un todo. Ello ha producido, como efecto colateral, cierta tendencia a evitar el estudio del cambio social de las sociedades globales. "Las grandes teorías - ha señalado Etzioni- fueron inadecuada guía de la investigación sociológica pero ninguna teoría moderna de cambio social las ha reemplazado" (Etzioni, 1964: 75). Hay que notar sin embargo que en años recientes se han hecho considerables esfuerzos para construir una teoría general del cambio social que "abandone las explicaciones basadas en causas fundamentales externas al sistema social y en un solo factor" (Moore, 1960: 811).

En segundo lugar hay que puntualizar que, con la excepción de muy pocas obras, los estudios sobre Latinoamérica no se destacan por 
su aporte a la teoría sociológica. No es por tanto extraño que las teorías de los clásicos en el campo del cambio social se hayan mantenido implícitamente detrás de estudios orientados por preocupaciones empíricas inmediatas.

De acuerdo al criterio de los factores predominantes, las teorías de cambio social en América Latina se pueden clasificar en dos categorías: externalistas e inmanentistas ${ }^{2}$. Se llaman aquí "externalistas" a las teorías que consideran las fuerzas externas al sistema social -herencia y ambiente no-humano- como los factores principales en el cambio social, e "inmanentistas" las que atribuyen el rol principal a los factores internos del sistema social. La segunda categoría - teorías inmanentistas - se divide, a su vez, en dos subcategorías: "exogenistas" y "endogenistas" ${ }^{3}$. Se llaman aquí teorías exogenistas de cambio social las que explican el cambio predominantemente en función de factores externos al particular sistema o sistemas sociales estudiados y endogenistas las que lo hacen principalmente por sus factores internos.

\section{TEORÍAS EXTERNALISTAS ${ }^{4}$ TEORÍAS BIOPSICOLÓGICAS}

Las interpretaciones biológicas de lo social disfrutaron de gran popularidad entre la intelligentsia latinoamericana a comienzos de la presente centuria. Ello se interpreta, en parte, como reflejo del biologismo predominante en la cultura occidental en aquel momento y en parte también como instrumento ideológico para justificar políticas sociales de las élites criollas gobernantes. La variedad latinoamericana de este tipo de teorías es no obstante más una suave y bastante inconsistente interpretación biopsicológica que un extremo biologismo.

En el campo de la dinámica el darwinismo social que fue el patrón dominante, constituye un claro ejemplo de lo que Parsons llama "el dilema utilitario" (Cfr. Parsons, 1937: Parte I). Porque teniendo sus raíces intelectuales en el individualismo positivista finalmente termina desembocando en una interpretación "positivista radical" de la acción social en la que los factores hereditarios, fisiológicos y mentales, determinan la estructura, los cambios sociales y hasta la estratificación internacional. Es decir, que los factores étnicos o los rasgos psicológicos de supuesto origen racial, determinan qué sociedades son superiores y cuales inferiores.

2 En este punto seguimos la terminología de Sorokin (1939-1941: Vol. IV, Caps. 12 a 14) y (1947: Caps. 44 a 46).

3 Estos términos se basan en Dahrendorf (1958).

4 Para un estudio más detenido de este tipo de teorías, véase Sorokin (1928), caps. 3 a 7, y Moore (1937), caps. 2 a 3. 
Todos los pensadores latinoamericanos de importancia de la pasada centuria hacen alguna alusión al factor racial. Algunos como Sarmiento, en Conflicto y armonías de las razas en América, ensayaron sin éxito una presentación más sistemática. Ya en la presente centuria ensayistas sociales como Bunge, Bomfin y Arguedas ${ }^{5}$ desarrollaron sus ideas a lo largo de un biopsicologismo autorrecriminatorio. Otros como Ingenieros combinan cierto moderado bioeconomismo con el progresismo idealista.

Las teorías organicistas aunque poderosas en un determinado momento de la historia intelectual de occidente tuvieron corta vida. Las inconsistencias de la interpretación biológica de la sociedad y las consecuencias del racismo en el escenario político mundial aceleraron su desuso. Sin embargo aún se encuentran rastros de biopsicologismo bajo los caracteres culturales de algunos estudios antropológicos norteamericanos sobre Latinoamérica (Cfr. por ejemplo, Gillin, 1951).

\section{TEORÍAS AMBIENTALISTAS}

Ideas ambientalistas se encuentran en muchos escritores latinoamericanos de los pasados ciento cincuenta años pero, como en el caso del biologismo, no aflora un estricto sistema de interpretación de los fenómenos sociales basado en el ambiente natural o no-humano. Muchos son los que mencionan clima, temperatura y otros elementos físicos como importantes factores para interpretar las respectivas historias nacionales latinoamericanas pero sin llegar a pretender que esos factores fueran directamente casuales. El uso, por ejemplo, tan frecuente hace unas décadas de los términos "civilización" y "barbarie" es ejemplo de la influencia de las tendencias que Sorokin agrupara bajo el nombre de "escuela geográfica" (Cfr. Moore, 1941).

Por otra parte no me parece sostenible la tesis de Crawford de que en la historia de las ideas latinoamericanas se produce una evolución que va de las interpretaciones biológicas y geográficas a las culturales. Muchos escritores de los comienzos del presente siglo como Agustín Álvarez, Carlos Octavio Bunge, Arguedas, Da Cunha y Hostos continúan haciendo uso de conceptos ambientalistas tanto como prominentes intelectuales contemporáneos como Freyre y Vasconcelos.

Ideas de tono más o menos geográfico determinista se han manifestado en todos los tiempos, pero un intento de ofrecerlas como ciencia social no tuvo lugar hasta la pasada centuria. Fue entonces cuando muchos filósofos sociales, sociólogos, historiadores, economistas y geógrafos se adhirieron a las aserciones de la llamada escue-

5 Las obras más representativas de estos tres autores son: Bunge, 1903; do Bomfin, 1903; y Arguedas, 1937. 
la geográfica. Dentro de ella la geopolítica alemana de Ritter y Ratzel, por un lado, y la obra de Huntington, por otro, trataron de relacionar las condiciones geográficas con los sistemas políticos y el auge o decadencia de las civilizaciones.

Las teorías ambientalistas, no obstante, pronto se desacreditaron. Si el fallo de las teorías biológicas fue la excesiva simplicidad, el de las ambientalistas fue su vaguedad. Y cuando las hipótesis geográfico-deterministas fueron sometidas a verificación no pudieron sostenerse frente a la abrumadora prueba en contrario. Además, en el campo teórico obras como la de Parsons pusieron en evidencia la falacia ambientalista de separar las condiciones de otros elementos de la acción social.

A pesar de todo ello, todavía se encuentran rastros de un vago enviromentalism en la obra de algunos científicos sociales norteamericanos especializados en Latinoamérica. Wagley, por ejemplo, en su estudio de un pueblo amazónico, se refiere a una correlación entre atraso y ambiente tropical que recuerda la teoría del Ecuatorian Drift de los ambientalistas (Wagley, 1953: Cap. I). Stewart descartando el evidente rol de la historia política, para comparar la evolución de Puerto Rico y del Sudoeste norteamericano se apoya teóricamente en "procesos de ecología cultural" que se explican por la posición geográfica y el ambiente físico circundante (Stewart, 1956: 15). Adams intenta sustituir la hipótesis de Redfield y la ideología indigenista de los estudios de comunidad de los antropólogos por una teoría de la "expansión" en la que la comunidad es vista como una "realidad ecológica" que tiende a extenderse a no ser que algo en el ambiente lo impida (Adams, 1962: 422-430). Desgraciadamente la teoría de Adams es confusa cuando aborda el crucial problema de separar el ambiente social humano del que no lo es ${ }^{6}$.

\section{TEORÍAS INMANENTISTAS ENDOGENISTAS}

IDEALISTAS

"La discusión más larga, profunda e importante" dentro de las grandes teorías inmanentistas tuvo lugar entre aquellos que veían la "esfera espiritual" como la fuerza primera del cambio y aquellos que creían que era la "esfera material" (Etzioni, 1964: 6-7). Esto, claro está, era un reflejo de las posiciones "idealista" y "materialista" en filosofía. Por otra parte en el esquema parsoniano de acción social son idealistas aquellas teorías en las que los elementos condicionales de acción social desaparecen y, por tanto, la acción social "se convierte en un pro-

6 Véase la crítica de Stavenhagen a la teoría de Adams (Stavenhagen, 1963 a y b). 
ceso de emanación o autoexpresión de factores ideales o normativos" (Parsons, 1937: 82).

Dentro de Occidente los países de habla ibérica son parte, como Alemania, de la tradición intelectual idealista. No es por tanto sorprendente que los pensadores latinoamericanos hayan subrayado las fuentes "espirituales" de cambio —el rol de las ideas, las normas y los valores- sobre las externas y "materiales". Lo que ha producido en el pensamiento latinoamericano una forma especial de nacionalismo que Graña ha llamado "nacionalismo cultural” (Graña, 1962 y 1963). De ahí arranca también el éxito que tuvo en su momento la reacción filosófica anti-positivista en cuyas filas militaron las figuras intelectuales más destacadas de Latinoamérica entre las dos guerras mundiales.

Para Samuel Ramos, por ejemplo, los cambios del México moderno derivan de su "carácter espiritual". Para Martínez Estrada, los cambios originados externamente solo producen "falsas normas" o "pseudo-estructuras de civilización”. Ellas solo producen "utopías", como dice Octavio Paz, que están en conflicto con la verdadera naturaleza de la nación. Cada cultura nacional, dirá Freyre, tiene su propio e intransferible tiempo y ritmo de cambio.

Hay además que tener en cuenta que el positivismo latinoamericano tiene conexiones con el idealismo y que el "idealismo positivista" resultante tiene, por tanto, hondas raíces en la tradición idealista. Aunque el idealismo positivista latinoamericano incluye, desde luego, entre sus conceptos clave las ideas de evolución y las analogías biológicas, las conecta a la noción de progreso moral heredada de la ilustración. Para Agustín Álvarez, Ingenieros o Justo Sierra la evolución significa tanto una tendencia linear constantemente ascendente como progreso moral y cultural en la búsqueda de la verdad y la libertad humana. Para los positivistas-idealistas latinoamericanos la evolución se presenta como un desarrollarse de cualidades internas siguiendo leyes particulares de cada sociedad.

Hay que referirse también a un tercer grupo de pensadores sociales latinoamericanos. Me refiero a los indigenistas, en su mayor parte mejicanos y peruanos, como Mariátegui, Castro Pozo, Sáenz o Gamio que pueden considerarse, aunque en forma particular, parte de la tradición intelectual idealista. Porque la filosofía general de los indigenistas es que la comunidad indígena es la unidad natural de las sociedades indo-americanas y que solamente ella puede producir formas "originales" de civilización en Latinoamérica. Para ellos las formas sociales o culturales son tan "falsas" como lo son para los pensadores liberales. Precisamente la atención de los estudios indigenistas a las culturas precolombinas es una derivación de este punto de vista. 


\section{REALISTAS}

Hasta hace poco las teorías que destacaban las fuentes internas de cambio eran exclusivamente idealistas. Ello no tenía por qué ser así en buena lógica, pero la atención de las ciencias sociales a los factores exógenos de cambio habían dejado un campo vacío. En las últimas décadas, sin embargo, las ciencias sociales se han esforzado por superar "el dilema positivismo-idealismo". De ello ha resultado una renovada atención por parte de los científicos sociales norteamericanos a las fuentes internas de cambio. Ha habido estudios sobre las condiciones de la sociedad receptora que hacen posible la aceptación de rasgos culturales nuevos, las luchas intestinas de carácter ideológico, las tensiones causadas por la desigualdad y el papel de los grupos subordinados en el desarrollo económico. Otros han intentado con más o menos éxito combinar el método funcional con la perspectiva histórica nacional en el estudio de las comunidades ${ }^{7}$.

Los científicos sociales latinoamericanos por su parte, se han afanado en buscar una interpretación causal más compleja. A ello han contribuido fundamentalmente la mejora de las relaciones con la comunidad científica internacional y las especiales necesidades de la ciencia social en Latinoamérica. Su interpretación se ha ido apartando de las previas tradiciones intelectuales exogénicas y materialistas. Germani, por ejemplo, se ha planteado recientemente los problemas del análisis de tensiones mientras que otros se han abocado a la revisión de la estereotipada imagen de la sociedad tradicional ${ }^{8}$. Finalmente debe mencionarse también el surgimiento de una intelectualidad marxista joven que ha encontrado expresión política en lo que Alexander ha llamado la "izquierda jacobina" y cuyo pensamiento aunque de fuentes marxistas y aún no terminado se aparta progresivamente del escolasticismo exogenista inicial (Cfr. Espartaco, 1964).

\section{EXOGENISTAS}

La mayor parte de los estudios de los científicos sociales norteamericanos sobre Latinoamérica han dado preferencia a los factores exógenos de cambio sobre los endógenos, siguiendo con ello los modelos funcionalistas dominantes y la ideología generalizada en el Occidente sobre los países coloniales y excoloniales (Cfr. De Vries, 1961: 27 y ss.). Las sociedades tradicionales son vistas como estáticas, integradas y en equilibrio; en ellas no hay vida espontánea y las relaciones socia-

7 Entre los trabajos más destacados pueden citarse Steward y Murphy, 1956; Redfield, 1950; Tumin, 1952; Hagen, 1962; y Lewis, 1951.

8 Obras representativas de esta tendencia son: Germani, 1964; Di Tella, 1966; y ECLA, 1963. 
les están estandarizadas. Solo un cambio es posible: el que resulta de factores exógenos, esto es, "el producto del impacto de Occidente". Redfield, uno de los más destacados latinoamericanistas de este siglo, que presenció la revolución mexicana con sus propios ojos la entendió como una forma de resistencia tradicional a los cambios modernos introducidos por el capitalismo (Redfield, 1930: LI). "Si no hay perturbación externa - escribió Redfield- la tendencia del camino en virtud del cual una comunidad persiste es en la dirección de mayor armonía e interdependencia de sus pares" (Redfield, 1940: 141).

Tal concepción de la sociedad tradicional no occidental no solo tuvo vigencia en la teoría antropológica. Los métodos de investigación utilizados en Latinoamérica, las disciplinas colindantes como la sociología rural y las propias ciencias sociales latinoamericanas fueron influenciadas por ella (Cfr. como ejemplo Fals Borda, 1964: 2122). Podemos finalmente afirmar que el estudio del cambio social en América Latina se ha centrado principalmente en las fuerzas exógenas innovadoras y en particular en los aspectos "materiales" de la cultura. Pero dentro de esta corriente general cabe distinguir tres tipos de teorías: estratificacionales, culturales y desarrollistas.

\section{ESTRATIFICACIONALES}

El llamado mito de la emergente clase media ha tenido gran influencia entre los estudiosos de Latinoamérica que la han contemplado única o preferentemente desde la perspectiva del sistema de estratificación. Como parte de la obra del mismo Marx, se trata de una observación histórica correcta que se transforma en una indebida o, por lo menos, no verificada generalización. Porque la teoría de la emergente clase media prevé un único curso de cambio de las sociedades latinoamericanas en el cual los aspectos ideológicos y estratificacionales se entretejen. Es decir, el llamado paso de la sociedad feudal de dos clases a la sociedad democrática dominada por la clase media.

El historiador John J. Johnson es no solamente el más representativo entre los sostenedores de esta teoría sino el que la ha ofrecido en forma de más coherente (Johnson, 1951, 1955 y 1958). Otros muchos, tanto norteamericanos como sudamericanos, han seguido sus huellas pero sin la misma fidelidad a la tesis central en la que han introducido modificaciones o bien incorporándola a diferentes contextos teóricos.

Lo que nos importa destacar aquí es el carácter exogenista de la teoría de la emergente clase media o sectores medios de Latinoamérica, que unida a la idea de la "alianza entre libertad y máquinas" hace que la tecnología juegue el papel de factor innovador. El argumento central de esta interpretación puede resumirse de la siguiente manera. Se introducen en Latinoamérica nuevas máquinas y técnicas que 
son empleadas en nuevas industrias y estas a su vez necesitan para funcionar de una nueva clase de empresarios, operarios y técnicos que nace con ellas 9 .

Pero la cadena del razonamiento no termina aquí. Esta nueva clase producida por innovación tecnológica constituye una nueva clase política que se convierte en opositora de los terratenientes y las élites tradicionales y que produce democracia política y progreso económico. De esta manera, argumentan los sostenedores de la teoría de la emergente clase media, los innovadores fomentan el cambio y ayudan a desarrollar una hasta entonces estática Latinoamérica.

\section{CULTURALES}

Los primeros trabajos llevados a cabo por los antropólogos para estudiar el paso de normas y objetos de una cultura a otra fueron llamados estudios de aculturación. Una definición muy conocida es la de que "la aculturación comprende aquellos fenómenos que resultan cuando grupos de individuos que tienen culturas diferentes se ponen en contacto en forma directa y continua, lo cual produce cambios en los patrones culturales originales de ambos grupos" (Herskovits, 1938: 10). En Latinoamérica, sin embargo, los estudios antropológicos de aculturación tuvieron en realidad el objetivo más limitado de estudiar el grado de asimilación de la cultura occidental por los pueblos nativos y en particular la sustitución de la supuestamente estática cultura indígena por la cultura hispánica.

La teoría de aculturación ha sido criticada en dos aspectos principales. En primer lugar como señaló Herskovits, por su falta de actitud crítica y su indiscriminada aceptación del postulado de que las culturas nativas son arrasadas por las técnicas europeas y, en segundo lugar, por la presunción de que la cultura dominante es como una bolsa en la que la selección de elementos se hace de forma azarosa o desconocida (Cfr. Foster, 1960).

La teoría de cambio social de Redfield, aunque bajo la influencia de las teorías sociológicas de Durkheim, Toennies y Maine, se deriva originariamente de los estudios de aculturación. Por eso a diferencia de los estudios difusionistas su foco recae no en trazos aislados de cultura sino en la unidad entera. La teoría de cambio de Redfield es básicamente una dicotomía, es decir, se trata esencialmente del cambio entre dos polos, cultura y civilización, que luego se transforma en un modelo de cambio en tres etapas. Para Redfield el cambio social es un fenómeno único que forma la cadena de la historia de occidente:

9 Un ejemplo frecuentemente citado en la literatura norteamericana es el del impacto de la construcción del canal en la sociedad panameña. Véase Biesanz (1950). 
"el proceso de civilización" (Redfield, 1940: 349). Siendo una teoría fundada en los estudios de aculturación no es sorprendente que causas exógenas, externas a los pueblos folk, sean las únicas que se consideran como promotoras de cambio. Las conmociones internas aun cuando sean tan visibles como la revolución mexicana, son descartadas porque no encajan en el esquema teórico redfieldeano ${ }^{10}$.

Las ideas de Redfield han tenido gran influencia no solamente entre sus discípulos y colaboradores sino en la comunidad de investigadores de las ciencias sociales en general y en particular en la obra de antropólogos latinoamericanistas tales como Hutchinson, Steward, Wagley, Harris, etcétera.

\section{DESARROLLISTAS}

Quedan ya muy pocos vestigios de determinismo tecnológico en la literatura de las ciencias sociales sobre Latinoamérica aunque algunos estudiosos como T. Lynn Smith todavía mencionan la teoría del cultural lag. Sin embargo la teoría del desarrollo económico que tan amplia aceptación ha tenido entre los científicos sociales de Latinoamérica puede considerarse en cierta manera como una versión más sutil de la clásica teoría de prioridad tecnológica en el cambio. Algunos sociólogos han señalado que ella supone "un renacimiento del neo-evolucionismo" en el sentido de que la dirección de cambio se presenta también como "acumulativa y directiva" (Etzioni, 1964: 255; y Moore, 1963: 40).

Por otra parte, el modelo de desarrollo económico en tres etapas se centra principalmente en la acción de causas externas de cambio. Porque como dicen Feldman y Moore "durante la transición el industrialismo es visto como un sistema inducido externamente que tiene un impacto problematizador sobre la presuntamente estática y resistente estructura tradicional" (Feldman y Moore, 1964, II: 152-163).

Sociólogos latinoamericanos como Costa Pinto, Di Tella, Germani y Fals Borda hacen uso de ese modelo. Germani, por ejemplo, destaca el rol del "efecto de demostración" y llama la atención sobre el impacto de elementos tecnológicos exógenos en diferentes sectores de la sociedad tales como familia, población, ideología y política y las "resistencias y obstáculos" que la sociedad tradicional ofrece al cambio social así también como a las características del período de transición o desajuste (Germani, 1962: 82, 95, 102, 109, 110, 112, 253 et passim).

Otra importante vertiente de expresión de la teoría desarrollista del cambio social se halla en la obra de Prébisch y la CEPAL. La doc-

10 Recuérdese la excelente crítica de Lewis (1963). 
trina de Prébisch aunque dentro del contexto disciplinario de la ciencia económica, ha tenido grandes implicaciones para la teoría sobre el cambio social en Latinoamérica y ha disfrutado de considerable ascendencia entre los científicos sociales de la zona. Para Prébisch, como es bien conocido, las condiciones del comercio mundial producen la división del mundo en áreas centrales y periféricas, y es el centro según su punto de vista quien obtiene el fruto del incremento de la productividad de los países situados en la periferia. Por tanto, mientras que las sociedades del centro progresan, las de la periferia se estancan o retroceden. La clave, pues, del cambio social en los países situados como Latinoamérica en la zona periférica, está en el rol de factores económicos exógenos.

\section{TEORÍAS DEL CAMBIO SOCIAL SEGÚN LA DIRECCIÓN DEL CAMBIO}

Las teorías de cambio social en América Latina se pueden agrupar también de acuerdo a su posición respecto a la dirección del cambio. A fin de simplificar la gran variedad de formas que puede tomar la dirección del cambio usaremos aquí solamente la división tripartita de Sorokin: lineal, cíclica y variable. Para evitar una innecesaria repetición de la literatura se ofrece a continuación en forma resumida algunas de las tendencias y autores más representativos.

\section{LINEALES}

Se llaman aquí lineales las teorías de cambio social que lo caracterizan como una línea que conecta directamente dos puntos o un nivel con otro. Si la línea es ascendente se las llama evolucionistas o progresistas y si es descendente, regresistas o primitivistas.

\section{PROGRESISTAS O EVOLUCIONISTAS}

1. Forman un primer subgrupo las teorías que ven el cambio social como una línea recta que conecta un punto con otro. Los siguientes son ejemplos de esta tendencia:

- Positivismo idealista. De la barbarie a la civilización (Agustín Álvarez, Letelier, Sierra, Ingenieros).

- Progresismo anti-positivista. De la cultura imitativa colonial a la cultura genuina y nacional (Ramos, Paz).

- Aculturacionismo y difusionismo. De la cultura folk a la civilización (Herskovits, Steward, Tshopick, Gillin, Tax, Elsie, Parsons). 
2. Variedades más recientes y elaboradas de la vieja teoría evolucionista han seguido un modelo de tres etapas o niveles. La dirección ascendente se produce únicamente en el período intermedio, es decir, entre el primero y el último nivel. "Neo-evolucionismo" de este tipo se encuentra en varios tipos de teorías.

- La teoría de Redfield. De la sociedad folk a la sociedad urbana a través de un período de transición y desorganización social.

- Teoría de la clase media emergente. De la sociedad feudal de dos clases a la sociedad democrática de clase media (J. J. Johnson, Lieuwen, Bryson, Alba).

- Teorías de cambio social de la nueva sociología latinoamericana. De la sociedad tradicional a la sociedad de masas (Germani, Di Tella, Costa Pinto, Fals Borda).

\section{REGRESISTAS O PRIMITIVISTAS}

Biopsicologismo y ambientalismo. Bunge, Arguedas, Bomfin sostuvieron que los pueblos latinoamericanos por razón de ciertos rasgos biopsicológicos o ambientales no pueden progresar. Por tanto hasta que esas condiciones no cambiaran permanecerían estancados o retrocederían en relación al avance de las sociedades occidentales (la teoría de Prébisch sobre el condicionamiento periférico de Latinoamérica se aproxima a esta formulación teórica en cuanto a la dirección del cambio económico-social en el área).

El indigenismo representa una forma genuina de primitivismo pues presume que las sociedades latinoamericanas han ido retrocediendo desde las formas de vida social "natural" del período precolombino a falsas formas de civilización europea (Mariátegui, Castro Pozo, Sáenz, Gamio).

Diversas variedades intelectuales de origen europeo y muy particularmente el hispanismo, español o latinoamericano, son manifestación de un regresismo direccional implícito de carácter exogenista.

\section{CÍCLICAS}

En la obra de pensadores sociales latinoamericanos como Martí, Arciniegas, Murena y Martínez Estrada se encuentra frecuentemente una concepción cíclica de la historia de acuerdo a la cual el cambio social sigue un proceso de oscilación regular entre dos polos culturales o ideológicos a los que se denomina libertad, despotismo o formas similares. El antipositivismo intelectual que tan fuerte influencia tuvo en Latinoamérica después de la Primera Guerra Mundial fomentó en 
materia de la dirección del cambio tanto esta concepción cíclica como una más radical visión, no directiva, del devenir histórico social.

\section{VARIABLES O ERRÁTICAS}

El antipositivismo radical representa también un irracionalismo histórico. Para los antipositivistas radicales que siguieron en Latinoamérica las enseñanzas de Dilthey y Rickert la realidad humana es esencialmente histórica en el sentido de que está hecha de acontecimientos originales e irrepetibles. No hay, pues, regularidades observables en el curso del cambio histórico y social. No son tampoco posibles, obviamente, ciencias sociales propiamente dichas. Es interesante señalar que un estudio elaborado por los sociólogos de la CEPAL sostiene también que el desarrollo social y económico de Latinoamérica ha sido errático, es decir, sin una dirección fija (ECLA, 1963: 1 y 76).

Si combinamos ahora los dos principales criterios utilizados en los apartados anteriores (factores y dirección de cambio) para construir tipologías resulta el siguiente cuadro:

\section{Cuadro $\mathrm{N}^{\circ} 1$}

Teorías de cambio social en Latinoamérica según su posición respecto a factores y dirección

\begin{tabular}{|c|c|c|c|c|}
\hline \multicolumn{5}{|c|}{ Dirección dominante } \\
\hline \multicolumn{3}{|c|}{ Lineal } & Cíclica & Sin dirección \\
\hline $\begin{array}{l}\text { Factores } \\
\text { predominantes: } \\
\text { Externos }\end{array}$ & $\begin{array}{l}\text { Ascendente } \\
\text { (Progreso) }\end{array}$ & $\begin{array}{l}\text { Descendente } \\
\text { (Retroceso) } \\
\text { Ambientalismo y } \\
\text { biopsicologismo } \\
\text { autodenigratorio }\end{array}$ & & \\
\hline $\begin{array}{l}\text { Inmanentes: } \\
\text { Exógenos }\end{array}$ & $\begin{array}{l}\text { Modelo de } \\
\text { transición: } \\
\text { Estratificacional } \\
\text { Cultural } \\
\text { Desarrollista }\end{array}$ & $\begin{array}{l}\text { Asimetría económica } \\
\text { internacional } \\
\text { Hispanismo }\end{array}$ & & \\
\hline Endógenos & $\begin{array}{l}\text { Positivismo } \\
\text { idealista y } \\
\text { progresismo } \\
\text { idealista } \\
\text { Análisis de } \\
\text { tensiones } \\
\text { Neo-marxismo }\end{array}$ & Indigenismo & $\begin{array}{l}\text { Moderado } \\
\text { anti-positivismo } \\
\text { intelectual }\end{array}$ & $\begin{array}{l}\text { Radical } \\
\text { irracionalismo } \\
\text { Intelectual } \\
\text { Desarrollo } \\
\text { errático }\end{array}$ \\
\hline
\end{tabular}




\section{CONCLUSIÓN}

En vista del cuadro anterior creo que se pueden hacer las siguientes observaciones:

1. La mayor parte de las teorías son lineales, que es la forma más cruda de representación del cambio.

2. A diferencia de los latinoamericanos, los autores norteamericanos se han inclinado por interpretaciones optimistas y progresistas.

3. Las teorías estadounidenses sobre el cambio social en América Latina tienden a ser exogenistas mientras que las de los latinoamericanos tienden a ser, actualmente, endogenistas y en el pasado, externalistas.

4. La difusión de las teorías de cambio social tienen lugar a través de estilos y patrones de pensamiento disciplinario y subculturas intelectuales.

5. Las teorías latinoamericanas de cambio social reflejan en sus comienzos teorías extranjeras que son luego modificadas y expresadas con diferente énfasis. El ambientalismo y biologismo progresista occidental se transforma en autodenigratorio en América Latina, la ideología del desarrollo económico se utiliza para explicar el estancamiento y el romanticismo antropológico se convierte en indigenismo ideológico.

6. Se puede señalar esperanzadoramente que hay una reciente tendencia en las ciencias sociales a centrar su atención en el análisis de tensiones y la sociología del conflicto. Hay también ciertos signos de un renovado interés en los problemas ideológicos latinoamericanos y del rol de la intelectualidad. Ambas tendencias harían posibles una mayor convergencia en la literatura sobre cambio social de Estados Unidos y Latinoamérica, cuyos intereses han sido tradicionalmente distintos.

Las anteriores observaciones provienen de las tipologías ensayadas en este artículo. Ello es resultado de una tarea de síntesis y sumaria codificación que puede haber desnaturalizado o descartado matices en algunas de las fuentes originarias más complejas. Por tanto, cualesquiera consecuencias que de ellas se deriven deben tomarse con carácter provisional hasta tanto no se lleve a cabo un estudio más preciso del material aquí tratado. Pero, no obstante su modestia metodológica, conviene recordar que, como dicen Barton y Lazarsfeld, "nunca debe ser subestimada la importancia del primer paso de la investigación que consiste en poner datos desordenados en una primera clasifica- 
ción. Hasta que los datos se ordenan de alguna manera el análisis de las relaciones no puede empezar (Barton y Lazarsfeld, 1961: 102-103).

\section{BIBLIOGRAFÍA}

Adams, R. N. 1962 "The community in Latin America” en The Centennial Review, Vol. VI, pp. 422-430.

Arguedas, A. 1937 Un pueblo enfermo. Contribución a la psicología de los pueblos hispanoamericanos (Santiago de Chile: Ercilla) $3^{\mathrm{a}}$ edición.

Barton, A. H. y Lazarsfeld, P. F. 1961 "Some functions of qualitative analysis in social research" en Lipset, S. M. y Smelser, N. (eds.) Sociology. The progress of a decade (Nueva Jersey: Prentice-Hall).

Biesanz, J. 1950 "The middle class in Panama” en Crevenna, T. (ed.) Materiales para el estudio de la clase media en América Latina (Washington: Pan American Union).

Bottomore, T. B. 1963 Sociology (Nueva Jersey: Prentice-Hall).

Bunge, C. O. 1903 Nuestra América (Barcelona: Heinrich y Cía.).

Crevenna, T. 1950 Materiales para el estudio de la clase media en América Latina (Washington: Pan American Union).

Dahrendorf, R. 1958 "Toward a theory of social conflict" en The Journal of Conflict Resolution, Vol. X, $\mathrm{N}^{\circ} 2$.

De Vries, E. 1961 Man in Rapid Social Change (Garden City: Doubleday \& Co.).

Di Tella, T. S. 1966 La teoría del primer impacto del crecimiento económico (Entre Ríos: Universidad Nacional del Litoral).

Do Bomfin, M. J. 1903 O parasitismo social e evolução: A América Latina (Río de Janeiro: s/d) $3^{a}$ edición.

ECLA 1963 Social development of Latin America in the post-war period (Santiago de Chile: ONU).

Espartaco 1964 "Crítica del modelo político-económico de la izquierda oficial” en El Trimestre Económico, Vol. 31, № 121, pp. 67-92.

Etzioni, E. 1964 Social change: sources, patterns, and consequences (Nueva York: Basic Books).

Fals Borda, O. 1964 "The role of violence in the break of traditionalism: the Colombian case" en Transactions of the Fifth World Congress of Sociology, Vol. 3.

Feldman, A. S. y Moore, W. E. 1964 "Industrialisation and industrialism: convergence and differentiation" en Transactions of the Fifth World Congress of Sociology, Vol. 2. 
Foster, G. M. 1960 Culture and conquest (Nueva York: Wenner-Gren Foundation).

Garaña, C. 1962 y 1963 "Cultural nationalism: the idea of historical destiny in Spanish America” en Social Research, Vol. XXIX, $\mathrm{N}^{\circ} 4$ y Vol. XXX, N 1.

Germani, G. 1962 Política y sociedad en una época de transición (Buenos Aires: Paidós).

Germani, G. 1964 "Social change and intergroup conflict", en Horowitz, I. L. (ed.) The New Sociology (Nueva York: Oxford University Press).

Gillin, J. 1951 The culture of security in San Carlos. A study of a Guatemalan community of Indian and Ladinos (Nueva Orleans: Tulane University).

Hagen, E. E. 1962 On the theory of social change (Homewood, Illinois: The Dorsey Press).

Herskovits, M. J. 1938 Acculturation (Nueva York: T. T. Augustin).

Johnson, J. J. 1951 "Latin American Middle sectors" en The Annals of the American Academy of Political and Social Science, enero.

Johnson, J. J. 1955 "The new Latin America and the United States" en The Pacific Spectator, Vol. IX, verano.

Johnson, J. J. 1958 Political Change in Latin America (Stanford: Stanford University Press).

Lewis, O. 1951 Life in a mexican village: Tepoztlan Restudied (Urbana: University of Illinois Press).

Lipset, S. M. y Smelser, N. (eds.) 1961 Sociology. The progress of a decade (Nueva Jersey: Prentice-Hall).

Mac Iver, R. M. y Page, C. H. 1949 Society: an introductory analysis (Nueva York: Rinehart).

Marsal, J. F. 1965 The image of a changing Latin America: a sociological criticism of some American and Latin American models (Princeton University) tesis doctoral inédita.

Moore, W. E. 1937 Current sociological theories in Argentina (University of Oregon) tesis de maestría inédita.

Moore, W. E. 1941 "Rural-urban conflict in Argentine sociological theories” en Rural Sociology, Vol. VI, N 2.

Moore, W. E. 1960 "A reconsideration of the theories of social change" en American Sociological Review, Vol. XXV, diciembre.

Moore, W. E. 1963 Social change (Nueva Jersey: Prentice-Hall).

Moore, W. E. 1964 Man, Time and Society (Nueva York: Wiley).

Parsons, T. 1937 The structure of social action (Nueva York: McGraw-Hill). 
Redfield, R. 1930 Tepoztlan, Mexican village (Chicago: University of Chicago Press).

Redfield, R. 1940 The folk culture of Yucatan (Chicago: University of Chicago Press).

Redfield, R. 1950 A village that chose progress (Chicago: University of Chicago Press).

Sorokin, P. A. 1928 Contemporary sociological theories (Nueva York: Harper).

Sorokin, P. A. 1939-1941 Social and cultural dynamics (Nueva York: American Books).

Sorokin, P. A. 1947 Society, Culture and Personality (Nueva York: Harper).

Stavenhagen, R. 1963 "Reseña de R. N. Adams, The community in Latin America" en América Latina, Vol. 6, N² 2, pp. 131-132.

Steward, J. H. 1956 The people of Puerto Rico (Urbana: University of Illinois Press).

Steward, J. H. y Murphy, R. F. 1956 "Tappers and trappers: parallel process in acculturation" en Economic development and cultural change, Vol. V, julio.

Tumin, M. M. 1952 Caste in peasant society (Princeton: Princeton University Press).

Wagley, Ch. 1953 Amazon Town. A study of man in the tropics (Nueva York: Macmillan). 


\section{Ignacio Sotelo}

\section{MARGINALIDAD Y DEPENDENCIA*}

EN LOS TRES ÚLTIMOS capítulos, al describir las estructuras básicas del área, nos hemos encontrado en distintas ocasiones con el "hecho" de la "marginalidad" rural y urbana, así como hemos hablado de la "dependencia externa" en relación con el proceso de urbanización y de industrialización. Estos dos conceptos, claves en la "nueva sociología latinoamericana", precisan consideración especial, en cuanto constituyen los dos pilotes sobre los que se ha levantado todo el armazón teórico para dar cuenta de la problemática socio-económica de la región.

\section{PRIMERA DEFINICIÓN DE LA MARGINALIDAD}

El concepto de "población marginal" empezó a emplearse en la América Latina después de la Segunda Guerra Mundial, para designar a los "pobladores" del cinturón de miseria que iba rodeando a las grandes ciudades del área. También se utilizó para referirse a la población indígena o campesina, no integrada en la vida nacional. "Marginal" hace referencia a un centro - vida urbana, cultura nacional- respecto al cual, el fenómeno que se describe, queda al margen. Más tarde,

* Sotelo, Ignacio 1975 "Marginalidad y dependencia" en Sociología de América Latina: estructuras y problemas (Madrid: Tecnos) Capítulo VII, pp. 128-147. 
el concepto de marginalidad pasó a designar las características sociales y culturales de la "población marginal". En este sentido, como instrumento para un "diagnóstico de la situación social" de la América Latina, ha adquirido un primer desarrollo teórico en los trabajos de DESAL ${ }^{1}$.

El grupo marginal se define, por referencia al "sistema social" dominante, como aquel no incorporado. Desde esta dimensión, el concepto de marginalidad implica de por sí una dicotomía entre vida social integrada y marginal. La participación o no, en los recursos, valores, actividades y bienes de la sociedad, confiere la calidad de incorporado o de marginado. Grupos marginados serán aquellos que "participan mínimamente de la seguridad social, constituyen las reservas del desempleo y presentan las tasas más bajas de alfabetización, de vivienda, de atención médica y sanitaria”. Se establecen una serie de indicadores, desde el tipo de alimentación y vivienda, hasta relaciones familiares y sistema de valores, para aislar en un extremo, aquellos que participan en menor medida de los bienes y formas de vida que caracterizan a la sociedad global. La marginalidad queda así caracterizada por una falta de "participación" en los bienes y actitudes, actividades y pautas que constituyen a la sociedad en cuestión.

Pero ¿por qué no participa una proporción creciente de los habitantes de un país, en los bienes y recursos de que dispone la sociedad? DESAL revierte la falta de "participación pasiva" a la falta de "participación activa o contributiva": los grupos marginales no participan "pasivamente" de los bienes de la sociedad, porque no participan "activamente" en la toma de decisiones sociales, que conciernen al todo de la sociedad, o por lo menos a su grupo específico. Esta falta de "participación activa" se explica a su vez, por la pulverización atomizante de los sectores marginales, en los que no cabe ninguna forma de actividad solidaria. La causa remota y última de la desintegración atomística y cultural que caracteriza a los grupos marginales, haciéndolos impotentes para una participación activa y pasiva, es el hecho de la conquista europea. La dicotomía actual entre población incorporada - con un ingreso anual medio de 800 dólares per capita, similar al de Europa meridional-y población marginal urbana o rural, que no alcanza siquiera los 80 dólares, reflejaría la "superposición" originaria de la minoría europea sobre las "masas indígenas" (Vekemans y Silva Fuenzalida, 1969).

1 DESAL, Centro para el Desarrollo Económico y Social de la América Latina, institución científica católica, radicada en Santiago de Chile, especializada en estudios sobre el desarrollo social, especialmente el problema de la marginalidad. 
En dos supuestos se basa el análisis de DESAL:

1. Las dificultades para asimilar a la población marginal, no radican en la "sociedad moderna", sino en la población marginal misma: desintegración cultural.

2. La atomización y falta de identidad cultural de los grupos marginales, que los condena a vegetar pasivamente, es resultado de la conquista ibérica. Integrarse en la "sociedad moderna", supone superar definitivamente el trauma de la colonia, acabando con el régimen de casta que aquella implantó. Pervive la vieja idea decimonónica, aunque ahora remozada con un nuevo concepto, de que el problema de América Latina consistiría en deshacerse de los residuos coloniales, integrándose por completo en el "mundo moderno", es decir, anglosajón y capitalista. Las fuerzas "progresistas" de la Iglesia se han acomodado a los nuevos tiempos, pasando de la apología de lo hispánico, a la exaltación de la "modernidad" norteamericana.

Los dos conceptos de participación que se emplean para dar cuenta de la marginalidad, son tan endebles, que resulta difícil librarse de la impresión, de que este concepto en DESAL, no tenga otra función que remozar y apuntalar la teoría "dualista" de la modernización. En efecto, la participación pasiva constituye un continuo estadístico, sin que sea posible determinar a qué nivel de no participación en el bienestar social, quepa hablar de marginalidad. Si por marginalidad se entienden simplemente las capas sociales con ingresos más bajos, es un concepto superfluo que bien pudiera sustituirse por el tradicional de pobreza: los pobres son, por definición, los que no participan en el bienestar que ofrece una sociedad determinada. Oscar Lewis ha estudiado grupos marginales en la ciudad y en el campo, subsumiendo sus características psicosociales en el concepto de "cultura de la pobreza". Los rasgos que menciona Lewis para acuñar este concepto - desempleo o subempleo, bajo índice de alfabetización, malas condiciones de vivienda, especificidad de valores y pautas de conducta- coinciden con los que recoge DESAL para definir la participación pasiva.

Mucho más problemático es el concepto de participación activa, apenas asequible a una investigación empírica, al exigir criterios difíciles de concretizar. En todo caso, cabe preguntarse hasta qué punto el individuo socialmente incorporado participa realmente en la toma de decisiones que configuran la fisonomía de un país, incluso, en las más modestas, que afectan a la empresa en que trabaja, o a la ciudad en la que vive. Si la falta de participación activa constituye el rasgo específico que distinguiría lo marginal de la simple pobreza, habría 
que considerar marginal al 99,9 por 100 de la población, en realidad no participante "activamente", perdiendo así toda significación.

Además, aunque la extrema miseria lleva consigo una pasividad extrema, lo que ha actualizado la problemática de los suburbios, es la capacidad de violencia -invasión de tierras, oposición a las medidas policiales de desalojamiento (Cardona, 1969)—, así como el grado de solidaridad y organización de que han dado muestras los "pobladores" para mantener la reivindicación esencial: el derecho a instalarse en la ciudad, aunque no sea más que en una vivienda provisional. La posible movilización política de los grupos marginales, constituye una de las incógnitas más significativas para el futuro de la región. Una cosa parece, sin embargo, clara: las formas de organización que adopten estos grupos, se distinguirán de las que hasta ahora nos son conocidas, por la práctica del proletariado industrial en la primera experiencia de industrialización europea. Ello, sin embargo, no nos permite hablar de incapacidad de organización o pasividad constitutiva de estos grupos.

No menos peregrina es la causa última de "marginalidad" que se aduce: la superposición de culturas que implicó la conquista. Las "castas" sometidas en la colonia - la población indígena y de colorabastecen sin duda, en cuanto miembros de las capas sociales más bajas, a los grupos marginales. Pero el hecho racial no define la frontera que divide a los grupos marginales de los incorporados. Individuos de color o de directa ascendencia indígena, pueden estar perfectamente integrados como mano de obra industrial e incluso, haber ascendido a los sectores medios y hasta excepcionalmente, a las capas superiores de la sociedad. Por otro lado, el creciente aumento de la población marginal -incluso en países, que como Argentina cuentan con escasa población de origen indígena- no corresponde, ni de lejos, a las fronteras culturales que resultaron de la conquista. Cabría acudir a ella para explicar el fenómeno, si marginal designara únicamente a la población indígena no asimilada, y que vive, más o menos aislada, en un régimen de autosubsistencia. Pero los 30 millones de habitantes, es decir, el 15 por 100 de la población total, que según cálculos de DESAL habitan en núcleos "marginales" de las grandes ciudades latinoamericanas, no constituyen un grupo étnicamente homogéneo que pueda identificarse sin más con los pueblos sometidos.

Pese a que no pueda aceptarse como explicación suficiente de la expansión actual de los grupos marginales, la superposición de razas y de culturas que originó la conquista, no por ello, es este un problema inexistente en los países en que abunda la población de origen indígena o africano. Pablo González Casanova ha señalado en México, a pesar del proindigenismo oficial, un racismo, que incluye en el 
concepto de "colonialismo interno". Lo que distingue al colonialismo interno de las meras relaciones de clase, es que la explotación se produce entre grupos culturales heterogéneos (González Casanova, 1963 y 1965). Las relaciones clasistas se producen en el interior de una relación interétnica, por la que un pueblo en su totalidad queda sometidos a todos y cada uno de los miembros de la cultura dominante, sea cual fuere su situación en la escala social ${ }^{2}$. En Brasil, Florestan Fernandes (Fernandes, 1965) y Octavio Ianni (Ianni, 1966) han puesto de manifiesto una discriminación racial latente, que fortalece las estructuras de clase dominantes. Aun así, los problemas que plantea el racismo, residuo estructural de la colonia, no deben confundirse con la cuestión de la marginalidad, aunque resulten evidentes las interferencias entre ambas temáticas.

\section{EL CONCEPTO ESTRUCTURAL DE MARGINALIDAD}

La teoría expuesta de la marginalidad sirve de fundamento a una política social que pone el énfasis en la capacitación psicosocial de los grupos marginales, para que vayan incorporándose a los sectores modernos de la sociedad, en vez de propugnar cambios en las estructuras de base, como se desprendería lógicamente si resultase que los mismos sectores modernos producen la marginalidad. A pesar de los esfuerzos realizados en este sentido - "desarrollo comunal" en Venezuela, "acción comunal" en Colombia, "promoción popular" en Chile, "cooperación popular" e Perú- los grupos marginales aumentan con la desocupación creciente en el área.

Según estimaciones de la OIT, el paro en la América Latina ha pasado de 5,6 por 100 en 1950 , a 9,1 por 100 en 1960 y a 11,1 por 100 en 1965. En este mismo año, el subempleo se calcula, según las zonas, entre un 20 y 30 por 100 (Organización Internacional del Trabajo, 1968: 14-16). Sumando paro abierto y subempleo, la desocupación sobrepasa en algunos países el 40 por 100 de la población. El rasgo definitorio que caracteriza a la población marginal es su falta de integración en el proceso de producción (desocupación): de ahí la escasa participación en el consumo, y los caracteres específicos del tipo de vida y mentalidad. Al hablarse de población marginal, ha de entenderse, en primer lugar, población desocupada, que ejerce muy distintas actividades, legales -agricultura de subsistencia, comercio callejero-, semilegales — prostitución, mendicidad-, o delictivas. Por qué introducir entonces el concepto de marginalidad, si el fenómeno ha sido convenientemente descrito por la economía clásica con el de "mano

2 Para un estudio de la interrelación étnica y clasista en los altos de Chiapas, véase el estudio de Stavenhagen, 1963. 
de obra desocupada", o en Marx con el de "ejército industrial de reserva". Únicamente, perfilándose frente a estos dos conceptos, adquiere el de marginalidad significación analítica propia ${ }^{3}$.

Por lo pronto, esta aproximación histórico-estructural al concepto de marginalidad supera la dicotomía subyacente en su primera definición - población marginal por referencia a una población integrada - para resaltar la interdependencia estructural de estos dos aspectos. La población marginal no queda fuera del "sistema", por no poseer las características psicosociales necesarias para su integración, sino que es una población que el "sistema" mismo origina, pero integrándola de manera especial, es decir, marginalmente. La población marginal no antecede históricamente al "sistema" — población indígena sometida - que no ha logrado todavía integrarse, sino que la produce el "sistema" directamente. Así, la "modernización" del sector rural, una vez incorporado en el mercado nacional e internacional, origina población marginal: las nuevas relaciones de producción capitalistas rompen el equilibrio tradicional entre mano de obra y fuerzas productivas, sin lograr absorber la población excedente. La técnica moderna de transporte y comunicación - carreteras, ferrocarriles, radio- acaba con el aislamiento de la población rural, quedando deslumbrada ante la vida urbana, por la que siente natural atracción. La medicina moderna reduce considerablemente la mortalidad, sin que se modifique la tasa "natural" de natalidad. En una palabra, la incorporación capitalista del sector rural, expulsa población sobrante. El fenómeno ni es nuevo ni puede sorprender: "la transición de las sociedades preindustriales al capitalismo industrial implicó la transferencia de la mayor parte de la población del sector agrario, del campo a la ciudad, del control de los medios de producción al estado de asalariado" (Hobsbawm, 1969: 237). Lo nuevo sería la imposibilidad estructural de que esta población excedente logre incorporarse en el sector modernizado.

A principios del siglo XIX, los países europeos que iniciaban su industrialización, contaban con una población marginal en aumento -un campesinado miserable huyendo a las ciudades o refugiándose en el vagabundaje- que parecía también imposible asimilar. En los primeros decenios de la industrialización, el capitalismo tampoco creaba empleos a la velocidad con que se expandía su fuerza productiva: hasta 1840 , cada máquina que se ponía en funcionamiento, dejaba sin pan a un buen número de obreros. A comienzos de nuestro siglo, los países industriales habían resuelto el problema de la "marginali-

3 En la determinación histórico-estructural de población marginal han contribuido especialmente Nun, 1969; y Quijano, 1970; Quijano, s/f. 
dad", solo conociendo, con excepción de las crisis cada vez más controladas, un desempleo coyuntural, que no suele pasar del 5 por 100 de la fuerza de trabajo. En estos últimos años, sin embargo, y en el país con la mayor capacidad industrial del mundo, los Estados Unidos, se observa el crecimiento de un paro estructural, que al afectar sobre todo a los grupos raciales discriminados, toma el carácter de marginal. La población marginal, por consiguiente, no es, sin más, población desocupada, sino que esta desocupación se califica de estructural -inmodificable dentro de las estructuras dominantes, al ser producida por ellas - alcanzando una cifra constantemente alta, con tendencia a aumentar.

La diferencia específica entre masa marginal y "ejército industrial de reserva", radica en que mientras este cumple una función en el sistema, aquella es afuncional o disfuncional a su respecto. En efecto el "ejército industrial de reserva" cumple una doble función:

1. Mantiene el salario a su nivel más bajo, ante la amenaza continua de sustituir la mano de obra empleada por la que espera en la reserva.

2. Constituye una mano de obra disponible, dispuesta a ocupar los nuevos puestos de trabajo que se vayan creando en el ulterior desarrollo industrial.

La población desempleada o subempleada de la América Latina, que como hemos dicho alcanza en algunos países hasta la mitad de la población activa, no puede considerarse un enorme "ejército industrial de reserva", al no cumplir ninguna de estas dos funciones:

1. Los salarios del sector industrial, sobre todo, en las industrias de mayor productividad, sobrepasan con mucho la media nacional de ingreso, sin que influya en su determinación la masa enorme de desocupados. En la industria dinámica, el salario depende tanto de lo que se pague por la misma actividad en los países industrializados —-siendo este el tope máximo inalcanzable- como del grado de organización y combatividad sindical. La presión sindical, la legislación laboral y la cualificación que requiere el obrero industrial, impiden sustituir la mano de obra ocupada por la masa marginal. Entre ambas no existe, por tanto, un acomodo funcional.

2. El desarrollo industrial, al nivel tecnológico de nuestro tiempo, conlleva una expansión de la capacidad productiva, sin aumentar significativamente la mano de obra empleada. 
En 1925, la industria manufacturera latinoamericana absorbía el 13,6 por 100 de la población activa; en 1965, el 14,2 por 100. De esta cifra, el 7,7 por 100 está empleada en la industria fabril, mientras que el 6,5 restante en la artesanía. Tan solo el 7,7 por 100 de la población activa de América Latina está ocupada en la industria fabril y desde 1945, cuando es más rápida la expansión industrial, se registra de hecho un estancamiento en la capacidad de absorción de mano de obra por la industria. En estas condiciones, difícilmente puede considerarse "ejército industrial de reserva" esta masa marginal sin posibilidad inmediata ni futura de integrarse en el sector productivo, ni de influir sobre él.

La cuestión radica en el plazo que incluya este futuro. Europa ha necesitado para asimilar la masa marginal casi un siglo desde que inició la industrialización. A largo plazo, podría pensarse que la población marginal latinoamericana también terminará por integrarse, según avance el desarrollo económico de la región. En la hora actual, lo decisivo no sería propugnar una política de pleno empleo, ilusoria y a largo plazo incluso perjudicial, sino proseguir con las inversiones altamente productivas: una vez alcanzado el nivel de desarrollo de los países industrializados, la población marginal habrá quedado asimilada de por sí.

Por el contrario, la médula del concepto de marginalidad, lo que le diferencia del concepto de "población desocupada" o de "ejército industrial de reserva", es la presunción de que permaneciendo las actuales estructuras, es absolutamente imposible que se repita la experiencia de los primeros países industriales. En los países subdesarrollados de hoy no se dan tres condiciones esenciales que contribuyeron a que los países industrializados en la primera hora, lograran casi un siglo más tarde el pleno empleo:

1. Europa pudo expulsar a lo largo del siglo XIX una gran parte de la población sobrante: Estados Unidos, Australia, Sudáfrica, Argentina, aceptaban emigración prácticamente sin cortapisa. Entre 1812 y 1914, emigraron de las Islas Británicas más de 20 millones de personas. Solo en el período de 1870 y 1900 emigraron unos 2.300.000 alemanes y 3.500.000 italianos.

2. Los primeros países industriales pudieron ampliar rápidamente su capacidad industrial, al contar con un mercado más amplio que el nacional. Las manufacturas inglesas produjeron para la exportación en una proporción considerable. El reparto del mundo que caracterizó al primer imperialismo, con el fin de reservarse materias primas a precios bajos y asegurarse un mercado sin competencia extraña para los propios productos 
manufacturados, constituyó un factor decisivo para la absorción progresiva de mano de obra.

3. El primer capitalismo ha desarrollado una tecnología propia, partiendo de un nivel arcaico que precisaba abundante mano de obra no calificada. Así, por ejemplo, el carbón, que constituía la fuente de energía por antonomasia, se obtenía de forma técnicamente muy primitiva, en base al esfuerzo humano: de esta manera, el rápido crecimiento de la demanda de carbón, amplió considerablemente la mano de obra empleada en esta rama. En Gran Bretaña, las minas de carbón llegaron a emplear 1,2 millones de personas, en su mayoría sin calificación, lo que representaba el 10 por 100 de la población masculina activa. El desarrollo técnico está en correspondencia con el mercado de trabajo. Una tecnología que absorbe una proporción decreciente de mano de obra, surge en el momento en que lo hace aconsejable el pleno empleo. Ello explica también el que la automación se mantenga hoy dentro de los límites que impone el mercado de trabajo. Por otro lado, una alta capacidad productiva permite la expansión de un sector terciario, en este caso no parasitario, imprescindible para mantener el ritmo de crecimiento industrial. Los servicios educacionales, sanitarios, culturales, los medios de comunicación e información, etc., absorben cada vez mayor proporción de mano de obra altamente calificada.

Estas tres condiciones, que explican el que los primeros países industriales consiguieran reabsorber su población marginal, no se dan en los países subdesarrollados. Al contrario, se enfrentan con una situación que se caracteriza, precisamente, por la imposibilidad de colocar en el exterior la mano de obra excedente, la congelación de un mercado interno, sin acceso al internacional como exportadores de productos industriales y sin una tecnología propia que se adapte a las condiciones específicas de estos países en su actual momento de desarrollo.

Aunque resulta impensable una repetición de las condiciones que hicieron posible el primer proceso de industrialización - la historia no se repite- no por ello hay que dejar de considerar las nuevas condiciones, que en cierto modo, pueden compensar la desaparición de las arriba mencionadas. Cierto, una emigración masiva en los países subdesarrollados para aligerar su paro estructural, resulta hoy inconcebible; sin embargo, en el área mediterránea la emigración de italianos, yugoslavos, españoles, griegos, turcos, a los centros industriales del norte de Europa, ha permitido a algunos de estos países un cierto 
desahogo para acelerar su desarrollo. Este factor va a seguir influyendo en el futuro: Alemania Occidental calcula pasar de la actual cifra de 2 millones de trabajadores extranjeros a 8 millones para 1980. Un respiro semejante - en México es ya actuante- tiene poca similitud para la América Latina en su conjunto donde el norte industrial cuenta con una población desocupada no calificada con tendencia a aumentar. Los Estados Unidos absorben un pequeñísimo número de latinoamericanos, pero precisamente los mejor calificados - fuga de cerebros- (Dillon Soares y De Soares, 1966), lo que constituye una pérdida grave para la región.

La alternativa contemporánea a la emigración masiva es el control de la natalidad, única receta de los poderosos. A ello se oponen en América Latina, tanto los valores culturales y religiosos dominantes, como la ausencia de una política estatal en este sentido, por razones ideológicas, políticas — se trata de medidas impopulares-y financieras (los programas efectivos son muy caros). A largo plazo, el control de la natalidad es un imperativo insoslayable, pero más que punto de partida para un desarrollo económico, resulta de su consolidación a un determinado nivel (Stycos, 1967).

La transformación de las grandes corporaciones en unidades económicas multinacionales, con intereses que sobrepasan con mucho a los del país de origen, hace dudoso el que todavía tenga validez el principio decimonónico de evitar a toda costa la competencia extranjera. Las compañías multinacionales producen allí donde las condiciones les son más favorables, teniendo una significación muy secundaria, consideraciones de orden nacional. Cierto, la falta de una infraestructura suficiente y la lejanía de los mercados, no hace plausible levantar grandes y modernas fábricas en América Latina, pero de ello no se deriva la prohibición de exportar, como un principio inmodificable. Por otro lado, se perfila una nueva división internacional del trabajo en la que los países del "tercer mundo" con mayor potencial económico se reserven la exportación de productos manufacturados, más ligados al sector artesanal: zapatos, textiles, confección, conservas, etc. Una tecnología media podría asimismo cuajar, colocando en el mercado utensilios y maquinaria, más idóneos a las necesidades de estos países.

Estas consideraciones, de alcance muy reducido y de valor harto hipotético, quieren simplemente llamar la atención sobre el hecho de que, si bien no pueden reproducirse las condiciones que impulsaron al primer proceso de industrialización, no por ello cabe concluir un estancamiento insuperable. Como se cierra una puerta, se abre otra, si es que un impedimento general no mantiene bloqueados todos los caminos. El concepto de marginalidad tiene sentido únicamente si se patentiza este impedimento básico y fundamental: la dependencia. El 
quid de la cuestión radica en último término, en el valor analítico de un tal concepto.

\section{MARGINALIDAD Y DEPENDENCIA}

La marginalidad se define como un subproducto disfuncional del "sistema". El que el "sistema" produzca una "masa marginal" que no puede integrar, se debe a su carácter "dependiente". Se trata, pues, de hacer patente la relación intrínseca entre dependencia y marginalidad.

La marginalidad nace en el campo, al acoplarse la vieja estructura tradicional a los intereses exportadores. La combinación de los viejos sistemas de tenencia y formas de explotación de la mano de obra, al servicio de una economía de exportación de materias primas, ha creado en el campo el binomio de una agricultura modernizada dedicada al mercado externo y una economía marginal. La noción de "economía de subsistencia" resulta adecuada tan solo para dar cuenta de grupos minoritarios por completo alejados de la economía de mercado. Marginal no quiere decir desconectada del sistema económico dominante, sino que su conexión lo es al margen y controlado por el sector dominante de la economía. Su campo de acción y sus posibilidades de crecimiento están determinados por el sector monopolístico, que controla tanto la tierra como los mercados internacionales. Innegable que entre ambos polos existe una agricultura media, dedicada al mercado nacional, pero dado la superabundancia de mano de obra, tiende a reproducir las mismas formas de dominación y se integra de hecho en el sector dominante. Como vimos en el Capítulo IV, la estructura agraria de la región produce un excedente en aumento de mano de obra desocupada, que huye a la ciudad. El "éxodo rural" es, en último término, traslación de la marginalidad rural a la ciudad. Los centros urbanos, que también crean su propia masa marginal, tienen que acoger parte de la que se produce en el campo. La confluencia de la población excedente urbana y rural en los cinturones de miseria suburbanos es lo que en un principio llevó a identificar el problema de la marginalidad con la cuestión de las "barriadas".

Esta masa marginal se acumula en las "barriadas", porque no puede ser asimilada por el sector manufacturero. La limitación intrínseca de asimilar mano de obra de que da prueba la industria latinoamericana, se debería a su carácter "dependiente". La dependencia de la industria latinoamericana respecto a los grandes centros hegemónicos es, como hemos visto en el capítulo anterior, doble: financiera y tecnológica. Hasta la depresión de los años treinta, el capital extranjero afluía: 


\section{Al sector primario extractivo.}

2. A la infraestructura de servicios, sobre todo medios de transportes, directamente conectados con el sector exportador.

3. A la deuda pública. La política de inversiones extranjeras cambia, en el momento en que la "industrialización por sustitución de importaciones", impone una política proteccionista de la naciente industria nacional.

Solo a través del control de esta industria es posible conservar los mercados tradicionales. Los grandes consorcios se acoplan a esta nueva situación, estableciendo filiales o comprando las industrias establecidas que pudieran ocasionar competencia. Conservar los mercados implica sustituir la exportación de los productos finales, por la de capitales y de bienes de producción, para fabricar aquellos detrás de las barreras proteccionistas. La industria nacional de bienes de consumo, escasa de capital, de saber técnico y de capacidad organizativa, se asocia complacida con las empresas internacionales, que les aseguran por lo menos unos ingresos seguros y crecientes. Las industrias más dinámicas, que precisan de mayores capitales y conocimientos técnicos -industria automotriz, petroquímica, etc.- cuando no fueron financiadas directamente por el Estado - y es la excepción- pertenecen totalmente al capital extranjero. Las cifras son significativas a este respecto: en 1939, el 4 por 100 del capital extranjero invertido en México, lo estaba en el sector industrial; en 1960, el 56 por 100. Hacia 1959, la inversión extranjera en Brasil, alcanza unos 3.500 millones de dólares, de los que más de una tercera parte se radica en industrias manufactureras, sobre todo en la industria siderúrgica y mecánica. En 1964 el 56,3 por 100 de las inversiones norteamericanas en la Argentina se hallan en el sector industrial. En 1966, las inversiones norteamericanas en América Latina contabilizaban un valor total de 9.853 millones de dólares; la mayor parte, 3.077 millones, en el sector industrial, seguidas de cerca por las inversiones petroleras, $2.902 \mathrm{mi}-$ llones (Wionczek, 19684).

El control extranjero de la industria latinoamericana sería la causa del estancamiento estructural, que produce la marginalidad. El proceso de industrialización se paraliza una vez cubierto el mercado de productos de consumo para una minoría social de clase alta y media. El capital invierte exclusivamente en aquellos sectores, de los que se espera un beneficio rápido y seguro. Así una gran parte de inversiones extranjeras se pierden en los servicios, sobre todo co-

4 Al final del artículo se encuentran cuadros con abundante material estadístico. 
mercio: en 1966, los Estados Unidos habían invertido 1.158 millones de dólares en esta rama. Faltan, en cambio, las inversiones infraestructurales, que producen bajos beneficios y a largo plazo, pero que son imprescindibles para el desarrollo económico de la región. Las inversiones extranjeras llevan consigo, por otro lado, una descapitalización continua: según datos de la CEPAL, las utilidades obtenidas por las empresas de inversión directa fueron muy superiores a las entras netas de capital en concepto de utilidad que importa como inversión neta ${ }^{5}$. Sociológicamente, la consecuencia más significativa de la inversión extranjera, es la absorción de los empresarios nacionales, transformados en meros gestores de intereses foráneos. Un desarrollo capitalista independiente, desaparecido el sujeto activo, el empresario, es ya prácticamente imposible.

La tecnología importada, además de contribuir a la descapitalización al tener que pagar precios muy altos por los bienes de capital, utilización de patentes, refuerza los mecanismos que producen la marginalidad, al aumentar la capacidad productiva sin ampliar el número de empleos. El sector más dinámico de la industria ocupa poca mano de obra, pero relativamente bien calificada. Sus características personales así como su nivel de ingresos, están muy por encima de la media nacional. Frente a este sector hegemónico monopolista, la mayor parte de la población puede considerarse marginal. Con ello, claro está, no pierde su condición de "ejército industrial de reserva" frente a otras ramas de la producción. Un marginal frente a la industria petroquímica, puede constituir ejército de reserva frente a la construcción. La disfuncionalidad frente a un polo central, puede ser funcional frente a otros centros secundarios y sometidos.

El concepto de marginalidad implica, si quiere tener una significación específica que no se confunda con la pobreza y el desempleo, una dependencia de centros hegemónicos, fuera del sistema, que lo congelan en un marco reducido de posibilidades. La dependencia explicaría en último término la especificidad del capitalismo latinoamericano, incapaz de saltar por encima de sus propias contradicciones, para propiciar un desarrollo continuo y autónomo. Esa especificidad es lo que quiere expresar el concepto, por otro lado no muy feliz, de marginalidad. Su validez depende de la que tenga el concepto clave de dependencia.

5 CEPAL calcula que para el período 1944-1962 en 14.600 millones de dólares las utilidades de las empresas extranjeras realizadas en la América Latina, mientras que las entradas netas de capital en dichas empresas alcanzaron solo 8.100 millones de dólares, por lo que el saldo negativo en detrimento de la región puede ser estimado en unos 6.500 millones de dólares en 17 años (CEPAL, 1964: 188). 


\section{MULTIVOCIDAD DEL CONCEPTO DE DEPENDENCIA POPULARIDAD DEL CONCEPTO}

Hasta mediados de la década de los sesenta, apenas recibía atención la dependencia externa, como factor coadyuvante a la perpetuación del subdesarrollo. Todo el interés se centraba en los obstáculos internos, que la sociología norteamericana había reducido en último término a una cuestión psico-social de "mentalidad" y de "valores" arcaicos. En estos últimos años, y como reacción bien comprensible a la anterior ignorancia, la dependencia ha pasado a considerarse la causa primaria del subdesarrollo. Aparte del contenido analítico que pueda tener este concepto y de la significación real de las relaciones a que alude, este cambio se explica por el fracaso de los reformismos "constitucionales" o "populistas". La impotencia política de que dieron prueba los sectores medios para llevar a cabo las reformas -reforma agraria, reforma fiscal, etc.- imprescindibles para el desarrollo interno de la región, terminó encontrando justificación, al caerse en la cuenta de que las estructuras dominantes resultaban invencibles por su vinculación con el poder omnímodo de los centros hegemónicos. América Latina estaría amarrada al imperialismo capitalista, del que sus propias estructuras no serían más que reflejo y configuración subsidiaria. Con ello se planteó un problema bien real -las relaciones de dependencia son indiscutibles-, pero en un contexto ideológico, que hace difícil y confusa la discusión sobre el tema. Por un lado, la sociología establecida, al servicio de las potencias hegemónicas, no acepta una problemática que contradice su supuesto básico: el subdesarrollo proviene del alejamiento en "mentalidad", "formas de vida", "tipo de relaciones socioeconómicas" de los países dominantes y no, como ahora se piensa, de su excesiva presencia. Por otro, los sectores medios frustrados encuentran explicación satisfactoria para su propia inercia: qué se podría hacer contra el coloso yanqui que controla en su beneficio toda la economía latinoamericana. La impotencia política no deja otro resquicio que la protesta irracional y violenta. La violencia anarquizante de grupos minoritarios elitistas, es expresión de la frustración política de los sectores medios. Otra cosa muy distinta, es la violencia revolucionaria, violencia de masas, y que surge por canales muy diferentes de los que plantean estas minorías, aunque a la larga sea canalizada por ellas. No sin razón se ha comparado al actual antiimperialismo latinoamericano con el anticlericalismo que caracterizó al liberalismo enteco del siglo XIX. Ambos atacaron a un problema real, pero hipertrofiando su significación para ocultar una misma impotencia.

Estas consideraciones no intentan nada más que dar cuenta de un hecho sorprendente: la rapidez con que se ha extendido por el subconti- 
nente la retórica antiimperialista en la que coinciden los sectores políticos y sociales más opuestos. La eficacia operativa de un tal consenso no es despreciable, si se canaliza para llevar a cabo una política de reformas internas, y no para justificar la falta de reformas. El antiimperialismo como bandera de un nacionalismo a nivel regional, que impulse una integración no controlada por las actuales oligarquías, pudiera tener una significación histórica de primer orden. Pero para ello, es preciso plantear en su contexto real, el problema de la de la dependencia.

Antes dos observaciones, no tan obvias como pudiera parecer, teniendo en cuenta la poca atención que se las presta. Primera: la interdependencia de los fenómenos sociales es la constatación primaria que constituye a las ciencias sociales. Con ello se niega implícitamente lo que en el siglo XIX definió la meta de la sociología: "explicar lo social por lo social", como reza una de las reglas del método sociológico de Durkheim. La razón analítica funciona separando y objetivizando planos independientes de conocimiento; la razón dialéctica, mostrando la interdependencia constitutiva, dentro de una misma totalidad. Desde su perspectiva, las estructuras sociales, económicas y políticas dependen y se influyen mutuamente. La independencia de cada plano de la realidad, es para la razón analítica tan constitutiva, como la dependencia para la razón dialéctica. Con el cambio de perspectiva metodológica, han cambiado también los problemas. El de la dependencia de estructuras, países o individuos, pasa así a ser fundamental.

Segunda, la dependencia alude desde la dimensión que aquí se trata, a un hecho sobre el que no caben muchas dudas, y es que las naciones están en mutua relación, y dado los distintos grados de concentración de poder, ello implica una escala jerárquica de mayor o menor sometimiento. Esta constatación, en sí obvia, se hace necesaria únicamente frente a la presunción, meramente jurídica y normativa, de la igualdad e independencia soberana de los Estados. En la práctica real de las relaciones internacionales, la interdependencia conlleva relaciones de dominación. Cuanto mayor es el desnivel de poder económico y militar entre los Estados en relación, mayor el grado de subordinación entre ellos. La vida internacional ha evidenciado que la verdad de esta afirmación general no viene sustancialmente por el régimen político-social de los Estados en relación.

\section{DEPENDENCIA COMO FACTOR EXTERNO}

La dependencia alude en primer lugar al hecho de que los países latinoamericanos se desenvuelven en un mundo fuertemente jerarquizado, alrededor de un centro hegemónico, con un grado de desarrollo económico, tecnológico y militar muy superior al del área. Ello puede revelarse bien como un factor "dinamizador", al marcar un horizonte 
de posibilidades y ofrecer, por lo menos potencialmente, recursos técnicos y financieros, bien como un "obstáculo", al imponer una relación de subordinación, de la que se derivan formas específicas de explotación. De ahí la interminable discusión ideológica sobre beneficios y maleficios del factor externo. Según la posición que se adopte, cabe recalcar unilateralmente los beneficios - participación en la ciencia y tecnología de los países más desarrollados, posibilidad de aprender de sus experiencias positivas y negativas, etc.- como los maleficios -subordinación política y militar, explotación de las propias riquezas al servicio de intereses foráneos, apoyo externo a las oligarquías dominantes, como medida de orden y de estabilidad a la "zona de influencia”- - La mera apología o condena no tiene, sin embargo, otro sentido que el de abastecer a los bandos políticos de argumentos y pseudoargumentos para la batalla ideológica. A pesar de la frecuencia con que se habla y escribe de los males de la dependencia, escasean los estudios empíricos sobre el tema. Por lo general, no existen otras cifras que las que proporcionan los países hegemónicos, presentadas en forma global, que impiden un análisis específico sobre su significación concreta. Los latinoamericanos han trabajado más sobre los aspectos teóricos del concepto, que sobre su significación económica en un contexto delimitado. La cuestión básica en todo caso, consiste en desentrañar los aspectos positivos y negativos de las relaciones externas para el proceso de desarrollo, de modo que pueda esbozarse una estrategia que permita, paulatinamente, ir transformando los elementos más perjudiciales de las actuales relaciones ${ }^{6}$.

Reducir la subordinación externa, solo puede ser consecuencia de un fortalecimiento de la posición interna, de modo que sea posible negociar en mejores condiciones las inevitables relaciones con el exterior. Y ello se resume en la fórmula: fortalecimiento del poder del Estado, pero de un Estado capaz de llevar a cabo una reforma agraria, que aumente el mercado interno para los productos manufacturados y que cubra, con una productividad agrícola más alta, las necesidades crecientes de productos alimenticios a precios asequibles; un Estado capaz de ejercer un control del comercio internacional, de modo que se alcance una inversión óptima de las divisas obtenidas — sin que, como hasta ahora, se pierdan en el consumo suntuario o en las cuentas corrientes de bancos extranjeros-; un Estado que realice una redistribución de la renta nacional, favoreciendo el ahorro interno; en fin, un Estado que gestione directamente la obtención de capitales extranjeros, utilizándolos en proyectos de infraestructura, según las prioridades que establezca un plan de desarrollo.

6 Un trabajo pionero en este sentido es el de Sunkel, 1967. 
La situación actual, en cambio, se caracteriza por la debilidad del Estado, incapaz de realizar las reformas urgentes y basando, en último término, su liquidez en un crecimiento desproporcionado de la deuda pública. Mientras que en la década 1956-1966, el producto nacional bruto de la región aumentó en un 60 por 100, los pasivos externos latinoamericanos crecieron, según cálculos de Miguel Wionczek, en un 125 por 100. La deuda pública, con 15.000 millones de dólares, llegó a mediados de la década de los sesenta, a un punto crítico, al sobrepasar los gastos de amortización e intereses —unos 2.000 millones anuales - las nuevas entradas en calidad de créditos y préstamos (Wionczek, 1968: 70). Si los países acreedores exigieran los pagos en los plazos previstos, América Latina tendría que declararse insolvente, desencadenando una crisis semejante a la de los años treinta. La dependencia financiera de los gobiernos latinoamericanos frente a las potencias acreedoras es casi total, y no tanto por el temor de que se les exija el pago puntual de las deudas - lo que es poco verosímil, mientras se respeten las reglas del juego- como, porque no se concedan nuevos créditos en los plazos y en la cantidad precisos para sobrevivir. La mayoría de los créditos públicos que reciben los gobiernos latinoamericanos no se invierten productivamente, sino que sirven exclusivamente para sostener el aparato burocrático y represivo del Estado, así como un nivel mínimo de vida. Sin ayuda exterior no cabría mantener el statu quo, amenazando siempre con derrumbarse. A largo plazo, si no se producen cambios sustanciales, muchos de los países latinoamericanos podrían convertirse en una carga económica para la potencia económica. Es este en todo caso un límite preciso para la dependencia.

El segundo fenómeno, vinculado también a la incapacidad de realizar las reformas pertinentes, es la tendencia a disminuir, por lo menos relativamente, las inversiones extranjeras privadas. Las inversiones norteamericanas en la Europa occidental, Canadá y Australia, crecen más rápidamente que en la América Latina. Por un lado, el estancamiento económico por el que pasa la región, reduce enormemente las oportunidades de inversión; por otro lado, el traslado de las inversiones tradicionales, del sector extractivo primario y de los servicios, al industrial, permite aprovechar todas las oportunidades en este sector, sin desembolsar nuevos capitales. Además, los grandes beneficios que se obtienen en la industria, dado el proteccionismo y el régimen de monopolio imperantes, hacen innecesarias aportaciones nuevas de capital, para mantener el escaso ritmo de inversión que exige una economía prácticamente estancada. Este cuadro manifiesta claramente que el capital extranjero, no modifica las estructuras internas, sino que se acopla a ellas, utilizándolas en su provecho. Una vez 
alcanzado el límite de las inversiones rentables, el capital extranjero se repliega, contribuyendo a su vez al estancamiento de la región. La ayuda exterior, en ningún caso, sustituye la necesidad de realizar reformas internas, como ilusoriamente piensa la oligarquía, sino que a largo plazo agrava las contradicciones y el estancamiento. No hay pues una solución "externa" para América Latina.

\section{DEPENDENCIA ESTRUCTURAL}

La paradoja que define la situación latinoamericana, aumento desproporcionado del endeudamiento público y tendencia al descenso de las inversiones privadas, revela la magnitud de la crisis. Crisis que en gran parte se debe, a que América Latina, como región exportadora de materias primas, tiene significación cada vez menor para las potencias hegemónicas. La estructura de producción del área, tal como la condiciona el capitalismo industrial de la centuria pasada, se va haciendo superflua para el actual desarrollo de las fuerzas productivas en los países dominantes. La mayoría de las estructuras latinoamericanas resultan para la potencia hegemónica tan sin sentido, como el esclavo para su dueño, después de la invención de la máquina. De ahí las dificultades para readaptarse a las nuevas condiciones del comercio internacional, que ha pasado del tipo decimonónico, en el que prevalece el intercambio de productos manufacturados por materias primas, a predominar el intercambio de productos industriales entre países industriales. Si no se produjeran cambios estructurales masivos, la América Latina tenderá a transformarse en una región parasitaria de la potencia hegemónica, cuya dominación absoluta representaría a la larga una carga política, militar y económica considerable. Actualmente, es indiscutible una convergencia y mutuo acomodo de las estructuras oligárquicas internas y el capital extranjero. Pero, esta convergencia es consustancial e inmodificable o cabe pensar, como me inclino, en una divergencia creciente entre los intereses de la oligarquía latinoamericana y los de los centros monopolistas y multinacionales de poder económico. Esta hipótesis nos obliga a examinar el concepto estructural de dependencia.

Entre la nueva generación de sociólogos latinoamericanos predomina la opinión de que la distinción analítica entre factores externos e internos, oculta ideológicamente la unidad estructural entre ambos, estableciendo así el concepto de dependencia desde una nueva dimensión histórico-estructural (Quijano, 1968, 1970; Dos Santos, 1970; Dos Santos, 1968). Así como el concepto de marginalidad supera la dicotomía entre sector incorporado y sector marginal, resaltando la unidad estructural de ambos aspectos, el nuevo concepto de dependencia, supera la dicotomía externo-interno, mundo desarro- 
llado y mundo subdesarrollado, incluyendo a ambos en una estructura unitaria: el sistema capitalista mundial. La aparente oposición entre mundo desarrollado y mundo subdesarrollado, no representa más que dos aspectos recíprocos y complementarios de un mismo proceso: el desarrollo del capitalismo a nivel mundial, que crea a la vez desarrollo y subdesarrollo. Desde los centros hegemónicos, el estudio del capitalismo dio origen a la teoría del colonialismo y del imperialismo; desde los países periféricos, el estudio del capitalismo exige una teoría de la dependencia. Imperialismo y dependencia son así conceptos complementarios que enuncian una misma realidad, pero vista desde perspectivas opuestas.

Desde estos supuestos, dependencia significa el marco condicionante del desarrollo específico de los países que se integraron, impulsados desde el exterior, al sistema capitalista en expansión desde un determinado centro. Las regiones de la periferia tienen su economía condicionada por el desarrollo y expansión de la economía dominante. La superioridad tecnológica y organizatoria de los países dominantes permite imponer a los que no han alcanzado estos niveles de desarrollo "condiciones de explotación", arrebatándoles gran parte de los excedentes que producen. El condicionamiento externo de las economías precapitalistas, reestructura las relaciones internas a favor de la perpetuación de las relaciones de explotación: la dependencia articula de modo indisoluble los intereses dominantes en los centros hegemónicos con los intereses dominantes en las sociedades dependientes.

El mérito indiscutible de este concepto estructural de la dependencia es haber recuperado la dimensión dialéctica que vincula desarrollo y subdesarrollo en un proceso histórico unitario, cuestionando el binomio abstracto - factores endógenos y exógenos- que caracterizó a la "sociología del desarrollo" en su primera versión de la posguerra. Imposible comprender la historia latinoamericana fuera del marco de la dependencia que constituye sus relaciones con el mundo europeo y norteamericano. Las estructuras latinoamericanas se han ido consolidando en relación de complementariedad con las dominantes en Europa. Ha habido, cierto, un proceso de convergencia entre las minorías dominantes a ambos lados del Atlántico, estableciendo relaciones inequívocas de subordinación. Su defecto más grave, sin embargo, es la congelación dogmática de esta dialéctica, en una relación mecanicista de dominación, que reduce el "marco condicionante", totalidad dialéctica en el interior de la cual se produce la historia, al motor determinante de aquella. La dependencia deja de ser el marco condicionante para transformarse en la causa del subdesarrollo. La historia latinoamericana sería el resultado pasivo de la acción dominadora y explotadora de fuerzas externas, que la han confi- 
gurado según sus intereses específicos. A. G. Frank (1967), al concebir la dependencia como un factor inmutable y determinante, llega a la peregrina conclusión de que América Latina es dependiente y por tanto subdesarrollada en embrión, desde el primer día de la conquista.

Lo que se pierde en esta concepción es la dialéctica entre dominador y dominado, entre "señor y siervo", tal como Hegel la hizo explícita en la "Fenomenología del Espíritu". Las formas concretas de dominación crean dialécticamente las formas concretas de rebelión, que a su vez comportan nuevas formas de dominación, que son superadas por nuevas formas de protesta. Dejemos de lado la cuestión filosófica central de si este proceso de opresión y rebeldía puede llegar a un punto final, en el que desaparezca por completo la opresión, para constatar simplemente, que la historia hasta ahora vivida encaja en un esquema dialéctico semejante. Lo que importa, por tanto, es, no el dictaminar una dependencia abstracta como motor permanente de subordinación, sino el mostrar en cada momento histórico la dialéctica de la dominación, con todas sus posibilidades concretas de superación. Para desgracia del poderoso, la dialéctica de dominación crea las condiciones internas de su superación. Señalar a posteriori que se ha caído en una nueva forma de dominación - liberados del yugo "feudal" hispánico para quedar presos en las cadenas "capitalistas" del inglés - no tiene demasiada importancia mientras no se haga patente la nueva calidad de la dominación, así como las nuevas formas de lucha, vinculadas a grupos sociales distintos: las clases terratenientes criollas que se alzaron contra España, fueron las que abrieron las puertas al inglés. La lucha contra la dependencia capitalista, actualiza nuevos grupos emancipadores, así como lleva en su seno nuevas formas de opresión y de dependencia. Con ello no se defiende la tesis conservadora de que nada nuevo ocurre en la historia: la lucha entre dominador y dominante no es una repetición más que a un nivel de abstracción formalista. Históricamente no son equiparables la "dependencia" del esclavo a su amo, con la del obrero a su patrón. Se trata de situaciones cualitativamente distintas, que solo unifica un concepto abstracto, y por tanto huero, de dependencia.

Hablar de dependencia en abstracto o como causa determinante de la historia, es arramblar con las posibilidades concretas que incluye este concepto, dialécticamente aprehendido. En la situación actual lo esencial es hacer patente los distintos tipos de dependencia que operan en América Latina ${ }^{7}$, para estudiar en concreto las posibilida-

7 Así, Reyna (1967) distingue tres tipos de dependencia: en el primero, una clase local mantiene el dominio sobre los productos exportables, pero la comercialización 
des de transformarlos en nuevas formas de dependencia más convenientes para los intereses de la región. Partir de la oposición abstracta dependencia-libertad, aparte del valor emocional y propagandístico que esta oposición pueda tener para predicar la revolución, es negarse a concebir una política racional, para superar la etapa inmediata. Comprensible, sin embargo, que las nuevas clases ascendentes partan de un concepto abstracto y universal de emancipación, para ocultar la nueva opresión y la nueva dependencia que llevan en su seno. Política e ideológicamente es explicable esta actitud: una clase ascendente no se legitima más que en la universalidad de su pretensión: acabar definitivamente y de una vez por todas, con la opresión y la dependencia. Lo grave de esta ideologización es que comprime el futuro en una única disyuntiva: congelación cada vez más parasitaria de las actuales formas de dominación y de dependencia o explosión revolucionaria, absolutamente liberadora. En cambio, las revoluciones concretas que están tomando cuerpo en el área, tienen que plantear los problemas específicos de la dependencia externa de manera realista, sin desconocer el compromiso ni la negociación. De ahí la necesidad de establecer prioridades, sobre qué sectores han de pasar al control interno y en cuáles - y bajo qué condiciones, para ambas partes aceptables- es preciso contar con la colaboración de las empresas extranjeras. Ningún gobierno latinoamericano puede pasar por alto la cuestión concreta de "redefinir la dependencia" 8

El concepto de marginalidad — de ahí su debilidad teórica- se basa en un concepto abstracto y no dialéctico de dependencia, que la convierte en un obstáculo insuperable al desenvolvimiento económico: en las condiciones actuales de un capitalismo dependiente no hay posibilidad de asimilar la masa marginal. La afirmación es, sin embargo, correcta y por tanto el concepto de marginalidad utilizable, si se subraya actual $-\mathrm{y}$ dado la celeridad con que se acumulan

depende de las condiciones que impone el mercado mundial; en el segundo, la actividad primaria que produce los productos de exportación están controlados por empresas extranjeras: se trata de un imperialismo de "enclave". En el tercer tipo, existe ya una industria nacional de consumo, pero su desarrollo depende de la capacidad de importación de bienes de capital y materias primas complementarias. Desde luego no es lo mismo mantener un tipo u otro de dependencia para el desarrollo del país. Además, estos diferentes tipos se explican por factores internos, que condicionan la dependencia. En el futuro se perfila un cuarto tipo, en el que ya no existen ni enclaves económicos ni inversiones directas, sino que los capitales extranjeros solo pueden actuar controlados por el Estado y en los proyectos que defina un plan general de desarrollo. La lucha por pasar del tercero al cuarto tipo de dependencia va a caracterizar la próxima década en algunos países latinoamericanos.

8 Para una visión crítica de este replanteamiento de la dependencia por el gobierno militar peruano, véase Quijano, 1971. 
las contradicciones en el área, no hay plazo de espera-y se percibe, dialécticamente, cómo este capitalismo dependiente está creando las condiciones objetivas y de superación en un capitalismo de Estado. En el surgimiento y consolidación del Estado como la fuerza económica y social primaria, la masa marginal desempeña un papel importante, tanto porque los marginales tienden a confiar en la acción estatal, de la que esperan la solución de sus problemas, como porque su apoyo, como masa movilizable, resulta imprescindible para atemorizar a las oligarquías, y en su caso, para crear la violencia que las desplace o las aniquile. Entonces parecerá claro, que el capital externo, aunque hoy vinculado con estas oligarquías, no se confunde con ellas: confusión que proviene en último término de la falsa superación del binomio analítico —-factor endógeno-factor exógeno-, negándolo simplemente. El nuevo Estado, que se llame "socialista", "revolucionario", "de unidad nacional", necesariamente empeñado en controlar la economía básica del país, habrá de negociar los nuevos términos de la dependencia, de orden cualitativamente diferente, y por lo menos en un principio más favorable para ambas partes. La colaboración económica de los grandes consorcios multinacionales con las nuevas burocracias estatales, a pesar de que tropieza con no pocos intereses creados y malentendidos, es ya una realidad indiscutible en las relaciones económicas, en rápida expansión, entre los países del bloque oriental y occidental, relaciones que pueden servir de modelo para América Latina. La cuestión que queda abierta es determinar qué fuerzas sociales pueden hacerse cargo del Estado, en la función definida de motor de desarrollo socioeconómico.

\section{BIBLIOGRAFÍA}

Cardona, R. 1969 Las invasiones de terrenos urbanos. Elementos para un diagnóstico (Bogotá: Tercer Mundo).

CEPAL 1964 El financiamiento externo de América Latina (Nueva York: CEPAL) p. 188.

Dillon Soares, Glaucio Ary y De Soares, Mireya S. 1966 "La fuga de los intelectuales" en Aportes, $\mathrm{N}^{\circ} 2$.

Dos Santos, Theotonio 1968 El nuevo carácter de la dependencia (Santiago de Chile: CESO).

Dos Santos, Theotonio 1970 Dependencia económica y cambio revolucionario (Caracas: Nueva Izquierda).

Fernandes, Florestan 1965 A integração do negro na sociedade de classes (San Pablo: Dominus).

Frank, A. G. 1967 Capitalism and Underdevelopment (Nueva York: Holmes \& Meier). 
González Casanova, Pablo 1963 "Sociedad plural, colonialismo interno y desarrollo" en América Latina, Año 6, № 3.

González Casanova, Pablo 1965 La democracia en México (México: Era).

Hobsbawm, E. J. 1969 "La marginalidad social en la historia de la industrialización europea" en Revista Latinoamericana de Sociología, Vol. 2, p. 237.

Ianni, Octavio 1966 Raças e classes sociais no Brasil (Río de Janeiro: Civilização Brasileira).

Nun, José 1969 "Superpoblación relativa, ejército industrial de reserva y masa marginal" en Revista Latinoamericana de Sociología, $\mathrm{N}^{\circ} 2$.

Organización Internacional del Trabajo 1968 "El plan de Ottawa: un programa regional de fomento del empleo y de la formación", Documento 28/1, mimeo, pp. 14-16.

Quijano, Aníbal 1968 "Dependencia, cambio social y urbanización en Latinoamérica" en Revista Mexicana de Sociología, Vol. 30, № 3.

Quijano, Aníbal 1970 "Redefinición de la dependencia y proceso de marginalización en América Latina”, Documento 4/5 (Santiago de Chile: Instituto Latinoamericano de Planificación Económica y Social) mimeo.

Quijano, Aníbal 1971 "Nationalism and Capitalism in Peru: A Study in Neo-Imperialism" en Monthly Review, Vol. 23, $\mathrm{N}^{\circ} 3$.

Quijano, Aníbal s/f "Polo marginal de la economía y mano de obra marginalizada" (S/d: ECLA/AS) $\mathrm{N}^{\circ} 23$, mimeo.

Reyna, José Luis 1967 "Subdesarrollo y dependencia: el caso de América Latina” en Revista Mexicana de Sociología, Vol. 29, N 4.

Stavenhagen, Rodolfo 1963 "Clases, colonialismo y aculturación" en América Latina, Año 6, N 4.

Stycos, Mayone 1967 "Los anticonceptivos y el catolicismo en América Latina" en Revista Latinoamericana de Sociología, $\mathrm{N}^{\circ} 1$.

Sunkel, Osvaldo 1967 "Política nacional de desarrollo y dependencia externa" en Estudios Internacionales, Vol. 1, $\mathrm{N}^{\circ} 1$.

Vekemans, Roger y Silva Fuenzalida, Ismael 1969 "El concepto de marginalidad" en DESAL Marginalidad en América Latina. Un ensayo de diagnóstico (Barcelona: Herder).

Wionczek, Miguel S. 1968 "Aspectos sobresalientes de la dependencia económica de América Latina: el endeudamiento público externo y los cambios sectoriales en la inversión privada extranjera" en Revista de Economía Latinoamericana (Caracas) $\mathrm{N}^{\circ} 27$. 



\section{Pensando bajo el franquismo}





\section{SOCIOLOGÍA DEL CAMBIO ESTRUCTURAL Y METODOLOGÍA ANALÉCTICA*}

CUANDO UN INVESTIGADOR español de nuestros días estudia la realidad social iberoamericana, lo hace a un motivo más profundo que el que suele haber estimulado hasta ahora a emprender este mismo trabajo, tanto al científico norteamericano, como al francés, al inglés o al italiano; es decir, al sociólogo anglo-europeo. El español se pone a la obra - al menos tal es no solo mi caso personal, sino el de algunos otros colegas que venimos coincidiendo en este mismo campo de análisis-, movido por la convicción de que el cuerpo social iberoamericano ofrece una continuidad extraordinariamente notable con el suyo propio. Razón por la que a los problemas respectivos, españoles e iberoamericanos, dentro de los ámbitos parciales en que empiezan a ofrecer ya perspectivas de racionalización y explicación científica, pueden serles aplicables estos resultados, en gran medida, indistintamente. De igual manera que los numerosos aspectos colectivos que aún les quedan por explicar y racionalizar satisfactoriamente, parecen ofrecerles un dilatado campo, prácticamente ininterrumpido,

* Lizcano, Manuel 1965 "Sociología del cambio estructural y metodología analéctica" en La estructura social de Iberoamérica y España (Madrid: ISDIBER). [También publicado en la Revista de Estudios Agrosociales, 1965, N 52, pp. 41-98. Aquí, precisamente, se reproduce desde la página 41 hasta la página 56 de ese artículo.] 
de investigación común de hipótesis explicativas y de experimentación de soluciones para su desarrollo.

Hay que observar a este respecto que las denominaciones impuestas por la gran prensa a los más importantes fenómenos sociohistóricos de nuestro tiempo aparecerían como enteramente caprichosas si no sirviesen muy a las claras determinados intereses ideológicos. Tal ocurre con los términos "Oriente" y "Occidente", destinados a reservar el área de lo occidental, como paradigma universal de progreso y de prestigio, a los países anglosajones y a los continentales europeos; o con lo "americano", abusivamente restringido al ámbito estadounidense.

Pero el fraude cultural adquiere proporciones de escándalo con expresiones como lo "latinoamericano", con cuyo concepto se pretende dar la falsa idea de que el mundo iberoamericano consiste en una mezcla heterogénea y confusa de culturas y de idiomas. Para ello se parte de motivos tan desorbitados como la existencia en el Caribe de la antigua pequeña colonia francesa de Haití, el prestigio que irradió la cultura francesa durante el siglo XIX, o el origen italiano de Colón y de casi una mitad de los emigrantes llegados a Buenos Aires entre 1895 y 1947. Estos hechos pretenden ser equiparados a la civilización y poblamiento masivo de América por los españoles y portugueses entre 1500 y 1964, fecha en que por primera vez regresa a España un número de repatriados mayor que el de emigrantes a Ultramar. Lo mismo ocurre con la restricción forzada que se viene imponiendo al alcance de los contenidos culturales de términos como "lo hispánico", "lo ibérico" y "lo español", al limitarlos a realidades políticas nacionales, o ideológicas ocasionales, privativas de la Península Ibérica.

Todo ello obliga al sociólogo a emplear términos que, sin salir precisamente del léxico denominativo más genuino, permitan referir de nuevo estas ideas a conceptos inequívocos, fieles a la realidad que se trata de expresar. Así, al conjunto cultural, social, económico y políticamente coherente de Europa continental hasta las fronteras del área de influencia rusa en las distintas épocas, más las Islas Británicas, sus Estados asociados y los Estados Unidos, lo denominamos con el término de sociedad "angloeuropea". En tanto que llamamos sociedad "ibérica", o "indoibérica", al conjunto de los pueblos que se han configurado en base al marco de referencia estimativo del hombre ibérico, tanto en su originaria Península del extremo atlántico de Europa, como en toda la América que fue civilizada y cristianizada por el Estado indiano, más el reducto estrictamente ibérico que las Islas Filipinas siguen representando en el extremo oriental del continente asiático.

Es cierto que este cuerpo cultural ibérico no ofrece, ni ha ofrecido nunca, la imagen de una sociedad unitaria y espontáneamente centralizada, sino otra enérgicamente pluricentrada y llena de diversidad. 
Esta misma tensión y movilidad interna ha permitido incluso, a favor de cierto proceso de disociación de la mentalidad colectiva, poner en cuestión el dato mismo de la continuidad, o unidad cultural básica, del cuerpo social ibérico. Aunque haya sido al precio de que, automáticamente, tanto el conjunto como las partes hayan devenido una realidad social indescifrable, a la vista está cómo el tabú intelectual que prohibía afirmar la comunidad ibérica de vida, y que se proyectaba en una idea morbosa de autodenigración y autodestrucción, ha llegado a asegurar su inviolabilidad con sanciones severas y eficacísimas.

Comprendo que el científico social que ha de acometer la investigación acerca de su propia sociedad, en condiciones que ya resultan desusadamente patéticas desde su más elemental representación objetivadora, tiene que ser consciente del sesgo que amenaza a la fiabilidad de toda su operación de conocimiento. En pocos casos se encontrará, efectivamente, la sociología del conocimiento con un análisis tan necesitado de someterse a la crítica posterior sobre el condicionamiento cultural del científico. Pero, desde luego, uno de esos pocos casos en que tal crítica de los condicionamientos culturales del investigador resulta todavía mucho más evidentemente necesaria, es el análisis que acerca de los problemas peninsulares e iberoamericanos vienen acumulando hasta ahora, a partir de modelos de integración social extraños, casi todos los sociólogos angloeuropeos, y los ibéricos que no han podido adaptar todavía la experiencia de la ciencia social angloeuropea a las exigencias metodológicas específicas que obviamente plantea la investigación de su propia sociedad.

La mitificación seudocientífica de la sociedad angloeuropea y sus sistemas de vida se ha deslizado hasta extremos increíbles entre las categorías operatorias del investigador de la realidad social ibérica, en centenares de encuestas y análisis afectados de este sesgo desvirtuador: la confusión temática entre el cambio estructural que vienen atravesando nuestros países, en su actual transición rural-científica, y este otro pretendido proceso de transformación, despótica y alienadoramente proclamado desde muchos grupos económicos, políticos o controladores del libro, la escuela, la universidad y los grandes medios de comunicación, según el cual el desarrollo colectivo del hombre ibérico consistiría en su simple asimilación a la estructura estimativa y modos de vida, plenamente experimentados, del hombre angloeuropeo.

Resultado inevitable de tan forzada simplificación iba a ser, al no tardar en quedar al descubierto el absurdo sobre el que descansaba, el fácil cambio de objeto de la misma actitud mental. Con la misma falta de esfuerzo, iba a darse por supuesto que en el medio social ibérico era automáticamente posible reemplazar las pretensiones de establecer una situación de sometimiento burgués-capitalista, por otra de 
sometimiento marxista-comunista. En ambos supuestos se partía, por parte del científico social, de la cómoda base, en la que ya antes de él había visto olímpicamente instalado al político, de que la actividad creadora puede reemplazarse, en una comunidad de vida humana, por la copia irreflexiva de las obras ajenas. Sin advertir que, igual el político que el científico social, están declarando, desde tal mentalidad, bien su pertenencia a un cuerpo social marginal y decadente, bien su mero descastamiento o desvirtuación cultural personales, respecto de un cuerpo social en cuya vitalidad creadora no participan.

Dejando aparte, por ahora, el impacto social de esta actitud de los extensos sectores de la inteligencia social ibérica culturalmente desvirtuada, hemos de limitarnos a subrayar, en principio, su lógica infecundidad intelectual y científica. El papel innovador en el seno de una herencia cultural creadoramente transmitida, que corresponde al hombre de inteligencia o élite en toda comunidad de vida, queda frustrado así en su raíz; y de un modo especialmente intenso, queda frustrado el papel del científico social. Los problemas sometidos por él, en tales condiciones, a un análisis a veces, incluso, técnicamente impecable, han quedado, en último término, internamente intactos y solo manoseados en su superficie; sin que semejante pretendida investigación permita fundamentar ni el diagnóstico, ni menos todavía las soluciones correctas, en cuyo planteamiento tiene que comprometerse el sociólogo, sobre todo en circunstancias críticas o revolucionarias, si ha de cumplir con el papel y la confianza moral e intelectual que su sociedad le atribuye.

Nada de lo anterior me es permitido, en esta ocasión, hacer otra cosa que no sea dejarlo apenas formulado, dadas las dimensiones del presente trabajo. Solo puedo recoger ahora los lineamientos generales de otro estudio más extenso y detenido ${ }^{1}$, en el que la investigación en profundidad acerca del cambio estructural en curso en los países ibéricos es acometida ya por medio de un sistema metodológico y conceptual, el analéctico, que supone en sí mismo un resultado de la observación rigurosa y sistemática de este medio social, cuyo conocimiento se propone el sociólogo que investiga los problemas de la sociedad de países de lengua, o de cultura, española y portuguesa. Por consiguiente, no me es posible, en esta ocasión, ni hacer apenas referencias bibliográficas, ni fundamentar y documentar muchos aspectos del análisis, ni presentar sino en forma muy esquemática los juicios explicativos a los que nuestro trabajo científico se orienta.

1 Remito al lector, para el estudio detallado de todas cuestiones que en este artículo solo puedo plantear escuetamente, a la inmediata publicación de mi libro Los pueblos ibéricos. El cambio estructural en España, Portugal, Iberoamérica y Filipinas. 
El método analéctico, fiel al principio acumulativo que preside toda la investigación científica, se ha elaborado recogiendo, como era obligado, importantes aportaciones de los métodos estructural, funcional, tipológico, dialéctico y en profundidad; pero no sin sistematizarlas a su vez, a partir de la concepción peculiar del mundo de una sociedad trascendente ${ }^{2}$, en base a un criterio de sentido en el que, en lugar de perderse el investigador en el océano de una perpetua indiferenciación estimativa - resultado ella misma, como es obvio, de una particular idea del mundo-, llegan a valorarse y jerarquizarse con rigor los sucesivos factores estructurales y dialécticos analizados, según las exigencias trascendentes de su propia cosmovisión colectiva.

Es cierto que una tarea científica de estas características volverá a ofrecernos, como ya observábamos antes, un sesgo particular, que nos impedirá dar a sus resultados un valor de universalidad absoluto. Pero también presentará, en cambio, la ventaja no pequeña de contar ya de antemano, y de manera consciente, con su propio margen de error, mensurable en consecuencia, en vez de caer en el primitivo y fatuo sociocentrismo de tantos estudiosos que no perciben cómo la pretendida validez universal de los métodos y supuestos mentales, localmente condicionados, que utilizan en sus trabajos, solo pueden producir resultados de confusión al ser extrapolados sin discernimiento a marcos de referencia extraños.

Sucesivamente, exponemos ahora los cuadros conceptuales en los que descansa el método analéctico. En el Cuadro $\mathrm{N}^{\circ} 1$ se sistematizan y describen los campos de evolución desde cuya perspectiva necesita ser observada, con un tratamiento múltiple de sociología interdisciplinaria de las ciencias sociales particulares, cualquier realidad social compleja. El Cuadro $\mathrm{N}^{\circ} 2$ presenta una tipologización lógica de los factores estructurales que se dan en la realidad social. El Cuadro $\mathrm{N}^{\circ} 3$, los sectores de estructuras de un cuerpo social, con sus estructuras sectoriales respectivas. Y el Cuadro $\mathrm{N}^{\circ} 4$, los elementos que componen el juicio analéctico, presentado operatoriamente en forma de dialéctica de trascendenciación-inmanenciación, como explicación científica adecuada en el caso de una sociedad trascendente, del tipo de la ibérica.

2 Una concepción trascendente y otra inmanente, respecto del mundo, o del hombre en el mundo, se contraponen por su estimación respectiva del sentido de la experiencia humana, como algo que se consuma más allá del mundo y de la historia, o que queda condicionado y determinado por sus límites estrictos, intra-mundanos e intra-históricos. 


\section{Cuadro $\mathrm{N}^{\circ} 1$}

Campos de evolución de la realidad social

\begin{tabular}{l:c:c}
\hline \multicolumn{1}{c}{ Retrospección sociológica } & \multicolumn{1}{c}{ Cambio estructural } & \multicolumn{1}{c}{ Prospección social } \\
\hline Marcos de referencia culturales & Estudio objetivado y actual de & Aplicación de las leyes \\
sucesivos, en cuyo entorno & la realidad social, en todo el & obtenidas por las regularidades \\
de antecedentes deviene el & juego dialéctico y analéctico de & observadas, al conocimiento \\
proceso global de evolución de & sus estructuras, y proceso de & y racionalización de las \\
la realidad social actual. & cambio en curso. & alternativas determinantes \\
& & sobre las que tiene que decidir \\
& & sus opciones realmente \\
& & posibles el acto libre. \\
\hline
\end{tabular}

\section{Cuadro $\mathrm{N}^{\circ} 2$}

Factores estructurales de la realidad social (y sus niveles respectivos de análisis en profundidad)

\begin{tabular}{l:l:l}
\hline \multicolumn{1}{c}{ Situacionales o procesuales } & \multicolumn{1}{c}{ Formales o materiales } & \multicolumn{1}{|c}{ Ideales o significacionales } \\
\hline Situación histórica. & Ecológico-demográficos. & Modelos integradores. \\
Situación formal. & Organizaciones sociales. & Sistemas de referencia. \\
Situación ideal. & Conductas regularizadas. & Actitudes colectivas. \\
Situación analéctica. & Conductas innovadoras. & Motivaciones sociales. \\
& Tramas de papeles sociales. & Consensos colectivos. \\
& Herencia cultural. & Tradiciones colectivas. \\
& Tecnología y formas de & Estimativa colectiva. \\
& civilización material. & Concepción del mundo. \\
\hline
\end{tabular}

\section{Cuadro $\mathrm{N}^{\circ} 3$}

Sectores de estructuras de la realidad social (y sus sistemas de estructuras sectoriales)

\begin{tabular}{l:l:l}
\multicolumn{1}{c}{ Integración } & \multicolumn{1}{c}{ Organización } & \multicolumn{1}{c}{ Configuración } \\
\hline El pueblo histórico. & La civilización material. & El poder. \\
La población y el medio & El sistema de trabajo científico- & La vida sociorreligiosa. \\
geográfico, rural y urbano. & económico. & La modelación colectiva. \\
La vida familiar-generacional. & El sistema secundario. & El sistema de herencia- \\
Las clases sociales. & La normación-disociación & innovación cultural. \\
La vida asociacionista- & colectiva. & La estimativa colectiva. \\
comunitaria. & La comunicación secundaria. & \\
\hline
\end{tabular}

\section{Cuadro $\mathrm{N}^{\circ} 4$}

Los elementos del juicio analéctico (dialéctica de transcendenciación-inmanenciación)

\begin{tabular}{l:l:l}
\hline \multicolumn{1}{c}{ Dialéctica situacional } & \multicolumn{1}{c}{ Dialéctica formal } & \multicolumn{1}{c}{ Dialéctica ideal } \\
\hline $\begin{array}{l}\text { Creación-erosión (de } \\
\text { historicidad creativo- } \\
\text { decadente). }\end{array}$ & $\begin{array}{l}\text { Cualitativo-determinista } \\
\text { (de formalización primario- }\end{array}$ & $\begin{array}{l}\text { Mancomunación-sumisión (de } \\
\text { secundaria). }\end{array}$ \\
\hline
\end{tabular}




\section{SECTOR DE ESTRUCTURAS DE INTEGRACIÓN EL PUEBLO HISTÓRICO}

Se suele objetar al concepto de "pueblo" su gran ambigüedad e imprecisión. Esta es la razón, por ejemplo, de que el empleo de dicho término entre los sociólogos sea muy escaso y lleno de reservas. No obstante, a mi juicio, esta actitud está lejos de probar que las prevenciones hostiles con que se suele acoger dicho concepto sean válidas. Lo que prueba es, más bien, desde el planteamiento crítico que hemos adoptado, el peso de los preconceptos ideológicos que operan en los grupos de sociólogos de tradición científica angloeuropea.

Una investigación rigurosa y sistemática, es decir, netamente científica, no podrá prescindir, en cambio, ante la experiencia viva y directa de la realidad social, de objetivar en categorías válidas para el análisis un concepto como el de pueblo, acuñado por las necesidades más radicales y vitales del lenguaje humano; las mismas que, dentro de otros ámbitos de la realidad, significativos o no para el conocimiento sociológico, han creado términos como "naturaleza", "muerte", "Dios" o "tierra".

El concepto de pueblo hace así referencia, en principio, al grupo humano unido en base a un peculiar marco de referencia estimativo, expresado en un sistema específico de obras de cultura y de civilización, tanto de índole tecnológica como de herencia y de valores, sobre cuya base se organiza y se identifica a sí mismo como sociedad global, al nivel de la convivencia de un grupo local, comarcano o regional, de clase social, nacional e incluso internacional. Toda sociedad global es, si partimos de este planteamiento conceptual, un pueblo o un sistema de pueblos cuya existencia se nos ofrecen bien "en forma" social, o bien en situaciones patológicas o degenerativas; a cuyos vínculos colectivos de índole urbanizadora, tecnológica y de modelos económicos básicos denominamos civilización material, y a cuya herencia y marco de referencia histórica y sistema de obras de cultura, incluido el campo estimativo de los valores y de la concepción peculiar del mundo, consideramos como sus estructuras estimativa y de herencia-innovación cultural.

En realidad, el problema ya aludido de la aparente ambigüedad del concepto de pueblo, viene dado por la superficial confusión de sus dos básicas acepciones particularizadas: la de "pueblo histórico" y la de "pueblo trabajador". La noción de pueblo histórico hace referencia a la idea particularizada de sociedad global, protagonista de historia y creadora de cultura, colectivamente consciente de su propia personalidad cultural con respecto a las demás colectividades, pretéritas o actuales, de análogas características; y cuya síntesis radical de la propia concepción vital y telúrica, emocional y de matriz de sus peculiares consensos ideológicos, se expresa en la palabra "patria". La noción de 
pueblo trabajador, en cambio, hace referencia a un concepto de clase social. Se trata del cuerpo social matriz, creador colectivo y casi siempre anónimo de las obras de cultura básicas, que tanto en el orden de las estructuras materiales, como en las axiológicas y culturales, hacen posible la existencia efectiva e identificada de un pueblo histórico. Al menos, si esta afirmación puede resultar discutible desde la perspectiva histórica y sociológica de una sociedad como la norteamericana, resulta, en cambio, claramente válida para un tipo de sociedad como la ibérica, históricamente grávida de una rica herencia cultural.

Porque la estructura iberoamericana, y más radicalmente la ibérica global, representa, ante todo, el caso de un pueblo inacabado, interrumpido en su desarrollo histórico y material. La causa de tan curioso fenómeno, tras atenta reflexión y estudio, parece que no puede ser otra sino la enorme debilitación de sus minorías dirigentes, patológicamente distanciadas del resto del cuerpo social, y forzadas, por ello, a un respaldo extranjero permanente de tipo ideológico o material, o de ambos a la vez. Se trata del curioso proceso ibérico de desvirtuación cultural, en el que ha desembocado el de oligarquización previa de las élites ibéricas a través de largos períodos.

Esta situación se ha traducido en la curiosa apariencia de un cuerpo social entero, de formidables proporciones, cuya estructura idiomática castellana y portuguesa ocupa el tercer puesto, tras el chino y el inglés, en las lenguas actualmente habladas, que hubiera perdido su memoria colectiva. La verdad es que no es al cuerpo social en cuestión al que le afecta este traumatismo, sino a sus oligarquías interiores, desvirtuadas en la forma ya aludida. Pero el resultado, dados los medios de expresión y de acción que están en manos de las clases dirigentes, es siempre el mismo en estos países. No saben a dónde van. En rigor, lo que ocurre es que dichas élites desvirtuadas, como desenlace de su proceso de autodenigración contemporáneo, al término de su operación desvirtuadora colectiva, no saben de dónde vienen. La inteligencia, en casi todos los países ibéricos, lleva varias décadas formulándose la peregrina pregunta de quién somos colectivamente. Sin embargo, para una inteligencia que no hubiera cortado sus raíces con el propio pueblo, la pregunta carecería de sentido. No somos otra cosa que un pueblo ibérico de grandes proporciones, cuyos casi trescientos millones de seres humanos integrados en su cultura forman la décima parte de la humanidad actual. Un pueblo ibérico forjado, a partir de su matriz peninsular, por medio de una obra gigantesca de mestización espiritual y étnica, en la que ha hecho prevalecer permanentemente su imagen radical del hombre característica.

Esta sociedad, obra de varias series de generaciones empeñadas siempre en una fabulosa aventura colectiva, cuya expansión ultramari- 
na final, llena de desbordamientos y de repliegues de desusado tono épi$\mathrm{co}$, ha durado medio milenio ininterrumpido, constituye el dato primario sobre el cual ha de levantarse la investigación sistemática acerca de cualquier país o problema ibérico particular, si se aspira a que el estudio sociológico tenga una base objetivadora rigurosa. En cambio, negarse a ver que esta es la realidad última en que consistimos, manifiesta bien a las claras ese prejuicio ideológico culturalmente desvirtuador, cuya consecuencia, en este caso, es situar al científico temáticamente fuera de la realidad estudiada. Contrasentido en el vienen cayendo persistentemente las inteligencias ibéricas, drogadas e hipnotizadas por el hechizo que a su deseo oligárquico de dominación interna añadió, en los comienzos del siglo XIX, el triunfo de la cultura antagónica vecina: la sociedad burguesa de los pueblos angloeuropeos de Europa y Norteamérica.

En varios cuadros sucesivos, del 5 al 9, tratamos de tipologizar, a continuación, las principales categorías conceptuales que fundamentan nuestro análisis y que constituyen, en principio, el juego completo de variables sobre el que tiene que desarrollarse ulteriormente el estudio en profundidad que el tema requiere: focos dinamizadores principales, originariamente europeos, de la gran sociedad occidental moderna, y situación del ibérico entre ellos; datos cuantitativos que, en base al Anuario Estadístico de las Naciones Unidas de 1963 y a sus estimaciones prospectivas, sitúan al pueblo ibérico dentro del conjunto de las otras grandes sociedades humanas actuales; sistema de culturas particulares en el que se ha diversificado históricamente el mundo occidental; períodos internos de evolución de la propia cultura ibérica, y, finalmente, estructura global de la sociedad contemporánea del encuentro planetario de las culturas. Situación planetaria que nos emplaza ya, dentro del contexto de la impresionante reactivación suscitada por la civilización científica en todos los pueblos no angloeuropeos, ante el hecho categórico de una segunda evolución ibérica, que se encuentra en la coyuntura actual en pleno proceso de desarrollo.

Quizá uno de los temas más apasionantes que suscita el análisis de esta estructura de pueblo histórico, referida al caso de la sociedad ibérica, es el de la etiología de esta idea obsesiva de la autodenigración, llevada en momentos extremos al límite de la autodestrucción, en la que ha venido a dar el proceso de desvirtuación de la inteligencia en los distintos países ibéricos. En último término, la perspectiva de que España, o sea la imagen radical, el paradigma objetivado, con todas sus luces y sus sombras, de la comunidad ibérica de vida, impuso por la fuerza, fanáticamente, sus ideas a otros pueblos, hay que investigar si no es precisamente otra imagen, impuesta por la fuerza, fanáticamente, desde los cuadros burgueses triunfantes en la sociedad de las naciones angloeuropeas. 
Hay que analizar a fondo la perspectiva, perfectamente posible, de que lo que España hizo en Bélgica, en Inglaterra, en Francia, en Alemania, durante el siglo XVI, no fue imponer nada desde fuera, sino apoyar a las fuerzas que, desde la experiencia de su propio medio milenio de cruzada de Reconquista nacional, constituían los grupos de opinión trascendente y espiritualista de la Europa tradicional, en una coyuntura crítica, en la que la nueva inteligencia burguesa estaba a punto de imponer, como hizo con la derrota de España, una concepción nueva del mundo, violentamente contradictoria con la que había tenido vigencia hasta entonces.

Más tarde, el problema iba a reproducirse -y, en definitiva, esto es lo que el hombre español del Renacimiento intuyó que tenía que prevenir con su lucha quijotesca en Europa- en el seno de la misma sociedad ibérica. Cualesquiera que fuesen las tensiones internas inherentes a toda la hazaña de establecimiento del Estado indiano ibérico en América, la imagen autodenigratoria de lo español, de lo ibérico, de la estructura de personalidad misma del hombre iberoamericano, solo iba a aparecer a partir de las guerras de independencia nacionales. Lo que equivale a decir que esta imagen denigrante de lo español hace su aparición en el marco de la gran Guerra de Secesión ibérica, que marca en América y en la Península la disolución del Estado indiano anterior. A partir del desenlace de dicha Guerra de Secesión ibérica, preparada ya meticulosamente como fenómeno desintegrador por los cien años anteriores de ocupación de la Corte madrileña por la oligarquía "afrancesada" del grupo borbónico, la imagen denigratoria anti-ibérica de las minorías dirigentes angloeuropeas se transferirá a las oligarquías burguesistas que se apoderan de las nuevas naciones ibéricas desunidas, incluida la propia Península, en una definitiva imagen autodenigratoria.

\section{Cuadro $\mathrm{N}^{\circ} 5$}

Los dos triángulos de focos dinamizadores de la sociedad europea moderna

\begin{tabular}{|c|c|c|c|}
\hline \multicolumn{2}{|c|}{ Europa interior } & \multicolumn{2}{|c|}{ Europa periférica } \\
\hline París-Roma-Berlín & $\begin{array}{l}\text { Londres (desdoblado } \\
\text { más tarde en el foco de } \\
\text { Nueva York). }\end{array}$ & $\begin{array}{l}\text { Madrid } \\
\text { (desdoblado más tarde } \\
\text { en varias capitales } \\
\text { ibéricas ultramarinas). }\end{array}$ & $\begin{array}{l}\text { Moscú (desdoblado } \\
\text { recientemente en } \\
\text { los diversos focos de } \\
\text { las "colonizaciones" } \\
\text { ideológicas del mundo } \\
\text { comunista). }\end{array}$ \\
\hline \multicolumn{2}{|c|}{ Cultura angloeuropea (burguesa) } & $\begin{array}{l}\text { Cultura ibérica } \\
\text { (comunera) }\end{array}$ & Cultura rusa \\
\hline \multicolumn{4}{|l|}{ Cultura obrera } \\
\hline
\end{tabular}




\section{Cuadro $\mathrm{N}^{\circ} 6$}

Situación respectiva de la cultura indoibérica y las restantes que integran la sociedad del encuentro planetario de las culturas*

\begin{tabular}{|c|c|}
\hline Sistema de culturas de la sociedad occidental & Sistema de culturas de la sociedad oriental \\
\hline $\begin{array}{l}\text { Sociedad europea continental. } \\
\text { Área burguesa (unos } 250 \text { millones de habitantes). } \\
\text { Área marxista totalitaria (unos } 125 \text { millones). } \\
\text { Sociedad anglosajona. } \\
\text { Estados Unidos (cerca de } 200 \text { millones). } \\
\text { Gran Bretaña y población anglosajona de la } \\
\text { Commonwealth (unos } 100 \text { millones). } \\
\text { Sociedad rusa (unos } 230 \text { millones). }\end{array}$ & $\begin{array}{l}\text { Sociedad árabe-islámica (unos } 260 \text { millones de } \\
\text { habitantes). } \\
\text { Sociedad indostánica (unos } 460 \text { millones). } \\
\text { Sociedad china (unos } 650 \text { millones). } \\
\text { Sociedad japonesa (cerca de } 100 \text { millones). } \\
\text { Sociedad indonesia (cerca de } 100 \text { millones). } \\
\text { Sociedad del África negra (cerca de } 200 \\
\text { millones). }\end{array}$ \\
\hline $\begin{array}{l}\text { Sociedad ibérica, o indoibérica } \\
\text { (España, Portugal, Iberoamérica y Filipinas) } \\
\text { (cerca de } 300 \text { millones) }\end{array}$ & \\
\hline
\end{tabular}

* Cálculos en base a las estimaciones del "Anuario Estadístico de las Naciones Unidas" de 1963.

\section{Cuadro $\mathrm{N}^{\circ} 7$}

Sistema de culturas del mundo occidental

\begin{tabular}{l:l:l}
\hline $\begin{array}{l}\text { Cultura Romano-Germánica } \\
\text { En cuanto a su modelo básico trascendenciador, cultura } \\
\text { de cristiandad. }\end{array}$ & $\begin{array}{l}\text { Cultura Bizantina } \\
\text { Réplica helenístico-oriental de la cultura de } \\
\text { cristiandad, fronteriza con Asia y el Islam. }\end{array}$ \\
\hdashline Cultura Ibérica & Cultura Angloeuropea & Cultura Rusa \\
En cuanto a su modelo básico & En cuando a su modelo & En cuanto a su modelo \\
trascendenciador, cultura comunera. & básico inmanenciador, & básico, fundamentalmente \\
Consensos fundamentales escindidos, & cultura burguesa. & mágico-trascendenciadora; \\
por desvirtuación parcial de su & Consensos fundamentales & actualmente, a partir de la \\
modelo trascendenciador básico en & equilibrados, por la & violenta desvirtuación impuesta \\
dos campos o subculturas interiores & fácil identificación & por su revolución marxista \\
antagónicas, de base clasista. & generalizada de su & totalitaria, en dialéctica de \\
Subcultura interior tradicional & sociedad con el ideal & polarización trascendenciadora- \\
trascendenciadora (campo comunero). & intra-mundano de su & inmanenciadora y predominio \\
Subcultura interior desvirtuada & modelo inmanenciador & externo, al menos, de este \\
inmanenciadora (campo oligárquico). & básico. & factor.
\end{tabular}

Cultura Obrera

Primera cultura histórica que nace ya dentro del ámbito de la civilización industrial, en base a un modelo trascendenciador libertario-justiciero-fraternal, antagónico al que dinamiza históricamente a la sociedad burguesa. Consensos fundamentales escindidos, por desvirtuación parcial de su modelo trascendenciador básico, en dos campos o subculturas exteriores antagónicas, de base valorativa.

\begin{tabular}{|c|c|c|c|}
\hline \multicolumn{2}{|c|}{$\begin{array}{l}\text { Subcultura exterior tradicional trascendenciadora } \\
\text { (campo asociacionista) }\end{array}$} & \multicolumn{2}{|c|}{ Subcultura exterior desvirtuada } \\
\hline \multicolumn{2}{|c|}{$\begin{array}{l}\text { Consensos por diferenciación de los métodos de acción } \\
\text { revolucionaria en el campo asociacionista. }\end{array}$} & \multicolumn{2}{|c|}{$\begin{array}{l}\text { Consensos por diferenciación de los } \\
\text { métodos de acción revolucionaria en el } \\
\text { campo marxista. }\end{array}$} \\
\hline $\begin{array}{l}\text { Asociacionismo } \\
\text { no violento }\end{array}$ & Asociacionismo violento & Marxismo aburguesado & $\begin{array}{l}\text { Marxismo } \\
\text { totalitario }\end{array}$ \\
\hline
\end{tabular}


Cuadro $\mathrm{N}^{\circ} 8$

Tipología de los períodos de evolución de la cultura ibérica

\begin{tabular}{l:l:c:c}
\hline \multicolumn{1}{c}{ Primer período } & Segundo período & Tercer período & Cuarto período \\
\hline $\begin{array}{l}\text { Confederación hidalgo- } \\
\text { comunera peninsular } \\
\text { de la Reconquista }\end{array}$ & Estado indiano & Alienación burguesista & $\begin{array}{l}\text { Revolución comunera } \\
\text { indoibérica }\end{array}$ \\
\hline
\end{tabular}

\section{Cuadro $\mathrm{N}^{\circ} \mathbf{9}$}

Estructura de la sociedad del encuentro planetario de las culturas

1. Establecimiento forzado de la hegemonía mundial del inmanentismo occidental burgués-marxista.

2. Alienación mundial colonialista de los pueblos no occidentales.

3. Difusión planetaria simultánea de la experiencia científico-tecnológica configuradora de la nueva civilización industrial, y de la dialéctica ideal de trascendenciacióninmanenciación esencial a la herencia cultural de 0ccidente.

4. Comienzo de la reactivación mundial de los pueblos alienados.

5. Plena reactivación histórica prioritaria de la sociedad ibérica, primera cultura occidental que ha realizado ya, en base a la trascendenciación básica de su herencia cultural particularizada, la gran síntesis occidental-oriental hacia la que avanza la humanidad entera.

Una investigación rigurosa, capaz de explicar en toda su magnitud la formidable crisis que atraviesan los pueblos de habla o cultura española y portuguesa, no puede, ni mucho menos, descartar la hipótesis apuntada. Más bien parece estar cargada de sólidas razones en su favor esta interpretación de que fue el apoyo exterior de toda la sociedad burguesa triunfante en los pueblos angloeuropeos, al imponer a las minorías burguesistas como nueva clase oligárquica en la sociedad ibérica desunida, la causa que proyectó en el mundo cultural de los pueblos ibéricos contemporáneos la noción estereotipada de una España mezquina, forastera y dominante, allí donde solo se habían enfrentado en realidad, en una auténtica guerra de secesión, los grupos tradicional e innovador, monarquista y republicano, de una sociedad de la que ambos formaban parte por igual, dentro de un sistema de clases específico: peninsulares, criollos o "españoles americanos", indígenas americanos, mestizos, negros y mulatos. Al fin y al cabo, el enfrentamiento en guerra civil de tradicionales e innovadores, tras el desenlace ocasional de la victoria de los primeros en la Península y de los segundos en América, apenas iba a producir otro resultado político que no fuera la declaración de plena soberanía nacional a favor de los diferentes reinos o virreinatos integrados hasta entonces en la Corona única del Estado indiano. Fenómeno que no solo se desencadenó ampliamente en América, sino que constituyó 
una enérgica tendencia de toda la vida contemporánea en la propia "nación” española.

En definitiva, es bien difícil negar con datos y argumentos sólidos que la sociedad ibérica actual no sea el resultado, en parte frustrado, en parte meramente interrumpido, es decir, a medio camino todavía de su realización final, de un gran empeño quijotesco que haya dado a dicha cultura histórica esta dimensión esencial: la de la realización colectiva de una gigantesca empresa de evangelización ecuménica, al servicio de la inmemorial noción de la hombría ibérica. Al menos, esta perspectiva podría resultar abrumadoramente real si se refiere a la dimensión ibérica sustantiva que representa la mentalidad comunera. A mi juicio, en efecto, toda la evolución ibérica constituye básicamente la historia de este empeño. Y la barrera que a su realización se ha opuesto, mucho más que la triunfante agresión burguesista exterior, o la posterior marxista, consiste en el desistimiento, o traición, dialécticamente protagonizado por las clases oligárquicas en los países ibéricos. Y el análisis de este hecho constituye el nudo esencial para una interpretación correcta del desastre ibérico contemporáneo. Pero el desarrollo concreto de este tema corresponde ya a las estructuras de clases sociales, del poder y sociorreligiosa.

Añadamos solamente, desde esta perspectiva de profundidad, la puntualización que corresponde al concepto de "Latinoamérica", o "América Latina", como concepción político-cultural de la mencionada idea desvirtuadora y autodenigradora. La denominación aludida, en efecto, no tiene otro objeto que el de destruir el vínculo esencial de una herencia colectiva, sugiriendo la imagen gratuita de un nacimiento iberoamericano a la historia de los comienzos del siglo XIX, merced a la independización de unas factorías coloniales anteriores. Idea que solo parece transferir caprichosamente el esquema fundacional de los Estados Unidos, o del intento de la "Argelia francesa", o de la "Independencia" de Sudáfrica y Rodesia, a lo que parece no haber sido otra cosa que una guerra civil y de secesión de un pueblo tan viejo como fuertemente personalizado. Lo que habría nacido, en realidad, a comienzos del siglo XIX sería el período efectivamente colonial de la anfictionía desintegrada de los pueblos ibéricos. La violencia interior de tal situación nos habría conducido, por el camino de una alienación progresiva, al desastre que hoy preside la vida global de la sociedad ibérica. Y a lo que ahora estaríamos asistiendo es, simplemente, a un fenómeno de renacimiento interno, capaz de desencadenar esta segunda evolución ibérica que parece constituir el motor de las energías innovadoras en nuestras jóvenes generaciones actuales. Pero justamente toda esta vigorosa realidad palpitante del pueblo ibérico, es lo que escamotea la desvirtuadora denominación de "Latinoamérica". 



\section{Juan Maestre Alfonso}

\section{LA REVOLUCIÓN DEL 20 DE OCTUBRE*}

"LA COLONIA QUERÍA hacerse patria: hasta 1944, el país había sido testigo y víctima, pero no es protagonista de su historia", nos relata Eduardo Galeano. Es el 20 de octubre de ese mismo año cuando se cierra en el libro de la Historia una antigua era para comenzar otro de signo profundamente contrario. La trayectoria se ha podido detener o desviar, pero jamás podrá volver a ser como antaño; el pueblo fue sujetado de una política nacional y ello ha llegado a crear carácter y auténtica conciencia, si no en la totalidad, sí, al menos, en amplios sectores. Se conoce que las posibilidades de cambio pueden ser reales, y también se llegaron a palpar resultados positivos hasta entonces inimaginados a pesar de sus cortas pretensiones.

El proceso comenzó en realidad con anterioridad al 20 de octubre; en puridad podemos afirmar que se iba consumando con la acumulación de injusticias y actos de expoliación de que eran objeto los guatemaltecos. En junio de 1944 un movimiento de matiz nacionalista acompañado de una huelga general abundante en enfrentamientos en los que perdieron la vida sesenta personas, forzó a que, el 1 de julio, se viera obligado a presentar su dimisión el dictador Jorge Ubico, que

* Maestre Alfonso, Juan 1969 "La revolución del 20 de octubre" en Guatemala: subdesarrollo y violencia (Madrid: IEPAL) pp. 159-174. 
tomó el mismo camino de tantos otros tiranuelos latinoamericanos: un exilio salvaguardado por una fuerte cobertura económica. Cuando se marchaba hacia su dorado exilio advirtió a sus sucesores —auténticos continuadores, pues sus oponentes no consiguieron más que la sustitución personal-: "Tened cuidado con los comunistas y con los carcas".

A la renuncia de Ubico se hace cargo del poder una Junta presidida por los generales Eduardo Villagrán Ariza, Fernando Ponce y Eduardo Pineda. Este directorio prometió reunir la Asamblea Nacional que nombró presidente provisional al general Ponce.

En la noche oscura del 19 de octubre una multitud, compuesta principalmente por obreros, maestros y estudiantes, encuadrados por algunos oficiales jóvenes, se lanzó al asalto de los reductos militares de la capital guatemalteca. Se atacó, victoriosamente, los fuertes de San José y Matamoros, y, ya por último, el cuartel conocido por La Guardia de Honor. Ya era el 20 de octubre y la dictadura llamada de "los catorce años", ahora continuada por Ponce, había sido totalmente derrocada.

Al día siguiente, el 21 de octubre, el hambre, comprimida por siglos, hizo estallar en cólera a los llenos de mansedumbre indígenas de Patzicía, un municipio del Departamento de Chimaltenango, y se sublevaron por un conflicto de tierras que durante largos años no tuvo más resolución que la de la fuerza. Los indios y parte de los mestizos desposeídos cayeron sobre blancos y mestizos ricos, con su odio acumulado, ejecutando toda una serie de actos sangrientos. Los blancos y los mestizos de las poblaciones cercanas, secundados por unidades del Ejército y por voluntarios de la ciudad de Guatemala, actuaron rápidamente. Los amotinados, conscientes de su imposibilidad de resistir, huyeron a los sitios más inaccesibles y adonde pudieran obtener refugio y defensa: a los bosques que cubren las laderas de los volcanes y a los intrincados barrancos. Se organizó una implacable batida de caza de hombres. A los prisioneros se les fusiló en el acto. Fue una segunda versión, a escala reducida, de la sublevación de los pipiles en El Salvador. Una reiteración que a su vez sería repetida en varios países de América Latina. Una de tantas crónicas luctuosas que los "noticieros" de esta parte del mundo recogen solo cuando las consideran dignas de mención o cuando llega a conocimiento de los reporteros citadinos. Hoy las mujeres indígenas de Patzicía llevan con su aire alejado y abobalicado sus cántaros a la fuente y tejen en sus telares prehispánicos, pero a su uniforme vestimenta, compuesta de huilpiles de vivo rojo y de nagua azul grisáceo, han decidido incorporar, en señal de duelo por la tragedia, un collar de varias vueltas de cuentas negras.

El 20 de octubre, el general Ponce fue sustituido por el triunvirato formado por el mayor Javier Arana, el capitán Jacobo Arbenz Guzmán 
y Jorge Toriello. En diciembre del mismo año se celebran elecciones y uno de los candidatos, Juan José Arévalo, fue triunfalmente elegido, habiendo obtenido cinco veces más sufragios que sus dos competidores juntos. El 15 de marzo del año siguiente -1945- tomó posesión de su mandato.

Juan José Arévalo era un prestigioso profesor universitario que ya había alcanzado fama y celebridad internacional en 1935 con la publicación de su libro Istmania, en el que defendía a capa y espada la Unión Centroamericana como única y real solución para todos los países del Istmo. Durante la dictadura de Ubico vivió exiliado en la Argentina.

El período presidencial de Arévalo estuvo marcado por una serie de intentos de derrocar por fuerza el orden imperante. Al dejar el gobierno, el 15 de marzo de 1951, en su discurso de despedida, Arévalo hizo notar que durante su mandato había tenido que hacer frente a treinta y dos intentos de golpe de Estado (Galeano, 1967) ${ }^{1}$. De estos conatos, no todos tuvieron su origen por motivos políticos, algunos fueron por rencillas pretorianas entre los diversos componentes del Ejército, y otros motivados por pura y simple defensa de los intereses económicos.

A Arévalo le tocó el mérito y, a la vez, la dificultad de tener que aplicar la nueva Constitución, que fue promulgada solamente cuatro días antes de iniciar su mandato presidencial. Ya anteriormente, la Junta Revolucionaria de Gobierno plasmaba en el Decreto 17 las que debían ser normas programáticas de la nueva Constitución y resumen de los anhelos populares: práctica real de la democracia; no usar la fuerza pública para reprimir el reclamo de un derecho; justicia y bienestar social; probidad en el manejo de la cosa pública...

El Artículo $1^{\circ}$ de la Constitución declara a Guatemala como una República libre, soberana e independiente que se organiza con el fin de asegurar a sus habitantes el goce de la libertad, la cultura, el bienestar económico y la justicia social. Se establecen una serie de garantías, como las limitaciones al poder legislativo; la declaración de que el poder reside en el pueblo, que a su vez la delega en el Congreso (Art. 14). Los diputados no pueden ser reelegidos para un inmediato período legislativo al terminar sus funciones de cuatro años. Los ministros son responsables ante el Congreso, que los puede enjuiciar, y en caso de aprobarse un voto de desconfianza, el ministro ha de dimitir.

Se pone buen cuidado en procurar que un presidente no se pueda perpetuar en el cargo, como venía sucediendo en Guatemala del mismo modo que en otros países de América Latina. El presidente elegi-

1 Marcel Niedergang (1962) solo señala veintiocho. 
do, por sufragio popular, para un mandato de seis años solo puede ser reelegido transcurridos doce años de terminado su ejercicio anterior.

El sufragio es obligatorio y secreto para quienes sepan leer y escribir, y optativo y público para los analfabetos. La Constitución concede a la mujer iguales derechos de ciudadanía que al hombre. Toda mujer guatemalteca que tenga más de dieciocho años y sepa leer y escribir puede ser electora y elegible (Art. 38). El sufragio femenino es secreto y optativo. Diferentemente a otras constituciones latinoamericanas, se reconoce a los analfabetos el derecho a ocupar cargos, aunque restringiéndolo al gobierno municipal.

El Capítulo 11 de este mismo cuerpo legal está dedicado al trabajo y a las garantías sociales. Se reconoce la jornada de ocho horas, el descanso semanal remunerado, vacaciones anuales, igual salario a igual trabajo, protección a la mujer trabajadora y a los menores de edad, indemnización o reinstalación en casos de despido injustificado, derecho a la sindicación y a la huelga, protección a la familia, etcétera.

Otra disposición de gran transcendencia fue la que garantizó la autonomía universitaria y la que declaraba la instrucción primaria obligatoria y que, además, la sostenida por la nación sería laica y gratuita.

Muchos de estos principios eran, y son todavía, inaplicables; la realidad social del país constituye una barrera infranqueable a la aplicación. ¿Cómo se puede llegar a conseguir que la enseñanza primaria fuera obligatoria si no se cuenta con medios económicos y personales suficientes para ello? Y respecto a la obligación del voto, ¿hasta qué punto puede exigir a poblaciones que viven dispersas por montes, selvas y barrancos, y a quienes además su grado de marginación los coloca ante una apatía incurable - por el momento- que tomen posición ante la marcha de la política que ellos juzgan como cosa de ladinos o ricos?

Otras disposiciones evidenciaban el carácter moderado de esta, supuestamente, Revolución, y el marcado acento capitalista de aquello que algunos quisieron ver como síntomas inequívocos del matiz comunista del gobierno. El ser de izquierdas es una cuestión relativa determinada por quien está a la derecha. De modo claro y terminante se garantizó la propiedad privada siempre que cumpliera una función social (Art. 90).

Pero quizás los dos principios de más importancia que incluye esta Constitución son el Título IV sobre régimen hacendario y la reivindicación del territorio de Belice. En el Título IV se encierra el germen a partir del cual iba a prefigurarse la Reforma Agraria que se promulgaría en el período presidencial siguiente de Jacobo Arbenz. El problema de Belice era no solo de transcendencia nacional, sino internacional; el reivindicar este territorio nada menos que a Gran Bretaña, que lo estaba usurpando sin que hubiera habido reclamacio- 
nes de los regímenes políticos anteriores, constituye buena prueba del grado de conciencia nacional del nuevo gobierno. En la Constitución de 1945 se declara inequívocamente que se considera a Belice como parte integrante de la República de Guatemala.

Otras de las adquisiciones legales en el dominio social fue el Código de Trabajo (cuya importancia se hizo sentir entre las masas obreras que emigran desde el Altiplano a las plantaciones de la costa o a los dominios cafetaleros), regulando un sinfín de aspectos que constituían hasta entonces una flagrante violación del derecho a la dignidad humana.

Si en materia social se verificó un sensible progreso, no es menos desdeñable el avance que para el país y su sociedad se realizó en el dominio del desarrollo cultural. Es en este campo donde cabe casi con mayor acierto la frase de Luis Cardoza y Aragón que Guatemala entró en el siglo XX en 1944. El régimen de libertad de la cultura y el pensamiento fue total por primera vez en la Historia de Guatemala. Todas las tendencias doctrinales se dieron cita en esta República de Centroamérica, y quitando los primeros momentos del régimen y ya cuando la intervención extranjera estaba por consumarse, la libertad de prensa fue absoluta. La oposición usó y abusó en todo momento de esta libertad, incluyendo la época de la descarada preparación psicológica de la invasión desde Honduras.

Entre los componentes del nuevo gobierno, así como en el Congreso y en los diversos organismos estatales, se encontraron numerosos intelectuales, con cuyo apoyo se contó para el fomento de la cultura y el desarrollo de las actividades intelectuales. Las principales creaciones en este campo fueron las siguientes: la autonomía de la Universidad de San Carlos; la fundación de la Facultad de Humanidades, el Instituto de Antropología e Historia, el Instituto Indigenista, la Dirección General de Bellas Artes, la Orquesta Sinfónica, el Coro de Guatemala, la Escuela de Teatro y Danza, el Ballet de Guatemala y la Editorial del Ministerio de Educación; la creación del Certamen Permanente de Ciencias, Artes y Letras; asociaciones de artistas y escritores, como el grupo Saker-Ti; la Asociación de Profesores y Estudiantes de Bellas Artes (APEBA); la Casa de la Cultura Guatemalteca; la Sociedad Pro-Arte Musical; la renovación de la Asociación Filarmónica; grupos de teatro y las más diversas agrupaciones artísticas; publicaciones auspiciadas por el Estado, como la Revista de Guatemala, la Revista del Maestro, Revista de la Universidad, Revista Saker-Ti, Revista Infantil Alegría, Viento Nuevo... (Alvarado, 1967).

Entre las múltiples asociaciones culturales las había de signo bien diverso. Por ejemplo, la Sociedad Pro-Arte Musical, cuyo núcleo directivo estaba formado por elementos de la burguesía y de la clase media acomodada, se limitó a las presentaciones musicales. En otra posición 
se encontraba la Casa de la Cultura Guatemalteca, que, fundada por intelectuales democráticos y revolucionarios de distintas orientaciones, tendía a agrupar a los escritores y artistas de diversas tendencias artísticas y políticas, que tuvieran como preocupación central el desarrollo y la difusión del arte y de la literatura guatemaltecas. Más radical fue la posición de la Asociación Guatemalteca de Escritores y Artistas Revolucionarios (AGEAR), fundada por intelectuales que tenían una plena convicción revolucionaria y otros que solo pretendían "vivir la Revolución" (Alvarado, s/f).

Dos fueron los principios informadores de los jóvenes intelectuales guatemaltecos de esa época. El nacionalismo y la conciencia social. Su nacionalismo muchas veces cayó en un romanticismo debido a adoptar una cierta postura indigenista bastante inadecuada, pero que tuvo efectos beneficiosos al mostrar una preocupación por el grupo social más marginado del país. Por otro lado, el nacionalismo hizo tomar conciencia del estado de dependencia respecto de los monopolios extranjeros que imperaban en América Central y de cuáles debían ser las soluciones. La toma de conciencia de los problemas sociales iba íntimamente ligada a las tendencias sociales; eran dos aspectos de un mismo problema. En 1953, en una conclusión de una reunión de escritores y artistas guatemaltecos que decidieron discutir los problemas culturales, se sintetizó al respecto:

La democracia guatemalteca con sus tareas cotidianas y su libertad, con sus defensores y enemigos; el desarrollo de una conciencia antiimperialista y antifeudal, sumados al crecimiento del movimiento obrero, llevaría a nuestra generación por los caminos de la experiencia colectiva e individual, a conclusiones más correctas, que harían cambiar fundamentalmente aquella concepción artística. No fue, desde luego, un cambio rápido. El contacto diario con los obreros, el trato cotidiano con los campesinos, el conocimiento de la gente sencilla, y la cercanía al movimiento obrero fue lo que nos hizo ver el profundo error en que nos hallábamos. Al principio hubo un rechazo, después una posición nihilista de negación al papel del arte y la inteligencia, y, por último, la síntesis que nos permitiría comprender la situación real. ¿Y sobre qué bases se fundamentaba la síntesis? La clase obrera tendría que ser nuestra guía y maestro. Solo en su fuente encontraríamos la brújula que iba a orientarnos hacia la auténtica ruta. Convéngase, pues, en que solo en su dura lucha hemos visto el combate del pueblo y encontrarlo la raíz profunda que anima a Guatemala para conquistar un futuro mejor. Solamente en su definida posición, la única operante, hallamos y palpamos la realidad de nuestra época. (Alvarado, 1967) 
Pero la agrupación que adquirió mayor importancia fue la denominada Saker-Ti, vocablo cakchiquel que significa "amanecer", y que tuvo su origen en un grupo de estudiantes y obreros jóvenes que en el mes de diciembre de 1946 se reunieron con el fin de formar una asociación para responsabilizar a la juventud en los problemas que enfrentaba al hombre de su tiempo con la crisis de la cultura. Consideraban que la crisis de la cultura radicaba a su vez en la crisis de la base económica de la sociedad. Era una crisis general y no parcial, y, por tanto, la solución exigía cambios estructurales ("Notas sobre la evolución ideológica del grupo Saker-Ti", s/f).

El grupo Saker-Ti estuvo ingresado por jóvenes de la izquierda revolucionaria, que en un proceso de evolución ideológica, en su mayoría habían empezado a llegar a las riberas del marxismo (Alvarado, 1967). Aunque hace falta hacer constar que si bien los integrantes de este grupo en su mayoría tenían tendencias revolucionarias, la gama ideológica era bastante imprecisa y amplia, y, prácticamente, solo concretaba la aspiración revolucionaria en el deseo de la construcción de una sociedad mejor y más justa.

La línea ideológica del grupo Saker-Ti se concretaba en una especie de normas programáticas recogidas en las famosas Siete Afirmaciones, que tocaban los siguientes aspectos:

1. Esperanza en la superación del hombre.

2. Desigualdad económica de los hombres y deseo de lograr su liberación.

3. En un ambiente de libertad puede lograrse la realización del hombre.

4. El arte no puede someterse a ninguna sujeción.

5. Confianza en el surgimiento de una nueva educación que forje personalidades humanas.

6. Realización de un programa político-democrático.

7. Realidad germinal de la cultura americana y esperanza en la posición directriz del indoamericano.

Esta misma Asociación, en 1953, en su Primera Asamblea Nacional, publicó un informe titulado "Por un arte nacional, democrático y realista". En este informe se recoge la quintaesencia que el grupo SakerTi creía que debe ser integrante del arte. Definiendo así:

Un arte democrático que vaya dirigido a las grandes mayorías del país, a las que ayude en su lucha contra la opresión y la miseria y en su liberación. Entendiendo por pueblo guatemalteco a los trabajadores ma- 
nuales e intelectuales de la ciudad y del campo. Es decir, los obreros, los campesinos y diversos sectores de la clase media. Un arte realista, porque es producto del reflejo y representación de la vida del pueblo en la mente de los escritores y artistas revolucionarios. El arte es reflejo y representación creadora de la realidad y de la vida del pueblo en forma verídica, concreta y crítica. (Niedergang, 1962)

Durante el período que abarca la década que va de 1944 a 1954 Guatemala se convirtió en un foco de irradiación cultural. Muchos intelectuales centroamericanos formaron parte de las organizaciones culturales guatemaltecas y en esta República editaron sus libros. Varios exiliados españoles que desde 1939 residían en países de América Latina, principalmente en México, se trasladaron a Guatemala, donde muchos de ellos, prestigiosos especialistas y científicos, ejercieron eficientemente su actividad.

El 15 de marzo de 1951 Juan José Arévalo concluyó su mandato presidencial, y de acuerdo con lo estipulado en la Constitución cedió el puesto a su sucesor. Situación esta típica, no solo para Guatemala, sino para muchos países de América Latina, en la que los estadistas tienden a la perpetuación como inquilinos del Palacio Presidencial. Arévalo se limitó a dar un discurso de despedida haciendo un balance de su período presidencial con la consiguiente mención de las dificultades con que había contado, puestas de relieve por esos treinta y dos complots con que tuvo que hacer frente en seis años.

El sucesor de Arévalo para el período que abarcaba de 1951 a 1957 fue Jacobo Arbenz Guzmán, el cual había sido elegido por más de la mitad de los sufragios. Arbenz había tenido una lúcida actuación en su época de capitán del Ejército durante las gloriosas, y sangrientas jornadas de junio y octubre de 1944, a través de las cuales se había conseguido erradicar la dictadura ubiquista. El 20 de octubre de 1944 formó parte de la Junta Revolucionaria de Gobierno que habría de celebrar elecciones y gobernar al país hasta que se hiciera cargo el presidente electo.

En 1951 Arbenz no tenía más que treinta y siete años, con lo que se convertía en el Jefe de Estado más joven de todo el continente americano. Estaba casado con María Cristina Villanova, salvadoreña de gran belleza y estilo cosmopolita, y perteneciente a una de las catorce familias a las que, en la práctica, pertenece la República de El Salvador, frente a los dos millones y medio de salvadoreños que se encuentran totalmente desposeídos de lo más necesario. El padre de la primera dama guatemalteca había sido uno de los consejeros del presidente Martínez, que en 1931 había ejecutado una de las represiones más sangrientas conocidas en América desde la Conquista, al 
someter el motín comunistoide de los indios y mestizos (Cardoza y Aragón, 1955). Los miles de ejecutados crearon un trauma sicológico en María Cristina, que reaccionó compensatoriamente dejándose influir por doctrinas más o menos revolucionarias que, según algunos, se reflejaron, por su mediación, en su esposo.

Las directrices marcadas por la actuación de Jacobo Arbenz son las mismas, pero más elaboradas, que se gestaron el mismo 20 de octubre de 1944, y que recibieron sus primeros toques en los seis años en que el profesor Arévalo ocupó el Palacio Presidencial. Todavía no se podía haber dicho que se hubiera realizado ninguna reforma que fuera más allá de alguna declaración escrita. Los defectos estructurales que poseía Guatemala el 19 de octubre de 1944 se encontraban intactos; y la dependencia de la economía en la norteamericana tenía el mismo valor de los mejores años de la égida ubiquista. La renta per capita en el año 1952, que se consideró un año excelente, fue de 181 dólares. La exportación total ese mismo año se elevó a 87.462.600 dólares, absorbiendo los Estados Unidos el 83,2 por 100. Con respecto al café, el principal producto de exportación, el porcentaje adquirido por Norteamérica es todavía más alto, el 85,2 por 100 (Marcha, s/f).

Jacobo Arbenz personificaba el nacionalismo y el agrarismo. Pero durante su mandato adquirió extraordinario auge el comunismo, sobre todo viéndolo a través del prisma latinoamericano. Además, los comunistas aportaron su efectiva colaboración en las medidas reformistas que se estaban llevando a cabo. Sin embargo, los comunistas no fueron más que un puñado cuantitativamente insignificante. Tuvieron importancia numérica dentro de algunas instituciones culturales, y sobre todo en los sindicatos.

La actividad de los líderes comunistas destacó sobre la tradicional tónica de eficiencia moderada que ha caracterizado a los pobladores de América Latina. Esta actividad fue exagerada por la prensa extranjera en función de sus intereses en los momentos en que se quería creer a los países occidentales que lo que sucedía allí era otra cosa.

La colaboración comunista no solo catalizó la enemistad de los países extranjeros, principalmente de las naciones centroamericanas y de los Estados Unidos sino que también creó una serie de suspicacias entre muchos sectores de las clases medias que hicieron causa común la alta burguesía, que no estaba dispuesta a perder un ápice del poder económico y social que desde la Conquista viene detentando sin interferencia alguna. Para la oligarquía, la presencia activa de los comunistas era algo accesorio; lo que les predisponía contra el régimen revolucionario era el que estuviera dispuesto a llevar a efecto ciertas reformas. Por el contrario, esta última circunstancia fue ajena 
a muchos indios que, aconsejados por sus líderes religiosos, negaron toda colaboración al gobierno por considerarlo comunista.

El gobierno de Arbenz pasó rápidamente a la acción de acometer las obras necesarias para dotar al país de un mayor grado de independencia y para construir una sociedad más igualitaria entre todos los guatemaltecos. La Reforma Agraria fue la medida más importante; pretendía crear una "clase de pequeños propietarios rurales". La carretera al Atlántico para poner en comunicación esa parte de la República con el resto del país sin tener que someterse al monopolio de la United Fruit Company, fue encomendada a una empresa norteamericana. También fue notable la construcción del puerto de Matías Gálvez, en la costa atlántica, dado que allí solo existía uno perteneciente también a la compañía frutera. Otra de las medidas tomadas durante este período fue la de comenzar una débil campaña de alfabetización entre los indios, pero a base de usar las propias lenguas indígenas en vez del castellano. De máxima importancia para las necesidades de este país fue la creación de un régimen de seguridad social, aunque este solo cubría apenas los accidentes de trabajo y la maternidad. Por supuesto que todas estas medidas fueron calificadas por aquellos interesados de que no se llevaran a la práctica como signos clarividentes de la presencia comunista.

Los partidos políticos con los que el régimen contaba con mayor colaboración fueron el PAR (Partido de Acción Revolucionaria) y el PRG (Partido Revolucionario Guatemalteco), partidos ambos de composición pequeñoburguesa y con una fuerte dosis de intelectuales y técnicos, y carentes de la menor carga ideológica de tipo marxista.

Según las realizaciones iban tomando cuerpo, los temores de la alta burguesía y de los monopolios norteamericanos se iban convirtiendo en inquietudes que comenzaban a gestar las primeras etapas del complot que concluiría con el régimen revolucionario. La prensa nacional, dominada por los grupos económicos, y respaldándose en una auténtica libertad de prensa, desencadenó una feroz campaña contra el gobierno. Buena prueba de la realidad de las libertades informativas es el hecho de que en tanto la prensa gubernamental no alcanzaba una tirada de diez mil ejemplares, los periódicos antigubernamentales pasaban de los cincuenta mil.

La presión norteamericana también se fue acentuando merced a las gestiones del embajador de los Estados Unidos en Guatemala, míster John E. Peurifoy, que ocupó el cargo en esta Cancillería a finales de 1952. La incomprensión, o mejor dicho, los intereses de Wall Street y el Pentágono, hicieron que el régimen guatemalteco se deslizara paulatinamente hacia la izquierda. Existe una íntima correlación entre las presiones yanquis y de la oligarquía por un lado, con las posiciones 
ventajosas que los comunistas guatemaltecos fueron adquiriendo en la Administración Arbenz. Era desde todo punto de vista coherente que ante el abandono y enemistad de poderosísimas fuerzas, tanto internas como externas, el presidente buscara refugio entre aquellos que estaban dispuestos a dárselo y a arrostrar los riesgos que pudieran presentarse.

El complot necesitó de una cuidadosa preparación, que corrió a cargo de los Estados Unidos. Las fases iniciales tuvieron un encuadre internacional, en una doble perspectiva: la centroamericana y la de escala continental. Guatemala, que había sido uno de los paladines de todo tipo de unión entre los países del Istmo, se vio obligada a retirarse el 11 de abril de 1953 de la ODECA (Organización de Estados Centroamericanos) a causa de que varios países miembros de esta Organización trataban de minar la seguridad interna de Guatemala bajo el pretexto de combatir al comunismo.

La operación política a nivel continental contó con un artífice del maquiavelismo político: el propio Secretario de Estado, John Foster Dulles. La OEA se reunión en Caracas para condenar al régimen de Arbenz. Los representantes de las dictaduras más sangrientas que ha conocido la agitada historia de Latinoamérica se dieron cita en la capital venezolana para solicitar vivas garantías de la estabilidad latinoamericana. Odría, Pérez Jiménez, Rojas Pinilla, Somoza, Batista, Trujillo, fueron los indignados demócratas que, en defensa de la libertad continental, dieron su reprobación al régimen político de un pequeño Estado que intentaba modificar la situación de su hambrienta población. "Tanta corrupción sumada rompería cualquier computadora que se propusiera medirla", comenta al respecto de la Conferencia de Caracas Eduardo Galeano.

Los comunistas que colaboraban con el gobierno decidieron dar marcha atrás para no seguir comprometiendo a Arbenz y de este modo poder salvar las mejoras sociales que hasta el momento se habían logrado. Los más destacados dimitieron de sus puestos oficiales. La consigna del PGT (Partido Guatemalteco del Trabajo, nombre del Partido Comunista) fue la de no perturbar más al gobierno "nacionalburgués" del coronel Jacobo Arbenz. Sin embargo, el plan ya estaba en marcha y el comunismo, o los comunistas, no eran más que el pretexto.

Un complot internacional contando con la colaboración de los grupos económicos más fuertes de la nación es cosa difícil de ocultar. El gobierno de Arbenz se percató perfectamente de la tragedia que se avecinaba y trató por todos los medios de prepararse para el inminente temporal. Las gestiones diplomáticas fueron ineficaces y solo sirvieron para que los cancilleres guatemaltecos se llevaran los grandes bochornos al enfrentarse con la enemistad acordada por sus colegas latinoamericanos. 
Era evidente que el "tejemaneje" diplomático no era más que el telón de fondo que serviría para la puesta en marcha de un plan más vasto que por supuesto incluiría la intervención armada. Y para hacer frente al ataque se hacía necesaria la obtención de armamento suficiente. La compra de pertrechos militares fue sumamente difícil, dado que el oponente era Estados Unidos. Solo se consiguió comprar armas en los países socialistas; lo que sirvió a su vez, para argumentar con más fuerza que Guatemala estaba cayendo en "las garras del comunismo". La llegada del transporte Alfhem con material bélico para Guatemala fue uno de los motivos aparentes para comenzar la "liberación" por los exiliados y los mercenarios de la CIA comandados por Castillo Armas. En este buque se encontraban dos "Mig" rusos que no se pudieron usar, no solo por falta de pilotos que conocieran su manejo, sino también por el hecho de que se desconocía hasta el mero montaje de los aparatos. Una vez concluida la intervención, los norteamericanos pasearon los dos aviones para mostrarlos a la opinión pública de América Latina y así demostrar la veracidad de sus aseveraciones cuando afirmaban la intervención rusa en el Caribe. Quizá esto último sea un recurso de lógica utilización en la guerra psicológica y arma publicitaria a favor de una determinada política; pero lo que es difícil justificar es que los Estados Unidos se apropiaron los dos aviones en vez de habérselos entregado a las fuerzas áreas guatemaltecas.

La tensión nerviosa también se manifestó en una campaña de represión que desencadenó la propia Policía Nacional de Guatemala entre los elementos de la oposición y los componentes o cómplices de los planes conspirativos. Durante la represión se ejecutaron algunos actos cuya justificación es imposible, ni tan siquiera a costa de argumentar de que una vez los conspiradores en el poder su actividad represiva fue mayor tanto cuantitativa como cualitativamente. Es innegable que se atentó contra la vida y dignidad de las personas. Estas noticias fueron difundidas por los medios publicitarios dirigidos por la CIA con la correspondiente enorme dosis de exageración, lo que contribuyó efectivamente a la preparación del desenlace.

Estados Unidos, que mantenía los hilos de la conspiración - y era el principal ofendido-, sostuvo durante todo el tiempo a su embajador, que iba a jugar un papel primordial en las últimas jornadas del régimen revolucionario. Sin embargo, Honduras y Nicaragua retiraron su representante diplomático de Guatemala, lo que marcó el primer paso en la fase activa. Acto seguido, la CIA pertrechó de armamento a estos países y se instalaron unas bases de entrenamiento, también, en ambas naciones. Después los agentes norteamericanos procedieron a la formación de una tropa de invasión a base de agrupar a los no pocos guatemaltecos que vivían en el exilio y del alistamiento de mer- 
cenarios de varias nacionalidades, pero entre los que predominaban los hondureños, nicaragüenses y dominicanos. El armamento que se había entregado a Honduras y Nicaragua pasó a poder de esta fuerza.

Faltaba todavía encontrar al jefe que habría de ponerse al frente de este "movimiento de liberación". La CIA encontró al hombre oportuno encarnado en la figura del coronel Castillo Armas, militar graduado en Fort Leanvenworth, que vivía exiliado en México. Castillo Armas se había distinguido como miembro de la oposición y había sufrido prisión por ello. Un buen día consiguió evadirse de la Penitenciaría Central, situada en pleno corazón de la capital a pocos metros del edificio de la Municipalidad y del Banco de Guatemala, y bordeada por las calles más frecuentadas de la ciudad. La evasión pudo consumarse por el poco original método de abrir un agujero que diera a la calle en los gruesos muros que rodean al establecimiento penitenciario. Hay quien comenta en la actualidad que la fuga no hubiera podido llevarse a cabo si no se hubiera contado con la colaboración de las propias autoridades, llegando a señalar al propio Arbenz, del que se dice le unía amistad con Castillo Armas.

Se instaló un cuartel general en la propia Tegucigalpa, capital de la República de Honduras, país desde el que se iniciaron las operaciones el jueves 17 de junio de 1954. Los invasores ejecutaron acciones por tierra, mar y aire. A la par que se invadía el Departamento de Chiquimula, unas viejas lanchas rápidas provistas por Norteamérica intentaron adueñarse de Puerto Barrios, lo que no consiguieron, teniendo que infiltrarse por los ríos y lagunas que surcan las selvas vírgenes y las plantaciones de la costa atlántica.

El arma más eficaz con que contó Castillo Armas fue con la aviación, que al precio de un dólar aparato le fueron vendidos por los Estados Unidos; unos cuantos "DC-3" y "Thunderbolt" que despegaban de los aeropuertos nicaragüense y hondureños. En el precio de venta debió incluirse el piloto que en su mayoría eran norteamericanos. Con estos aparatos, que desde el primer momento se adueñaron del espacio aéreo guatemalteco - la aviación gubernamental no pudo actuar, ya que se encontraba carente, entre otras muchas cosas, de carburante-, se atemorizó a la población con algunos bombardeos de castigo, aparte de que jugaron un relevante papel en las operaciones militares, como en el bombardeo estratégico de la base de Zacapa y la voladura de un convoy militar cerca del Progreso. Marcel Niedergang dice que estos aviones causaron el mismo efecto sobre los atemorizados indios guatemaltecos que los caballos sobre los que vinieron montados Alvarado y demás conquistadores del siglo XVI.

La tropa de Castillo de Armas rebasaba escasamente el millar de hombres, pero procedió a una leva forzosa con los atemorizados 
campesinos de los territorios invadidos, con lo que fue progresando su ejército paulatinamente. Si se hubiera opuesto, una resistencia efectiva y técnicamente dirigida, este improvisado ejército se hubiera venido abajo produciéndose una gran desbandada. Pero las fuerzas armadas guatemaltecas dieron muestra de su incapacidad. La única acción auténticamente militar que tuvo que ejecutar Castillo Armas fue la toma de Chiquimula. Cuando comenzaba el asedio de Zacapa ya se había consumado la desintegración del gobierno guatemalteco.

En la capital, los estudiantes, junto a los intelectuales y a los trabajadores, formaron unidades paramilitares dispuestas a pasar a la ofensiva, pero el Ejército se negó a darles armas y los entretuvo hasta que la traición se consumó. En una ocasión, a una de estas unidades se le hizo ir a ejecutar movimientos de orden cerrado sin armas en un lugar descampado donde fue atacada por la aviación enemiga. También se esperó que se repartieran armas entre los campesinos y el pueblo, que en el peor de los casos hubieran podido llevar a cabo en unas condiciones muy favorables una eficaz guerra de guerrillas. Pero ello era pedir demasiado, para esto se hubiera necesitado la existencia de un auténtico régimen revolucionario, y ni Arbenz ni la mayoría de sus colaboradores lo eran. Arbenz prefirió, cuando el enemigo estaba a varios cientos de kilómetros de la capital, y solamente en su poder una cabecera departamental de tercer orden, radiodifundir un discurso y marcharse al exilio.

Una Junta presidida por el ministro del Ejército se hizo cargo del poder con la intención de llegar a un acuerdo con Castillo Armas que pudiera salvar "el honor" de las fuerzas armadas. La intervención de varios diplomáticos, entre los que se incluía el embajador estadounidense, fueron capaces de solventar la situación, y Castillo Armas hizo su entrada triunfal en Guatemala Ciudad, acompañado de la imagen del Santo Señor de Esquipulas. Aún días después hubo un pequeño enfrentamiento en los alrededores del Hospital Roosevelt entre las fuerzas del Ejército de Liberación y el Ejército Regular, principalmente con los cadetes, incidente que fue solventado, desfavorablemente al segundo grupo, gracias a la intervención del arzobispo de Guatemala.

\section{BIBLIOGRAFÍA}

Alvarado, Huberto s/f La Literatura y el Arte y la Revolución de Octubre (s/d).

Alvarado, Huberto 1967 Preocupaciones: Ensayos (Guatemala: Ediciones Vanguardia).

Cardoza y Aragón, Luis 1955 La Revolución Guatemalteca (México:

Cuadernos Americanos). 
Galeano, Eduardo 1967 Guatemala: país ocupado (México: Editorial Nuestro Tiempo).

Marcha s/f (Montevideo).

Niedergang, Marcel 1962 Les vingt Amériques latines (París: Pion).

"Notas sobre la evolución ideológica del grupo Saker-Ti” s/f (s/d). 

José Luis Rubio

\section{LA DESTRUCCIÓN DE LAS CAUSAS ÚLTIMAS: LA SOCIEDAD AUTOGESTIONADA*}

DESDE SU COMIENZO, la revolución peruana ha sido una concesión del poder, una revolución "otorgada" al pueblo por un grupo disciplinado que ha ocupado el gobierno. Desde el comienzo, el sector más audaz de este grupo ha proclamado la voluntad de que el proceso desemboque en una sociedad socialista no estatista, sino autogestionaria.

Esta es la gran contradicción del proceso peruano, puesto en marcha en un pueblo que inicialmente desconfiaba del Ejército, un pueblo que tiene inmensos sectores sumidos en un grado de pobreza e incultura que no permite la movilización política, un pueblo en que los sectores medios reformistas los controla aún en gran medida el "aprismo" y en el que la izquierda radical penetra escasísimamente fuera de los sectores universitarios.

Sin duda, una gran parte del grupo dirigente en el poder no tiene voluntad de ir más adelante, parece conformarse con una transformación agraria y con una agilización industrial por la vía capitalista aunque con algún control por parte del Estado. Pero esa autolimitación en las ambiciones revolucionarias concluiría necesariamente en

* Rubio, José Luis 1974 "La destrucción de las causas últimas: la sociedad autogestionada” en Aproximación a la revolución peruana (Barcelona: Acervo) Capítulo V, pp. 81-93. 
la vía del "desarrollo dependiente": es decir, en la colocación de nuevo en la periferia de un gran poder económico mundial. Esto, por mucha voluntad nacionalista que se muestre en el comienzo del proceso. El ejemplo de México, tras una revolución agraria y tras un nacionalismo lindante con la xenofobia, es bien evidente. Porque allí a pesar de ser el pueblo el primer agente de la revolución, fue después marginado, controlado por el aparato oficial del PRI, y hoy una nueva oligarquía burguesa industrial y financiera decide y manda sin ningún control desde la base nacional. Y esa oligarquía, desconectada del pueblo, acaba conectando a los grandes intereses económicos exteriores. El "capitalismo nacional", o hace pronto su propio Imperio, o es colonizado, es sometido a un Imperio ajeno. Así sucede con el "capitalismo nacional" mexicano, a pesar de todas las invocaciones nacionalistas de la "familia revolucionaria".

Este es el peligro de "mexicanización" que podía aparecer en el proceso peruano. Por eso, el sector más lúcido quiere invertir la experiencia de la revolución mexicana: es decir, quiere llegar a la movilización popular desde el control minoritario inicial. Comprende que solo la toma en sus manos por el pueblo puede convertir el proceso en algo realmente liberador, que solo el nacionalismo de todo el pueblo, ejercido por todo el pueblo, asegura la independencia nacional.

Sobre esta comprensión se montó por el régimen militar peruano el Sistema Nacional de Apoyo a la Movilización Social. En el mismo nombre se trató de precisar que no se trataba de movilizar al pueblo, sino de apoyar su automovilización. El SINAMOS es hoy una entidad combatida y polémica, que suscita incomprensiones en sectores gobernantes y un apasionado odio en la oposición. Para aquellos, es una experiencia que puede resultar peligrosa y conducir más allá de los límites que la revolución debe tener: un peligroso germen socialista. Para esta es un intento de partido oficial, que tratará de controlar a las masas desde arriba, para perpetuarse en el poder en un futuro seudodemocrático: un PRI como el de México.

Obstinadamente, los hombres del SINAMOS, desde el general Leónidas Rodríguez hasta el gran teórico de la revolución Carlos Delgado, desde el exguerrillero Héctor Béjar hasta el joven escritor progresista Hugo Neira, insistieron en lo contrario ante nosotros: se trataba de ayudar a que el pueblo se movilice, tome sus propias decisiones, se ponga en pie, se haga cargo del proceso. En cada pueblo, en cada barrio, en cada comunidad, en cada fábrica. Y, finalmente, en la comunidad nacional entera.

Con Hugo Neira, intelectual y periodista brillante que ha escrito libros muy reveladores sobre la realidad de su país —especialmente la relativa a las zonas campesinas y sus conflictos-, por la amistad que 
desde hace tiempo nos unía, tuvimos — un compañero de viaje y yoocasión de polemizar a fondo. A Hugo Neira le había exhortado en algunas ocasiones, cuando se movía entre los diversos centros intelectuales de Europa, a abandonar este camino teorizante para reintegrarse a las tareas de su pueblo. Incluso le acusé de estar convirtiéndose en un "peruanólogo" en vez de ser enteramente un "peruano". Ahora estaba integrado plenamente en la acción de su país y podíamos hablar de esta acción y de este país a fondo.

Extremamos al máximo la posición crítica hacia el proceso peruano, haciendo de "abogados del diablo", para provocar las respuestas más de fondo. Queríamos llegar al terreno de las disyuntivas extremas: revolución verdadera, independencia verdadera, patriotismo verdadero, o reforma social - positiva desde luego- como camino hacia una nueva servidumbre internacional. Por otra parte: estímulo a la automovilización del pueblo, o creación de un aparato de control de las masas.

Con ánimo de herir - cordialmente, pero herir - llevamos la conversación. Neira concedió algunas cosas sobre las debilidades iniciales del proceso, habló incluso del precio que tenía que pagar la revolución para mantener la unidad militar de un Ejército que no era en su totalidad revolucionario, que era incluso socialmente privilegiado, en torno a un equipo del mismo sinceramente revolucionario y con un espíritu enorme de sacrificio.

Neira insistía en que no había otra alternativa: o se ayudaba a profundizar la revolución colaborando con ese equipo decidido a transformar el Perú de arriba abajo, o se hacía, en la práctica, contrarrevolución. La oposición de izquierda era infecunda. Por eso la tarea a cumplir era no estar con esta oposición de ultra-izquierda sino con el pueblo, dándole instrumentos para que aprendiera a manifestarse, a organizarse y a actuar por sí solo. Era esa la razón del aparato montado con el "Sistema". No había detrás un intento de control a la mexicana, de creación de un gran tinglado para sujetar al pueblo y conducirlo como un rebaño.

Con precisión esta postura está recogida en la literatura difundida por SINAMOS. Esta literatura dista mucho de ser la retórica imprecisa y aparentemente rotunda de los populismos de años anteriores. Se adivina en su elaboración una mente ordenada que se siente ansiosa de exponer contenido más que palabras. Independientemente del curso de concreción u olvido que este contenido pudiera posteriormente tener. No está de más recoger aquí la parte teórica de una de estas expresiones definidoras del "Sistema":

La Revolución Peruana, con su vocación humanista y libertaria, se enrumba hacia la construcción de una "democracia social de participación 
plena" en la cual todos los sectores tradicionalmente marginados tengan acceso efectivo al ejercicio del poder y la toma de decisiones, frente a problemas de carácter estrictamente vecinal o frente a las más importantes y complejas cuestiones que envuelven el interés general del país. La transferencia de poder al pueblo se producirá en forma creciente, progresiva, como en una "escalada". El proceso en virtud del cual se transforma la estructura tradicional de poder y se abre ancho cauce a la participación real, efectiva y permanente de toda la población, tiene un nombre preciso: Movilización Social.

La Revolución Peruana aspira a que los ciudadanos (hombres y mujeres) intervengan en el planteamiento y solución de los problemas que surgen con relación a los múltiples servicios y necesidades del barrio donde viven, de las cuestiones que afectan la marcha de su centro de trabajo y de los establecimientos educacionales donde estudian sus hijos, etc. Y, a partir de allí, en forma ascendente, en los problemas relacionados con el manejo de los asuntos públicos de su pueblo, de su ciudad, de su región, de su país.

En el caso concreto del Perú, la movilización social implica que los grupos mayoritarios de nuestra social alteran irreversiblemente su ubicación en la estructura de poder, para pasar a ser, en esencia, una mayoría autogobernante. Nuestro pueblo tendrá que crear sus propias organizaciones autónomas, para expresar a través de ellas sus intereses y necesidades más sentidas. No hay movilización posible sin organización. La transferencia del poder de decisión a las organizaciones autónomas, sentarás las bases de un nuevo sistema de poder popular en el Perú. Cuando este se consolide, habrá de constituir la expresión política abierta y creadora del proceso revolucionario que hoy se está desarrollando en nuestro país.

La democracia social de participación plena que la Revolución se ha propuesto edificar en el país, ha de ser un sistema basado en un orden moral de solidaridad, no de individualismo; en una economía fundamentalmente autogestora, en la cual los medios de producción sean predominantemente de propiedad social; y en un ordenamiento político donde el poder de decisión, lejos de ser monopolio de oligarquías políticas o económicas, se difunda y radique esencialmente en instituciones sociales y políticas conducidas, sin intermediación o con el mínimo de ella, por los hombres y mujeres que las formen.

Los hombres y mujeres del Perú revolucionario deben abandonar para siempre la pasividad y el conformismo, para participar resueltamente en el desarrollo de la Revolución. (SINAMOS, 1972: 1-4)

Desde hace largo tiempo, numerosas corrientes ideológicas, múltiples movimientos sociales y bastantes experiencias políticas han proclamado su voluntad de llegar a una "tercera vía", a una "tercera solución" entre capitalismo y socialismo. Con frecuencia, esta tendencia varia del "tercerismo" se ha adjetivado en alguno de sus términos: se ha añadido "liberal" a capitalismo, o se ha añadido "comunista" 
a socialismo. En la práctica, estas experiencias no han sido verdaderamente terceristas: no han pasado de ser nuevas modalidades del sistema capitalista, abandonando su extremosidad liberal primitiva para introducir un intervencionismo del Estado que le obliga a "humanizarse". (Es algo universal en el mundo capitalista, en donde ya el esquema liberal puro no existe en ninguna parte).

La práctica solo muestra dos posiciones de hecho ante la propiedad de los medios de producción: la capitalista —el Capital es su titular- y la socialista — su titular es el Trabajo-. Lo que sucede es que, de la misma forma que la sustancia común nutre al capitalismo se manifiesta en múltiples variedades, también la sustancia común que nutre al socialismo se realiza en muy distintos sistemas. La gama es amplia y abierta a la imaginación humana: desde una concepción puramente estatista coercitiva — del marxismo en su versión más dogmática e inquisitorial-, hasta una concepción anarquista o libertaria — del baukinismo más ácrata-, pasando por modelos de un marxismo abierto, desdogmatizado, "con rostro humano" — como el intento checo-, de una autogestión económica sometida a un totalitarismo político — como el modelo yugoslavo-, de un antiburocratismo de constante control obrero - como el teórico modelo trotskista-, de una plasmación del Reino de Dios en la tierra — como las "reducciones jesuísticas" del Paraguay-, de una colectivización obrera y campesina - como la de las experiencias cenetistas de la guerra española-, de una fórmula comunitarista cristiana — como la de amplios sectores sindicales católicos de Iberoamérica...-.

Teóricamente, el proceso peruano se ha negado a adoptar el embanderamiento "tercerista". Se ha proclamado "libertario, socialista y humanista". Si ha rechazado al capitalismo en pleno, no ha rechazo al socialismo más que en su versión comunista. "Ni capitalismo, ni socialismo coercitivo", se dice. La palabra autorizada del máximo dirigente, del presidente Velasco Alvarado, que representa indudablemente el ala más avanzada del régimen, ha insistido en una fórmula propia para la revolución peruana: la empresa social de tipo autogestionario. Sin que la propiedad social signifique la anulación por entero de la privada, ni menos de la estatal, se anuncia que la fórmula más alentada, la que tendrá preponderancia, será la de tipo autogestionario.

Merece la pena detenerse en las palabras de Velasco Alvarado en este sentido, porque no se formularon el primer día de la acción militar, en el día de las promesas, sino que se han ido diciendo progresivamente, a medida que la revolución ha ido avanzando en su marcha, generando sus propias concepciones. Decía Velasco Alvarado el 28 de julio de 1970, en la conmemoración anual de la "Independencia": 
...ni el punto de partida conceptual, no el proceso de nuestro desarrollo revolucionario, ni el objetivo de la revolución obedecen a los moldes tradicionales de los sistemas capitalistas o comunistas. El comunismo y el capitalismo no son los "modelos" de nuestra revolución nacionalista. El ordenamiento tradicional contra el cual insurgió nuestra revolución fue un ordenamiento capitalista y conocemos muy bien la profunda raíz de injusticia que él encierra porque ese fue, precisamente, el sistema bajo cuya égida llegamos a ser una nación dependiente y subdesarrollada.

Pero si bien es cierto que el sistema capitalista, hoy duramente criticado también por la Iglesia católica, se abre a objeciones insalvables de carácter económico, ético y social, también desde nuestro punto de vista el comunismo resulta inválido para la realidad del Perú e inaceptable para los fines humanistas de nuestra revolución.

No es pues nuestro ideal ni un sistema que aliena al hombre, aherroja su libertad y le impide ser el verdadero constructor de su destino, ni tampoco un Estado todopoderoso, burocratizado y dogmático que absolutamente rige la vida de un sistema social también deshumanizado y alienante.

Lejos de utopías, esta revolución tiene conciencia certera de su rumbo. No va hacia una modernizada sociedad capitalista no hacia una sociedad comunista de importación, porque estamos seguros de que los problemas fundamentales que nos hemos propuesto resolver subsistirían en una forma u otra bajo cualquiera de esos dos sistemas. (Velasco Alvarado, 1970)

Tres años más tarde, al conmemorarse el quinto aniversario de la Revolución, Velasco Alvarado se refiere al "anteproyecto de ley del Sector de la Propiedad Social", y dice:

Sobre este asunto hemos hablado desde hace mucho tiempo. Porque en la base misma del planteamiento revolucionario está la noción fundamental de que una posición no capitalista y no comunista debe concretarse en empresas económicas basadas en la propiedad directa de los trabajadores y no en la propiedad privada, propia del capitalismo, ni en la propiedad estatal, propia de los regímenes comunistas.

Nunca hemos ocultado este propósito. Y es verdad que el proyecto de Propiedad Social resulta ser críticamente importante para nuestra Revolución. Rechazarlo, por lo tanto, implica necesariamente rechazar la esencia misma del proceso. Porque la médula de un planteamiento participatorio, vale decir, verdaderamente democrático, como el nuestro, hace indispensable la creación de formas económicas que sean también democráticas y participatorias. Y esas formas no pueden ser otras que aquellas en las que se consagra la propiedad de las empresas por parte de sus propios trabajadores. (Velasco Alvarado, 1973) 
Ahí la revolución peruana llega al fondo, a los niveles más hondos, a las últimas causas. De la construcción real, en la práctica, de este tipo de sociedad en cuya economía tenga carácter predominante la propiedad social, se reserve el Estado la de los factores de máxima importancia estratégica, y la privada solo afecte a sectores no decisivos, dependerá la realización plena de la revolución que el Ejército peruano se ha propuesto.

\section{BIBLIOGRAFÍA}

SINAMOS 1972 SINAMOS, ¿de quién y para qué? (Lima: SINAMOS). Velasco Alvarado, Juan 1970 "Mensaje a la Nación con motivo del 149 Aniversario de la Independencia" (Lima) 28 de julio.

Velasco Alvarado, Juan 1973 "Quinto Aniversario de la Revolución Nacional Peruana: Mensaje a la Nación” (Lima) 3 de octubre. 



\section{Saber y política en los laboratorios sociales latinoamericanos}





\section{Joan Garcés}

\section{ESTADO BURGUÉS Y GOBIERNO POPULAR*}

\section{DOS DISYUNTIVAS: SOCIALISMO-CAPITALISMO Y LIBERTAD-DICTADURA}

Libertad es un concepto positivo. Dictadura lo es negativo. En favor de la primera puede generarse cualquier clase de entusiasmo, provocarse acciones colectivas e individuales abnegadas e incluso heroicas. La "lucha por la libertad" ha legitimado —o idealizado- esfuerzos, sacrificios, generosidad y también errores. Por el contrario, la dictadura siempre ha necesitado de explicaciones y razones. Nadie ha intentado justificarla en sí misma y para sí misma, sino en función de algo estimado superior y más válido, cuya consecución impondría limitar o negar temporalmente lo que nuestra civilización entiende que es una de las más esenciales conquistas de la humanidad.

Todo el potencial propagandístico al servicio del poder burgués ha buscado vincular la suerte de la libertad al sistema social y político en que la clase dueña del capital domina los resortes fundamentales de la trama social. Y ello ha acaecido tanto en los regímenes de democracia liberal como en los de características fascistas. En nombre de la preservación de la libertad, por ejemplo, el Congreso chileno de-

* Garcés, Joan 1972 “Estado burgués y gobierno popular" en Chile: el camino político hacia el socialismo (Barcelona: Ariel) Capítulo V, pp. 171-210. 
cidió en 1938 declarar ilegal al Partido Comunista. Naturalmente, sin hacer extensiva la prohibición al movimiento nazi dirigido por Von Mareés. La campaña presidencial de Pedro Aguirre Cerda, como las sucesivas de Salvador Allende, han sido ocasión para que los defensores del sistema capitalista se autoproclamen garantes de la "libertad" contra la "dictadura".

El Gobierno de la Unidad Popular se ha propuesto transformar la estructura socio-económica de Chile para hacer posible la superación del sistema capitalista y el comienzo de la edificación del socialismo. Para el gobierno y los partidos políticos que lo integran la disyuntiva está entre socialismo y capitalismo. Socialismo entendido desde el punto definitorio esencial de la propiedad colectiva de los medios de producción. Meta final que, en el actual estadio de desarrollo del país, exige y permite socializar solo los medios fundamentales de producción, aquellos sobre os que reposa el poder económico del "gran capital" nacional o extranjero, y que tienen importancia estratégica para mejorar la satisfacción de las necesidades del pueblo chileno y desarrollar la economía nacional. Los límites del sector social han sido establecidos por el Programa Básico de Gobierno, reiterados día tras día por las Autoridades y respetadas por la Administración Pública.

Como en tantas circunstancias históricas, también ahora en Chile la estratagema de los sectores pro-capitalistas ha consistido en presentar las medidas que afectan al dominio económico, político o cultural de la clase dominante como un atentado a la libertad. Cualquier medida que tienda a desplazar parte del poder económico o político detentado por la clase dominante, en provecho de los sectores populares, es denunciado como un paso hacia la dictadura. Nacionalizar los Bancos significaría acabar con la libertad de trabajo de los empresarios medianos y pequeños - el gobierno, por su parte, ha aumentado la cantidad y mejorado las condiciones de los créditos a medianos y pequeños empresarios-. Nacionalizar las empresas monopólicas significaría acabar con la libertad de trabajo de los obreros, empleados y técnicos - la política del gobierno, en doce meses, ha reducido la cesantía forzosa heredada del 8,5 por ciento al 4,5 por ciento- Nacionalizar el monopolio de la Papelera de Puente Alto significaría acabar con la libertad de prensa - el presidente de la República ha propuesto que los propietarios de los periódicos nombren sus representantes en la dirección de la empresa distribuidora de papel, y que se creen cuantas empresas privadas para fabricar papel de periódico se desee- ${ }^{1}$.

1 Carta del Presidente Allende a Germán Picó Cañas, Presidente de la Asociación Nacional de la Prensa, de 25 de octubre de 1971. Fue publicada en El Mercurio de Santiago el 16 de noviembre siguiente. 
Que los partidos populares, que representan la mayoría del electorado y gobiernan el país, dispongan del 40 por ciento del tiraje periodístico y el 50 por ciento de las radioemisoras, representaría acabar con la libertad de información de medios de comunicación de masas que pertenecen a un puñado de familias ${ }^{2}$. Integrar las escuelas de Derecho y Economía en una sola Facultad, supondría acabar con la ciencia jurídica y el imperio de la ley en el orden social ${ }^{3}$. Aunque los que así argumentan no desconocen que hace muchos años la Universidad de París, y tantas otras, agrupa en una sola Facultad los estudios de Derecho y Ciencias Económicas. Pero en Chile ha sido tomado como pretexto por la oposición para crear tensiones en la Universidad. En último extremo, nacionalizar las empresas extractivas de minerales, en manos de capital norteamericano, podría comprometer la libertad de comercio internacional de Chile. Reemplazar el Parlamento bicameral actual por un Parlamento unicameral significaría el principio del fin de la democracia chilena ${ }^{4}$, aunque el gobierno mantienen exactamente los mismos principios y mecanismos para elegir a los diputados (sufragio universal, secreto, libre, proporcional e inorgánico). $\mathrm{Y}$ así sucesivamente. Los intereses capitalistas han intentado crear la imagen de que la real disyuntiva que enfrenta el país gira en torno de la libertad o la dictadura. Los partidos obreros, por definición, serían enemigos congénitos de la libertad.

Esta pugna en torno de la imagen tiene su relevancia. En Chile, en las presentes circunstancias, "el socialismo no asusta a nadie", como afirma la D.C., que desde el mes de junio ha creído conveniente definir su línea programática como socialista comunitaria. Lo contrario, sin embargo, no es cierto. Los movimientos políticos portavoces del 75 por ciento del electorado, en abril de 1971, se dicen anti-capitalistas. Mientras el dilema estribe entre capitalismo y socialismo, la opinión pública chilena opta hoy por el segundo. El único modo de atajar el progreso del pueblo de Chile para distanciarse del sistema capitalista por el camino seguido hasta ahora, consistiría en lograr la confusión que asocie democracia y libertad con instituciones económicas o po-

2 "La libertad de prensa en Chile", inserción de la D.C. denunciando "la intención totalitaria que anima a la Unidad Popular". El Mercurio, 26 de septiembre de 1971.

3 "Se perfila cuadro que atenta contra el Estado de Derecho", comunicado de la Directiva Nacional del P.D.C. El Mercurio, 12 de noviembre de 1971.

4 "La Cámara Única es una mascarada marxista", declaraciones de Luis Pareto, Jefe del Comité de Diputados D.C., La Prensa, Santiago, 7 de noviembre de 1971.

"Se trata en el actual contexto político, de un nuevo paso en la conocida táctica marxista de buscar a toda costa la totalidad del Poder". Declaración del Consejo Nacional del P.D.C., La Segunda, Santiago, 22 de noviembre de 1971. 
líticas capitalistas. La alta burguesía hizo lo imposible por lograrlo en 1970. Y, no obstante, Salvado Allende fue elegido presidente de la República. Después, el combate ideológico y de intoxicación propagandística ha descendido del nivel general al pragmático, de los principios a la defensa real de cada una de las fortalezas tras la que se parapeta el poder del capital frente al avance de las fuerzas representativas de los que viven de su trabajo. El combate propagandístico, ideológico y político se concentra en cada empresa monopolística, en la defensa de los medios de comunicación de masas servidores de los intereses de estas, de cada Banco, de la actual mayoría política en el Congreso, de la actual composición personal de la Corte Suprema, etc. En ocasiones se identifica la libertad con las instituciones, cuando de lo que se trata es de evitar que sean sustituidas. Y cuando se mantienen la institución, la libertad se personaliza en los individuos que actualmente desempeñan en ella funciones rectoras. Siempre, claro está, que sean individuos de probado compromiso con los intereses no-revolucionarios.

En el Parlamento, donde la oposición tiene mayoría, se censura al Presidente de la República de no tenerlo en cuenta y de desconocer sus facultades. En la Universidad de Chile, la mayoría del Consejo Normativo Superior es partidaria de la política de la Unidad Popular, la oposición defiende el poder personal del rector -elegido con el apoyo de la D.C. y la Derecha-, frente al órgano colegiado. El rector D.C. desconoce la autoridad del Consejo Normativo Superior y desea que las resoluciones de este último sean sometidas a referendos. Pero en el Parlamento, la oposición denuncia como "dictatorial" que el Ejecutivo desee incorporar a la Constitución la posibilidad de que el Presidente pueda disolver por una vez el Congreso y convocar nuevas elecciones legislativas. La inversión simétrica de papeles no puede ser más perfecta. Una misma tesis sería "democrática" si es patrocinada por los partidos burgueses y "dictatorial" si la propician los partidos populares.

En juego político entre gobierno y oposición, esto puede aparecer natural. Y de hecho lo es. Pero cuando el sistema político está enfrentado a un proceso revolucionario definido en términos de clases sociales, el carácter clasista de las posiciones ideológicas y políticas aparece con un relieve especial. La disyuntiva socialismo-capitalismo, en la confrontación de clases que en Chile estamos viviendo, es transformada en disyuntiva libertad-dictadura. Con la particularidad que solo la oposición al Gobierno Popular especula con la "dictadura". El presidente Allende ha afirmado que su gobierno persigue la hegemonía de las clases populares, pero sin propiciar métodos autoritarios de gobierno. La diferencia entre ambas posiciones dice mucho sobre el 
presente político-social de Chile y abre interesantes hipótesis prácticas sobre su evolución futura.

Pocas cosas hubieran sido más ventajosas para el capitalismo chileno - y, por extensión, para el internacional— que una actuación del Gobierno Popular reticente o adversa a las libertades públicas y cívicas. No ha ocurrido así. En primer lugar, porque las fuerzas organizadas sobre las que se apoya el gobierno tienen conciencia de que su unidad las hace mayoritarias en el país. En segundo lugar, porque tienen tras de sí más de tres generaciones de combate político y social, durante el cual han personalizado la lucha por el reconocimiento del pluralismo y las libertades, supuesto indispensable para su progreso por el camino que las ha conducido a la posición actual. En tercer lugar, porque el gobierno tiene razonables expectativas de poder llevar a cabo su Programa dentro de las coordenadas del sistema institucional y legal en vigor, susceptible de ser transformado mediante sucesivas innovaciones graduales.

Los logros sociales y económicos del primer año del Gobierno Popular han aumentado la libertad concreta de las grandes masas de trabajadores. Libertad esta que es fundamental para los socialistas y subsidiaria para los capitalistas. Sin embargo, el proceso revolucionario chileno persigue alcanzar las libertades sociales no solo manteniendo sino vigorizando las libertades políticas y cívicas al hacerlas más concretas. Aquí reside uno de los grandes desafíos que enfrenta la sociedad chilena. Con todo, el dinamismo y vigor de las libertades, contrariamente a lo que entienden algunos, no depende tanto de la "conciencia", de la voluntad de mantenerlas o disminuirlas, como de los "hechos", de los condicionamientos institucionales - económicos, sociales y políticos- que configuran la estructura de una sociedad.

Por más que el gobierno del presidente Allende quisiera y se esforzara por llevar adelante las transformaciones revolucionarias que la superación del sistema capitalista exige en un contexto de libertades políticas y cívicas irrestricto, ello se vería profundamente afectado si se dieran algunas situaciones que, hasta el momento, la realidad chilena no ha producido. Situaciones que podrían alterar sustancialmente la evolución del proceso revolucionario hacia el socialismo. Y en torno de las cuales pueden ser concretadas algunas de las características esenciales del combate político que se ha venido desarrollando desde el 4 de septiembre de 1970. Estas son:

- La Constitución y la legalidad.

- El orden público.

- El orden económico.

- Las relaciones entre los Poderes del Estado. 


\section{ALGUNOS SUPUESTOS GENERALES DEL PROCESO REVOLUCIONARIO CHILENO}

La experiencia revolucionaria chilena reúne características más que suficientes para despertar admiración entre quienes le prestan su apoyo y asombro o escepticismo ante los demás. Una rápida mirada hacia el pasado basta para constatar que es nota común a prácticamente todas las revoluciones, antiguas o modernas, su legitimación no institucional. Hasta el punto que la teoría política ha elaborado la categoría de legitimación revolucionaria para contraponerla a las restantes (religiosa, dinástica, histórica, democrática, etcétera). Los movimientos revolucionarios siempre han buscado justificar su razón de ser en las causas o metas que los han impulsado. Normalmente, estas últimas se han encontrado en conflicto con las que servían de fundamento al régimen de instituciones políticas preexistente. De ahí que revolución aparezca asociada a combate contra la institucionalidad, y que el triunfo de la revolución haya implicado el desplome institucional del régimen anterior. Habría, quizás, que remontarse a los siglos VI y V antes de Cristo para encontrar, en Atenas, un proceso político de cambios revolucionarios desarrollado con el explícito reconocimiento de la validez de los fundamentos institucionales sobre los que se apoyaba la polis, aunque su significado se modificó sustancialmente.

En su esencia profunda, el proceso chileno no se diferencia de la norma general. Una revolución auténtica supone transformación de las estructuras socio-económicas. Y ante un cambio de esta envergadura, ningún régimen político-institucional puede dejar de transformarse a su vez. De ahí que el establecimiento de una nueva institucionalidad política sea uno de los puntos programáticos fundamentales formulados por el Programa Básico de la Unidad Popular, que ha encontrado su primera concretización importante en el Proyecto de Reforma Constitucional presentado en noviembre de 1971 y que persigue reemplazar la estructura bicameral del Poder Legislativo, otorgar al Ejecutivo la facultad de disolver el Congreso y renovar la composición personal de la Corte Suprema.

Lo particular del caso chileno se refiere a algo distinto: a la gestación del nuevo poder político revolucionario a través de los mecanismos institucionales tradicionales. Normalmente, las fuerzas revolucionarias han debido quebrar el régimen político institucional para alcanzar el gobierno del país. La acción revolucionaria lo inhabilitaba de por sí. En general, mediante la violencia física, ha servido de instrumento de ejecución del cambio. A la que ha solido ir asociada la violencia "jurídica", el aluvión revolucionario arrastrando tanto a los mecanismos institucionales políticos como a la normativa legal que los animaba. En los sistemas de Constitución escrita, esta ha sido 
pura y simplemente ignorada, cuando más reemplazada por otras tras la interrupción brusca de su vigencia. Y, por supuesto, sin observar los procedimientos formales y materiales establecidos para su modificación. Hecho que explicaba el constitucionalista Karl Schmitt, en apoyo de un contexto contra-revolucionario, al afirmar que ninguna Constitución ha previsto su muerte.

En cambio, en Chile, el proceso revolucionario se viene desarrollando asociando las dos legitimaciones que siempre han aparecido contrapuestas: la revolucionaria y la institucional. La primera define la naturaleza y el contenido del Gobierno Popular. Pero la segunda le ha permitido instalarse e iniciar la ejecución de su programa de transformaciones estructurales. Esta presencia simultánea de ambas legitimaciones es de transcendencia fundamental para comprender el sentido del proceso revolucionario chileno.

\section{LA CONSTITUCIÓN Y LA LEGALIDAD}

Las características propias del sistema político chileno han hecho posible que las fuerzas sociales antisistema se desarrollaran dentro de un marco de comportamiento que no entraba en conflicto con las normas constitucionales y legales. Sin solución de continuidad, la evolución de la lucha social las ha llevado a asumir el gobierno dentro de un Estado que podríamos calificar de desarrollado en sus capacidades de control administrativo, económico, político y coercitivo del país. Cualesquiera indicadores que seleccionáramos para medir estas capacidades, su aplicación daría resultados netamente positivos. Pero un Estado que se caracteriza, además, por la total hegemonía - en lo formal y en lo material- del Ejecutivo. Lo que ha supuesto dos consecuencias:

1. En el aparato del Estado chileno, toda la capacidad de intervención económica, de dirección y gestión administrativa, de definición política y de utilización de las fuerzas de coerción, responden a la dinámica y orientación del Ejecutivo. Alcanzar la Presidencia de la República, no solo permite formar un gobierno con autonomía respecto al Parlamento, sino utilizar en su provecho todo ese cúmulo de capacidades.

2. El ejercicio del poder político está sometido a normas, procedimientos y formas. El nivel de institucionalización del Estado chileno es suficientemente alto, y los controles para-estatales o extra-estatales bastantes fuertes, para imponer al Ejecutivo que actúe en conformidad con el orden normativo vigente. So pena, en caso contrario, de quiebra del sistema político en vigor. 
Un gobierno como el que se instala en La Moneda el 3 de noviembre de 1970, no ya solo a través de los mecanismos constitucionales sino también gracias a la solidez de estos, pudo contar con la utilización de los mecanismos del Estado conforme a los criterios de su Programa. Pero con una condicionante fundamental: que no actuara fuera de las coordenadas que la Constitución y la ley le permitían. La razón de ello es sencilla. Dentro del aparato del Estado, en cualquiera de sus instancias y niveles, el Gobierno Popular coexiste con instituciones y fuerzas sociales que le son adversas en un grado mayor o menor y que, en cualquier caso, no comparten plenamente ni sus planteamientos ideológicos ni sus objetivos programáticos. El Estado chileno que alcanza a dirigir la Unidad Popular es un Estado de estructura predominante liberal-burguesa. Si estas instituciones del Estado - desde el Parlamento a la burocracia, pasando por la magistratura judicial— toleran y reconocen la autoridad del Gobierno Popular, es precisamente - y únicamente- por la legalidad institucional de este último. Su legitimidad revolucionaria no solo no la hacen suya, sino que la cuestionan o la impugnan.

El lazo que vincula, pues, el contenido burgués del Estado al Gobierno Popular, no es otro sino el del origen y comportamiento constitucional del Gobierno Popular. Lazo que puede ser tenue o sólido. Depende de la solidez del gobierno fuera del aparato del Estado. Es decir, de la fuerza política, social y económica que, en forma organizada y coherente, acumulan los movimientos e instituciones que integran o respaldan a la Unidad Popular. Pero cualquiera que pueda ser la solidez de las fuerzas populares, ello es algo distinto del vínculo que subordina el aparato del Estado al gobierno de Allende. Este vínculo puede romperse por varias causas, una de ellas es - sin lugar a dudas-que el Gobierno Popular no respete la Constitución o las leyes.

El ejemplo paradigmático de lo que estamos indicando lo constituye el de las fuerzas coercitivas del Estado. Creadas y desarrolladas en un espíritu de profundo respeto a su papel institucional -el primer requisito para que un Estado se institucionalice es que sus FF.AA. respeten y se integren a la institucionalidad-, han ejercido conscientemente el papel de respaldo armado del Estado. La dirección y orientación de este último se determina mediante mecanismos político-electorales, en los que no compete interferir a las FF.AA. En términos lógicos, mientras los mecanismos de designación de los dirigentes temporales del Estado funcionen normalmente, es exigencia del sistema político liberal-democrático vigente que las FF.AA. se limiten a desempeñar las funciones específicas que les corresponden. Sin embargo, esto que en términos político-institucionales es correcto, no bata por sí mismo. Hay que considerar, también, el contenido social —de clase- del aparato del Estado. 
Evidentemente, unas fuerzas armadas que socialmente se identifiquen con la aristocracia o a la alta burguesía, difícilmente puede concebirse que respalden a un gobierno de orientación anti-capitalista, por más institucionalizado que sea el Estado. El desajuste no puede resolverse sino mediante la eliminación de uno u otro de los términos contrapuestos. Del gobierno anti-capitalista, cuando vence la contrarrevolución; de las fuerzas armadas conservadoras, cuando triunfa la revolución. En un mismo Estado no pueden coexistir unas Fuerzas Armadas y un gobierno con características de clase antagónicas. Ello contradice las exigencias lógicas esenciales de un Estado.

Y esta constante histórica — qué necesidad hay de explicitarlotambién se da en Chile. La revolución política de nuestro país demuestra que el período de predominio político de los sectores medios, ora aliados con la Derecha, ora con la Izquierda, iniciado en la década de los años veinte, coincide con un contenido social de nuestras FF.AA. predominantemente vinculado a los sectores medios. Los gobiernos que se han sucedido en los últimos cuarenta años se sitúan dentro de un espectro político que recubre el centro-derecha, en unos casos, y el centro-izquierda, en los otros. Pero siempre con los sectores medios participando de modo decisivo.

Las FF.AA. chilenas han demostrado hasta la saciedad, excepto para quienes no quieran ver, que no se sienten ya involucradas en la defensa de los intereses económicos de los latifundistas y de la alta burguesía industrial-financiera. En el caso de los primeros, baste recordar que su eliminación social se inició con el gobierno de Frei, en medio de la resistencia más enérgica de los propietarios afectados y sus representantes. El Gobierno Popular no ha hecho sino continuar consumando, a ritmo más rápido, un proceso antilatifundista ya iniciado. En el caso de la segunda, las realizaciones del primer año de Gobierno Popular, sustrayendo del control privado los principales centros del poder económico burgués, hablan más elocuentemente que cualquier disquisición.

Quien se enfrente con realismo al Chile de nuestros días, debe tener el valor de reconocer que no hay antagonismo social, de clase, entre el gobierno de Allende y las fuerzas coercitivas del Estado. La afirmación puede parecer temeraria en estos albores del proceso revolucionario. No hay antagonismo por una razón fundamental: el gobierno del presidente Allende se ha comprometido a realizar el Programa de Gobierno de la Unidad Popular. Y este Programa, de modo explícito y coherente, se propone acabar con el poder económico de la alta burguesía y de los latifundistas - de la clase económica dominante- . Pero respeta a los sectores medios. No quiere ni conflictos ni enfrentamientos con estos. Toda la política económica y legislativa del 
gobierno ha buscado darles seguridad. Y evitar que se dejaran arrastrar a una oposición violenta al servicio de la clase dominante.

Es en función de estos elementos que adquiere su plena connotación la afirmación de Salvador Allende varias veces repetidas, de que mi mayor fuerza reposa en la legalidad. Únicamente observando la Constitución y las leyes, puede el Gobierno Popular utilizar en provecho de su acción a los enormes recursos de un Estado burgués moderno. Todo este potencial, su inercia, que ahora juega predominantemente en su favor - y el balance de los primeros doce meses de gobierno habla por sí solo-, se volvería en su contra si el gobierno tomara la iniciativa de actuar al margen de la legalidad.

Otra cosa es, naturalmente, el margen de amplitud de transformaciones que permite la actual legalidad. El artículo de Eduardo Novoa desarrolla con mayor detenimiento este punto. Las transformaciones estructurales en curso están produciendo un desajuste cada vez mayor con un régimen legal e institucional que regulaba una realidad social muy distinta, lo que encierra una contradicción que solo se resolverá modificando y desarrollando la normativa vigente. Cambios que no implican, por sí mismos, la obligación ineludible de desconocer la legalidad —y sus fuentes institucionales—, si tiene lugar lo propiciado por el presidente Allende en su Primer Mensaje al Congreso:

La flexibilidad de nuestro sistema institucional nos permite esperar que no será una rápida barrera de contención. Y que al igual que nuestro sistema legal, se adaptará a las nuevas exigencias para generar, a través de los cauces constitucionales, la institucionalidad nueva que exige la superación del capitalismo. ("Primer Mensaje al Congreso" en Allende, 1971: 36)

\section{EL ORDEN PÚBLICO}

El Estado es, ciertamente, el poder organizado al servicio de los intereses de la clase y sectores sociales que en un momento dado son hegemónicos. Por consiguiente, en forma derivada, es consubstancial al ser del Estado la función ordenadora. Cuando las fuerzas políticas revolucionarias están marginadas de la dirección del Estado, es uno de sus procedimientos tácticos cuestionar y desafiar al Estado conservador, para agudizar las tensiones entre las exigencias de la clase que lo utiliza, por un lado, y de las que lo aguantan, por otro lado. El desorden público, las presiones contra el orden del Estado - de la clase social que lo maneja- son la exteriorización de la lucha social. Que en su grado de mayor intensidad llega hasta la insurrección abierta y total.

La Unidad Popular ha alcanzado a controlar el centro dinámico y orientador del Estado chileno sin tener que conquistarlo mediante la insurrección violenta, sino utilizando los mecanismos regulares 
que en él previstos para designar a los representantes de la voluntad general en la dirección del aparato estatal. De nuevo, aquí se repite el esquema considerado en relación con la legalidad. El Gobierno Popular está dentro del Estado y puede servirse de las amplias facultades institucionalmente reconocidas al Ejecutivo. Pero ello exige, insoslayablemente, que no conculque las reglas internas que rigen la actuación y funcionamiento del Estado. Y que cumpla con las tareas esenciales inherentes a la dirección de este. Entre ellas, la de ordenación del proceso social. De la que es una manifestación, entre otras, el orden público.

Nos encontramos, aparentemente, ante un dilema. Orden público y revolución social siempre se han encontrado frente a frente, en relación excluyente, en el sistema capitalista. En nombre del primero, se han atacado las acciones externas de las tensiones revolucionarias. Para algunos, no deja de ser una paradoja que el Gobierno Popular quiera llevar a cabo una política socialmente revolucionaria, manteniendo el orden público.

No existe tal paradoja. Al contrario, ambos supuestos se complementan en estos momentos, interpenetrándose hasta tal punto que si uno dejara de darse, la línea táctica del gobierno de Allende sería insostenible y daría paso al enfrentamiento violento entre chilenos, eventualmente a la guerra civil. Si los cambios de contenido revolucionario fueran concebidos y ejecutados más lentamente de lo que el proceso exige y permite, el gobierno se vería obstaculizado y hostigado por quienes, siendo opuestos a él, tienen capacidad para obstruir su gestión económica y política. Así como se darían propicias condiciones para que no pudiera contener los intentos de desbordamiento por parte de los sectores revolucionarios más extremamente radicalizados. Probablemente, ambos fenómenos se complementarían uno a otro. Y en relación dialéctica.

De modo contrario, una acción gubernamental que permitiera la creación de un Estado de cosas en que el orden público se viera desconocido en un grado estimado significativo en la presente coyuntura, proporcionaría a la oposición el mejor pretexto para negar la existencia efectiva de la autoridad gubernamental. Lo que supondría rechazarle la legitimidad para usar los mecanismos ordenadores y coercitivos del Estado, abriendo el paso a la desobediencia cívica activa. En semejante circunstancia, el Gobierno Popular puede recurrir a dos medios de defensa, uno institucional y otro extra-institucional. El primero son las Fuerzas Armadas. El segundo, la movilización combativa de las masas y trabajadores organizados. En términos realistas, más allá de los principios formales, una circunstancia de desorden general semejante pondría a las Fuerzas Armadas en una posición cuando 
menos ambigua e incierta. No ya solo por el hecho de que la oposición invocaría su intervención para "restablecer el orden" (alterar el curso de la revolución), sino, sobre todo otra consideración, por la debilidad en que se encontraría el gobierno. En efecto, es obligatorio reconocer que el gobierno llegaría a esta situación con su autoridad negada por los sectores conservadores. Pero también discutida o desconocida por los sectores revolucionarios radicalizados. ¿En qué base reposa, en ese caso, la autoridad del gobierno? En una base muy endeble, y que institucionalmente se la califica de "minoritaria". Y es razonable pensar que el Gobierno Popular puede contar, en principio, con un apoyo de las Fuerzas Armadas directamente proporcional al respaldo popular con que cuenta. Y a la inversa. Por ello un gobierno sin ascendiente real sobre las grandes masas populares y atacado abiertamente por los sectores conservadores, difícilmente puede esperar que las Fuerzas Armadas se alienen unánimemente detrás del gobierno constituido.

El 8 de junio de 1970 tuvieron lugar acontecimientos reales que prueban el razonamiento anterior. El asesinato del exministro de la D.C. Eduardo Pérez Zujovic provocó la crisis más grave por la que ha atravesado el Gobierno Popular, hasta la fecha. Toda la oposición se unió para clamar con vehemencia la responsabilidad indirecta del gobierno en este crimen. Durante tres días, la invocación abierta de la intervención militar por unos, y el temor de que ello ocurriera, para otros, recorrió el ambiente político. No cabiendo al gobierno obra ni arte en la acción de un grupo de activistas paranoicos totalmente aislado, el gobierno superó la situación sin mayores consecuencias. Y las Fuerzas Armadas estuvieron, desde el principio hasta el fin, íntegramente, en la posición que institucionalmente es la suya. El gobierno, apenas dos meses después de la manifestación de respaldo popular que recibió en las elecciones municipales del 4 de abril, encontraba en este apoyo político y en su cohesión interna fuerza suficiente para hacer frente a la marejada de la oposición airada.

Aquí tenemos, pues, dos grandes factores que el Gobierno Popular tiene que equilibrar día a día: orden público y revolución social. Un desajuste entre ambos puede resultar grave para la continuidad del proceso. El gobierno tiene que encontrar una acción político cuyo desarrollo no los distancie, ya que en el equilibrio mutuo se halla uno de los supuestos de la vía política revolucionaria. El desequilibrio llevaría, por una concatenación de hechos perfectamente previsibles, al éxito de la contrarrevolución o al enfrentamiento armado.

Hay, sin embargo, dirigentes revolucionarios que no perciben suficientemente todas las modificaciones que supone el paso de la oposición al gobierno. La primera impone, particularmente al movimiento obrero, el recurso a la presión —en cualquiera de sus formas- para 
manifestar y, eventualmente, hacer muchas de las reivindicaciones que no logran abrirse camino por otro medio. Pero el manejo de los mecanismos institucionales reservados al gobierno permite, en general y particularmente en la estructura actual del Estado chileno y su contexto social, un campo de acción infinitamente mayor, más eficaz y profundo que los logros de cualquier tipo de presión. Las transformaciones llevadas a cabo por la Unidad Popular en sus primeros meses de gobierno, lo demuestran fehacientemente. Sin disparar un tiro, sin haber expuesto a la muerte a ningún trabajador, ha acumulado más realizaciones que muchas revoluciones armadas en el mismo período de tiempo - aún después de instaladas en el poder.

Lo cual no excluye pensar en el recurso de la presión social — desde la base- en determinados casos o para objetivos bien concretos. Y así ha ocurrido en muchas oportunidades en los meses últimos, pero en forma subsidiaria y subordinada a la acción gubernamental. Por ello representa una inversión de lo que es el realismo político y una visión deformada de lo que es un proceso político afirmar:

Nosotros le sugerimos a la U.P. y al gobierno que les habría resultado más serio y valiente referirse a los reales protagonistas del proceso social en marcha: entre febrero y octubre de este año han participado en huelgas y tomas ilegales 345.000 obreros, campesinos, pobladores y estudiantes que con sus familias suman más de 1.700 .000 personas en el país. (Declaración del Secretariado Nacional del Movimiento de Izquierda Revolucionaria, Santiago, 8 de noviembre de 1971)

Esta posición táctica, necesaria en una vía revolucionaria violenta, lleva en su seno - como característica propia y normal- la exigencia de recurrir a prácticas autoritarias de gobierno para hacer avanzar cualquier proceso revolucionario. Lo que, en el terreno de la prospectiva programada, no es deseado por el gobierno de Allende.

El mantenimiento del orden público, junto con ser una exigencia para todo gobierno, favorece siempre a quien controla a este último. En la situación chilena, un revolucionario que apoye el proceso actual con respeto por el orden público, requiere compartir previamente dos supuestos: a) el gobierno actual está llevando a cabo una política de orientación revolucionaria; b) el aparato institucional con que cuenta el gobierno le permite avanzar en su acción revolucionaria. Si niega alguno de ellos, es lógico que no acepte la idea de una revolución social que exige el orden público de un Estado con raíces burguesas. Pero si comporta ambos supuestos, debe ser consecuente en su razonamiento y entender la necesidad para el gobierno de llevar adelante su programa manteniendo el orden público. 
No es este el momento para extenderse enumerando las razones que dan a la obra del Gobierno Popular pleno sentido revolucionario. En cuanto a la flexibilidad del sistema institucional para franquear el paso al proceso revolucionario, es otra cuestión. Demostrarlo requiere un análisis detallado y pormenorizado. Pero que los máximos responsables de la dirección del gobierno lo creen posible, lo prueba en los hechos la orientación de su evolución y en lo pragmático las declaraciones de los partidos de gobierno, y particularmente del Presidente de la República:

Queremos, eso sí, que se tenga una comprensión muy clara de que una cosa es el orden público y otra cosa es un nuevo orden social. El orden público obedece a fórmulas jurídicas, a fórmulas legales. El orden social implica cosas materiales, posiciones de clase, enfrentamiento de intereses. El gobierno que yo presido es producto de un esfuerzo de los sectores populares. Hemos mantenido el orden público por esa es nuestra obligación. Haremos transformaciones sociales, porque para eso fuimos elegidos. Pero las estamos haciendo y las haremos dentro de un marco legal y jurídico. La Constitución Política de Chile franquea la posibilidad de dictar una nueva Constitución actual, y este es un camino que también utilizaremos. ("Discurso de inauguración de la VIII Feria Internacional de Talca", 6 de marzo de 1971, en Allende, 1971: 87-88)

En esta afirmación está resumido lo esencial de la posición del gobierno sobre el particular. En primer lugar, que respetando el orden legal e institucional se está progresando en la transformación social. Prerrequisito necesario para que pueda tener alguna posibilidad real de materialización la voluntad de mantener el orden público. En segundo lugar, la inevitabilidad de modificar el sistema institucional y legal para adecuarlo a la nueva realidad social en desarrollo. Aquí, de nuevo, un desajuste entre ambos procesos amenazaría con la quiebra del camino político actualmente seguido.

El Gobierno Popular debe esforzarse permanentemente en llevar adelante una política económica y social transformadora, con profundidad revolucionaria y toda la rapidez permitida por los recursos humanos y técnicos actualmente disponibles. Al mismo tiempo, sin embargo, debe calcular con antelación, y muy cuidadosamente, el plan de relaciones concretas y su concatenación, sus efectos manifiestos y latentes, para que estos se mantengan sincronizados con el incremento de la capacidad de control por parte de los movimientos populares y, particularmente, del gobierno. De modo tal que esta aumente significativamente y sea capaz de absorber o neutralizar las tensiones que los cambios están produciendo, tanto entre los sectores sociales cuyos privilegios se vean atacados, como también entre los sectores que asumen responsabilidades mayores y ven abiertas nuevas expectativas. 
Si en cualquier proceso revolucionario la unidad y cohesión de las fuerzas populares es de la mayor relevancia, en el caso chileno es un requisito sine qua non. Cuando un gobierno revolucionario dispone del monopolio de la fuerza coercitiva, subordinada a sus propios criterios políticos, puede pensar en utilizarla para preservar el futuro de su política ante quienes la amenazan dentro de la propia izquierda. Es lo que ha ocurrido, en un momento u otro, en todas las experiencias socialistas, con resultados positivos o negativos según casos y circunstancias. Pero en Chile, en los momentos presentes, cuando el aparato del Estado inspira y legitima su funcionamiento según fundamentos de orientación predominantemente burguesa, cuando la clase capitalista no solo conserva parte importante de su poder económico sino que tiene plena libertad para actuar como oposición política inclusive para hacer demagogia-, cuando el contorno internacional inmediato no se siente solidario del proceso revolucionario chileno - a nivel de Estado-, cuando el Gobierno Popular se apoya exclusivamente sobre la adhesión libremente expresada - y que solo libremente puede ser mantenida- de los sectores populares, fragmentar la identificación consciente de estos con el gobierno supondrá erosionar o quebrar, sencillamente, su base política. Y con mucha mayor gravedad si entre sectores populares se desarrolla ya no solo la indiferencia o la pasividad, sino la hostilidad activa hacia el Gobierno Popular. Mantener el orden público contra presiones anormales de los sectores populares, significaría enfrentar el gobierno consigo mismo. Con las consecuencias negativas que ello implica.

Por eso, desde el primer día, la oposición ha intentado quebrar la unidad de los sectores populares favorables al gobierno. Lo ha hecho con todos los recursos con que cuenta una oposición política que puede hablar - y ofrecer - sin responsabilidad. Tergiversando el sentido de las realizaciones que responden a la lógica de desarrollo hacia una organización socioeconómica socialista. Por ejemplo, la propiedad social de una empresa no significaría para sus trabajadores sino reemplazar al patrón particular por el patrón Estado, aunque los propios trabajadores asuman la más amplia responsabilidad en la gestión de su empresa. O contraponen a las realizaciones revolucionarias quimeras demagógicas que, puestas en práctica, significarían la disolución del cuerpo social a corto plazo, en medio del mayor caos. Por ejemplo, que la gestión de las empresas monopólicas nacionalizadas -incluidos los bancos- y su excedente sean dejados al libre arbitrio de sus trabajadores, en el seno de un sistema económico capitalista y de acuerdo con la lógica interna de este.

Pero el escepticismo, la quiebra del movimiento obrero, el enfrentamiento entre trabajadores, y aun el caos, es lo que durante todo 
el año 1971 ha venido buscando la oposición en forma sistemática y muy concreta. Porque de por sí, ello debilita al gobierno. Pero, además, lo pone ante un amargo dilema: o intenta mantener el orden público - lo que le enfrenta con los trabajadores-, o demuestra ser incapaz de mantenerlo - lo que abre la puerta a soluciones autoritarias de "pacificación"- Tanto en uno como en otro caso, la contrarrevolución sincroniza la plena utilización de su capacidad perturbadora con las tensiones trabajadores-Gobierno Popular, para hundir definitivamente a este y reprimir después a aquellos. Es la triste lección de la II República española.

Día tras día, desde la misma fecha en que Salvador Allende asumió la presidencia, la primera página de todos los periódicos de oposición ha recogido y magnificado cualquier incidente que pudiera ser interpretado anormal o desordenado. Desde los relevantes hasta los nimios, tanto si su causa se encuentra en una acción política consciente o en circunstancias totalmente ajenas a la dinámica del Gobierno Popular. El objetivo es manifiesto: crear la imagen de desgobierno o caos. Así, poco importa que el número de propiedades agrícolas ocupadas por los campesinos no supere el 0,5\% del total del país. La situación es presentada como anarquía y violencia en el campo. Campaña inteligente de utilización de la información orientada, a la que ha contribuido - bien a su pesar - la incapacidad técnica manifestada abundantemente por los mass-media de izquierda, no ya solo para elaborar una información con criterios modernos y eficaces, sino ni siquiera la contra-información de respuesta a las campañas de la oposición.

Algo totalmente distinto sería el supuesto contrario: que el desorden público tuviera como agente a movimientos, grupos o personas conservadoras. Si la cohesión del movimiento popular se mantiene sólida junto al gobierno, este puede contar con la seguridad de disponer de la fuerza coercitiva institucional para hacer real la función ordenadora del Estado. Quizás la mejor prueba de ello, a contrario, ha sido la extrema precaución que la oposición -inclusive la fascistaha tenido para no crear una situación semejante durante 1971. Cuando, llevados por la pasión y los nervios pierden la serenidad y fuerzan la entrada del Palacio de la Moneda, el 18 de noviembre, hacen regalo al gobierno de la posibilidad de someter a la ley de Seguridad Interior del Estado a quince diputados de oposición. Querella de la que se hace parte, también, el propio Cuerpo de Carabineros.

Mientras el Gobierno Popular cuente con el respaldo popular mayoritario, organizado y disciplinado, cualquier alteración del orden público por los sectores conservadores enfrenta a estos con la propia lógica represiva del Estado liberal. Y no es paradoja, aunque lo parezca, en un Estado en cuya dirección está confiada, institucionalmente, 
a los representantes de la mayoría de la volonté générale rousseauniana. La aparente paradoja no es fruto sino del hecho esencial de que los propios mecanismos del sistema político liberal han sido utilizados con éxito por los movimientos socialistas para la conquista del Estado, empezando de esa forma a cambiar el sentido de clase de este. Pues no son tanto las instituciones las que dan a un aparato estatal la naturaleza burguesa, sino las fuerzas sociales que lo animan y lo utilizan.

\section{EL ORDEN ECONÓMICO}

El socialismo persigue crear las condiciones materiales y culturales que hagan del hombre un ser libre en todas las manifestaciones del vivir humano. El crecimiento de las fuerzas sociales revolucionarias y de los valores políticos anticapitalistas es fruto, en primer lugar, de la explotación económica, subordinación social y miseria a que el sistema económico capitalista condena a las grandes masas populares. En cada país, los movimientos anti-sistema alcanzan un nivel de poder mayor o menor, en términos absolutos, según la expansión que de su potencialidad interna ha logrado cada estructura económica particular. Pero la explotación, subordinación y miseria, hablando en términos relativos, diferencia a unas clases sociales de otras en cualquier país capitalista. En la rebelión contra esta situación se halla la causa y legitimación de las revoluciones modernas.

La conciencia política acerca de un régimen socioeconómico no siempre es concreta y precisa. Particularmente entre los sectores sociales de menor nivel cultural. En una sociedad capitalista contemporánea, el control directo o indirecto ejercido por las instituciones del capital sobre los engranajes neurálgicos del proceso social es tan grande, y puede ser tan eficaz con los medios tecnológicos y científicos actuales, que se requiere un cúmulo de circunstancias muy excepcionales para lograr que las grandes masas lo eludan y logren hacer explícitos y manifiestos los valores, creencias y sentimientos anti-capitalistas. Se necesita mucho tiempo, además de esfuerzo perseverante, para ello.

Resultaría vano pensar que solo cuando los nuevos valores políticos favorables al socialismo se han hecho concretos y específicos entre la mayoría de la población, solo entonces un movimiento político revolucionario puede esperar recibir su respaldo. Nunca ha ocurrido así y no tiene por qué ocurrir. En primer lugar, porque no todos los sectores sociales - aunque explotados y discriminados- reúnen las condiciones económicas y socioculturales para generar una conciencia política revolucionaria socialista. Si siempre se ha afirmado que sería el proletariado quien asumiera la vanguardia del combate contra el régimen capitalista, es porque el proletariado -más que ningún otro sector social- reúne esas condiciones. Pero nunca el proletariado 
propiamente dicho, en una sociedad industrial moderna, ha ido más allá del tercio de la población económicamente activa. Y, con mayor motivo, en los sistemas económicos de menor desarrollo industrial. Ha tenido que aliarse a otros sectores sociales explotados, tanto en la etapa de lucha por el poder político como en la de transición al socialismo, después de conquistado el poder.

En segundo lugar, porque en la realidad política no se requiere que los valores políticos lleguen a ser explícitos y concretos para que influyan en el proceso político. Aun encontrándose en estado latente, pueden actuar en sentido funcional al desarrollo del movimiento social en torno del cual giran.

Con lo anterior quiero significar que en el 36,2\% del electorado que votó en septiembre de 1970 en favor del Programa de Gobierno de la Unidad Popular, y en el 50\% que respalda en abril siguiente al gobierno de Salvador Allende, solo un porcentaje limitado - cuya amplitud exacta sería demasiado complejo estudiar aquí- está votando conscientemente en favor de concepciones socialistas de ordenación económica, política y social. El resto actúa por rechazo deliberado a las manifestaciones negativas que sobre su vida personal o de grupo hace pesar el régimen económico vigente. Y que, en su concreción material más hiriente, son bien conocidas: miseria económica y fisiológica - stricto sensu-, cesantía forzosa, desempleo disfrazado, altísimas tasas de inflación crónica, falta de viviendas, etc. Resultantes de una estructura económica profundamente desequilibrada, estancada y sometida a limitaciones internas y externas para su desarrollo.

Un gobierno revolucionario como el del presidente Allende, cuyo origen formal y cuya autoridad real reposa en la adhesión libremente expresada de las masas postergadas, enfrenta el temible desafío que supone tener que satisfacer — simultáneamente- parte de las necesidades materiales más dolorosamente sentidas por los trabajadores, campesinos, empleados y demás sectores postergados, por un lado, y llevar a cabo las profundas transformaciones socioeconómicas que el proceso revolucionario exige, por otro lado.

En todas las experiencias de revolución hacia el socialismo que han precedido a la chilena, este problema ha sido atendido mediante múltiples y variadas fórmulas. Pero todas ellas caracterizada por una nota común: la supresión de la libertad de demanda, según las normas del mercado capitalista. El Estado ha controlado no solo la oferta de bienes y servicios, sino también la demanda en torno de estos. Cuando ciertos productos no es posible ofrecerlos, por una razón u otra, el Estado dispone de los mecanismos económicos adecuados para controlar esta situación. Desde la supresión total de la venta del producto, hasta su racionamiento en cualquiera de sus formas. Y el 
Estado también ha contado con el aparato administrativo y político necesario para demostrar y persuadir a la ciudadanía de la razón de ser de esta ausencia. En último extremo, el control de la información y mass-media incluso permite evitar que juegue en torno de estos bienes el "efecto de demostración", estimulando la sensación de carencia.

Lo anterior implica que el sistema económico funcione sobre supuestos totalmente distintos a los del capitalismo. No son las grandes empresas las que orientan la producción y el consumo, a través de sus vastos y sofisticados engranajes, buscando el aumento incesante del consumo según las reglas del mayor lucro, sino el Estado, de acuerdo con criterios orientadores que persiguen satisfacer las necesidades generales según criterios de prioridad social y humana superiores en su racionalidad, a los que se subordina la producción económica de empresas socializadas - al menos, las fundamentales-. Lo que exige, en forma complementaria, controlar la demanda para ajustarla al proceso de producción general.

Implica, también, que el poder del Estado socialista repose en supuestos muy distintos de los que informan la actividad del Estado liberal-democrático. En una etapa del desarrollo económico en que las necesidades de todo tipo, individuales y colectivas, son muy superiores a la capacidad de satisfacerlas, controlar la libre expresión de la demanda económica lleva a otra exigencia derivada: limitar, cuando no suprimir, la libre manifestación de la expresión política. La que siempre explota en su provecho las demandas - económicas tanto como políticas - no satisfechas. Cualquier oposición tiende a subrayar las expectativas existentes, y a crear nuevas.

Parece este un círculo vicioso. Un gobierno revolucionario, para llevar adelante las transformaciones económicas, sociales y políticas, necesita limitar o suprimir las reglas capitalistas del mercado que rigen la demanda. Y esto puede llevarle, de grado o por fuerza, a limitar la libre expresión —y aun la existencia- de la oposición política. ¿No es posible, acaso, transformar un sistema económico capitalista aceptando la oposición política?

Desde el punto de vista teórico, la transición hacia el socialismo no implica, necesariamente, suprimir la libertad de oposición al gobierno revolucionario. Todo depende de las circunstancias en que se desarrolla el proceso. Y, fundamentalmente, de la correlación de fuerzas entre el movimiento revolucionario y la oposición no revolucionaria. No solo en el interior del país, sino también en el contorno externo y aún mundial. En el último tercio del siglo XX, con el grado de integración e interdependencia alcanzado a nivel planetario, ningún proceso nacional puede desarrollarse independientemente de la situación concreta en el resto del mundo. Y en la lucha entre socialismo y 
capitalismo, del estado en que se encuentren los bloques capitalistas y socialistas, así como de las relaciones entre ellos.

Cuando el enfrentamiento violento entre fuerzas revolucionarias y anti-revolucionarias tiene lugar en circunstancias de recíproca exclusión y de precaria superioridad de una sobre otra, la preponderancia de las segundas ha implicado el baño de sangre para los trabajadores y la dictadura autoritaria de la reacción. Y el predominio de las primeras, la exigencia de afirmarse y consolidarse mediante la sumisión forzada de los anti-revolucionarios. En uno u otro caso, la negación de la oposición aparece como requisito de sobrevivencia. La dura realidad de los hechos se impone sobre los deseos más tolerantes.

Sin embargo, es posible concebir el desarrollo de la revolución hacia el socialismo en un régimen de respeto a la libre oposición. En primer lugar, se requiere que el movimiento revolucionario haya logrado crear los factores sociales, económicos y políticos que le permitan considerarse en una situación objetiva de superioridad sobre las fuerzas capitalistas organizadas adversas - nacionales y extranjeras-. En segundo lugar, el sistema político debe haber alcanzado un alto nivel de institucionalización democrática, que le permita absorber las actividades de la oposición sin el riesgo permanente de derrumbe institucional.

En la medida que el gobierno del presidente Allende incremente su base popular, que desarrolle la organización de los partidos y sindicatos que le respaldan, y que avance en la transformación de los valores políticos de las grandes masas, puede pensarse razonablemente que se está asegurando la solidez suficiente para continuar la revolución reconociendo a la oposición política. Contando con el apoyo mayoritario del país, la nueva institucionalidad puede ser construida progresivamente sin ruptura violenta de la heredada.

Para vencer este magno desafío, el Gobierno Popular tiene que superar dificultades enormes, que se suceden cuando no se acumulan. En el terreno estrictamente económico, aparece claro que el gobierno tiene una gran capacidad de control de la oferta a través de los mecanismos de intervención que ha venido reuniendo el Estado de Chile, de larga trayectoria. No así en el caso de la demanda, para la que tiene que hacer uso de los mecanismos tradicionales de precios y salarios, profundamente viciados y tarados por la inflación crónica arrastrada durante decenios. El consumidor chileno se guía según los criterios de la libertad de demanda, y alterar este factor entra en contradicción con el contexto de plena libertad política, en todas sus proyecciones, para la oposición. El gobierno no controla la información, ni mucho menos la propaganda. Apenas el 50 por ciento de las emisoras y prensa periódica responde a su línea política. Su política económica está al servicio 
de las masas en situación más mísera y postergada. Necesita satisfacer sus necesidades más imperiosas a un ritmo rápido, si no veloz. En caso contrario, los sectores de menor conciencia política pueden verse atraídos por las promesas demagógicas de la oposición. El gobierno de Allende tiene que demostrar algo bien poco usual, que revolución significa mejoras materiales inmediatas y no solo futuras. Necesita aumentar la capacidad de consumo de las masas. Pero en un contexto de economía de mercado en que rige plenamente aquella clásica norma según la cual las necesidades subjetivas aumentan con los recursos materiales disponibles. Y donde, por consiguiente, el mayor poder de compra exige la existencia de los bienes buscados. Recurrir al racionamiento de algunos de ellos es presentado por la oposición como un fracaso del gobierno. Y sentido así por la mayoría de los consumidores. Lo que se refleja, inevitablemente, en el comportamiento electoral.

El Gobierno Popular necesita de la expansión económica ininterrumpida y acelerada. Asegurar una mayor capacidad de satisfacción al consumo. De ahí la insistencia con que se ha llevado a cabo, durante todo 1971, la movilización en torno de la batalla de la producción. Solo un incremento espectacular de este puede permitir evitar la escasez generalizada o el racionamiento de bienes.

Es esta una simple manifestación parcial de un supuesto más general. El poder político del Gobierno Popular está indisolublemente unido a su éxito económico a corto plazo. Las revoluciones socialistas que se han consolidado han podido sobrevivir profundas crisis económicas porque su poder reposaba sobre fundamentos totalmente distintos de los del gobierno de Allende. El camino que se ha trazado el gobierno chileno exige como requisito sine qua non la eficacia económica.

De nuevo surge el interrogante. ¿Es posible la transformación de las estructuras socioeconómicas sin menoscabo del crecimiento económico? No hay respuesta definitiva aún. Como en el caso del orden público, el gobierno de Allende tiene la obligación institucional —y la exigencia revolucionaria- de lograr el buen orden económico. Puede alcanzarlo en la medida que controle los factores económicos internos estratégicos, y que los utilice adecuadamente. Necesita, también, que los factores económicos externos a Chile, cuyo control le escapa, no le sean excesivamente adversos. Todo ello, según secuencias de tiempo que no supongan retrasos pero tampoco precipitaciones temerarias.

De algo podemos convencernos. Avanzar por sendero tan angosto habrá supuesto la demostración que las fuerzas anti-capitalistas chilenas son objetivamente más poderosas que las capitalistas. En el interior del país. Y que en el contorno internacional de Chile, el capitalismo ya no puede derrotar fácilmente una revolución naciente. 


\section{LAS RELACIONES ENTRE LOS PODERES DEL ESTADO}

La estructura actual del Estado chileno es la de separación de Poderes. Una de las más rígidas separaciones establecidas en las Constituciones modernas. El Poder judicial es más independiente del Ejecutivo en Chile que en Estados Unidos. En Washington, los ministros de la Corte Suprema son nombrados por el Jefe del Estado con la aprobación de la Cámara Alta del Congreso. En Santiago, es la propia Corte Suprema quien presenta la quina de entre cuyos miembros el Jefe del Estado nombra al nuevo ministro del más alto tribunal de Justicia. El Ejecutivo chileno no puede disolver el Congreso, y solo después de 1969 se le reconoció la facultad de intentar superar la oposición del Parlamento mediante el recurso al referéndum. Pero ello únicamente cuando se trata de reformar el texto de la Constitución y tras un largo y complicado procedimiento en cuyo transcurso el Parlamento puede alterar profundamente la iniciativa del Ejecutivo, de modo tal que el texto finalmente sometido a consulta popular puede ser totalmente diferente del inicialmente propuesto por el Ejecutivo.

Un gobierno como el de la Unidad Popular, minoritario en el Parlamento, puede, por lo tanto, verse enfrentado a la obstrucción y bloqueo institucional. Tanto más cuanto que el Parlamento puede acusar, juzgar y condenar a los ministros por desacato a la Constitución. Así como al propio Presidente de la República. De modo que uno de los requisitos esenciales sobre los que reposa el proceso chileno, la ausencia de enfrentamiento entre el Gobierno Popular y el régimen constitucional, puede hipotéticamente ser provocado por la oposición parlamentaria sin que el Ejecutivo disponga de mecanismos legales adecuados para superarlo. Hipótesis que fue públicamente lanzada como programa de acción por un senador de Derecha, de la Democracia Radical, el 13 de enero de $1971^{5}$.

El Gobierno Popular se ha esforzado por evitar que se presentara una situación de enfrentamiento con los otros Poderes independientes del Estado. Ha respetado las decisiones de los Tribunales de Justicia, aunque denunciando vigorosamente el espíritu de clase que anima algunas de sus sentencias (p.ej. el rechazo por la Corte Suprema, a comienzos de 1971, de la petición de desafuero al senador Morales Adriasola, acusado de conspirar contra la seguridad del Estado para evitar que Salvador Allende asumiera la Presidencia). De hecho, sin embargo, durante 1971 ninguna materia de importancia vital para la acción del gobierno llegó a la consideración de los tribunales jurisdiccionales. No se ha dado aún, por consiguiente, la oportunidad real que hiciera posible un enfrentamiento Ejecutivo-Poder Judicial. Es una

5 Discurso de R. Morales Adriasola en el Club Audax, el 13 de enero de 1971. 
situación sobre cuyas características y consecuencias habrá que reflexionar cuando se produzca. Por el momento, esta no ha sido causa de conflicto para el gobierno.

Sí han sido de trascendencia, por el contrario, las materias de las que ha tenido que ocuparse la Contraloría General de la República. Como organismo institucional autónomo de fiscalización de la Administración Pública, la vasta acción transformadora e innovadora llevada a cabo por el Gobierno Popular, en uso de su potestad administrativa, no ha podido evitar el conflicto con las prácticas y criterios de actuación tradicional de la Contraloría. En particular, al proceder a poner bajo control directo del Estado y de los trabajadores empresas de propiedad privada. Si las decisiones de la Contraloría hubieran sido en sí mismas inapelables, el conflicto entre ella y el gobierno hubiera sido insoluble. La confrontación habría terminado en crisis. Pero no es este el caso. El gobierno ha ejercido en varias oportunidades la facultad regular del Decreto de Insistencia, que le permite superar la oposición de la Contraloría. La cual al remitirse al Parlamento, en otras tantas oportunidades ha dado ocasión a que el Poder Legislativo enjuicie y sancione las decisiones del gobierno.

Con lo que llegamos al centro de gravedad de la oposición institucional al Gobierno Popular. El Parlamento. En el momento de hacer el balance de lo que ha sido el primer año de Gobierno Popular, en sus relaciones con el Parlamento, uno podría recurrir a lo manifestado reiteradamente por el presidente Allende: "Ningún Presidente de la República ha hecho menos reproches al Parlamento que yo". ¿Por qué? En primer lugar, porque el gobierno ha rehuido el enfrentamiento con el Poder Legislativo. Pero ello es más bien efecto derivado que causa. Las razones fundamentales son dos, complementarias:

- $1^{\circ}$, porque el Ejecutivo dispone, institucionalmente, de un amplísimo complejo de facultades, normadas o discrecionales, para llevar a cabo su programa político en todos los órdenes, sin la intervención del Parlamento;

- $2^{\circ}$, porque el Partido eje del Parlamento, el Demócrata Cristiano, no ha querido aparecer negándose abiertamente a los cambios sociales promovidos por la Unidad Popular.

Detrás de estas dos razones políticas, hay otras de naturaleza social que las hacen posible. En primer lugar, que el Gobierno Popular cuenta con un amplio respaldo popular, en algo grado consciente y organizado. Que fue ratificado en las elecciones municipales del 4 de abril de 1971. En segundo lugar, que lo que algunos han denominado "empate electoral" a nivel nacional entre gobierno y oposición, es algo 
muy diferente de "empate político". El primero ha sido una realidad en 1971. El segundo, no. Desde el momento que un sector importante del principal Partido de oposición, de la D.C., comparte muchos de los fundamentos programáticos de la Unidad Popular, aunque no su instrumentación y sus metas últimas, el empate político resultaba imposible. Porque mientras el bloque de la coalición de gobierno tiene un programa homogéneo, en el bloque de la oposición hay un sector importante que está más identificado con una política anti-capitalista y anti-imperialista que no pro-imperialista y anti-socialista.

Del hecho que no hay empate político en Chile, sino desequilibrio social en favor de transformaciones revolucionarias, se han derivado consecuencias de la mayor transcendencia:

\section{NACIONALIZACIÓN DEL COBRE}

La mayoría opositora que controla ambas Cámaras del Congreso aprobó por unanimidad la nacionalización de las grandes minas del cobre, en conformidad con los criterios fundamentales propuestos por el gobierno —11 de julio de 1971—. Que legitimó la decisión del presidente Allende de reducir del monto la indemnización en 774 millones de dólares, por concepto de utilidades excesivas de las empresas norteamericanas entre 1955 y 1969 —Decreto del 28 de septiembre de 1971 - Lo que implica, de hecho, que la más transcendente medida de enfrentamiento con el capital norteamericano la ha llevado a cabo el gobierno de Allende sin prácticamente pago de indemnización, pero con el respaldo institucional y político explícito de todo Chile. Lo que supone una gran victoria nacional, sin precedente equivalente.

La nacionalización del cobre pudo hacerse de este modo porque el gobierno optó por incorporarla al texto de la Constitución. Ello le abría el paso al referéndum en el supuesto de que el Congreso se opusiera. Lo que implicó una gran presión política sobre los partidos de oposición. Ya que hubiera significado para ellos un grave costo político regalarle al Gobierno Popular una fácil victoria electoral, en la que la postura nacional la hubiera asumido Allende y la pro-norteamericana la oposición.

\section{LEGITIMACIÓN CONSTITUCIONAL DE LA POLÍTICA DEL GOBIERNO}

Se ha aludido anteriormente a la hegemonía del Ejecutivo en la estructura vigente del Estado chileno. También, a las amplias facultades legales que han acumulado los sucesivos gobiernos en un sistema político históricamente caracterizado por la intervención y control profundo del proceso económico por el aparato del Estado burgués. Ambos supuestos eran indispensables para que el Gobierno Popular pudiera empezar a aplicar su Programa respetando la normativa legal. 
Pero qué duda cabe que, en último extremo, se trata de un aparato de Estado burgués, utilizado por un gobierno esencialmente anticapitalista. Resultaba inevitable que no aparecieran contradicciones. Así como que el gobierno actuara, en ciertas medidas fundamentales como el traspaso de monopolios privados al área socializada, en el límite de tolerancia de la legalidad.

El Parlamento ha registrado esas contradicciones y actuacioneslímite. En múltiples y agitados debates. Pero también mediante acusaciones constitucionales a varios ministros. Sucesivamente, el Partido Nacional ha acusado de violación de la Constitución, de las normas legales, a los ministros de Justicia, Trabajo y Economía ${ }^{6}$. Pero han resultado infructuosas y, finalmente, desestimadas precisamente porque en el país no hay empate político social. El P.D.C. ha negado en el Parlamento su decisivo apoyo para que progresaran.

El gobierno ha eludido el enfrentamiento con el Parlamento. El P.D.C. lo ha esquivado con el Gobierno Popular. Es la principal características política del primer año del presidente Allende. Pero ello no ha impedido, naturalmente, que el P.D.C. haya rechazado de plano medidas legislativas del Ejecutivo - por ejemplo, la creación de Tribunales Vecinales o de Barrio, sustitución del régimen Bicameral por el Unicameral-, lo que no ha terminado en impasse porque el gobierno ha retirado la "urgencia a estos proyectos, sustrayéndolos del debate parlamentario. Como tampoco ha impedido que la D.C. haya aceptado legislar sobre materias propuestas por el Ejecutivo, pero empleando su role decisivo para tratar de imponer sus propios criterios sobre los del gobierno. Como en el caso fundamental del proyecto de ley estableciendo las tres áreas de la economía, que permite legalizar la nacionalización de las empresas estratégicas y los mecanismos de participación de los obreros en su gestión, hasta hoy llevados a efecto por la vía "administrativa"7. El debate parlamentario está en curso, pero la D.C. ha enmendado casi en su totalidad la proposición original del gobierno.

En síntesis, los supuestos tácticos que han permitido al Gobierno Popular llevar a cabo su política durante 1971 sin crisis con el Parlamento son: a) la disponibilidad de un amplio margen de acción reservado a decisiones propias de la potestad ordenadora y administrativa del Ejecutivo; b) la deliberada voluntad de evitar entrar en conflicto con los sectores medios y sus instituciones representativas (en lo so-

6 El Partido Nacional acusó constitucionalmente al ministro de Justicia en enero de 1971, al ministro de Trabajo el 10 de marzo, y al de Economía el 7 de septiembre.

7 El Proyecto de Ley de las Tres Áreas y la participación de los trabajadores fue firmado por el presidente Allende el 19 de octubre de 1971. 
cial, económico y político); c) la decisión del gobierno de actuar dentro del marco institucional.

Por su parte, la Democracia Cristiana ha guiado su actuación durante 1971 de acuerdo con principios propios de una oposición que desea moverse dentro el marco democrático del sistema chileno, buscando objetivos como los siguientes: a) deteriorar la imagen del gobierno, presentándose como alternativa que asegura mejor la "evolución social en libertad", b) erosionar la base popular del gobierno, estimulando aquello que pudiera hacer entrar en contradicción a trabajadores con el gobierno (aumento de salarios, satisfacción inmediata de necesidades sociales, propiedad privada de tierras expropiadas, "empresas de los trabajadores", etcétera); c) mantener la actual correlación de fuerzas en el Parlamento, que la sitúa en el fiel de la balanza. $\mathrm{Y}$ asegurar la continuidad en sus funciones de las personas que actualmente dirigen el Poder Judicial, rechazando su renovación mediante la limitación temporal en el ejercicio del cargo de los ministros de la Corte Suprema, como propuso el Ejecutivo en el Proyecto de Reforma Constitucional del 10 de noviembre de 1971.

En cuanto a la Derecha - Partido Nacional y Democracia Radical-, su aislamiento relativo les ha reducido a tener que ser la fuerza de apoyo de la D.C. cuando de oponerse al gobierno se trataba. Supeditándose, por consiguiente, a las posibilidades que la política parlamentaria democristiana les permitía.

Pero el proceso revolucionario ha progresado considerablemente a lo largo de 1971. Y las posiciones de partida se han modificado correlativamente. El que en noviembre de 1970 era un "amplio espacio" de poder reglamentario a disposición del Ejecutivo, ha sido cubierto en su mayor parte. Cada vez son más imperiosas las transformaciones en la estructura institucional del Estado para ajustarla a la nueva realidad socioeconómica y a su dinámica. Por otro lado, las diferencias iniciales con el P.D.C. han aumentado en conformidad con el desarrollo lógico de las contradicciones existentes entre la línea programática de la Unidad Popular y la Democristiana. El hecho de que el 3 de diciembre la Dirección Nacional del P.D.C. haya resuelto, por 10 votos contra 8, acusar constitucionalmente al ministro del Interior, es un buen testimonio de ello y prefigura el endurecimiento de este partido contra el gobierno. Así como la crisis interna que ella concitará.

La próxima consulta electoral debe tener lugar en marzo de 1973, para elegir a la totalidad de los miembros de la Cámara de Diputados y a la mitad de los del Senado. Queda por delante todo 1972, un año difícil pero decisivo, en el que, eventualmente, podría tener lugar un enfrentamiento electoral definitivo en la medida que el proyecto de Reforma Constitucional presentado en noviembre desemboque en el referéndum. 
La revolución chilena exige imperiosamente transformaciones institucionales para proseguir por la vía que se ha trazado. La llave para ellas se encuentra en el Parlamento, cuya composición socio-política depende de la voluntad electoral del pueblo. En sus manos está decidir el contenido y el camino futuro para la supresión del régimen capitalista en Chile. Voluntad que estará en función, particularmente, de la fortuna con que se hayan desarrollado los elementos considerados en las páginas anteriores.

\section{BIBLIOGRAFÍA}

Allende, Salvador 1971 Nuestro camino al socialismo. La vía chilena (Buenos Aires: Papiro). 



\section{Manuel Castells}

\section{PARA LEER ESTE LIBRO CON LOS PUÑOS CERRADOS*}

DUELE ESCRIBIR, de nuevo, sobre Chile en 1974. Y sin embargo, no es momento para que el pulso tiemble. Se trata, por el contrario, de hacer de cada pequeño gesto, por insignificante que sea (un libro, por ejemplo), un instrumento acerado para el largo combate que ahora ha emprendido el pueblo chileno.

Por eso, es necesario precisar el alcance, objetivos y límites de este libro, escrito en el fragor del movimiento popular chileno entre junio y noviembre de 1972 y que solo ha podido publicarse hoy, cuando puede aparecer como superado por los acontecimientos. Si hemos mantenido su publicación es porque su posible utilidad nos parece más vigente que nunca. Pues no se trata de una historia de la Unidad Popular sino de los análisis de los elementos que concurrieron a figurar históricamente la forma que asumió la lucha de clases en una coyuntura decisiva para Chile. $\mathrm{O}$, si se quiere, de las condiciones en que tuvieron que operar las diversas líneas políticas en el momento del enfrentamiento de 1972-73. En efecto, la distribución de las fuerzas sociales en dos grandes bloques antagónicos, el bloque obrero y popular de un lado y el bloque constituido en torno a la burguesía y

* Castells, Manuel 1974 "Para leer este libro con los puños cerrados" en La lucha de clases en Chile (México: Siglo XXI) pp. 11-19. 
al imperialismo, de otro, quedó sellada con la gran huelga patronal de octubre de 1972 y la contraofensiva del pueblo que con su extraordinaria movilización salvó al gobierno popular y cerró el paso a la primera ofensiva general de la burguesía y sus aliados. Tal es la coyuntura en que se cierra este libro. Una situación en la que se vislumbraban grandes esperanzas ante la capacidad política y la combatividad de los trabajadores chilenos. Pero una situación en la que el frente reaccionario había engrosado sus filas y endurecido sus posiciones, replegándose y preparándose para un nuevo asalto con otros medios.

A partir de octubre de 1972, la situación chilena pasa a ser enteramente analizable en términos de táctica y escena política. Las luchas y las alianzas de clase habían ya cristalizado las clases y fracciones en frentes políticos, en tendencias y en aparatos. Y puede decirse que, en lo esencial, la correlación de fuerzas (desfavorable al movimiento popular, como luego se vio) estaba ya creada. Este libro intenta explicar por qué, es decir, a través de qué articulaciones de las luchas y las alianzas de clase en el proceso abierto por la Unidad Popular, se llegó al orden de batalla desigual que los ejércitos del pueblo y de la reacción libran, en formas diferentes, de octubre de 1972 a septiembre de 1973 .

¿Quiere decir esto que en octubre de 1972 ya no había nada que hacer? ¿Que la suerte estaba echada? ¡De ningún modo! Se trata simplemente de que las distintas clases y fracciones ya habían cristalizado sus posiciones políticas definiendo así las condiciones históricas concretas en que podía plantearse por parte del movimiento obrero la línea política de conducción hacia objetivos revolucionarios.

Así, pues, este texto apenas entra en la discusión de los problemas tácticos que domina hoy los análisis y comentarios sobre la experiencia chilena. Se sitúa más bien en un plano previo, en el de cómo y por qué se llegó a la coyuntura histórica en que se produjo la sangrienta derrota del pueblo chileno, sin entrar a "dar lecciones" de cómo se debía o se podía haber hecho en tal situación para obtener otro resultado.

En efecto, la contraofensiva popular de octubre de 1972 estabilizó la situación y obligó a la burguesía a un compromiso momentáneo: un gobierno popular pero con importancia creciente de las Fuerzas Armadas, aunque se tratase del sector allendista. En esas condiciones, la corriente "centrista" de la reacción impuso de nuevo la línea de golpe de Estado "legal" intentando ganar por aplastante mayoría las elecciones parlamentarias de marzo de 1973 y así disponer de suficiente mayoría para destituir a Allende.

La Unidad Popular llevó también de nuevo la batalla a este terreno parlamentario consiguiendo un éxito resonante: un fuerte au- 
mento en número de votos que mejoraba sus posiciones (aún minoritarias) en el Parlamento cerrando toda posibilidad de obstrucción legal al mantenimiento del gobierno popular. Pero dado el nivel de enfrentamiento de clase al que se había llegado en todos los planos y dado el proceso acelerado de organización y radicalización de las masas populares desde la crisis de octubre, la nueva estabilización de posiciones en el plano parlamentario no hizo sino obligar a desplazar definitivamente la lucha por el poder al exterior de las instituciones democrático-burguesas.

En efecto, la experiencia práctica realizada por las clases populares en octubre de 1972, produjo un cambio cualitativo en las masas, en lo que se refiere a su nivel de lucha, y, sobre todo, de organización política de masas. El haber hecho funcionar el país un mes entero no solo sin sino contra los patronos y sus servidores, y pese a una huelga general de transportistas y comerciantes, hizo que el pueblo chileno sintiese su fuerza, su capacidad, la posibilidad material de tomar en sus manos la sociedad a todos los niveles. Allí se gestan entonces las nuevas formas de organización que prefiguraban el poder popular: los cordones industriales, reunión de los obreros de las distintas empresas de un mismo sector geográfico con el fin de ligar los intereses políticos de la clase obrera, por encima de las diversas situaciones económicas y sociales; los comandos comunales, desarrollo incipiente de coordinación a nivel local de las distintas organizaciones de masas; las JAP, organización de control del consumo popular; los consejos campesinos en las regiones agrarias; $y$, en general, todas las expresiones de iniciativa de las masas en la gestión de su vida cotidiana.

Sin embargo, es necesario puntualizar y relativizar el proceso de emergencia de estos nuevos órganos de poder popular, sobre todo teniendo en cuenta el verdadero proceso de mistificación al que hoy asistimos por algunas tendencias del romanticismo político. Por un lado, tales fenómenos, cualitativamente importantísimos, fueron extremadamente embrionarios y minoritarios. En particular, los comandos comunales apenas si existieron prácticamente, en la medida en que el desarrollo general de las organizaciones de masa extrasindicales no fue suficiente como para exigir realmente una coordinación y una impulsión local de sus orientaciones. Pero incluso los cordones industriales se limitaron a algunas zonas industriales de Santiago en donde se concentraba la vanguardia del proletariado (Maipú-Cerrillos y Vicuña-Mackenna, esencialmente) mientras que en el resto del país los "cordones" se reducían a menudo a etiquetas autopronunciadas por los destacamentos más avanzados del proletariado industrial. Pero la precisión más importante corresponde al carácter mismo de estas nuevas formas de organización de las masas. En ningún mo- 
mento fueron "órganos de poder por abajo" como pretende hoy día cierta corriente utópica autogestionaria. En ningún momento pudieron dichos organismos asumir la gestión de la sociedad prescindiendo del aparato del Estado, del gobierno, de los sindicatos. Por la sencilla razón de que los problemas planteados con carácter previo eran los problemas políticos del proceso de toma del poder, sin los cuales ninguna transformación de las relaciones sociales era posible. Por eso, los cordones, los incipientes comandos y las JAP, pasaron de hecho de organizaciones económico-reivindicativas a organizaciones de lucha política de las masas, planteándose incluso en algunos de ellos la preparación del asalto militar al poder, o como mínimo, cierta organización de autodefensa.

El progreso rápido de este proceso, aún minoritario, fue, al mismo tiempo, la gran esperanza de la revolución chilena y lo que indicó a la burguesía que el proceso era irreversible y que los trabajadores chilenos no aceptarían nunca volver atrás si no era bajo la amenaza de las bayonetas.

Tanto más cuanto que el último reducto de la burguesía, el aparato armado del Estado, había entrado en un proceso de división y fraccionamiento hábilmente llevado por Allende y el PC a nivel jerárquico y por todos los partidos obreros a nivel de base. Generales como Prats, Bachelet, Urbina, etcétera, se pronunciaban claramente por la legalidad constitucional, lo cual, en el contexto concreto chileno, quería decir ponerse al lado de la Unidad Popular y contra la burguesía. ¡Claro que su actitud era ambigua! Pero haber aplastado al ala reaccionaria del ejército hubiera significado una correlación de fuerzas definitivamente favorable al movimiento popular y la disminución del obstáculo decisivo en la destrucción-transformación del Estado burgués basándose, a la vez, en las posiciones conquistadas en su seno y en la movilización de las masas populares.

Por eso la burguesía y el imperialismo decidieron jugar su última carta, basándose en el amplio apoyo de que disponían entre las clases medias y en la neutralización de algunos sectores populares. Basándose también en las ilusiones legalistas de una parte de la Unidad Popular y en la ausencia de línea política concreta por parte de las tendencias políticas de izquierda en el seno del movimiento obrero; vale decir en la desorientación política del movimiento popular una vez que se agotó, por las condiciones objetivas, la única línea política coherente que había sido hegemónica entre las masas chilenas: la del Partido Comunista.

La estrategia golpista se desarrolló en tres fases, impulsada por la extrema derecha (Patria y Libertad, Partido Nacional, Eduardo Frei), sostenida activamente por el imperialismo y asumida poco a poco por 
el conjunto de las fuerzas burguesas. En un primer momento, una vez perdidas las elecciones, la reacción operó el bloqueo definitivo del aparato del Estado. Con un Parlamento, una Magistratura y una Administración sistemáticamente hostiles, la Unidad Popular verificó en la práctica la vieja ley sobre el contenido de clase del Estado. A partir de ese momento, el gobierno popular quedó prácticamente condenado a la disyuntiva entre ilegalidad o inactividad. El Estado construido por la burguesía chilena ya no sirvió más al gobierno popular, siendo así que este tampoco podía transformarlo teniendo en cuenta el recurso último que significaba el Ejército, garante de una constitucionalidad burguesa convertida en camisa de fuerza paralizante.

Desde este punto de vista, la práctica aportó una respuesta a las preguntas suscitadas en nuestro texto respecto a las posibilidades de transformación del aparato del Estado. Hubo posibilidad de hacerlo funcionar, aun en forma deficiente, en beneficio de los intereses inmediatos de las clases populares. Pero en cuanto se trató de utilizarlo para la realización de sus intereses históricos, políticos, quedó bloqueado por la contradicción entre la lógica social subyacente a su organización institucional y las orientaciones políticas de quienes detentaban puestos claves en el Ejecutivo.

Con el Parlamento votando sistemáticamente en contra, con la Contraloría alegando la ilegalidad de las decisiones presidenciales, con la Magistratura cubriendo abiertamente la sedición, con un buen número de funcionarios en actitud de sabotaje de las instituciones, la máquina estatal perdió su capacidad autónoma de ejecución y no puede funcionar más que a partir de los impulsos directos recibidos de las clases en lucha y de sus aparatos. Y aquí es donde se mostró que el Estado no es sino un aparato de las clases dominantes aunque en circunstancias históricas, en función de la correlación de fuerzas, puede ser parcialmente ocupado por las clases dominadas. En efecto, en último recurso el Estado se funda en el monopolio de la violencia organizada, en la policía y en el Ejército. Y aquí es donde la burguesía movilizó todas sus fuerzas para impedir que la descomposición de su aparato del Estado alcanzara estos órganos esenciales. Puesto que una vez bloqueada la situación, por la imposibilidad en que se encontraba el gobierno popular de hacer funcionar los organismos legales, su desbloqueo solo podía venir de una irrupción de las masas populares o de una reconstitución de las posiciones burguesas en el Estado a partir de los recursos que le quedaban, y en particular el Ejército. Para eso había que detener el proceso de división del Ejército que había iniciado hábilmente la Unidad Popular. De ahí, el intento de golpe, minoritario, de las tendencias fascistas del Ejército, el 20 de junio de 1973, el "Tancazo". Rápidamente controlado por el general Prats 
al frente de las tropas legalistas, su real importancia fue el mostrar concretamente al Ejército el peligro inminente de un enfrentamiento armado entre sus dos fracciones.

A partir de ese momento, quedó claro que ganaría el Ejército aquella fracción que más garantías ofreciese para preservar su unidad. Y aquí la derecha tenía todas las de ganar. Por un lado, porque el ala fascista había mostrado que estaba dispuesta a llegar hasta el final de su lógica golpista, mientras que la oficialidad constitucional no pretendía sino mantener una situación que de hecho era insostenible. Y esto por un segundo elemento que es el decisivo en la caracterización del Ejército, a saber su componente de clase. No solo por el origen social y la ideología de los oficiales, no solo por la verticalidad del mando que hace extremadamente difícil una revuelta de la base mientras el aparato en su conjunto no esté parcialmente dislocado, sino fundamentalmente por el carácter mismo del Ejército por su tipo de funcionamiento, por su papel social, que no podían subsistir en un nuevo tipo de relaciones sociales. En este sentido, el Ejército chileno tal como era solo podía subsistir en un orden social burgués. Y esto predeterminaba la radicalidad fascista de sus tendencias conservadoras y la pusilanimidad pequeñoburguesa de sus fracciones legalistas.

Pese a ello, después del 29 de junio, en el momento en que los generales leales habían tomado una posición firme, en que los fascistas habían sufrido una cierta desbandada y en que, sobre todo, las masas estaban a la ofensiva, pudo haberse ejercido una represión decisiva contra las tendencias golpistas entre la oficialidad, como, según parece, se propuso por parte de algunas tendencias en el gobierno. No se hizo. Y fue probablemente la última oportunidad de llevar adelante la ofensiva popular en condiciones favorables. A partir de ahí, el deterioro de las posiciones obreras y populares fue continuo. No tenemos elementos para explicar el porqué de la indecisión del gobierno en ese momento ni para juzgar de la táctica que se hubiese tenido que seguir. Constatamos tan solo que desde mediados de julio en el Ejército se acelera el proceso de unificación en torno a las posiciones golpistas, se aísla a los oficiales leales, se reprime a la izquierda, se aterroriza a la tropa. Obtenido el desencadenamiento de tal proceso, punto clave para el éxito final, la reacción pasa a la fase final, a la ofensiva hacia el golpe, en una extraordinaria lección de cómo combinar la lucha legal y la ilegal, los lamentos en la prensa, la acción en el Parlamento y la violencia más salvaje. Nueva huelga de camioneros que paraliza el país, sin voluntad alguna de negociar; acusación parlamentaria contra Allende; campaña general de intoxicación en la prensa, radio y TV; manifestaciones estudiantiles; ola de atentados terroristas, cada vez más importantes; terror contra los militantes de izquierda; sobre todo, 
movilización general de los gremios patronales y de las clases medias con paralización de servicios esenciales (como los médicos); en fin, agitación constante entre la oficialidad, amagos de golpe y campaña personal contra Prats que se ve obligado a dimitir el 20 de agosto, dejando la jefatura del Ejército a Pinochet, amigo personal de Frei.

Por parte de las masas populares, había conciencia clara de que la situación había cambiado, de que la línea legalista de la UP se había agotado, de que se iba, a corto plazo, al enfrentamiento. Pero, ¿qué hacer? ¿Cómo hacer? En los testimonios actuales de los militantes chilenos, lo que más claramente aparece es la desorientación que ganó las masas cuando la única línea coherente que había podido ir siendo desarrollada, la del PC, dejó de corresponder al nivel de la lucha de clases, a la coyuntura precisa en que se encontraba Chile. Cierto, el MIR y otras tendencias de extrema izquierda intentaron preparar política y militarmente el "enfrentamiento". Los cordones industriales, en general, bajo hegemonía de la izquierda socialista se convirtieron en destacamentos avanzados del proletariado y en algunos casos se acumularon depósitos de armas y se organizaron incipientes milicias obreras.

Pero, contra cierta crítica de la ultraizquierda europea y americana, nunca se pensó seriamente en la posibilidad de construir un aparato militar popular capaz de enfrentarse y derrotar a un Ejército unido y armado hasta los dientes con los medios técnicos más modernos. Los grupos armados de los cordones y de los partidos de izquierda (entre los cuales, probablemente era el Partido Comunista quien contaba con la mejor organización militar) no estaban en condiciones de ser sino grupos de apoyo a una fracción leal del Ejército. Y no podía ser de otra forma puesto que no existe ejemplo histórico de un ejército no descompuesto que deje armarse y organizarse a las masas sin intervenir de inmediato. Quienes sostienen que lo que debía haber hecho Allende era "armar al pueblo" dan por resuelto el problema esencial: ¿Cómo armar al pueblo sin desarmar al Ejército? Y ¿cómo desarmar al Ejército? Por la división del mismo. Este es el problema clave que las distintas fuerzas populares intentaron abordar, en desorden y a última hora. Por un lado, desde el gobierno, al nivel de la oficialidad. Y se perdió la batalla por las razones señaladas. Por otro lado, desde la base, como hizo el MIR en la Marina o el PC en Carabineros. Pero los intentos más serios fueron desarticulados y bárbaramente reprimidos (en particular, los marinos miristas en Valparaíso). La razón fundamental hay que buscarla en el hecho de que el funcionamiento interno del Ejército (la verticalidad del mando, la disciplina estricta, la arbitrariedad, la represión salvaje) es tal que intentos aislados de organización en su seno son fácilmente reprimibles si no cuentan con 
un apoyo real entre la oficialidad o si no se inscriben en una coyuntura más amplia en que la correlación de fuerzas sea favorable al pueblo y disuada a los opresores. O sea que la revuelta de la base, en un ejército que no se haya descompuesto (como fue el caso en la revolución soviética) dependía del avance en los dos otros factores (oficialidad, correlación general de fuerzas) que ya observamos como desfavorables.

En esas circunstancias, las tendencias fascistas pudieron dedicarse tranquilamente a limpiar el terreno antes del golpe final. Registros; detenciones masivas; asesinatos; terror; desarticulación de unidades armadas; desorganización de sindicatos; partidos y cordones; psicosis general de desorden y de barbarie; desmoralización de las masas; golpes contra la prensa y radio de izquierdas; y, sobre todo, desmantelamiento de las tendencias de izquierda en las Fuerzas Armadas. Así se llegó al 11 de septiembre. Al bombardeo de la Moneda y de las fábricas y poblaciones. Al asesinato de Allende y de miles de trabajadores chilenos. Al repliegue necesario de las fuerzas populares ante una correlación de fuerzas extremadamente desfavorable.

Y, a partir de ahí, al terror que estrangula a Chile desde ese momento, a la represión salvaje, al asesinato como práctica cotidiana de gobierno, al Estadio Nacional, a la isla Dawson, al campo de Chacabuco, a la larga noche de sangre y de exterminio que viven las masas más politizadas de América Latina. También a la destrucción de toda la obra económica y social del gobierno popular; a la devolución de las fábricas y fundos, a la indemnización de las compañías yanquis, a la vuelta a la inflación galopante sin reajuste, a la humillación continua. Y ahora, sin libertades políticas para el pueblo. Se trata de una derrota. De una derrota histórica para el pueblo chileno, para América Latina, para los pueblos del mundo.

La Junta Militar tiene base social, como nos parece que demuestra nuestro libro. Hay formado un bloque de clases dominantes, con la burguesía proimperialista como fracción hegemónica y con un fuerte apoyo entre las clases intermedias. Cuentan con un movimiento de gremios que puede ser la base para un encuadramiento represivo de las masas, de tipo fascista. Cuentan con el apoyo incondicional del imperialismo americano. Con un Ejército y una política galvanizados por la práctica sangrienta de la masacre que han llevado a cabo. En contra, el pueblo chileno, los pueblos del mundo, la opinión democrática chilena e internacional. Pero saben que este es el precio a pagar durante años para asegurar su dominación sobre nuevas bases. Lo esencial para ellos es la destrucción completa del movimiento obrero y popular chileno aún no desarticulado.

Lo esencial para el pueblo es preservar su capacidad política y organizativa de la única manera posible: luchando. Pero en el nivel 
y con las formas de lucha que permite la correlación de fuerzas en cada momento. El pueblo chileno emprende ahora una larga marcha en la noche del fascismo. Toda nuestra vida estará marcada por estos años y esta lucha. Toda nuestra vida proseguiremos, desde donde podamos y en lo que podamos, el trabajo y el contacto con las masas chilenas de los que este libro es el reflejo. Y apretaremos los puños. Para transformar la rabia y el dolor en fuerza para golpear. Con el puño cerrado. 



\section{Xabier Gorostiaga}

\section{LOS DILEMAS DE LA REVOLUCIÓN SANDINISTA A TRES AÑOS DEL TRIUNFO*}

\section{LOS DILEMAS QUE ENFRENTA HOY LA REVOLUCIÓN SANDINISTA}

Entrevistamos al P. Xabier Gorostiaga (S. J.) para que ampliara y profundizara en este texto los conceptos vertidos en su disertación del 30 de mayo en el Seminario de la Asociación Nicaragüense de Científicos Sociales sobre "Las relaciones de Estados Unidos con Nicaragua". Gorostiaga se desempeña como Director del Instituto Nicaragüense de Investigaciones Económicas y Sociales (INIES) con sede en Managua.

Lo que se pretendía en la reunión de Científicos Sociales al analizar las relaciones entre Estados Unidos y Nicaragua, era vital el caer en un legalismo interpretativo que fue un poco la tendencia dominante en varias exposiciones de los compañeros norteamericanos. Pretendía señalar algunos temas estructurales con toda la problemática que estos temas encierran. Algunas de las soluciones que allí se dieron no tendrían mucho sentido si no se enfoca la problemática de Nicaragua y la región dentro de los grandes dilemas estructurales. Este acercamiento pretende dar una especie de marco para ubicar los problemas de Nicaragua y de la región.

Los conflictos que hoy vivimos en Nicaragua se pueden reducir a tres grandes dilemas: primero, los dilemas internos, segundo, los

* Gorostiaga, Xabier 1982 "Los dilemas de la revolución sandinista a tres años del triunfo" en Revista Envio (Managua) N 13. 
dilemas provocados por la crisis regional, y el tercer tipo de dilema, son los provocados por la inserción de la revolución sandinista en la coyuntura internacional.

\section{LOS DILEMAS INTERNOS DE LA REVOLUCIÓN SANDINISTA EL DILEMA ECONÓMICO}

¿Cómo satisfacer las necesidades básicas de la gran mayoría de la población, al mismo tiempo que se mantiene una economía mixta que principalmente está en manos "privadas"? ¿Cómo hacer que esta economía mixta, mayoritariamente en manos privadas, responda a la lógica de las mayorías más que a la lógica de rendimientos para el capital?

Este es un tema y un dilema esencial en la revolución sandinista. Cuando la empresa privada se queja de la "falta de clima", lo hace únicamente desde las perspectivas de los beneficios del capital. El pueblo se queja, por su parte, de "falta de clima" en relación con la empresa privada, porque percibe que la empresa privada no satisface las necesidades básicas de las grandes mayorías. Entonces este dilema encierra el dilema de dos lógicas distintas: una lógica de las mayorías, una lógica de una economía social, de satisfacción de las necesidades básicas de la población y una lógica al servicio de los intereses de los propietarios del capital.

¿Cómo satisfacer estas dos necesidades que entre sí parecen contradictorias? Es un grave problema para la revolución, que no tiene fácil solución. El hecho de que la revolución sandinista haya mantenido por tres años la economía mayoritariamente en manos privadas es un ejemplo del esfuerzo enorme que la revolución realiza por mantener este pluralismo económico. La Revolución Sandinista ha dejado bien claro que la lógica de las mayorías es la lógica dominante en esta economía mixta, que no es una economía yuxtapuesta, sino que es una economía organizada al servicio del pueblo que obtuvo la victoria contra el sistema somocista, y contra el sistema económico-político opresor que dominó históricamente.

Por economía yuxtapuesta se quiere señalar aquellas otras experiencias de economía mixta, donde se da el sector privado por un lado y el sector público por otro, guardando ambos sectores dinámicas distintas, en las que el sector público no hace sino subsidiar socialmente los intereses del sector privado. En el caso del modelo sandinista se tiende a crear una economía mixta planificada (economía mixta programada en el momento actual por una incapacidad informática, técnica e institucional de planificación). Esta economía mixta programada, es una economía mixta bajo la lógica de las mayorías, donde el sector privado tiene sentido, tiene finalidad, puede ser una solución estratégica a largo plazo, en cuanto el sector privado 
acepte la lógica de las mayorías y esté al servicio de las necesidades fundamentales del pueblo.

Los economistas hablan del efecto "cascada" (trickle down effect), efecto por el que se producen los bienes y el crecimiento y estos, después, chorrean hacia los sectores bajos. La revolución sandinista busca una dinámica contraria, sería un trickle up effect de abajo para arriba, satisfaciendo primero las necesidades básicas, para subir luego hacia los sectores medios los beneficios de la economía, y llegar finalmente al consumo no necesario y la acumulación privada, una vez que las necesidades básicas y necesarias de las grandes mayorías hayan sido satisfechas. Son dos concepciones que responden a dos lógicas diferentes: la lógica de la acumulación privada y la lógica de la satisfacción de las necesidades de las mayorías, para iniciar después la acumulación social y el desarrollo. La tarea hoy en Nicaragua es la superación de los dos sectores económicos yuxtapuestos, para crear una economía programada, integrada, planificada bajo la lógica de las mayorías. Obviamente este modelo crea tensiones, pero ¿existe otra forma mejor de superar el dilema?

\section{EL DILEMA POLÍTICO}

¿Cómo mantener un pluralismo político al mismo tiempo que se responde a una expectativa creada por la insurrección popular masiva de la población contra la dictadura y contra el sistema de opresión económico-político, que, obviamente, levantó expectativas de poder popular y exigencias de un cambio de estructuras y del poder político tradicional en el país?

Los sectores privados perciben que este poder político afecta a sus antiguos privilegios políticos y consideran que este poder popular no es democrático, sino totalitario. Sin embargo, la proporción de representación política que tienen los sectores privados es superior a lo que les correspondería en términos estadísticos. La participación que, por ejemplo, tiene la empresa privada y los representantes de los sectores privados y de la oposición dentro del Consejo de Estado, no correspondería al número real de gente con la que ellos cuentan en el país.

Dentro de los 51 miembros que componen el Consejo de Estado, el número de representantes de la oposición es de 11 - empresarios y partidos políticos-que representa el 21,6\%. Las organizaciones políticas y sindicales de izquierda reúnen 7 representantes que significa el 13,7\%. Las organizaciones independientes representantes de las iglesias, organizaciones sindicales y de profesionales independientes tienen 8 representantes que significa un 15,8\%. Por último los representantes del FSLN y las organizaciones de masas identificadas con este reúnen 25 representantes que significa el 49\%. Mi tesis es que la 
oposición en este país (la oposición militante contra la revolución) no llega al 21,6\% y que por lo tanto estos sectores están excesivamente representados en relación a una proporción estadística de posibles votantes que estos sectores tendrían.

Conviene, por otra parte, distinguir entre oposición y descontentos. Existen descontentos y desilusionados con la Revolución por no haber llenado esta todas las expectativas creadas por la misma revolución. Pero estos sectores jamás votarían por una oposición de derecha, sino por una radicalización del proceso que satisfaga más rápido sus aspiraciones. No todos los descontentos, ni mucho menos, son de derecha en la Nicaragua de hoy.

El dilema político se mantiene dentro de una notable estabilidad política, en una Centroamérica convulsionada, gracias a una creciente hegemonía del poder popular vanguardizado por el FSLN, que en medio de naturales tensiones respeta la proporción de poder político real que tienen los sectores de la empresa privada y los grupos de la oposición.

La tensión política interna, sin embargo, se ha agudizado desde marzo, al tenerse que declarar el Estado de Emergencia Nacional y abocarse el país a la defensa de la revolución popular sandinista ante las amenazas y agresiones reales padecidas en estos últimos meses. El Estado de Emergencia lo ha padecido especialmente el sector opositor, que es el que más ha sufrido la suspensión temporal de algunas garantías del estatuto fundamental y del Estatuto de Derechos, garantías de los nicaragüenses. El Estado de Emergencia no es un producto original de la Revolución, sino una medida defensiva que se terminará en cuanto se inicien las negociaciones con los EE.UU. Y se eliminen las causas de la amenaza externa.

Este dilema político puede, sin embargo, permanecer e inclusive agudizarse, dependiendo de las fuerzas contrarrevolucionarias internas y externas (en Honduras y Costa Rica principalmente), y sobre todo, de la posición que siga manteniendo la administración Reagan sobre Nicaragua.

¿Cómo mantener y acrecentar la participación popular a todos los niveles, a la vez que se mantiene un pluralismo político que no impida las transformaciones sociales y culturales exigidas por una sociedad donde los pobres han adquirido derechos y poder cívico por primera vez en la historia política del país? ¿Cómo realizar todo esto sin grandes tensiones sociales y políticas?

\section{EL DILEMA NACIONAL}

¿Cómo hacer en Nicaragua, Estado situado en un área estratégica y vital para los intereses norteamericanos, un país independiente y soberano que sea respetado por los EE.UU.? 
Es indudable que después de tantos años de lucha, el Pueblo nicaragüense no solamente ha conquistado el derecho a una justicia social, sino que ha conquistado el derecho a una dignidad nacional. Nicaragua ha dejado de ser para siempre una "República Banana" y ha comenzado a ser un Estado libre y soberano. La contradicción en el dilema está entre la soberanía nueva, recién adquirida, y los intereses estratégicos que los Estados Unidos tienen en esta área, que consideran como un área de hegemonía no compartida. El hecho de mantener un país con soberanía e independencia resulta una quiebra de esta hegemonía absoluta que Estados Unidos intenta mantener en el área. Resulta además, un ejemplo peligroso. Por otro lado, con la crisis del Vietnam, los fracasos de la política exterior norteamericana en diversas partes del mundo, la crisis económica internacional, etc., la presente Administración Reagan está intentando demostrar en Centroamérica y especialmente en el caso de Nicaragua, que todavía Estados Unidos es la potencia hegemónica mundial. Es aquí donde tenemos el choque, el dilema y las tensiones provocadas por esta contradicción entre soberanía nacional de Nicaragua e intereses estratégicos norteamericanos en el área.

\section{SIGNIFICADO DE ESTOS TRES DILEMAS}

Estos tres dilemas internos, extraordinariamente difíciles de manejar, la Revolución popular sandinista los ha enfocado de una forma pragmática con gran realismo y flexibilidad. ¿Existe alguna solución mágica a estas tensiones? ¿Ha presentado la oposición una sola propuesta para resolverlos?

La originalidad del sandinismo es más significativa cuando brota, después de cuarenta y cinco años de una férrea dictadura y una cruenta guerra de liberación. Es indudable que la revolución popular sandinista ganó una legitimidad y respeto internacional que la presente administración Reagan considera altamente peligrosa por haberse convertido en un punto de referencia para los pueblos de la región y otros muchos del Tercer Mundo. Es esta legitimidad y la presentación de un nuevo modelo, lo que la Administración norteamericana está tratando de destruir en Nicaragua. Nicaragua es un ejemplo peligroso y difícil de ser manejado por una Administración con una visión tan simplista de la realidad internacional.

Es indudable que ha habido deficiencias y errores, falta de capacidad técnica y de recursos humanos para resolver dilemas tan complejos. Sería ingenuo y deshonesto no reconocerlos y aprender de los mismos con una sana crítica. Sin embargo, cuando se analizan las críticas de la oposición interna y externa a la revolución popular sandinista, que no reconocen ninguno de los logros y solo resalta los 
errores, queda patente un gran vacío de propuestas concretas. Son críticas diletantes que no presentan alternativas ni se enfrentan constructivamente a estos dilemas que están insoslayablemente en la base de la problemática actual de Nicaragua.

\section{LOS DILEMAS PROVOCADOS POR LA CRISIS REGIONAL}

\section{LA REVOLUCIÓN POPULAR SANDINISTA Y LA CRISIS CENTROAMERICANA}

¿Cómo realizar una transformación social y política, una transformación nacional en Nicaragua, dentro de una región en una profunda crisis económica y política? La revolución popular sandinista no se hace en un vacío regional, no se construye en una isla, sino que se hace en una región profundamente integrada políticamente y económicamente. En este momento la región centroamericana vive la mayor crisis económica y política de su Historia. En estas circunstancias, ¿cómo realizar, cómo solventar este dilema de hacer pacíficamente, al menor costo social posible, la transformación revolucionaria en Nicaragua dentro de esta coyuntura de crisis económica-política de Centroamérica, especialmente en un momento en que esta área ha sido elegida como campo de batalla por la Administración Reagan? Todo esto, además, en el marco de tensiones internacionales de considerable magnitud: la tensión Este-Oeste, la tensión entre la Internacional Socialista y la Democracia Cristiana que están dirimiendo problemas tanto europeos como latinoamericanos a nivel de Centroamérica, el conflicto también entre las subpotencias latinoamericanas como son México, Venezuela, Brasil, que están interviniendo por diversos intereses en la región.

Dentro de toda esta conflictividad concretada en la región centroamericana se da el fenómeno de la Revolución Popular Sandinista, la primera revolución en el Continente en los últimos 20 años. Indudablemente que esto crea dificultades y dilemas de tipo regional.

La Revolución sandinista se siente hermanada con la lucha de los pueblos de El Salvador y Guatemala por más de cien años de conflictos semejantes contra la dominación norteamericana y oligárquica. ¿Cómo no manifestar esta hermandad y al mismo tiempo mantener una posición de no intervención en los asuntos internos de otros países?

\section{LA REVOLUCIÓN POPULAR SANDINISTA Y LA AGRESIVIDAD YANQUI}

¿Cómo realizar esta revolución en la región centroamericana con la presente administración Reagan? Es importante analizar, como lo han hecho algunos congresistas norteamericanos, por ejemplo, el congresista Tom Harkin, y tratar de visualizar lo que hoy podría ser Centroamérica sin Reagan. Posiblemente la Revolución Popular Sandinista mantendría unas relaciones suficientemente cordiales tanto económicas como políticas con los Estados Unidos. Si se hubiese 
aceptado la negociación con Estados Unidos propuesta por Nicaragua para resolver algunos de estos dilemas.

Posiblemente sin la Administración Reagan, en El Salvador hubiera habido negociaciones internas entre las fuerzas populares y el antiguo gobierno de Duarte, sin haber llegado a unas elecciones que han endurecido aún más el dilema salvadoreño. Posiblemente sin la Administración Reagan, hoy habría negociaciones establecidas con Honduras, con una vigilancia conjunta en la frontera hondureña y un control de los miles de ex-guardias somocistas entrenados y financiados por la Administración Reagan. Posiblemente sin la Administración Reagan hoy, en vez de darse el fenómeno divisor de Centroamérica con la llamada Comunidad Democrática Centroamericana, que divide en contra de todos los principios centroamericanos a la región, política y económicamente, posiblemente se hubiesen dado algunos pasos para encontrar una salida conjunta regional.

Sin embargo, estas hipótesis no son objetivas. Tenemos la administración norteamericana más simplista y más dura, más militarista, con indudables rasgos fascistas, que impide el visualizar una solución negociada y pacífica a la región. Toda la retórica y la propaganda internacional de Estados Unidos intenta presentar a Nicaragua como el promotor del conflicto y de la tensión regional, usando la región para aumentar la crisis Este-Oeste, cuando más bien esa tensión proviene del centro del imperio hacia la región y no viceversa.

El hecho de que actualmente Nicaragua esté padeciendo un Estado de Emergencia no es producto de una radicalización y una rigidez de la Revolución Popular Sandinista, sino que es el producto de una amenaza y una agresión externas. Al comienzo de este año, la Revolución Popular Sandinista tenía programado un proyecto para reforzar la unidad nacional a base de leyes de incentivos económicos, de promover una ley de inversión extranjera, etc. Todo esto se vino abajo con la aprobación el 1 de diciembre de 1981 por el presidente Reagan de las operaciones encubiertas, que se han materializado en los primeros meses de 1982 con repetidas amenazas y ataques que han costado unos 200 muertos y grandes pérdidas económicas para Nicaragua.

Parece contradictorio, pero estas operaciones encubiertas son en estos momentos públicas, porque han sido aprobadas públicamente y reconocidas por los principales dirigentes del gobierno y de la administración Reagan. A diferencia de las operaciones encubiertas contra Allende en Chile, que siempre fueron negadas por la Administración norteamericana, estas son públicamente reconocidas.

El dilema regional es entonces ¿cómo realizar al menor costo social para nuestro pueblo y para la región, la revolución exigida por las condiciones históricas de Nicaragua, y al mismo tiempo enfrentar a la 
Administración más simplista, militante, que ha tenido el gobierno de Norteamérica posiblemente en este siglo?

\section{ALTERNATIVAS DE REAGAN PARA LA REGIÓN}

¿Qué salidas se prevén a este dilema regional? En síntesis, se podrían visualizar tres escenarios:

- La posibilidad de intervención directa de los Estados Unidos, alternativa que se vio muy factible en el mes de marzo, actualmente ha decrecido por la oposición interna dentro del pueblo de los Estados Unidos (el 87\% se opone a esta intervención como lo ha señalado la encuesta de Newsweek en mayo de 1982). Por otra parte, la oposición internacional y latinoamericana a esta intervención ha sido acrecentada con la guerra de Las Malvinas y la hace menos posible. Pero, sobre todo, debido a la capacidad defensiva creada por el mismo pueblo nicaragüense. Sin embargo, no se puede eliminar la posibilidad de esta intervención militar, porque la lógica y el análisis han sido repetidas veces sobrepasados por la irracionalidad de muchas políticas que ha usado el imperio a través de la historia.

- Se ve como más probable una intervención, utilizando grupos de mercenarios y tropas latinoamericanas. También, sin embargo, parece que esta posibilidad ha decretado por la crisis de Las Malvinas que ha provocado, según informes provenientes de Gran Bretaña, que unos 250 asesores argentinos hayan sido removidos de la región. Por otro lado, el apoyo de Estados Unidos a Gran Bretaña en las islas Malvinas ha debilitado la posibilidad de que Estados Unidos convoque al TIAR (Tratado Interamericano de Asistencia Recíproca) para atacar Nicaragua. En este sentido las posibilidades de una intervención militar a nivel latinoamericano están debilitadas.

- Sin embargo, quedan abiertas las posibilidades de un ataque de los Guardias somocistas y del grupo de países del Triángulo norte: Guatemala, El Salvador y Honduras. Esta posibilidad sigue vigente pues podría ser usada como una "salida" a la crisis salvadoreña y Nicaragua podría ser usada como un "chivo expiatorio". No es posible en este momento separar lo que ha sido la lucha histórica del pueblo salvadoreño con la del pueblo nicaragüense. Y a pesar de la actitud de Nicaragua de no apoyar en forma directa a El Salvador, se sigue acusando a Nicaragua de tal ayuda, si bien los Estados Unidos nunca han podido presentar prueba alguna. 
La Revolución Sandinista si no se diese en el marco de las revoluciones que impulsan los países hermanos de Centroamérica, hubiese podido actuar con más rapidez y profundidad y posiblemente con más radicalismo. Pero la revolución sandinista prueba de nuevo su pragmatismo y originalidad al ubicar su propio proceso dentro de toda la crisis regional de manera de no perjudicar a pueblos hermanos y provocar a una Administración estadounidense tan militarista.

Ante todo esto la Revolución Sandinista ha ofrecido negociaciones tanto con los Estados Unidos con los países vecinos. Se plantearon propuestas concretas de paz en el Consejo de Seguridad de las Naciones Unidas que se recibió por respuesta el veto de los Estados Unidos. Desde la perspectiva nicaragüense parece irónico, por no decir cínico, que se acuse de amenazante a la Revolución Sandinista, cuando la revolución en todos los fueros internacionales está ofreciendo negociaciones de paz y son los que acusan de "peligrosa" a la revolución sandinista los que vetan esas negociaciones de paz.

Estos son los grandes dilemas regionales que crean una dificultad enorme al proceso nicaragüense, por ello, cuando se escuchan "salidas simplistas" que se le proponen a la Revolución se percibe la falta de un análisis en profundidad de cuáles son los problemas estructurales que debe enfrentar esta joven revolución, o una falta de respeto a un pueblo que sacrificó a miles de sus hijos para ganar una identidad y dignidad nacional.

\section{NUEVA TÁCTICA: LA DESESTABILIZACIÓN ECONÓMICA}

Después de analizar las posibilidades de intervención debemos ubicar cómo la Administración Reagan está intentando una desestabilización económica considerable de la Revolución Sandinista que provoque una caída fuerte en la tasa de crecimiento del Proyecto Interno Bruto en 1982 (comparado al 80 un 10\% y al 81 un 6\%). Esta caída se vería agravada aún más por el desastre producido por las inundaciones de fines de mayo y comienzos de junio (más de 300 millones de dólares en pérdidas según CEPAL). Todos estos factores producirían una escasez que iría en aumento hasta llegar a finales de 1982 obligando a una marcada austeridad que afectaría el nivel de vida de las grandes mayorías. A pesar del espíritu nicaragüense, esta situación económica podría provocar descontento popular que podría ser utilizado por la oposición para fomentar la desestabilización política.

\section{LOS DILEMAS PROVOCADOS POR LA REVOLUCIÓN SANDINISTA EN LA ACTUAL COYUNTURA INTERNACIONAL}

Nicaragua es un país pequeño, pobre, subdesarrollado en recursos productivos y también en recursos humanos. También es un país ex- 
traordinariamente dependiente y abierto al mercado internacional. Nicaragua no puede aislarse, debe seguir ligada al mercado internacional. El problema es ¿cómo hacerlo?

La política económica del gobierno de Nicaragua se ha basado en el principio de diversificar la dependencia con Estados Unidos, aumentar la interrelación con los países de Europa, América Latina y los No Alineados, e iniciar una nueva relación económico-diplomático-política con los países socialistas. En los años cincuenta la dependencia de las relaciones económicas de Nicaragua hacia los Estados Unidos era inmensa. Cerca del 60 o 70\% de esas relaciones se realizaban con el país del norte. Actualmente se intenta diversificar esas relaciones para lograr flexibilidad y una cierta armonía. Se necesita caminar sobre "cuatro patas": una cuarta parte del total de las relaciones económicas con Estados Unidos, una cuarta parte con los países de Europa, una cuarta parte con los países de América Latina y los No Alineados y se está iniciando un proceso tendiente a establecer la última cuarta parte con los países socialistas. Este es un proceso lento. Hasta este momento las relaciones con los países socialistas son muy pequeñas y están en el orden de un 5 a un $7 \%$ de todas nuestras relaciones internacionales.

Nicaragua ha sido acusada de ser parte del bloque soviético. La última visita del Comandante Daniel Ortega fue presentada por la prensa norteamericana como el "alineamiento definitivo" de Nicaragua con la URSS. Sin embargo, el hecho de que otro miembro de la Junta, Sergio Ramírez haya visitado España, Austria, Holanda, Suecia, Irlanda, Grecia, etc., fue disminuido en la prensa internacional. Aún mucho menos se habló del viaje del compañero Rafael Córdova Rivas, tercer miembro de la Junta, a Venezuela y Costa Rica. La Revolución Sandinista mantiene su proyecto de soberanía e independencia a partir del cual establece relaciones a todo nivel y con todos los países. Esto es una exigencia producto de la dependencia, pequeñez y subdesarrollo de nuestro país.

Sin embargo, este dilema estructural en nuestras relaciones internacionales se complica porque los países amigos del bloque capitalista no metropolitano, tanto de Europa como de América Latina, los países llamados socialdemócratas o de capitalismo social, han proveído una ayuda que en valores absolutos parece grande pero que en términos relativos es pequeña.

Se adjunta un cuadro con el orden de magnitud de la destrucción y descapitalización que ha tenido que enfrentar la Revolución Popular Sandinista en estos tres primeros años. 


\section{Cuadro $\mathrm{N}^{\circ} 1$}

\begin{tabular}{l:c}
\hline Destrucción de infraestructura física durante la guerra de liberación & 481 \\
\hdashline Descapitalización y robo en 1978-1979 & \\
\hdashline Pérdidas por inactividad económica 1978-1979 & 518 \\
\hdashline Deuda externa heredada & 1246 \\
\hdashline Servicios de la deuda externa 1978-1979 & 1650 \\
\hdashline Total de daños materiales, descapitalización y deuda heredada del somocismo & 4144 \\
\hline
\end{tabular}

Nota: Todas las cifras son en millones de dólares.

Fuente: CEPAL y Banco Central de Nicaragua.

Nada semejante a esos 4144 millones de dólares se ha recibido ni se ha generado en el país en estos tres años. Por tanto el país está sufriendo una crisis de descapitalización a pesar de que la empresa privada dice que se han recibido enormes cantidades de ayuda y financiamiento que, sin embargo, no alcanzan ni a la mitad de este monto.

El nuevo dilema es que los países capitalistas no metropolitanos que han ayudado a Nicaragua no han cubierto ni la mitad de las necesidades dejadas por la tragedia de la destrucción y la guerra y ni siquiera han permitido con su ayuda y financiamiento iniciar el proceso de desarrollo hacia la nueva economía que el país necesita. Es llamativo por ejemplo que de todos los préstamos y donaciones recibidas por Nicaragua, el 49\% viene de países No Alineados, del Tercer Mundo y solo el $32 \%$ viene de los países capitalistas desarrollados, mientras que el $18 \%$ restante viene de los países socialistas incluyendo Cuba. Es decir, que para aquellos que dicen que la solución al dilema internacional de la Revolución Sandinista son los países capitalistas no metropolitanos, como los socialdemócratas, vemos que la Revolución Sandinista se encuentra con que esos países han tenido buenas palabras, buen apoyo, pero no se han comprometido con esta revolución en los términos en que se necesita.

Por otro lado, están los países socialistas entre los cuales sobresale la extraordinaria generosidad y compromiso de la Revolución Cubana a pesar de sus limitados recursos. Sabemos que la Revolución Cubana al mantener esa solidaridad está compartiendo su austeridad quitándose "el pan de la boca" y esto no puede ser un proceso permanente. Por otra parte, los países socialistas han iniciado un proceso de acercamiento y solidaridad con la Revolución Sandinista en forma creciente, pero todavía insuficiente. Esta insuficiencia de la ayuda tiene explicaciones estructurales como son la enorme distancia geográfica y económica que separa a Nicaragua de los países socialistas europeos y por otra parte las dificultades económicas en que 
se encuentran estos países, especialmente debido al compromiso que tienen en ayudar a Polonia a solventar su crisis económica, financiera y política. Por otro lado, el apoyo de los países socialistas está limitado por una problemática de tipo tecnológico dado que Nicaragua al haber estado dentro de la zona de influencia norteamericana tiene una tecnología fundamentalmente norteamericana y la tecnología de los países socialistas no se adecúa con facilidad. Además el nivel pequeño de nuestro mercado y el grande de nuestro subdesarrollo tecnológico impide una transferencia rápida de la tecnología actual a la nueva tecnología socialista.

Estamos de nuevo metidos en un grave dilema y una extraña paradoja. Una situación sorprendente en la cual la Administración Reagan pareciera que está empujando a Nicaragua hacia el bloque socialista. Esto se manifiesta tanto a nivel de la ayuda militar como de la económica. Las autoridades norteamericanas encarcelaron a los pilotos nicaragüenses que fueron a comprar helicópteros civiles y se han negado repetidamente a vender armas a Nicaragua. Por otra parte, Estados Unidos protesta ante Francia por la venta de un escaso equipo militar a Nicaragua. ¿Qué se pretende? Mantener a la Revolución Popular Sandinista sin fuerza aérea, sin fuerza naval, mientras Estados Unidos arma, en una forma desproporcionada, a Honduras y El Salvador.

Por otra parte, Estados Unidos corta toda la ayuda económica, crea presiones fuertes a las ayudas multilaterales del Banco Mundial, del Banco Interamericano de Desarrollo, crea presiones fuertes a países amigos para que no otorguen apoyo económico a Nicaragua (en el caso de Canadá, presionó para que Canadá no eligiera a Nicaragua sino a Honduras como país de concentración de ayuda económica en la región). Crea presiones contra Venezuela y con otros países europeos para que no sigan ayudando a la Revolución Sandinista.

Además la Administración Reagan presiona sobre la banca privada internacional para que no otorgue financiamiento a Nicaragua a pesar de que nuestro país está cumpliendo todos los compromisos financieros internacionales, incluso los de la deuda externa contraída por Somoza.

Es indudable que la Revolución Sandinista no va a permitir este boicot militar y económico y buscará recursos allí donde los pueda encontrar. La misma presión y amenaza norteamericana fuerza a Nicaragua a buscar la supervivencia en los países socialistas. Entonces la gran pregunta, la paradoja que presenta este dilema es: ¿ será que la Administración Reagan está buscando que la revolución nicaragüense se alinee cada vez más con el bloque socialista, con el fin de deslegitimar su originalidad con el fin de evitar que este modelo de eco- 
nomía mixta y pluralismo político no resulte? ¿Con el fin de evitar el éxito económico de la revolución nicaragüense intentando demostrar que es imposible mantener una economía popular eficiente? ¿Será posible que la Administración Reagan que no ha demostrado gran capacidad de manejo de la coyuntura intencional haya sido tan astuta y sutil como para provocar una estrategia de empujar a la Revolución Sandinista hacia el bloque soviético, de obligarla a usar sistemas políticos y económicos más rígidos, menos flexibles, menos originales, con el fin de deslegitimarla y aislarla de aquellos países amigos que la han apoyado?

En síntesis, tenemos aquí el gran dilema a nivel internacional. La Revolución nicaragüense necesita estructuralmente mantenerse abierta al área capitalista no metropolitana, sin embargo, estos países no se han comprometido en la forma que a Revolución lo requiere. Los países socialistas, por otro lado, no están en un momento económico como para comprometer según los requerimientos de la Revolución Sandinista. Por otro lado, el pequeño tamaño y la distancia que nos separa geográficamente de los países socialistas tampoco premian una trabazón económica muy fuerte con ellos. Al mismo tiempo, la administración Reagan pareciera estar usando una táctica de presión que obliga a la Revolución Sandinista a inclinarse hacia el bloque socialista como tabla de salvación y de esta forma intentar aislar a la Revolución de América Latina y de Europa.

Con estos tres grandes dilemas: el interno, el regional y el internacional se pretende sintetizar los grandes problemas estructurales que tiene que enfrentar la Revolución Sandinista y evitar análisis demasiados simplistas o legalistas. Se reconocen pues los errores cometidos, no todo ha sido ni podía haber sido perfecto, pero se intenta presentar toda la complejidad de ese panorama actual. Por otra parte, estos dilemas, en ningún momento pretenden sugerir que se tiene la solución. La solución es estar dentro del mismo proceso. Se intuyen algunas salidas, pero las soluciones van a surgir del mismo pueblo organizado en el proceso y de la misma marcha de construcción de la Nueva Sociedad y el Hombre Nuevo. Cuanto más participación popular, más autocrítica y más solidaridad internacional existan, más fácil será evitar los errores y encontrar las salidas más eficientes para resolver los problemas de nuestro pueblo a la vez que se busca una salida a la crisis centroamericana. Esta es la gran tarea del Tercer Aniversario de la Revolución Popular Sandinista. 



\section{La opción por los pobres y la teología de la liberación}



Ignacio Ellacuría

\section{LA TEOLOGÍA DE LA LIBERACIÓN FRENTE AL CAMBIO SOCIOHISTÓRICO DE AMÉRICA LATINA*}

LA TEOLOGÍA DE LA LIBERACIÓN pretende un cambio no solo en las personas y en la sociedad, sino también en las estructuras sociohistóricas de América Latina y, por extensión, de otras partes del mundo, en cada caso según sus circunstancias. Ese camino se nombra e interpreta en términos de liberación. Esa liberación que en términos teológicos puede expresarse paulatinamente como una liberación del pecado, de la ley y de la muerte, puede expresarse en términos históricos como liberación de todo aquello que oprime al hombre y le impide gozar de su vocación de hijo libre de Dios. Esta teología parte de una experiencia fundante, que le acompaña en todo su desarrollo teórico, consistente en la comprobación física y en la vivencia de que la mayor parte de la población latinoamericana vive en condiciones de pobreza y/o miseria y de opresión social y política, resultado de una injusticia estructural histórica, de la cual son responsables por comisión u omisión distintos sujetos sociales (clases, naciones, imperios) y distintos dinamismos económicos y políticos. Ante esta situación la teología de la liberación, primero como movimiento de fe más o menos reflexiva, y después como reflexión racional explícita, se pregunta qué dice la fe

* Ellacuría, Ignacio 1987 "La teología de la liberación frente al cambio sociohistórico de América Latina” en Revista Latinoamericana de Teología, º 12, pp. 241-263. 
cristiana tanto en el orden de las causas como en el orden de las soluciones, y se pregunta asimismo qué debe hacerse desde esa fe para conseguir que los pueblos oprimidos consigan a través de procesos de liberación convertirse en pueblos libres, que como tales pueden realizar y gozar lo que es posible históricamente de la presencia del reino de Dios entre los hombres.

Esto se plantea de forma distinta si se subraya la liberación de la teología (Segundo) o si se subraya la teología de la liberación (Gutiérrez). En el primer caso, lo que se pretende más inmediatamente es que la fe y la teología se liberen en lo que ellas mismas han tenido de contribución ideológica y social a que la religión y/o la fe cristiana hayan sido parte de la opresión, quedando así dispuestas a desempeñar su propia función de acompañar debidamente los procesos personales y sociales de liberación. En el segundo caso, lo que se pretende más inmediatamente es utilizar la fuerza social de la fe y de la Iglesia en la liberación socio-histórica de los pueblos. Lo que más importa de la teología de la liberación, se nos dice, es la liberación, pero en el primer caso el objetivo inmediato es la liberación de la teología, mientras que en el segundo caso es la liberación de la injusticia estructural, lo cual obligará forzosamente a una liberación de la teología. Pero tanto en un caso como en el otro lo que se pretende es hacer una auténtica y total teología y, antes, un auténtico y total proceso cristiano, que abarque todas las exigencias del reino de Dios.

Es importante resaltar que aun en el segundo caso, y con mayor razón en el primero, la teología de la liberación pretende ser, primero algo estrictamente teológico y, segundo, algo que pueda estimarse como una teología total. Lo primero significa que la teología de la liberación pretende situarse en la tradición teológica y pretende situarse en aquel modo de racionalidad que pretende ser la teología, sin desconocer el hecho de que la teología se ha entendido a sí misma como saber desde distintas formas de racionalidad. No es, por tanto, la teología de la liberación una sociología o una politología, sino un modo de saber específico, cuyas fuentes o principios son la revelación, la tradición y el magisterio, a cuyo servicio se ponen ciertas mediaciones. Si entre estas mediaciones tiene cierta importancia la de las ciencias socio-económico-histórico-políticas no implica necesariamente que se transforme en una de estas ciencias con lenguaje teológico, así como la preferencia clásica por la mediación de la filosofía no hacía necesariamente de la teología anterior una forma de filosofía. En la intención, en la metodología, en los hechos, la teología de la liberación se muestra cada vez más como una teología.

Lo segundo que ha de resaltarse en consonancia con lo primero es que la teología de la liberación no es una teología regional, sino una 
teología total, no es una teología de lo político, sino que es una teología del reino de Dios. Ciertamente tiene una clara vocación política, pues político es pretender la liberación no solo de las personas, sino de los pueblos, no solo de las opresiones psicológicas, sino también de las socio-históricas. Esta pretensión, necesita tenerse muy en cuenta, pues hace que, al menos en parte, la teología sea una teología política, pero no de tal modo que de la teología solo importe su significado y su eficacia políticos, ya que ella tiene su estricta consistencia teológica. Y esta consistencia hace que forzosamente tome como objeto (distíngase objeto tratado de objetivo pretendido) lo que se juzga ser el objeto de una teología total. El entender este objeto como reino o reinado de Dios hace que, por un lado, no se deje fuera nada de lo que es el mensaje revelado y, por otro, permite acercarse connaturalmente a las cosas de este mundo, porque en definitiva el reino de Dios, punto central del mensaje de Jesús, alude a la presencia reinante de Dios en este mundo, al Dios que se hace historia para que la historia se alce hasta Dios, a la humanización y mundanización de Dios para que el hombre y el mundo se divinicen. Todo ello en la persuasión creyente de que el hombre solo cuando sea más que hombre por la donación de Dios podrá llegar a ser hombre, según el pensamiento tradicional que en San Agustín tienen tan felices expresiones. Y lo mismo que vale del hombre, vale también del mundo y de la historia.

Pero insistir en el carácter teológico total de la teología de la liberación no debe impedir su eficacia política, porque la fe y la teología tienen o deben tener una clara vocación liberadora del pecado en todas sus formas, no excluidas sus objetivaciones; de la ley en todos sus modos a través de los cuales el poder se impone sobre quien no lo tiene tanto dentro como fuera de lo religioso; de la muerte en todos aquellos procesos que van anulando la vida o aun arrebatándola antes de tiempo.

La teología de la liberación, como forma plena de entender la fe cristiana y de llevarla a la práctica, no es, sin embargo, suficiente por sí misma para traer la liberación integral a las personas y a los pueblos. Por otra parte, se encuentra con otras fuerzas, que también se han percatado del estado de opresión en que viven las mayorías populares, que se han conmovido por ello y que, como fuerzas sociohistóricas, se han propuesto desde su propia especificidad luchar por esta liberación. Esto plantea la cuestión de cuál debe ser la relación de la teología de la liberación con esas otras fuerzas, sin las cuales no se puede obtener la liberación, que dice pretender como objetivo la primera para que efectivamente Dios reine en el mundo, para que Dios sea todo en todo. La cuestión surge sobre todo, tanto práctica como teóricamente, en relación con los llamados movimientos revoluciona- 
rios que han levantado la bandera de la liberación popular, pero también respecto de cualquier otro movimiento histórico que realmente pretenda el mismo objetivo. Hipotéticamente puede suponerse que la teología de la liberación no es suficiente de por sí para llevar a los pueblos una liberación efectiva y que los movimientos de liberación no son suficientes por sí para dar a los pueblos una liberación integral. Tal hipótesis arranca del presupuesto creyente de que sin Dios tal como se nos da y revela en Jesús no hay salvación (liberación), pero es una hipótesis que, por otro lado, se apoya en la constatación de que la salvación de Jesús, lejos de separarse de los procesos históricos de liberación, los reclama en función de la unidad transcendental de la historia de la salvación. No hay dos historias, sino una sola historia en la cual se articulan la presencia del Dios liberador y la presencia del hombre liberado y liberador. Las antiguas formulaciones de cómo aunar en lo interpretativo la fe y la razón y en lo realizable, la gracia y la naturaleza, se presentan de forma nueva en la teología de la liberación, la cual se pregunta cómo interpretar unitariamente el mundo desde la teología que es una fe en busca de entendimiento y cómo realizar históricamente el reino de Dios, que no deja fuera de sí nada de lo que es, nada de lo que ha sido creado.

\section{TIPOLOGÍA DE ALGUNAS ACTITUDES ANTE EL DESAFÍO POLÍTICO DE LA TEOLOGÍA DE LA LIBERACIÓN}

La teología de la liberación tiene que ver con lo político y esto hace que tenga que ver con la política. Tiene un claro propósito de liberación y de liberación efectiva, sobre todo en el modelo de teología de la liberación. Es este modelo el que presenta problemas más difíciles, pues el de la liberación de la teología, más que entrar en relación con procesos estrictamente políticos y revolucionarios, entra en relación con problemas de desideologización, que permiten cierta separación de la praxis política. Las dificultades surgen del tipo de actitud con la cual se enfrenta el problema, entendiendo por actitud la posición y disposición fundamental que se adoptan al querer hacer efectiva en la historia la teología de la liberación, la liberación que esa teología propone, que ha de aliarse de algún modo con aquellas fuerzas que también luchan por la liberación de las mayorías populares, por la liberación integral a partir de la liberación de los pobres.

El moralismo ingenuo no es una actitud usual entre quienes se mueven en el ámbito de la teología de la liberación, pero en lo que puede tener de verdad se hace presente de una manera o de otra. El moralismo ingenuo, por un lado, supone que la fe cristiana se ha de ceñir al ámbito de la moral, tanto personal, como social y política, y además, que la fe cristiana en su propósito de liberación, no ha de 
mancharse las manos con las prácticas poco morales de la política o con los males más o menos necesarios de los movimientos políticos. Propende a convertirse en un moralismo abstractizante, general y universal, que huye el enfrentamiento con los hechos concretos con el pretexto de que estos tienen siempre algo de política (mala o ambigua) y mucho más que huye de apuntar hacia objetivos políticos determinados históricamente, pues ninguno de ellos se adecúa con las exigencias del reino. En su caso más extremo quiere reducir la función de la liberación estrictamente cristiana al cambio de los corazones y a la proclamación de ideales abstractos y busca no ser tildada de partidista, como si todas las fuerzas sociales y políticas fueran igualmente buenas o igualmente malas y no se pudiera desde la fe discernir cuál es la que más contribuye a la liberación iluminada con la luz del evangelio. Señala bien esta actitud las diferencias entre el modo de buscar la liberación por parte de la fe y por parte de la acción política, pero no consigue la debida articulación. Se trata de dos cosas distintas, dos cosas que tienen relación, pero esa relación se establece más en términos de paralelismo que de determinación mutua y, en algunos casos, de interacción.

El fanatismo fundamentalista y el simplismo mesiánico son actitudes que esperan toda la liberación solo de la fe. Supone que hay una solución específicamente cristiana a los problemas políticos, económicos y sociales, aunque tal vez no para los problemas tecnológicos. No son necesarias otras mediaciones teóricas para descubrir las causas y proponer soluciones ni tampoco mediaciones prácticas para ponerlas en práctica. Basta con vivir el cristianismo desnudamente para encontrar por connaturalidad lo que realmente liberará al pobre. No se trata de un espiritualismo sino que, al contrario, se trata de extender connaturalmente el mensaje liberador del evangelio a cuanto problema humano se presente. No hay problema real para el cual no se pueda encontrar solución desde la fe. Esto lleva con frecuencia a un radicalismo indiferenciado en las denuncias y a un idealismo utópico en las propuestas de solución. Se trata del evangelio sin glosa no solo para la vida personal, sino para la vida social. Basta con la voluntad y el compromiso para terminar con la opresión. Para la negación, sobre todo, hay total facilidad, aunque siempre sea un poco más difícil delinear el contenido de la afirmación. Todo lo que no sea el ideal evangélico de sentar a los pobres en el trono y de derrocar al poderoso de su sede son componendas, y no es aceptable. En el mejor de los casos basta con un mínimo de esquemas interpretativos y de organización para conseguir el poder y transformar la realidad. La praxis liberadora irá dictando lo que se debe destruir y lo que se debe construir. Esta radicalidad, que es más bien radicalismo, lleva fácilmente a medir la 
bondad o maldad, la eficacia o ineficacia, por el grado de radicalismo sin medir mucho las consecuencias ni calcular los tiempos. Hay una fe ciega en la bondad de la propia actitud y posición y una seguridad mesiánica del triunfo. Lo importante es que no se apague el fuego, que no se extinga la esperanza ni la pasión. El retraso en el triunfo o los cadáveres que quedan en el camino no importan. Dios acabará triunfando con su pueblo. Aquí también puede gritarse "revolución o muerte", el todo o la nada. Señala bien esa actitud la fuerza de la fe y su historicidad, su capacidad de hacer historia por sí misma y de realizar de algún modo la liberación, pero no atiende a la terquedad y opacidad de la realidad opresora, a la posible lentitud de los tiempos históricos, a la totalidad de la complejidad histórica, que no puede ser denominada ni teórica ni prácticamente por los contenidos de la fe, ni siquiera por la luz de la fe en busca de nuevos contenidos.

El reduccionismo toma una doble forma. Por un lado, se interesa solo por aquellos aspectos de la fe cristiana, que tienen inmediata relevancia política, dejando en penumbra o en suspenso otros aspectos y aun la dimensión transcendente de la acción histórica. Por otro lado, hace de la fe, por lo menos en su relación con lo político, una pura instancia previa o, en el mejor de los casos, actual, pero subordinada a las exigencias de la acción política. La fe se convierte en propedéutica de la acción política y, cuando mucho, se la conserva como motor accesorio del compromiso, pero no como iluminación y crítica de los propios hechos históricos, tarea encomendada a las ciencias sociales y, en particular, al análisis marxista. Se supone que basta con los análisis científicos y con las propuestas que de ellos se derivan para emprender las acciones correctas e incluso para formar a los hombres que las van a realizar. La fe despertó tal vez la conciencia y preparó para el salto a la acción política, pero tiene el peligro de interferir con la lógica política y, por tanto, es mejor dejarla en suspenso, cuando no suprimirla. El compromiso de fe, la vivencia de la fe quedan abandonados en el supuesto implícito de que basta con amar a los hombres para amar a Dios, de que basta con promover la justicia para hacer el servicio que la fe reclama, de que basta con encarnarse políticamente entre los pobres para servir a Jesús del reino, oculto en ellos. Ante la presión de la acción política o no hay tiempo para el cultivo de la fe o se considera que la acción misma conducirá a la profundización de la fe en el compromiso. De todos modos, se permitirá y aun se fomentará el cultivo de la fe tanto cuanto promocione la acción política revolucionaria, incluso cuando pone ciertos límites a esta tanto en el orden de los sentimientos (canje del odio por el amor) como en el orden de las acciones (reducción de la violencia al mínimo necesario). En definitiva, se piensa que lo esencia de la confluencia entre el mensaje 
liberador de la fe y el compromiso político revolucionario está en la lucha por la liberación de los pobres, pero de tal modo que el mensaje debe subordinarse a la efectividad de la lucha y del triunfo. Si esto se logra la fe habrá conseguido su cometido y debe ser así porque la esperanza y la fe son transitorias, mientras que el amor es lo definitivo y más valioso.

El realismo supone y representa una actitud equilibrada que tiene en cuenta tanto lo positivo del aporte evangélico para la propia acción política como los límites de ese aporte, precisamente por la relatividad específica y la autonomía de los dos ámbitos; tiene también en cuenta tanto lo positivo de la acción política para la realización del reino de Dios como los límites que le son propios. Debido a ello considera igualmente lo que de relativamente específico tienen la acción política y sus resultados políticos (abiertos o cerrados a la transcendencia) y la realización del reino de Dios, no obstante su referencia a determinadas situaciones históricas, las cuales pueden ser conformes o disconformes con él. Esta actitud de realismo creyente sostiene que el mensaje evangélico es indispensable para que haya una total liberación de los hombres, de los pueblos y de las estructuras; de modo que, si esta sal se desvanece, se desvanecen también las posibilidades reales de que esa liberación total se vaya historizando. Pero sostiene también que no basta con el mensaje evangélico porque este no tiene armas propias ni para discernir las causas de la opresión y las propuestas de liberación, ni menos para llevarlas a cabo. El realismo lleva también a la convicción de que ninguna forma política se acomoda perfectamente a las exigencias del reino, pero no por ello las iguala a todas o prescinde de todas ellas en razón de un purismo, el cual no tiene sentido en un mundo histórico.

Esto hace que, en primer lugar, no sea indiferente y pueda, por ejemplo, rechazar en América Latina las distintas formas de capitalismo que han sido las principales responsables de la situación en la que vive la mayoría de la población; esto hace, en segundo lugar, que favorezca a aquellos movimientos políticos que más trabajan no solo a favor de los pobres y de las mayorías populares, sino que procuran el que estas mayorías populares vayan convirtiéndose en sujetos sociales y políticos más activos.

Todo ello supone, ante todo, que se ha de potenciar al máximo la fuerza liberadora de la fe, lo cual, negativamente, pide erradicar todo lo que en su predicación, reglamentación y vivencia hay de coartador de su potencial liberador y positivamente exige potenciar entre los creyentes, tanto de las bases como de la jerarquía, lo que la fe misma tiene de exigencia intrínseca de compromiso con la promoción de la justicia. Supone, después, la superación de actitudes ingenuas, 
lo cual exige un conocimiento cada vez más objetivo y fundado de las mediaciones teóricas y prácticas, a través de las cuales se interpreta y transforma el mundo en una u otra dirección. Junto a ello pide un permanente discernimiento de los signos de los tiempos, el cual para ser correcto deberá incluir en el aporte de la fe el análisis correspondiente. Supone, finalmente, la creación de formas de colaboración en los procesos de liberación, las cuales pueden ser diversas para la Iglesia como institución y para los creyentes, especialmente los laicos, que deseen comprometerse directamente con determinadas líneas políticas y aun con partidos y organizaciones concretas. La opción preferencial por los pobres, entendida en forma realista, es la que debe regir en estas opciones, pero teniendo cuidado de buscar aquellos procesos que más conduzcan a la liberación total, no dejándose engañar por las mil formas encubridoras que pueden tomar los sistemas de dominación y aun las propias debilidades personales, grupales o institucionales.

Esta breve tipología de actitudes no pretende ser exhaustiva ni como tipología general ni como descripción de cada uno de los tipos. Sirve, sobre todo, al propósito de mostrar a la cuarta de ellas como la más apropiada para ir encontrando el modo concreto más efectivo de conciliar la autonomía de la fe con la exigencia inexcusable de que esa fe promueva eficazmente la justicia y la liberación. La cuarta actitud es la más apropiada porque cumple mejor con una serie de principios que han de estimarse como esenciales en este problema. Tales son: a) la salvación (liberación) desde su principio en la creación se ha de entender como una acción de Dios, la cual debe ser conocida y aceptada consciente y aun temáticamente; b) esa concientización y aceptación supone el máximo ejercicio posible de la fe , que, cuanto más sea cultivada, estará en mejor disposición para promover ese proceso de salvación (liberación); c) esa fe debe ser operativa y lo debe ser en términos de liberación, la cual no puede reducirse a ser una liberación del pecado como culpa, sino que debe ser una liberación del pecado y del mal como objetivaciones dominantes en busca de una libertad que se refleje en el engrandecimiento personal y en la constitución de un mundo nuevo donde se favorezca la existencia del hombre nuevo; d) la operatividad de la fe exige entrar en relación articulada con aquellos procesos y aun grupos sociales y políticos que más favorezcan la liberación, supuesto que esta es siempre un proceso querido por Dios; e) en esa articulación la fe debe aportar lo más específico de ella como fuerza de liberación y de esperanza y también como criterio operativo de lo que no debe ser e iluminativo utópico de lo que debería ser; e) en esta línea el trabajo con las personas y las comunidades cobra un especial significado siempre que se revitalice una fe que viene de Dios. Una fe que está en la persona, pero que debe abrirse a una acción en 
el mundo, todo ello con el propósito de hacer realidad en las personas y en el mundo la visión y los valores evangélicos como levadura en la transformación de aquel; f) la opción preferencial por los pobres implica un criterio concreto de discernimiento, en cuanto el mayor bien de las mayorías populares pobres se convierte en la piedra de toque de cualquier proceso y grupo político.

\section{MODELOS DE RELACIÓN CON LOS MOVIMIENTOS SOCIALES Y POLÍTICOS}

El predominio de una u otra actitud de las desarrolladas en el apartado anterior leva a adoptar un modelo en las relaciones prácticas con los movimientos sociales y políticos, que luchan efectivamente por la liberación de las mayorías populares, y de los pobres. Caben muchos modelos de relación. Teniendo en cuenta lo que se ha ido dando hasta ahora se pueden utilizar y esquematizar los hechos convertidos en modelos-tipo. No se trata evidentemente de que todos ellos sean ejemplares o de que todos tengan el mismo valor cristiano; son más bien, modelos en el sentido de que esquematizan toda una serie de comportamientos.

El modelo de sustitución o de anulación supone que lo realmente importante en lo que pretende la teología de la liberación, es la liberación y, fundamentalmente, la liberación socio-económico-política. La predicación y la realización del reino de Dios van dirigidas a esa liberación, que una vez lograda podrá abrirse a otros valores. Lo más necesario ahora y, consiguientemente lo más valioso, es la consecución del triunfo revolucionario. Cuando de lo que se trata es de sobrevivir, las demás cosas, incluso las cosas de la fe, pueden esperar. Si en algún caso tiene sentido el hacerse anatema por los hermanos, es precisamente en este de trabajar por su liberación, ante la cual todo debe subordinarse. Si incluso quiere defenderse el sentido teológico de esta postura, habría que decir que nadie tiene más amor que el que da su vida por los demás y que se puede estar sirviendo a Jesús, aunque no se sepa que él está en el hambriento, en el encarcelado, en el perseguido, y últimamente en el pobre. Desde esta perspectiva no solo puede llegar el momento de que se vuelva necesario el romper con la Iglesia institucional y con mucha mayor razón desobedecer sus prescripciones cuando sea necesario, sino el abandonar el cultivo de la fe, en cuanto este cultivo puede impedir o frenar la lucha revolucionaria. En la formulación extrema, si son excluyentes el ser revolucionario y el ser cristiano, hay que optar por ser revolucionario, ya que esta es la exigencia ética fundamental y este es el mandato más imperioso en un mundo donde predomina la injusticia, la explotación y la dominación. La teología de la liberación ya hace bastante con introducir a la lucha 
política. La pastoral de la liberación lo que debe preparar es que los cuadros mejores abandonen el ministerio de la palabra y se constituyan en promotores de la liberación, en ejecutores efectivos e aquellas acciones que realmente liberen a los pueblos, objetivo último tanto de la acción religiosa como de la acción política. Esto supone, desde luego, una plena subordinación de la organización eclesial, en concreto de las comunidades de base o de otras estructuras eclesiásticas, a la organización política y la subordinación de la fidelidad a la institución eclesial a la fidelidad al movimiento revolucionario, y puede llegar a suponer la sustitución de la vivencia y los valores cristianos por la vivencia y los valores políticos.

A este extremo se puede llegar por dos caminos: uno, por la presión partidista que a la larga ve en la fe cristiana un freno para revolución; otro, por la presión práctica de la lucha de clases revolucionarias, que, se supone leninistamente, es el mejor antídoto teórico y práctico contra los desvíos de la religión. En el fondo de todo ese proceso hay una secularización revolucionaria de los principios y valores subversivos del evangelio. La fe puede ser el pedagogo inicial que despierte del sueño dogmático y de la inmovilidad popular, pero es, en el mejor de los casos, un estado transitorio, el cual idealmente debe desaparecer y que se tolera mientras no entre en conflicto con la dictadura del partido. En la interpretación más positiva, la lucha revolucionaria es la superación dialéctica de la fe, la cual es subsumida en el estudio superior del proceso revolucionario, una vez negadas sus limitaciones y aprovechados sus dinamismos. Lo que le sucede a la antítesis en la síntesis es lo que sucede a la fe en el proceso revolucionario.

El modelo de prestación y apoyo mantiene la autonomía de la fe, procura que esa fe se dinamice y potencie, pero hace lo posible para que esa fe dinamizada y potenciada se ponga al servicio efectivo de los movimientos revolucionarios o, más en general, del proceso socialista. Este modelo no sustenta explícitamente que la fe liberadora sea para el proceso histórico revolucionario de modo que en ese "para" agote su razón de ser, pero piensa que una de las misiones importantes de la fe es la de promover la lucha por la justicia y que esto no puede hacerse de modo efectivo más que optando por alguno de los movimientos políticos, a los cuales se les ayuda religiosa y políticamente y frente a los cuales se limita lo que de crítica pueda tener la fe.

En este modelo no basta con ponerse autónomamente al servicio de los pobres y de los oprimidos, ni siquiera ponerse al servicio del proceso revolucionario desde una posición independiente, sino que se busca ponerse al servicio de aquella organización concreta, que en cada caso resulte ser la vanguardia del proceso revolucionario. No se estima en mucho lo que la fe y aun la institución eclesial puedan 
hacer autónomamente en favor de los pobres y de la revolución. Se prefiere potenciar a las fuerzas que realmente pueden tomar el poder o mantenerse en él, perdonándoles aquellas debilidades que la lucha política por el poder lleva necesariamente consigo. No supone esto una manipulación de la fe, por lo menos en principio e idealmente. La promoción de la justicia a través de una opción política no tiene por qué separarse de la fe ni menos suponer una mengua de esta; al contrario, siempre en principio e idealmente, cuanto más vigorosa y encarnada sea la fe, mayor será su contribución a la causa de la justicia. Más aún, la elección partidista está hecha desde la fe.

Efectivamente, la fe impulsa al compromiso político; impulsa, en segundo lugar, al compromiso político revolucionario en aquellas situaciones donde la injusticia estructural es el carácter definitorio de las mismas; impulsa, finalmente, a ser efectivo y, por tanto, a apoyar aquellas instancias capaces de combatir la injusticia y de instaurar un nuevo orden social. Es la fe la que excluye la pertenencia a partidos que, de una u otra forma, cohonestan el status quo y es la fe la que impulsa a ponerse al servicio de los partidos que combaten ese status quo y que tratan de sustituirlo por otro que favorezca las causas populares. Esto puede hacerse desde una opción personal, integrándose plenamente en un partido político o en un movimiento revolucionario, al cual tratará de impulsar en su esfuerzo transformador, sin prestar atención prioritaria a que en los medios y en los objetivos inmediatos se hagan presentes los valores evangélicos. Puede hacerse también desde una opción de grupo cuando una comunidad de base o un conjunto de ellas se ponen al servicio de una determinada organización política sin abdicar de su vocación cristiana, pero dedicando toda su acción temporal al apoyo de la misma, en lo que ella determine como prioritario. Puede hacerse también desde una opción institucional cuando una parte de la Iglesia institucional o toda ella se enfrenta contra una determinada opción política y se pone a favor de otra opción social o política, como en el caso de la jerarquía polaca mientras se enfrentó más o menos abiertamente al régimen comunista y apoyó el sindicalismo de Solidaridad, mostrando con ello que algo así es posible en la dirección contraria en la cual se movió la Iglesia polaca. En todo esos casos no se trata de crear una tendencia crítica disidente de los cristianos dentro del partido o del movimiento revolucionario, porque se estaría más por lo común que por lo diferenciado, más por sumar que por restar.

El modelo de colaboración social se fundamenta en la convicción de lo que es específico de la fe y de la institución eclesial y de lo que es su limitación. Lo específico de la fe y de la Iglesia no es la promoción de aquellos aspectos políticos y técnicos, necesarios para la realiza- 
ción del reino de Dios en la historia, pero que no agotan la constitución del reino ni son posibilidad inmediata para el creyente en cuanto creyente o para la Iglesia en cuanto Iglesia.

Los aspectos políticos y técnicos del reino de Dios, así como los científicos, culturales, lúdicos, etc., no son objeto específico de la fe en cuanto son formalmente tales, sino en cuanto favorecen o desfavorecen el anuncio del reino de Dios. Dicho de una manera inexacta en su exclusividad, pero acertada en su direccionalidad, podría decirse que en la unidad del reino de Dios, el que "Dios reine" es el objetivo de la salvación (liberación), lo es el que el reino sea de Dios; pero cómo ha de configurarse, el reino, en tanto que realidad socio-histórica, es el objetivo de la historia. En la historia de salvación se conjugan para bien y para mal los dinamismos de la historia y los dinamismos de la salvación; hay entre ellos una mitad estructural de modo que se codeterminan mutuamente hasta el punto que esa unidad, más que los elementos que la constituyen, es el reino de Dios, es la historia de la salvación. Pero esto no obsta a que esos elementos sean distintos y que necesiten permanecer distintos para que la unidad tenga la riqueza y la autenticidad que le corresponden. Atendiendo solo al elemento político - pero lo mismo valdría en distinto grado para otros elementos como lo científico, lo tecnológico, lo cultura, etcétera-, puede decirse que determina y es determinado por el elemento cristiano sea cual fuere el modo como se realiza esa determinación, pero no por eso se confunde con él ni se sustenta, ni menos se realiza, por las características y los dinamismos del elemento cristiano. Lo político siendo político determina y es determinado por lo cristiano siendo cristiano no en forma de paralelismo ni necesariamente en forma de causalidad, aunque por simplificar la cuestión podría aceptarse que se da cierta interacción.

Aceptando ese esquema explicativo fundamentado en la unidad estructural y en la codeterminación de varios elementos, los cuales no son sin más "elementos", sino "elementos de" la unidad estructural, pero que tampoco son la pura unidad del "de", sino algo que tiene sus notas propias por ser tal elemento, podemos entender por qué el modelo de colaboración social sin romper la unidad con lo político tampoco se confunde con él ni se sitúa en el mismo plano.

Esto es más obvio en cuanto la salvación (liberación) se refiere a las personas y en ello no hay problema especial. La persona debe ser liberada del pecado, de la concupiscencia en sus múltiples formas (de la carne, del dinero, del poder) y debe, en su interioridad así como en su comunicación personal con los demás, convertirse en una criatura nueva, en un hombre nuevo, concretamente en otro Cristo, de modo que en la nueva vida ya no sea el yo viejo, sino Cristo quien sea princi- 
pio de la vida, de los modos de ser y de los modos de actuar. Ya desde este punto de vista es medible la diferencia entre el aporte cristiano y el aporte de lo político. Pero esto es también comprobable en la dimensión colectiva de la fe más allá de la dimensión personal o interpersonal. Los hombres liberados cristianamente pueden hacer mucho por la revolución o el cambio social, pero no se reduce a eso la misión social de la fe y de la institución eclesial. Veámoslo.

No puede negarse que la institución eclesial es una fuerza social. Prescindiendo ahora de toda consideración de fe, es una institución formada por millones de hombres enlazados entre sí dentro de un orden jerárquico, que tiene una doctrina propia y múltiples canales de acción frente a otras fuerzas sociales. Esta fuerza social le ha llevado con frecuencia a la tentación de convertirse en fuerza política. Si, para entendernos, hacemos un corte entre lo que es propio de la sociedad y lo que es propio del Estado - pasamos por alto la precisión y la actualidad de esta situación y podríamos hablar también de sociedad civil y de sociedad política-, debemos decir que la institución eclesial debe situarse formalmente en el ámbito de lo social, en el ámbito de la sociedad civil. Si por otra parte hacemos también un corte entre lo que es el poder político y lo que es el poder social, esto es, entre el poder que viene de, va a y está en la compleja estructura social, debemos decir que la institución eclesial debe situarse formalmente en el ámbito del poder social. Pues bien, el modelo de colaboración social, a través del cual la fe y la institución eclesial quieren contribuir a la realización del reino de Dios, y, en concreto al cambio social exigido por la injusticia de las estructuras, se atiene a que la institución eclesial es y debe ser una fuerza que se mueve directa y formalmente en el ámbito de lo social y no de lo estatal y que echa mano del poder social y no del poder político para realizar su misión.

Hay o puede haber una eficacia autónoma de la Iglesia y de la fe en la configuración de lo social. No solo es que la Iglesia sea en sí una fuerza social, la cual ejercida evangélicamente, no es otra cosa que el despliegue de su misión, sino que pretende ser una fuerza política, sea dominando a otras fuerzas políticas o poniéndose a su servicio, es como la sal que pierde su sabor. Sin profundizar ni extendernos en las razones de que esto ocurra - y el que haya ocurrido siempre debería ser ya un buen aviso probatorio- se puede apelar a aquella sentencia esencial del evangelio, que asegura que el hijo del hombre no ha venido a ser servido sino a servir, que, por tanto, el hijo del hombre y sus discípulos no deberán actuar como los señores de este mundo que pretenden dominar. En estas sentencias se señala la diferencia profunda entre el poder político y la fuerza social, entre la dinámica de la dominación y la dinámica de la liberación entre la ambición del 
mando y la sumisión de servicio. No por ello ha de renunciarse a la eficacia, pero la eficacia en este caso viene de la presión social, a través de la palabra y del gesto, y no del manejo del poder político. Cuando esta presión social se pone entera en favor de las mayorías populares y del movimiento popular con el consiguiente choque frente a las clases y estructuras dominantes, se entrará sin duda en conflicto, pero no en un conflicto por ir en contra de nadie, sino por ir en favor de las mayorías populares oprimidas. Es una labor parcial, que no agota todo lo que debe hacerse por otras instancias, pero es una labor propia de la Iglesia como fuerza social, y una labor en la que la fuerza de la fe aporta algo insustituible. Ejemplos como el de Monseñor Romero, con su Iglesia de San Salvador, muestran que este modelo tiene su peculiaridad y su eficacia.

Con este planteamiento se salva la especificidad y la autonomía de la fe y de la institución eclesial. Ni la Iglesia, ni ninguna parte de ella, ni siquiera un cristiano en tanto que cristiano ha de subordinarse a ninguna instancia política y, desde luego, a ningún gobierno. Especialmente esto es válido de la Iglesia como institución y de sus distintas partes, no excluidas las comunidades de base. Una cosa es el compromiso social en favor de la justicia y otra la subordinación a otras organizaciones, sobre todo de tipo político, de las cuales se reciben órdenes o consignas de actuación. Puede que la acción o la línea determinada autónomamente por la Iglesia o por partes de ella favorezcan más a una organización que a otra, pero esto debe ser como una consecuencia, no como un principio. No es aceptable la identificación de la opción en favor de los pobres con la opción en favor de la revolución, ni la opción por la revolución con la opción por una determinada organización revolucionaria, ni la opción por una determinada opción revolucionaria con la opción por una determinada vanguardia. El presumir estas identificaciones es un error de enormes consecuencias.

Hay una estricta gradación y el compromiso formal de la Iglesia debe ser por las mayorías populares desde el evangelio, quedando su compromiso con el resto de escalones condicionado a un discernimiento permanente. Solo en casos excepcionales se da la ocasión para que el compromiso institucional pueda sobrepasar el nivel de favorecer los cambios estructurales, requeridos por las mayorías populares para ir realizando su propia liberación. Monseñor Romero habla de la posible y peligrosa absolutización de las organizaciones populares, cuanto más de la subordinación a cualquier organización popular absolutizada.

Solo la desconfianza en la eficacia histórica de la fe puede llevar a abandonar su crecimiento para dedicarse al crecimiento de otras 
instancias. Esas otras instancias políticas son necesarias, como lo son también las instancias científicas, tecnológicas, etc. La fe tiene una palabra sobre ellas, unas veces de denuncia y otras de aliento. La fe puede lanzar a un trabajo estrictamente político en cuanto la política puede entenderse como un modo más universal de vivir la caridad. Pero difícilmente se dará el caso en que sea más beneficioso para el pueblo y las mayorías populares el que la Iglesia abandone la predicación y la realización de la fe en favor de un compromiso político. Hay tanto que hacer en la dimensión de lo social y desde lo social se puede presionar tanto sobre lo político, que no debe caerse fácilmente en la tentación de transformar la dimensión social de la fe en dimensión política. La política, en última instancia, se mueve en el plano de lo supra-estructural, mientras que la acción social se mueve en el plano de los sujetos humanos y también en el de lo estructural. La vida está más en lo social que en lo político, y lo social representa un lugar más natural para la Iglesia a la par que representa una tentación menor. Este recurso a lo social no se hace en la línea de separarse del mundo o de rehuir el compromiso; no se trata de potenciar a la Iglesia o evitarle peligros, se trata más bien de contribuir a la historización del reino, a su realización histórica en lo que es más propio de la Iglesia y en lo que más necesitan los hombres. No se pueden hacer separaciones estrictas. Se trata más bien de acentos. Pero los acentos son importantes.

Esta atención a lo social, en vez de a lo político, radica en el carácter social no político de la institución eclesial como en el carácter más real de lo social, en el carácter más participativo de los hombres en lo social y a través de lo social. Por ejemplo, está todo el campo de lo sindical o de lo educacional, donde la fe puede promover e inspirar estilos de acción de manera eficaz. Aunque nominalmente se da la posibilidad de que haya partidos o gobiernos de inspiración cristiana, en realidad esto no se da y lleva enormes peligros de manipulación del cristianismo. Así como pueden darse políticos de inspiración cristiana, es improbable que se den partidos y gobiernos de inspiración cristiana, mucho menos confesionalmente cristianos. En cambio, es más hacedero, aunque no sea fácil, ponerse en relación con fuerzas sociales para impulsarlas y orientarlas desde una inspiración cristiana. Todo ello repercutirá últimamente en la esfera de lo político, sobre lo cual debe presionarse como fuerza social y a través de las fuerzas sociales.

\section{LA TEOLOGÍA DE LA LIBERACIÓN Y LOS MOVIMIENTOS MARXISTAS}

No se trata aquí de discutir la relación de la teología de la liberación con el marxismo de un modo general. Esto ya se ha hecho en repetidas ocasiones y desborda, además, los límites de esta presentación. De lo 
que aquí se trata, a modo de ejemplo, es de situar al movimiento de la teología de la liberación en relación con las distintas formas sociales y políticas de orientación marxistas, que pretenden el cambio sociohistórico de América Latina.

La teología de la liberación ha surgido en buena medida de la experiencia del desastre humano que ha supuesto la vigencia de distintas formas de capitalismo en América Latina. Esa experiencia es en su inmediatez una experiencia de la pobreza y aun de la miseria injustas, que se abaten sobre la mayor parte de la población. Se trata primeramente de una experiencia ético-religiosa, semejante a la que tuvo Moisés, cuando se percató de cómo vivía su pueblo en Egipto. Él atribuyó esa situación a la opresión del faraón y, más en general, de la clase dominante egipcia. La teología de la liberación en América Latina atribuye también a los ricos y poderosos la situación que hace clamar a los pobres como un clamor que llega hasta el cielo.

Es una atribución de tipo ético-religiosa, quizá referida más a las personas que a las estructuras, a voluntades personales más que a leyes sociales. Serían los "ricos" los responsables de la situación de los "pobres", no solo porque no los socorren como fuera debido - punto tradicional en la predicación usual histórica de la Iglesia-, sino porque de una u otra manera serían responsables y causantes de la pobreza. De ahí la espontánea reacción ético-religiosa de ponerse a favor de los pobres y solo como consecuencia en contra de los ricos.

Esta experiencia fundamental y fundante se encuentra con una teoría que pretende explicar científicamente ese fenómeno y que propone no solo una alternativa al mismo, sino un modo de superación real. Es el caso del marxismo; pero es aquella parte del marxismo que explica los mecanismos de explotación del capitalismo, que propone un sistema económico distinto con su correspondiente sistema político y que arbitra una praxis revolucionaria capaz de derrocar el sistema capitalista y de implantar el sistema marxista. Se tiene, además, la vivencia de que solo los movimientos marxistas están haciendo algo efectivo por terminar con la etapa de explotación capitalista. De ahí se concluye que, si se desea hacer algo efectivo en la superación de la injusticia y en la liberación de las mayorías populares se debe sacar provecho de lo que el marxismo está haciendo tanto en el campo teórico como en el campo práctico. En un primer momento se apreciaron más las ventajas de los aportes del marxismo que las dificultades tanto inmediatas como mediatas que de él pudieran desprenderse.

En un primer momento, la teología de la liberación, en su afán de ponerse al servicio de la liberación de las mayorías populares, se hizo radicalmente anticapitalista y en esto coincidió con las posiciones marxistas. La Iglesia universal en su doctrina social había ido también 
logrando la persuasión de que un capitalismo no moderado por principios morales estaba siendo una verdadera plaga para la humanidad. Tanto la Gaudium et spes del Vaticano II como las últimas encíclicas papales han denunciado cada vez con mayor penetración y severidad los desmanes del capitalismo. Pero lejos de pensar que el capitalismo era intrínsecamente malo, se ha querido ver en él el modelo adecuado para el desarrollo democrático de los pueblos. Debe ser corregido, debe ser reformado, según las orientaciones de la moral cristiana, pero no tiene por qué ser abolido. Máxime, que la otra alternativa, la del socialismo real, le ha parecido a la Iglesia mucho peor, sobre todo para ella misma, pero también para los pueblos. Se ha comparado la situación de los países capitalistas noratlánticos con la situación de los países donde se ha impuesto un régimen socialista y de ello se ha concluido que era todo punto incomparablemente mejor lo que ocurría en aquellos que lo que ocurría en estos. Se tenía muy poco en cuenta lo que sucedía en el resto del mundo, donde otras formas de capitalismo daban como resultado situaciones desastrosas en lo económico, en lo social y en lo político. Por todo ello se pensaba que una reforma del capitalismo sería el sistema adecuado para resolver los problemas y que ese sistema supondría el mejor contexto en el cual podría consolidarse el ser de la Iglesia y su misión. Puede decirse así que la doctrina social de la Iglesia es un intento de reforma y de humanización del capitalismo.

Pero la experiencia liberadora en América Latina era distinta. El capitalismo aparecería en sus realizaciones históricas, no solo como intrínsecamente malo, sino como sustancialmente antievangélico. El capitalismo era irreformable. Podría conseguirse que hiciera males menores, pero no podía concebirse como el modelo ideal en el que el hombre fuera verdaderamente hombre y en el que las mayorías populares tuvieran la posición que merecen a los ojos de Dios. El capitalismo es bueno para los fuertes y los débiles pueden aprovecharse de él en tanto que los fuertes se enriquezcan más y distribuyan algo de su riqueza. Esto no es evangélico. Lo evangélico, la exigencia del reino de Dios, es que se alcance un sistema en que las mayorías populares, los pobres, sean el verdadero sujeto de la historia, si no por ser pobres, al menos por representar a la mayoría de los pueblos y a la mayoría de la humanidad. Había una experiencia real del capitalismo y de sus males y no había una experiencia real del socialismo y de sus males. Esto hace que la teología de la liberación, en vez de pretender y propiciar una reforma del capitalismo, se esfuerce en conseguir una reforma del socialismo. El socialismo, se pensaba, es un sistema más conveniente para la causa de los pobres y es, consiguientemente en virtud de la opción preferencial por lo pobres, más congruentes con la realización histórica del reino que debe impulsar la fe cristiana. 
Se pasa así de una posición anticapitalista a una posición prosocialista. Lo primero es la posición anticapitalista, al percatarse no solo vivencialmente, sino racionalmente de que los males de América Latina no vienen de la dureza de corazón de los ricos, sino de la estructura misma del sistema, tanto en su configuración interna como en su conexión con el capitalismo mundial, especialmente con el de Estados Unidos, que se constituye en el guardián político y militar de ese orden. El anticapitalismo lleva al antiimperialismo norteamericano. La liberación de América Latina debe ser no solo una liberación del sistema capitalista, sino también una liberación de la dominación norteamericana. Apoyar las causas y los procesos anticapitalistas y antiimperialistas se convierte así en uno de los modos de acción histórica de la teología de la liberación. Así se llega a una colaboración obvia con los movimientos revolucionarios marxistas que están entregados totalmente a esa tarea, no obstante que se aprecien defectos tanto en la teoría como en la práctica de los mismos. Sin embargo y en consecuencia con lo anterior, se es anticapitalista, pero no se es de la misma forma promarxista, cuanto menos se es marxista. La teología de la liberación y los movimientos que están bajo su inspiración es y son cristianos, aunque sus distintas actitudes y los diversos modelos frente al cambio social los pueden llevar a ciertas desviaciones prácticas, que a la larga pueden transmutar su realidad. Pero en este caso se ha abandonado lo que es la teología de la liberación: por lo tanto no es justo atribuirle lo que ya no es propio de ella.

Uno de los puntos en los que tiende a darse una convergencia es en la cuestión de los pobres por un lado y de las clases oprimidas por otro, de modo que la lucha de clases se convierte tanto para la teología de la liberación como para el marxismo en un punto de coincidencia. Se piensa que la preocupación de la teología de la liberación por los pobres, a la hora de buscar efectividad real, debiera inclinarse naturalmente a la interpretación clasista de esa categoría bíblica y, consecuentemente a una práctica política de lucha de clases, la cual es esencial al marxismo, al menos en su forma más ortodoxa. Sin embargo, conviene hacer ciertas aclaraciones para no caer en simplismos. Tal vez no siempre se ha tenido un cuidado en este punto y, aunque los teólogos de la liberación no han solidado caer en confusiones, tal vez en algunas acciones prácticas y en algunos movimientos de base sí se ha podido caer en ellas y también en exageraciones. Ante todo, no está de más recordar el famoso texto de Marx referido a la lucha de clases:

Por lo que a mí se refiere, no me cabe el mérito de haber descubierto la existencia de clases en la sociedad ni la lucha entre ellas. Mucho antes que yo, algunos historiadores burgueses habían expuesto ya el desarrollo histórico de esta lucha y algunos economistas burgueses 
la anatomía económica de estas. Lo que yo he aportado de nuevo ha sido demostrar: 1) que la existencia de clases solo va unida a determinadas fases históricas del desarrollo de la producción; 2) que la lucha de clases conduce necesariamente a la dictadura del proletariado; 3 ) que esta misma dictadura no es de por sí más que el tránsito hacia la abolición de todas las clases y hacia una sociedad sin clases (Carta de Marx a Weydemeyer, 5 de marzo de 1852).

Del texto se desprende que las clases y la lucha de clases se dan históricamente de una cierta manera espontánea, lo cual ya había sido descubierto como una cierta ley de la historia por autores premarxistas. Este punto es importante porque la teología de la liberación habría reconocido esta interpretación, hasta cierto punto neutral, de que efectivamente se están dando clases y luchas de clases, con el agravante de que la situación en América Latina muestra que son las clases dominantes las que han iniciado la lucha y la violencia no solo para construir las clases dominadas, sino para mantenerlas en la dominación, de modo que las incipientes respuestas históricas de las clases dominadas son eso: respuestas a una violencia anterior, respuestas provocada no solo por la situación objetiva de las clases dominadas, definida por la miseria y la injusticia, sino por la percepción de que esa situación se debe a la violencia cometida contra ella.

Del marxismo, entonces, se ha tomado que ese fenómeno de las clases primero y de la lucha de clases después se da específicamente en una determinada fase histórica del desarrollo de la producción; para el caso latinoamericano esa fase histórica sigue siendo la fase actual, cosa que tal vez no se da en los países más desarrollados donde la producción ha tomado otros derroteros. Del marxismo se ha tomado también - y esto muy en consonancia con la inspiración cristianaque es necesario llegar a la abolición de las clases, conducente a una sociedad sin clases, tal como el lenguaje metafórico se anuncia con fuerza en el mensaje bíblico.

Todos esos puntos de convergencia tienden a concluir que los pobres de los que habla la Biblia son el proletariado del que habla Marx y que, por consiguiente, el modo de liberación de esos pobres pasa por una dictadura del proletariado. Sin embargo, la teología de la liberación más madura y crítica no acepta estas proposiciones. Entre decir que los pobres bíblicos son las clases dominadas, entendidas estas como categoría socio-histórica, sea de los pensadores burgueses o marxistas, y el asegurar que los pobres bíblicos no tienen nada que ver con esas clases, la teología de la liberación sostiene una posición mucho más diferenciada.

Los pobres bíblicos tienen muchas semejanzas materiales con las clases oprimidas, pero no se identifican con ellas por las siguientes 
razones: 1) aunque el grueso de los pobres bíblicos y la razón de su pobreza tienen mucho que ver con las clases oprimidas, el concepto de pobre bíblico es más amplio y, en concreto, no puede identificarse con el proletariado estrictamente entendido; 2) la especial preferencia de Dios por los pobres no se reduce a su liberación puramente socioeconómica sino que atiende a su condición personal y a su liberación histórico-transcendente; 3 ) los pobres de Yahvé, teniendo como tienen una estricta realidad socio-histórica, no se reducen a ser una categoría socio-histórica; 4) los pobres para que contribuyan plenamente como sujetos activos a la liberación integral propia y de los demás, sin abandonar su condición histórica, deben incorporar el espíritu del mensaje cristiano de modo que sean auténticamente pobres con espíritu; 5) aunque puede haber tramos de coincidencia en la lucha histórica con las clases sociales oprimidas, lo que las clases oprimidas pueden hacer con sus luchas revolucionarias, no es suficiente ni para la liberación integral ni siquiera para la liberación exclusivamente histórica; 6) esa coincidencia difícilmente pasa por la dictadura del proletariado, tal como se ha venido danto históricamente a través de las vanguardias de los partidos.

Esta posición diferenciada lleva a conclusiones prácticas. La teología de la liberación no puede menos de aprobar y en muchos casos de apoyar a aquellos movimientos marxistas auténticamente revolucionarios y no puramente burocráticos, sobre todo en lo que tienen de preocupación y trabajo por los pobres tanto a la hora de la denuncia de las opresiones del sistema capitalista como a la hora de procurar eficazmente la superación de las distintas formas de miseria, injusticia y opresión. Esto se da sobre todo cuando se trata de organizaciones populares, respecto de las cuales el marxismo y la toma del poder no son elementos esenciales, sino aspectos instrumentales en la lucha para que las mayorías populares se conviertan en sujetos activos de su propio destino histórico. Pero al mismo tiempo la teología de la liberación no puede menos de diferenciarse de las políticas marxistas y esto de diversas formas. La teología de la liberación pretenderá, ante todo, el robustecimiento creyente de las mayorías populares, lo cual no implica su debilitamiento social comprometido, pero sí su responsabilización en lo que tienen de sector preferencialmente elegido por Dios para traer a la historia una liberación integral, que va más allá de un planteamiento exclusivamente político. En este sentido hay una autonomía que debe ser respetada. La teología de la liberación pretenderá, también, robustecer el aporte de la fe cristiana al cambio social por cuanto, aun sin subordinarse a ninguna instancia política, la fe, los que viven la fe y la Iglesia tiene una fuerza propia que debe ponerse autónomamente al servicio de la realización histórica del rei- 
no. Finalmente, la teología de la liberación impulsará el que los movimientos políticos y/o sociales, los cuales dicen estar al servicio de las clases oprimidas, lo estén de hecho y primariamente, sin subordinar ese servicio a la consolidación institucional de esos movimientos y además que en la elección de los medios y en la jerarquía de los valores se acomoden a lo que la fe cristiana propone como espíritu de toda liberación posible.

Con estos principios la teología de la liberación no solo desecha el anatema político e ideológico que pesa sobre el marxismo y sobre cualquier posición progresista en muchos círculos de América Latina, no excluidos amplios sectores populares, sino que se esfuerza en colaborar con el marxismo de una forma positiva. Esa colaboración no llega a aceptar puntos más bien filosóficos del marxismo en lo que pueda tener de sistema materialista cerrado, sino que se ciñe en lo teórico a la utilización más bien heurística de lo que el marxismo tiene de análisis científico en cuestiones socio-históricas y específicamente económicas y en lo práctico se dedica a promover todo lo que de positivo puede haber en los movimientos populares y en los movimientos de liberación, sin olvidarse de criticar lo que de malo pueda haber en ellos o de impulsar aquellos elementos que pueden ser mejorados. Se da así una clara distinción con otras posiciones dentro de la Iglesia y ello constituye uno de los puntos de debate frente a la teología de la liberación. Pero para que ese debate sea útil no puede llevarse a cabo caricaturizando la posición global de la teología de la liberación, tal como ocurre en la primera de las instrucciones de la Sagrada Congregación para la Doctrina de la Fe sobre la teología de la liberación. Ni el marxismo ha desfigurado la interpretación que la teología de la liberación hace de los puntos esenciales del mensaje cristiano, ni aquella mantiene una posición ingenua ante la práctica política de los distintos movimientos marxistas. Más bien se mueve con distintos matices y diferentes tendencias el marco aquí descrito.

\section{LA TEOLOGÍA DE LA LIBERACIÓN Y LA VIOLENCIA}

La teología de la liberación no solo es relacionada con la lucha de clases, sino más específicamente con la violencia revolucionaria. Con la incitación al odio, la lucha de clases se extendería y radicalizaría y, desde ella, la violencia revolucionaria sería el arma propia de las masas en la conquista del poder. Odio, lucha de clases, violencia revolucionaria no solo serían toleradas en la teología de la liberación, sino que además serían provocadas por ella. Sin embargo, si esto no es así de simple en el marxismo, lo es mucho menos en la teología de la liberación.

Al contrario, la teología de la liberación surge de la vivencia profunda del estado de violencia y de los actos de violencia, que consti- 
tuyen el entramado social de América Latina y se propone con todas sus fuerzas la anulación de esos actos y la superación de ese estado. Desde este punto de vista, la teología de la liberación pretende ser una instancia desideologizadora de la violencia. De ningún modo se atiene a aquel principio de que la violencia es mala, venga de donde venga. Ciertamente puede aceptar que todo acto de violencia, todo acto que por la fuerza haga algún mal, no es bueno, pero para afirmar inmediatamente que la violencia se predica y se afirma de muchas maneras y que todas esas maneras de ninguna forma son unívocas ni menos uniformes. Hay unas violencias peores que otras. La moral clásica, tan gustosa de distinguir especies y matices en los pecados desde muchos puntos de vista, debiera utilizar la misma precisión al hablar de la distinta gravedad de las diversas formas de violencia. La teología de la liberación pretende formalmente y en última instancia que se supere toda forma de violencia, que desaparezca la violencia en todas sus formas, pero no por eso permite el que, so pretexto de que toda violencia es mala, las más graves formas de violencia se consoliden. Por eso se pregunta por las distintas formas de violencia y por sus efectos, según el criterio y la perspectiva desde la cual enfoca sus problemas, el de la opción preferencia por los pobres, el de la situación de las mayorías populares.

Desde esta perspectiva, la cual está en plena consonancia con el mensaje bíblico, la teología de la liberación atiende, en primer lugar, a aquella violencia que se abate sobre las mayorías populares en forma de injusticia estructural. Se trata de aquella injusticia que afecta al conjunto de las estructuras sociales, económicas, políticas, culturales, etc., en las cuales forzosamente ha de vivir el hombre y que por su propia estructuración le impiden vivir humanamente. No se trata solo de que esas estructuras no le den facilidades para llevar una vida humana, sino que se lo impiden al privarle por la fuerza, muchas veces legalizada e institucionalizada, de aquellos medios indispensables para poder vivir como hombre. La opresión en todas sus formas y, más en general, todo modo de injusticia estructural, es la mayor de las violencias por cuanto afecta a la mayoría de la población y la afecta en aquello que le es más sagrado y profundo: la conservación y el perfeccionamiento de la propia vida. Y es la mayor de las violencias, no obstante que se presenta con modos y maneras desprovistos del dramatismo aparente de otras formas de violencia. Todo lo que la teología de la liberación denuncia como pecado social, que en la situación de América Latina es en gran parte resultado del capitalismo imperante, tanto en la relación centro-periferia, norte-sur, como en su reflejo correspondiente dentro de cada país, se considera como violencia y origen de violencia. El reflejo principal, pero no único, de 
esta violencia es la situación de pobreza y miseria que afecta de forma fundamental no a la calidad de la vida, sino al hecho mismo del vivir.

La represión es también parte de esta violencia estructural y, cuando no es una represión puramente ideológica de engaño por la imagen y la propaganda, sino que se convierte en represión policial o en represión a través de los escuadrones de la muerte, tiende a cobrar formas extremas, las cuales subjetiva y objetivamente, tienden a aniquilar a sus víctimas. El estado de violencia en que se está en razón de la injusticia estructural no puede ser mantenido más que por la fuerza injusta de una violencia sobreañadida. Esta represión trata de impedir la lucha contra la injusticia ya sea preventivamente, ya sea con un desatado terrorismo de Estado o de clase, cuando ya han surgido los movimientos revolucionarios y aun anteriormente cuando ha surgido la protesta popular contra una situación que se va haciendo insostenible, no solo por la hiriente desigualdad entre los pocos que lo tienen todo y las mayorías que apenas tienen nada, sino por los mecanismos de acumulación y explotación que han dado origen a esa situación. Estas descripciones no son fantasías académicas, sino constataciones de las formas como se presenta la violencia en muchos pueblos de América Latina.

La teología de la liberación hace de esta situación un dato primario. No solo se percata de que es una realidad que afecta profundamente a la mayor parte de la población, sobre todo en los países más pobres, sino que la estigmatiza como un gravísimo pecado. Lo que el Éxodo plantea como el gran clamor de un pueblo que llega hasta la presencia de Yahvé, como un reclamo creciente de liberación, lo hace asimismo la teología de la liberación, la cual lee en los mismos términos la situación latinoamericana. La lectura del Éxodo en este estudio del análisis lleva, en primer lugar, a entender como justicia primaria el anhelo de liberación de este pueblo así oprimido y reprimido y, en segundo lugar, a buscar, como en el caso de Moisés, aquellos medios efectivos que puedan traer la liberación. Pero en el momento actual hay una separación histórica de las dos dimensiones de Moisés, la política y la religiosa. La teología de la liberación se sitúa más bien en la dimensión religiosa, pero busca la relación con la otra dimensión política, que en su radicalidad solo es mantenida por los movimientos revolucionarios.

La teología de la liberación, entonces, acepta en principio la moralidad y aun la coherencia cristiana de la violencia liberadora de las otras formas radicales de violencia, siempre que se dé en el contexto y con las condiciones debidas. Sigue en esto la misma línea de la moral clásica solo que de una forma más rigurosa y restringida al permitir ciertas formas de violencia solo frente a la violencia estructural, re- 
presiva y opresora. La violencia de la injusticia estructural, sobre todo cuando llega a extremos de impedir la realización de la vida humana y de cerrar todos los caminos menos violentos de buscar el remedio, es un mal máximo que puede y aún debe ser combatido con medios eficaces, incluida la lucha armada. En la caracterización del mal la teología de la liberación resalta el carácter social de la injusticia estructural más que el carácter político (tiranía), al cual solía referirse la moral clásica, considerando que lo social es más definitorio que lo político. Pero, no obstante la licitud limitada de la lucha armada, esta es siempre un mal, y solo puede sr usada en proporción con el mal mayor que se quiere evitar. Ese mal ha de medirse sobre todo en relación con los daños que a corta y larga distancia se dan para las mayorías. Cuando, en cambio, se da una subordinación del bien de las mayorías populares a la conquista del poder político por parte de un movimiento revolucionario o al mantenimiento en él, queda inválido el derecho a la lucha armada.

Por otro lado, no cualesquiera medios violentos pueden ser empleados. Hay medios tan intrínseca y totalmente malos, que su utilización está vedada. De ahí que la violencia revolucionaria no debe tomar nunca la forma de terrorismo. Se entiende por terrorismo aquel conjunto de acciones hechas contra personas indefensas de forma violenta que ponga en peligro su vida o su integridad física. Algo no es terrorismo porque proceda de grupos cualificados anteriormente como terroristas, sino que el terrorismo y el terrorista deben medirse por las acciones perpetradas. Desde este punto de vista hasta gobiernos legalmente establecidos pueden ser estrictamente terroristas en distinto grado. Los movimientos revolucionarios caen también con frecuencia en la tentación de cometer acciones terroristas.

Tampoco es aceptable propicias como condición subjetiva, favorecedora de la violencia revolucionaria, el odio en ninguna de sus formas. El enemigo no deja de ser persona humana, a quien se pretende liberar de su papel de opresor o represor violento. La difícil tarea de armar al enemigo, incluido el enemigo social, no deja de ser un desafío para el cristiano. Ciertamente las clases no son personas que se pueden amar u odiar, pero hay el peligro de introducir en el rechazo de la clase el rechazo de las personas que pertenecen a ella. La lucha revolucionaria no debe hacer olvidar que el evangelio está más en favor de la paz que de la guerra, más del servicio que de la dominación, más del amor que del enfrentamiento.

Es posible que la teología de la liberación haya sido en algunos momentos y en algunos lugares un tanto ingenua sobre las posibilidades reales de violencia revolucionaria, sobre su mezcla de males y de bienes. Puede aceptarse que los cambios revolucionarios necesarios 
en América Latina no pueden conseguirse sin movimientos traumáticos. Todo el cuerpo social y político está organizado con vistas al bienestar y al dominio de las élites dominantes y al servicio de los imperialismos, lo cual, si se quiere cambiar urgente y drásticamente, implica transformaciones que encuentran una resistencia fortísima. Pero en estos casos no cabe pasar fácilmente de la necesidad ética a la posibilidad política. Los triunfos revolucionarios en Cuba y Nicaragua hicieron que se viera como inminente un cambio revolucionario global en toda América Latina o, al menos, en algunos países. Los fracasos en Argentina, Uruguay, Chile, Bolivia, Brasil, el feroz desangramiento ocurrido en Colombia y Guatemala, la dureza de la lucha en El Salvador, han hecho que no se pueda caer en ingenuidades políticas. Los fundamentalismos religiosos pueden llevar a suicidios sociales.

Por otro lado, el uso de la fuerza para mantenerse en el poder y los escasos resultados económicos van haciendo más cauta a la teología de la liberación. Ciertamente regímenes levemente reformistas no están trayendo una mínima liberación a las mayorías populares ni las democracias políticas están generando democracias sociales, ni siquiera están produciendo la ruptura del círculo de la miseria y de la injusticia estructural. Por todo ello, aunque la teología de la liberación propende a simpatizar más con las organizaciones populares y con los movimientos revolucionarios, no por eso cae en el simplismo de identificar su propósito utópico con las formas concretas que aquellas y estos toman. Tal vez puede aceptar como mal menor algunos procesos revolucionarios y mantenerse frente a ellos en posición de vigilante crítica y de apoyo ponderado, pero no puede caer en fáciles simplificaciones, las cuales desconocen la relatividad y la pecabilidad insertas en las personas que conducen los procesos, y la complejidad de los procesos sociales, la cual implica un proyecto nacional.

\section{A MODO DE CONCLUSIÓN}

La teología de la liberación, de hecho, ha tenido y sigue teniendo un tremendo significado político. Así se vio en el Informe Rockefeller, en los planteamientos de Santa Fe, en los constantes ataques a los que se ve sometida por las fuerzas conservadoras fuera y dentro de la Iglesia. Se estima que, aunque ella misma no sea por sí sola una fuerza capaz de transformar revolucionariamente la situación de América Latina, puede convertirse en un factor importante en el conjunto de fuerzas que constituyen el movimiento revolucionario. Incluso algunos de los movimientos marxistas no solo han quitado a la fe que propugna la teología de la liberación el sambenito de ser opio del pueblo, sino que le atribuyen un papel positivo en las luchas liberadoras. 
Tal reconocimiento no es infundado. La fe, la religión y la Iglesia siguen siendo elementos especialmente significativos e influyentes en la contextura social, especialmente entre los más pobres de Latinoamérica. Si la fe y la Iglesia se ponen de lleno a favor de la causa popular, si intra y extraeclesiasmente hacen efectiva la opción preferencial por los pobres y dejan de amparar conservadoramente el orden establecido, algo importante se habría conseguido. Medellín y Puebla alertaron a las fuerzas reaccionarias, las cuales midieron bien lo que podía significar para el continente un cambio tan sustancial de la Iglesia y de su predicación. Los partidarios de la seguridad nacional han llamado a esto marxistización de la fe y marxistización de la Iglesia, porque todo cuanto entra en conflicto con los dictados de la teoría de la seguridad nacional y con las exigencias del capitalismo es tildado de marxismo. Las acusaciones no son solo verbales. Son muchísimos los que en los últimos diez años han sido asesinados para obligar a la Iglesia y a los más avanzados de ella —obispos, sacerdotes, laicos- a abandonar su nueva posición de denuncia y de aliento a los movimientos reivindicativos y revolucionarios. Pero ello no ha detenido el movimiento. La teología de la liberación sigue expandiéndose y consolidándose como movimiento estrictamente teológico, pero también como praxis pastoral. Por ambos flancos sigue contribuyendo al cambio social en América Latina.

En dos campos sigue este avance y consolidación. El primero de ellos está dentro de la Iglesia, no sin enormes resistencias. Este campo es decisivo. Si se lograra que la Iglesia latinoamericana en cuanto tal se pusiera efectivamente en la línea de Medellín y Puebla, no solo se lograría una profunda transformación eclesial mucho más evangélica y evangelizadora, sino que se constituiría en una fuerza muy importante para el avance de la liberación y para que esa liberación se conformara según los valores evangélicos. El otro campo es el de poner esta fuerza en relación con las necesidades populares de liberación. No se ha encontrado siempre el modo de hacerlo, un modo que junte la eficacia a corto y largo plazo con el respeto a la propia mismidad cristiana y a la relativa autonomía de esa mismidad. Se trata de un problema difícil al cual todavía no se ha dado una respuesta para siempre. Hay todavía vacilaciones y discusiones. Sobre los puntos que han sido tratados en esta exposición hay ya mucho escrito, hay también intentos prácticos diversos, los cuales no coinciden con las líneas aquí desarrolladas. No es esta la ocasión oportuna para discutir analíticamente otras posiciones. Con lo escrito puede bastar para plantear el problema y para situar algunas cuestiones fundamentales en la perspectiva debida. Lo importante en definitiva es salvar la plenitud del mensaje revelador y liberador de Dios en Jesucristo y de lograr su 
plena eficacia en la historia, en la convicción de que cuanto mejor se desarrolle el primer empeño más eficaz será el segundo; pero también en la convicción de que es necesaria la praxis, la realización histórica del reino de Dios para alcanzar teórica, vivencial y eficazmente la plenitud de ese mensaje. Las cosas se han puesto ya en marcha. Lo importante ahora es que no se ahogue el espíritu nuevo. De momento todavía hay esperanzas de que esto no vaya a ocurrir. 



\section{Pedro Casaldáliga}

\section{OPCIÓN POR LOS POBRES, INCULTURACIÓN Y COMUNITARIDAD*}

IGLESIA VIVA ME PIDE una contribución - a mi aire, naturalmente- en torno a "los aportes del diseño evangelizador de la Iglesia de los pobres para un proyecto no-eurocéntrico de evangelización". Intentaré apuntar algunas preocupaciones y aspiraciones que agitan mi fe y mi ministerio acerca de ese tema y que muchos otros y otras comparten, sobre todo en el Tercer Mundo (en la Tercera Iglesia). Diré someramente lo que hacemos o queremos hacer y quizás así diga también lo que aportamos o podemos aportar.

\section{I}

Parece que eI Vaticano II quiso enseñarle a la Iglesia el diálogo, preterido o mal llevado, con el mundo moderno: con el mundo europeo, decimos nosotros aquí; o, en todo caso, con el Primer Mundo. El "otro" mundo, los mundos "otros", prácticamente no entraron en consideración. Por lo menos no entraron en una consideración eficaz. La larga tradición europea, o del norte, de la Iglesia, su hábitat como connatural, seguía imponiéndose. (También para Ia Iglesia, oficialmente hablando, con demasiada frecuencia parece que no existe el sur...). Todas las transformaciones pastorales, litúrgicas,

* Casaldáliga, Pedro 1992 “Opción por los pobres, inculturación y comunitaridad" en Iglesia Viva: Revista de Pensamiento Cristiano, $\mathrm{N}^{\circ} 157$, pp. 67-76. 
jurídicas que el Concilio posibilitó y que se oficializaron después, venían direccionadas por las necesidades y aspiraciones de ese mundo casero para la Iglesia. Verdad es que la teología del Vaticano II, más concretamente en la Lumen Gentium y en Ad Gentes, daba pie para vuelos mayores hacia los mundos "otros"; pero una vez más no se dio el paso de la teología a la práctica. Y muchos ensayos que se han venido haciendo, en el posconcilio, han caído en la sospecha o en la interdicción.

La pregunta para el Concilio era: Iglesia de Cristo, ¿qué dices de ti? A "ese" mundo, se entendía. Y la respuesta fue para "ese" mundo: el mundo blanco y rico, dicho sea más agresivamente. Ni los no-blancos ni los pobres fueron considerados efectivamente. Los pobres - los empobrecidos-, en concreto, entraron solo de soslayo en el Concilio. La intuición de Juan XXIII y la aspiración del cardenal Lercaro y de aquel pequeño grupo de profetas de los pobres no cuajaron en la conciencia y en la programación pastoral del grueso de los padres conciliares. Los no-blancos, los "otros", permanecieron fuera. Los noblancos y los pobres, subrayo; los pobres y los otros.

Cuando ahora se nos habla, con insistencia, legítima en buena parte, del diálogo con la modernidad — ahí, en el Primer Mundo, parece que ya estarían en una nebulosa pos-modernidad de vuelta-, nosotros, aquí, en los arrabales del mundo, nos preguntamos, escaldados: ¿ya nos están olvidando otra vez? Nuestra cultura, nuestras culturas, ¿son precisamente "modernas"? Lo que hay entre nosotros de cultura moderna, dominante además, ¿es el verdadero desafío o el desafío mayor que se le plantea a nuestra Iglesia? La cultura "adveniente" a que se refiere con preferencia la documentación preparatoria para Santo Domingo, ¿es el verdadero suelo vital de nuestros Pueblos y de nuestras Iglesias? ¿Qué espacio vamos a dar a las culturas-raíz? ¿Los Pueblos Indígenas de Amerindia y sus culturas - secularmente satanizadas o marginadas o folclorizadas, pero resistentes y en afirmación ascendiente ahora - tendrán voz y voto? ¿Reconoceremos, por fin, la existencia y la dignidad de la Afroamérica?

En un encuentro reciente de nuestros teólogos, alguien destacaba, con preocupación crítica, una serie de elementos de reflexión pastoral que deben ser tenidos en cuenta en los preparativos de la IV Conferencia del Episcopado Latinoamericano. La advertencia del teólogo es más que oportuna, también para subrayar la validez de los "aportes" que voy a indicar y hasta para situarlos en su lugar debido. Está claro, por ejemplo, que la inculturación que pido no es la preocupación por o con la cultura adveniente. La atención hacia esa cultura (o modernidad) no puede dislocar el eje de nuestra pastoral: de la pobreza-justicia hacia la cultura. Sería una "solución cultural para un 
problema económico" y social. "El problema de la pobreza creciente en América Latina... ¿ no es el gran desafío para la fe cristiana y para la pastoral de la Iglesia, de acuerdo con la tradición Medellín-Puebla?". También, pasar ahora de una Iglesia Pueblo de Dios a "una Iglesia obediencial", jerarquicista, piramidal, sería impedir en nuestra Iglesia el crecimiento de "la comunión y la participación", estimuladas por varios documentos oficiales. Una centralizadora identidad "católicoromana” —romanicista, diríamos-, cerrada sobre sí misma, negaría la legítima alteridad latinoamericana dentro de la catolicidad. Una Iglesia proselitista, combativa, con poder —con poder económico también, modernamente poderosa, en competencia con los poderes de este mundo-, arrinconaría la fuerza del testimonio de nuestra lglesia, pobre, perseguida y martirial. "En América Latina continúa grande el número de los mártires". Sería negar nuestro pueblo y el Evangelio de Jesús salirse ahora "de la opción por los Pobres para una opción preferencial por las clases medias”...

\section{II}

Y voy a los "aportes". Personalmente yo, europeo en primera instancia, aun viniendo de aquella España previa a la Comunidad Europea, me estoy convenciendo cada día más de que el gran desafío pastoral -las grandes preguntas no respondidas, mal respondidas secularmente-que se le presentan a la Iglesia de Jesús son:

- salirse del eurocentrismo y realizarse en catolicidad de hecho;

- ser solidaria y hasta pobre con los Pobres de la Tierra, contra la injusticia de Ia pobreza; en la pobreza del Evangelio;

- descentralizarse y ministerializarse, haciéndose comunitaria y servidora, desde la base hasta la cúpula.

Tres preguntas, tres respuestas que contestarían proféticamente al pecado estructural del mundo — del Primer Mundo, más exactamente: imperialista y colonizador; rico y usurero, egoísta y excluidor-. Pienso que los aportes que "la Iglesia de los Pobres" puede y quiere ofrecer a "un proyecto no-eurocéntrico de evangelización" van por estas tres dimensiones —que responden a esas tres preguntas-: $1^{\mathrm{a}}$, La inculturación; $2^{\mathrm{a}}$, La opción por los pobres; $3^{\mathrm{a}}$, La comunitaridad.

Más de cerca, ciñéndome a nuestra Iglesia latinoamericana, los dos providenciales "concilios" que hemos vivido - Medellín y Puebla- y el nuevo "concilio" que próximamente esperamos vivir, en Santo Domingo, abordan precisamente esas tres grandes vertientes de la eclesialidad evangelizadora. Medellín optó por los pobres. Puebla canonizó las Comunidades Eclesiales de Base. Y Santo Domingo 
- aun en medio de las fluctuaciones de esta hora de involución y de centralismos- habrá de asumir la inculturación.

En los tres "concilios" esas opciones no parten necesariamente de una iluminada espontánea decisión del episcopado, al margen del caminar de sus Iglesias y/o de sus Pueblos. (El episcopado latinoamericano sigue siendo conservador, en su mayoría). América Latina está haciendo así a la Iglesia de América Latina. América Latina y el Espíritu de Jesús. Los empobrecidos y los evangélicamente pobres. Los rebeldes y los profetas. Las víctimas y los mártires. Y entiendo que unos y otros - hombres y mujeres, adultos y niños, individuos y comunidades-coinciden muchas veces en las mismas fecundas personas.

Ya se ha dicho repetidamente, entre nosotros, que más optaron los Pobres por la Iglesia que la Iglesia por los Pobres. Pero, en última instancia, nos hemos visto saludablemente obligados a proclamar que optamos por los Pobres y a optar por ellos, en buena medida también. (Estoy hablando de "la Iglesia" en el sentido restrictivo viciado de la palabra: la jerarquía y sus estructuras. Porque, en el sentido más ampliamente correcto, la Iglesia, en América Latina, es mayoritariamente "los Pobres").

La rebeldía libertadora y hasta revolucionaria con que se ha erguido el Continente frente a los imperialismos y colonialismos, oligarquías y dictaduras tradicionales, ha contagiado benéficamente, primero a ciertos sectores minoritarios del laicado y gradativamente a las bases comunitarias de la Iglesia. Benéficamente, digo; aunque también con mucho sufrimiento y en medio de ciertas ambigüedades inevitables. El "autodescubrimiento" que ha empezado hace tiempo en círculos intelectuales, artísticos y militantes de nuestra América viene reclamando también de nuestra Iglesia un rostro y un quehacer autóctonos. La Iglesia latinoamericana se está "autodescubriendo". Leonardo Boff Io recordaba en el número de Concilium dedicado a "La voz de las víctimas" (en portugués, $\mathrm{N}^{\circ} 232$, p. 128): "La nueva evangelización echa raíces en esa tradición profético-pastoral. Ella se está haciendo bajo el signo de la liberación. Da origen a un cristianismo singular, de cuño popular, mestizo, blanco, latino, indígena y negro que apunta hacia formas nuevas de estructuración eclesial y también como una de las formas de cambio social en el Continente".

Cortar el proceso de este "cristianismo singular" equivaldría a un suicidio eclesial en América Latina y sería privar al resto de la Iglesia de esa contribución que la Iglesia latinoamericana ya está dando y que podrá seguir dando, con mayor abundancia y en paz mayor, si se le respetan la vocación y la hora. Las tres dimensiones -inculturación, opción por los pobres y comunitaridad-se reclaman mutuamente y se completan entre sí. La misma Teología de la Liberación, inicialmen- 
te más preocupada con el cautiverio y la explotación socio-económica de nuestros Pueblos, ha ido asumiendo cada día más explícitamente los desafíos de la marginación étnico-cultural de esos mismos Pueblos, pobres y "otros". Como se ha despertado, con creciente sensibilidad, ante la marginación específica de las mujeres y por sus justísimas reivindicaciones, en la Sociedad y en la Iglesia.

\section{III}

Esas tres dimensiones van adquiriendo carta de ciudadanía en nuestra Iglesia. No en todo lugar; no sin dificultades e incomprensiones y, a veces, en la escala evangélica del fermento escondido. Esa ciudadanía la ejercitan tanto en Ia Espiritualidad y en la Teología como en la Liturgia y en la Catequesis o en la Caridad social y política y en la organicidad pastoral. En Brasil, concretamente, los sectores populares más sometidos a dominación o a marginación han hecho surgir Pastorales específicas -"las pastorales", como se denominan simplemente, o "las Pastorales sociales"-:

- El CIMI, Consejo Indigenista Misionero.

- La CPl, Comisión Pastoral de la Tierra.

- La PO, Pastoral Obrera.

- La Pastoral de la Mujer marginada.

- La Pastoral del Menor.

- La Pastoral de los Migrantes.

- La Pastoral de los Favelados o "los sin techo" y otras.

Son pastorales al servicio del Pobre, diaconías sociales, ya no en la línea del asistencialismo o de la beneficencia. Ecuménicas, normalmente. Salen al encuentro de los derechos y las reivindicaciones de esos Pobres y de sus organizaciones, cuando estas existen o estimulan la creación de las mismas. Ponen a su disposición la presencia, la solidaridad, la denuncia, la acción de la Iglesia. Con frecuencia también la cruz y la sangre. La sangre de esos Pobres y la de sus agentes de pastoral se han mezclado muchas veces; siguen mezclándose hoy, en esta seudodemocracia neoliberal que nos han impuesto.

La alteridad indígena y afroamericana de millones de habitantes de este Continente - los indígenas son unos 70 millones y el Brasil es el segundo país negro del mundo- están obligando a la Teología y a la Pastoral a profundas revisiones. Nuestro CIMI, en su última asamblea nacional, asumió el diálogo de tú a tú con las religiones indígenas como un postulado fundamental de la evangelización. Admitir ese diálogo solo con las religiones llamadas "grandes" y no con 
las "pequeñas" también, es una discriminación injustificable. La Pastoral Negra, incluso con sus agentes —obispos, sacerdotes, religiosos y laicos- es ya una realidad afianzada aquí. Ambas pastorales, sin embargo, viven más de escucha y diálogo, de ensayos y esperas, que de soluciones pragmáticas. Fue demasiado "fácil" y muy poco evangelizador evangelizar compulsivamente como se vino haciendo a lo largo de esos 500 años y ahora nos toca rever, "des-evangelizar" y, en alguna medida, empezar de nuevo. Evangelizar no es ignorar ni imponer. La verdadera inculturación será una difícil hermosa aventura para nuestra Iglesia. Cada día sentimos más el fuego - les decía yo a unos compañeros del CIMI- pero cada día nos creemos con menos luces...

Las Comunidades Eclesiales de Base - CEBs-, cuyo número variará según los criterios con que se las quiera definir, son indudablemente la fuerza mayor de comunitaridad de nuestras Iglesias. Definidas, en un Encuentro Intereclesial como "un nuevo modo de ser Iglesia" —comunitario en todo y a partir de la base popular-, en otro Intereclesial las CEBs fueron ya definidas, con mayor audacia, como la inspiración y la presión que pretenden que "toda la Iglesia sea de un modo nuevo": en comunitaridad y a partir de la base.

A veces me preguntan cuántas CEBs tenemos en la prelatura o diócesis de São Félix do Araguaia y yo respondo que no lo sé; ni me preocupa saberlo; que lo que me interesa de verdad es que toda la línea pastoral - vivencia y acción - de nuestra Iglesia particular sea "comunitaria" y "desde la base"; que seamos y hagamos base de comunidad - humana y eclesial-; que no nos despeguemos nunca de la base, social y evangélica, donde están los Pobres y sus luchas y sus esperanzas. Porque esta fue la opción y la práctica de Jesús.

Claro está que las Comunidades Eclesiales de Base son "fórmula" eficaz y hasta "test" de esa comunitaridad eclesial que pretendemos. Con ellas se construye. Sin ellas - como fermento y células- difícilmente. Lo cual tampoco significa que antes de inventarse las Comunidades Eclesiales de Base no hubiera habido comunitaridad eclesial ni comunión con los Pobres en la Iglesia de Jesucristo. Las CEBs son las primeras que apelan a la tradición, a los Hechos de los Apóstoles...

Esa comunitaridad va atravesando gradualmente todo el tejido eclesiástico y ya resulta anormal programar o actuar pastoralmente sin contar con ella. La Comunidad, las Comunidades, saben reivindicar sus derechos y sus deberes de mayoridad corresponsable, como Iglesia que son. Los obispos nos vemos obligados a ser obispos de otro modo; más llano y menos autoritario; con las excepciones que confirman la regla, como es natural. En nuestra Asamblea anual de la CNBB participan religiosas y laicos y también hermanos evangélicos. Y la temática y su tratamiento, en esas asambleas, postulan mucha 
participación y son de un mordiente bien contextuado y práctico. Y ese mordiente llevan los documentos de Ia CNBB; así como muchas cartas pastorales de los obispos, que son más "cartas".

El sacerdote ya no puede ser el gerente omnímodo de una parroquia o comunidad. El Pueblo sabe pedir cuentas y tomar decisiones. Y en este pueblo está muy presente - con frecuencia en mayoría y dirección-la Mujer. Tenemos, además, la ventaja de padecer muy excepcionalmente, entre nosotros, aquellas escisiones "paracismáticas" que quizás se sufren en algunas áreas del Primer Mundo. Aquí —obispo yo, a fin de cuentas- quisiera hacer constar que el "cisma" tanto puede venir del pastor como de los fieles. Los Consejos diocesanos, regionales o por sectores, locales o de cada parroquia y comunidad, se van tornando la verdadera gerencia pastoral de las Iglesias.

Se multiplican los ministerios y los ministros o animadores, al mismo tiempo que se ponen menos hieráticos o segregados. Quizás por necesidad también; por aquello de que la necesidad crea el órgano. En Brasil el 70\% de las celebraciones dominicales - la Palabra y la Comunión- se realizan sin sacerdote. La Vida Religiosa -sobre todo de ellas - se ha acercado a la periferia, al margen, con una incontestable ejemplaridad de encarnación. Como se sabe, son muchas las comunidades "insertas" en toda América Latina. Pienso que la CLAR, incomprendida y maltratada, cuando se escriba la Historia serenamente será considerada como una de las más benéficas instituciones que la Iglesia haya tenido en este continente, en los duros y fecundos años de transición y persecución que nos ha tocado vivir.

Nuestras celebraciones de la Fe, realizadas con libertad de espíritu, atentas a la vida del Pueblo, sus dolores y alegrías, sus luchas y esperanzas, e incorporando, en grado mayor o menor su cultura, se tornan por eso mismo expresión creciente de la inculturación y del comprometimiento de nuestra Iglesia. En ellas entran todos los instrumentos musicales, los más variados símbolos de la vida, del trabajo, de la fiesta; la danza y el canto autóctonos; la memoria, los nombres, el rostro, de los mártires del Pueblo y sus causas; y cada vez más el alma y el cuerpo de la Patria Grande entera. Nuestra Iglesia se va poniendo latinoamericana. Y este es ya uno de los frutos palpables del V Centenario, sean cuales fueren la acción o la omisión oficiales.

Esta celebración, más encarnada, más popular, más participada, de la Fe se expresa en las romerías de los Mártires, de la Tierra, del Trabajo; muchas veces en santuarios tradicionales pero aireados con un espíritu nuevo o en lugares históricos de lucha por la liberación. En las novenas de Navidad y en los Viacrucis —alargados por todo el tiempo litúrgico de Adviento y de Cuaresma- realizados por gru- 
pos de vecinos. En las novenas patronales y en otras manifestaciones de la Religiosidad Popular, asumidas y renovadas, así como en las Campañas más oficiales - la Campaña de la Fraternidad, por ejemplo, promovida oficialmente por la CNBB, con temas y lemas penetrados de vida y de compromiso social; el mes de la Biblia, el mes de las Vocaciones, el mes de las Misiones...

La Liturgia se ha empapado de Pueblo en las Iglesias locales que ya tienen una pastoral orgánica definida en esa línea de inserción y también en muchas comunidades de Iglesias más refractarias. Sin que deje de ser Liturgia, según nos parece y creemos que también le parece así al Espíritu. Los símbolos que ambientan, las ofrendas que se hacen, los nombres de personas, lugares y causas que invaden las oraciones o los "mementos", nuestras letanías, diferentes, de santos y ruegos bien próximos y estimulantes. La compenetración familiar entre el celebrante que preside y el Pueblo que también celebra. En nuestras celebraciones normalmente "no hace frío"...

La Biblia en manos del Pueblo es un hecho providencial, de enormes repercusiones evangelizadoras en todo el Continente. Especialistas, publicaciones, entidades bíblicas explícitamente creadas para este ministerio, como nuestro CEBI, asesoran y estimulan esta floración bíblica. Y otros Centros de formación y los cursos —-multitudinarios o más restrictos, como los que organiza el CESEP — así como las publicaciones periódicas, las versiones popularizadas de documentos, los carteles, los videos, las camisetas alusivas, etc. iluminan y sustentan esa renovada movilización pastoral.

Hablando de la nueva Evangelización, escribía yo, en una carta circular reciente, que hay tres referenciales insoslayables que condicionan y posibilitan esta nueva Evangelización entre nosotros. (Porque solo será "nueva" si es, por fin, "nuestra"):

1. El nuevo contexto de dominación, de marginación y de muerte de América Latina (de todo el Tercer Mundo), dentro del enfrentamiento Norte/Sur.

2. La nueva conciencia y experiencia del Continente, a partir de los procesos de Liberación, vividos en las cuatro últimas décadas y que nos convocan colectivamente a la autonomía, a la participación, a la alternatividad.

3. El nuevo modo de ser y de hacer Iglesia: por la Espiritualidad y la Teología de la Liberación, por las Comunidades Eclesiales de Base, por la Religiosidad Popular ensamblada con el compromiso sociopolítico, por los nacientes ensayos de inculturación de la Fe, por la Biblia en manos del Pueblo. 
Para nosotros aquí y para los hermanos y hermanas de ahí, si les valen también como "aportes" de evangelización — porque la evangelización es cuestión de espiritualidad ante todo-, yo describía así las 7 actitudes del Pueblo Nuevo (el Hombre Nuevo y la Mujer Nueva, pero ya en Comunidad):

- Contemplar sobre la marcha

- Descodificar la realidad

- Compadecer todo sufrimiento

- Compartir la pobreza

- Estructurar la solidaridad

- Organizar las luchas, las victorias, Ia esperanza

- Anunciar, testimoniar, celebrar, esperar el Reino.

Hay una Iglesia "diferente" entre nosotros, "emergente", a veces con apariencias de "insurgente" también; pero nunca "paralela" ni cismática, contrariamente a lo que digan personalidades o documentos. La Iglesia, peyorativamente tildada de "popular", no es una secta. Sin ser inmaculada, esta Iglesia está bastante llena de Espíritu y es sellada diariamente por sangre mártir. La Espiritualidad, en esta Iglesia, es hoy día una verdadera efervescencia de búsquedas, de experiencias, de intercambios. Una Espiritualidad "ubicada" que intenta superar toda dicotomía. Una Espiritualidad contemplativa y política. Son ya muchos los cristianos latinoamericanos que están demostrando con su vida que la contemplación y la política pueden y deben caminar juntas y besarse, como la Justicia y la Paz bíblicas.

Tengo para mí que esta Iglesia latinoamericana se ha hecho ya con una herencia irreversible que es también un "aporte" de renovación para toda la Iglesia. He sintetizado esta herencia en la opción por los Pobres, la Inculturación y la Comunitaridad. Claro está que nos gustaría que esa herencia - que es Historia y Misión- fuera compartida, cada día más, por otras instancias de Ia Iglesia de Dios. Y está más que claro que necesitamos igualmente de los "aportes" de otras Iglesias, de su comprensión y complementariedad. La solidaridad va y viene. Y el Espíritu trabaja en ambos Mundos. Entre tensiones y búsquedas, salva la Esperanza y hasta el buen humor; salva la Fraternidad — católica, ecuménica, universal—, todos estamos dentro de la gran Comunión de los santos... pecadores. 



\section{Jon Sobrino}

\section{¿QUÉ QUEDA DE LA TEOLOGÍA DE LA LIBERACIÓN?*}

\section{DIVERSAS PERSPECTIVAS E INTERESES TRAS LA PREGUNTA}

Qué queda, qué puede y qué debe quedar de la teología de la liberación son preguntas que hoy se repiten con frecuencia. Unos proclaman su desaparición después de la caída del socialismo. Y otros se mantienen en su defensa. "La teología de la liberación ha celebrado simbólicamente sus 25 años de vida militante y de salud evangelizadora. No voy a defenderla de nuevo, porque se defiende sola mientras haya Dios de los pobres y Evangelio de Jesús e Iglesia samaritana", dice don Pedro Casaldáliga. Otros lo dicen en lenguaje más técnico. "Las intuiciones fundamentales de la teología de la liberación no solo están vigentes, sino que pueden constituir los ingredientes fundamentales de toda teología que quiera reflexionar a la altura planetaria del siglo que se avecina" (González, 1995: 675).

¿Quién tiene razón? Antes de intentar responder a la pregunta notemos una diferencia importante entre las dos posturas. La primera declara el fin de la teología de la liberación y, normalmente, no comunica ninguna sensación de que, de ser verdad, algo importante hayamos perdido. No hay tristeza, sino más bien alivio, porque, después de 30 años, "ya pasó el chaparrón". La segunda afirma que la teología de

* Sobrino, Jon 1997 “¿Qué queda de la teología de la liberación?” en Éxodo, N 38, pp. $48-53$. 
la liberación perdura (aunque debe ser evaluada críticamente), y además expresa el anhelo de que no desaparezca, pues sería pérdida grande para la Iglesia, para los pobres y, si se nos permite el lenguaje, para Dios. En otras palabras, la primera postura solo habla, con mejores o peores razones, de facticidades. La segunda habla de ser y deber ser, de realidad, de esperanza y de exigencia, pues el mundo y la fe cristiana siguen exigiendo una teología que mantenga, historizadamente, la intuición fundamental: hacer central — seria y consecuentemente- la relación entre Dios y víctimas de este mundo. Veámoslo en dos citas recientes que no son de teólogos latinoamericanos.

J. Moltmann acaba de decir que el mundo actual exige más y no menos teología de la liberación. "La injusticia e inhumanidad crece también en los países industrializados...La globalización de la economía lleva claramente a la insolidaridad de nuestras sociedades" (Moltmann, 1996: 204). Y concluye: "La teología de la liberación latinoamericana es la primera teología alternativa al capitalismo", al que hoy se le denomina como "la mercadeización global de todas las cosas. Ya no es solo una teología contextual latinoamericana, sino que, con el desarrollo mencionado, se convierte en teología contextual universal" (Moltmann, 1996: 205).

Alois Pieris, cristiano, asiático y teólogo, afirma —al menos por implicación- que la fe en Dios y su Cristo exige más y no menos teología de la liberación. Confrontado con el problema del universalismo cristiano, establece dos principios fundamentales - por lo que niega y rechaza, y por lo que afirma y propicia - para comprender la vigencia universal de Jesús. Afirma dos cosas: (1) Jesús es la contradicción entre "mammon" (el dinero) y Yahvé; 2) Jesús encarna la alianza defensora entre los oprimidos y Yahvé (Pieris, 1995: 164). "La universalidad del cristianismo se basa en estos dos principios" (Pieris, 1995: 166) ${ }^{1}$. La cita puede sonar radical, pero la intuición queda bien expresada: la realidad del mundo de hoy exige poner en relación —-negativamentela riqueza/ídolos y la pobreza/oprimidos. Y, positivamente, exige poner en relación a Dios con los pobres, reproduciendo la práctica de Jesús.

Este poner en relación teología y pobres para liberarlos — por más que haya que actualizar con rigor la relación- es lo fundamental de la teología de la liberación y no es nada evidente en la historia de la teología. En el artículo citado, Moltmann lo dice con absoluta sencillez usando simbología muy querida para nosotros aquí en El Salvador.

1 Es decisivo continuar con la cita, pues ahí se halla el meollo de la cuestión para la teología de la liberación y debiera serlo para toda teología cristiana. "Pero volver a estos elementos básicos equivale cargar de nuevo con la cruz, la cruz que hemos abandonado durante siglos". 
"Thomas Becket murió en el altar en Canterbury, porque defendió los derechos de la Iglesia; Oscar Arnulfo Romero murió en el altar en San Salvador porque defendió los derechos de los pobres. Esta es la nueva dirección" (Moltmann, 1996: 205)².

\section{QUÉ SIGNIFICA QUEDAR Y PASAR}

Volvamos ahora a la pregunta inicial. En su conjunto, hoy no se repiten los ataques despiadados de las dos últimas décadas contra la teología de la liberación, pero se intenta relegarla al pasado, preguntándose elegantemente qué queda de ella o haciéndola morir la muerte de mil silencios, porque ya habría dado de sí todo lo que podía dar. Para nosotros habría sido una moda que solo habría tocado la realidad pasajera y superficial de una época, pero no la realidad verdadera. Sin embargo, en las palabras de don Luciano Méndez de Almeida, la teología de la liberación "ha puesto el dedo en la llaga de la realidad". No estamos, pues, ante una moda - aunque creo también que así ha sido tratada por quienes solo buscan novedades en el ágora-.

Que se diga que ya "ha pasado", es algo que hay que analizar más cuidadosamente. Gustavo Gutiérrez dice con toda naturalidad, que "la teología de la liberación pasará como pasan todas las teologías". "Pasar", pues, no es el problema, pero sí puede serlo el simplismo con que se puede llegar a proclamar el hecho, "ya pasó", y, sobre todo, la ligereza en el análisis de lo que significa "pasar". Y es que una cosa es "pasar", en el sentido de desaparecer de la historia y otra cosa es pasar dejando en la historia algo perenne, en sentido de clásico. Eso me parece que es lo que ha ocurrido. Y así, en la teología, en la Iglesia, en movimientos de solidaridad, en comunidades, incluso entre no creyentes, existen hoy modos de ver el cristianismo que se deben a ella.

Persisten los siguientes elementos metodológicos: 1) Tomar en serio los signos de los tiempos de modo que hacer teología sea elevar la realidad a concepto y no meramente interpretar la realidad desde conceptos previos, bíblicos, conciliares, teológicos. 2) Hacer de los pobres y de las víctimas lugar teológico en el cual se auscultan los mencionados signos de los tiempos, y desde el cual las fuentes de la teología dan más de sí, y sobre todo facilitan descubrir la correlación trascendental entre Dios y pobres. 3) La autocomprensión de la teología como la teoría de una praxis, es decir, como la teoría cristiana de la construcción del Reino de Dios (no solo la teoría para conocer a Dios), de modo que el quehacer teológico puede ser reformulado esencialmente como intellectus amoris. 4) La autocomprensión de la teología como

2 El autor hace referencia a un poema sobre Monseñor Romero de José María Valverde. 
posibilitada por lo que es "otro" y "buena noticia", el evangelio, Dios y su Cristo Jesús, y los pobres, sus testigos, de modo que el quehacer teológico está transido de gracia, y puede ser reformulado también como intellectus gratiae.

Persisten los siguientes contenidos sistemáticos: 1) El énfasis en el Jesús histórico, la Iglesia de los pobres, y, por supuesto, la salvación como liberación de toda opresión. 2) La dialéctica del Dios de vida e ídolos de muerte, de Reino de Dios y antirreino, de gracia y pecado, de fe e idolatría. 3) Elementos de espiritualidad: el pathos de la honradez, la verdad y la misericordia, la praxis de la justicia, el proseguimiento de Jesús. 4) La realidad del misterio del Dios de Jesús, cercano y buena noticia, Padre en quien se puede confiar, y misterio inmanipulable ante quien hay que estar disponible. En otras palabras, un Dios que es Padre y un Padre que es Dios, el misterio del Deus semper maior y, a la vez, el Deus semper minor.

Estos temas siguen siendo actuales, pero además, por redescubierta raigambre evangélica y por el eco que encuentran en la condición humana, se han convertido de alguna manera, más o menos según los casos, en lo que con modestia podemos llamar clásicos de la teología.

\section{LA INTUICIÓN Y EL PATHOS DEL ORIGEN: EL ENCUENTRO CON EL POBRE}

En nuestra opinión, lo que "queda" y "debe quedar" de la teología de la liberación es, ante todo la intuición y el pathos que está en su origen. El "recuerda Israel" vale también aquí. Pues bien, en el origen de la teología de la liberación hay un dejarse impactar y afectar por la realidad verdadera, no solo por su concepto o por su significado. Por esa razón, la teología va a estar guiada por el "principio realidad", con lo cual va a ser una teología sustancialmente "histórica", y no solo una teología "cultural" porque el "sentido" fuese su problema, y va a ser una teología "espiritual", pues la realidad que impacta es tal, que llega a todas las dimensiones del espíritu del ser humano. Pues bien, la realidad que se descubre es la "irrupción del pobre".

Este impacto de la realidad, formulado en Medellín como cosa central, fungió como la experiencia fundante en la teología. Dicho gráficamente, el Ellacuría filósofo aprehendió la realidad ante todo como inhumana pobreza, como muerte cruel e injusta de las mayorías, hasta el punto de que se atrevió a desafiar a Heidegger: "quizás en vez de preguntarse por qué hay más bien ente que nada, debería haberse preguntado por qué hay nada - no ser, no realidad, no verdad, etc.- en vez de ente" (Ellacuría, 1985: 50)3․ Y el Ellacuría teólogo insistió en que en-

3 Ellacuría está haciendo alusión a la conocida pregunta de Heidegger de por qué hay algo y no nada en Was ist Metaphysik? 
tre tantos signos como siempre se dan, unos llamativos y otros apenas perceptibles, hay cada tiempo uno que es el principal, a cuya luz deben discernirse e interpretarse todos los demás. Ese signo es siempre el pueblo históricamente crucificado, que junta a su permanencia la siempre distinta forma histórica de su crucifixión" (Ellacuría, 1981: 58)4.

De estas palabras quiero recalcar ahora dos cosas. Ellacuría dice que entre los diversos signos "uno es el principal", es decir, está exigiendo a la teología jerarquizar los "signos de los tiempos" (análogamente a la jerarquía de verdades que pide el Vaticano II), lo cual es decisivo para no suavizar la realidad "del pueblo históricamente crucificado" considerándolo — quizás - como una entre varias posibles realidades, sino como la central, el analogatum princeps de la presencia de Dios en el mundo y la interpelación fundamental a la teología. Si se me permite la ironía, Ellacuría nos pone en guardia contra una actitud del ágora ateniense: "a ver qué ideas nuevas nos traen hoy", y nos remite a la seriedad de lo real, sea nuevo o sea "lo de siempre". Eran aquellos tiempos en que L. Boff decía que hay que hacer teología (también) con indignación, y que Hugo Assmann acusaba de cinismo a una teología que no se preocupase por los millones de muertos anuales por hambre. La otra cosa que quiero destacar es la insistencia en el "siempre" del pueblo crucificado. Ellacuría admite "la siempre distinta forma" de crucifixión, que hoy no tiene por qué ser en América Latina la de oligarquías con regímenes militaristas y la doctrina de la seguridad nacional, pero sigue siendo "crucifixión".

En el origen, este encuentro con el pobre, con el pueblo crucificado, produjo, pues, una experiencia fundante, y para la teología lo más importante de esa experiencia fue su dimensión globalizante. No fue una experiencia "regional" que llevó solo a una pastoral caritativa o a un puro moralismo, sino que desde el principio - al menos potencialmente- se expresó en todas las dimensiones del ser humano y del teólogo: en el saber, el esperar, el hacer y el celebrar, y siguiendo el imaginario kantiano, todo ello "después de haber despertado" del sueño de inhumanidad.

A esto queremos añadir que la teología se concibió también y esencialmente, como teología espiritual, porque la realidad del pobre fungió como mediación de una experiencia de ultimidad, de la experiencia de Dios. También para la teología - y para el teólogo- esta experiencia es necesaria, debe ser previa a su quehacer y lo debe configurar. Así lo vieron en Europa los teólogos más lúcidos. Urs von Balthasar, precisamente en el contexto de la incipiente teología política, hablaba

4 En este párrafo Ellacuría está usando el concepto "signo" (de los tiempos) en su sentido estrictamente teologal como lugar de presencia de Dios o de sus planes (Cfr. Gaudium et Spes, 11). 
de superar la insoportable separación entre teología y espiritualidad. K. Rahner, remitiéndose a Santo Tomás, abogaba por superar la horrible división entre teología y vida espiritual. Y Metz, en plena teología política, hablaba de la mística y la política del seguimiento.

En este contexto, lo específico de la teología de la liberación fue relacionar la experiencia de Dios con la realidad de los pobres, de lo cual surgió una espiritualidad teologal dialéctica: la espiritualidad del Dios liberador y la del Dios escondido. Y también creemos que esa experiencia fungió realmente como fuente de conocimiento de Dios - con todos los peligros de subjetivismo que eso trae consigo-, pero también con las ventajas. Para decir "Dios es esto o lo otro", la teología se remitió también a la experiencia de ultimidad: Dios es experimentado (por el teólogo, por la comunidad, por los pobres, por los mártires) de una o de otra forma. Esta experiencia, correspondiente a la irrupción de los pobres, es gracia, en definitiva, y hace que la teología de la liberación sea también intellectus gratiae.

\section{PROBLEMAS Y TAREAS}

Esto es lo que queda y, en cualquier caso, lo que creemos que debe quedar. Pero junto a ello hay en la teología de la liberación latinoamericana limitaciones que debe superar. Enumeramos simplemente, en forma de tareas, las que nos parecen más importantes: 1) Asumir y profundizar las diversas formas de opresión, no solo la socioeconómica, sino también la cultural, étnica y religiosa, la de la mujer y la del niño, la de la naturaleza. 2) Analizar no solo lo que en el pobre hay de carencia, sino también lo que tiene de fe propia suya, lo cual ofrece luz a la teología. 3) Ayudar liberadoramente al pobre en momentos de revolución, pero ayudarlo también en su humanización en la cotidianeidad. 4) Reconocer y asumir los cambios en el mundo, con las consecuencias para los caminos de liberación y sus mediaciones, aunque sin caer en la trampa: cayó el socialismo, ergo desapareció la teología de la liberación, y reafirmando los graves males de los que sigue transido este mundo en cambio. 5) Superar las deficiencias y limitaciones en conocimientos exegéticos, sistemáticos, históricos. 6) Comprenderse realmente como teología ecuménica en la profundidad de lo humano ante Dios y junto con otros seres humanos. 7) Ser una teología eclesial, enraizada en la base de la Iglesia, los pobres reales, y liberadora también de la opresión intraeclesial. 8) En definitiva, ser una teología evangélica que ofrece la buena noticia de Dios, redescubierta en el mundo de los pobres, ofrecida directamente a ellos y, a través de ellos, a todos para que haya liberación y humanización.

Estas son las tareas que nos parecen más importantes para superar limitaciones y fallos, pero queremos terminar recordando el 
marco fundamental dentro del cual la teología de la liberación puede seguir siendo fructífera. En nuestra opinión, esta teología - y desde su propia comprensión- necesita estar enmarcada en una realidad más amplia para ser eficaz. Supone tradiciones y movimientos históricos (a veces hablamos de ingeniería de la liberación, economía de la liberación, medicina de la liberación...). Supone un liderazgo eclesial, colegiado como el de la generación dorada de obispos de hace unos años: don Hélder, Proaño, Angelleli, Mons. Romero, don Sergio... Y supone sobre todo, la realidad popular, la realidad de los pobres, los destinatarios directos del Evangelio. Históricamente, eso se desarrolla en las comunidades eclesiales de base.

Con otras teologías, pues, sobre todo las del tercer mundo pobre y lo que hay de teologías solidarias en el primer mundo, con tradiciones y movimientos de liberación, con un colegio episcopal como el que hubo hace unos años y con comunidades de base, la teología de la liberación puede seguir siendo muy fructífera.

¿Qué queda de la teología de la liberación? Al nivel de producción teológica convencional creemos que hoy no existe una generación de teólogos comparable a la de sus fundadores (G. Gutiérrez, J. L. Segundo, I. Ellacuría). Pero eso no quiere decir que su intuición fundamental no siga presente de varias maneras y que no sea necesaria.

Y una última palabra, breve e indefensa. Los teólogos de la liberación han sido difamados injustamente y perseguidos cruelmente. Algunos han sido asesinados, y son mártires como Jesús. Y esto hay que tenerlo en cuenta cuando se hace la pregunta de "qué queda de la teología de la liberación". Esta, como los mártires, pueden seguir presentes de muchas maneras, solo que su presencia depende ya de nosotros. Así, si dejamos que la palabra de Monseñor Romero y de Ignacio Ellacuría configuren nuestra vida como seres humanos y nuestro pensar como teólogos, entonces queda mucho de la teología de la liberación.

\section{BIBLIOGRAFÍA}

Ellacuría, I. 1981 "Discernir el signo de los tiempos" en Diakonia, N 17, p. 58.

Ellacuría, I. 1985 “Función liberadora de la filosofía” en $E C A, \mathrm{~N}^{\circ}$ 435436, p. 50.

González, A. 1995 "La vigencia del 'método teológico' de la teología de la liberación" en Sal Terrae, octubre, p. 675.

Moltmann, J. 1996 "Die Theologie unserer Befreiung” en Orientierung, 15 de octubre, p. 204.

Pieris, Alois 1995 “UUniversalidad del cristianismo?” en AAVV Universalidad de Cristo. Universalidad del pobre (Santander) p. 164. 



\section{De las transiciones democráticas a las nuevas experiencias políticas}





\section{Manuel Alcántara}

\section{DE LA DEMOCRACIA EN AMÉRICA LATINA AL COMENZAR EL SIGLO XXI*}

EL PRESENTE TRABAJO reflexiona sobre el estado actual de la democracia en una región específica como es América Latina ${ }^{1}$ y los elementos que lastran su porvenir partiendo de diversas evidencias empíricas generadas por medio de diferentes indicadores entre los que los estudios de opinión pública de las masas y de las élites tienen un peso evidente. Se trata de una región que con mucha frecuencia queda alejada de los circuitos de gestación del pensamiento a pesar de constituir un escenario que aporta un material para el análisis y el estudio extremadamente rico. Ello se lleva a cabo en un momento en que parecen agostarse los ecos de la literatura académica de hace apenas una década que, tras agotar el estudio de las transiciones a la democracia, ponía el acento sobre la consolidación de las nuevas democracias, los factores que las articulaban y los retos que se cernían sobre ellas ${ }^{2}$, para ser sustituidos por una nueva

1 En otro trabajo he analizado el papel de los partidos políticos. Véase Alcántara (2002).

2 Véase Alcántara (1991 y 1992).

* Alcántara, Manuel 2003 "De la democracia en América Latina al comenzar el siglo XXI” en Quórum: Revista de Pensamiento Iberoamericano, No 5-6, pp. 206-220. 
discusión sobre la calidad de la democracia en términos tanto de los mecanismos institucionales de la misma que producían su bonanza como del nivel de satisfacción de las expectativas generadas en sus "usuarios". Sin dejar de lado otras aproximaciones más o menos novedosas a la Ciencia Política desarrolladas en el puro ámbito latinoamericano como pudiera ser la articulada bajo el concepto de "democracia delegativa"

\section{UN DIAGNÓSTICO DE LA POLÍTICA LATINOAMERICANA DURANTE LA DÉCADA DEL NOVENTA}

La política tiene un doble componente de búsqueda de mecanismos de consenso y de medios para afrontar el conflicto, reúne una serie de instrumentos de corte institucional para abordar y plantear soluciones para alcanzar el primero y superar el segundo. Desde esta perspectiva, los principales elementos de la agenda política de América Latina a lo largo de la década del noventa, en lo referido a la evolución de la democracia, permiten ser agrupados en cinco categorías de naturaleza diferente, pero que pretenden proyectar una imagen general de la región: se trata, en primer lugar, del mantenimiento de un mismo patrón de recambio democrático del liderazgo político; de la búsqueda, en segundo término, de mecanismos institucionales más idóneos para favorecer la acción del gobierno mediante los procesos de reforma política a través de cambios en el entramado constitucional; en tercer lugar, del mantenimiento de un tipo de Estado débil que, además, ha contemplado la elaboración de políticas tendentes a sustituir su histórico papel central en la economía por el del mercado; en cuarto lugar, del surgimiento de fenómenos populistas que, frente a modelos pretéritos, han optado por un marcado contenido antipolítico; y, por último, de un incremento de su posición marginal en la sociedad internacional como consecuencia del fin de la guerra fría y de la potenciación de otros nuevos escenarios. A continuación se desarrollan estos puntos.

Los procesos electorales han satisfecho correctamente sus funciones de recambio y/o de ratificación de la clase política como raramente y de forma tan generalizada con anterioridad habían hecho. Las elecciones se han llevado a cabo bajo prácticas de competencia libre, honesta e igualitaria, estando ausentes los otrora habituales mecanismos de fraude, fuera por la vía de la proscripción o de la manipulación del voto. Paralelamente, la alternancia de la clase política gracias a procedimientos constitucionales ha sido la norma,

3 Véase O’Donnell (1994). 
pudiéndose afirmar que los comicios se han convertido en el único medio legítimo sancionador del recambio político ${ }^{4}$.

Durante la década del noventa los países latinoamericanos han buscado de manera generalizada, mediante el rediseño de sus esquemas constitucionales, diferentes objetivos. De forma sucinta cabe referirse a seis ejes sobre los que han basculado las diferentes reformas políticas llevadas a cabo, reformas que, a veces, se han simultaneado en el mismo país. El primero, y más relevante, ha venido dirigido para asegurar el predominio del Poder Ejecutivo en el sistema político mediante la introducción de la reelección presidencial en Argentina, Brasil, Perú y Venezuela ${ }^{5}$, el incremento del periodo de mandato presidencial en Bolivia y Venezuela, el aumento de las facilidades para articular la legislación delegada, la parálisis hacia mayores formas de control desde el Poder Legislativo $^{6}$, básicamente mediante el juicio político a presidentes ${ }^{7}$ o a otros altos funcionarios. El segundo, en consonancia con el anterior, proyecta un Poder Legislativo más débil que ha perdido centralidad en el juego político como consecuencia de la tendencia registrada a articularlo en una sola cámara, como ocurrió tras las reformas constitucionales de Perú de 1993 y de Venezuela de 1999. El tercero ha buscado una mayor legitimidad y operatividad de los procesos electorales. Para ello

4 Solo en Ecuador se pueden contabilizar en dos ocasiones consecutivas la sustitución del Presidente de la República por mecanismos no estrictamente constitucionales como aconteció en 1998 y en 2000 aunque la solución finalmente alcanzada tuviera un soporte constitucional al ser reemplazado el Presidente depuesto por el presidente del Congreso y por el Vicepresidente respectivamente.

5 Si bien en Panamá no se consiguió como consecuencia de la derrota del proyecto de reforma constitucional realizado bajo el gobierno de Pérez Balladares en 1999.

6 Véase Morgenstern y Nacif (2002).

7 Los procesos de destitución, mediante una forma u otra de juicio político, de los presidentes Fernando Collor de Mello en Brasil, Carlos Andrés Pérez en Venezuela, Raúl Cubas en Paraguay, Abdalá Bucaram de Ecuador, sin que por ello el sistema se quebrara, son una prueba del correcto funcionamiento de las instituciones. También lo fue la solución dada por el Congreso guatemalteco a la crisis abierta por el presidente Jorge Serrano. Véase Pérez Liñan (2000). Ernesto Samper fue igualmente sometido a juicio político aunque quedó exonerado de la acusación vertida contra él de haber recibido fondos del narcotráfico para su campaña electoral presidencial. Pero asimismo las crisis políticas que afectaron a los Poderes Ejecutivos se resolvieron con una notable operatividad sin que se quebrara el orden constitucional como aconteció en los procesos de sustitución presidencial regular de Jamil Mahuad en Ecuador, Alberto Fujimori en Perú y Fernando de la Rúa en Argentina, acontecidos todos ellos durante 2001, el año de mayor inestabilidad en la región de los últimos tiempos, o en la superación de la crisis como ocurrió tras el fracaso de los golpes de Estado de Paraguay contra Juan Carlos Wasmosy en abril de 1996 y contra Hugo Chávez en Venezuela en abril de 2002.

8 A las que se podría añadir la propuesta por el presidente Uribe de Colombia. 
se ha incidido en cuatro niveles: la mejora de la administración electoral para asegurar la confiabilidad de las elecciones ${ }^{9}$; la extensión a un número mayoritario de casos del ballotage como forma electoral presidencial que dote a los candidatos electos de un mayor nivel de legitimidad ${ }^{10}$; la incorporación en la Constitución o en la legislación atinente a los partidos políticos de fórmulas de democracia interna tanto para su funcionamiento como para la elección de sus candidatos ${ }^{11}$ y el tímido avance en los mecanismos de control del gasto político junto con el paulatino incremento del peso de la financiación pública de la política. El cuarto eje ha redefinido el papel del Estado en la economía y en sus relaciones con el derecho de propiedad para permitir la introducción del modelo neoliberal ${ }^{12}$. El quinto ha continuado la tendencia de la década anterior proclive a la descentralización política y administrativa en busca de una mayor eficiencia y de una aproximación a los ciudadanos ${ }^{13}$; de esta manera se pusieron en marcha procesos de elección popular de autoridades locales ${ }^{14}$ y se potenciaron las figuras de las entidades territoriales ya existentes. Finalmente el sexto eje ha supuesto la incorporación de nuevas figuras institucionales en los ordenamientos jurídicos latinoamericanos que van desde la introducción en los textos constitucionales de organismos tendentes a la organización, administración y gobierno del Poder Judicial, o de la defensoría del pueblo, al reconocimiento del carácter pluricultural y multirracial de las sociedades ${ }^{15}$.

El Estado latinoamericano ha profundizado su histórica debilidad a lo largo de la década del noventa. A sus tradicionales carencias de poder tener el monopolio de la violencia legítima, de control del territorio ${ }^{16}$ y de construcción de una ciudadanía portadora de valores

9 El caso más evidente es el de México mediante la potenciación de la figura del Instituto Federal Electoral.

10 Véase Molina (2000).

11 Véase Alcántara (2001).

12 Uno de los casos de análisis más interesante es el mexicano puesto que la Constitución de 1917 suponía un modelo "duro" de economía fuertemente nacionalizada y estatizada que, no obstante, fue desmantelado en distintas etapas a lo largo de la década del noventa.

13 Véase Jordana (2001).

14 Las reformas tendentes a la primera elección popular de alcaldes en Colombia en 1989 fueron coetáneas de las que llevaron a la elección de gobernadores en Venezuela. Más adelante las reformas constitucionales de Colombia, Argentina y México propiciaron la elección de los gobernadores de los Departamentos en el primero, y de los alcaldes de la Capital Federal argentina y del regente del Distrito Federal en México.

15 Como es el caso de la Constitución ecuatoriana de 1998.

16 El caso más evidente es el de Colombia, donde el propio Estado ha concedido una "zona de despeje" a la guerrilla y donde diferentes actores no estatales llegan 
cívicos y republicanos y sujeto de derechos universales con capacidad plena para ejercerlos ${ }^{17}$, se debe incorporar el legado del consenso de Washington ${ }^{18}$. Dicho consenso impuso la austeridad fiscal, en lo atinente, fundamentalmente, a la constricción del gasto público, la privatización de activos públicos, la liberalización de los mercados y la desregulación, aspectos todos ellos que limaron la ya de por sí reducida capacidad operativa del Estado latinoamericano. En términos generales, el Estado dejó de tener capacidad operativa para ser el implementador de políticas públicas que pudiera diseñar el gobierno para alcanzar ciertos objetivos programáticos acordes con las reivindicaciones y necesidades de las sociedades latinoamericanas.

América Latina ha registrado, igualmente, la continuidad de expresiones populistas que se creían periclitadas y que se han producido en un número relativamente bajo de países. La novedad, sin embargo, ha sido la aparición de fórmulas imbuidas por su carácter desmovilizador y reivindicador de comportamientos antipolíticos. Frente al populismo exhibido por Carlos S. Menem, fuertemente arropado por la maquinaria política del histórico Partido Justicialista o el de Abdalá Bucaram asido al Partido Roldosista Ecuatoriano, se suscitó el de Alberto Fujimori quien diseñó una actuación destinada a alejar a la política de su acción de gobierno para lo cual desdeñó la movilidad social y/o política que pudo haber articulado mediante algún movimiento o partido, pero que renunció expresamente a ello y despolitizó todas aquellas otras instancias en que pudieran quedar rescoldos de la hoguera política precedente: de esta manera desvirtuó y redujo a la más mínima expresión el papel del Congreso, pero también de las Municipalidades que quedaron convertidas en oficinas de gestión técnica de proyectos varios. En un espacio intermedio, Hugo Chávez se alza como el populista fustigador de la clase política anterior, pero frente a la partidocracia de entonces no renuncia a crear su propio aparato movilizador y a fortalecer el instrumento institucional en el que se ha apoyado en los últimos años, sin dejar el carácter personalista, de discurso emotivo y bañado en míticas referencias cargadas de fuerte simbolismo que imbuye a su acción política.

a controlar cerca del cuarenta por ciento del territorio nacional. Pero igualmente cabría referirse a Perú, Brasil y, en menor medida, México. En los dos primeros países carteles de la droga y traficantes madereros imponen su ley ante la ausencia del Estado. En México, la guerrilla zapatista tiene un santuario en la Sierra Lacandona que inhibe la acción del Estado.

17 Véase Méndez et al. (1999).

18 Sobre el contenido del mismo puede verse Williamson (1994: 26-28). 
Finalmente, América Latina ha contemplado a lo largo de la década del noventa cómo su posición en el escenario internacional se ha ido marginando. Un problema que siempre ha tenido la región ha sido su carácter heterogéneo, sus intereses variopintos y su liderazgo disperso. Todos estos factores han imposibilitado la existencia de una única voz producto de posturas mínimamente comunes, lo cual ha generado cierta inconsistencia e incluso contradicción en su posición que ha proyectado una imagen de debilidad de su presencia en el foro internacional ${ }^{19}$. Por otra parte, la caída del muro de Berlín eliminó el referente del socialismo real para amplios sectores de la Izquierda, redujo a la mínima expresión los apoyos procedentes de aquel espacio, hizo desaparecer en el imaginario de Washington la idea de que su "patio trasero" pudiera caer en manos enemigas, redujo su peso específico en los organismos internacionales en los que la tradicional alineación con las posturas de Estados Unidos le hacía gozar de una tímida posición "de chantaje", y desplazó la centralidad de la política hacia el este de Europa, bien por los procesos de transición política y económica que se suscitaron, bien por el estallido del conflicto de los Balcanes. Paralelamente, América Latina siguió perdiendo peso en la economía mundial como consecuencia del hundimiento al que había llegado su modelo económico establecido medio siglo atrás, del mayor dinamismo de las economías del sudeste asiático y de la atención que requería la más dramática situación, en términos de demanda de ayuda, del África subsahariana. Si bien los lazos de institucionalización formal con el norte del continente dieron paso a la primera Cumbre de las América en 1994 y cinco años más tarde a la primera Cumbre Unión Europea, América Latina y Caribe, los resultados no fueron muy boyantes ${ }^{20}$. América Latina apenas si ocupaba dos renglones en la agenda internacional referidos al narcotráfico y a la emigración, únicos aspectos con capacidad de impacto y de cierta respuesta en Estados Unidos ${ }^{21}$ y la Unión Europea.

19 Al iniciarse el siglo XXI América Latina contaba con líderes de la talla de Fernando H. Cardoso, Fidel Castro, Hugo Chávez y Vicente Fox cuyo grado de heterogeneidad y de disparidad en su talante, personalidad, ideología y vinculación partidista era evidente.

20 Con la Unión Europea, y a pesar del impulso que supuso en las relaciones entre ambas partes el ingreso de España y de Portugal en 1986, entre 1980 y 2000 la parte del comercio latinoamericano que representa la Unión Europea cayó del 20 al 15 por ciento y, lo que era más grave, en el año 2000 las importaciones europeas procedentes de América Latina apenas si representaban el 4,7 por ciento del total importado por la Unión Europea y las exportaciones a América Latina alcanzaban un exiguo 5,8 por ciento del total exportado, siendo cinco años antes estos porcentajes del 5,2 por ciento y del 5,7 por ciento respectivamente.

21 El Plan Colombia sería el ejemplo más evidente como "producto estrella" de la Administración norteamericana para con América Latina. 


\section{SOBRE LA CALIDAD DE LA DEMOCRACIA EN AMÉRICA LATINA AL COMIENZO DEL SIGLO XXI}

El nuevo elemento que ha supuesto la expansión de los derechos políticos contrasta con el mantenimiento de viejos patrones en lo relativo al déficit de derechos civiles básicos y de derechos sociales en los sectores populares, aspectos que no son sino el reflejo de las profundas desigualdades que imperan en la región ${ }^{22}$ y de los efectos de la aguda crisis económica que la ha asolado a lo largo de buena parte de la década del noventa. Diferentes instrumentos para medir la situación política en un momento dado que pueden recoger su dinamismo a lo largo de un determinado periodo ponen de reflejo la enorme variación que se da entre los países latinoamericanos y que a veces tiende a ser ocultada por aproximaciones demasiado generales realizadas desde una supuesta perspectiva regional. Las clasificaciones que estos instrumentos permiten establecer (ver Cuadros 1 y 2) son funcionales para, una vez determinado el orden, poder diseñar una tipología de países "democráticamente más avanzados", "intermedios" y países "democráticamente menos avanzados". Con ello pueden establecerse desde la enunciación de las principales características de sus sistemas políticos los elementos que mejor pueden incidir en la calidad de su política.

La combinación de las clasificaciones de Fitzgibbon ${ }^{23}$ y de Freedom House permiten hacer la citada triple clasificación de manera que aparecen como los países latinoamericanos democráticamente más avanzados: Argentina, Brasil, Costa Rica, Chile, México, República Dominicana y Uruguay; los intermedios: Bolivia, Colombia, Ecuador, El Salvador, Honduras, Nicaragua, Panamá, Perú y Venezuela; y los democráticamente menos avanzados: Cuba, Guatemala, Haití y Paraguay.

22 Véase O’Donnell (2002: 43).

23 La encuesta Fitzgibbon se lleva a cabo desde 1945. La metodología de la misma se basa en la clasificación de los países latinoamericanos de acuerdo con quince criterios por parte de distinguidos académicos latinoamericanistas que son adecuados en niveles de medida ordinales y de intervalo. La encuesta de 2000 contó con la participación de 103 especialistas. 


\section{Cuadro $\mathrm{N}^{\circ} 1$}

Clasificación de las democracias latinoamericanas en el año 2000 de acuerdo con la encuesta Fitzgibbon

\begin{tabular}{|c|c|c|c|}
\hline 1. Costa Rica & 2,344 & 11. Nicaragua & 4,470 \\
\hline 2. Uruguay & 2,722 & 12. Colombia & 4,514 \\
\hline 3. Chile & 2,774 & 13. Ecuador & 4,608 \\
\hline 4. Argentina & 3,079 & 14. Bolivia & 4,667 \\
\hline 5. Brasil & 3,460 & 15. Cuba & 4,676 \\
\hline 6. México & 3,502 & 16. Honduras & 4,739 \\
\hline 7. Venezuela & 3,975 & 17. Paraguay & 4,797 \\
\hline 8. Panamá & 4,005 & 18. Perú & 5,019 \\
\hline 9. Rep. Dominicana & 4,304 & 19. Guatemala & $\begin{array}{l}5,028 \\
5,0 \ldots \ldots\end{array}$ \\
\hline 10. El Salvador & 4,435 & 20. Haití & 6,151 \\
\hline
\end{tabular}

Fuente: Lasa Forum, Vol. XXXIII I, 1. Primavera de 2002, p. 12.

Ahora bien, estas clasificaciones pueden ser complementadas mediante las percepciones que de la política tienen los actores de América Latina y que tienen que ver con el énfasis dado al papel que las aspiraciones democráticas de la ciudadanía desempeñan en relación con la calidad de la política. Dichas aspiraciones, en un primer momento, se confunden con la legitimidad democrática que poseen un alto componente subjetivo según el cual los individuos creen que un determinado sistema, unas reglas procedimentales o un conjunto de políticas son objeto de aceptación y de obediencia y, más aún, son considerados como capaces de resolver sus problemas más inmediatos y relevantes. Si bien en un primer momento la democracia es evaluada per se, como el mecanismo institucional más idóneo, respetable y valioso en sí mismo, con el paso del tiempo la acción política se confunde con el ámbito más genérico que define a las reglas y que no es sino la democracia. El desgaste del gobierno de turno, de sus políticas, y todos sus desarreglos terminan por apoderarse asimismo del ámbito donde aquellas se llevan a cabo. 


\section{Cuadro $\mathrm{N}^{\circ} 2$}

Evolución de la clasificación de los países latinoamericanos de acuerdo con los índices de Freedom House

\begin{tabular}{|c|c|c|c|c|c|c|c|c|c|c|c|c|c|}
\hline \multirow{2}{*}{ País } & \multicolumn{2}{|c|}{ 1976-1977 } & \multicolumn{2}{|c|}{$1990-1991$} & \multicolumn{2}{|c|}{$2001-2002$} & \multirow{2}{*}{ País } & \multicolumn{2}{|c|}{$1976-1977$} & \multicolumn{2}{|c|}{$1980-1991$} & \multicolumn{2}{|c|}{$2001-2002$} \\
\hline & $\mathrm{DP}$ & LC & $\mathrm{DP}$ & LC & $\mathrm{DP}$ & LC & & $\mathrm{DP}$ & LC & $\mathrm{DP}$ & LC & $\mathrm{DP}$ & LC \\
\hline Argentina & 6 & 5 & 1 & 3 & 2 & 3 & Haití & 6 & 6 & 4 & 4 & 6 & 6 \\
\hline Bolivia & 6 & 4 & 2 & 3 & 1 & 3 & Honduras & 6 & 3 & 2 & 3 & 3 & 3 \\
\hline Brasil & 4 & 5 & 2 & 3 & 3 & 3 & México & 4 & 4 & 4 & 4 & 2 & 3 \\
\hline Colombia & 2 & 3 & 3 & 4 & 4 & 4 & Nicaragua & 5 & 5 & 3 & 3 & 3 & 3 \\
\hline Chile & 7 & 5 & 2 & 2 & 2 & 2 & Panamá & 7 & 6 & 4 & 2 & 1 & 2 \\
\hline Costa Rica & 1 & 1 & 1 & 1 & 1 & 2 & Paraguay & 5 & 6 & 4 & 3 & 4 & 3 \\
\hline Cuba & 7 & 6 & 7 & 7 & 7 & 7 & Perú & 6 & 4 & 3 & 4 & 1 & 3 \\
\hline Ecuador & 6 & 5 & 2 & 2 & 3 & 3 & R. Dominicana & 4 & 3 & 3 & 3 & 2 & 2 \\
\hline El Salvador & 3 & 3 & 3 & 4 & 2 & 3 & Uruguay & 6 & 6 & 1 & 2 & 1 & 1 \\
\hline Guatemala & 4 & 3 & 3 & 4 & 3 & 4 & Venezuela & 1 & 2 & 1 & 3 & 3 & 5 \\
\hline
\end{tabular}

Fuente: Freedom in the World: The Annual Survey of Political Rights and Civil Liberties (Londres: Freedom House), p. 200.

Notas:

DP: Derechos Políticos; LC: Libertades Civiles.

El rango supone la categoría de "países libres" a los que se sitúan en promedio entre 1 y 3 ; "países parcialmente libres" a los que se sitúan entre 3 y 5,5; y "no libres" a los que se sitúan entre 5,5 y 7 .

En América Latina el último lustro ha supuesto un fuerte deterioro de las economías nacionales que ha llevado a sus ciudadanos a cotas preocupantes de precariedad en sus condiciones de vida cotidiana y que, junto con el crecimiento del conocimiento de los escándalos de corrupción política, ha contribuido a un fuerte descenso de la credibilidad de la política sin que por ello necesariamente hayan surgido ofertas no democráticas que gozaran de apoyo manifiesto por parte de la ciudadanía ni hayan debilitado el progreso indudable que con respecto al pasado inmediato goza el apoyo a la democracia. En términos eastonianos ${ }^{24}$ se ha seguido manteniendo un apoyo difuso que garantiza legitimidad a la democracia. Ello no ha impedido que, de forma puntual, la percepción de los latinoamericanos sobre la preferencia de la democracia frente a otra forma de gobierno haya sufrido un retroceso que, con matices, puede considerarse generalizado en 2002 con respecto a los años precedentes (véase Cuadro $\mathrm{N}^{\circ} 3$ ). Los datos de la evolución de las preferencias de los ciudadanos muestran un inequívoco descenso en la mayoría de los países en la valoración de la

24 Véase Easton (1975). 
democracia donde solamente México y Venezuela poseen los valores más altos de preferencia de la democracia como forma de gobierno en 2002 de entre las series temporales de ambos países. Si en 1996 siete de los diecisiete países considerados tenían valores favorables a la preferencia de la democracia iguales o superiores al sesenta por ciento y todos menos dos (Honduras y Brasil) tenían valores superiores al cincuenta por ciento, en 2002 eran seis los países que mantenían valores superiores al sesenta por ciento y otros seis valores inferiores al cincuenta por ciento. En el polo opuesto, las preferencias a favor de un gobierno autoritario han descendido sensiblemente, ya que si en 1996 cinco países tenían valores de apoyo a este tipo de gobierno en porcentajes de su población superiores o iguales al veinte por ciento, en 2002 dicho número había descendido a tres.

Por otra parte, las series de respuestas de los ciudadanos en el periodo considerado muestran un declive más pronunciado de las preferencias democráticas en torno a los quince puntos porcentuales en seis países: Brasil, Colombia, El Salvador, Nicaragua, Panamá y Paraguay. Sin embargo, las preferencias autoritarias no han crecido en proporción paralela. De hecho, en la mayoría de los casos se han mantenido e incluso han disminuido. Únicamente se ha registrado un incremento importante en Panamá y, sobre todo, Paraguay. Ello conduce a mantener la existencia de una bolsa relevante de población superior a una cuarta parte de la población entrevistada en un buen número de países (diez) que sostiene una posición tercera reflejada en la idea de que "a la gente como yo nos da lo mismo el tipo de régimen político existente”. Esta población apática es el principal efecto de la crisis de la década del noventa y puede considerarse como un "ejército de reserva" para acompañar cualquier tipo de aventura política que se pudiera poner en marcha.

Los países latinoamericanos que destacan por su mayor nivel de preferencia de la democracia a cualquier otra forma de gobierno por parte de la población entrevistada y que, a su vez, mantienen valores estables a lo largo del periodo 1996-2002 con una media superior al sesenta por ciento son Argentina, Costa Rica, Honduras, Nicaragua, Panamá, Perú, Uruguay y Venezuela, de los que destacan sobremanera Costa Rica y Uruguay con valores constantes en torno al ochenta por ciento, lo que viene a suponer una categoría especial. Por el contrario, los países que se sitúan en el rango de menor nivel de preferencia, con valores medios inferiores al cincuenta por ciento son Ecuador, Guatemala y Paraguay. Brasil, Colombia y El Salvador son países sin preferencia por el tipo de gobierno, actitud más constante en los dos primeros, donde el cinismo político tiene mayor presencia, que en el tercero puesto que esta tendencia no se hace patente sino en 2001. 
Cuadro $\mathrm{N}^{\circ} 3$

Preferencias sobre formas de gobierno

\begin{tabular}{|c|c|c|c|c|c|c|c|c|c|c|c|c|}
\hline \multicolumn{13}{|c|}{ ¿Con cuál de las siguientes afirmaciones está usted más de acuerdo? (\%) } \\
\hline & \multicolumn{6}{|c|}{$\begin{array}{l}\text { La democracia es preferible a cualquier otra } \\
\text { forma de gobierno }\end{array}$} & \multicolumn{6}{|c|}{$\begin{array}{l}\text { En algunas circunstancias es preferible un } \\
\text { gobierno autoritario }\end{array}$} \\
\hline & 1996 & 1997 & 1998 & 2000 & 2001 & 2002 & 1996 & 1997 & 1998 & 2000 & 2001 & 2002 \\
\hline Argentina & 71 & 75 & 73 & 71 & 58 & 65 & 15 & 15 & 16 & 16 & 21 & 17 \\
\hline Bolivia & 64 & 66 & 55 & 62 & 54 & 56 & 17 & 16 & 22 & 13 & 17 & 20 \\
\hline Brasil & 50 & 50 & 48 & 39 & 30 & 37 & 24 & 19 & 18 & 24 & 18 & 15 \\
\hline Chile & 54 & 61 & 53 & 57 & 45 & 50 & 19 & 16 & 16 & 19 & 19 & 14 \\
\hline Colombia & 60 & 69 & 55 & 50 & 36 & 39 & 20 & 13 & 17 & 23 & 16 & 11 \\
\hline Costa Rica & 80 & 83 & 69 & 83 & 71 & 77 & 7 & 9 & 21 & 6 & 8 & 8 \\
\hline Ecuador & 52 & 41 & 57 & 54 & 40 & 49 & 18 & 23 & 19 & 12 & 23 & 18 \\
\hline El Salvador & 56 & 66 & 79 & 63 & 25 & 40 & 12 & 13 & 10 & 10 & 10 & 16 \\
\hline Guatemala & 51 & 48 & 54 & 45 & 33 & 45 & 21 & 26 & 29 & 21 & 21 & 12 \\
\hline Honduras & 42 & 63 & 57 & 64 & 57 & 57 & 14 & 17 & 9 & 15 & 8 & 14 \\
\hline México & 53 & 52 & 51 & 45 & 46 & 63 & 23 & 31 & 28 & 34 & 35 & 20 \\
\hline Nicaragua & 59 & 68 & 72 & 64 & 43 & 63 & 14 & 19 & 9 & 6 & 22 & 12 \\
\hline Panamá & 75 & 71 & 71 & 62 & 34 & 55 & 10 & 10 & 8 & 18 & 23 & 16 \\
\hline Paraguay & 59 & 44 & 51 & 48 & 35 & 45 & 26 & 42 & 36 & 39 & 43 & 38 \\
\hline Perú & 63 & 60 & 63 & 64 & 62 & 57 & 13 & 16 & 12 & 13 & 12 & 16 \\
\hline Uruguay & 80 & 86 & 80 & 84 & 79 & 78 & 9 & 7 & 9 & 9 & 10 & 10 \\
\hline Venezuela & 62 & 64 & 60 & 61 & 57 & 75 & 19 & 17 & 25 & 24 & 20 & 12 \\
\hline
\end{tabular}

Fuente: “Latinobarómetro" en The Economist, 28 de julio de 2001 y 15 de agosto de 2002.

Como complemento a la evolución de las preferencias populares sobre el tipo de gobierno existente en su país puede considerarse la opinión de la clase política acerca del grado de estabilidad que la democracia tiene en su país (véase Cuadro $\left.\mathrm{N}^{\circ} 4\right)^{25}$. Si bien se trata ahora de evaluaciones de un sector de la clase política con obvios supuestos mentales diferentes a los de la generalidad de la población, su percepción de la vida política en términos agregados, por la posición que ocupan, es valiosa. De esta manera, y dentro de los dieciséis casos de los que se tienen datos, pueden establecerse tres grupos de países que son un

25 Se trata de los resultados de una investigación llevada a cabo en el seno del Instituto Interuniversitario de Estudios de Iberoamérica y Portugal de la Universidad de Salamanca desde 1994 referida a las actitudes, valores y opiniones de los diputados latinoamericanos y que ha contado con el apoyo del Programa Nacional de Ciencia y Tecnología y otras entidades públicas y privadas. 
reflejo de las profundas diferencias existentes entre los mismos: los de alta estabilidad (Argentina, Chile, Costa Rica y Uruguay), los de estabilidad media (Bolivia, Colombia, Honduras y República Dominicana), y los de baja estabilidad (Ecuador, El Salvador, Guatemala, México, Nicaragua, Paraguay, Perú y Venezuela).

Cuadro $\mathrm{N}^{\circ} 4$

El grado de estabilidad de la democracia*

\begin{tabular}{|c|c|c|c|c|c|c|c|c|}
\hline País & Congreso & $\begin{array}{c}\text { Muy } \\
\text { estable }\end{array}$ & $\begin{array}{l}\text { Bastante } \\
\text { estable }\end{array}$ & $\begin{array}{l}\text { Poco } \\
\text { estable }\end{array}$ & $\begin{array}{l}\text { Nada } \\
\text { estable }\end{array}$ & N.S. & N.C. & (N) \\
\hline Argentina & $(95-97)$ & 49,7 & 47,0 & 3,2 & 0,0 & 0,0 & 0,0 & $(68)$ \\
\hline Argentina & $(97-01)$ & 59,4 & 34,4 & 3,9 & 0,0 & 0,0 & 2,3 & (128) \\
\hline Bolivia & $(97-02)$ & 27,6 & 57,1 & 14,3 & 1,0 & 0,0 & 0,0 & $(98)$ \\
\hline Chile & $(93-97)$ & 32,7 & 64,3 & 3,0 & 0,0 & 0,0 & 0,0 & $(93)$ \\
\hline Chile & $(97-01)$ & 33,7 & 62,9 & 3,4 & 0,0 & 0,0 & 0,0 & $(89)$ \\
\hline Colombia & $(98-02)$ & 20,9 & 61,0 & 16,0 & 2,2 & 0,0 & 0,0 & $(88)$ \\
\hline Costa Rica & $(94-98)$ & 61,5 & 38,5 & 0,0 & 0,0 & 0,0 & 0,0 & $(52)$ \\
\hline Costa Rica & $(98-02)$ & 46,9 & 44,9 & 8,2 & 0,0 & 0,0 & 0,0 & $(49)$ \\
\hline Ecuador & $(96-98)$ & 11,3 & 76,7 & 6,6 & 2,9 & 0,0 & 2,5 & $(72)$ \\
\hline Ecuador & $(98-02)$ & 5,4 & 49,5 & 35,1 & 7,2 & 0,0 & 2,7 & $(111)$ \\
\hline El Salvador & $(94-97)$ & 4,6 & 44,4 & 36,9 & 6,3 & 1,7 & 6,1 & $(46)$ \\
\hline El Salvador & $(97-00)$ & 7,4 & 51,6 & 35,8 & 0,0 & 0,0 & 5,2 & $(58)$ \\
\hline El Salvador & $(00-03)$ & 19,5 & 36,1 & 41,6 & 0,0 & 0,0 & 2,8 & $(64)$ \\
\hline Guatemala & $(95-99)$ & 17,5 & 30,2 & 46,0 & 3,2 & 0,0 & 3,2 & $(63)$ \\
\hline Honduras & $(94-97)$ & 19,8 & 62,7 & 14,4 & 0,0 & 3,0 & 0,0 & $(67)$ \\
\hline Honduras & $(97-01)$ & 29,6 & 54,9 & 15,5 & 0,0 & 0,0 & 0,0 & $(71)$ \\
\hline Nicaragua & $(96-01)$ & 4,3 & 27,1 & 57,1 & 10,0 & 1,4 & 0,0 & $(70)$ \\
\hline México & $(94-97)$ & 10,3 & 26,0 & 32,3 & 26,3 & 0,6 & 4,5 & $(123)$ \\
\hline México & $(97-00)$ & 9,5 & 38,1 & 44,4 & 6,3 & 1,6 & 0,0 & (126) \\
\hline México & $(00-03)$ & 15,7 & 48,8 & 33,1 & 2,5 & 0,0 & 0,0 & $(121)$ \\
\hline Paraguay & $(93-98)$ & 4,3 & 37,0 & 56,7 & 2,0 & 0,0 & 0,0 & $(47)$ \\
\hline Paraguay & $(98-03)$ & 1,5 & 40,0 & 52,3 & 6,2 & 0,0 & 0,0 & $(65)$ \\
\hline Perú & $(01-06)$ & 5,1 & 26,5 & 62,5 & 3,8 & 0,0 & 2,2 & $(83)$ \\
\hline R. Dominicana & $(94-98)$ & 30,8 & 22,3 & 35,0 & 8,7 & 0,0 & 3,3 & $(62)$ \\
\hline R. Dominicana & $(98-02)$ & 46,6 & 44,7 & 8,7 & 0,0 & 0,0 & 0,0 & $(103)$ \\
\hline Uruguay & $(00-05)$ & 66,5 & 29,5 & 4,0 & 0,0 & 0,0 & 0,0 & $(68)$ \\
\hline Venezuela & $(00-05)$ & 17,8 & 45,3 & 26,3 & 3,9 & 0,0 & 6,6 & $(100)$ \\
\hline
\end{tabular}

* Pregunta: En su opinión, ¿la democracia en su país es hoy: muy estable, bastante estable, poco estable o nada estable? Fuente: Proyecto Élites Parlamentarias Latinoamericanas. Salamanca, 1994-2005. 
La integración en una única clasificación ${ }^{26}$, de acuerdo con los dos criterios recién enunciados, proyecta el escenario que se presenta en el Cuadro $\mathrm{N}^{\circ}$ 5. Los dieciséis casos nacionales recogidos cubren nueve de las doce casillas definidas lo cual es un indicador que refleja la validez de las taxonomías establecidas. A pesar de la severa crisis que asola Argentina desde finales de 2001, este país, junto con Costa Rica y Uruguay se sitúa en una posición de máxima bonanza democrática. Esta es una posición que mantiene una clara disonancia con el repudio manifiesto hacia la clase política argentina. Mientras que la democracia parece alcanzar cotas de gran vigor, la política, como actividad cotidiana registra el rechazo masivo de los ciudadanos ${ }^{27}$. De esta forma, la decepción con respecto al liderazgo político se ha convertido en el principal factor de debilitamiento de la percepción de estabilidad de la democracia en condiciones en que se sigue manteniendo una clara preferencia por la misma. El cuestionamiento del liderazgo del peruano Alejandro Toledo ${ }^{28}$, la polarización en torno al liderazgo del venezolano Hugo Chávez y la disputa entre el nuevo presidente de Nicaragua Bolaños y el saliente Arnoldo Alemán pueden estar en la base de la explicación de la ubicación de estos tres países en un espacio con obvias categorías disonantes de alta preferencia por el gobierno democrático y bajo grado de percepción de estabilidad de la democracia.

26 Debe tenerse en cuenta a efectos metodológicos la circunstancia de coincidir dos ámbitos muéstrales diferentes como son, por una parte, los ciudadanos y, por otra, los diputados.

27 Ver a este respecto el índice de Confianza en el Gobierno (ICG) elaborado por la Universidad Torcuato Di Telia de Buenos Aires (<www.utdt.edu>). El ICG argentino pasa, en una escala de 0 a 5 del 1,36 en enero de 2002 a 0,42 en agosto del mismo año. 28 El Grupo de Opinión Pública de la Universidad de Lima evaluaba en el 74,2 por ciento la desaprobación ciudadana a la gestión de Alejandro Toledo en el barómetro de agosto (<www.ulima.edu.pe >). 


\section{Cuadro $\mathrm{N}^{\circ} 5$}

Los países latinoamericanos de acuerdo con sus preferencias ante un gobierno democrático y a la estabilidad de la democracia

\begin{tabular}{|c|c|c|c|}
\hline & $\begin{array}{l}\text { Países de alto grado } \\
\text { de percepción de } \\
\text { estabilidad de la } \\
\text { democracia }\end{array}$ & $\begin{array}{c}\text { Países de grado } \\
\text { medio de percepción } \\
\text { de estabilidad de la } \\
\text { democracia }\end{array}$ & $\begin{array}{l}\text { Países de bajo grado } \\
\text { de percepción de } \\
\text { estabilidad de la } \\
\text { democracia }\end{array}$ \\
\hline $\begin{array}{l}\text { Países con clara } \\
\text { preferencia } \\
\text { por el gobierno } \\
\text { democrático* }\end{array}$ & $\begin{array}{l}\text { Argentina } \\
\text { Costa Rica } \\
\text { Uruguay }\end{array}$ & $\begin{array}{l}\text { Honduras } \\
\text { República Dominicana }\end{array}$ & $\begin{array}{l}\text { Perú } \\
\text { Nicaragua } \\
\text { Venezuela }\end{array}$ \\
\hline $\begin{array}{l}\text { Países con leve } \\
\text { preferencia } \\
\text { por el gobierno } \\
\text { democrático }\end{array}$ & Chile & Bolivia & $\begin{array}{l}\text { Ecuador } \\
\text { México } \\
\text { Guatemala }\end{array}$ \\
\hline $\begin{array}{l}\text { Países con mayor } \\
\text { preferencia por el } \\
\text { gobierno autoritario }\end{array}$ & & & Paraguay \\
\hline $\begin{array}{l}\text { Países sin } \\
\text { preferencia por el } \\
\text { tipo de gobierno** }\end{array}$ & & Colombia & El Salvador \\
\hline
\end{tabular}

*Aquí se encontraría Panamá pero no hay datos de Élites Parlamentarias sobre su grado de estabilidad.

${ }^{\star *}$ Aquí se encontraría Brasil pero no hay datos de Élites Parlamentarias sobre su grado de estabilidad.

Fuente: Elaboración propia.

Otro factor a ser considerado por su notable impacto en la calidad de la política es la corrupción. Medida desde las percepciones que tienen diferentes actores en contacto con las realidades políticas nacionales latinoamericanas, la corrupción tiene un nivel de presencia muy diferente en la región y sus efectos son claramente identificables. Los tres países latinoamericanos que se sitúan en la parte alta de la clasificación establecida con respecto al índice de Percepción de Corrupción ${ }^{29}$ : Chile, Uruguay y Costa Rica están asimismo al frente de una supuesta clasificación en la calidad de su política.

\section{CONCLUSIONES}

La democracia se encuentra asentada en América Latina como nunca antes en su historia en términos de continuidad y de presencia en

29 De acuerdo con el índice de Percepción de Corrupción (IPC) elaborado y publicado el 28.8.02 por Transparency International (<www.transparency.org $>$ ) en una escala de diez puntos los países latinoamericanos obtuvieron las siguientes puntuaciones: Chile: 7,5; Uruguay: 5,1; Costa Rica: 4,5; Brasil: 4,0; Perú: 4,0; Colombia: 3,6; México: 3,6; R. Dominicana: 3.5; El Salvador: 3,4; Panamá: 3,0; Argentina: 2,8; Honduras: 2,7; Guatemala: 2,5; Nicaragua: 2,5; Venezuela: 2,5; Bolivia: 2,2; Ecuador: 2,2 y Paraguay: 1,7. 
mayor número de países. La perdurabilidad de la misma a lo largo del último cuarto de siglo es consecuencia fundamentalmente de la extensión del propio credo democrático entre diferentes actores relevantes que han interiorizado sus valores e incluso adoptado una posición de promoción de los mismos. Empresarios, militares, nuevos movimientos sociales y la clase política han asumido la democracia como "el único juego posible" 30 . Pero también el favorable escenario internacional ha sido un elemento de indudable impacto. Estas dos circunstancias han contrastado con el pobre rendimiento de la economía cuyo comportamiento no ha contribuido, como los teóricos de la teoría de la modernización habrían esperado, a su asentamiento ${ }^{31}$.

El asentamiento de la democracia en América Latina no es óbice para que el desempeño de la política suponga constantes situaciones que, con frecuencia, generan malestar entre los ciudadanos como consecuencia de la no resolución de sus problemas más acuciantes o incluso de la extensión de la convicción de que ellos ni siquiera son abordados por las autoridades competentes. En cierta medida ello es consecuencia de diseños institucionales propios entre los que destacan la forma de gobierno presidencialista, las peculiares relaciones conformadas en el triángulo compuesto por el Poder Ejecutivo, el Poder Legislativo y los partidos políticos, pero también lo es a causa de determinados elementos constitutivos de una cultura política definida por cotas alarmantes de desconfianza en lo público y en las distintas maneras de ejercer la autoridad en dicho ámbito, y, finalmente, se encuentra el menor espacio dejado por el entramado internacional que apenas si permite una mínima autonomía para la toma de decisiones propias. Así mismo se halla la necesaria redefinición del papel del Estado ninguneado por el avance del denominado neoliberalismo articulado en clave de "pensamiento único". El Estado aparece ante diferentes sectores sociales o ámbitos territoriales en un escenario ambiguo definido tanto en lo relativo a su histórica y manifiesta ausencia y en su incapacidad para aplicar el monopolio legítimo de la fuerza como en sus relaciones con la sociedad en el reino de la economía. Espacio al que tampoco ha sido ajena la agudización reciente de los procesos de globalización más activos, si cabe, en dicho terreno de la economía.

Todo ello no es sino un patrón de normalización de la política en América Latina, como nunca antes había ocurrido en su historia. El conflicto, el disenso y la mejor o peor calidad de la implementación de decisiones políticas con sus correspondientes efectos, esperados o no,

30 Expresión usada por Linz (1990: 29) para referirse a una concepción minimalista de la consolidación democrática.

31 Véase el desarrollo de estos puntos en Mainwaring (1999). 
son aspectos de la vida cotidiana que, a su vez, se ve inmersa en dificultades en el avance de los ciudadanos como agentes en un marco regido por las reglas de la poliarquía. La institucionalización de la política, de acuerdo con pautas poliárquicas, es una evidencia de la realidad latinoamericana que afronta un futuro en condiciones muy diferentes a las de hace un cuarto de siglo donde, como ha quedado de manifiesto en las páginas anteriores, se da un escenario de claroscuros.

Se trata no solo de que el juego político funcione mediante reglas democráticas sino también que estas penetren en el interior de las mismas. La demanda ahora no se basa en la libertad de la competencia partidista real, ni en las elecciones a órganos colegiados o no de gobierno y de control, se proyecta en la imponderable articulación democrática en el interior de los mismos, en la democracia interna en los partidos, en los parlamentos y en las reglas de relación entre diferentes poderes. Además, se trata de incorporar a sectores marginales que, en unas ocasiones, acarrean siglos de marginación, pero que en otras son consecuencia del desarrollo desigual. Estos sectores ignoran con frecuencia las reglas de la poliarquía o incluso mantienen comportamientos claramente de anomia y están completamente huérfanos de capital político ${ }^{32}$.

El funcionamiento de las instituciones se alza como un reto fundamental en el devenir de la política. Unas instituciones con mecanismos de actuación concretos que, muchas veces, producen efectos diferentes a los inicialmente esperados o que, en otras ocasiones, han sido incorporadas sin tener en cuenta la realidad del lugar de su ubicación. La atención más que nunca a estos extremos es un imperativo obligatorio en el desempeño de la política. Paralelamente, el comportamiento de los actores, enmarcados en roles y posibilidades de actuación en la política novedosas, supone un frente de inquietudes que no debe ignorarse aunque en muchos casos se trate de actores que continúan incorporando el legado del pasado. Por último, la internacionalización de problemas, hasta hace poco considerados como locales, que comportan soluciones que rompen principios clásicos basados en la soberanía nacional ha introducido un sesgo distinto en la política latinoamericana muy diferente al escenario vislumbrado en las décadas de 1960 y de 1970 por los seguidores de la Teoría de la Dependencia.

La democracia en el último cuarto de siglo en América Latina superó una primera etapa en la que la oleada de transiciones fue su elemento definitorio ${ }^{33}$. Durante la misma se evitó el primer desafío

32 Se entiende por capital político la presencia de confianza política y en las instituciones, de disponibilidad cívica y compromiso político. Véase Mateos (2002: 153).

33 Véase Tanaka (1999: 16). 
que representaban las involuciones autoritarias, la economía gozó de cierta estabilidad lográndose una relativa distribución de la riqueza y se asentaron las reglas de juego democráticas como consecuencia, sobretodo, de acuerdos entre las élites. Posteriormente pasó por una segunda etapa en la que el elemento protagonista fue la transición económica como consecuencia de la quiebra de la matriz Estado-céntrica. Mientras que el desafío político de ese momento consistió en la derrota de los intereses articulados en torno al Estado, el desafío económico giró alrededor del ajuste y de la reforma estructural orientada hacia el mercado. En esta etapa los partidos se asentaron y se rutinizaron diferentes mecanismos institucionales de la poliarquía que, no obstante, mantuvieron cierta debilidad. La reestructuración económica trajo consigo serios costos sociales y se terminaron imponiendo liderazgos autoritarios de nuevo cuño. La tercera etapa en la que se entra al final de la década del noventa tiene como principales desafíos el fortalecimiento institucional y el crecimiento económico sostenido con distribución. Las amenazas proceden de desarreglos en el interior de las instituciones como consecuencia de deficiencias en su funcionamiento y debilidades de la organización y de retos exógenos a las instituciones en la esfera de la sociedad, como serían los estragos de la pobreza y los efectos psicológicos de la inseguridad ciudadana, y en el ámbito internacional como consecuencia de la política autista de Estados Unidos. Sendas amenazas podrían tener efectos en el medio y largo plazo sobre una cultura política en la que perviven rasgos de paternalismo y de clientelismo alimentando una reacción de la ciudadanía que abogase por soluciones en clave de antipolítica ${ }^{34}$ como las que de manera salpicada se han ido dando principalmente en los países andinos a lo largo de los dos últimos lustros.

\section{BIBLIOGRAFÍA}

Alcántara, Manuel 1991 "Sobre el concepto de países en vías de consolidación democrática en América Latina" en Revista de Estudios Políticos, $\mathrm{N}^{\mathrm{o}} 74$, octubre-diciembre (Madrid: Centro de Estudios Constitucionales) pp. 113-130.

Alcántara, Manuel 1992 ¿Democracias inciertas o democracias consolidadas en América Latina?” en Revista Mexicana de Sociología, Vol. 54, No 1, pp. 205-223.

Alcántara, Manuel 2001 "Experimentos de democracia interna: Las primarias de partidos en América Latina" en Papeles de Trabajo (México: FLACSO).

34 Véase Kenney (1997) y Mayorga (1995). 
Alcántara, Manuel 2002 ¿Instituciones o máquinas ideológicas? Origen, programa y organización de los partidos politicos latinoamericanos (Madrid: Istmo).

Easton, David 1975 "A Re-assessment of the Concept of Political Support" en Britisth Journal of Political Science, $\mathrm{N}^{\circ}$ 5, pp. 435-457.

Jordana, Jacint 2001 Relaciones intergubernamentales y descentralización en América Latina: una perspectiva institucional (Washington: Banco Interamericano de Desarrollo) Serie de Documentos de Trabajo I-22UE.

Kenney, Charles 1997 "Anti-Políticos, Intrusos y Política

Democrática” en E politiké (Morón) $\mathrm{N}^{\mathrm{o}} 3$, pp. 28-42.

Linz, Juan J. 1990 "Transiciones a la democracia” en Revista Española de Investigaciones Sociológicas (Madrid) No 51, pp. 9-33.

Mainwaring, Scott 1999 "La durabilidad de la democracia en América Latina" en Política y Gobierno, Vol. VI, N 2, pp. 315-363.

Mateos, Araceli 2002 "Cultura política y participación: las subculturas de los electores de 2000", tesis doctoral (Salamanca: Universidad de Salamanca).

Mayorga, Rene 1995 Antipolítica y neopopulismo (La Paz: CEBEM).

Méndez, Juan E.; O’Donnell, Guillermo y Pinheiro, Paulo Sergio (eds.) 1999 The (Un)Rule of Law \& the Unprivileged in Latin America (Notre Dame: University of Notre Dame Press).

Molina, José Enrique 2000 "Los sistemas electorales de América Latina" en Cuadernos de Capel, (San José de Costa Rica) N 45.

Morgenstern, Scott y Nacif, Benito (eds.) 2002 Legislative Politics in Latin America (Cambridge: Cambridge University Press).

O'Donnell, Guillermo 1994 “Delegative Democracy” en Journal of Democracy, Vol. 5, No 1, pp. 55-69.

O'Donnell, Guillermo 2002 "Human Development, human rights and democracy" en Documento de Trabajo 1. Taller "Calidad de la democracia y desarrollo humano en América Latina" (Heredia, Costa Rica). Disponible en <http://wwwi.estadonacion.or.cr>.

Pérez Liñán, Aníbal 2000 “Juicio político o golpe legislativo? Sobre las crisis constitucionales en los años noventa" en América Latina Hoy, Vol. 26, pp. 67-74.

Tanaka, Martin 1999 "La consolidación de la democracia en América Latina y la importancia de la competencia política: lecciones desde la experiencia peruana" en Occasional Paper (Suiza: The Japan Center for Area Studies) $\mathrm{N}^{\circ} 4$.

Williamson, John 1994 The Political Economy of Policy Reform (Washington: Institute of International Economics). 


\section{Ludolfo Paramio}

\section{LA IZQUIERDA EN AMÉRICA LATINA*}

\section{BÚSQUEDA Y DESORIENTACIÓN}

Desde los años ochenta la izquierda se ha encontrado en todo el mundo en un terreno nuevo, porque sus estrategias políticas estaban diseñadas para aglutinar a las mayorías populares, trabajadores y clases medias, mediante políticas que solo podían ser plenamente eficaces en el marco de economías cerradas, impulsando la demanda desde el Estado y contando con que la inversión privada vendría después. Pero las condiciones para el éxito de esas políticas habían dejado de existir.

Los reveses económicos de la Unidad Popular en Chile (1971-73) y de la primera fase del gobierno socialista francés (1981-83) mostraron, independientemente de sus muy distintos efectos políticos, que las políticas de gestión de la demanda encontraban pronto límites en economías dependientes o abiertas. El contexto crecientemente globalizado de la economía mundial hizo cada vez más patente el agotamiento de las estrategias tradicionales.

Desde entonces cobraron nueva vida las viejas polémicas sobre los rasgos definitorios de la izquierda y sobre la hipotética convergencia de izquierda y derecha en un terreno común o intermedio de pragmatismo

* Paramio, Ludolfo 2008 "La izquierda en América Latina” en Quórum: Revista de Pensamiento Iberoamericano, $\mathrm{N}^{\circ}$ 22, pp. 21-29. 
económico. Es posible que estas polémicas tengan sentido, pero cabe pensar que solo se producen cuando la izquierda o la derecha modifican sus anteriores planteamientos para adaptarse a una situación nueva.

En la Europa de posguerra, las políticas de bienestar fueron abrazadas por la derecha tanto como por la izquierda, y los conservadores reclamaban incluso que aquellas habían sido introducidas por vez primera por algunos de sus grandes líderes, aunque sin recordar que lo hicieron con el propósito de deslegitimar o mantener proscritas a las organizaciones obreras de izquierda. Y luego, en 1971, Richard Nixon dijo aquello de que "ahora todos somos keynesianos".

Se podía pensar entonces que el llamado consenso keynesiano reflejaba una convergencia de la derecha hacia las posiciones de la izquierda. Pero el final de la era de Bretton Woods obligó a la izquierda a buscar nuevas estrategias para adaptarse a un mundo en el que ya no funcionaban las políticas keynesianas, y esa búsqueda permitió que renaciera la idea de una convergencia entre izquierda y derecha. El problema, sin embargo, era que esa polémica en parte expresaba una profunda desorientación de los electores ante los giros estratégicos de los partidos de izquierda.

A la hora de decidir su voto, las personas emiten un juicio de confianza - mayor o menor- hacia un partido concreto. Esta confianza puede reflejar una identificación con ese partido o un simple cálculo sobre lo que cabe esperar de él si forma gobierno, en relación con los intereses particulares del elector o con lo que este entiende que son los intereses colectivos del país. En ambos aspectos, identificación o cálculo, un giro estratégico del partido significa un factor de desorientación para el elector.

En efecto, la identificación, independientemente de los mecanismos sociales a través de los cuales se desarrolle, implica una valoración de la trayectoria de ese partido. Un cambio de estrategia implica un cambio de trayectoria, y en ese sentido pone en peligro la anterior identificación. Pero el cálculo también se basa en la trayectoria anterior: no es posible calcular cuál será el impacto — sobre los intereses personales o colectivos- de un gobierno si ya no cabe prever cuáles serán sus políticas.

En otras palabras, los giros de los partidos de izquierda para gobernar en el nuevo contexto económico desde los años ochenta han causado una desorientación mayor o menor de sus electores y del electorado en general. Pero, además, las nuevas reglas de la economía y los cambios sociales anteriores han creado un mapa social distinto en el que muchos grupos se sienten carentes de representación política. Porque sus partidos de siempre han cambiado o porque se trata de grupos en los que ningún partido parece pensar. 


\section{CRISIS DE REPRESENTACIÓN}

El resultado, bastante perceptible en muchos países de América Latina, es la aparición de una crisis de representación, de una envergadura similar a la que se produjo en los años treinta a consecuencia de los cambios producidos primero por el desarrollo exportador y luego por la crisis de 1929. La comparación resulta especialmente sugestiva porque ambas coyunturas se caracterizan por la aparición de liderazgos populistas, en el sentido de personalistas y con un discurso agresivo contra los partidos políticos anteriores.

Para situar mejor este fenómeno puede ser útil recordar la secuencia que lleva de la crisis de la deuda, en los años ochenta, a la actual fase de crecimiento económico, desde finales de 2002. Independientemente de las primeras interpretaciones de la crisis, a finales de los años ochenta se había extendido la percepción de que se trataba de una crisis estructural, que exigía un drástico cambio en la actuación económica del Estado, y en particular una reducción del crónico déficit público, entendido ahora como déficit estructural.

En ese contexto se extendió el llamado Consenso de Washington y se llevaron a cabo en los primeros años noventa en buena parte de América Latina las llamadas reformas estructurales, activamente impulsadas por el Fondo Monetario Internacional y los distintos organismos financieros multilaterales. Aquella agenda de reformas era discutible en muchos aspectos, pero probablemente se puede afirmar que sin emprenderlas no era posible para los países de la región obtener la financiación, pública y privada, necesaria para volver a crecer, ya que los inversores no confiarían en los países que no las realizaran.

En países con bajas tasas de ahorro y asfixiados por la deuda, resultaba imprescindible la financiación exterior. No es posible generalizar, ya que la capacidad exportadora de Brasil, por ejemplo, creaba unas condiciones distintas, pero la necesidad de obtener financiación y de cortar los procesos hiperinflacionarios explica en buena medida la aceptación de la agenda de las reformas estructurales. Los gobiernos no tenían otra alternativa que llevarlas a cabo para obtener la confianza de los mercados.

Las inversiones traídas por la ola de privatizaciones, y la nueva estabilidad macroeconómica impulsaron una fase de crecimiento regional que se vería cortado por un choque externo, el impacto de la crisis asiática de 1997. Desde 1998 hasta finales de 2002, y pese a un repunte del crecimiento en 2000 , se extendió por la región un clima de frustración, ante la promesa incumplida de que las reformas estructurales iban a traer un crecimiento estable y sin nuevas crisis.

Ese sentimiento de frustración era ya patente en Venezuela en 1998, pues el gobierno de Rafael Caldera no había satisfecho las ex- 
pectativas sociales, y la crisis de los dos partidos tradicionales llevó a la presidencia en 1999 a Hugo Chávez. En enero de 2000 Lucio Gutiérrez encabezó una efímera junta en Ecuador, preámbulo de su victoria electoral en 2003, como Chávez se había beneficiado de su intento de golpe en 1992 contra el "neo-liberalismo" de Carlos Andrés Pérez.

En diciembre de 2001 se produjo el colapso de la convertibilidad argentina, que había pasado de ser una garantía de estabilidad y crecimiento a convertirse en un corsé asfixiante de la economía nacional. Con la convertibilidad cayó el gobierno de Fernando de la Rúa, que a su vez arrastró a una completa pérdida de credibilidad a la UCR y al Frepaso que le habían apoyado. En mayo de 2003 resultó elegido Néstor Kirchner. Ese mismo año, en octubre, el presidente boliviano Gonzalo Sánchez de Lozada abandonó el país y fue sustituido por el vicepresidente Carlos Mesa, en medio de una situación de creciente ingobernabilidad que llevaría a la victoria arrolladora de Evo Morales en diciembre de 2005.

No resulta muy arriesgado vincular estas turbulencias a la frustración de las expectativas que habían creado las reformas estructurales. Aunque el peor coste social de las reformas ya se había absorbido en parte, el sentimiento de que se había pagado un alto precio sin resolver los problemas sociales se fue extendiendo en amplias capas, incluyendo las clases medias. Era casi inevitable que brotara una profunda agresividad contra los gobernantes y los partidos que habían impulsado las reformas o que, simplemente, habían tenido la desgracia de estar en el poder después de 1998, cuando se vieron incumplidas las promesas de las reformas.

\section{¿DOS IZQUIERDAS?}

Como es sabido, en pocos países de América Latina existen opciones partidarias que se puedan identificar como de izquierda según los modelos y tradiciones europeas: se podría decir que solo en el espectro político chileno. Sin embargo la rebelión contra los partidos preexistentes ha llevado a hablar de la aparición de dos tipos de izquierda en América Latina.

Por un lado tendríamos partidos como el PS y el PPD chilenos, el Frente Amplio uruguayo y el PT brasileño, que impulsan una agenda política de centro-izquierda. Y por otro partidos de reciente creación, como el MAS boliviano, el nuevo PSUV que pretende aglutinar el apoyo político a Chávez en Venezuela, el movimiento PAÍS de Rafael Correa en Ecuador o el Partido Nacionalista Peruano de Ollanta Humala, que representan una marcada opción de ruptura, y a los que a menudo se encuadra como representantes de un "nuevo populismo". 
Esta dicotomía deja fuera, sin embargo, gran parte del mapa político de la izquierda. No solo partidos herederos de la izquierda radical de los años setenta, como el FMLN salvadoreño o el Polo Democrático Alternativo en Colombia, sino también partidos que tradicionalmente se podían considerar populistas, como el peronismo argentino, que actualmente desarrolla políticas próximas al centro-izquierda, pero manteniendo un discurso populista (o nacional-popular) y una dinámica de gobierno que le aproxima al nuevo populismo.

La pregunta que cabe hacerse, a la vista de la coyuntura actual, es si el nuevo populismo define una tendencia histórica o es un fenómeno fechado, arraigado en unas circunstancias muy específicas. En primer lugar, es evidente que la aparición de liderazgos populistas solo se ha producido hasta ahora en países en los que previamente se había producido el colapso del sistema de partidos, con una pérdida de credibilidad simultánea de los partidos preexistentes.

En segundo lugar, y aunque pueda parecer paradójico, una condición para la extensión del nuevo populismo parece haber sido la percepción social de que el alza de los precios de los hidrocarburos y de las exportaciones primarias permitía a los gobiernos hacer una política de redistribución a la vieja usanza, y alejarse de las reglas del Consenso de Washington. Para entender este segundo punto basta recordar las dos etapas de la presidencia de Chávez, antes y después del efímero golpe de 2002 y de la posterior huelga de PDVSA.

En la primera fase, pese a la dinámica de movilización política impulsada por Chávez, sus apoyos se debilitaron por la ausencia de resultados económicos. Fue la subida de los precios del petróleo, y de los ingresos por su exportación, lo que permitió el reasentamiento de esos apoyos en una situación de fuerte polarización política. Dicho de otra forma: lo que ha caracterizado políticamente al nuevo populismo es esa dinámica de polarización, pero lo que le ha permitido consolidarse, y extenderse de Venezuela a otros países, ha sido el auge de los precios de los hidrocarburos y de las materias primas en el mercado mundial.

Esto podría significar que el futuro de los nuevos populismos depende de la continuidad de ese auge, que en estos momentos (septiembre de 2008) no está asegurado. Un hipotético estancamiento de la economía global, incluso si China e India continúan creciendo, traería un entorno desfavorable para unos gobiernos cuya principal apuesta es redistribuir los ingresos de las exportaciones, y que sufren no solo fuertes tensiones inflacionarias sino situaciones de desabastecimiento interno en parte como consecuencia de sus deseos de controlar los precios.

Esa dependencia del mercado global es probablemente la principal debilidad de gobiernos cuyo discurso incluye de forma explícita el rechazo de las reglas "neoliberales" del mercado. Pero quizá es in- 
evitable una vez que su dinámica de polarización política les enfrenta con los sectores empresariales internos y desincentiva la inversión. La gran pregunta es si existen alternativas a esa polarización.

Quizá el gobierno de Evo Morales sea un buen ejemplo del problema. Los movimientos y grupos sociales con presencia local y sectorial que le apoyan no habían desarrollado una mediación política común antes de su triunfo electoral de 2005. Lo que les une es el rechazo del "régimen neoliberal", y por ello coinciden en la confrontación y se dividen ante cualquier posible concesión. Dado que sin concesiones mutuas es casi imposible una negociación con éxito, solo se ha llegado a hablar de acuerdo con la oposición después de que las tensiones hayan alcanzado el límite de la violencia.

Más en general, en la medida en que el ascenso del "nuevo populismo" es la expresión de la agresividad de los ciudadanos contra los partidos políticos anteriores, a los que consideran culpables de la frustración de sus expectativas o incapaces para asumir sus problemas, el nuevo gobernante tiene todos los incentivos para mantener una polarización que refuerce esos sentimientos, y ninguno para negociar acuerdos que puedan ser vistos como una traición a los intereses populares.

Eso significa una gran dificultad para llegar a reglas de juego aceptables - objetiva y no solo subjetivamente- para los sectores empresariales y las clases medias, y una fuerte tentación para reemplazarlos desde un nuevo y ampliado sector de economía estatal o social. El riesgo de que esto lleve a la desinversión y al retroceso económico es muy grande, y el nuevo sector público puede ser poco competitivo a la larga y depender exclusivamente de los ingresos por exportaciones de hidrocarburos.

Una pregunta inevitable, entonces, es la de si el nuevo populismo podrá sobrevivir a una caída de los precios de los hidrocarburos y otras materias primas. La respuesta puede estar ligada a la cuestión central al analizar la historia, la situación actual y las perspectivas de la izquierda en América Latina: sus dificultades para crear partidos políticos con un perfil ideológico definido y con una identidad duradera en el tiempo.

\section{¿PERSONALIDADES O PARTIDOS?}

En estos momentos se diría que el problema de la creación y consolidación de partidos de izquierda resulta especialmente difícil de resolver, dado que el ascenso de los medios audiovisuales ha llevado a una fuerte personalización de la política. Hoy más que nunca los ciudadanos eligen entre personas, no entre programas o partidos. La proximidad a los candidatos que permite la televisión deja muy en 
segundo plano a las organizaciones que los apoyan, y solo permite discutir sus propuestas a partir de enunciados muy generales y a menudo imprecisos.

No es evidente que tenga que ser así, como si la televisión condujera inevitablemente al empobrecimiento del debate político. Pero la forma en que actualmente se desarrollan las campañas conduce casi inevitablemente a este resultado: se seleccionan los mensajes por su impacto mediático, no para ejemplificar políticas públicas concretas o resumir la coherencia de un programa. La escasez (o simple ausencia) de debates entre los candidatos favorece la demagogia y la banalización del discurso.

Además, la inexistencia de financiación pública de las campañas -que permitiría imponer reglas sobre su desarrollo-, no solo permite esta trivialización, sino que crea mecanismos perversos de vinculación entre los candidatos y las personas y grupos que poseen recursos financieros, lo que siempre es malo para la independencia de los políticos democráticos, pero puede ser peor si las fuentes de esos recursos son ilegales: hay ya demasiados casos de la llamada narcopolítica.

Más allá de los cambios que serían necesarios para evitar que la comunicación política a través de los medios produzca un empobrecimiento del debate político, lo que parece poco discutible es que en la actualidad es mucho más fácil crear un partido político a partir de un candidato que posea una cierta popularidad o una personalidad atractiva. Y no se trata de una cuestión de fotogenia, como revelan claramente algunos casos del nuevo populismo.

Pero, a la vez, es mucho más difícil que ese partido se institucionalice hasta el punto de ofrecer un perfil político propio, capaz de crear lealtades duraderas más allá de candidatos o dirigentes particulares. Las siglas políticas son hoy un producto perecedero y secundario, como entendió muy bien el presidente Fujimori al crear partidos políticos nuevos a su servicio para cada elección. El contraste con un partido con arraigo social y estructura organizada, como el APRA, es bastante revelador.

La fungibilidad de los partidos políticos presenta graves problemas para el funcionamiento de la democracia. El primero y muy evidente es que, si un partido sirve solo para un proceso electoral, los electores no tienen a quién castigar con su voto en el siguiente proceso si su actuación ha resultado desastrosa. El segundo es que la fuerza de las personalidades y la debilidad de las siglas conduce casi inevitablemente al "reeleccionismo" en el caso de presidentes que terminan su mandato con alta popularidad, ya que a la preferencia de los gobernantes por permanecer se suma la incertidumbre de sus seguidores sobre los resultados de unas elecciones sin el candidato al que los electores han apoyado y apoyan. 
Pero hay un problema mayor. Excepto en los casos de reelección, la discontinuidad o simple debilidad de las siglas partidarias provoca en cada convocatoria electoral un comienzo desde cero de las políticas públicas, políticas cuya eficacia depende muy a menudo precisamente de su continuidad, del carácter gradualmente acumulativo de sus resultados. Unos partidos políticos volátiles conducen casi inevitablemente a unas políticas públicas improvisadas y sin continuidad, excepto cuando los condicionamientos externos obligan a mantenerlas aunque por razones electorales se hayan denunciado las del gobierno anterior, como frecuentemente sucede con la gestión macroeconómica ortodoxa.

\section{PERSONALISMO O INSTITUCIONES}

A todos estos inconvenientes de la personalización de la política se suma el que resulta central para los propósitos de esta nota: es mucho más fácil crear nuevos partidos ${ }^{1}$ que mantenerlos con un perfil político duradero. Esto atañe también a las fuerzas del "nuevo populismo": si sus líderes se desgastan o pierden el gobierno es difícil imaginar la continuidad de sus actuales organizaciones de apoyo, especialmente si estas son una coalición laxa de movimientos y colectivos sociales.

El problema tiene al menos dos dimensiones. La primera es que los liderazgos personales fuertes no intentan normalmente institucionalizar sus bases de apoyo, en parte por pensar que su carisma no puede "rutinizarse", en la expresión de Weber, y en parte porque en un partido institucionalizado es más verosímil la rebelión contra el líder y su desplazamiento. Sea por una concepción mística del propio liderazgo, sea por deseo de mantener el poder, es infrecuente el caso de líderes "carismáticos" que se proponen crear un partido fuerte. En este sentido llama la atención el caso de Chávez y su intento de pasar del Movimiento V República a un Partido Socialista Unido de Venezuela. La clave es probablemente el deseo de seguir el modelo cubano, pero también un cálculo - que podría resultar equivocado- para cortar la indisciplina entre sus apoyos y seguidores iniciales.

Con la habitual excepción de Chile, donde los partidos de izquierda han mantenido desde los años treinta perfiles ideológicos definidos - lo que les ha exigido un laborioso proceso de "renovación" para adaptarse a los cambios sociales-, los dos grandes partidos de izquierda en la región que han llegado al gobierno son el PT brasileño

1 Hay excepciones: la legislación mexicana dificulta la entrada de nuevos partidos en el sistema, pero los que lo logran consiguen perpetuarse mediante acuerdos con los partidos tradicionales, lo que reduce considerablemente la competitividad efectiva y favorece el desdibujamiento programático. 
y el Frente Amplio uruguayo, por más que este sea una coalición de partidos. ¿Cabe imaginar un proceso de creación de nuevos partidos con posibilidades de llegar al poder?

A la vista de los ejemplos citados, se podría pensar que el primer factor para ello es que no se produzca un éxito demasiado rápido: un largo tiempo en la oposición puede ser la clave para llegar a una cierta coherencia interna. Pero los dos ejemplos muestran también la importancia de un liderazgo claro que asegure la cohesión del partido. Las dificultades para definir ese liderazgo pueden ser mayores incluso que las derivadas de una previa heterogeneidad ideológica: diferentes culturas pueden coexistir en una misma organización en la medida en que se reconocen en un mismo liderazgo.

Esta es la contradicción entre las dos exigencias fundamentales para la construcción de una nueva fuerza de izquierda. Por una parte la dinámica electoral y política favorece el personalismo, y este tiende a dejar en segundo plano el desarrollo organizativo, institucional y programático de un verdadero partido político. Pero, por otra parte, es poco probable que una fuerza política atraviese el necesario proceso de maduración — sin disgregarse o perder toda credibilidad- en ausencia de un liderazgo interno reconocido.

El descrédito de la política institucionalizada, la personalización de la política y el riesgo de trivialización del debate político son hechos propios de nuestro tiempo. Pero en cambio no es nueva la necesidad de contar con un liderazgo claro y a la vez desarrollar un largo trabajo de organización. Lo difícil es hacerlo en tiempos de impaciencia y de volatilidad electoral. 



\section{Marisa Revilla Blanco}

\section{AMÉRICA LATINA Y LOS MOVIMIENTOS SOCIALES}

\section{EL PRESENTE DE LA “REBELIÓN DEL CORO”*}

EL ANÁLISIS DE LOS MOVIMIENTOS sociales en América Latina ${ }^{1}$, de las experiencias de movilización en las últimas décadas del siglo XX y en esta primera década del siglo XXI, es especialmente relevante, porque se ha consolidado la especificidad de la acción colectiva: por un lado, la acción colectiva popular incorpora una fuerte dinámica de solidaridad grupal; por otro, la capacidad de movilización se ha demostrado en muy diversas ocasiones y ha llegado a provocar rupturas institucionales. Además, resulta pertinente, en América Latina, la hipótesis sobre una posible "normalización de la protesta" (Van Aelst y Walgrave, 2001: 461-486): la aceptación de algunos modos de acción y diversificación de los grupos sociales que participan en ella, fenómeno ya observado en los repertorios de acción colectiva de Europa y Estados Unidos.

En este trabajo consideraré la solidaridad grupal como capacidad para la acción colectiva, y el aprendizaje de ciudadanía como el resul-

1 Una puntualización inicial y necesaria: utilizo América Latina como un referente social, económico, político, geográfico y cultural, pero entiendo la región de un modo diverso y complejo, ajeno a una concepción unitaria.

* Revilla Blanco, Marisa 2010 "América Latina y los movimientos sociales: el presente de la 'rebelión del coro'” en Nueva Sociedad, N²27, pp. 51-67. 
tado más permanente y consolidado de la acción; intentaré explicar las circunstancias que condicionan el desarrollo de la acción colectiva de confrontación ${ }^{2}$ (para lo cual rebato un excesivo economicismo en la explicación e introduzco factores políticos, sociales y culturales); y por último, avanzaré sobre la diversificación de los grupos sociales que participan en la acción, en particular la inclusión de las clases medias en la acción colectiva de confrontación.

\section{SIGLO XXI: CIUDADANÍA Y MOVIMIENTOS SOCIALES}

En América Latina, la primera década del siglo XXI estuvo marcada por grandes movilizaciones sociales: hemos reconocido en "indígenas", "piqueteros", "desocupados", "pingüinos" o "cocaleros" a actores con presencia, organización y capacidad de movilización. Del mismo modo, cuando hablamos de "cortes de ruta", "caceroladas" o "marchas por la dignidad", nos remitimos a repertorios de acción colectiva propios de la región.

Un par de décadas antes, reconocíamos en las Madres de Plaza de Mayo, el Movimiento de los Trabajadores Sin Tierra (MST), las asociaciones de familiares de detenidos desaparecidos, los comedores populares, las tomas de terreno, los comités de vaso de leche, los movimientos de mujeres y los grupos ecologistas, entre tantas otras movilizaciones, lo que José Nun llamó la "rebelión del coro", una cierta rebeldía de la vida cotidiana que habla sin que se espere y se sale así del lugar asignado al coro (Nun, 1989).

Así, se podría decir que el siglo se ha iniciado con una reivindicación de la política en la calle. Bajo esa puesta en escena, se han presentado las demandas, se ha puesto en jaque, en algunas ocasiones, a los gobiernos nacionales y, en varios países (en algunos más de una vez), los presidentes han debido dejar sus gobiernos por la puerta de atrás de la historia, empujados por ese coro rebelado.

2 Resulta necesario comenzar con una referencia a la distinción, dentro de la acción colectiva, de lo que Tilly definió como acción colectiva "de confrontación". La idea central es que la mayor parte de la acción colectiva tiene lugar dentro de las instituciones y es llevada a cabo por grupos constituidos que promueven valores e intereses ampliamente reconocidos políticamente y no exentos de conflicto. Encontramos así formas de acción como la que llevan a cabo los partidos políticos y los grupos de interés. La acción colectiva recibe el calificativo de "confrontación" cuando es llevada adelante por grupos que carecen de acceso a las instituciones y que actúan promoviendo valores, creencias e intereses no aceptados o nuevos, y que se constituyen como "amenaza" (según el concepto de Tilly) para la acción de los grupos reconocidos. Los movimientos sociales, como escribió Tarrow, son la forma organizativa de esta acción colectiva de confrontación que mantiene la interacción con sus oponentes o con las autoridades (Tilly, 1978; MacAdam, Tarrow y Tilly, 2001; Tarrow, 1997). 
Si nos detenemos en el análisis de los últimos 30 años en la región, el periodo en el que los países de América Latina retornaron a la democracia y la vieron consolidarse como sistema de gobierno, podremos observar que los movimientos sociales fueron claves tanto en la oposición a las dictaduras como en las transiciones a la democracia. Aunque evidentemente podríamos distinguir fases y tendencias en los distintos países de la región y en las distintas áreas geopolíticas, lo cierto es que los movimientos sociales han estado presentes a lo largo de esas tres décadas. También es cierto que ha habido cambios en esos actores: unos se han mantenido, otros desaparecieron y algunos más se constituyeron en los últimos años.

Antes de entrar en el análisis concreto de la acción colectiva, conviene resaltar los aspectos comunes de los movimientos sociales y aquello que los caracteriza como experiencias contemporáneas en América Latina. Como han señalado Arturo Escobar, Sonia Álvarez y Evelina Dagnino, estos movimientos - "sus participantes, sus instituciones, sus procesos, sus programas y sus alcances" - están implicados en las luchas por la demarcación del escenario político (Escobar, Álvarez y Dagnino, 2001: 17). Aunque en general los movimientos sociales producen demandas de reconocimiento por parte de los otros actores y del sistema político, en el caso de los movimientos sociales latinoamericanos contemporáneos se involucran en la producción de una concepción alternativa de ciudadanía. Así, estos movimientos sociales están implicados fundamentalmente en "la multiplicación de escenarios públicos en los cuales se pueda cuestionar y volver a dar significado a la exclusión socio-cultural, de género, étnica y económica (y no solo a la política)" (Escobar, Álvarez y Dagnino, 2001: 42).

Es esta la perspectiva que me interesa en el análisis de los movimientos sociales, tanto en el plano teórico como en el plano concreto. Aquí debo detenerme y explicarme. Los movimientos sociales suelen asociarse a grandes palabras, tales como rebeldía, lucha, resistencia, desobediencia, insurrección, protesta; en general, su lenguaje está plagado de "antis": anticapitalismo, antiestatal... Ese mismo lenguaje es utilizado por algunos científicos sociales para analizar los movimientos sociales. Sin embargo, el resultado de su acción suele ser mucho más positivo, proactivo y transformador de lo que dichos sustantivos y calificativos dan a entender. Es cierto que los protagonistas de las acciones realizan un ejercicio de autoafirmación consciente de sus derechos y de sus capacidades, incluido el potencial de cambio. Pero ese mismo lenguaje es el que se puede utilizar desde los espacios constituidos de poder para calificar cualquier acción que implique una manifestación de descontento, una reclamación, la visibilización de una exclusión o una propuesta transformadora: rebelión, rebeldía, lucha, 
protesta. Y cuando este lenguaje se utiliza desde el poder, el objetivo que se persigue es la deslegitimación de la acción, con el logro, en algunas ocasiones, de la criminalización de la movilización.

Así, la única voz que se reconoce políticamente como propia de la ciudadanía es la que se proclama a través de los altavoces electorales: es, de acuerdo con esta perspectiva, la única vía legítima de participación política. En esa posición, la política en la calle solo se reconoce cuando se convoca desde el poder constituido, esto es, cuando se realizan manifestaciones de apoyo. Es claro que esta interpretación no es solo política: también en la academia hay muchos que abogan por ella; el ejemplo más claro probablemente sea la distinción, ya clásica, entre participación convencional y no convencional.

Desde mi punto de vista, los movimientos sociales son uno de los medios existentes para hacer visibles las reivindicaciones, propuestas, demandas y problemas sociales. Pero son también mucho más que un medio: son el espacio en el que se crean, recrean y transmutan las identidades colectivas. Son la voz de la sociedad, los mensajes que la sociedad envía a los que ejercen el poder, a quienes gobiernan, a quienes están implicados en la gestión de lo público.

Los movimientos sociales como procesos de identificación colectiva, como ejercicios de autoafirmación y como prácticas de solidaridad grupal son, ante todo, una escuela de ciudadanía: fantasías colectivas que van abriendo paso en la historia (Bengoa, 1990). No son política alternativa: son política. Por eso, para su comprensión, y para la comprensión de los fenómenos políticos y sociales de los que son parte, es necesario hacer viajes constantes de ida y vuelta entre las propuestas teóricas y los casos que analizamos. Esto permite contribuir tanto a la propia existencia de los movimientos sociales, de la acción colectiva de confrontación, como a la ampliación de los escenarios políticos y de los repertorios de acción a disposición de la ciudadanía.

\section{DÉCADAS DE ANÁLISIS DE LOS MOVIMIENTOS SOCIALES}

Más de tres décadas de análisis de la acción colectiva y los movimientos sociales, de propuestas teóricas y empíricas, han aportado grandes avances. Esos avances han permitido consolidar un marco teórico común, una serie de premisas que, al día de hoy, prácticamente nadie discute y que, en el fondo, constituyen los cimientos sobre los que se asienta esta propuesta de análisis de la dinámica política de acción colectiva. Entre esas premisas destacaría las siguientes (haciendo gala, sin duda, de un cierto eclecticismo):

1. La acción colectiva es la que lleva a cabo un sujeto colectivo; es decir, es distinta de la suma de acciones individuales. Por lo 
tanto, la dimensión individual de la acción interesa en la medida en que los individuos constituyen los sujetos colectivos: atribuyen significados a su acción, se reconocen en los otros y con los otros y llevan a cabo actos intencionados. Es decir, hay un vínculo necesario entre acción colectiva y acción individual, y ese vínculo es el que se reconoce como una dimensión potencial del análisis.

2. La acción colectiva es siempre un proceso interactivo y comunicativo: implica otros actores, recursos, capacidades organizativas, habilidades de liderazgo, circunstancias coyunturales y condiciones estructurales. Esos procesos configuran escenarios en los que se hace posible o no la acción colectiva y en los que se condiciona la forma que adopta la acción, si es que existen posibilidades de existencia.

3. Como consecuencia de lo anterior, la existencia de agravios o condiciones estructurales o coyunturales de conflicto potencial, aun pudiendo ser considerada una condición necesaria, no es suficiente para explicar la acción colectiva.

4. El proceso de la acción colectiva es un proceso de construcción de identidades colectivas: los actores, al definir la identidad, se definen a sí mismos y sus relaciones con otros actores de acuerdo con los recursos disponibles y con las oportunidades y restricciones del medio.

5. La acción colectiva es siempre acción racional; es decir, existe una racionalidad compartida. Cabe por lo tanto esperar situaciones de elección equivalentes en la historia, y también que los actores, que nunca son los mismos, se comporten, una y otra vez, de modos semejantes.

6. En el proceso de la acción se pone en juego una dimensión instrumental y también una dimensión expresiva. Debido a la primera dimensión, la acción colectiva es el medio para alcanzar ciertos fines; por la segunda, la acción colectiva en sí misma es el fin que se pretende (la expresión de valores y conflictos, la construcción y movilización de una identidad colectiva, la demostración de la propia fuerza, etc.).

Para avanzar en la aplicación concreta de estas premisas, propongo tres niveles de trabajo: la revisión de los repertorios de acción, la distinción entre episodios y procesos y, por último, la consideración dinámica del proceso de la acción colectiva. 


\section{REPERTORIOS DE ACCIÓN}

En el estudio de la acción colectiva, la noción de "repertorio" alude no solo a lo que los participantes hacen cuando están inmersos en un conflicto contra otros, sino a lo que saben hacer y a lo que los otros esperan que hagan (Tarrow, 1997). Es un concepto, tal y como plantea Sidney Tarrow, a la vez estructural y cultural. Los cambios fundamentales en la acción colectiva dependen de grandes fluctuaciones en los intereses, las oportunidades y la organización. Estos, a su vez, van acompañados de transformaciones en los Estados y el capitalismo.

Para una mejor aproximación a la comprensión de los posibles cambios en los repertorios de acción en América Latina, es preciso detenerse brevemente en el concepto y en las tipologías de repertorios. En un trabajo dedicado al análisis de los repertorios de acción en los conflictos comunitarios (Morán, Revilla, Fernández de Mosteyrín y Medina, 2007), distinguíamos tres tipos básicos de repertorios de acción colectiva de acuerdo con su relación con la política convencional, la probabilidad de alterar el orden público y el riesgo de violencia implicado en la acción:

- Repertorio de acción colectiva contenida. Constituye un repertorio en general conocido, comprendido y aceptado; no supone un gran compromiso e implica escaso riesgo en su ejecución (independientemente de que sea un repertorio que se utilice en la competición electoral o no). Se basa en rutinas que la gente conoce y que son aceptadas por las autoridades, quienes pueden incluso llegar a facilitarlas. Por ello predominan numéricamente estas acciones y también por ello se explica su institucionalización. Las acciones concretas que se incluyen son mítines, campañas, propaganda, manifiestos, firma de peticiones, manifestaciones, marchas y huelgas.

- Repertorio de confrontación. Se trata de acciones que conllevan cierto riesgo de alteración del orden público o de uso de la violencia (daños contra la propiedad) e implican un modo de organización, unos beneficios y unos costes particulares. Son formas de acción que rompen con la rutina, sorprenden a los observadores y pueden desorientar a los gobernantes, al menos durante un tiempo. La alteración del orden público es el origen de buena parte de los cambios en los repertorios y del poder de los actores. Sin embargo, es un recurso inestable y puede degenerar fácilmente en violencia. Se incluyen, dentro de esta categoría, acciones con bajo riesgo de alteración del orden público o violencia, dado que involucran escasa interacción física (huelgas de hambre, campañas de desobediencia civil, 
boicots), y acciones con alto riesgo de alteración del orden público o violencia (ocupación de edificios, bloqueos del tráfico, pintadas, daños a la propiedad).

- Repertorio de violencia. La clave para separar la violencia en un repertorio específico se encuentra en lo que entendemos como "un paso más en la escalada": la violencia contra las personas. Aquí ya no es posible distinguir lucha armada, conflicto armado, terrorismo, guerrilla (sí se puede distinguir en lo que se refiere a la definición del actor, no respecto del repertorio de acción). Por ello, hablamos tan solo de la utilización de la violencia contra las personas como medio de acción colectiva, lo que nos permite distinguir esta acción del uso de la violencia sin fines políticos (es decir, la asociada a la delincuencia común o a la delincuencia organizada).

En ese mismo trabajo, destacábamos dos características formuladas en las investigaciones más recientes para el análisis de los repertorios de acción colectiva en la actualidad:

1. Mayor predominio de la acción colectiva contenida. En la actualidad existen condiciones para que se desarrolle con mayor frecuencia la acción colectiva contenida, que está disponible para una mayor variedad de organizaciones y para la participación de un número mayor de personas (Tarrow, 1997). En cierto modo, como algunos autores sugieren, podríamos asistir a una "democratización” de la acción colectiva (Van Aelst y Walgrave, 2001).

2. Normalización de algunos medios de acción. En relación con lo anterior, es posible derivar esta característica: la creciente aceptación de algunos medios frente al mayor rechazo que generan otros. En este caso, es necesario señalar que asistimos (como efecto de causas diversas y dimensiones entremezcladas) a una creciente pérdida de legitimidad del uso de la violencia, a un mayor rechazo del repertorio de violencia. Por otro lado, en la tesis de la normalización se incluye la diversificación de los grupos sociales implicados en la acción colectiva, especialmente en lo que se refiere a la inclusión creciente de las mujeres y de las clases medias (Van Aelst y Walgrave, 2001).

\section{EPISODIOS Y PROCESOS: ¿CAMBIOS EN LOS REPERTORIOS DE ACCIÓN EN AMÉRICA LATINA?}

Como explico a continuación, el análisis de los datos de los últimos años permite formular con cierta seguridad hipótesis sobre el cambio en los repertorios de acción en América Latina, que afectan tanto a los 
medios que se utilizan como a los grupos sociales que se movilizan. Antes de ello, sin embargo, es necesario abordar la distinción entre episodios y procesos de acción colectiva. Es un fenómeno conocido: los movimientos sociales, la acción colectiva en general, atraviesa fases de visibilidad y, como como las definió Alberto Melucci, fases de latencia. En palabras de Guillermo Almeyra, "las luchas sociales son como los ríos cársicos, que a veces dejan la superficie y parecen hundirse en la arena para aparecer algunos kilómetros más abajo, reforzados por otras surgientes y por las aguas subterráneas, y proseguir su camino hacia el mar". Y sigue: "Solo en la visión anárquica, los trabajadores, obreros o campesinos pueden estar constantemente movilizados y en la calle" (Almeyra, 2008).

El énfasis en el análisis de los repertorios de la acción puede parecer limitado a lo visible, a la superficie de esos ríos que se hunden y se ocultan en la tierra. Es decir, un análisis centrado en los episodios de la acción. Sin embargo, la definición de los repertorios como hechos a su vez culturales y estructurales plantea la necesidad de estudiarlos inmersos en los procesos de movilización de que son parte: la fase de latencia. Para que los trabajadores, obreros o campesinos, los ciudadanos y las ciudadanas en general, lleguen a movilizarse en algún episodio concreto de acción, es necesario que exista organización, comunicación, identidad, liderazgo, intercambio, etc.: el periodo de inactividad movilizadora, de invisibilidad, suele ser el tiempo en el que se tejen las redes que serán la base de la movilización.

Volvamos a las dos características que se han formulado para la acción colectiva en la actualidad e intentemos seguir su pista en la acción colectiva en América Latina en los últimos años. Si tomamos la primera, la del predominio o la mayor presencia de la acción colectiva contenida, es necesario atender a una primera fuente, la del Observatorio Social de América Latina (OSAL) del Consejo Latinoamericano de Ciencias Sociales (CLACSO). Allí se demuestra que, desde finales de los noventa, se observa una tendencia general al incremento de la conflictividad. La conflictividad en ese periodo se concentra en la zona andina, mientras que en el Cono Sur se puede observar una disminución, con las excepciones de Argentina y Paraguay. Dentro de la tendencia general y fijándonos en las tendencias regionales, se pueden observar coyunturas de agudización de los niveles de conflictividad social por periodos y países. Así ha ocurrido en Argentina, Bolivia, Chile, Ecuador, Honduras y Nicaragua. Otra fuente, el Informe Latinobarómetro $2006^{3}$, analizaba la situación del siguiente modo:

3 Corporación Latinobarómetro, informes anuales en <www.latinobarometro.org>. 
hay capital social potencial y latente, y no hay suficiente oferta de canalización de ese capital social existente. Ello lo evidencian las calles de la región, [que] están llenas de manifestantes que protestan para defender sus derechos. Si se mide la participación como los latinoamericanos la ejercen, nos encontramos con un movimiento participatorio en todos aquellos países donde los pueblos se han levantado a reclamar sus derechos a una vida digna, los casos de México y Bolivia son emblemáticos. Nunca antes había habido en democracia tantos movimientos de protesta pacíficos, controlados por los sistemas de policía y seguridad de los Estados. Hay países como México y Chile, donde por distintos motivos las cifras de manifestantes han alcanzado el millón de personas. (...) Estos movimientos de protesta apuntan a la deficiencia de una sociedad civil estructurada institucionalmente, con organizaciones que defienden grupos determinados, salvo quizás en el caso indígena y medioambiental, que son los temas más emergentes. Lo que tenemos es una masa de población, dispuesta a defender derechos pero sin canales de organización. (Informe Latinobarómetro, 2006: 28)

Aparentemente, por lo tanto, se asiste a una mayor presencia cívica de los ciudadanos y ciudadanas que expresan, reclaman, reivindican y, utilizando la palabra de moda, se empoderan, cubriendo también las propias insuficiencias de los sistemas de representación o modificándolos (la aparición exitosa de partidos políticos y de liderazgos políticos renovados en las elecciones de diversos países de la región así lo atestigua). Por lo tanto, los medios de este repertorio de acción colectiva, sobre todo la firma de peticiones, las manifestaciones, las marchas y las huelgas, parecen incorporar una mayor variedad de organizaciones y un mayor número de personas.

El Informe Latinobarómetro 2008 es el último que recoge la evolución de la participación en algunas de estas formas de acción. Según los datos que proporciona este estudio, el porcentaje (sobre el total de encuestados en América Latina) de los que responden haber participado en firmas de peticiones se mantiene estable, desde 1995, en torno de 17\%. En el caso de la asistencia a manifestaciones autorizadas, ha disminuido, entre 1995 y 2008 , de $25 \%$ a $12 \%{ }^{4}$. Sin embargo, yo destacaría que la disminución se produjo entre 1995 y 2000, ya que desde ese año hasta este último informe el porcentaje se ha estabilizado, situándose entre 14\% y 12\% (Informe Latinobarómetro, 2008: 100).

La segunda característica señalada aludía a la normalización de algunos repertorios de acción; esto es, la aceptación creciente de algu-

4 En ambas variables, el porcentaje de respuesta que se indica es el de "la ha realizado". 
nos modos de acción y la incorporación de mujeres y clases medias a la acción colectiva.

Las dos últimas encuestas de Latinobarómetro (2008 y 2009) han incluido una pregunta sobre la opinión del entrevistado respecto de marchas, protestas y manifestaciones en la calle. La respuesta "Son normales en democracia" obtiene, para el conjunto de América Latina, un acuerdo de $92 \%$ en 2009 y de 63\% en 2008 (en ambos casos se suman las respuestas "muy de acuerdo" y "de acuerdo"). La diferencia entre los dos años, $29 \%$, es muy alta. La explicación que ofrece el Informe Latinobarómetro 2009 remite a un doble efecto -el hecho de que 2009 fue un año electoral en muchos países y el efecto de la crisis económica- que reactivaría las movilizaciones y aumentaría su visibilidad.

Hay otras dos preguntas incluidas en el estudio que nos pueden indicar la valoración de estos medios de acción más allá de la consideración sobre su normalidad en democracia. En concreto, apuntan más bien a la efectividad de esos medios. En 2008, 59\% de los entrevistados expresaba su aceptación (muy de acuerdo + de acuerdo) con la frase: "[Las marchas, protestas y manifestaciones] son indispensables para que las demandas sean escuchadas", mientras que $49 \%$ se inclinaba por la alternativa: "Solo producen desmanes y destrozos" 5 En la encuesta de 2009, aunque cambia la formulación de la respuesta, se mantiene el sentido sobre la efectividad de la acción: 59\% considera que "Los movimientos sociales son necesarios" y 50\% considera que "Los movimientos sociales generan desorden".

En estos casos, y más allá de la escasa información que nos ofrecen los datos, me parece importante resaltar dos consideraciones respecto de las manifestaciones y marchas: la primera es que son un ejemplo de la importancia simbólica de la ocupación del espacio público y que su estudio redundará en todo lo referente al análisis de la dimensión espacial de la acción colectiva. La segunda es la capacidad de estos dos medios de acción para llamar la atención: se trata de acciones atractivas para su visibilización a través de los medios de comunicación y, por lo tanto, pueden ser consideradas efectivas incluso por quienes no las aprueban.

La mayor aceptación y presencia del repertorio de acción contenida se complementa con el mayor rechazo al repertorio de violencia. No disponemos de datos que nos permitan sustentar esta hipótesis en la opinión pública. Pero se puede hacer una aproximación a esta cuestión a través de un clima (global) de opinión que rechaza la actuación del terrorismo (en sus diversas procedencias) y que aplica el

5 Es una batería de preguntas: la suma de los porcentajes no es 100. 
calificativo de "terrorista" a organizaciones que antes no ostentaban esa calificación ${ }^{6}$.

La última parte de la normalización de la acción colectiva tiene que ver con la incorporación de mujeres y clases medias a la movilización. En el primer caso, es evidente la presencia de movimientos y organizaciones de mujeres en todos los países de América Latina, así como su creciente participación en movimientos y organizaciones que no presentan demandas de género (no así en sus liderazgos, salvo honrosas excepciones) (García y Valdivieso, 2005; Zibechi, 2003). Sin embargo, no contamos con instrumentos que nos permitan conocer con certeza el grado de implicación de las mujeres en episodios concretos de acción como los referidos en párrafos anteriores:

Los datos que manejamos para el análisis de las transformaciones en la implicación política de las mujeres latinoamericanas son extremadamente limitados. Y ello no es solo debido al hecho de que no hayamos incorporado al estudio el peso de otras variables clave -la edad, el nivel de estudios, la situación laboral, entre otras- sino, fundamentalmente, por la forma en la que están formuladas las propias preguntas del Latinobarómetro. Para empezar, el tipo de organizaciones por las que inquiere la encuesta incorpora lo que podríamos llamar un "sesgo claramente masculino". En este punto, no debe descartarse que la aparente "ausencia" de las mujeres que reflejan los datos analizados pueda explicarse porque la participación de las mujeres tenga lugar en mayor medida en grupos informales, en redes cotidianas, que no tienen cabida bajo ninguno de los modos de acción propuestos. Y ello supone que también se olviden algunos de los repertorios asociados a este tipo de organizaciones. Conviene detenerse un poco más en este punto. Si el Latinobarómetro no incluye ni siquiera a los grupos feministas, ¿dónde encajarían los grupos de autoayuda, los comedores populares, y similares? Es decir, no podemos ni siquiera asomarnos a todas esas formas de acción que, siguiendo a Tilly, constituirían la "acción colectiva popular".

Íntimamente vinculado con el punto anterior, parece necesario considerar que el tipo de repertorios que se mencionan en la encuesta también contribuyen a ocultar el papel de las mujeres en la vida social y política de sus comunidades. Posiblemente, debamos considerar que los repertorios en los que están implicadas las mujeres tengan más que ver con la autoorganización y, al mismo tiempo, canalicen, en

6 Este tema trasciende los objetivos de este artículo. Tan solo anoto aquí que, tras los atentados del 11 de septiembre de 2001, las medidas y las políticas de seguridad y la elaboración de listas de organizaciones terroristas configuran el contexto en que se define lo que se considera como terrorismo. 
algunos casos, demandas más expresivas que instrumentales, y más finalistas y menos demandantes de reconocimiento en otros. Si esto fuera así, nos encontraríamos con que, en la medida en que este tipo de acciones y repertorios no son considerados en un buen número de investigaciones, contribuimos a prescindir, una vez más, del papel de las mujeres en la política de la protesta (Morán y Revilla, 2008).

Respecto de la incorporación de las clases medias a la acción colectiva, es un rasgo que nos permite distinguir, por ejemplo en Argentina, los cortes de ruta de los piqueteros de la movilización contra el "corralito" de 2001. O en Ecuador, diferenciar los alzamientos que desalojaron del poder a Abdalá Bucaram o Jamil Mahuad del último derrocamiento de Lucio Gutiérrez. En Ecuador, el movimiento indígena fue el actor social protagonista de los dos primeros alzamientos y la movilización abarcó todo el territorio. La llamada "rebelión forajida", que tuvo lugar principalmente en Quito, tiene más en común con la movilización argentina de diciembre de 2001 que acabó con el gobierno de Fernando de la Rúa que con los alzamientos indígenas. De hecho, podríamos hablar de un efecto "contagio" o "imitación" de los repertorios de movilización utilizados en Argentina contra el corralito: caceroladas, el lema "Que se vayan todos" (frente al "Nada solo para los indios" del levantamiento ecuatoriano de 2001), el impulso posterior a las asambleas populares, etc. En todo caso, se trata de un tema en el que, más allá de algunos análisis, hay mucho terreno para continuar la investigación.

\section{LA CONSIDERACIÓN DINÁMICA DEL PROCESO DE LA ACCIÓN COLECTIVA}

He dejado para el final el argumento que engloba todos los anteriores, que pone en relación episodios y procesos y que, más allá de sus postulados teóricos, permite afrontar el análisis de los movimientos sociales, comprendiendo tanto los procesos de identificación colectiva como las relaciones de poder en las que se insertan y los factores contextuales que pueden favorecer la movilización.

Entre las premisas teóricas expuestas anteriormente, la número tres llama la atención sobre el hecho de que la existencia de agravios y perjuicios sobre grupos sociales concretos, ya sean coyunturales o estructurales, si bien puede ser condición necesaria en la explicación de los movimientos sociales, no es, en ningún caso, condición suficiente. Así, en concreto, la desestructuración social, consecuencia de las reformas de ajuste estructural o la agudización de la crisis, es el contexto en el que las movilizaciones adquieren mayor presencia. Sin embargo, por sí mismas no explican la acción colectiva ni los movimientos sociales. Desde mi punto de vista, son explicaciones marca- 
das por un excesivo economicismo, que han de ser completadas con la consideración de factores eminentemente políticos, tanto institucionales como sociales.

Entre los factores institucionales, los que considero de mayor impacto en la existencia de movimientos sociales son la rigidez institucional de los sistemas presidenciales (el presidencialismo como sistema político introduce dificultades extra para la resolución de crisis políticas por su mayor facilidad para traducir las crisis de gobierno en crisis de sistema); el cuestionamiento de las instituciones representativas (desapego hacia la democracia; desconfianza hacia la clase política, descrédito electoral, etc.); y la destrucción de espacios de concertación social como consecuencia de la aplicación de las reformas neoliberales. Estos factores coinciden en que generan una disminución de la posibilidad de utilización de canales institucionalizados para la expresión y resolución de conflictos sociales y políticos.

Además de las condiciones institucionales, es necesario atender a las condiciones sociopolíticas de la población que incrementan la capacidad de movilización: el acceso a la alfabetización y a la educación; el aumento de la capacidad autoorganizativa y de las habilidades políticas; la propia experiencia democrática; y, por último, la incidencia de los procesos de globalización en el desarrollo de la acción colectiva. Todos estos factores, considerados sin ánimo de exhaustividad, constituyen algunas de las condiciones que median entre esas situaciones potenciales de conflictividad y la realización de los procesos de acción colectiva ${ }^{7}$.

\section{UNA AGENDA DE INVESTIGACIÓN}

En estas páginas se realizaron algunas propuestas mínimas para el análisis de los movimientos sociales que recogen las características y las transformaciones de los episodios y los procesos de la acción colectiva. Modestamente, considero que existe un terreno abonado para una sociología de los movimientos sociales en América Latina que puede dar frutos fecundos. Esos frutos se sumarán a lo que la rica tradición de análisis latinoamericana ya ha producido. Los aportes a una sociología de los movimientos sociales deben incluir también la mejora de los métodos y los instrumentos que utilizamos en la investigación de la acción colectiva.

Es necesario que el análisis de los movimientos sociales dé cuenta de los procesos de identificación colectiva y de cómo los factores indicados, más otros que podrían desgranarse, inciden en el proceso de la acción colectiva. La atención debe dirigirse tanto a los procesos

7 Para un análisis más detallado de este tema, ver Revilla, 2005. 
macro en los que se inscribe la acción (condiciones estructurales nacionales e internacionales, procesos de cambio social, características de los sistemas políticos y electorales) y los niveles meso donde se encuentran estructuras e intenciones (relaciones con otros actores, canales de participación, etc.), como al nivel micro, referido a la interacción y las relaciones de los individuos (capacidades organizativas, procesos de enmarcamiento, liderazgo, etcétera).

Es precisamente la riqueza de las experiencias de la acción colectiva y los movimientos sociales en América Latina lo que puede guiarnos en el rigor y el reconocimiento a los esfuerzos por ampliar la capacidad de inclusión de la democracia, en el convencimiento de que esas experiencias contribuyen a formar una ciudadanía más hábil para la participación política y más consciente de sus capacidades.

\section{BIBLIOGRAFÍA}

Almeyra, Guillermo 2008 "Los vaivenes de los movimientos sociales en México" en Revista del OSAL, № 24.

Bengoa, José 1990 "El tiempo que viene" en Proposiciones (Santiago: Sur) № 18 .

Escobar, Arturo; Álvarez, Sonia y Dagnino, Evelina 2001

"Introducción: lo cultural y lo político en los movimientos sociales latinoamericanos" en Escobar, Arturo; Álvarez, Sonia y Dagnino, Evelina (eds.) Política cultural y cultura política. Una nueva mirada sobre los movimientos sociales latinoamericanos (Bogotá: Taurus / ICANH) p. 17.

García, Carmen Teresa y Valdivieso, Magdalena 2005 “Una aproximación al movimiento de mujeres en América Latina" en Revista del OSAL, № 18.

Informe Latinobarómetro 2006 (Santiago: Corp. Latinobarómetro). Informe Latinobarómetro 2008 (Santiago: Corp. Latinobarómetro). MacAdam, Doug; Tarrow, Sydney y Tilly, Charles 2001 Dynamics of Contention (Cambridge: Cambridge University Press).

Morán, María Luz y Revilla, Marisa 2008 "Mujeres y política en América Latina: más allá de la participación política formal” en Prieto, Mercedes (ed.) Mujeres y escenarios ciudadanos (Quito: FLACSO-Ecuador / Ministerio de Cultura de Ecuador).

Morán, María Luz; Revilla, Marisa; Fernández de Mosteyrín, Laura y Medina, María Claudia 2007 "Means and Repertoires of Action in Community Conflicts" en Proyecto peace.com Peace Processes in Community Conflicts: From Understanding the Roots of Conflicts to Conflict Resolution, Sexto programa marco, prioridad 
7: "Citizens and Governance in a Knowledge Based Society" (Bruselas: Proyecto Peace).

Nun, José 1989 La rebelión del coro. Estudios sobre la racionalidad política y el sentido común (Buenos Aires: Nueva Visión).

Revilla, Marisa 2005 "Ciudadanía y acción colectiva en América Latina. Tendencias recientes” en Estudios Políticos, № 27.

Tarrow, Sidney 1997 El poder en movimiento. Los movimientos sociales, la acción colectiva y la política (Madrid: Alianza Universidad).

Tilly, Charles 1978 From Mobilization to Revolution (Reading: Addison-Wesley).

Van Aelst, Peter y Walgrave, Stefaan 2001 "Who is That (Wo) Man in the Street? From the Normalization of Protest to the Normalization of the Protester" en European Journal of Political Research, № 39, pp. 461-486.

Zibechi, Raúl 2003 "Los movimientos sociales latinoamericanos: desafíos y tendencias" en Revista del OSAL, № 9. 



\section{Juan Carlos Monedero}

\section{DEMOCRACIA Y ESTADO EN AMÉRICA LATINA: POR UNA IMPRUDENTE REINVENCIÓN DE LA POLÍTICA*}

\section{PREGUNTAS DE UN POLITÓLOGO LECTOR}

“(...) El joven Alejandro conquistó la India. ¿El solo? César venció a los galos. ¿No llevaba siquiera a un cocinero? Felipe II lloró al saber su flota hundida. ¿No lloró más que él?

Federico de Prusia ganó la guerra de los Treinta Años.

¿Quién ganó también? Un triunfo en cada página. ¿Quién preparaba los festines? Un gran hombre cada diez años. ¿Quién pagaba los gastos? Tantos informes. Tantas preguntas."

Bertolt Brecht, Preguntas de un obrero lector

¿Es el mismo Estado el que encarceló a Álvaro García Linera en los años noventa y el que hoy dirigen este antiguo proscrito y el presidente indígena Evo Morales? ¿Es el mismo Estado el que hoy referencia Hugo Chávez que aquel contra el que se levantó en armas siendo este comandante menos de una década antes? ¿Es el mismo Estado aquel

* Monedero, Juan Carlos 2011 "Democracia y Estado en América Latina: por una imprudente reinvención de la política” en Documentos de Política (Madrid: Instituto Complutense de Estudios Internacionales) $\mathrm{N}^{\circ} 1$. 
en el que se asesinó a Gaitán en 1948 que el que sembró en Colombia, bajo la presidencia de Uribe, los "falsos positivos" cincuenta años después? ¿Es el mismo Estado el que llenó Brasil, en la expresión de Frei Betto, de pobretariados, que el que había sacado a 20 millones de personas de la pobreza tras el final del mandato de Lula Da Silva? ¿Es el mismo Estado el que vio el levantamiento zapatista en 1994 que el que otorgó la victoria a Felipe Calderón en 2006 bajo fuertes acusaciones de sospecha y bajo la mirada displicente de los indígenas? ¿Es el mismo Estado el salido del golpe de Estado contra el Frente Popular de Salvador Allende que el regido por Sebastián Piñera en Chile tras una victoria electoral? ¿Es el mismo Estado el que tenía en la Escuela Mecánica de la Armada un centro de detención y tortura de argentinas y argentinos que el que lo vio convertido en "Espacio para la Memoria y para la Promoción y Defensa de los Derechos Humanos”? ¿Es el mismo Estado el que persiguió, baleó y encarceló a José Múgica en Uruguay que el que hoy es regido por este antiguo Tupamaro? ¿Es el mismo Estado el que vio su economía dolarizarse que el que hoy, en Ecuador, expulsa la última base norteamericana de su territorio? $¿$ Es el mismo Estado el que pertenece a un tratado de libre comercio que el que se integra en formas supranacionales guiadas por la complementariedad y no por la competitividad? Tantos informes, tantas preguntas.

\section{LA IMPRUDENTE RECONSTRUCCIÓN DE UNA POLÍTICA PRUDENTE}

"El concepto de gobierno de los movimientos sociales es una contradicción en sí misma, sí. ¿Y qué? Hay que vivir la contradicción. La salida es vivir esa contradicción".

Álvaro García Linera, La construcción del Estado

Una de las principales trampas del análisis político tiene que ver con la naturalización del acontecer social. La advertencia marxista acerca de la historicidad de los procesos sociales se deja de lado, y una suerte de fatalismo e inmutabilidad viene a dejar su impronta no solo en aquellos momentos en los que todo lo sólido pudiera disolverse en el aire, sino que se convierte en el patrón de interpretación de la cotidianeidad. La naturalización del modelo económico neoliberal está en el núcleo de estos análisis. De esta manera, toda la gestión política se mide en virtud de la aplicación - $\mathrm{O}$ no- de unas recetas que, al venir emanadas de los países centrales, forman parte del patrón científico necesario. Buscar otras salidas parecen subterfugios de quienes 
no quieren entender esa condición necesaria del recetario económico sancionado por las academias nacionales, los organismos de Washington y la Academia Nobel. Las miradas alternativas — por ejemplo, la que considera que la condición imperialista directa o indirecta de los países centrales sobre los países subalternos es la continuación del modelo de clase que venía operando a la interna de cada país-, pasan a considerarse inferiores por pertenecer a modelos interpretativos supuestamente periclitados, a lecturas ideologizadas o a pretensiones periféricas voluntaristas. La falacia de todo este entramado interesado la resumió Joseph Stiglitz en 2003 recomendando a los países de la periferia: "Haced lo que nosotros hicimos, no lo que decimos"1. Para salir de la indignación moral o la sustitución de marcos interpretativos por meros principios, se hace obligatoria una teoría - por modesta que sea- que permita ubicar los datos de la realidad en un discurso lógico que a su vez permita entender los márgenes del cambio social. Solo puede saberse cuánto es bastante cuando se sabe cuánto es demasiado. Saberlo por la práctica, es imprudente. Saberlo por la teoría, juicioso. La teoría y la práctica son dos caras de una misma mirada. De lo contrario, insistimos, la realidad - incluida la acción colectivaserá vista como un Factum frente al cual no cabe sino la resignación o el seguimiento acrítico. Una teoría del Estado, en tiempos en que la tecnología ha desbordado a los Estados, se hace tanto más necesaria cuanto más se aleja de su posibilidad. Aunque sea una teoría del Estado (Monedero, 2009a).

¿Puede hablarse del Estado mirando hacia el pasado? Más allá del nombre, del registro en Naciones Unidas, de las tradiciones familiares, de la continuidad de la lengua ¿estamos hablando de lo mismo? Si se despoja al Estado de sus rasgos históricos - tiempo y espacio-, ¿se gana manejabilidad o se pierde precisión? Si el Estado es la máquina más perfecta de conseguir obediencia, ¿es indiferente a quién se obedece?

Siguiendo la advertencia de Koselleck sobre la necesidad de vincular los conceptos a una historia que, por definición, es frágil, subjetiva y puro movimiento, y no dejándonos engañar por las palabras que, por su permanencia, pretenden convertir a los conceptos en estatuas, podemos afirmar que las "categorías se comprenden cuando se pregunta quién las emplea" (Villacañas y Oncina, 2006: 27). Es así como podrán entenderse tantos adjetivos que hoy acompañan a la institución estatal, todos creados desde centros de poder que necesitan anatematizar el Estado - un universal evolutivo al servicio de la disciplina social- cuando se pone al servicio de lógicas que dificultan

1 Disponible en <www.project-syndicate.org/commentary/stiglitz31/Spanish>. 
los procesos de acumulación de quienes, tradicionalmente, han tenido fuerza material y simbólica para hacerlos valer. Es desde esa lógica de poder donde hay que enmarcar la ubicación en el basurero de la historia - siempre por imputaciones desde el centro- de supuestos Estados canallas, Estados fallidos, Estados terroristas, así como desestabilizadoras naciones y pueblos sin Estado, de arcaicos pueblos originarios, etcétera.

Una de las virtudes de entender el centro en relación obligatoria con la periferia ayuda a entender que la reacción frente a estos intentos de estigmatización devora igualmente buena parte de los recursos de las gestiones políticas alternativas, a las que se fuerza a un frente externo permanente que dificulta las reformas internas. Mientras que los Estados poderosos se gestionan desde su soberanía, los procesos de colonización imperialista obligan a otros muchos países a mantener un duelo permanente para poner fin a la guerra civil externa e interna - alimentada desde fuera o por las élites transnacionalizadas que operan al interior como una quinta columna real o mediática-y que marcaría el comienzo de su gestión moderna pero que se dificulta por la existencia de ejércitos hostiles en forma de agresiones militares, chantajes financieros, ataques jurídicos, etcétera.

Si es cierto que detrás de la palabra Estado se encierra un concepto político, y que la esencia de lo político es el conflicto - politizar es conflictuar y despolitizar desconflictuar-, llegaremos a la conclusión de que el perfil del Estado en su devenir histórico está ligado a cómo se solvente en cada tiempo y lugar ese conflicto. El Estado es la ratio última encargada de garantizar en lo material y en lo simbólico el orden social existente. Identifíquense las principales causas potenciales de conflicto - aquellas donde seres humanos racionales puedan preguntarse por algo que entienden como una falta, una ausencia, como algo que se les está hurtando-, y se tendrá el mosaico de lugares en donde el Estado estará trabajando para acabar con ese conflicto ocultándolo, reprimiéndolo o solventándolo en un nuevo orden que termine con esa reclamación. De ahí que podamos afirmar: al Estado se le comprende cuando se pregunta a quién sirve.

Esto nos llevaría a entender que pese a que la palabra Estado sea de larga data, el concepto que encierra se modula con el tiempo. Allá donde existan conflictos habrá política. La política desaparecería solo cuando las pretensiones de superación de las diferencias desaparecieran. La política termina solo cuando acabe la conciencia desdichada de la que habló Hegel. Marx lo simplificó — aún con brillantez- en la sociedad sin clases. El consumismo lo simplificó — con éxito vulgar y apoyo mediático- en el mero deseo universalizado de posesión de bienes materiales mercantilizados. 
En el tiempo de la aceleración tecnológica, donde los contemporáneos somos "seres póstumos", las crisis parecen haber acelerado la frecuencia de las ondas largas y cortas en las que se movía el capitalismo. El Estado real cambia con la misma aceleración, y no hay teoría que pueda dar cuenta de él. Tiene una inercia - los conflictos históricamente solventados y que han cristalizado en sus estructuras, protocolos, leyes, simbolismos, tradiciones, etcétera-, pero al tiempo debe dar cuenta de las exigencias del presente ${ }^{2}$. Lo que diferenciará a un gestor de un estadista estará en la capacidad de prever el rumbo de la historia, entendiendo igualmente las grandes lecturas de sí mismos que hagan los pueblos. En ausencia de una teoría general, los gobernantes, obligados a prescindir de la misma, operan con ensayo y error, pierden tiempo y recursos y dedican buena parte de su tiempo a labores de propaganda. El Estado, que lleva la "st" de lo indeleble en su nombre (en la tradición lingüística indoeuropea, aparece en las palabras que implican permanencia, tales como estructura, estabilidad, estatua, institución, estatus, etc.) está sometido a la ley de la aceleración formulada por Henry Adams en 1904. Un Estado que no se anticipe al futuro es un Estado desbordado por los hechos. Pero solo puede anticiparse lo que es regular. ¿Y cómo operar en el mundo irregular de las bifurcaciones? Afirma Wallerstein:

[...] hemos entrado después de treinta años en la fase terminal del sistema capital. Lo que diferencia fundamentalmente esa fase de la sucesión ininterrumpida de los ciclos coyunturales anteriores, es que el capitalismo ya no llega a "hacer sistema", en el sentido en el que lo entiende el físico y químico Ilya Prigogine (1917-2003): cuando un sistema, biológico, químico o social, se desvía demasiado y demasiado a menudo de su situación de estabilidad, ya no llega a encontrar el equilibrio, y se asiste entonces a una bifurcación. La situación se hace caótica, incontrolable por las fuerzas que la han dominado hasta ese momento, y se ve aparecer una lucha, y no entre los poseedores y adversarios del sistema, sino entre todos los actores, para determinar lo que lo va a reemplazar. Reservo el uso de la palabra "crisis" a ese tipo de período. Ahora bien, estamos en crisis. El capitalismo se acaba. (Wallerstein, 2008)

Si Koselleck plantea hacer "una ciencia del pronóstico que mida los márgenes de posibilidad del acontecimiento", la perspectiva política

2 El Estado debe solventar las crisis de hegemonía — garantizando la obediencia-, las crisis de acumulación - garantizando la reproducción económica, y las crisis de confianza — garantizando la reciprocidad social—. Recientemente, Álvaro García Linera ha referido que el Estado es institución, creencias, monopolio y correlación de fuerzas. Véase García Linera, 2010. 
emancipatoria debiera identificar lo posible de lo imposible y operar en sus límites. Luego, reinventar los recuerdos, pues la historia reinicia "en el lugar de los recuerdos" (sin arbitrariedades, pues las fuentes, insiste Koselleck, tienen "derecho de veto") (Koselleck, 2009). Luego se trata de negociar entre esos recuerdos dialogados, un camino de un futuro que dé sentido a todos los esfuerzos, a los caídos, a los derrotados. Que rompa las inercias, pero no olvide que es el presente quien presta los excedentes para pensar la alternativa. Que rompa las inercias, pero no sacrifique los avances. Que deconstruya las cárceles conceptuales y logre la movilización social. Que reinvente un nuevo sentido común desde la confianza, la legitimidad y la acumulación realmente existentes. Una política imprudentemente prudente.

\section{DEMOCRACIA Y ESTADO: ¿CONCEPTOS PARA LA EMANCIPACIÓN O PARA LA REGULACIÓN?}

Si hablar de democracia siempre ha sido una referencia compleja, podemos añadir que ahora, además, es una llamada a la confusión. La comprensión de la democracia siempre se ha hecho en referencia a los Estados nacionales, como una suerte de derivación de las antiguas polis griega, donde viera la luz la idea de un gobierno basado en las decisiones de la mayoría. Si bien es cierto que los derechos de ciudadanía que configuran el corpus democrático (de identidad, civiles, políticos y sociales) no se dejan explicar por fáciles oleadas ordenadas y sucesivas - que crean la mentira de que los derechos son jerarquizables y que los derechos sociales son inferiores a los civiles-, es cierto que la Declaración Universal de los Derechos Humanos de París de 1948 ayudó a afirmar una suerte de acumulación retórica (no en la realidad, pero sí en el discurso) respecto de lo que eran los contenidos de la democracia. En ese marco, la decisión de los miembros de la comunidad en elecciones libres y plurales era la referencia central.

Sin embargo, las necesidades de acumulación del sistema capitalista, estrangulado a mediados de los años setenta del siglo XX por la incapacidad del keynesianismo de compatibilizar el mantenimiento de la tasa de ganancia, la paz social y la hegemonía estatal, se solventó rompiendo los corsés estatales nacionales, dando paso a un nuevo modelo más internacionalizado al que le sobraban las restricciones marcadas por los Estados nacionales. La globalización neoliberal referenciaba la economía en el ámbito supranacional, otorgando a los mercados internacionales, y en especial a los financieros, un poder omnímodo frente al que postulaban una supuesta impotencia (razón que llevó a acuñar la expresión pensamiento único, equívoca al no recoger la multitud de opiniones hoy existentes pero acertada al señalar 
el consenso generalizado entre los gobiernos y los equipos económicos respecto de las recetas económicas) ${ }^{3}$.

Si bien la guerra siempre ha sido una solución recurrente en los problemas de valorización del sistema capitalista en los últimos dos siglos, el siglo XXI contempla un nuevo escenario de batalla más sutil que refuerza el recurso al concepto marxiano de alienación y a la renovación foucaultiana del mismo con la idea de biopolítica. Nos referimos a los medios de comunicación y, en especial, a la creación de un nuevo sujeto cuya existencia solo existe sobre el papel pero que, como en el principio de Thomas, hace que cosas que son tomadas por reales sean reales en sus consecuencias: la opinión pública. Si en la discusión tradicional, la democracia hacía referencia a la participación y posteriormente a la representación, ahora pasaba a señalar de manera general su mediatización (esto es, su representación no electoral sino mediática), donde, es necesario señalarlo, los medios públicos habían perdido su monopolio en favor de grandes empresas con intereses variados y con enorme capacidad de presión sobre los gobiernos ${ }^{4}$.

3 Llamamos globalización al proceso de transterritorialización de los flujos sociales (económicos, jurídicos, políticos y culturales) que mayoritariamente tenían lugar dentro de las fronteras del Estado nacional. Esta movilidad de los flujos sociales ha afectado con mayor énfasis a los intercambios económicos, especialmente financieros, necesitados desde finales de los años sesenta de mercados más amplios para garantizar la reproducción del capital. Pero en modo alguno puede reducirse al campo económico. Aún más, en términos clarificadores debiéramos hablar de mundializaciones o globalizaciones (Appadurai, Santos) pues son múltiples los aspectos que ya no están limitados geográficamente. Esta transterritorialización opera también cuando diferentes actores en diferentes lugares del mundo coordinan sus actividades de manera global (por ejemplo, cuando obtienen información en tiempo real o se buscan referencias de un producto que se va a vender solo localmente con los precios mundiales o cuando se comparan desarrollos tecnológicos o científicos locales con los de otros lugares). Esta transformación social cuantitativa y cualitativa está impulsada por las necesidades económicas de acumulación capitalista —estrangulada en el modelo keynesiano- , que es la que ha extendido su dominio por el resto de sistemas sociales contaminando con su lógica las demás lógicas (incluidas las que pertenecen al mundo de la vida y a la manera subjetiva con que los individuos se reconocen a sí mismos). Igualmente, la transterritorialización ha sido dirigida a través de decisiones políticas tanto en los países del Norte -impulsores-como en los países del Sur — receptores, pero con élites globalizadas que igualmente obtenían beneficio-; y detrás de estos cambios, posibilitándolos, está un fuerte desarrollo tecnológico, en concreto en los sectores de transportes y telecomunicaciones, sin los cuales su alcance sería otro bien diferente. Por último, no puede entenderse este proceso si no se incorpora el hecho de que ha tenido lugar en un momento de hegemonía de los Estados Unidos, lo que le ha permitido influir mundialmente en todo el proceso y moldear esa estatalidad superadora del Estado nacional en virtud a los intereses de sus élites. Véase Monedero, 2009a.

4 Es Manin quien habla de "democracia de audiencia". Véase Manin, 1998. Para una evolución de la idea de democracia, Schmidt, 1997. 
El escenario de confusión hace especial referencia a la falta de criterios para analizar y confrontar la realidad social. Baste señalar que en 2009, el premio Nobel de la Paz fue otorgado al presidente norteamericano Barack Obama casi en el mismo momento en el que ordenaba incrementar el número de tropas en Afganistán y hacía una defensa pública de esa guerra. En ese mismo instante, dentro de su país chocaba contra el muro de los intereses de las corporaciones médicas a la hora de establecer públicamente un seguro universal para los 40 millones de norteamericanos que carecen de ese derecho. En definitiva, y como ha señalado Boaventura de Sousa Santos, una de las paradojas del naciente siglo XXI está en que al tiempo que se ha dado un evidente crecimiento de las democracias en el mundo, se constata igualmente un vacío en lo que concierne a la calidad de esas democracias, entendiendo esta como la participación ciudadana generalizada en las ventajas de la vida social (De Sousa Santos y Avritzer, 2002)

Las elecciones legislativas en Colombia en marzo de 2010 presentaban un escenario útil para comprender esa ambigüedad entre reforzamiento nominal de la democracia y vaciamiento institucional. Varias organizaciones internacionales presentes en el proceso electoral daban cuenta de esta paradoja:

El escándalo de la parapolítica (nombre que se da a los vínculos políticos y económicos de congresistas, gobernadores y alcaldes con los jefes de los grupos paramilitares responsables de miles de asesinatos atroces), que llevó a la cárcel a 30 congresistas y que provocó el procesamiento de otros 60 legisladores, sacudió con fuerza a Colombia durante la pasada legislatura. Pese a la vergüenza nacional que en cualquier país habría provocado tener un Congreso tan indigno, la ejemplar actuación de la Justicia colombiana no sirvió para nada. Los electores no solo no han castigado a los senadores y diputados ligados a las mafias, sino que los premiaron al llevar a las Cámaras a sus parientes y testaferros. De esta manera, los escaños de los parapolíticos encarcelados o procesados los ocuparán sus familiares. Las elecciones legislativas de Colombia están bajo múltiples sospechas. La compra descarada de votos en numerosas regiones del país, la violación generalizada del secreto del voto, las presiones a los electores y el dinero de

5 Qué hace de un país una democracia es una pregunta igualmente complicada. La respuesta hegemónica para obtener el certificado de "país democrático" se basa en la existencia de elecciones multipartidistas (de ahí que el grueso de la ciencia política haya derivado hacia una suerte de ciencia electora formal), al margen del nivel de desigualdades, niveles de participación/abstención y formas de las mismas, violencia, compra del voto, etc. De ahí que le corresponda a una institución privada, Freedom House, establecer el baremo más utilizado por la corriente principal de la academia. Puede consultarse: <www.freedomhouse.org>. 
origen ilícito que corrió a raudales plantean serios cuestionamientos a la limpieza del proceso. El diario bogotano El Tiempo denunció que al menos 35 de los 102 senadores electos el domingo tienen vínculos con condenados o con personas investigadas por tener nexos con grupos paramilitares de ultraderecha. En un análisis sobre los comicios, el periódico señala que la renovación en el Senado "quedó otra vez en veremos" porque "ni los partidos ni los electores castigaron a los herederos de la parapolítica”. En Colombia no se habla de fraude, pero las denuncias son tan serias que plantean serias dudas sobre la legitimidad de los comicios. Los representantes de la Organización de Estados Americanos (OEA) y de la Misión de Observación Electoral (MOE) que durante los últimos meses supervisaron el proceso electoral, denuncian la compra de votos "como nunca antes se había visto en Colombia”. Alejandra Barrios, directora nacional de MOE, declara a este diario que la compra de votos fue escandalosa en todo el país: "De norte a sur, de este a oeste, esta práctica fue descarada, como nunca. El dinero de las mafias corrió a raudales. Lo más grave no es que se compraran votos, sino que la gente exigiera dinero o un cargo por apoyar a tal o cual candidato; este comportamiento muestra la baja calidad de la ciudadanía". Y otro tanto ocurre con la OEA: "Enrique Correa, jefe de la delegación de la OEA, comentó a este periódico que los observadores constataron compra de votos en seis de las más importantes regiones del país: Atlántico, Bolívar, Cundinamarca, Magdalena, Nariño y Norte de Santander. "No hubo secreto del voto en gran número de mesas, lo que constituye un aspecto crítico del proceso. En casi la mitad de los colegios no se respetó el carácter secreto del sufragio”. Correa señaló que los partidos tuvieron dificultades para disponer de supervisores en las mesas de votación, como máximo hubo testigos de los partidos en un $20 \%$ de las mesas ${ }^{6}$.

A todas estas situaciones ancladas en la debilidad institucional del continente latinoamericano, hay que añadir el hecho incontrovertible de la presencia constante de los Estados Unidos en la política del continente. En otros términos, es imposible entender la democracia latinoamericana al margen de la intervención política, económica o militar del poderoso vecino del norte. Si los estudios poscoloniales han demostrado la imposibilidad de entender Europa sin incorporar a América Latina, lo mismo es válido para los Estados Unidos, agravado por el hecho de la conversión de la doctrina Monroe emitida a finales del siglo XIX en una suerte de sentido común generalizado en la ciudadanía y la política norteamericana. Como se ha repetido mil veces, si Washington estornuda, el resto del continente se resfría. De ahí que la crisis económica abriera la fundada duda de en qué medida

6 Véase Ibarz, 2010. 
las consecuencias de la misma iban, de nuevo, a afectar al desarrollo democrático del continente.

Sin embargo, tanto la menor repercusión de la crisis mundial en América Latina, como las mejoras tanto en el bienestar de la población como en su actitud hacia soluciones democráticas, está claramente relacionado con la existencia desde finales de los años noventa de unos gobiernos comprometidos con unos modelos de gestión política alejados de los marcados por los principios del consenso de Washington o de las propuestas de gobernabilidad de la Trilateral a mediados de los setenta. El posicionamiento de los nuevos gobiernos respecto de las reformas que enseñorearon al mercado, la mayor presencia del Estado, especialmente en la recuperación del control de las riquezas naturales, la posición crítica respecto de los organismos multilaterales, así como el mantenimiento equilibrado de las magnitudes macroeconómicas, permiten hablar de una nueva etapa en el continente que ha generado una nueva corriente de opinión respecto de la situación en marcha ${ }^{7}$.

Sabe la ciencia política que las tensiones entre actores son uno de los elementos consustanciales, junto a la trayectoria histórica (la path dependence), de las configuraciones de los sistemas políticos, partidistas, territoriales e, incluso, de la inserción internacional de cada país ${ }^{8}$. De ahí que podamos afirmar que la nueva democracia en América Latina se posicione respecto de quienes planteen formas alternativas de organización social. Y, como se ha constatado recientemente, no existen formas alternativas que no estén refrendadas por las decisiones norteamericanas. La existencia, por un lado, de gobiernos que reclaman con vehemencia la necesidad de recuperar la soberanía nacional (y, para ello, quieren hacer valer la soberanía popular), y, por otro, de una oposición que, invariablemente, plantea algún tipo de regreso al pasado y reclama la tutela norteamericana, establece un escenario que otorga mucha información sobre los futuros desarrollos políticos de la región, donde el papel de Estados Unidos vuelve a ser de estricta relevancia

7 La crisis económica, nacida en los países ricos, ha afectado a la región principalmente en lo referente a las exportaciones (con una caída en torno al 10\% en 2009), aunque no ha tenido el efecto social que tuvieron crisis anteriores. Para los efectos de la actual crisis en América Latina, con especial énfasis en las medidas anticíclicas puestas en marcha por los gobiernos de la región, puede consultarse el informe de la CEPAL, 2010.

8 Es la base de la dialéctica hegeliana; está en la idea de la lucha de clases como motor de la historia en Marx; es la base de los cleavages (las líneas de tensión) de Stein Rokann; y ha sido recientemente "descubierta" por los economistas norteamericanos para entender la importancia de las instituciones en el desarrollo histórico. Véase Pierson, 2000. 
tras el fracaso de la aventura en Oriente medio iniciada por Georg W. Bush. La reactivación de la IV Flota (desactivada tras la Segunda Guerra Mundial al ser su objetivo los submarinos nazis en el Caribe); el aval (pese a la condena formal) del golpe militar en Honduras; el apoyo al bombardeo de un territorio extranjero por parte de otro país (Colombia sobre Ecuador); la toma militar norteamericana de Haití tras el terremoto que asoló el país en enero de 2010; los constantes señalamientos de colaboración con el terrorismo (o de tibieza con el narcotráfico) por parte del Departamento de Estado a los países que han roto con la dependencia respecto de las directrices de Washington, e, incluso, las amenazas a países subordinados como México de ser catalogados como "Estados fallidos" son todas señales de las tensiones que atraviesan el continente finalizada la primera década del siglo XXI.

La democracia en América Latina se va a definir en relación con estos parámetros. De ahí la estricta necesidad de recuperar análisis que permitan quitar los velos que una interpretación interesada ha colocado sobre un continente que ha recuperado una vitalidad negada durante dos siglos.

\section{¿QUIÉN DICE QUÉ?: LA NECESIDAD DE DESCOLONIZAR LOS ANÁLISIS SOBRE EL ESTADO EN AMÉRICA LATINA}

Hay algunos lugares casi comunes en la discusión sobre América Latina que, como se dice de las leyes, se acatan pero no se cumplen. En otras palabras, forman parte de los elementos que se enumeran con la intención de conjurar simplificaciones analíticas, pero con frecuencia quedan al margen de ese análisis supuestamente problematizador, como si las interpretaciones tradicionales impusieran su memoria hasta impedir las matizaciones a las que obligaría una mirada alternativa atenta a esas peculiaridades. Son los lugares que tienen que ver con la heterogeneidad del continente (para luego, sin embargo, sacarse conclusiones homogeneizadoras), la señalada path dependence (para luego ignorar el papel desempeñado por los Estados Unidos en las diferentes historias nacionales latinoamericanas, o por la desigual inserción de cada país en el capitalismo global), las diferencias en cuanto renta per cápita (para luego ignorar las políticas públicas que crean compensaciones en especie $\mathrm{u}$ otros tipos de mediciones), las desigualdades sociales (para luego desproblematizar el papel de las mayorías o minorías indígenas o la importancia de lo que se puede llamar, siguiendo a Frei Betto, pobretariado) o la mayor debilidad o fortaleza del entramado institucional y del sistema de partidos (para luego dejar de lado el hecho de que la democracia representativa vino en el continente a legitimar situaciones de exclusión que afectaban, en muchos de esos países, a uno de cada dos ciudadanos). 
El resultado final que ofrecen esos análisis suele venir de la mano de forzadas categorías que pretenden medir la calidad de la democracia, signadas por categorías occidentales que se aplican con dureza al continente americano y con mayor flexibilidad a los países europeos, con conclusiones asentadas en análisis de élites y no en estudios que den cuenta de las actitudes reales de las poblaciones respecto de los gobernantes (lo que obligaría a formas de sociología política cualitativa) y que dejan ver un Erkenntnisinterese (un interés previo respecto de aquello que se quiere conocer) guiado por el modelo tradicional de partidos y la estructura clásica del parlamentarismo liberal que incluso deja de lado el hecho de que vivimos en lo que, como veíamos, Manin ha llamado democracias de audiencia. De hecho, lo que no terminan de entender esos análisis es que el papel de la ciudadanía referenciada como pueblo (a la búsqueda de nuevas identidades y comportamientos políticos, politizado por tanto, y sujeto de formas renovadas de acción colectiva), ha trastocado buena parte de ese marco. Conjurar esas limitaciones con apelaciones al populismo no ilumina los ángulos que surgen de la quiebra del antiguo marco. Y aún menos si asumimos que lo que se quiere descalificar con esa nominación - populismo - no es sino un momento clave del proceso de politización de una comunidad en donde se había roto el principio básico de homogeneidad social que permite su discurrir pacífico y ético9 .

No mejoró la comprensión con la extensión de la marea de fuerzas políticas de izquierda que tumbaban gobiernos, que juzgaban como criminales a las administraciones anteriores, paralizaban países desde un discurso de izquierda, reclamaban soberanía y dignidad nacional, ocupaban palacios presidenciales, ahora por las urnas, y reclamaban nuevas categorías de entender y hacer América Latina. Durante décadas, ese latinoamericanismo fue complaciente con lo que pasaba al Sur del Río Grande. Lo mismo que denunció Edward Said con el orientalismo, cliché al servicio de formas coloniales o poscoloniales, es válido para el latinoamericanismo, que sentaba las bases para unas relaciones políticas signadas por la subordinación política, económica e intelectual (con el ejemplo evidente del diseño y contenido de Cumbres, celebraciones, seminarios y encuentros, pero también en las reuniones de la OMC, los intentos de aprobar Tratados de Libre Comercio o acuerdos comerciales claramente ventajosos para los países desarrollados) (Said, 1990) ${ }^{10}$. Cuando llegaron los cambios, no es extraño encontrar en esas interpretaciones argumentos para justificar

9 Un ejemplo del uso descalificador del "populismo", en Alcántara, 2009. Para la interpretación contraria, siguiendo la estela de Laclau, véase Panizza, 2009.

10 Véase igualmente Prada, 2010. 
su silencio o su deficiente capacidad de predicción. Lo planteado por Fernando Coronil para Venezuela es válido para todo el continente. La historia de los países latinoamericanos es un laberinto que "transcurre en el seno de un laberinto mayor" que produce, por el metabolismo propio del sistema capitalista, "centros y periferias en íntima relación, y no como un sistema autogenerado que se expande desde regiones modernas y activas, y engulle sociedades tradicionales y pasivas" 11 .

Una parte sustancial de las explicaciones dan cuenta del neoliberalismo como si de un fenómeno meteorológico - por tanto naturalfuera. Documentos desclasificados demostraban la injerencia, aún en 2001 y 2002, de los EEUU en Bolivia con el fin de "debilitar la base política” de Evo Morales. No es válido sin más, como plantea Paramio, que "los paradigmas de políticas siguen un curso similar a los paradigmas científicos", que solo se abandonan "cuando este marco les crea crecientes anomalías para entender la realidad, momento en el que, a partir de ideas antes marginales, se articula un nuevo paradigma. Este sería el caso de la recuperación de las ideas de Hayek y de Milton Friedman" (Paramio, 2008: 33). El neoliberalismo no fue simplemente una sustitución bienintencionada de una paradigma quebrado —el keynesianismo- , sino un intento de reconstruir la tasa de ganancia al precio de superar el marco regulador de los Estados nacionales, de cargar sobre amplios sectores de la población el ajuste económico y de construir un modelo de desarrollo desigual que terminaría por crear las mayores diferencias de renta en la historia de la humanidad conocidas $^{12}$. La escasa base fiscal de las haciendas latinoamericanas reforzaba su comportamiento nada virtuoso con los principales mitos del mensaje neoliberal: primar el crecimiento frente a la redistribución; reducción de los impuestos, especialmente a las rentas más altas; recortes salariales; facilitación de los despidos; venta de los activos públicos y privatización de sectores estratégicos; apertura de fronteras; etc. No es una casualidad que se dé una correlación cuasi perfecta entre las variaciones anuales del Producto Interno Bruto y del Gasto social total, pues la estrategia neoliberal consiste precisamente en eso, difiriendo para el futuro el hecho de que el sistema funciona con recurrentes crisis y que, por tanto, los pequeños ajustes no son sino preparaciones para un ajuste mayor como el que empezó a vivirse a finales de 2008. El modelo parlamentario liberal, que primaba el mo-

11 Coronil prefiere hablar de occidentalismo. Véase Coronil, 2002, especialmente el capítulo "El Estado mágico y el occidentalismo". La idea de un centro y una periferia capitalistas está ya en Gramsci, pero sería Wallerstein quien la popularizara.

12 Para los efectos de las terapias de choque como forma de ajuste en América Latina, véase Hubert y Solt, 2004. 
mento electoral sobre el momento emancipador participativo, fue utilizado para esa recuperación de la tasa de ganancia, de manera que la fragmentación social y la pérdida de homogeneidad de las sociedades latinoamericanas terminarían trasladando su propósito a referencias políticas que, necesariamente, tenían que estar en los márgenes de aquellos que habían situado a dos tercios de la población en situación de emergencia, además de devastar buena parte del planeta (Jessop, 2008) ${ }^{13}$. Si las elecciones han sido el momento de concretar la autorización a través de la representación, ese entramado se disolvía, hasta el punto de que, como demostraría los casos de Bolivia o de Argentina, ganar unas elecciones ya no supone sin más una garantía para ejercer la tarea de gobierno.

Esa ciencia social lastrada importó puntualmente cada uno de los conceptos con los que se pretendió frenar el pensamiento alternativo. El latinoamericanismo encontró nuevas formas bajo los paradigmas de la modernización, luego la transición y consolidación a la democracia, más tarde la gobernabilidad, luego la gobernanza, mientras tanto las teorías gerencialistas, la conceptualización del ciudadano como cliente, para cerrar con la asunción de la globalización como un concepto neutro y científico. Finalmente, y de manera más claramente beligerante, prefirió readaptar conceptos viejos — con el de populismo como buque insignia - para intentar reconstruir una explicación a la que le interesaba principalmente dejar fuera de juego la vertiente conflictual de lo político y seguir primando la veta institucional-funcional integrada. El populismo no fue utilizado para explicar las nuevas mediocracias, tales como las que desarrollaron Collor de Melo, Menem o Fujimori, sino que empezaría a ser un concepto en uso con la victoria de gobiernos con un claro mensaje de cambio y alternativa al modelo neoliberal.

La evidente crisis social del Consenso de Washington evidenció, además de los problemas de autorización política y del asalto al Esta$d o$ de gobiernos contrarios al paradigma neoliberal, impulsados por amplios movimientos populares ajenos a los partidos tradicionales, la aparición de respuestas que reclamaban un Estado neoweberiano que enfrentara una renovada responsabilidad con el fin de frenar el barrido del viejo esquema. Es aquí donde se explica el informe del Banco Mundial de 1997 sobre "El Estado en un mundo en transformación", la conferencia del Fondo Monetario Internacional de 1999 sobre las "reformas de segunda generación" y el estudio del Programa de Naciones Unidas para el Desarrollo dirigido por O’Donnell y publicado

13 Véase igualmente Milanovic, 2006. 
en 2004 "El Estado de la Democracia en América Latina. Hacia una democracia de ciudadanas y ciudadanos" (Monedero, Jerez, Ramos y Fernández, 2009).

La década de los noventa, como venimos señalando, abrió el paso a otras realidades que no podían explicarse con las categorías al uso. El caso del zapatismo fue el más emblemático, especialmente cuando, en un giro sorpresivo, cambiaron la estrategia guerrillera tradicional por el uso de rifles de madera y frases llenas de adjetivos sonoros. Su irrupción en el escenario mexicano, coincidiendo con la entrada en vigor del Acuerdo de Libre Comercio entre los Estados Unidos, Canadá y México en enero de 1994, creaba un conflicto que ya no podía explicarse con las estrictas categorías de la guerra fría. Aunque solo fuera porque el sujeto principal de la transformación eran los indígenas, algo bien lejos de las teorías sociales sobre el cambio y la transformación política radical. La "utopía desarmada" de Jorge Castañeda, la versión mexicana del "fin de la historia" de Francis Fukuyama publicada unos meses antes, se vaciaba de pronto por culpa de un imaginario social de opresión que terminaría cautivando, en la figura del escarabajo rebelde "Durito", incluso al desesperanzado Octavio Paz.

Entre tanto, la caída del Muro de Berlín en 1989 había señalado el fin de una época, seguida por la disolución de la Unión Soviética dos años después y el estrepitoso derrumbe del discurso de la izquierda. En ese escenario histórico, la mirada eurocéntrica sobre la izquierda perdía mucho de su validez y se convertía en obscena, pues el fin del socialismo realmente existente y el abandono europeo de la crítica al capitalismo coincidían con el Caracazo, la respuesta espontánea y ajena a cualquier teoría que enfrentó en las calles de Venezuela las medidas neoliberales de Carlos Andrés Pérez. Más adelante, el declinar de las diferentes Internacionales izquierdistas se veía contrastado por la emergencia del Foro Social Mundial (cuya primera convocatoria en Porto Alegre tuvo lugar en enero de 2001, convocado por ATTAC y el PT brasileño). Allá donde en las filas de la izquierda una diferente interpretación creaba una fracción enemiga de su formación originaria, ahora lo relevante era lo que se compartía. Como dice Boaventura de Sousa Santos, tuvo que caerse la Unión Soviética para que el capitalismo se hiciera marxista - para que dejara de ser social y organizado-, y tuvieron que caerse las Internacionales comunistas para que surgiera esa nueva izquierda que representa el Foro Social Mundial nacido en Porto Alegre en 2000 como foro alternativo al encuentro económico de la globalización de Davos.

Un elemento común de toda la nueva izquierda latinoamericana tiene que ver con la resurrección de los liderazgos populares, descalificados desde la vecchia académica y los monopolios mediáticos, según 
decíamos, como populismo. En países devastados económicamente por el vendaval neoliberal, con las estructuras administrativas, laborales, sindicales, ciudadanas y partidistas desestructuradas, con un historial de ineficiencia ligado al uso patrimonial del Estado como "consejo de administración de los intereses globales de la burguesía", con escasa autoestima nacional, la única posibilidad de pagar la deuda social acumulada pasaba por la identificación recia con un líder que prestara el cemento social ausente. Y aún más cuando la vía para dirigir los cambios es la electoral. Liderazgos capaces de unificar, con la fuerza de la esperanza, la tradicional desunión de la izquierda, de superar la hegemonía mediática neoliberal y la consiguiente debilidad del voto popular ante el acarreo, de vencer con argumentos la compra de voluntades y el clientelismo de los partidos tradicionales. Es indudable que la subida de los precios de los hidrocarburos ha ayudado a la consolidación de este proceso, pero sería un reduccionismo querer insistir en este factor sin considerar el agotamiento anterior del modelo. Baste considerar que hay países en los cuales el petróleo también desempeña una importante función (México) en donde los cambios no han tenido lugar.

En el mismo sendero de la manipulación está la diferenciación popularizada por un conocido escritor peruano entre una izquierda vegetariana - la que no cuestiona el sistema- y la izquierda carnivora - la que ha tocado estructuras de poder-, pretendiendo fragmentar el viento compartido de cambio en el continente. Esta diferencia la inició Jorge Castañeda en su libro La utopía desarmada y la continuó el que fuera jefe de campaña de Manuel Rosales en las elecciones venezolanas de 2006, Teodoro Pettkoff, y forma un intento recurrente de demonizar a los que caen en el lado malditizado ${ }^{14}$. Una Europa en donde las fuerzas transformadoras sufren una de sus más profundas crisis, necesita diferenciar entre una "izquierda buena" y una "izquierda mala", con el fin de debilitar la acción común y la integración regional (en buena medida impulsada por la "izquierda mala" como forma de defenderse de la globalización neoliberal) y, sobre todo, para

14 A finales de mayo de 2009, tuvo lugar en Caracas, organizado por el CEDICE, un think tank neoliberal, un encuentro donde se reunió buena parte de la derecha radical latinoamericana (ex miembros de gobiernos de dictaduras o con acusaciones de genocidio como el Chile de Pinochet, la Bolivia de Banzer, El Salvador de Arena o el breve gobierno del golpista Carmona Estanga en Venezuela), arropados por figuras de calado intelectual como Mario Vargas Llosa o Enrique Krauze. Uno de los elementos centrales de ese foro consistió precisamente en diferenciar, una vez más, entre Venezuela, Bolivia, Ecuador y Nicaragua por un lado, y Chile y Brasil por otro. Como ejemplo conspicuo de esta articulación, véase Mendoza, Montaner y Vargas Llosa, 1996. Igualmente Petkoff, 2005. 
recuperar la influencia perdida por las tradicionales organizaciones vinculadas a la Internacional Socialista o la cambiante Internacional democristiana, centrista o liberal. Disparidad que está a la altura de esa diferenciación académica entre revoluciones de colores y problemas de ingobernabilidad o de reclamaciones de autonomía o exigencias de respeto a las fronteras dadas, dependiendo el uso de unos u otros de si las protestas provienen de los sectores de clase media y alta o de sectores populares, de si se trata de conflictos con corbata y traje o reclamaciones con poncho, chompa o franelas ${ }^{15}$.

Esta estrategia de división, enmascarada como protesta civil "de colores" y que tuvo su principal laboratorio en Yugoslavia (con el hito de la independencia de Kosovo), va a convertirse en una de las principales armas de los opositores a la nueva izquierda latinoamericana en el poder. Es la estrategia que se intentó articular con la propuesta secesionista del Zulia en Venezuela, de la media luna, dirigida por Santa Cruz, en Bolivia, de Guayaquil en Ecuador. Territorios todos, además, muy ricos en materias primas y con una estratégica ubicación geopolítica y económica. No debiera, pues, llamar la atención que para la embajada norteamericana en la Bolivia atravesada de tensiones secesionistas fuera nombrado Philip Goldberg, quien estuvo al cargo de la misión estadounidense en Kosovo durante la disgregación de Bosnia y Serbia. El pensamiento crítico, que renunció a las teorías conspirativas por simplistas, perezosas y poco elegantes, necesita recuperar el trigo que arrojó con la paja cuando depuró esos análisis. Lo mismo debe decirse de los tanques de pensamiento neoconservadores, que llevan tres décadas diseñando la criminalización de la izquierda, y la difusión del capitalismo global y de su justificación. Tiempo es de interpretar integralmente el siglo XXI que avanza en-

15 De manera analítica, Moreira, Raus y Gómez Leyton han diferenciado entre gobiernos gradualistas y gobiernos populista-rupturistas (con el caso híbrido de Argentina). Por su parte, Reynoso, en el mismo trabajo, diferencia entre institucionalistas y decisionistas. Los gobiernos de izquierda racional y gradualista se caracterizarían por los siguientes rasgos: un mayor respeto a los límites estructurales del mercado; defensa del concepto de ciudadano, institucionalización partidista, mayor estabilidad electoral e institucional, y proclividad a la búsqueda de consensos. Pertenecerían a esta categoría Chile, Brasil y Uruguay. Las tendencias populistas y rupturistas estarían, por su parte, caracterizados por una mayor movilización popular (señal también de una mayor respuesta opositora), la utilización del concepto de pueblo frente al de ciudadanía (por sus rasgos movilizadores), la alta fragmentación del sistema de partidos, una mayor inestabilidad y debilidad institucional, una mayor concentración de la autoridad (con el riesgo claro de tendencias caudillistas), una falta de diálogo con la oposición (que se explicaría por el carácter involucionista de la misma), y una apuesta clara por la integración latinoamericana y el señalamiento a los Estados Unidos como el polo enemigo respecto del cual armar la propia estrategia. Este grupo lo compondrían Venezuela, Bolivia y Ecuador. Véase Moreira, Raus y Gómez Leyton, 2008. 
tendiendo que a una nueva izquierda latinoamericana le corresponde necesariamente una nueva anti-izquierda que será global como los intereses que defiende ${ }^{16}$.

El papel desempeñado por la República Bolivariana de Venezuela reclama una atención especial. Pese a los intentos para crear una matriz de opinión que diferencia entre una izquierda buena y otra mala, la influencia del presidente Hugo Chávez sobre todo el espectro alternativo latinoamericano, desde la socialdemocracia al comunismo, desde el indigenismo al nacionalismo, desde el bolivarianismo al marxismo, es un hecho difícilmente cuestionable, reforzado si cabe con la reelección en diciembre de 2006 con una participación del 73\% y el $63 \%$ de los votos, 25 puntos por encima de una oposición que, por vez primera en el último lustro aceptó un resultado electoral que le era adverso ${ }^{17}$.

El principal problema de la ciencia política, el de la obediencia, tiene detrás el requisito previo de la homogeneidad social. Detrás del interés general, del cuidado de la sociedad como un todo está el hecho de que toda agrupación humana que no descanse sobre algún valor compartido estará o bien organizada sobre la base del uso extremo de la fuerza, o bien sometida a fuertes tensiones centrífugas que la amenazarán como colectivo. En una mirada histórica que se remonta a varios siglos, vemos que este valor homogéneo ha obtenido diferentes respuestas repetidas: raza, religión, procedimientos, liderazgo, propiedad pública de los medios de producción, inclusión social... En contextos de desestructuración social como los que ha creado el neoliberalismo, con la enorme fragmentación construida,

16 La estrategia encaminada a construir un nuevo sentido común conservador, impulsado desde los Estados Unidos, la estudia George Lakoff en No pienses en un elefante (2007), resaltando el papel del juez Powell (autor del memorándum Powell) y el apoyo de la administración Nixon.

17 La imagen e influencia de Chávez ha sido sujeto de múltiples encuestas más o menos sofisticadas. El Latinobarómetro de 2005 se vio obligado a incorporar la valoración de líderes, donde, desde entonces, Chávez siempre es el más controvertido (con grandes apoyos y grandes rechazos) Por su parte, la revista Nueva Sociedad, auspiciada por la Fundación socialdemócrata alemana Friedrich Ebert, titulaba su número de septiembre-octubre de 2006 “América Latina en tiempos de Chávez". La revista Time organizó en diciembre de 2006 una encuesta a través de la red para nombrar Personaje del año. Cuando Chávez se acercaba al 40\% de las preferencias, la revista suspendió la votación y concedió el galardón finalmente a los cibernautas. El encuentro en abril de 2009 entre Barack Obama y Hugo Chávez con motivo de la V Cumbre de las Américas, en Trinidad y Tobago fue quizá el punto álgido de esa presencia internacional. El saludo entre ambos presidentes fue portada mundial, y el libro con el que el venezolano obsequió al norteamericano, Las venas abiertas en América Latina, del uruguayo Eduardo Galeano, alcanzó los primeros puestos en la librería electrónica Amazon.com. 
con la emergencia de identidades antaño ocultas, con las enormes desigualdades sociales, con la falta de protocolos institucionalizados de comportamiento público virtuoso, el abanico de soluciones se multiplica y complejiza.

¿Es el actual momento latinoamericano el de una recuperación de liderazgos populares fuertes? ¿Se trata de una reedición de formas caudillistas sobre la base de políticas clientelares o estamos ante un nuevo tipo de contrato social? ¿Es la rearticulación de nuevas formas sociopolíticas la solución a los problemas de representación en América Latina? ¿Puede nacer así una alternativa que concilie democracia directa y democracia representativa? ¿Hay una síntesis posible entre los partidos políticos y los movimientos sociales? ¿No hay, en cualquier caso, detrás de las transformaciones en América Latina un impulso electoral que las diferencia radicalmente de los intentos emancipadores que tuvieron lugar durante la guerra fría ${ }^{18}$ ?

\section{A VUELTAS CON EL SUJETO POLÍTICO: LA PLURALIDAD COMO NORMA}

En política cualquier orden siempre se construye contra sus alternativas (sus enemigos). Esto es válido para el nacimiento de los Estados, para la creación de los sistemas de partidos, de un tipo u otro de sociedad civil o para la inclinación ideológica de un régimen ${ }^{19}$. Por eso, un mismo camino, el de la emancipación, no tiene necesariamente que discurrir por los mismos senderos. Fue el error del modelo modernizador en los sesenta; es la falacia que hay detrás del mecanicismo de las etapas del crecimiento; es, como ha reconocido Joseph Stiglitz, el catecismo omnímodo, invasivo y violentador de los planes de ajuste en los ochentas y noventas impulsados por el FMI y el Banco Mundial y aplicados por doquier. Y también fue el error de una izquierda que desconoció las diferentes historias, composiciones sociales y valores de las diferentes poblaciones a las que quiso aplicar un modelo re-

18 Repárese en que estas preguntas difieren tanto en énfasis como en contenido de las que han protagonizado la tarea de la ciencia social en los últimos decenios: presidencialismo vs. parlamentarismo; unicameralismo vs. bicameralismo; introducción del ballotage; ingenierías electorales —umbrales, gerrymanderismo, voto preferencial, una o dos vueltas, etc.- - financiación de los partidos; cuantitativización del análisis político, etcétera.

19 Es la base de la explicación de lo político en Carl Schmitt, pero también es el criterio seguido por Stein Rokkan en su desarrollo de los cleavages, de Michael Mann para dar cuenta de las fuentes del poder social, de Charles Tilly para explicar los orígenes de la formación estatal o, en términos de escuela, del marxismo que recuerda que cada modo de producción crea su "propio sepulturero". Es una simplificación presentar la confrontación "amigo/enemigo" como una desinencia del nazismo de Schmitt. Me he ocupado de esto en Monedero, 2009b. 
petido. En las interminables discusiones de la sociología histórica se ha argumentado cómo diferentes sociedades civiles, propiedades de la tierra, pervivencias de la influencia de la iglesia, proporciones de campesinado y de proletarios, articulación clientelar, influencia externa, consolidación de organizaciones obreras, entre otras variables, donde también tiene su responsabilidad el azar, condicionan una u otra respuesta popular al uso oligárquico del poder estatal. Es una tentación demasiado sencilla el intentar leer los procesos en América Latina desde la conformación política del Norte, agregándose como argumento determinante un buenismo eurocéntrico según el cual que lo que ha sido "positivo" para el Norte ha de serlo para los procesos políticos del Sur. El elemento determinante para entender cualquier configuración política hay que buscarlo tanto en los recursos propios como en las características de aquello frente a lo que se construye. Traslaciones simplistas solo funcionan como argumentos legitimadores de propuestas construidas a priori. Y opera de la misma manera en la dirección contraria. Hablando de América Latina, y antes de que la crisis económica hiciera de esos comportamientos el lugar común de las políticas económicas europeas y norteamericanas, podía leerse:

Todos estos gobiernos (Venezuela, Argentina, Bolivia y Ecuador) han demostrado hasta ahora una marcada preocupación por la estabilidad monetaria, que no permite encasillarlos en lo que Dornbusch y Edwards llamaron "populismo macroeconómico". Uno de los principios fundamentales del Consenso de Washington, la estabilidad macroeconómica y monetaria, parece haberse incorporado, por tanto, al sentido común y a la práctica de los gobiernos que más critican el neoliberalismo de los años noventa. (Paramio, 2009: 28-29)

Otro tanto ocurre cuando se quieren trasladar a comienzos del siglo XXI nociones que nacieron para explicar sucesos de los años setenta. Allí donde el populismo quería explicarse sobre la base de la existencia de líderes carismáticos y omnipotentes, una orientación nacionalista que identificaba pueblo y Estado y una propuesta igualitaria de redistribución de la renta, hoy hay que entender que la participación popular, en una miríada de formas no reducibles ni a partidos ni a movimientos ni a agrupaciones ni a asociaciones, se ha incorporado de manera determinante en la reconfiguración política del nuevo siglo. La política de tierra quemada en la que desembocó el neoliberalismo generó anticuerpos sociales integrales, de manera que las respuestas lo son en todos los ámbitos de lo social (económico, político, normativo e identitario y cultural). La principal característica de los cambios políticos en América Latina tiene que ver con esa renovada participación. Si el neoliberalismo construyó intencionalmente, siguiendo las catego- 
rías de Hirschmann (1981), "salida" del sistema, la ciudadanía ha regresado ejerciendo la "voz" y saliéndose de la salida, es decir, entrando desde ese afuera al que la había expulsado la utopía neoliberal. De ahí que la variable independiente que tiene que ser analizada en los nuevos procesos tenga que ser la participación. De ahí la sutileza que es menester ante cualquier simplificación que pueda ahogar la misma ${ }^{20}$.

América Latina se ha caracterizado por unas élites con la capacidad de formar parte de esa minoría transnacionalizada al tiempo que sus países caían en problemas crecientes de gobierno. El único éxito logrado por el neoliberalismo ha sido, y no en todos los casos, la reducción de la inflación. Los fondomonetaristas y bancomundialistas más ortodoxos siempre han estado en los equipos económicos de las naciones suramericanas, responsables de convertir las economías en modelos exportadores, aunque se descuidase la alimentación del pueblo; de fomentar la apertura de fronteras, lo que ha implicado la desestructuración de los mercados internos; de vender la propiedad pública, forma indirecta de regalar a grupos privados las riquezas nacionales; y de impulsar la firma de Tratados de Libre Comercio que entregan los países a las grandes corporaciones transnacionales. Es por esto que a América Latina le ha costado tanto mirarse a sí misma, encontrarse a sí misma, cuidarse a sí misma. Sin estos elementos es imposible entender el nuevo espacio que ocupan los gobiernos de cambio latinoamericanos ${ }^{21}$.

20 En toda novedad siempre hay retornos de cosas pasadas. Sin embargo, si bien es cierto que los años ochenta visualizaron una presencia de movimientos sociales a los que se adjetivaron como "nuevos" — que en análisis optimistas como los de Alain Touraine se entendió como el advenimiento de un nuevo tipo de democracia - , los cambios cualitativos de todo tipo no permiten fáciles comparaciones que quieran zanjar la discusión afirmando que "no hay nada nuevo bajo el sol". El MAS en Venezuela, el PT brasileño, el PRD mexicano, el sandinismo nicaragüense, la izquierda Unida de Perú fueron todas agrupaciones políticas que reclamaban una presencia firme y oída de los movimientos sociales. El Foro Social Mundial, en marcha desde el año 2000, ha supuesto una revitalización y replanteamiento de estos intentos.

21 El modelo neoliberal es un nuevo contrato social que nació para enfrentar con los argumentos liberales no el feudalismo sino la extensión de los Estados sociales. A partir de los setenta, este modelo, ampliamente generalizado, se ha nutrido esencialmente de la falta de alternativas que él mismo construye. De ahí que su principal éxito sea el discursivo. Su práctica ha dependido de los mimbres sociales y políticos existentes para frenar su aplicación. Este freno, mientras tuvo su mayor éxito en Europa y Asia, experimentó un rotundo fracaso en América Latina y África. Por eso los efectos han sido allí más devastadores. La política neoliberal salió de estación en los momentos finales de la Segunda Guerra Mundial como forma de oposición al keynesianismo laborista inglés. Su principal teórico, el austriaco Friedrich Hayek, publicaba en 1944 Camino de servidumbre, poniendo en el mismo platillo de la balanza al fascismo hitleriano y a lo que se presentaba como liberticidio laborista perpetrado desde un Es- 
Salvo excepciones en algunos países y en algunos momentos, el continente latinoamericano no ha sido dueño de sus decisiones. Valga decir que la soberanía nacional es más un mito que una realidad. Ni siquiera en los países supuestamente poderosos se somete a las elecciones otra cosa que lo adjetivo ${ }^{22}$. Ningún país ha presentado como opción la democratización radical de sus cuerpos de seguridad, las grandes riquezas, las empresas de medios de comunicación de masas, la iglesia o los organismos internacionales. Pero conforme se viaja del centro a la periferia el problema se agrava. En América Latina, la democracia no ha sido garantía ni de derechos civiles ni de derechos sociales. Cuando América Latina recuperó el pulso de las democracias formales en los años ochenta, este cambio coincidió con la hegemonía neoliberal. El derecho al voto venía acompañado, una vez más, con el derecho al hambre, al desempleo, a la enfermedad y a la miseria.

tado intervencionista. Sin embargo, no sería hasta 1973 que encontraría una versión práctica tras el golpe de Estado en Chile contra Salvador Allende dirigido por Augusto Pinochet y auspiciado por los Estados Unidos. Posteriormente, el neoliberalismo sería exportado al mundo desde la experiencia thatcheriana a partir de 1979 (servido espiritualmente por el anticomunismo de Juan Pablo II). El programa neoliberal buscaba principalmente cinco objetivos: equilibrar las cifras macroeconómicas, especialmente a través del control de los precios (y una vez señaladas las variables monetarias como las realmente relevantes); aumentar las ganancias empresariales - bajo el presupuesto de que la "tarta" debía primero crecer para después poder repartirse-; incrementar inicialmente el desempleo — con el fin de lograr una "tasa natural" de paro que debilitase a los sindicatos y forzase a la baja a los salarios-; crear una estructura social desigual que incentivase el esfuerzo y el aumento de la productividad; integrar a las fracciones de clase globales en el modelo mundial de acumulación, utilizando para ello, cuando fuera menester, la guerra o los preparativos para la misma. Las propuestas del llamado Consenso de Washington - privatizaciones, liberalización fiscal, apertura de fronteras, reducción del gasto social, desregulación laboral y garantías de la propiedad privada - precisaban de una mutación del Estado que dejase todo el espacio libre posible tanto a un mercado crecientemente inmanejable como a las empresas. Esta transformación estatal es lo que en ocasiones se ha identificado como crisis del Estado nación - a menudo naturalizada como devenir necesario por el desarrollo tecnológico propio de la globalización - pero que, en realidad, es más correcto entenderlo como la rearticulación del sistema de dominación a la nueva forma global de acumulación. Ésta iba a asentarse en la especulación financiera y no en la inversión productiva. Mientras que el Estado mantenía la responsabilidad de garantizar la propiedad privada y el orden social nacionales, crecía un complejo Estado transnacional que respondía a las necesidades de una economía que ya no atendía a los patrones propios de los siglos anteriores. Los cambios en el patrón de acumulación explican que los resultados, lejos de los inicialmente planteados — salvo en el caso de la hiperinflación-, no fueran sino el aumento tanto de la pobreza como de las desigualdades sociales y la consiguiente fragmentación e incremento de la violencia social. Puede consultarse Monedero, 2009a.

22 Hubo que esperar a junio de 2009 para que la OEA revocara el acuerdo, impuesto por los Estados Unidos, que expulsaba de la organización a Cuba al abrazar los principios del marxismo-leninismo. 
Y una vez más, el compromiso político de la población se distanciaba del modelo liberal burgués. La ciencia política del Norte empezó a definir esa desafección. Es ahí donde se reelabora el concepto de caudillismo, de populismo, se adjetiva el indigenismo como radical, o se generaliza desde los organismos internacionales, como meta política, la búsqueda de gobernabilidad, un concepto que solo se puede aplicar cuando hay pueblo en la calle pero no cuando, por ejemplo, el 50\% del pueblo está en el nivel de la pobreza, pero no ejerce ninguna forma de acción colectiva.

\section{LOS PARTIDOS Y LA DEMOCRACIA LIBERAL: LA EMANCIPACIÓN DEMEDIADA}

Los partidos, como parte de la sociedad y gestores del Estado, son un reflejo tanto de los conflictos sociales como de esa estructura institucional en la que se incardinan. No puede ser igual un sistema de partidos en Estados que manejan la mitad de la riqueza de un país que otros en donde apenas se gestiona un 20\% de la misma. No puede ser igual un sistema de partidos que asume la responsabilidad de la reproducción social que otro que asume su impotencia frente a los mercados financieros internacionales. La lectura social de los partidos políticos no puede ser la misma allí donde funciona algún tipo efectivo de rendición de cuentas que revierte en formas más equilibradas de la renta que en otro lugar donde el entramado político no es sino una red de intereses clientelares. No es el mismo Estado el que se precisa para garantizar la acumulación económica de las élites que un Estado que se dispone a pagar la deuda social acumulada de un país. Sin embargo, no solo en América Latina, sino también en Europa, existe una creciente distancia entre los parlamentos, los partidos políticos y la ciudadanía. Tanto en un lugar como en otro esa descomposición se solventa bien con un creciente abstencionismo y desafección política, bien con el nacimiento de liderazgos fuertes capaces de frenar las tendencias centrífugas gracias a una confianza personal que acerca las democracias a formas plebiscitarias. El alejamiento de los lugares tradicionales de la democracia es constante en prácticamente todos los países, salvo aquellos que mantienen Estados sociales efectivos o se han enfrentado a elecciones con un alto grado de politización al concurrir circunstancias especiales (existencia de un candidato fuera del sistema o que supone una amenaza a un amplio sector de la población, o en caso de que la polarización esté dirigida más para evitar que salga un candidato que para apoyar a otro $)^{23}$.

23 Las democracias de partidos vienen siendo catalogadas como plebiscitarias desde los años treinta del siglo pasado. La importancia de los liderazgos y la intrascenden- 
Algunos ejemplos ilustran esta novedad. El 70\% puede declararse en Venezuela "contento con su democracia", pero no acudir a votar a sus diputados y diputadas en la Asamblea Nacional. Más del 90\% del Parlamento francés puede votar a favor de la Constitución Europea, pero si se somete a referéndum es derrotada por la votación popular. Líderes que se entienden como "ajenos al sistema”, ganan elecciones con gran apoyo popular al margen de los partidos tradicionales e, incluso, al margen de un partido consolidado. $\mathrm{O}$, regresando de nuevo a una democracia consolidada, tras las elecciones francesas de mayo de 2007, por vez primera se recibió al ganador con manifestaciones callejeras, quema de coches y enfrentamientos con la policía. Mientras que en el siglo pasado los conflictos sociales se canalizaron a través de los Parlamentos y del juego electoral, el siglo XXI está reclamando otras formas de participación política. Como sostiene Rigoberto Lanz, la posmodernidad está llamando a la puerta también en el caso de los partidos políticos. Hay bastantes probabilidades de que América Latina pase del siglo XIX al siglo XXI sin haber nunca consolidado el modelo parlamentario y partidista propio del campo occidental durante el siglo XX. En expresión de Ernesto Laclau:

Las consecuencias de esta doble crisis (militarismo y economía neoliberal) son claras: una crisis de las instituciones como canales de vehiculización de las demandas sociales, y una proliferación de estas últimas en movimientos horizontales de protesta que no se integraban verticalmente al sistema político. (Laclau, 2006)

Pero esto es solo un síntoma de una función rota, no de una solución alternativa. Como se vio en Argentina, el que se vayan todos no significa sino que vuelvan los que sean capaces de estructurar una respuesta (donde "los de siempre" tienen más facilidades para gestionar el poder político concreto, esto es, el Estado). Atendiendo a su trayectoria anterior, podemos afirmar que solo debido al desarrollo concreto de las luchas sociales se sensibilizó el gobierno de Kirchner con las demandas sociales tanto en lo económico como en lo que atañe a los derechos humanos. La confusión propia de la crisis de paradigma actual,

cia de los militantes ya estaba apuntada en el trabajo señalado de Robert Michels. La entrada de los medios de comunicación en las campañas, hasta hacerse el factor esencial, completan ese viaje. Calificar ahora de plebiscitarias a las democracias, aun siendo cierto, ocultan que esa tendencia estaba inscrita en el modelo liberal. La diferencia ahora, la hace a quién se apoya desde los diferentes establishments. Como dijo Roosevelt de Somoza, "es un hijo de puta, pero es nuestro hijo de puta", o, en palabras más amables de Laclau, "es característico de todos nuestros reaccionarios, de izquierda o de derecha, que denuncien la dictadura en Mario pero la defiendan en Sila”. Véase Laclau, 2006. 
de este momento de indefinición entre el pasado y el futuro, lleva a un momento de ensayo y error que tiene la virtud de abrir nuevas vías pero también el riesgo de cometer errores - alejamientos de la meta trazada-difícilmente reparables.

No es gratuito que los cambios políticos profundos que están afectando a América Latina se inicien en esta nueva fase con cambios constitucionales. El yermo que ha dejado el neoliberalismo en el continente reclama cambios a la altura de lo deshecho. La alternativa tiene que ser, pues, constituyente. Los cambios, como venimos defendiendo, no son simplemente económicos. Hay una respuesta integral, holística, que quiere recrear la vida social desde parámetros diferentes en lo económico, en lo cultural, en lo político y en lo normativo. No se trata de poner parches a los rotos neoliberales. Es momento - basta ver los contenidos de las alternativas- de reinventar otra economía, otra articulación política, recuperar y reinventar los lazos culturales y las identidades, así como replantear las obligaciones normativas. Es por esto que los indicadores tradicionales nunca van a poder medir ni dar cuenta de las nuevas transformaciones. La reconstrucción democrática va a necesitar una reconstrucción de los indicadores sociales (El Troudi y Monedero, 2006).

Las instituciones, como ya hemos señalado, son trasuntos de los pueblos en donde se desarrollan. La falta de consonancia entre gobierno y pueblo termina siempre en alguna forma de ajuste donde ambos se reencuentran. Los Estados tienen vocación de permanencia y por ello necesitan legitimarse. Una parte puede entregarse a la violencia y otra parte a la rutina, pero es necesario construir tanto la justificación de la obediencia como la inclusión ciudadana que garantice el orden social. Las elecciones siguen desempeñando aquí un espacio esencial, con el añadido de que los pueblos están empezando a desarrollar una accountability movimientista que exige resultados concretos en el corto plazo. Estamos ante una reconstrucción del contrato social que nace de la negación del contrato social neoliberal. La Bolivia de los movimientos sociales, que desemboca en la definición de un nuevo tipo de Estado —el Estado plurinacional— es el ejemplo más claro.

Esto no quiere decir que todo el pueblo tiene que inclinarse hacia una misma opción partidista. El carácter periódico de las elecciones busca confiar la dirección política a diferentes opciones que respondan a las exigencias de la representación. Pero sí es obligatorio que haya un acuerdo general sobre las reglas de juego. Cómo una minoría se transforma en mayoría forma parte de la discusión acerca de los requisitos de una verdadera democracia. Al tiempo que la democracia tiene derecho a defenderse de quienes quieren acabar con ella, debe incorporar la contingencia del acuerdo social, es decir, la posibilidad 
real de que cambien las reglas del juego. El poder constituyente se define con voluntad de permanencia pero está sometido a la decisión popular de cada día. Es un lugar común decir, en el caso de la II República Española (1931-1936), que se trataba de una república sin republicanos. Vale igual para crear un socialismo sin socialistas e, incluso, una democracia sin demócratas. Cuando un gobierno está por delante del conjunto de la población — por ejemplo, forzando la marcha de la emancipación-, o invierte en consciencia democrática de manera urgente o el viento de la historia lo barrerá. Y ni siquiera así tiene garantías de éxito. Hay en la América Latina del cambio un neoliberalismo sociológico que afecta a varias generaciones. Aprender Poder Constituyente y Democracia en las escuelas es un requisito de la paz social en el marco político renovado. Si no se comparten las reglas generales de juego, la sociedad está en peligro. Y no basta decretar su importancia. La democracia no es una idea que se asume, sino una creencia que se vive muy desde dentro. Lejos de la linealidad de la construcción de ciudadanía que planteó Marshall, las transformaciones democratizadoras siguen estando fuertemente amenazadas.

\section{CONCLUSIÓN: POR UNA IMPRUDENTE REINVENCIÓN DEMOCRÁTICA}

La recuperación de los Estados por fuerzas políticas que cuestionaban el modelo neoliberal, y en especial la subordinación del sur al norte en el nuevo proceso de acumulación del centro, llevó como veíamos al establishment académico a resucitar peyorativamente el concepto de populismo. El uso del populismo como categoría se ha convertido en un arma de combate político, dardo conceptual dirigido especialmente para aquellos gobiernos a los que cabría denominar como de "nueva izquierda", que se caracterizan por su voluntad de superar el neoliberalismo y el capitalismo y por democratizar la política y la sociedad apoyados en movimientos sociales activos y en una ciudadanía ganada para la acción colectiva (Chávez, Rodríguez Garavito y Barrett, 2005).

Resulta interesante comprobar que la acusación de populismo precede al análisis académico. Estas adjetivaciones se articulan previamente en los medios de comunicación hasta crear un marco de referencia, convirtiéndose en un lugar común aplicado a cualquier gobierno que se aleja de las formas tradicionales de la democracia representativa y del capitalismo neoliberal. De manera más clara, el adjetivo se aplica invariablemente a aquellas propuestas que pretenden la nacionalización de los recursos naturales. Posteriormente, y una vez creado ese marco de referencia en los medios, la descalificación del populismo como forma de gobernar pretende cerrar el marco 
analítico que prepara una nueva correlación de fuerzas. De manera más clara, tanto la diferenciación entre izquierdas "buenas" ("pragmáticas, sensatas y realistas") y "malas" ("izquierdistas infantiles, autoritarias y viejas") o las acusaciones de populismo, las peticiones del fin de la soberanía, la crítica a los frenos al libre comercio y la defensa de grandes espacios de libertad a las empresas transnacionales pertenecen más al debate político que al análisis objetivo. Es una vez más Ludolfo Paramio quien afirma:

Pero el populismo, incluso si se somete a las reglas de juego de la democracia, no es un proyecto democrático. Divide a la sociedad a través de su distinción maniquea entre sectores populares y oligárquicos, basa su discurso en la confrontación, y no pretende crear ciudadanos sino seguidores. Por otra parte, la dinámica política del populismo puede derivar fácilmente en políticas económicas poco o nada responsables, ya que su prioridad es la redistribución clientelar, no la inversión y la transformación de la sociedad. (Paramio, 2009: 33)

En el escenario de crisis económica que empezó a experimentar el mundo occidental a partir de 2008, esta acusación resulta sorprendente. Venezuela experimentaba hasta abril de 2009, veinte trimestres consecutivos de crecimiento del PIB, al igual que un crecimiento ininterrumpido del Índice de Desarrollo Humano que mide el PNUD. Su coeficiente de Gini sigue siendo el más bajo de América Latina ${ }^{24}$. A esa fecha, Chávez había ganado doce elecciones (al igual que había perdido un referéndum y aceptó, pese al anuncio en buena parte de los medios de comunicación mundiales de que no lo haría, el resultado de las elecciones que lo adversaron en la reforma constitucional). Lo ridículo del análisis se agrava cuando se considera que fueron países nada populistas quienes iniciaron un proceso de desestabilización como la invasión de Irak (Estados Unidos, Gran Bretaña y España). En términos de confrontación, la política mundial, influida por los medios de comunicación y la simplificación ideológica, está cayendo en un bipartidismo generalizado, lo que genera necesariamente un incremento de la polarización, aún más cuando las empresas de medios de comunicación trabajan invariablemente para alguno de los dos polos. No deja de ser igualmente engañoso hablar de polarización en casos como el boliviano, el ecuatoriano o el venezolano, e ignorar el grado de confrontación que experimentó el enfrentamiento entre

24 Lo cual no implica que la crisis económica no afecte a su resultado, más aun teniendo en cuenta su vinculación a los precios internacionales del petróleo. En cualquier caso, la crisis económica fue producida en Estados Unidos y Europa y desde ahí exportada a América Latina. 
Bush y Kerry (con el añadido de las papeletas controvertidas de Florida), entre Obama y McKein o, por traerlo a Europa, entre Zapatero y Rajoy (que incluiría la denuncia por parte del Partido Popular de la supuesta participación del PSOE en el atentado de Atocha, atribuido por el gobierno de Aznar a ETA, y la petición de invalidar las elecciones). Las dos varas de medir, un escenario repetido en la política y también en los medios, no está ausente en el análisis académico.

Detrás de la caracterización de un gobierno como populista hay un conjunto de presuposiciones, de mitos que actúan como tales gracias a la capacidad hegemónica neoliberal de convertir visiones parciales en sentido común. Contra esos mitos se configura buena parte de la agenda alternativa de la nueva izquierda latinoamericana. En una somera lista tendríamos los siguientes mitos: el mito de que es posible regresar a una suerte de capitalismo con rostro humano, ignorándose que el keynesianismo colapsó desde dentro por su incapacidad de solventar el ataque conjunto de la inflación y el estancamiento a comienzos de los setenta. El mito de que el mercado sigue siendo un asignador eficiente de recursos, apenas regulado en aquellos momentos en que experimente dificultades; el mito de que la globalización se impuso de forma natural y sin violencia; el mito de que la democracia representativa agota las posibilidades de la democracia; el mito de que el sujeto político es la clase obrera, el ciudadano entendido como cliente o ese sujeto virtual llamado la opinión pública; el mito de que basta ganar unas elecciones y acceder al aparato del Estado para tener el poder; el mito de que la politización social es negativa; el mito de que la calidad de la democracia se mide por variables cuantitativas pensadas en, desde y para los países desarrollados; el mito de que lo que hicieron los países europeos en su momento de formación no puede ser repetido en los países en desarrollo, de manera que ese momento de acumulación política originaria se lee en el caso de Europa como momento heroico y en el caso actual de América Latina como desviación democrática; el mito de que los gobiernos de la nueva izquierda tienen la obligación de presentar resultados inmejorables en cualquier circunstancia y en tiempos récord, sin considerar las dificultades que crea la clase política saliente y sus conexiones económicas; el mito de que el nivel óptimo de movilización social es el que está por debajo del nivel de institucionalización; el mito de que los medios de comunicación son instrumentos objetivos al servicio de la democracia ${ }^{25}$.

25 A estos mitos desde la derecha, habría que añadir algunos otros desde la izquierda, como que es posible el hundimiento del neoliberalismo sin antes haber sido derribado o sustituido por otro; que es posible "cambiar el mundo sin tomar el poder", esto es, al margen del aparato estatal; que la política es intrascendente o le hace el 
En un momento histórico en donde se debate si la crisis económica es una crisis en el capitalismo o una crisis del capitalismo, los gobiernos de la nueva izquierda latinoamericana están intentando vías alternativas que obligan al capitalismo occidental a repensar su salida. Ni el aumento del déficit público, ni el agravamiento de la expoliación de la naturaleza, ni el aumento de la explotación de los países del Sur (vía tratados de libre comercio, usufructo de sus recursos naturales, pago de deuda o invasiones) son posibilidades hoy abiertas como fue el caso en los años setenta, ochenta y noventa del siglo pasado. Las dificultades del capitalismo occidental que pretende cargar sobre los hombres de América Latina sus problemas de acumulación obligan a diferentes posicionamientos desde el análisis politológico. Los países del Sur intentan enfrentar, sin duda con contradicciones, el hecho de que no hay modelos y que corresponde asumir el principio de Simón Rodríguez “inventamos o erramos". Como denuncia Laclau, frente a esto se verifica una pusilanimidad que consiste en ceder en las palabras para ceder posteriormente en la sustancia: "Una de las formas principales que toma esta pusilanimidad en la actualidad es el remplazo del análisis por la condenación ética" (Laclau, 2005). La recuperación del concepto de populismo para descalificar esos intentos forma parte de la colonialidad del saber occidental y, como tal, y por su peso normativo, está más al servicio de inclinaciones política que de inquietudes académicas. Una inclinación política que mira con desconfianza el empoderamiento popular y la superación del modelo capitalista y de las formas de democracia de baja intensidad que sostienen ese modelo.

Eso no significa que baste la existencia de una oposición con un programa político férreo de regreso al pasado, apoyado además por los Estados Unidos, para conjurar todos los retos de la democracia en el continente. Fórmulas como el socialismo del siglo XXI, la incorporación constitucional de la "buena vida" (sumak kawsay) o del "vivir bien" (suma qamaña) a las constituciones ecuatoriana y boliviana, la redefinición de las repúblicas como Estados plurinacionales, la puesta en marcha de políticas públicas participadas popularmente, la apuesta por un modelo de desarrollo endógeno o la búsqueda de una integración regional basada en la complementariedad como forma de superar las limitaciones de la periferia para la integración en la econo-

juego, desde los Estados nacionales, a la pequeña burguesía; que los movimientos sociales deben estar al margen de la política; que los procesos de integración regional —incluido la ALBA — refuerzan el capitalismo; o que los problemas internos —ineficiencia, corrupción- no son sino señales de la falta de coraje gubernamental para, construir la alternativa. Véase Sader, 2009. 
mía internacional, son todos aspectos que sugieren una reinvención democrática que va más allá del modelo neoliberal inaugurado con el golpe de Estado de Pinochet (con apoyo estadounidense) contra el Frente Popular de Salvador Allende en 1973.

Igualmente, la existencia de gobiernos que reclaman la reinvención de la democracia incorporando los ángulos ciegos del modelo representativo vigente durante el siglo XX en el continente, no implica sin más la superación del marco neoliberal y su sustitución por un modelo integralmente alternativo. Por eso, la prudencia obliga a hablar de transiciones hacia el postneoliberalismo (Borón, 2005) ${ }^{26}$ que empiecen a experimentar nuevas formas de democracia basadas en formas experimentales apoyadas por los nuevos gobiernos. El principio de subsidiariedad parece una buena base de ordenamiento. A diferencia de algunos autores que cifran todo en la creación de respuestas globales (es el caso del último Bauman, 2010), es importante reforzar las bases nacionales, regionales y locales antes de emprender aventuras en el ámbito global, donde todo se hace etéreo. Pero sin que esto signifique, ni mucho menos, abandonar esa nueva arena que vino para quedarse que es el mundo global. El principio de subsidiariedad deja que la parte más pequeña con capacidad se haga cargo de la gestión de los asuntos públicos, pero con la cláusula que obliga a la parte organizada inmediatamente superior acudir en su ayuda en caso de necesidad. Para que este esquema funcione, es imprescindible la capacidad y la voluntad de toda la ciudadanía organizada (en formas de democracia deliberativa), y la disponibilidad de cada parte superior (comunas, municipios, regiones, estados centrales, organismos supranacionales) para apoyar cada escuela de ciudadanía democrática que implica la autogestión popular. Sin una conciencia superior, que no haga de la participación una carga sino una responsabilidad, es difícil que las formas de democracia participativa superen a la oferta de irresponsabilidad de la democracia representativa. Solo en ese caso, el Estado, que debe ejercer de palanca esencial, podrá desempeñar esa labor sin caer rehén de la mayor disponibilidad histórica de satisfacer unos intereses y no otros.

De ahí que la movilización, lejos de ser un suceso excepcional, debe convertirse en un recurso diario. Las formas de rendición de cuentas horizontales, en el día a día, a través de una opinión pública que posea canales de comunicación democráticos, es la alternativa obligatoria. Solo esa rendición de cuentas horizontal, asentada en una corresponsabilidad esgrimida por una ciudadanía consciente, puede frenar la vertiginosa creación de nuevas nomenclaturas que sustituyan

26 Aunque en el discurso de Chávez, de Evo Morales y Álvaro García Linera o de Rafael Correa se habla nítidamente de transición al socialismo. 
a los antiguos cuerpos de funcionario y perpetúen su lógica de Estado patrimonialista.

Por eso, la construcción de una democracia postneoliberal orientada hacia la construcción del socialismo pero que entienda que las fases de transición son espacios de discusión y colaboración entre el reformismo, la revolución y la rebeldía- pasa por la construcción de una esfera pública no dominada por empresas de medios de comunicación con intereses particulares incompatibles, por definición, con el interés general. E, igualmente, emplaza a la ciudadanía a hacer cierto el "mandar obedeciendo" que resucitó el zapatismo y que está en el corazón de la propuesta democrática republicana basada en la virtud y que, todavía, sigue sin necesitar confiar en "dioses, reyes ni tribunos" esa responsabilidad que debe reposar estrictamente en la dignidad que acompaña a cada uno de los seres humanos.

\section{BIBLIOGRAFÍA}

Alcántara, Manuel 2009 "América Latina: la política inconclusa" en Alcántara, Manuel (org.) Revista Sistema, Dossier "La política de América Latina", No 208-209, enero.

Bauman, Zigmunt 2010 Mundo consumo (Barcelona: Paidós).

Borón, Atilio 2005 "Promesas y desafíos: la izquierda latinoamericana a principios del siglo XXI" en Chávez, Daniel; Rodríguez Garavito, César y Barret, Patrick (eds.) La nueva izquierda en América Latina (Bogotá: Norma).

CEPAL 2010 Espacios de convergencia y de cooperación regional. Cumbre de Alto Nivel de América Latina y el Caribe, Cancún (México: febrero. Disponible en: <www.eclac.cl/publicaciones/ xml/4/38524/Espacios_convergencia_cooperacion_regional.pdf > .

Chávez, Daniel; Rodríguez Garavito, César y Barrett, Patrick 2005 “¿Utopía revivida? Introducción al estudio de la nueva izquierda latinoamericana" en Chávez, Daniel; Rodríguez Garavito, César y Barret, Patrick (eds.) La nueva izquierda en América Latina (Bogotá: Norma).

Coronil, Fernando 2002 El Estado mágico. Naturaleza, dinero y modernidad en Venezuela (Caracas: Nueva Sociedad).

De Sousa Santos, Boaventura y Avritzer, Leonardo 2002 “Introdução: para ampliar o cânone democrático" en De Sousa Santos, Boaventura (org.) Democratizar a democracia. Os caminhos da democracia participativa (Río de Janeiro: Civilização Brasileira).

El Troudi, Haiman y Monedero, Juan Carlos 2006 Empresas de producción social. Instrumento para el socialismo del siglo XXI (Caracas: Centro Internacional Miranda). 
García Linera, Álvaro 2010 “Conferencia Magistral: La construcción del Estado" en Facultad de Derecho de la UBA (Buenos Aires: 9 de abril. Disponible en: <argentina.indymedia.org/ news/2010/04/727678.php >.

Hirschmann, Albert O. 1981 Salida, voz y lealtad (México: FCE). Hubert, Evelyne y Solt, Frederick 2004 "Successes and Failures of Neoliberalism" en Latin American Research Review, $\mathrm{N}^{\circ} 39$ (3).

Ibarz, Joaquim 2010 "Votos manchados de sangre" en La Vanguardia, $19 / 03$.

Jessop, Robert 2008 El futuro del Estado capitalista (Madrid: Catarata).

Koselleck, Reinhart 2009 "La investigación de una historia conceptual y su sentido socio-político" en Revista Anthropos (Barcelona) $\mathrm{N}^{\circ} 223$.

Laclau, Ernesto 2005 La razón populista (Buenos Aires: FCE).

Laclau, Ernesto 2006 "Deriva populista y centroizquierda latinoamericana" en Página 12, 8 de octubre. Disponible en: <www.pagina12.com.ar/diario/elpais/1-74196-2006-10-08.html>.

Lakoff, George 2007 No pienses en un elefante (Madrid: Universidad Complutense de Madrid).

Manin, Bernard 1998 Los principios del gobierno representativo (Madrid: Alianza).

Mendoza, Plinio Apuleyo; Montaner, Carlos Alberto y Vargas Llosa, Álvaro 1996 Manual del perfecto idiota latinoamericano (Barcelona: Plaza y Janés).

Milanovic, Branco 2006 La era de las desigualdades. Dimensiones de la desigualdad internacional y global (Madrid: Sistema).

Monedero, Juan Carlos (dir.); Jerez, Ariel; Ramos, Alfredo y Fernández, José Luis 2009 Materiales para el estudio de la participación en América Latina (Caracas: CLAD) manuscrito.

Monedero, Juan Carlos 2009a Disfraces del Leviatán. El papel del Estado en la globalización neoliberal (Madrid: Akal).

Monedero, Juan Carlos 2009b El gobierno de las palabras. Política para tiempos de confusión (Madrid: FCE).

Moreira, Carlos; Raus, Diego y Gómez Leyton, Juan Carlos (coords.) 2008 La Nueva Política en América Latina. Rupturas y continuidades (México: Trilce).

Panizza, Francisco (comp.) 2009 El populismo como espejo de democracia (Buenos Aires: FCE).

Paramio, Ludolfo 2008 "El regreso del Estado: entre el populismo y la regulación" en Revista del CLAD. Reforma y democracia, $\mathrm{N}^{\circ} 42$, octubre, p. 33. 
Paramio, Ludolfo 2009 "Izquierda y populismo en América Latina" en Alcántara, Manuel (org.) Revista Sistema, Dossier "La política de América Latina", N $\mathrm{N}^{\circ}$ 208-209, enero, pp. 28-29.

Petkoff, Teodoro 2005 Las dos izquierdas (Caracas: Alfadil).

Pierson, Paul 2000 "Increasing Returns, Path Dependence, and the Study of Politics" en American Political Science Review, junio.

Prada, Raúl 2010 "Corrientes discursivas de la descolonización" en $<$ www.cambio.bo/noticia.php?fecha=2010-04-08\&idn=16874> .

Sader, Emir 2009 El nuevo topo. Los caminos de la izquierda latinoamericana (Buenos Aires: Siglo XXI).

Said, Edward 1990 (1978) Orientalismo (Madrid: Libertarias/ Prodhufi).

Schmidt, Manfred G. 1997 Demokratietheorien (Opladen: Leske+Budrich).

Villacañas, José Luis y Oncina, Faustino 2006 "Introducción" en Koselleck, R. y Gadamer, H. G. Historia y hermenéutica (Barcelona: Paidós) p. 27.

Wallerstein, Immanuel 2008 Entrevista con Antoine Reverchon en Le Monde, 12 de octubre. Disponible en <www.rebelion.org/noticia. php?id=74554>. 

Caminos de

ida y vuelta 



\section{Enrique V. Iglesias}

\section{EL PAPEL DEL ESTADO Y LOS PARADIGMAS ECONÓMICOS EN AMÉRICA LATINA*}

ESTE ARTÍCULO EXAMINA los grandes paradigmas de desarrollo que sucesivamente prevalecieron en América Latina en la segunda mitad del siglo XX, concentrándose en el papel asignado al Estado. En el paradigma cepalino se ve cómo amplias tareas de guía, estimulador y partícipe directo en el desarrollo productivo fueron perdiendo eficacia, a medida que el Estado era capturado por intereses particulares sin que instituciones sólidas fueran capaces de ponerle coto. Posteriormente, la extrema debilitación del Estado experimentada desde la vigencia del Consenso de Washington impidió la adecuada regulación de las actividades privatizadas e hizo perder la visión de largo plazo y la preocupación por la concentración de ingresos. El artículo alude a la demanda social por un nuevo tipo de Estado y analiza los requisitos y objetivos para que, entre otras cosas, este facilite un funcionamiento eficaz de los mercados y se preocupe por disminuir las desigualdades sociales.

* Iglesias, Enrique V. 2006 "El papel del Estado y los paradigmas económicos en América Latina" en Revista de la CEPAL, No 90, pp. 7-15. [Este artículo recoge la conferencia magistral dictada por el autor en la Comisión Económica para América Latina y el Caribe (Santiago de Chile, 28 de agosto de 2006), en el marco de la Sexta Cátedra Raúl Prébisch.] 


\section{INTRODUCCIÓN}

Por una amable invitación que me extendiera mi gran amigo y colega José Luis Machinea, participé recientemente en una reunión muy especial de la CEPAL, convocada para conmemorar a Raúl Prébisch, insigne economista de nuestra región y contemporáneo ilustre de muchos de los que se hallaban en ese acto. Su memoria nos evoca la época de oro del pensamiento económico del desarrollo en la segunda mitad del siglo pasado, que él lideró con tanta sabiduría en nuestra América Latina y que proyectó al ámbito académico internacional y de prestigiosas instituciones especializadas, como la Comisión Económica para América Latina y el Caribe, el Instituto Latinoamericano y del Caribe de Planificación Económica y Social, y la Conferencia de las Naciones Unidas sobre Comercio y Desarrollo. Su vida fue rica en pensamiento y acción, que en el transcurso del tiempo ha inspirado la formación de nuevas generaciones de profesionales comprometidos con la causa del progreso económico y social de nuestros pueblos, a la vez que sus ideas son valoradas con debida justicia por numerosos y destacados economistas del mundo académico actual. Para mí su memoria es verdaderamente emocionante, como el maestro que abrió mis ojos al mundo de la economía real latinoamericana y mundial y como el amigo generoso cuyos ejemplos, consejos y apoyo fueron determinantes en mi carrera y dedicación al desarrollo económico y social de América Latina y el Caribe. A ello se unió en ese momento mi nostalgia de los años pasados en la que fue y siento mi casa, la CEPAL, cuna de ensueños y experiencias compartidas a través de tantos años. Mucho agradezco la oportunidad que se me brindó para sentir el reencuentro con las memorias que ella encierra y con tan buenos amigos y compañeros de ruta.

\section{LOS PARADIGMAS ECONÓMICOS}

La búsqueda de paradigmas económicos ha sido una constante en la región desde mediados del siglo pasado. Pocas regiones han conocido un debate tan encendido y ensayos tan variados como América Latina. Nuestra región ha constituido un verdadero laboratorio de ideas y propuestas de política impulsadas por las ideologías de turno, en muchos casos siguiendo enseñanzas originadas en otras partes del mundo.

De esa búsqueda se derivan lecciones diversas. Una primera lección aprendida en mi experiencia de casi medio siglo es que el subdesarrollo económico es mucho más complejo que lo que pensábamos hace cincuenta años. Y ello a pesar de que en aquella época se realizaron grandes esfuerzos de reflexión. La CEPAL fue, en cierta medida, un semillero de ideas impulsadas con tanto brillo por Raúl Prébisch. Pero ella fue también un centro de investigación y conocimiento de la 
realidad económica de cada país, en numerosos casos con la cooperación estrecha de los gobiernos. Como parte de esa vivencia, aprendimos a conocer mejor la complejidad económica de cada país y de su entorno internacional.

Así, una lección muy importante de esa experiencia de tantos años es saber evitar los reducimientos o simplificaciones excesivas de la realidad que suelen acompañar la búsqueda de los paradigmas. Esas simplificaciones han estado presentes casi en todas las formulaciones teóricas y sus respectivas propuestas de política. En mi experiencia personal he observado dos tipos de simplificaciones excesivas: las del ámbito económico y las relativas a los marcos social y político.

¿Cómo superar las simplificaciones de la teoría? El avance del análisis macroeconómico ha hecho una enorme contribución al mejoramiento de la formulación de políticas. Los modelos macroeconómicos han progresado extraordinariamente en su capacidad de análisis y de prescripción de políticas. Tres áreas en las que ese avance ha sido notable y útil corresponden al campo monetario y financiero; al de formación de los precios, inclusive la inflación, y al de comercio exterior.

Sin embargo, me parece que en muchos casos se ha sacrificado la realidad en beneficio de la elegancia formal y matemática de los modelos. No es cuestión de menospreciar la contribución de los modelos macroeconómicos al conocimiento y la praxis de la política, pero a veces se tiende a anteponer su elegancia formal a la complejidad de la realidad económica, social y política.

Talvez, para fines ilustrativos, podamos hacer un símil con la construcción de una casa. Para esto se requiere el aporte de un buen ingeniero que asegure la idoneidad de sus cimientos e infraestructura. Simplemente no habrá casa segura sin ello. Pero, además, se requiere la contribución del arquitecto que aporte el diseño apropiado a las aspiraciones y necesidades de sus moradores. Pienso que en la búsqueda de paradigmas económicos ocurre algo semejante. Se necesitan buenos ingenieros económicos para asegurar la coherencia de los modelos económicos y formular sus condiciones de óptimo. Pero también se necesitan arquitectos económicos que aseguren la correspondencia entre la racionalidad de la ingeniería económica y las exigencias de la realidad social y política. Considero que el avance en la ingeniería económica ha superado lejos a la arquitectura de los paradigmas económicos. Las experiencias de los años pasados muestran a menudo que ha habido déficit en cuanto al diseño de la casa, mientras abundó la elegancia formal de su estructura.

¿Cuál ha sido la experiencia con relación a los paradigmas sociopolíticos? En los empeños por conocer y aprehender la realidad se ha recurrido a ideas y categorías de análisis sociológico y político. Por ahí 
nos acercamos a una visión integral de la realidad. Sin embargo, esa comprensión de los factores sociales o políticos condicionantes ha sido en muchos casos seducida inevitablemente por ideologías o concepciones apriorísticas, que siendo útiles para entender los fenómenos sociales, corren el riesgo de colocar las ideologías delante de las realidades. Y esto conlleva una simplificación tan peligrosa como la anterior.

Por lo tanto, una de las lecciones más valiosas de los años pasados es la necesidad de evitar uno u otro tipo de simplificación. En un caso arriesgamos el quedarnos con economías sin sociedad. Y en el otro, quedarnos con sociedad sin economía. Los paradigmas encierran uno $\mathrm{u}$ otro riesgo, por lo que debemos cuidarnos de las simplificaciones excesivas si queremos tener una visión integral de la realidad sobre la cual aplicar políticas económicas y sociales relevantes y viables.

Lo anterior no significa ignorar el papel de las ideas y de las ideologías, que han probado ser tan valiosas a lo largo de la historia. Lo que reconozco en mi experiencia personal es que en la búsqueda de los paradigmas económicos y sociales es preciso aprehender las realidades nacionales e internacionales, y en ellas identificar los obstáculos y condiciones impuestos por la aplicación de las distintas propuestas de política.

Entre los factores condicionantes de las realidades económicas, políticas y sociales, las instituciones tienen un papel crucial, como se ha venido reconociendo cada vez más. Y entre ellas se destaca el Estado. En América Latina un factor fundamental de los grandes paradigmas de desarrollo ha sido el papel asignado al Estado.

Este tema no es nuevo, pero me propongo abordarlo aquí porque puede ser de interés mirarlo a la luz de mi experiencia personal, aprovechando especialmente los resultados de los trabajos que realizamos en el Banco Interamericano de Desarrollo (BID) en años recientes. Allí montamos una unidad dedicada especialmente al análisis de los problemas políticos en el desarrollo latinoamericano y, en particular, del papel del Estado. Con ello simplemente nos sumamos a la corriente institucionalista de los últimos años, que ha venido poniendo de relieve el rol fundamental de las instituciones en lo que se refiere a explicar y combatir los problemas del desarrollo.

Quisiera discurrir aquí sobre el papel del Estado en cada uno de los dos principales paradigmas de política económica de los últimos 50 años en América Latina: el paradigma de la CEPAL y el del Consenso de Washington. De ese examen y de las lecciones aprendidas surge la necesidad de repensar el rol del Estado en el marco de las nuevas realidades de América Latina y de las estrategias económicas que se están aplicando en la región. 


\section{EL PARADIGMA CEPALINO}

El primer gran encuentro entre Estado y paradigma que nuestra generación observó en América Latina surgió de la propuesta cepalina. Como bien sabemos, el marco de este paradigma incluyó un conjunto de ideas fuerza, entre las que se destacan: i) el encuadre del paradigma en la relación centro-periferia; ii) la orientación del desarrollo hacia adentro; iii) el papel de la tecnología; iv) la industrialización sustitutiva, y v) el rol activo del Estado. A su vez, la implementación de esa estrategia de desarrollo descansaba en un conjunto de instrumentos y políticas específicas de carácter arancelario, tributario, cambiario, crediticio y de incentivos fiscales al desarrollo industrial, y en la atención del crecimiento explosivo de las demandas sociales generadas por las migraciones del campo a las ciudades.

En ese contexto correspondía al Estado cumplir un papel protagónico, para lo cual se crearon ministerios especializados, oficinas de planificación, y bancos de desarrollo destinados a movilizar recursos financieros y tecnologías. La ampliación y fortalecimiento del aparato estatal fue el instrumento básico de la política económica. El desarrollo impulsado por esta estrategia transformó profundamente el perfil económico y social latinoamericano. Un aspecto destacado de la transformación social lo constituyó el intenso proceso de urbanización. En el plano económico, el sector manufacturero aumentó su gravitación en el producto global y en el empleo, mientras declinaba o se estancaba la producción agrícola, se aceleraba la expansión de los servicios e inclusive el aumento del empleo en el sector público, y adquirían una ponderación cada vez mayor las burocracias y la absorción de recursos por parte del Estado. La población urbana alcanzó niveles de ingreso crecientes y sensiblemente más altos que los del ámbito rural, aunque su dinámica expansiva se debilitó marcadamente entre la década del sesenta y la del setenta.

¿Por qué ese agotamiento progresivo del desarrollo latinoamericano? ¿No fueron esos mismos postulados de las políticas de desarrollo los aplicados exitosamente por los "tigres asiáticos"? ¿Por qué entonces América Latina no consiguió hacer viable una economía industrial progresiva y, en cambio, perdió posiciones significativas frente a países que iniciaron su industrialización desde bases más débiles? Ciertamente las causas fueron muchas, pero hubo factores que tuvieron una incidencia nefasta importante en los resultados.

El Estado asiático disfrutó de mayor autonomía que el latinoamericano, y estuvo precedido por tradiciones burocráticas eficientes y libres de la influencia de intereses particulares. En cambio, la experiencia en América Latina fue muy distinta, no tanto por la naturaleza de las políticas, sino más bien por su implementación. Las bases fiscales 
fueron insuficientes, debido en gran medida a la ausencia de un auténtico pacto social y político redistributivo. El Estado fue fácilmente dominado por intereses particulares, entre otros, los de las agrupaciones o partidos políticos, grupos económicos, líderes militares, caudillos o dictadores, los cuales fortalecieron su poder político y económico por la vía del Estado. Eso explica también el carácter clientelista del empleo y de la gestión del gasto público por los regímenes autoritarios o semidemocráticos.

En suma, el Estado que acompañó al paradigma cepalino fue omnipresente, centralista y cautivo. Además, en pocos países de América Latina se consiguió avanzar en la construcción de un sólido Estado democrático, condición indispensable para asegurar la autonomía frente a los intereses particulares y la confianza en el imperio de la ley. Estas deficiencias condujeron a la inestabilidad política y al déficit democrático.

En los estudios hechos en el BID se analizó ese déficit democrático a partir de dos relaciones: las del Estado con el mercado y las del Estado con la sociedad. Los vacíos o fallas en esas relaciones erosionaron la viabilidad de un desarrollo sustentable y equitativo.

La usurpación del Estado por los intereses privados condujo a intervenciones estatales que entorpecieron el funcionamiento eficiente del mercado y promovieron el rentalismo, la especulación y la corrupción. A su vez, las políticas públicas capturadas por intereses particulares no pudieron responder a las demandas de la mayoría de los ciudadanos, contribuyendo así a excluir de los beneficios del crecimiento a amplios sectores de la población y a la pérdida de legitimidad del Estado.

El agotamiento del modelo heterodoxo de la CEPAL precipitó la crisis del Estado. No es esta la oportunidad de examinar las causas del agotamiento de ese modelo. Lo cierto es que la crisis sufrida en la década del ochenta, que tuvo su máxima expresión en la crisis de la deuda, aceleró los procesos inflacionarios, acentuó la pérdida de competitividad de la economía y aumentó las distancias sociales. En el plano institucional, se destruyeron los bancos centrales, los ministerios de planificación y las instituciones financieras y de fomento. Pero igualmente grave, o aun peor, fue que en la formulación de la política de desarrollo se perdieron las perspectivas de largo plazo. Los problemas de la sobrevivencia económica y las crisis de corto plazo acapararon la atención de las políticas en la mayoría de los países. Esto y, en especial, los problemas derivados de la crisis de la deuda, nos llamaron a principios del decenio de 1980 a alertar desde la CEPAL sobre la inminencia de una "década perdida", la que de hecho y lamentablemente ocurrió y cuyos graves efectos adversos se proyectaron a los ámbitos económico y social de nuestros países. 
La gravedad de la crisis llevó al abandono del modelo heterodoxo y al retorno del modelo ortodoxo y la adopción del Consenso de Washington.

\section{EL CONSENSO DE WASHINGTON}

El retorno de la ortodoxia significó la adopción de las reglas de juego del mercado, la vigencia del sistema de precios como principal mecanismo de asignación de recursos, la aplicación de fuertes programas de estabilización, la apertura al comercio internacional, el ingreso de recursos financieros y de la inversión privada extranjera, y una política generalizada de privatizaciones. Las reformas económicas fueron alentadas en buena medida por los organismos financieros en Washington, en particular los surgidos de la Conferencia de Bretton Woods. Estos constituyeron un instrumento importante para impulsar la realización de las reformas.

La concepción del Estado liberal patrocinado por el Consenso de Washington estuvo dominada por una actitud antiestatista generalizada, que basó su justificación en la crisis enfrentada por el Estado heterodoxo, así como en su ineficiencia, el peso de la burocracia y especialmente la corrupción.

Asimismo, no dejó de tener influencia la expansión generalizada del mercado en un creciente número de economías emergentes, tanto entre los países en desarrollo como en la esfera socialista.

El nuevo concepto de Estado lo caracterizó como minimalista y prescindente. Se estimó que abundaban los argumentos para descalificar al Estado como mecanismo de asignación de recursos, principalmente los relativos a su ineficiencia, la corrupción, el clientelismo y su desborde burocrático. Esto llevó a patrocinar un Estado minimizado, lo cual significó el cierre de instituciones, la eliminación de instrumentos de política y el recorte de su intervencionismo excesivo. Por ejemplo, las políticas industriales y agrícolas fueron eliminadas. Y, sobre todo, se perdió la visión de largo plazo.

Así, las reformas cayeron en un grave error, el de dar la espalda al Estado. La prescindencia del Estado en la realización de las reformas hizo que estas experimentaran una pérdida generalizada de credibilidad. Según las encuestas de Latinobarómetro, solamente un tercio de la población latinoamericana cree en las reformas. Esto condujo a una creciente pérdida de legitimidad de las reformas y del mercado en las grandes mayorías de la población. Esa crisis de credibilidad se sumó al sentimiento generalizado de frustración y de fatiga debido a la insuficiencia del progreso y la dureza de los sacrificios hechos en la aplicación de las reformas. 
Ahora bien, ¿cómo se relaciona el Estado con el mercado y con los ciudadanos en este nuevo paradigma? En cuanto a su relación con el mercado, hubo cambios importantes en las políticas económicas, como: i) las privatizaciones y la apertura al mercado de sectores completos de la economía; ii) el debilitamiento o la ausencia de los marcos de regulación requeridos para fomentar la competencia y proteger el interés de los consumidores; iii) la oposición continuada de los intereses corporativos a los procesos de reforma; iv) la falta de mecanismos adecuados de concertación entre ganadores y perdedores de la aplicación de las reformas; v) el abandono de las medidas de promoción de sectores productivos específicos; vi) el escaso avance en la realización de reformas fiscales auténticas, y vii) una baja y decreciente inversión pública en infraestructura.

Respecto a la relación del Estado con los ciudadanos resaltan algunos aspectos importantes. En muchos países siguen ausentes las condiciones necesarias para un auténtico imperio de la ley y la justicia. Por una parte, los sistemas judiciales son poco confiables, lo cual acentúa la falta de seguridad jurídica. A su vez, el Estado carece de la capacidad necesaria para promover pactos sociales redistributivos.

Analicemos ahora cuál ha sido la atención prestada por las nuevas estrategias del desarrollo a la definición del papel del Estado. En general, en los últimos años del siglo XX y primeros años del siglo XXI ha resurgido una marcada preocupación por el desarrollo social. De una manera u otra, también se han sentido en todo el mundo los efectos de los trágicos acontecimientos del 11 de septiembre de 2001, destacándose entre ellos el énfasis en las medidas de seguridad impulsadas por el Estado.

La relación del Estado con el mercado y los ciudadanos en este nuevo paradigma conllevó una baja capacidad de la administración pública para elaborar e implementar las políticas, debido en gran medida a las crisis fiscales sufridas. Las reformas de la administración pública derivaron más en reformas fiscales que en ejercicios específicos de reorganización. En los procesos de reforma de la administración pública se privilegió su orientación tecnocrática y se descuidó la realización de un auténtico cambio de estructura del Estado.

Por ello, en los últimos años ha surgido el interés por redefinir el papel del Estado en el contexto de las nuevas estrategias de desarrollo y, como lo señalamos anteriormente, se ha hecho hincapié en la preocupación por el desarrollo social y, desde el año 2001, en las medidas de seguridad nacional. Esto coincide con tendencias favorables en el plano económico internacional, un crecimiento significativo del producto y del comercio mundial, el mejoramiento de los precios de las materias primas y la expansión de los flujos financieros y de la inver- 
sión privada extranjera. Por cierto, este clima de bonanza económica internacional ha tenido efectos favorables para América Latina, a lo cual se suma la buena gestión macroeconómica que hoy prevalece en la mayoría de nuestros países. En ellos tanto la gestión de la deuda externa como el desempeño exportador han enfrentado condiciones externas favorables.

Las nuevas estrategias económicas se proyectan en un marco general en que prevalecen, en el plano externo, condiciones de balanza de pagos más favorables que en el pasado y la presencia de nuevos actores en el escenario internacional, como China e India, que ofrecen grandes oportunidades a la región y a la vez plantean grandes desafíos; y en el orden interno, la consolidación de una buena gestión macroeconómica, una renovada atención a los problemas macroeconómicos, y la reivindicación tanto de las políticas públicas especialmente orientadas a corregir fallas de mercado como de la acción del Estado. En todos estos temas la CEPAL ha venido trabajando desde su misma creación.

\section{UN NUEVO CONCEPTO DEL ESTADO: SUS OBJETIVOS Y LOS REQUISITOS PARA ALCANZARLOS}

El tema sobre el que debemos reflexionar es, por tanto, la noción del nuevo concepto del Estado, aprovechando las buenas y malas lecciones dejadas por su papel en los dos paradigmas precedentes. A partir de esas experiencias, quisiera identificar ahora algunos objetivos que me parecen relevantes en la búsqueda de ese nuevo Estado.

\section{OBJETIVOS}

Un primer objetivo es el de lograr un Estado capaz de hacer viable la eficiencia del mercado. El Estado es importante, si acaso no indispensable, para la consecución de un mercado eficiente. Esto supone la existencia de un sistema legal y judicial cierto y creíble en su desempeño, que garantice la efectividad de los derechos de propiedad e individuales. A ello se suma la necesidad de marcos de regulación que aseguren el equilibrio entre los intereses públicos y privados. También es necesaria la creación y defensa de una competencia que garantice la eficiencia del mercado. La experiencia nos enseña cuán nefastos son los resultados de la privatización de empresas estatales cuando, por la falta de las condiciones antes señaladas, se reemplaza el monopolio público por el privado. En suma, para que el mercado funcione con eficiencia, en términos de crecimiento y de generación de oportunidades para toda la población, se necesita un Estado capaz de intervenir eficazmente donde le corresponde, aunque no debe hacerlo donde no le corresponde. 
Segundo, se necesita un Estado impulsor de la capacidad productiva, con lo cual no abogamos por una propuesta apriorística de un Estado productor, aunque tampoco se excluye esta opción. En este concepto del papel del Estado se destaca la aplicación de políticas públicas orientadas a fortalecer la capacidad productiva en los sectores de mayor prioridad para el desarrollo, como es el caso, por ejemplo, de aquellos vinculados a la innovación tecnológica y productiva. Proponemos intervenciones inteligentes por parte del Estado, pero no contra el mercado, y evitar la exclusión dogmática del Estado como la que hicimos en años anteriores.

Tercero, se necesita un Estado que tenga la responsabilidad de disminuir las desigualdades sociales. El Estado cumple un papel indispensable en la defensa activa de la cohesión social y la lucha contra la pobreza. La eficiencia de los derechos políticos y civiles depende de un aparato estatal que garantice la observancia de la legalidad y condiciones materiales de vida dignas para la población, por la vía del reconocimiento y la cobertura de sus derechos económicos y sociales. Esto implica que el Estado asume dos funciones fundamentales: la de habilitador y la de compensador. Habilitador del ciudadano para que este acceda a una mayor igualdad de oportunidades a través de la educación, y compensador porque debe velar por el bienestar de los desamparados de la sociedad. Esto no significa asignar al Estado un papel protagónico en el crecimiento económico como vía para resolver los problemas de pobreza, lo que suplantaría las responsabilidades del sector privado en la esfera económica.

Cuarto, la experiencia moderna pone de relieve un nuevo relacionamiento del Estado con la empresa privada, del cual se han derivado importantes dividendos económicos y sociales. En ese campo cabe identificar nuevas modalidades de cooperación, como, por ejemplo, la coparticipación del Estado y la empresa privada en el financiamiento de la infraestructura, que sin duda será uno de los mayores retos para la economía regional en los próximos años.

Quinto, con relación al papel del Estado frente a la sociedad civil, se entiende hoy claramente que el fortalecimiento de la sociedad civil es algo estrechamente asociado a la reforma del Estado. Desde el BID sostuvimos repetidamente que no hay Estado capaz con una sociedad civil débil ni viceversa. Esto es, que no existe una sociedad civil fuerte sin el amparo de un Estado fuerte y eficiente. Sin embargo, no debe confundirse tamaño con fuerza ni grasa con músculo, como Prébisch lo señaló a menudo. El desarrollo requiere más Estado, más mercado y más sociedad civil, pero de manera coherente, que permita la convivencia y el refuerzo mutuo de las potencialidades máximas de cada una de las partes. Debe reforzarse creativamente esa relación, 
fomentando mecanismos de participación de la sociedad civil en las funciones del Estado. Esto es sin duda un gran desafío, que debe enfrentarse empezando por la eliminación de las sospechas recíprocas comunes en esta relación.

Sexto, el Estado tiene un papel fundamental en la orientación y formulación de las políticas de inserción internacional. Corresponde al Estado, en consulta y colaboración con el sector privado, adoptar las grandes decisiones que permitan desarrollar las relaciones de inserción internacional de los países. Esa tarea tiene importancia crítica en las actuales condiciones de creciente complejidad de las relaciones internacionales, tanto en el plano regional como a nivel mundial. El rol del Estado es de particular relevancia en el proceso de integración regional. Las solidaridades de hecho sobre las que se construye la integración económica y política dependen de un proceso de convergencia de intereses, valores y culturas, cuya columna vertebral depende de las capacidades institucionales de los países y, en particular, del papel del Estado. La integración es un proceso complejo y dinámico, que avanza mediante la superación de conflictos de adaptación de las estructuras económicas, políticas y sociales de los países. Todo ello difícilmente puede lograrse sin el liderazgo de las instituciones del Estado. Jean Monet solía decir que nada es posible sin las personas, pero que nada es duradero sin las instituciones. La integración regional, que en sí misma es un proceso de reforma del Estado, difícilmente puede avanzar sin la presencia de Estados capaces de enfrentar eficazmente los problemas de adaptación que ella trae consigo.

Séptimo, el Estado desempeña un papel de suma importancia en la innovación tecnológica. En las primeras etapas de la formación de las naciones, el Estado tuvo un rol fundamental en la educación del ciudadano. Hoy en día, la nueva frontera que se abre a la responsabilidad primaria del Estado es el apoyo al desarrollo de la tecnología y de la innovación tecnológica. Lo que ayer era la educación hoy es la extensión y la calidad de la educación. Lo de hoy es, además, la promoción de la investigación científica y la innovación tecnológica. Esto no desconoce el papel fundamental de la actividad privada en este campo, pero las distancias que nos separan del mundo desarrollado pueden aumentar si dejamos de hacer un esfuerzo masivo de desarrollo tecnológico, el cual requiere inevitablemente una acción efectiva del Estado.

Octavo, en el mundo cada vez más complejo en que vivimos es menester fortalecer la capacidad de análisis de las tendencias fundamentales de la economía, la sociedad y la política en el ámbito internacional. Vivimos en un mundo que avanza en todos los campos a ritmos sin precedente, dominados por las fuerzas de la globaliza- 
ción y el desarrollo vertiginoso de las tecnologías de la información y de las comunicaciones. Frente a ello debemos mantener, como condición de la más alta prioridad, la mayor capacidad de observación y seguimiento que nos sea posible. En esta tarea el Estado moderno debe promover un proceso permanente de reflexión por los sectores público y privado, que nos permita enfrentar los retos y aprovechar las oportunidades que nos plantean las distintas vertientes de la globalización.

Noveno, un componente institucional de probada idoneidad en el desarrollo de la capacidad de análisis de las grandes tendencias económicas, sociales y políticas en el ámbito nacional e internacional, lo constituyen las oficinas de planificación. Debemos corregir pasados abandonos de las tareas de análisis y de reflexión sobre el futuro. El pensamiento a largo plazo debe volver a ser un objetivo importante del Estado contemporáneo. No estamos abogando por el tipo de planificación centralizada, sino por la capacidad para proyectar tendencias a largo plazo sobre las cuales fundar las estrategias de desarrollo.

Décimo, otra función prioritaria del Estado moderno es la de promover los grandes consensos nacionales. Como sabemos, la concertación a distintos niveles entre Estado, empresa privada, sindicatos y sociedad civil ha sido una valiosa experiencia de muchos países desarrollados. Sin pretender diluir las responsabilidades propias de cada estamento, es útil apuntar a mecanismos que contribuyan a grandes consensos nacionales, que en las condiciones actuales de la región parecen tan útiles y necesarios. Considero que la formación y el fortalecimiento de los consejos económicos y sociales deberían ser merecedores de especial atención por parte del Estado.

Este verdadero decálogo de objetivos del nuevo Estado debería ser complementado con la definición o identificación de los requisitos e instrumentos idóneos y necesarios para lograrlos.

\section{REQUISITOS}

A mi juicio, la primera condición es la de contar con un sistema democrático robusto. Sin duda este es el requisito más importante y quizás su mención resulte algo novedosa. Tal vez sea novedoso ligar el sostenimiento y profundización de la democracia con las capacidades del Estado. Pero es relativamente común vincular el mal funcionamiento de la democracia al desarrollo de su componente liberal, relacionando este con la debilidad de los mecanismos de limitación y división efectiva del poder que aseguran la protección de los derechos y libertades civiles y políticas. Sin embargo, se ha resaltado menos la debilidad causada por el déficit del llamado componente republicano de la democracia, según el cual el ejercicio de cargos públicos debe ser una 
actividad virtuosa, que supone una estricta sujeción a la ley y obediencia al interés público, sacrificando muchas veces el interés privado.

Una segunda condición es la de crear un servicio civil profesional, con una sólida posición institucional y sentido del deber, amparado por un marco normativo apropiado. La autonomía institucional del servicio civil, cubierto por estrictos criterios de igualdad, mérito y capacidad en el acceso y en el ordenamiento de la carrera, funciona en las democracias avanzadas como un contrapeso a la discrecionalidad política y del gobierno y como un freno a la arbitrariedad, salvaguardando los valores de la legalidad sin los cuales sería difícil la protección efectiva de los derechos y libertades de los ciudadanos. La democracia no se consolidará sin una reforma del Estado que apueste por la institucionalización de un servicio civil profesional. El progreso de la democracia política, económica y social en los países desarrollados no se puede entender sin reconocer la fortaleza de sus instituciones administrativas. Como tampoco cabe extrañarse de que los países de la región con los mejores indicadores de cohesión social sean aquellos de mayor tradición institucional pública, inclusive con un servicio civil de carrera. Por tanto, se debe superar la politización de la administración pública y evitar su captura por intereses particulares que llevan al clientelismo y la influencia de las amistades. Este es un paso fundamental en el camino hacia el Estado que la democracia de América Latina necesita hoy en día.

Existe, asimismo, la necesidad de aumentar y mejorar la capacidad de gestión del gasto público. Un crecimiento sostenible y equitativo depende también de la calidad y la eficiencia de las políticas y de la gestión pública. Es indispensable entonces elevar la capacidad fiscal de los gobiernos, a la vez que su responsabilidad. En particular, es prioritario adaptar los sistemas de asignación de recursos para que respondan a las necesidades de los más pobres, y acomodar los sistemas de prestación a sus circunstancias específicas, permitiéndoles la participación y el compromiso directo. Para lograr todo ello, es imprescindible superar la politización de la administración pública y su captura por intereses particulares, como ya se señaló. La administración pública está llamada a constituir la plataforma institucional básica para el diseño e implementación de políticas públicas que respondan a los intereses generales de la sociedad.

Finalmente, cualquier planteamiento relativo a la reforma del Estado tendrá que superar tanto las hipotecas ideológicas relacionadas con ella, como la lógica que las reduce a simples problemas técnicos. La reforma del Estado es realizable solo a través de ajustes incrementales, que sean concebidos desde la economía política de lo posible. La realidad demuestra que son las ideas y no las ideologías las que per- 
miten avanzar paulatinamente en la solución de los problemas. Eso afecta también el diseño del Estado, en que no hay muchas opciones viables unidas a banderas de diverso color, sino espacios de cambios graduales, normalmente transversales, que requieren grandes consensos y apoyos de la sociedad en su conjunto.

Del mismo modo, concebir la reforma del Estado como un problema exclusivamente técnico, separado de la política, significa desconocer una realidad que reaparece con el tiempo bajo formas insospechadas. Es cada vez más evidente que los países que han sido capaces de progresar en forma sostenible no son los que han subordinado la lógica política a criterios puramente técnicos. Solo cuando la racionalidad técnica y política ha encontrado su acomodo armónico, donde las reformas se han presentado y discutido con transparencia y sin miedo a sus costos políticos, donde se ha invertido de forma transversal en conocimiento local y apropiación colectiva de planes y proyectos, solo en esos casos constatamos avances, quizás más lentos, pero también más sostenibles y equitativos.

Es importante destacar que, más allá de algunos consensos básicos en los equilibrios a nivel macro, los países con mayor éxito presentan una combinación muy diversa de modelos institucionales y políticos de reforma. Pero a la vez coinciden en haber desarrollado procesos innovadores en la búsqueda de respuesta a sus problemas, que representan equilibrios peculiares entre la racionalidad política y la técnica. Esta es quizá la lección más importante del proceso de reformas en países como Chile y Brasil. 


\section{Marcos Roitman}

\section{LAS MALDICIONES DE PENSAR AMÉRICA LATINA*}

LA REALIDAD LATINOAMERICANA está maldita porque formó parte del capitalismo colonial. Nostalgia de no ser países imperialistas. Negamos la historia de los pueblos y comunidades indígenas y los devolvemos a la vida para corroborar las tesis racistas que recalcan su incapacidad para apoyar las fuerzas del progreso. En el mejor de los casos, los presentamos como subculturas o imperios que explotaban y sojuzgaban a sus iguales. Pueblos guerreros y despóticos. Con este mito, la sociedad blanca mestiza ladina colonial y los Estados-nación del siglo XIX realizan su proyecto de dominación y explotación. Su legitimidad deviene de imponer un orden fundado en la civilización occidental cuyos valores son las libertades individuales y el progreso científico-técnico. Así, explicamos el capitalismo colonial como un mal menor que fue capaz de poner la primera piedra para la construcción de un edificio donde asentar los valores de la civilización católica, apostólica y romana. De esa manera, se deja intacto el proceso de destrucción y expoliación al que fueron sometidos los pueblos indios por el poder regio y el posterior orden republicano.

* Roitman, Marcos 2008 "Las maldiciones de pensar América Latina" en Pensar América Latina. El desarrollo de la sociología latinoamericana (Buenos Aires: CLACSO) pp. 15-30. 
La frustración de no ser europeos, de no compartir sus virtudes y grandezas, nos carcome. No hemos sido capaces de construir historia, por ello repetimos y reproducimos la de otros. América Latina existe como apéndice de los cambios y transformaciones que se suceden a nivel mundial. Es esta maldición la que se encuentra presente en la forma de construcción del pensamiento social latinoamericano.

Cada cierto tiempo nos apegamos a nuevos paradigmas que suelen reinterpretar nuestra historia, y son muchos los que se regocijan en ello. Primero al liberalismo político del siglo XIX, luego al keynesianismo y ahora a la posmodernidad, la globalización y el liberalismo social de nuevo cuño. También le cabe un lugar al debate sobre el socialismo y la revolución social. Todo emerge como una mala copia de los procesos impulsados en el Primer Mundo. No hay tiempo para digerir los procesos, para separar el polvo de la paja, para establecer y pensar en las diferencias históricas. Todo parece un despropósito. Se quiere tener un Lenin y revivir la Revolución Rusa, crear un partido a imagen y semejanza del bolchevique, así no queda tiempo para comprender la historia de la Revolución Mexicana, la guerra hispanocubano-norteamericana o la historia de las luchas de Sandino, salvo cuando triunfa cuarenta años más tarde un Frente de Liberación que lleva su nombre.

Todo ello somete la realidad latinoamericana a discusiones que han derivado acerca de la condición subalterna en la que existimos. Si fuésemos más inteligentes, estaríamos en condiciones de romper el subdesarrollo. La tensión del pensamiento se pone en verificar hasta qué punto realizamos las reformas necesarias para no perder el tren del progreso y estar por fin a las puertas del ansiado crecimiento económico que nos lleve a la gloria de la modernización y transformación tecnológica.

Lo anterior requiere ser bañado en un discurso pragmático y coherente que recuerde el déficit de modernidad en que se encuentra el continente. Pecados y maldiciones que impiden una rápida ubicación en el nuevo mundo globalizado. Continuamente se llama la atención a no repetir las experiencias que se han mostrado esquivas y reticentes a la marcha del "universo". Ni populismo, ni desarrollismo, ni locuras izquierdistas, ni pensamiento crítico, ni siquiera pensar. Solo actuar en la lógica racional de Occidente y su proceso de transnacionalización del capital. Somos pecadores y debemos vivir como tales. Las oportunidades para salir del pozo en que nos han dejado sumidos las viejas ideas de un proyecto propio deben dejar paso a una visión amplia capaz de recoger lo mejor de las transformaciones que presenta la globalización productiva. En este orden, el pensamiento reaccionario propone un proyecto social sin un contenido ético y moral limitado a 
la economía de mercado. Los aprendices de brujo se transforman en vendedores de perfumes que acaban por dormir la conciencia y el juicio crítico. Por consiguiente, los intentos por romper esta visión son puestos en el escaparate de las propuestas utópicas.

De tal guisa, pensar alternativamente se menosprecia y se reduce a un esfuerzo intelectual de academia sin operatividad política. A partir de ese instante, emerge una especie de sincretismo teórico donde se unen pensadores y pensamientos disímiles sin conexión posible. En un mismo saco caben positivistas, liberales, conservadores, nacionalistas, antiimperialistas y también socialistas, demócratas, radicales, comunistas y anticapitalistas. Bolívar, Sarmiento, Martí, Mariátegui, Allende, Che Guevara, Torrijos, Sandino, Perón, Velasco, Fidel Castro, Cárdenas, Arbenz, Goulart o Vargas son presentados sin vínculos con su realidad. Todo da igual. Así surgen debates y discusiones teóricas que empiezan y terminan en lugares comunes, y los problemas no se superan. Las ciencias sociales entran en un impasse que transmuta el conocimiento por la búsqueda de datos empíricos que sustituyen el argumento o, peor aún, son los datos la expresión de las ciencias sociales. El Latinobarómetro se ha convertido en el santo grial de la ciencia política; ya no es una herramienta, es la ciencia en sí misma. Lo que no se puede medir no es conocimiento y por ende debe ser desechado. Aquí radica la maldición de la sociología latinoamericana. Buscar una relación que determine que un 2\% de Estado más un $70 \%$ de participación electoral y un $45 \%$ de libertades individuales hacen un $90 \%$ de gobernabilidad es el resultado esperpéntico que hoy presenta la sociología y la ciencia política en América Latina. Cuestión que, no hay que olvidarlo, también proviene del nuevo pensamiento débil.

Quizás lo más inmediato sea recuperar la sensatez, abrir la puerta y dejar salir el imperialismo cultural que ha impuesto un pensamiento débil sobre lo que Aníbal Quijano denominó señeramente la colonialidad del saber. Se trata de no confundir la capacidad explicativa de los conceptos y categorías de las ciencias sociales, de sus teóricos, de su historicidad, de los procesos históricos donde se desarrollan y la ideología que los contiene, como de los valores en los cuales se encuentran inmersos. No es un problema de neutralidad valorativa de las ciencias, más bien es de articulación de un lenguaje y de una semántica desde la cual comprender los fenómenos históricos, separando método, coyuntura, sentido y contexto.

Un ejemplo de esta maldición, si la proyectamos en América Latina sobre la ley de gravitación universal, presupondría discutir acerca del color, tamaño y forma de la manzana que le cayó a Newton en la cabeza. Distinción que ubicaría a la manzana latinoamericana, sin 
decir por qué, en una situación de inferioridad por diferencia cualitativa. La manzana de Newton era roja y no verde, no pesaba 100 sino 150 gramos y su forma no era del todo redonda. Diferencias que permiten concluir que la ley de gravitación universal no funciona bien en nuestro continente. En cualquier caso, no se podría establecer una relación entre principio explicativo y conocimiento teórico. Para que la ley se cumpla hay que producir manzanas newtonianas, de lo contrario la ley de gravitación se cumplirá a medias y seremos un apéndice del conocimiento proveniente de la mecánica clásica imperial.

Este ejemplo, llevado al campo de las ciencias sociales en América Latina, tiene un correlato: América Latina no creó los conceptos y categorías fundacionales en las ciencias sociales; por ello, el conocimiento de su realidad debe primero reproducir las condiciones sobre las cuales se asienta la Revolución Industrial, el proceso de modernización y de cambio social.

La maldición emerge. La sociología en América Latina se comprende como una "recepción" del cuadro de mando que ubica la historia en una dirección que hay que venerar y desde la cual ofrecer una respuesta adecuada. La capacidad crítica, fuente de todo pensamiento, es marginada como factor relevante en el ámbito teórico de discusión en las ciencias sociales. De aquí que la dificultad de acercarse a comprender nuestras estructuras provenga del rechazo a la explicación de un método selectivo capaz de incorporar aquellos conceptos previamente elaborados y validados por la ciencia.

El obstáculo sistemático de una sociedad atrasada se radica en un momento esencial: su propio conjunto de determinaciones la hace incapaz de volverse sobre sí misma, las propias evasiones y fragmentaciones cognoscitivas aquí son como una prolongación del desconocimiento de esas determinaciones, las compensaciones son el principio y el fin de todos sus modos de conciencia y, en general, se puede decir que es una sociedad que carece de capacidad de autoconocimiento, que no tiene los datos más pobres de base como para describirse. Con relación a su propio ojo teórico esta sociedad se vuelve un noúmeno. (Zavaleta Mercado, 1979)

El conocimiento de la realidad social es visto como un péndulo que oscila entre la sociología empírica y la sociología crítica, pasando por la sociología de la praxis o posmoderna. Es decir, todo cabe en una explicación que hace coincidir los tiempos de oscilación del péndulo con los momentos de velocidad del mismo. La interpretación queda subsumida a aceptar mecánicamente el movimiento sugerido por el péndulo. No es posible una ruptura, solo cabe acortar o ampliar el tiempo del movimiento que mecánicamente realiza la bola pendular. 
Plantearse su ubicación, su capacidad de oscilación, las determinaciones que hacen posible explicar su especificidad no entra en el campo de condiciones sobre las cuales debe iniciarse la discusión para explicar su funcionamiento.

El pensar que las ciencias sociales y en concreto la sociología, en América Latina, se inician cuando se recibe el cuadro teórico-metodológico que le proporciona el estatus de ciencia es tener una concepción estrecha. Fue Durkheim quien afirmó que Aristóteles era el primer sociólogo, estableciendo una línea argumental donde no hay distancias entre ensayistas y sociólogos profesionales. De seguir la propuesta institucional, se termina por excluir a Marx, quien no poseía título. Resulta indudable que hacer ciencias sociales y sociología va más allá de poseer un título universitario, y no puede caerse en un reduccionismo academicista. Pero la visión de hacer sociología desde la racionalidad capitalista de la sociedad occidental está presente en el conjunto de las ciencias sociales en América Latina. José Martí o José Carlos Mariátegui no eran sociólogos, por tanto sus análisis, aunque posean una gran capacidad de explicación de la realidad social latinoamericana, no se fundamentan en un conocimiento racional propio del método científico. La sociología como ciencia social concreta comienza con Max Weber.

La pasión por la integración de la sociedad y la idea de que su integración es fundamentalmente efecto de un proceso intelectual, un hecho de conciencia y de ciencia, ha sido el hilo conductor de la sociología. No obstante sus variaciones de perspectivas heurísticas, énfasis conceptuales, construcciones metodológicas, intereses ideológicos, posturas políticas, la constante de la integración social es propia de sus "padres fundadores" franceses: Saint-Simón, Comte, Durkheim. Permanece en su fundador alemán Max Weber y en su fundador norteamericano, Talcott Parsons. Se repite en México, desde los "científicos" Gabino Becerra y Justo Sierra, hasta su cultivo sistemático a partir de los años cuarenta, marcado teórica y metodológicamente por la recepción que los sociólogos mexicanos hacen del positivismo francés, el materialismo histórico marxista y el estructural-funcionalismo norteamericano. (Aguilar Villanueva, 1987: 132)

La sociología, transformada en un análisis del poder, del cambio social, de la racionalidad del orden y de las formas como sociología comprensiva de la acción social no miró hacia América Latina como una anomalía. Pero sus hacedores empiristas y del marxismo vulgar la transformaron en caricatura. En la región, sus categorías eran una parte del problema. Las ciencias sociales no eran ciencias sociales, fueron vistas con recelo y se consideraron parte de un sistema de do- 
minación política. Se estigmatizó a Weber y se demonizó a Marx; en definitiva, se intentó matar o encarcelar al mensajero. La sociología se redujo a una sociología del cambio social, del orden, del poder o del desarrollo. Esta es otra de las maldiciones que recae sobre el pensamiento social latinoamericano.

En este sentido, se han reproducido esquemáticamente debates, problemas e interpretaciones originales posmodernas de la ciencia social inglesa, americana, francesa y alemana. Se trata de una situación incomprensible. Se fundamentan análisis sin realidad, que impiden ver aquello que constituye conocimiento formativo. A partir de aquí surge un dogma que solo genera productos de moda en función de autores. No existe un intento de rescatar el pensamiento teórico de los autores clásicos y situarlos en el contexto latinoamericano; el resultado es grotesco. La realidad social en América Latina se construye como una realidad inconclusa. Es deficitaria. Nos sobran dictaduras y nos faltan democracias. Hay ausencia de modernización y exceso de tradicionalismo. Existimos por déficit o por exceso, no como somos.

No existe una verdadera clase dirigente en América Latina, ni siquiera en Monterrey o en São Paulo. La única figura verdaderamente modernizadora en el continente es la de las grandes empresas industriales o financieras públicas: Nacional Financiera, Petrobras, Corfo, por dar solo unos cuantos ejemplos del más alto nivel. Toda América Latina sigue careciendo de empresarios nacionales, de la investigación tecnológica y de la inversión productiva en general. Por su parte los elementos revolucionarios son más débiles de lo que parece indicar su inmensa popularidad. Las acciones del Che no tuvieron mayor influencia porque eran desesperadas y no provocaron más que fracasos en el continente. El modelo cubano, cualquiera que sea el juicio que se aplique, de hecho sigue siendo exterior a América Latina, mientras que el movimiento sandinista estuvo casi constantemente dividido entre un leninismo de tipo castrista y un populismo muy radical que ha terminado, con Ortega, por integrarse al modelo latinoamericano, aunque solo después de un espectacular fracaso económico e incluso político. (Touraine, 1993: 36)

Y en otro trabajo:

En América Latina, la política precede a las realidades económicas y a las fuerzas sociales. Esto aproxima a los países latinoamericanos con los países eurolatinos, como Francia, Italia y España. Pero lo que más asombra en América Latina es la gran desarticulación de la vida intelectual y de la vida social o hasta política [...] Además de la dualización y la desarticulación, el rasgo más importante de la vida política y social 
del continente es la ausencia de separación entre vida pública y vida privada. Lo que opone claramente a la América Latina frente a la Europa occidental y América del Norte industrializadas. (Touraine, 1989)

Es decir, cuando no nos parecemos a Japón o Indonesia, a Francia o Italia, o a Estados Unidos, o se es la Suiza de Centroamérica o la Suecia del Cono Sur, no somos nada. Nuestras burguesías son lumpemburguesías; nuestro proletariado es lumpemproletariado; el desarrollo, subdesarrollo; la Revolución Industrial, proceso de industrialización; la Revolución Burguesa, modernización política. Todo encaja como las piezas de un puzzle.

En ser buenos imitadores, en calcar los procesos históricos de conocimiento y de globalización productiva, radica el éxito. Cuando no se reproduce, surge lo imprevisto, la anomalía de América Latina. Y tan anómala resulta ser la Revolución Mexicana, como la Revolución Cubana, la Unidad Popular en Chile, Lula en Brasil, el sandinismo en Nicaragua, el EZLN en México, el MAS en Bolivia, Correa en Ecuador o Hugo Chávez en Venezuela. En otros términos, lo que sucede a partir de las condiciones estructurales sobre las que se asientan el desarrollo y la configuración del sistema de explotación y dominación en América Latina es un exceso o un déficit. Así se apostilla; es mejor dejar de lado la historia, la memoria, la trayectoria política, social, económica y cultural propia. No tienen razón de ser en tiempos de globalización; son un lastre. Constituyen el pasado, hay que insertarse en las grandes tendencias del cambio social y la modernidad, ahora precedida del post.

La maldición sugiere una interpretación donde la especificidad de las estructuras de explotación y de dominio no termine por cuestionar el orden imperante. Las formas de análisis han buscado dejar intacto un sistema de explicación y argumentación sustentado en la falacia de ser las ciencias sociales y la sociología el resultado de una institucionalización académica del conocimiento social.

Así, las ciencias sociales serían una suma de técnicas y métodos de investigación cuya finalidad se encuentra en solventar los procesos de racionalidad política, cambio social y modernización económica. A los problemas de pensar una sociología disminuida y postrada en silla de ruedas, necesitando alguien que la empuje o de mandos para movilizarse, se le une la dirección del esfuerzo. América Latina se ha convertido en un laboratorio de pruebas de aprendices de brujo que hacen sus primeros trucos donde obtienen fama y éxito a base de encandilar con interpretaciones que luego descartan o rectifican y que nunca proponen en sus respectivos escenarios naturales. Me estoy refiriendo a la recepción de sociólogos. 
Los inicios de la sociología coinciden con el surgimiento de sociólogos cuyas propuestas se realizan a partir de establecer líneas de comparación negativa con sus sociedades de procedencia. Sociedades duales, etapas de crecimiento, feudalismo. Surge un doble problema. Es preciso luchar contra tópicos y simplificaciones que derivan, la más de las veces, de concepciones donde la historia de América Latina apenas está presente y, cuando lo está, es para corroborar tesis acerca de la inferioridad, la falta de racionalidad, la inacabada construcción del orden, etc. Somos productores de defectos sociológicos y monstruos políticos.

La afirmación anterior no intenta negar las aportaciones de orden teórico que supone el desarrollo del conocimiento y la teoría sociológica. Por el contrario, busca separar aquello que pertenece al acervo de las ciencias sociales de las interpretaciones producidas por científicos sociales que hacen de América Latina un campo para elaborar un tipo de conocimiento que guarda relación con sus fantasmas teóricos.

Lo más negativo es que se pierde tiempo discutiendo. Una guerra de propuestas acompañada de una recepción de lecturas que no se sabe por qué razón hay que realizar o a qué motivo responden. La formación del pensamiento sociológico se transforma en un acumular datos, citas y textos cuya lectura solo tiene como objetivo el hacer más fuerte la erudición del ensayista y producir una mejor y mayor cantidad de trabajos para su carrera académica. A una cita le sigue otra hasta el infinito. Cúmulo de citas que pierden efectividad al ser separadas del contexto en el cual cobraron vida.

En última instancia, la ciencia social está constituida por dos elementos: un método — de investigación, de análisis, de ordenamiento, de interpretación-y unos resultados de la aplicación del método. Uno de los más graves errores cometidos en el ámbito de diversas corrientes de pensamiento ha consistido en no ver y comprender estos elementos como expresiones de una realidad histórica (tiempo y espacio), asignándoles unos valores absolutos. El método aparece así como un recetario artificial y abstracto de las formas del conocimiento social, y los resultados de su aplicación como una dogmática [...] El liberalismo llegó a la América Latina como una dogmática [...] pero el marxismo también. Sin una capacidad de comprensión del marxismo como método crítico de pensamiento, la "inteligencia" herética de la América Latina, después de la primera post-guerra, solo podía tomar el marxismo como un cuerpo intangible de dogmas, resultado de la aplicación del método en las formaciones capitalistas más desarrolladas. Así se configuró el fenómeno de la transfiguración, de un pensamiento crítico en una escolástica de izquierda. (García, 1972: 5) 
Esta forma maldita que nos acompaña no ha dejado de mostrar su perdurabilidad en el tiempo. Hemos estado discutiendo con gigantes de barro que al desmoronarse nos dejan sin enemigo visible. Pero la maldición tiene su lógica. Por inercia, produce nuevos gigantes y más grandes. No son molinos de viento, son nuestras propias formas de articular el debate lo que trae consigo el éxito de la maldición.

Sin embargo, será dentro de la corriente intelectual, conceptualizada por Antonio García como escolástica de izquierda, donde la maldición se hace más firme. Ellos radican fuera del continente y su experiencia latinoamericana ha servido para su mejor ubicación en sus respectivos escalafones administrativos de los organigramas de las carreras profesionales individuales. No por ello dejan de hacer visitas para presentarnos las últimas novedades sobre las cuales están investigando o desarrollando sus virtuosos trucos de magia.

André Gunder Frank se convirtió en el teórico del desarrollo del subdesarrollo para hacerse un mea culpa y terminar en el desarrollo posible; Regis Debray hizo la revolución en la revolución y luego la crítica de las armas; Jaques Lambert dualizó las sociedades latinoamericanas y luego las transformó en feudales; Alain Touraine pasó de ser teórico dependentista en Brasil y Chile con un texto cuyo título se inicia con las voces "Las sociedades dependientes..." a concluir lacónicamente en 1992 que "el dependentismo había sido el insumo más nefasto de las ideologías de las diferentes luchas armadas" (Touraine, 1993). Manuel Castells beatificó los movimientos sociales, los hizo revolucionarios y luego desde Berkeley desconoce su etapa "marxista" para negar el análisis de clases sociales. Hoy, son los tigres asiáticos y las nuevas tecnologías su preocupación intelectual. La nueva izquierda es pues el resultado de la vieja escolástica dogmática que vive, aún hoy, a costa de sus trabajos que ahora desconocen como parte de su historia intelectual.

La descripción es un síntoma de cómo se articula la maldición en América Latina. No se trata, como bien señalara Agustín Cueva, de hacer culminar nuestra crítica con "la creencia chovinista-populista de que para conocer la realidad latinoamericana es necesario inventar una teoría propia, rompiendo lanzas contra todos los conceptos tildados de 'eurocentristas"' (Cueva, 1979: 77). Afirmación a la que añadiría que tampoco se busca eliminar las aportaciones teóricas de científicos sociales no latinoamericanos con el fin de potenciar de manera pueril a los científicos sociales del continente. Se procura poner en evidencia, como lo hace Florestan Fernandes, los límites de una sociología que se realiza como tema y no como problema teórico a resolver.

El seguidismo intelectual de las corrientes en boga es uno de los límites que tienen que superar las nuevas generaciones de científicos 
sociales latinoamericanos que se ven enfrentadas a resolver problemáticas que son más un ejercicio de malabarismo intelectual que expresión de preguntas realizadas desde la realidad que los configura.

Otro de los graves problemas del que somos víctimas es que las ciencias sociales han sido realizadas, la más de las veces, por quienes han tenido un doble vínculo con la academia y el quehacer teórico. Este doble vínculo es otra de las peculiaridades que mantiene viva la maldición sobre el pensamiento social latinoamericano. Así, se radicalizan en la academia y se domestican en la política. En ocasiones hablan desde el púlpito de la política contingente, y en otras, desde el sillón de escritorio de los despachos de las universidades. De esta forma, el resultado es un continuo vaivén de dimes y diretes que responden a coyunturas políticas más que a cambios sociales de las estructuras de poder y explotación. Múltiples ejemplos hay que corroboran lo afirmado.

Si comenzamos por el final del camino, podemos tomar el caso de Brasil. Fernando Henrique Cardoso, ex presidente de ese país, fue uno de los creadores de la "teoría de la dependencia": su crítico más mordaz, Francisco Weffort, se convirtió en su ministro de Cultura. Pero también Luciano Martins o Helio Jaguaribe han participado de gobiernos socialdemócratas, liberales, neoconservadores en Brasil. Lo común es que se renuncia a la elaboración teórica o se reniega de lo producido intelectualmente en los períodos de receso político. Así, la sociología latinoamericana se hace a retales y en situaciones que son el resultado de golpes de Estado, exilios o depresiones personales por no ser presidente o ministro. Chile es otro caso singular. Quienes más desarrollaron las críticas al proceso de refundación del orden realizado por la dictadura militar en el terreno político, económico, cultural y social no han dejado de alabar el fin del tradicionalismo en la política en Chile. Los más destacados sociólogos antiliberales en la época de Pinochet se han transformado en sus máximos defensores a tiro pasado. Valgan como ejemplo Ricardo Lagos, Álvaro Briones, Alejandro Foxley, Carlos Ominami o José Miguel Insulza, actual secretario general de la OEA. Desde democratacristianos hasta socialistas y comunistas han variado su crítica teórica a la hora de ocupar puestos de responsabilidad política en los gobiernos de Patricio Alwyn, Eduardo Frei o Ricardo Lagos. Argentina, Uruguay o Perú no se quedan atrás. De teóricos a diputados y asesores presidenciales.

Las ciencias sociales resultan ser un momento que permite situarse académicamente en tanto que se está fuera de la arena política. Pero cuando surge la opción de ejercer políticamente una responsabilidad pública se renuncia, quién sabe por qué, a los análisis que se realizaron. Esta situación crea un vacío teórico que es llenado por 
discursos aleatorios que tienden a negar lo dicho y a afirmar todo lo contrario. "Donde dije digo, digo Diego". Esta situación, que en principio no debería ser negativa si aceptamos que no hay por qué renunciar a la acción política como ciudadano y miembro activo de la sociedad nacional, sí resulta un contrasentido cuando ello se produce a expensas de renunciar a lo planteado desde la razón crítica.

Un caso típico en este sentido lo constituye Jorge Castañeda, que pasó de ser un ferviente leninista y dependentista a un ardiente defensor del neoliberalismo social como ministro de Asuntos Exteriores de Vicente Fox. Así escribía en 1978 en un ensayo compartido con Enrique Hett, El economismo dependentista.

Que teóricos de izquierda asignen a una producción capitalista la nacionalidad de primitivo es una prueba más de su permeabilidad al derecho burgués y de su respeto por la propiedad privada. Si las compañías extranjeras repatrían beneficios, no es gracias a un supuesto Derecho que les daría su inversión primitiva sino al dominio de las transnacionales sobre sus propias inversiones. (Castañeda y Hett, 1978: 19)

En un alarde de crítica leninista a Gunder Frank y a los teóricos dependentistas, apuntan:

Los efectos de la dependencia en Lenin no son los mismos que en las teorías de la dependencia: esta diferencia rige para todas las demás. Sus efectos en el caso de Lenin son efectos de dominación sectorial y coyuntural. Para los dependentistas, la dependencia es constitutiva; para nuestro autor no solo no es constitutiva sino que es efecto de la existencia de relaciones capitalistas, de flujos capitalistas cuyos efectos son el desarrollo (desigual, contradictorio) del capitalismo cualesquiera que sean sus repercusiones en la competencia capitalista y en el aspecto de dominación que conlleva [...] Para quien ha leído con atención los textos de Lenin es imposible confundir estas dos nociones de dependencia. (Castañeda y Hett, 1978: 67)

Pero la cosa no termina aquí:

En un régimen capitalista, si no hay relaciones sociales de producción, si no hay clases sociales, los conflictos se reducen a conflictos entre hombres. La explotación es así un robo; el poder, una usurpación. Se combaten los abusos originados por la situación histórica de la propiedad privada y de la dependencia, desaparecidas estas y con ellas abusos, usurpación y despojo, nada se interpone entre los hombres. Están desnudos frente a la naturaleza. No se enfrentan más que a los problemas técnicos que plantea su explotación. La exclusión de la política es la irrupción de la tecnocracia. La afirmación del humanismo 
introduce el socialismo como imperio del economicismo. La esencia del socialismo de la dependencia es el desarrollo de la economía para el bien de la humanidad. (Castañeda y Hett, 1978: 84-85)

Con estas críticas no se salva ni el socialismo, ni Lenin ni Marx. Pero los autores se convierten en los más férreos defensores de la ortodoxia teórica. Las interpretaciones correctas son las suyas. Quince años después, en 1993, ya en solitario, Castañeda escribe otro trabajo con las mismas pautas descalificadoras que en el anteriormente descripto: La utopía desarmada. ¿Cuándo hay que creerle? Hoy es un político afincado en los tiempos del liberalismo social y se maldice a sí mismo, con una nota a pie de página, donde se reconoce pecador marxistaleninista. La luz le ha llegado y la revelación le pertenece.

Los ejemplos pueden repetirse, pero basta señalar el del actual ministro de Asuntos Exteriores de Chile del gobierno de la socialista Michelle Bachelet, el democratacristiano Alejandro Foxley:

Pinochet realizó una transformación, sobre todo en la economía chilena, la más importante que ha habido en este siglo. Tuvo el mérito de anticiparse al proceso de globalización que ocurrió una década después, al cual están tratando de encaramarse todos los países del mundo, descentralizar, desregular, etc. Esa es una contribución histórica que va a perdurar por muchas décadas en Chile y que, quienes fuimos críticos con algunos aspectos de ese proceso es su momento, hoy lo reconocemos como un proceso de importancia histórica para Chile, que ha terminado siendo aceptado prácticamente por todos los sectores. Además ha pasado el test de lo que significa hacer historia, pues terminó cambiando el modo de vida de todos los chilenos, para bien, no para mal. Eso es lo que yo creo, y eso sitúa a Pinochet en la historia de Chile en un alto lugar. (Foxley en Portales, 2000)

Como observamos, los debates tienen nombres y apellidos, cuestión que dificulta aún más la crítica teórica, ya que en este sentido amistades y vínculos afectivos terminan por evitar cualquier tipo de quiebre en las relaciones personales. Las críticas se realizan en pequeños comités y no salen a la luz; quienes lo intentan se transforman en malditos y son apartados de la discusión. El discurso se hace plano. La responsabilidad teórica da paso a un conformismo que acaba por hacer de las ciencias sociales una charla de cafés y tertulias periodísticas y televisivas.

Desde luego, la maldición ha tenido pensadores herejes. No tanto por ser despreciados, sino porque sus trabajos no han formado parte de la discusión y formulación de la sociología hegemónica. Teóricos que al romper la maldición ponen en evidencia los límites estrechos 
sobre los cuales se han ido tejiendo las argumentaciones que sostienen y hacen posible que la maldición se reproduzca. Son científicos sociales que no transitan ni deambulan de las ciencias sociales a la política y de esta a los despachos de ministerios. Su pensamiento está ligado a la actividad docente o de investigación sin pretender un espacio distinto de aquel que constituye la ética del compromiso y la responsabilidad teórica con los principios defendidos. No importa que su saber sea adscripto a la escuela conservadora, marxista, neomarxista, anarquista, estructuralista o posmoderna. Los identifica su continua dedicación a la formación del conocimiento social latinoamericano. Así, sus debates se insertan en una dinámica más profunda e independiente de su adscripción política, manteniendo una honestidad intelectual sobre la cual fundamentan sus proposiciones teóricas. En algunos casos han participado políticamente en sus respectivos países, pero han abandonado el espacio político en cuanto que sus contradicciones los han hecho decidir entre intereses inmediatos y su razón ética.

No hablamos de "pureza de raza teórica", eruditos o científicos locos desconectados del mundo. Por el contrario, se encuentran apegados a un compromiso social con el análisis de su realidad y su problemática concreta. Su ortodoxia se expresa en la articulación de propuestas que se adhieren a principios de explicación cuyas causas no se hallan fuera de América Latina o en el seguimiento de modas académicas. Su heterodoxia responde a un continuo reexamen de sus propuestas y a una capacidad crítica capaz de lograr un avance en el conocimiento social no apegándose a críticas ideológicas dependientes de propuestas políticas. Sus textos se recuperan como expresión acabada de un pensamiento ético no pragmático. Su lectura no se recomienda y, si por algún motivo se realiza, es para mostrar que altos niveles de teoría llevan a una disolución práctica de la capacidad de actuación política.

El pensamiento hereje en las ciencias sociales latinoamericanas se encuentra en todas las disciplinas y es el verdadero artífice del desarrollo del conocimiento social de la realidad latinoamericana. Más que padres fundadores, son científicos sociales apegados a la terquedad de un pensamiento fundamentado en sus convicciones y no a desarrollar una lógica apegada a los designios y apetencias del poder.

Baste como ejemplo los casos de los ya desaparecidos Agustín Cueva, René Zavaleta Mercado, Pedro Vuskovic, Silva Michelena, Sergio Bagú, Gerard Pierre Charles, Julio César Jobet, Celso Furtado, Octavio Ianni, Gregorio Selser, Alberto Flores Galindo, Florestan Fernandes, Ricaurte Soler, Raúl Prébisch o José Aricó, por solo citar aquellos de mayor presencia académica. Sirva como demostración de 
lo apuntado la cita de un científico social proveniente de la economía, Raúl Prébisch, quien sin renunciar a sus principios e ideas-fuerza, concepción centro-periferia, termina señalando en su último libro, hoy ya olvidado:

Tras larga observación de los hechos y mucha reflexión, me he convencido de que las grandes fallas del desarrollo latinoamericano carecen de solución dentro del sistema prevaleciente. Hay que transformarlo. Muy serias son las contradicciones que allí se presentan: prosperidad, y a veces opulencia, en un extremo; pobreza en el otro. Es un sistema excluyente. Difícilmente pudo haberse imaginado hace algunos decenios el impulso notable de la industrialización, la capacidad, iniciativa y empuje de muchos empresarios y las crecientes aptitudes de la fuerza de trabajo. Se han alcanzado elevadas tasas de desarrollo y se está aprendiendo a exportar manufacturas contra obstáculos internos y externos que antes parecían muy difíciles de superar. Y está penetrando el progreso técnico donde tardaba en llegar, especialmente en la agricultura tradicional. Pero el desarrollo se ha extraviado desde un punto de vista social y gran parte de esas energías vitales del sistema se malogran para el bienestar colectivo. Trátese de fallas de un capitalismo imitativo. Se está desvaneciendo el mito de que podríamos desarrollarnos a imagen y semejanza de los centros. Y también el mito de la expansión espontánea del capitalismo en la órbita planetaria. El capitalismo desarrollado es esencialmente centrípeto, absorbente y dominante. Se expande para aprovechar la periferia. Pero no para desarrollarla. Muy seria contradicción en el sistema mundial. Y muy seria también en el desarrollo interno de la periferia. Contradicción entre proceso económico y proceso democrático. Porque el primero tiende a circunscribir los frutos del desarrollo a un ámbito limitado de la sociedad. En tanto que la democratización tiende a difundirlos socialmente. Y esta contradicción, esta tendencia conflictiva del sistema, tiende fatalmente a su crisis. (Prébisch, 1981: 14)

Prébisch, quien durante muchos años fuera criticado, muestra con esta reflexión un ejemplo de unidad de principios, ética y compromiso teórico, exigencia mínima que se debe poseer para el quehacer de las ciencias sociales latinoamericanas. Más allá de salvar su prestigio, Prébisch llama a repensar desde sus categorías y conceptos las contradicciones del capitalismo periférico. Si se observan sus primeros trabajos, nos damos cuenta de que su mayor conocimiento y su capacidad de debatir e intercambiar proposiciones sin dogmatismo es lo que abre la propuesta a un replanteamiento para explicar las transformaciones que se han operado desde su primera formulación hasta su visión última.

Pero a Raúl Prébisch lo maldijeron y a su obra también. Quienes antes lo alabaron, formando parte de su corte, se apresuraron a exco- 
mulgarlo. Ahora se lo recuerda como un heterodoxo de la economía que no supo o quiso adaptarse al cambio de los tiempos posmodernos. Quizás si hubiese renegado y abdicado de toda su vida intelectual señalando los errores profundos de su concepción del desarrollo latinoamericano, compartiría pedestal con los aprendices de brujo que se presentan como grandes transformistas y creadores de ilusiones para el mañana.

Lo que hay que dejar patente es que el proceso de creación intelectual que ha dado vida a las ciencias sociales latinoamericanas proviene de todos los ámbitos ideológicos sin excepción. Ni el ser marxista es símbolo de buen razonar, ni el no serlo supone la incapacidad para crear pensamiento. El problema surge cuando las crisis políticas o las transformaciones del sistema social de explotación y dominio intentan hacer coincidir crisis personales con crisis en el pensamiento sociológico. La sociología en América Latina se debate entre una necesaria renovación en las formas del pensamiento pero también de pensadores. Renovación teórica que no supone un tirar por la borda todo el conocimiento acumulado y que debe servir para fortalecer la capacidad de juicio, el sentido de la historia y la acción propedéutica.

Pues el "sano sentido común", llamado también "entendimiento común", se caracteriza de hecho de una manera decisiva por la capacidad de juzgar. Lo que constituye la diferencia entre el idiota y el discreto es que aquel carece de la capacidad de juicio, esto es, no está en condiciones de subsumir correctamente ni en consecuencia de aplicar correctamente lo que ha aprendido y lo que sabe. (Gadamer, 1979: 61)

Es en la búsqueda por recuperar la capacidad de juicio extraviada en los avatares de luchas intestinas donde se sitúa el problema. No se trata de ser el más rápido en abandonar los principios de la razón crítica para caer en los brazos del poder donde está la solución, menos aún en señalar que hay crisis de teorías; más bien existe crisis de teóricos. Bajo este campo de condiciones, y en un esfuerzo por buscar una explicación a la falta de ética política y teórica, se impone aclarar:

La tarea política del investigador social que acepta los ideales de libertad y razón es, creo yo, dedicar su trabajo a cada uno de los tres tipos de hombre que yo he distinguido en relación con el poder y la sabiduría. A los que tienen el poder y lo saben, les imputa grados variables de responsabilidad por las consecuencias estructurales que descubre por su trabajo que están decisivamente influidas por sus decisiones o por sus omisiones. A aquellos cuyas acciones tienen esas consecuencias, pero que parecen no saberlo, les atribuye todo lo que ha descubierto acerca de aquellas consecuencias. Intenta educar y después, de nuevo, 
imputa una responsabilidad. A quienes regularmente carecen de tal poder y cuyo conocimiento se limita a su ambiente cotidiano, les revela con su trabajo el sentido de las tendencias y decisiones estructurales en relación con dicho ambiente y los modos como las inquietudes personales están conectadas con problemas públicos; en el curso de esos esfuerzos, dice lo que ha descubierto concerniente a las acciones de los más poderosos. Estas son sus principales tareas educativas, y son sus principales tareas públicas cuando habla a grandes auditorios. (Wright Mills, 1977: 196-197)

El preguntarse qué piensan y cómo piensan las nuevas generaciones de científicos sociales en América Latina es algo que no inquieta demasiado a quienes, desde su pedestal y fama, se preocupan por avanzar posiciones de poder abandonando definitivamente el campo del saber teórico. Hoy nos encontramos en una disyuntiva que no es generacional o de cambio de paradigmas, sino de educar y formar científicos sociales con capacidad de razonar y pensar abiertamente más allá de falsas crisis de paradigmas y de teorías. Es hora de comenzar a romper las maldiciones del pensamiento social latinoamericano.

Si la sociología y las ciencias sociales se han desarrollado en América Latina, ha sido por esta relación que los maestros formadores imprimían a sus clases, investigaciones, obligando a leer y sobre todo a pensar. Hoy se dan recetas para no reflexionar. Se enseña a no pensar. Usted no piense, otros ya lo han hecho por usted. Su nueva función es ser ejecutivo del pensamiento, vender en el mercado, saber qué es lo que demandan las instituciones, los centros privados, las agencias gubernamentales y no gubernamentales. Conviértase en un mercader de oficio. No es necesario aprehender sociología. Maneje datos, mucha información periodística, consuma teorías de usar y tirar y mucha basura informática. Lo demás es sobrante o en el mejor de los casos florituras teóricas que no aportan. Lea manuales y haga resúmenes. Proteste si le mandan leer a los clásicos.

Así, el científico social se transforma en una persona que puede hablar de todo sin saber de nada. Ahora se requieren dotes de persuasión, no conocimientos. Este es el mensaje que se extiende, salvo excepciones que se asimilan a los herejes y malditos que aún creen en la posibilidad de un conocer humanista y formador de conciencias críticas. Entre más pronto se desvelen las maldiciones que recaen sobre la sociología latinoamericana, más temprano se estará en condiciones de romper el hechizo. 


\section{BIBLIOGRAFÍA}

Aguilar Villanueva, Luis 1987 "Recepción de la sociología en México. Una aproximación” en Textos de Ciencias Sociales (México DF: UNAM).

Castañeda, Jorge y Hett, Jorge 1978 El economismo dependentista (México DF: Siglo XXI).

Cueva, Agustín 1979 "El desarrollo de nuestras ciencias sociales en el último período" en Teoría social y procesos políticos en América Latina (México DF: Edicol).

Gadamer, Hans-Georg 1979 Verdad y método (Salamanca: Sígueme) Vol. 1.

García, Antonio 1972 Atraso y dependencia en América Latina. Hacia una teoría latinoamericana del desarrollo (Buenos Aires: Ateneo).

Portales, Felipe 2000 "Sobre el concepto de democracia experimentado por el liderazgo de la Concertación en Chile" en Cosas, 5 de mayo, disponible en <www.elclarin.cl $>$.

Prébisch, Raúl 1981 Capitalismo periférico. Crisis y transformación (México DF: Fondo de Cultura Económica).

Touraine, Alain 1993 "La sociología de la acción en América Latina" en Pozas, Ricardo H. (coord.) Las ciencias sociales en los años noventa (México DF: Instituto de Investigaciones Sociales / UNAM).

Touraine, Alain 1989 "Los problemas de una sociología propia en América Latina" en Revista Mexicana de Sociología (México DF: UNAM) $\mathrm{N}^{\circ} 3$.

Wright Mills, Charles 1977 La imaginación sociológica (México DF: Fondo de Cultura Económica).

Zavaleta Mercado, René 1979 "Bolivia: la revolución democrática de 1952 y las tendencias sociológicas emergentes" en Camacho, Daniel (comp.) Debates sobre la teoría de la dependencia y la sociología latinoamericana (San José: Educa). 



\section{Jesús Martín Barbero}

\section{PENSAR LA COMUNICACIÓN EN LATINOAMÉRICA*}

\section{AÑOS SESENTA/SETENTA: \\ LA CONSTRUCCIÓN DEL CAMPO DE ESTUDIOS}

La construcción del campo de estudios de la comunicación se inicia en América Latina en los años sesenta amalgamando procesos e ideas propias gestadas en la "Teoría de la dependencia", con la formación académica tanto norteamericana como europea de varios investigadores, y a partir de un aglutinante decisivo: la voluntad de insertar los medios de comunicación en procesos de desarrollo social y democratización política de nuestros países. Frente a la concepción funcional-difusionista propiciada por las agencias norteamericanas en esos años que, al identificar a los países latinoamericanos como subdesarrollados, ligaba el "desarrollo" directamente al crecimiento cuantitativo del número de ejemplares de periódicos vendidos o de aparatos de radio y televisión por número de habitantes, la "teoría de la comunicación" que se gestaba desde estos países proporcionó un enfoque histórico-social que hacía imposible desligar la acción de los medios de comunicación del contexto y los procesos políticos de la

* Martín Barbero, Jesús 2014 "Pensar la comunicación en Latinoamérica" en Redes.com: Revista de Estudios para el Desarrollo Social de la Comunicación, $\mathrm{N}^{\circ} 10$, pp. 21-39. 
región. Lo que en últimas puso realmente en disputa la investigación latinoamericana en sus primeros años no fue el peso de los medios en la modernización de estos países sino el sentido de la comunicación en la emancipación de nuestras sociedades. De ahí que la formación académica sobre comunicación naciera marcada por una doble función: estudiar la acción y conformación de los medios masivos, en su mayoría comerciales, buscando introducir en sus páginas y programas las voces de los actores sociales que estaban normalmente ausentes, y trabajando en la gestación de medios alternativos que en su misma conformación resultaran democráticos.

El primer hito de esa "teoría propia" fue la idea de comunicación que Paulo Freire introdujo en el inicio mismo de los años sesenta como ingrediente clave de un programa de educación de adultos, nacido en el Nordeste brasileño con el nombre de "Educación liberadora". Alfabetizar será para el adulto poder apropiarse de su lengua, de tal manera que el escribir le posibilite "contar su propia historia", o sea comunicar, participar y decidir. La pedagogía de P. Freire (1963 y 1967) se inicia con la pregunta: ¿qué es un analfabeto?, a la que respondía diciendo: analfabeto es el hombre impedido de decir su palabra, impedido de ejercer de ciudadano. Para P. Freire, la lengua no está hecha solo de sintaxis y semántica sino también de la pragmática, pues el lenguaje hace parte de la acción, incluye un programa de acción, el proceso de liberación de la palabra propia. Pues la dominación que habita el lenguaje amordaza la acción y de ahí el gusto por la palabra hueca y la palabrería que no es sino la contracara del mutismo profundo que se expresa en la ausencia de participación de las mayorías en la vida social y política.

Un segundo hito será la institucionalización del estudio de la comunicación y la investigación de los medios masivos en la Universidad Central de Venezuela llevada a cabo por Antonio Pasquali con la creación, el año 1974, del Instituto de Investigaciones de la Comunicación (ININCO) con Oswaldo Capriles, Elisabet Zafar, Luis Aníbal Gómez; y del Proyecto RATELVE que inicia el estudio sobre políticas que aseguren espacios al servicio público de comunicación. De alguna manera tanto la institucionalización de los estudios como el proyecto de políticas públicas de comunicación se apoyan en un libro pionero publicado en 1970, Comprender la comunicación de A. Pasquali, y en el que de primera mano, llegaba a Latinoamérica la teoría crítica de la Escuela de Frankfurt y el debate sobre las diferencias entre la comunicación y la información.

El tercer hito lo conforman un conjunto de voces e instituciones que van a insertar la teoría alternativa en investigaciones y propuestas políticas mediante la puesta en relación de la comunicación, la 
educación y desarrollo. Las investigaciones van a descubrir la existencia de prácticas y experiencias pioneras en el uso educativo y social de un medio masivo, la radio, el más importante y característico en sociedades que eran aun culturalmente orales: Radio Sutatenza en Colombia, creada y actuada por una organización católica; las Radios mineras de Bolivia, creadas y regidas por los sindicatos mineros y apoyadas por organizaciones religiosas y educativas tras la nacionalización del estaño; en 1950 eran 33 las emisoras asociadas. Recogiendo explícitamente el legado de dos de sus profesores norteamericanos -Everett Rogers y Wilbur Schramm- un boliviano que conocía de cerca las experiencias colombiana y boliviana, Luis Ramiro Beltrán, va a dinamizar una asociación informal con el paraguayo Díaz Bordenave, el brasileño Bosco Pinto y el uruguayo Mario Kaplun, el chileno Reyes Mata, para poner el discurso crítico en común y "en acción": en el año 1973 CIESPAL (Centro Internacional de Estudios Superiores de Periodismo) convoca en Costa Rica un primer Seminario sobre "La investigación de la Comunicación en América Latina" que sienta las bases para una investigación implicada en la creación de políticas nacionales de comunicación. Y el año 1976 se logra realizar, también en Costa Rica, la Primera Conferencia Regional de Unesco en Políticas de Comunicación. En esa Conferencia se hará visible las experiencias a partir de las cuales los latinoamericanos - Antonio Paquali y Juan Somavía-tendrán una decisiva participación en la elaboración del Informe MacBride (1978) sobre El nuevo orden mundial de la Comunicación y la Información (UNESCO, 1980).

En Chile y Argentina se configuró también un grupo de estudiosos e investigadores que marcará un hito: el que, juntando marxismo y semiología estructuralista con algunos elementos de la Teoría de la dependencia, elabora tanto una propuesta teórica como metodológica para el análisis ideológico de los mensajes en los medios masivos, que se aplicará especialmente a la prensa y la televisión. A la cabeza de ese grupo se hallaban Armand Mattelart desde Chile y Hector Schmucler desde Argentina, de cuya acción conjunta nacerá la primera revista con vocación latinoamericana: Comunicación y Cultura, cuyo subtítulo era La comunicación masiva en el proceso político latinoamericano. Contra la enorme dificultad que América Latina tenía entonces para la difusión y circulación de las revistas y los libros, Comunicación y cultura se volvió muy pronto el lugar de debates y "conversaciones" que implicaban a investigadores de todos nuestros países. Y lo mismo sucedió con la gran circulación de los libros de A. Mattelart (1970; 1973) y especialmente del que escriben A. Mattelart y A. Dorfman Para leer al Pato Donald (1974) con prólogo de H. Schmucler. 
Finalmente, el hito quizá más significativo de todos, la pronta gestación, en el año 1978, de ALAIC (Asociación Latinoamericana de Investigadores de Comunicación), y de FELAFACS (Federación Latinoamericana de Facultades de Comunicación Social) en 1981. Nacida entre Caracas y Lima, ALAIC amalgama múltiples actores y proyectos, diversos movimientos intelectuales y opciones políticas. Con ALAIC adquiere figura internacional el pensamiento latinoamericano tanto en términos de la investigación como de su representación en los diferentes foros mundiales como los convocados por AIERI-IAMCR, la UNESCO o IBERCOM. En la creación de ALAIC convergen necesidades "de comunicación" entre los diversos espacios regionales -andino, Centroamérica, el cono sur- con el exilio que arrancó de sus países a muchos investigadores del sur llevándolos hacia México y Centroamérica principalmente. Hay como un basculamiento desde el sur hacia México, país que tenía ya una larga experiencia de acoger exilados, de manera que ese país va a convertirse por una década en el polo de atracción de Instituciones Internacionales como el ILET (Instituto Latinoamericano de Estudios Transnacionales) o la FELAP (Federación Latinoamericana de Periodistas) y también como nuevo lugar de dirección y publicación de revistas como Comunicación y cultura, o del ensanchamiento latinoamericano de editoriales como Siglo XXI. Muy pobre de recursos en sus comienzos ALAIC disfrutó de una gran imaginación para reunir a sus miembros incluyendo su presencia en muchos congresos y seminarios internacionales sobre otros temas, transportando en sus valijas de mano los libros escritos por sus miembros para que circularan por fuera del país en que fueron editados. Y promoviendo una primera colección de libros que recogieron el estado de la investigación por países en Venezuela, Colombia, Perú, Chile y Argentina en un primer momento.

FELAFACS nace en Lima en 1981 con el propósito de renovar profundamente la formación profesional/universitaria de los comunicadores, mediante la creación y el desarrollo de posgrados encaminados a la actualización de los docentes. Su principal campo de acción será promover la relación, el intercambio de ideas y experiencias entre las asociaciones y facultades de comunicación social en América Latina y en otras regiones. FELAFACS impulsará tanto el acompañamiento y apoyo a las experiencias académicas de formación de comunicadores que fueran ejemplos de renovación como a la creación de pensamiento propio a través de la revista Diálogos de la Comunicación que ha llegado a su número 84.

A fines de la década de los setenta se inicia un desplazamiento del análisis de los medios hacia la comprensión de los procesos socioculturales. Y ello a partir de una complejización de los dispositivos del 
poder que devela y configura el pensamiento de M. Foucault: de meros aparatos de Estado, los medios pasan a verse mediados por procesos, prácticas y dispositivos de poder que desbordan la ideología, vinculando la función comunicativa de los medios con la gestión de los tiempos y de los cuerpos. El análisis de los discursos no es ya uno de los instrumentos sino de aquello que hace parte del cuerpo mismo del poder (Martín Barbero, 1978).

\section{AÑOS OCHENTA/NOVENTA: INVESTIGANDO LA COMUNICACIÓN DESDE LA(S) CULTURA(S)}

En los años ochenta la configuración de los estudios de comunicación muestra ya cambios de fondo, que provienen no solo ni principalmente del interior propio de ese campo sino de cambios en las ciencias sociales de Latinoamérica. Primero, los desplazamientos con que se buscará rehacer conceptual y metodológicamente el campo de la comunicación provendrán tanto de la experiencia de los movimientos sociales como de la reflexión que aportan los estudios culturales. Se inicia entonces un corrimiento de los linderos que demarcaban el campo de la comunicación: las fronteras, las vecindades y las topografías no son las mismas de hace apenas diez años ni están tan claras: desde la comunicación se comienzan a trabajar procesos y dimensiones que incorporan preguntas y saberes históricos, antropológicos, estéticos. Al mismo tiempo que la sociología, la antropología y la ciencia política empiezan a hacer cargo, ya no de forma marginal, de los medios y de los modos como operan las industrias culturales. De la sociología que investiga el lugar que ocupan los medios en las trasformaciones culturales a la tematización de los medios en los consumos y las políticas culturales. De la historia barrial de las culturas cotidianas en los sectores populares en el Buenos Aires de comienzos de siglo, a la historia de las trasformaciones sufridas por la música negra en Brasil en el recorrido que la lleva de las haciendas esclavistas a la ciudad masificada y su legitimación por la radio y el disco como música urbana y nacional. De la antropología que da cuenta de los cambios en el sistema de producción y en la economía simbólica de las artesanías a la que indaga permanencias y rupturas en los rituales urbanos del carnaval o en los juegos del alma y del cuerpo que encarnan las prácticas religiosas. $\mathrm{O}$ de las transformaciones de la comunicación en las grandes ciudades a las nuevas culturas urbanas de los jóvenes.

Hay un punto crucial del entrecruzamiento de los estudios de comunicación con la investigación social y cultural, se trata del seminario organizado por CLACSO (Consejo Latinoamericano de Ciencias Sociales) en octubre del 83, en Buenos Aires, coincidiendo con las primeras elecciones después del periodo trágico del régimen militar, y 
en el momento del regreso de un grupo grande de exiliados a la Argentina. Ese Seminario sobre comunicación y culturas populares constituirá un momento clave del diálogo y el debate de los estudiosos de la comunicación con historiadores, politólogos, analistas de los cambios culturales, críticos de arte. Y entre las muchas publicaciones que dan cuenta de lo que tuvo su punto de eclosión en aquel seminario citaremos cuatro libros cuyos títulos dan buena cuenta de lo que allí se fraguó: García Canclini y Roncagliolo, 1988; Herlinghaus y Walter, 1994; García Canclini, 1990; Brunner, 1992. Una dimensión estratégica de lo que ha cambiado se halla en la manera como lo que pasa en los medios es referido al complejo mundo de lo real social. Y de lo que es un claro ejemplo el estudio de la televisión ya no referido únicamente a su estructura comercial sino a lo que pone a ese medio en relación a la vida pública: Oscar Landi (1992).

De otra parte la globalización larvada, aún con el nombre de trasnacionalización, hace visible el conflicto entre el carácter transnacional de la estructura económica y el carácter nacional de la esfera política. Una contradicción que aparece asociada a la recomposición de las fuerzas políticas, y aun de los campos de lucha, pues dejan de estar tan nítidamente deslindados como unos años antes. Y tomar conciencia de lo anterior significaba que la época de las "grandes denuncias" - siempre necesarias_estaba dando paso a un trabajo más oscuro pero no menos arriesgado y difícil: la lucha contra la amalgama ecléctica que funcionalizaba la crítica y la lucha desde un neopositivismo-ambiente. Un neopositivismo que había dejado de ser solo de derechas y se hallaba también camuflado en el cierto pensamiento de izquierdas, como el marxismo althusseriano, que seguía reduciendo los medios, y las "nuevas" tecnologías, a "aparatos ideológicos" de la clase dominante y del Estado. Lo que implicaba desconocer lo que en esas tecnologías - satélites, antenas parabólicas, interconexiones mediáticas-empezaba a configurarse: el estratégico paso del instrumental mediático a la configuración de un nuevo modelo de sociedad, y por tanto también de un nuevo entramado político-cultural. Pues solamente puestas en relación con el modelo de sociedad es que las nuevas tecnologías dejaban ver los cambios de fondo que con ellas se iniciaba. Stuart Hall $(1981 ; 1984)$ nos ayudó a comprender su verdadero alcance: "las comunicaciones están penetrando hasta el corazón del trabajo y del sistema productivo", y ello especialmente a través de "una idea de la información en cuanto materia prima de cualquier producción" con lo que "es todo el modelo democrático occidental el que está siendo afectado por la dirección en que marcha la sociedad informatizada". Y entonces fue la relación estratégica entre cultura e industria la que se emancipó del determinismo frankfurtiano gracias 
los análisis de S. Hall (1984) y de Murdock y Golding (1985) que comenzaron a descifrar la determinación social e ideológica ya no "en términos de contenidos sino de fijación de límites e imposición de demarcaciones". Lo que hará posible investigar el otro sentido de las "estructuras de producción", esto es, en cuanto dispositivos de relación entre tecnologías, mercado y "rutinas productivas": códigos que, en cuanto sistema de operaciones tecno-discursivas, regulan el hacer del camarógrafo o el editor de TV, generando un saber que ellos adquieren ejerciendo su oficio y a través del cual se materializa un modo de ver y de contar lo que se ve. Ese nuevo horizonte del análisis fue retomado en Latinoamérica por el estudio de los usos sociales de unas tecnologías que, por primera vez no nos llegaban "de segunda mano", pero que las condiciones sociales en que vivían las mayorías les impedían acceder a ellas sin que en sus usos se introdujeran destiempo y anacronías que hacían visible la heterogeneidad de nuestras culturas, y con ellas todo lo que un mero análisis ideológico de los contenidos no lograba pensar.

Pues más que una alternativa en sí misma - fuente de idealizaciones y maniqueísmos-lo que las prácticas de comunicación popular nos develaron fue el empobrecimiento radical que la mercantilización de la vida social estaba produciendo sobre la comunicación cotidiana o festiva de las mayorías. Y frente al idealismo de una teoría de la diferencia, que colocaba las culturas indígenas en situación de exterioridad al desarrollo capitalista, y de una teoría de la resistencia que sobrevalora la capacidad de supervivencia cultural de las etnias, $\mathrm{N}$. García Canclini (1982) propuso "un camino entre dos vértigos: ni las culturas indígenas pueden existir con la autonomía pretendida por ciertos antropólogos o folcloristas, ni son tampoco meros apéndices atípicos de un capitalismo que todo lo devora".

Se configuraba así un mapa nuevo: lejos de ser mera marginalidad, lo popular constituye un espacio social, económico y simbólico, en continua lucha contra la entropía, a la vez que resulta estratégico para comprender la formación de las masas en la ciudad. Los modos populares de comunicación con la modernidad se convertían en claves de comprensión del mestizaje cultural en Latinoamérica. Pues el mestizaje no es cosa del pasado, aquel hecho racial del que vienen estos países y pueblos, sino la trama de modernidades y discontinuidades culturales, de memoria largas e imaginarios efímeros que entrelazan lo indígena con lo rural y lo rural con lo urbano, el viejo folclor con las culturas populares y lo popular con la cultura masiva que representan los medios (Martín Barbero, 1987).

Debemos a un conjunto de mujeres investigadoras el haber sabido poner en valor al medio más presente en la vida de la mayoría de la 
gente pero el más invisible para los investigadores, la radio, y desde lo que con ella hacen sus escuchas más que desde sus artimañas. Como si la "lectura de género", de la que tanto se habla hoy, hubiera comenzado en América Latina por un femenino modo de escuchar en la radio "el habla de las gentes del pueblo". En Argentina Patricia Terrero (1981) puso las bases a una historia de la radio teniendo como eje el análisis de "los espacios de continuidad" entre tradiciones populares y cultura de masa, esto es la proximidad de ciertas expresiones del imaginario nacional y popular con procesos de mitificación y creencias populares que juegan un papel clave en la formación de la identidad social y cultural de los sectores populares. Desde la tradición de los payadores o copleros la radio recoge un largo proceso de sedimentación cultural que desembocará en el discurso populista, y con él en la conformación de las masas urbanas. En Chile, Giselle Munizaga y Paulina Gutiérrez (1983) indagan la especial capacidad de la radio para hacer el enlace de la racionalidad expresivo-simbólica popular y la modernizadora racionalidad informativo-instrumental. A través de la sonoridad-voz, música, efectos—que posibilita la superposición de tiempos y tareas y la "explotación" de la expresividad coloquial, la radio no solo encauza sino que desencadena o impulsa un despliegue de una subjetividad que, al no encontrar cabida en la actividad política muy formalizada se desplaza hacia el mercado cultural. En Perú, los trabajos de Rosa María Alfaro (1987 y 1990) han trazado un mapa detallado de los modos en que la radio "capta" la densidad y la diversidad de condiciones de existencia de lo popular. La emisora popular urbana tiene un espacio propio pero bajo la dirección populista de otros sectores que lo cautelan desde fuera, pero aun así el mundo popular se hace ahí presente bajo la identidad unificante de lo criollo: concursos en que se escenifica la pobreza y las ingeniosidades de la gente, un lenguaje que lleva a la radio la fonética, el vocabulario y la sintaxis de la calle y una presencia grande de la música en que se plasma hoy el mestizaje urbano en Lima: la "chicha". En Argentina también María Cristina Mata (1987 y 1988) realizó un profundo análisis de la cotidianidad construida desde el discurso radiofónico mediante los dispositivos con que ella se construye: primero la continuidad de la jornada, lograda mediante el enlace de unas voces que "leen" para su audiencia el acontecer diario; y segundo, continuidad en el tiempo de los locutores y los oyentes, una memoria que junta a los vecinos interpelados por la radio como integrantes de una comunidad barrial y unos usuarios y demandantes de servicios e instituciones públicas. Y en Brasil, Maria Immacolata Vasallo (1988) investigó las representaciones expresivas de los sectores populares en ciertos programas producidos por narradores que llevaban a la radio el lenguaje de la mayoría urbana vertién- 
dolo en narrativas de corte policial o novela negra, en las que emergen situaciones y estilos de vida de las poblaciones más marginales, y que a su vez proceden del periodismo y la crónica roja.

El estudio de la televisión en América Latina también va a desbordar pronto el análisis de sus contenidos para insertarse en el estudio de su papel en las transformaciones de la vida urbana, pues países que había llegado a los años sesenta con la mayoría de su población en el campo vivían acelerados procesos de desplazamiento de las mayorías a las ciudades. Uno de los primeros estudiosos de esa relación entre cine, televisión y ciudad fue el mexicano Carlos Monsiváis (1988 y 1995) al dar visibilidad al juego cultural y comunicativo de las sensibilidades y sentimentalidades de las masas urbanas hecha con poéticas musicales desde la ranchera hasta el tango y con melodramas del cine y la televisión. Pues en pocos años el melodrama televisivo latinoamericano, la "telenovela", se convirtió no solo en un fenómeno comercial fabuloso-especialmente en México y Brasil, Colombia y Venezuela-sino en una producción cultural cuyo éxito exigió una lectura en profundidad de los mestizajes narrativos, sociales y políticos que operan en la telenovela. Hay mucho más que dominación a analizar en un melodrama moderno hecho de complicidades, resistencias e invenciones, de viejas moralidades familiares y nuevos contextos de conflictividad y rebeldías, de un denso reconocimiento cultural de los humillados y excluidos cuya verdad constituye un profundo desafío a las estéticas de los eruditos y a las éticas intelectualizadas (Ortiz, 1989; Martín Barbero y Muñoz, 1992; Vasallo, 2002).

La cuestión de las audiencias o de la recepción y el consumo de medios se va a convertir en un ámbito de investigación cada vez más densa desde comienzos de los noventa. Se trata de una investigación que rebasa los paradigmas tanto el de la transmisión como el de los efectos, exigiendo un acercamiento transdisciplinar capaz de asumir su envergadura histórica y antropológica. Desde el punto de vista conceptual lo que moviliza el estudio es el análisis de las mediaciones -socioeconómicas, político-culturales y técnicas- que regulan las formas del consumo y las modalidades de la recepción. Pues se trata de hacer emerger las figuras y el porqué del re-conocimiento que los públicos populares experimentan evidenciando un nosotros hasta ahora desconocido por la investigación de la comunicación (Orozco, 1991, 1994; De Sousa, 1995; Jacks, 2011).

Y la otra línea de estudio en esos años fueron las relaciones de la comunicación con la política, pasando del análisis de la política como contenido de los medios al nuevo lugar, estratégico, de la comunicación en los procesos y las prácticas políticas. Pioneros en ese campo fueron los estudios del argentino Nicolás Casullo (1985) al re- 
colocar las cuestiones de fondo: qué están significando para la política las transformaciones tecnológicas de los medios al fragmentar las audiencias y rehacer los modos de circulación de la información y de formación de la opinión pública. Desde el otro lado, el estallido brutal de una tubería que semidestruyó un barrio popular muy poblado de la ciudad de Guadalajara, en México, fue tomado por Rossana Reguillo (1996) para investigar desde abajo, desde la irrupción del miedo en la vida cotidiana de miles de personas y la interrupción de todos los servicios públicos, tanto la movilización inmediata de la solidaridad entre los pobres como la tardía e incapaz participación de las instituciones públicas de la ciudad. Y mientras la desconfianza de la gente en la política se acrecienta crecen las figuras de protección basadas en la eficacia simbólica de los mitos y los rituales. Este último aspecto será retomado por la investigadora mexicana (2000) en una de las primeras investigaciones etnográficas sobre las formas de comunicación entre los jóvenes y de ellos con la sociedad; y unos años después (2006) sobre las desubicaciones de la política ante las nuevas inseguridades sociales y las nuevas visibilidades ciudadanas. Desde Colombia, German Rey (1998) estudia las nuevas massmediaciones de la política: el nuevo lugar de los nuevos y las tecnologías al convertirse en escenarios cruciales de la vida pública. De un lado se trata de investigar la reconfiguración conceptual de "lo público" como "lo común a todos, en cuanto difundido, hecho público" proveniente de H. Arendt y R. Sennet, y a su vez las relaciones entre el interés común, el espacio ciudadano y la interacción comunicativa. Lo que se traduce en el reconocimiento de nuevos derechos de los ciudadanos: a ser informados pero también poder informar, a ser escuchados y poder hablar, a hacerse visibles en toda la gama de las desigualdades sociales y las diversidades culturales. Unos años después (2009) lo que marca la agenda de investigación será la nueva complejidad de las políticas públicas en el cruce de las comunicaciones con las nuevas culturas.

\section{CAMBIO DE SIGLO: GLOBALIZACIÓN Y MUTACIÓN TECNOCULTURAL DE LA COMUNICACIÓN}

La globalización no es un puro avatar de la economía y el mercado sino un movimiento que, al hacer de la comunicación y la información la clave de un nuevo modelo de sociedad, empuja todas las sociedades hacia una intensificación de sus contactos y sus conflictos, exponiendo todas las culturas unas a otras como jamás antes lo estuvieron. De ahí que la ubicación del estudio de la comunicación en los nuevos escenarios esté implicando desconcertantes desafíos, como el que entraña pensar el denso espesor sociocultural de la mediación tecnológica no solo de la comunicación sino de la producción e incluso de 
la sociedad en su conjunto. Pues las trasformaciones de la tecnología remiten hoy más que a la novedad de unos aparatos a nuevos modos de percepción y de lenguaje, a nuevas sensibilidades y escrituras. Estamos ante una mutación cultural que implica la asociación del nuevo modo de producir con un nuevo modo de comunicar que convierte al conocimiento en fuerza productiva directa. Lo que en el mundo de la comunicación cambia hoy es haberse convertido en el eje de una mutación tecnocultural que afecta a nuestras sociedades desde dentro y por entero. Pero como repite una y otra vez Manuel Castells (1997, 31-32) "la tecnología no determina a la sociedad: la plasma. Y plasma especialmente su capacidad de transformarse. La tecnología es sociedad y esta no puede ser comprendida o representada sin sus herramientas técnicas".

Lo que la comunicación nos está exigiendo pensar es la hegemonía de una razón comunicacional cuyos dispositivos - la fragmentación que disloca y descentra, el flujo que globaliza y comprime, la conexión que desmaterializa e hibrida- agencian el devenir del mercado de la sociedad. Y lo que desde Latinoamérica se está buscando pensar es justamente la hegemonía comunicacional del mercado en la sociedad: la comunicación convertida en el más eficaz motor del desenganche e inserción de las culturas -étnicas, nacionales o locales-en el espacio/tiempo del mercado. En el mismo sentido estamos necesitando pensar el lugar estratégico que ha pasado a ocupar la comunicación en la configuración de los nuevos modelos de sociedad.

Ello está exigiéndonos distinguir dos proyectos muy diferentes. Uno que, partiendo de la envergadura económico-cultural que han adquirido las tecnologías audiovisuales e informáticas en los acelerados procesos de globalización, busca hacerse cargo de las tecnologías a la hora de construir políticas culturales que hagan frente a los efectos desocializadores del neoliberalismo e inserten explícitamente las industrias culturales en la construcción económica y política de la región. El otro resulta de la combinación del optimismo tecnológico con el más radical pesimismo político, y lo que busca es legitimar, tras el poder de las tecnologías, la omnipresencia mediadora del mercado. Pervirtiendo el sentido de las demandas políticas y culturales, que encuentran de algún modo expresión en las trasformaciones tecnológicas, se deslegitima cualquier cuestionamiento de un orden social al que solo el mercado y las tecnologías permitirían darse forma. Pero, ¿cómo asumir entonces el espesor social y perceptivo que hoy revisten las tecnologías comunicacionales, sus modos transversales de presencia en la cotidianidad desde el trabajo al juego, sus espesas formas de mediación tanto del conocimiento como de la política, sin ceder al realismo de lo inevitable que produce la fascinación tecnológica, y su 
complicidad neoliberal con el mercado como único principio organizador de la sociedad en su conjunto?

Desde la sociología de la cultura, Renato Ortiz (1994 y 2006) introduce la necesidad de diferenciar las lógicas unificantes de la globalización económica de las que mundializan la cultura. Pues la mundialización cultural no opera desde un afuera sobre esferas dotadas de autonomía como lo nacional o lo local. La mundialización es un proceso que se hace y deshace incesantemente. Y ello hace imposible hablar de una cultura-mundo que se situaría por encima de las culturas nacionales o locales. La mundialización no puede confundirse con la estandarización de los diferentes ámbitos de la vida que fue lo que produjo la industrialización, incluido el ámbito de la cultura, esa "industria cultural" que fue el objeto de análisis de la Escuela de Frankfurt. Ahora nos encontramos ante otro tipo de proceso, que se expresa en una cultura de la modernidad-mundo, que es una nueva manera de estar en el mundo. De la que hablan los hondos cambios producidos en el mundo de la vida: en el trabajo, la pareja, la comida, el ocio. Es porque la jornada continua ha hecho imposible para millones de personas almorzar en casa, y porque cada día más mujeres trabajan fuera ella, y porque los hijos se autonomizan de los padres muy tempranamente, y porque la figura patriarcal se ha devaluado tanto como se ha valorizado el trabajo de la mujer, que la comida ha dejado de ser un ritual que congrega a la familia. Y desimbolizada, la comida diaria ha encontrado su forma en el fast-food. De ahí que el éxito de McDonald's o de las pizzas Hut hable menos de la imposición de la comida norteamericana que de los profundos cambios en la vida cotidiana de la gente, cambios que esos productos sin duda expresan y rentabilizan. Pues desincronizada de los tiempos rituales de antaño y de los lugares que simbolizaban la convocatoria familiar y el respeto a la autoridad patriarcal, los nuevos modos y productos de la alimentación "pierden la rigidez de los territorios y las costumbres convirtiéndose en informaciones ajustadas a la polisemia de los contextos". Reconocer eso no significa desconocer la creciente monopolización de la distribución, o la descentralización que concentra poder y el desarraigo empujando la hibridación de las culturas. Ligados estructuralmente a la globalización económica pero sin agotarse en ella, se producen fenómenos de mundialización de imaginarios ligados a músicas, a imágenes y personajes que representan estilos y valores desterritorializados y a los que corresponden también nueva figuras de la memoria.

Desde la geografía política, Milton Santos, ya en 1996, planteó cómo la ausencia de categorías analíticas mantiene a las ciencias sociales ancladas en el eje del Estado-nación cuando lo que estamos necesitando pensar ahora es el mundo, esto es el paso de la interna- 
cionalización a la mundialización. Y no porque esa categoría y esa sociedad no sigan teniendo vigencia - la expansión y exasperación de los nacionalismos de toda laya así lo atestigua - sino porque el conocimiento acumulado sobre lo nacional responde a un paradigma que no puede ya dar cuenta ni histórica ni teóricamente de toda la realidad en la que se insertan hoy individuos y clases, naciones y nacionalidades, culturas y civilizaciones. Y en su último libro publicado en vida, el año 2004, su pensamiento expone una desafiante visión de la globalización a la vez como perversidad y como posibilidad: esa paradoja cuyo vértigo amenaza con paralizar tanto el pensamiento como la acción capaz de transformar su curso. Pues de un lado la globalización fabula el proceso avasallador del mercado, un proceso que al mismo tiempo que uniforma el planeta profundiza las desigualdades pues lo desune cada día más. De ahí la perversidad sistémica que implica y produce el aumento de la pobreza y la desigualdad, del desempleo tornado ya crónico, de enfermedades que, como el sida, se tornan epidemia devastadora en los continentes no más pobres sino más saqueados. Pero la globalización representa también un conjunto extraordinario de posibilidades, cambios ahora posibles que se apoyan en hechos radicalmente nuevos entre los que sobresalen dos: uno, la enorme y densa mezcla de pueblos, razas, culturas y gustos que se producen hoy-aunque con grandes diferencias y asimetrías-en todos los continentes, una mezcla posible solo en la medida en que emergen con mucha fuerza cosmovisiones otras que ponen en crisis la hegemonía del racionalismo occidental; y el otro, unas nuevas tecnologías que están siendo crecientemente apropiadas por grupos de los sectores subalternos posibilitándoles una verdadera "revancha sociocultural", esto es la construcción de una contrahegemonía a lo largo y ancho del mundo. Ese conjunto de posibilidades abre la humanidad por primera vez en la historia a una "universalidad empírica" y de ahí a una nueva narrativa histórica. Pero la construcción de esa narrativa pasa por una "mutación política", un nuevo tipo de utopía capaz de asumir la envergadura de los siguientes desafíos:

- La existencia de un nuevo sistema técnico a escala planetaria que transforma el uso del tiempo al producir la convergencia y simultaneidad de los momentos en todo el mundo.

- El atravesamiento de las viejas tecnologías por las nuevas llevándonos de una influencia puntual - por efectos de cada técnica aisladamente como lo fue hasta ahora- a una conexión e influencia transversal que afecta directa o indirectamente al conjunto de cada país. 
- Lo que implica la actual mediación de la política, pues si la producción se fragmenta como nunca antes por medio de la técnica, nunca fue más fuerte la unidad política que articula las fases y comanda el conjunto a través de una poderosa "unidad de motor" que deja atrás la pluralidad de motores y ritmos con los que trabajaba el viejo imperialismo. El nuevo tipo de motor que mueve la globalización es la "competitividad exponencial" entre empresas de todo el mundo "exigiendo cada día más ciencia, más tecnología y mejor organización".

- La peculiaridad de la crisis que atraviesa el capitalismo reside entonces en el entrechoque continuo de los factores de cambio que ahora rebasan las viejas gradaciones y mensurabilidades desbordando territorios, países y continentes.

- Ese entrechoque, hecho de una extrema movilidad de las relaciones y una gran adaptabilidad de los actores reintroduce "la centralidad de la periferia", no solo en el plano de los países sino de lo social marginado por la economía y ahora recentrado como "la nueva base en la afirmación del reino de la política".

Desde la antropología y la crítica cultural N. García Canclini (1999) inicia una propuesta de agenda sobre la interculturalidad, pues ella nombra tanto la densidad de los conflictos sociales como la densidad de los intercambios que viven las etnias, las regiones y las naciones; y nombra también el lugar epistémico desde el que abarcar conflictos e intercambios comprensivamente, que continuará (2006) enfrentando las polémicas y los malentendidos que se producen cuando se pretenden solucionar las indiluibles desigualdades sociales con la sola defensa de la diferencia cultural, y también cuando se pretende explicar desde el ámbito socioeconómico la densidad simbólica de los problemas y los derechos culturales. Lo que le exigirá una puesta de lo latinoamericano en el mundo, (2002) ligando explícitamente la cuestión de la globalización a la pregunta que mira tanto hacia las transformaciones del mundo como a las inercias mentales que arrastran aún la visión folclórica o su contraria la de un pesimismo determinista.

Entonces, tanto o más que objetos de políticas, las tecnologías de la comunicación, la información y la cultura constituyen hoy un campo primordial de batalla política: el estratégico escenario que le exige a la política recuperar su dimensión simbólica — su capacidad de representar el vínculo entre los ciudadanos, el sentimiento de pertenencia a una comunidad- para enfrentar la erosión del orden colectivo. Que es lo que no puede hacer el mercado por más eficaz que sea su simulacro. 
Al llegar al balance final de este mapa trazado a mano alzada debo dejar constancia de tres nombres que escapan tanto a las cronologías como a las temáticas. Eliseo Verón, que fue el pionero en el análisis complejo de los discursos mediáticos y en hacer emerger la figura del sujeto/receptor activo en el proceso de comunicación $(1969,1988)$ hasta sus últimos trabajos sobre la cultura visual y el concepto de agenda (2002). Aníbal Ford, proveniente del mundo de la producción editorial y periodista, entra en el estudio de la comunicación a mediados de los ochenta con su libro sobre culturas populares (1985) para ponerlas después en relación con las culturas y las narrativas electrónicas desde un análisis que entrelaza la estética con la política (1994) y culmina en un estudio fuertemente crítico de la globalización (1999) cuyo título suena a apocalíptico sin que el libro lo sea. Y José Márquez de Melo, investigador y hombre de acción, fundó y presidió INTERCOM, la Sociedad Brasilera de Estudos da Comunicação, ha sido el presidente más duradero de ALAIC, y gestiona un centro de estudios dedicado a valorar el pensamiento latinoamericano en Comunicación; de ahí que desde sus comienzos (1974) hasta su más reciente publicación (2008) los paradigmas propios de la investigación latinoamericana, y sus limitaciones, hayan sido su tema y su obsesión.

\section{BIBLIOGRAFÍA}

Alfaro, R. Ma. 1987 De la conquista de la ciudad a la apropiación de la palabra (Lima: Tarea).

Alfaro, R. Ma. 1990 Cultura de masas y cultura popular en la radio peruana (Lima: Calandria/Tarea).

Beltrán, L. R. 1976 "Premisas, objetos y métodos foráneos en la investigación sobre comunicación en Latinoamérica" en Chasqui (Quito) $\mathrm{N}^{\circ} 1$.

Beltrán, L. R. 1976 La investigación en comunicación en Latinoamérica: ¿indagación con anteojeras? (Caracas) mimeo.

Brunner, J. J. 1992 América Latina: cultura y modernidad (México: Grijalbo).

Brunner, J. J. y Catalán, C. C. A. 1989 Chile: transformaciones culturales y conflictos de la modernidad (Santiago: Flacso).

Canclini, N. G. 1982 Las culturas populares en el capitalismo (México: Nueva Imagen).

Canclini, N. G. 1990 Culturas híbridas (México: Grijalbo).

Canclini, N. G. (edit.) 1994 Políticas culturales en América Latina (México: Grijalbo). 
Canclini, N. G. 1999 La globalización imaginada (Barcelona: Paidós).

Canclini, N. G. 2002 Latinoamericanos buscando lugar en este siglo (Buenos Aires: Paidós).

Canclini, N. G. 2006 Diferentes, desiguales y desconectados (Barcelona: Gedisa).

Canclini, N. G. y Roncagliolo, R. (eds.) 1988 Cultura trasnacional y cultural populares (Lima: IPAL).

Castells, M. 1997 La sociedad red. Vol. 1: La era de la Información (Madrid: Alianza).

Casullo, N. (edit.) 1985 Comunicación: la democracia difícil (Buenos Aires: ILET/Folios).

Da Matta, R. 1981 Carnavais, malandros, heróis (Río de Janeiro: Zahar).

De Mello, J. M. 1974 Comunicação social: teoria e pesquisa (Petrópolis: Vozes).

De Mello, J. M. 1998 Teoria de a comunicação: paradigmas latinoamericanos (Petrópolis: Vozes).

De Mello, J. M. 2008 História Política das Ciências da Comunicação (Río de Janeiro: Editora Mauad X).

De Sousa, M. W (org.) 1995 Sujeito, o lado escuro do receptor (San Pablo: Brasiliense).

Ford, A. 1985 Medios de comunicación y cultura popular (Buenos Aires: Legasa).

Ford, A. 1994 Navegaciones: comunicación, cultura y crisis (Buenos Aires: Amorrortu).

Ford, A. 1999 La marca de la bestia: identificación, desigualdades e infoentretenimiento en la sociedad contemporánea (Buenos Aires: Norma).

Freire, P. 1963 Alfabetização e conscientização (Porto Alegre: Editora Emma).

Freire, P. 1967 Educação como prática da liberdade (San Pablo: Paz e Terra).

Golding, P. 1985 "Capitalismo, comunicaciones y relaciones de clase" en Murdock, G. y Golding, P. (eds.) Sociedad y comunicación de masas (México: FCE).

Gutiérrez, L. y Romero, L. A. 1985 Sectores populares y cultura política (Buenos Aires: Sudamericana).

Hall, S. 1981 "La cultura, los medios de comunicación: el efecto ideológico" en Curran, J.; Gurevitch, M. y Woollacott, J. (eds.) Sociedad y comunicación de masas (México: FCE).

Hall, S. 1984 "Estudios culturales: dos paradigmas" en Hueso (Lima) $\mathrm{N}^{\circ} 19$. 
Herlinghaus, H. y Walter, M. 1994 Posmodernidad en la periferia: enfoques latinoamericanos de la teoría cultural (Berlín: Langer Verlag).

Jacks, N. (coord.) Análisis de la recepción en América Latina (Quito: Ciespal).

Kaplun, M. 1973 La comunicación de masas en América Latina (Montevideo: Ediciones Paulinas).

Kaplun, M. 1988 Una pedagogía de la comunicación (Madrid: La Torre).

Landi, O. 1992 Devórame otra vez: qué hizo la televisión con la gente, qué hace la gente con la televisión (Buenos Aires: Planeta).

MacBride, S. / UNESCO 1980 Un solo mundo, voces múltiples: comunicación e información en nuestro tiempo (México: FCE).

Martín Barbero, J. 1978 Comunicación masiva, discurso y poder (Quito: Ciespal).

Martín Barbero, J. 1987 De los medios a las mediaciones (Barcelona: Gustavo Gili).

Martín Barbero, J. y Muñoz, S. 1992 Televisión y melodrama (Bogotá: Tercer Mundo).

Martín Barbero, J. y Rey, G. 1999 Los ejercicios del ver (Barcelona: Gedisa).

Mata, Ma. C. 1987 Cuando la comunicación puede ser sentida como propia, una experiencia de radio popular, en Comunicación y culturas populares (México: Gustavo Gili).

Mata, Ma. C. 1988 "Radios y públicos populares" en Diálogos de la Comunicación (Lima) No 19.

Mattelart, A. 1970 La ideología de la dominación en una sociedad dependiente (Buenos Aires: Signos).

Mattelart, A. 1973 La comunicación masiva en el proceso de liberación (Buenos Aires: Siglo XXI).

Mattelart, A. y Dorfman, A. 1974 Para leer al Pato Donald (Buenos Aires: Siglo XXI).

Monsiváis, C. 1988 Escenas de pudor y liviandad (México: Grijalbo).

Monsiváis, C. 1995 Los rituales del caos (México: Ediciones Era).

Orozco, G. 1991 Recepción televisiva. Tres aproximaciones para su estudio (México: Univ. Iberoamericana).

Orozco, G. 1994 Televidencia. Perspectivas para el análisis de la recepción televisiva (México: Univ. Iberoamericana).

Ortiz, R. (coord.) 1989 Telenovela: história e produção (San Pablo: Brasiliense). 
Ortiz, R. 1994 Mundialização e cultura (San Pablo: Brasiliense).

Ortiz, R. 2006 Mundialização: saberes e crenças (San Pablo: Brasiliense).

Pasquali, A. 1970 Comprender la comunicación (Caracas: Monte Ávila).

Reguillo, R. 1996 La construcción simbólica de la ciudad: sociedad, desastre, comunicación (Guadalajara: Iteso).

Reguillo, R. 2000 Estrategias del desencanto. Emergencia de culturas juveniles (Buenos Aires: Norma).

Rey, G. 1998 Balsas y medusas: visibilidad comunicativa y narrativas políticas (Bogotá: Fescol).

Rey, G. 2009 Industrias culturales. Creatividad y desarrollo (Madrid: AECI).

Santos, M. 1996 A natureza do espaço (San Pablo: Hucitec).

Santos, M. 2004 Por otra globalización (Bogotá: CAB).

Sodré, M. 1983 A verdade seduzida. Por um conceito de cultura no Brasil (Río de Janeiro: Codecrí).

Squef, E. y Wisnik, J. M. 1983 O nacional e o popular na cultura brasileira: música (San Pablo: Brasiliense).

Terrero, P. 1981 El radioteatro (Buenos Aires: CEAL).

Vassallo, M. I. 1988 La radio de los pobres: estudio de comunicación de masas, ideología y marginalidad social (San Pablo: Edições Loyola).

Vassallo, M. I. (coord.) 2002 Vivendo com a Telenovela (San Pablo: Summus).

Verón, E. 1969 Ideología y comunicación de masas (Buenos Aires: Nueva Visión).

Verón, E. 1988 La semiosis social (Barcelona: Gedisa).

Verón, E. 2002 Espacios mentales: Efectos de agenda 2 (Barcelona: Gedisa).

VV. AA. 1987 Comunicación y culturas populares en Latinoamérica (México: G. Gili). 


\section{SOBRE LOS AUTORES}

\section{FRANCISCO AYALA}

\section{(GRANADA, 1906-MADRID, 2009)}

Pertenece, junto a José Medina Echavarría y a Luis Recasens Siches, a la generación de la sociología del exilio republicano español. Se graduó en Derecho en la Universidad de Madrid en 1929. Tras licenciarse consiguió una beca para estudiar Derecho Político en la Universidad de Berlín junto a Herman Heller. Tras esa estancia para ampliar estudios, se doctoró en Derecho, ganó las oposiciones a Letrado de las Cortes republicanas y, más tarde, a catedrático de Derecho Político en la Universidad de Madrid, cargo en el que permaneció hasta 1936. Por esos años fue colaborador de la Revista de Occidente, de la Gaceta Literaria y de la colección de Sociología de la Revista de Derecho Privado. Durante los años de la Guerra Civil española, entre 1936 y 1939, sirvió como funcionario de la República en tareas diplomáticas en la legación de España en Praga. Llegó exiliado a Argentina en el año 1939 y desde 1940 fue miembro titular del Instituto Argentino de Filosofía Jurídica y Social. Fue traductor para la editorial Losada, dirigiendo además su colección "Biblioteca de Sociología" desde 1941. Colaboró también en la editorial Sudamericana. En la Universidad Nacional del Litoral se hizo cargo de la cátedra de Sociología hasta 1943. Además, en esos años, participó en el Instituto de Sociología de la Facultad de 
Filosofía y Letras de la Universidad de Buenos Aires, fundado por Ricardo Levene en 1941. Allí coincidió con sociólogos argentinos como Alberto Baldrich, Jordán B. Genta, Raúl Orgaz o Alfredo Poviña, y con los italianos Gino Germani y Renato Treves. Fundó en esa época la revista Realidad. Revista de ideas y participó, asimismo, en la revista jurídica La Ley, en la revista Sur y en el diario La Nación. Marchó a Brasil en 1945 para dar un curso de sociología para altos funcionarios en Río de Janeiro, regresando a Buenos Aires en 1946, año en que dicta un curso de Sociología en el Colegio Libre de Estudios Superiores. En 1950 se trasladó a San Juan de Puerto Rico, en cuya universidad enseñó Sociología, además de dirigir el departamento editorial y crear una nueva revista, La Torre. Las dos últimas décadas de su exilio, hasta su regreso definitivo a España en 1976, transcurrieron en Estados Unidos, donde ejerció como profesor de literatura en diversas universidades, como la de Princeton, Chicago y Nueva York. Ayala es autor de una extensa obra ensayística y literaria en la que caben, a su vez, la reflexión teórica y la mirada sociológica. Algunas de sus obras más representativas de su sociología, de su ensayismo social y de su particular impronta hispanoamericana, son, Razón del mundo: un examen de conciencia intelectual, de 1944; Tratado de Sociología, de 1947; Los usurpadores, de 1949; Ensayos de sociología política, de 1952; Introducción a las Ciencias Sociales, de 1952; Historia de macacos, de 1955; o La integración social en América, de 1958. Ayala obtuvo el Premio Nacional de Literatura en 1983. En 1984 ingresó en la Real Academia Española. Su rica y extensa obra literaria fue distinguida con los premios Cervantes, en 1991, y el Príncipe de Asturias de las Letras, en 1998. En los últimos años han aparecido publicados varios volúmenes de sus Obras completas y la Fundación Francisco Ayala, creada en 1998, difunde el legado vivo de este gran intelectual y literato, pero también fino sociólogo.

\section{JOSÉ MEDINA ECHAVARRÍA}

\section{(CASTELLÓN DE LA PLANA, 1903-SANTIAGO DE CHILE, 1977)}

Sociólogo del exilio republicano español, es considerado, junto con Gino Germani y Florestan Fernandes, uno de los institucionalizadores más destacados de la disciplina en América Latina al abrir perspectivas y al haber formado a las primeras generaciones de científicos sociales de la región. Medina Echavarría recibió su doctorado en Derecho por la Universidad de Madrid en 1929. En 1930 viajó a la Universidad de Marburgo (Alemania), donde completó su formación y se interesó, principalmente, por la sociología comprensiva alemana, el historicismo y la fenomenología, corrientes que irá incorporando progresivamente en sus inquietudes intelectuales y que 
tratará de difundir en lengua castellana. En 1932 accedió al cuerpo de letrados del Congreso de los Diputados de la recién instaurada Segunda República. Obtiene en 1935 una cátedra de Filosofía del Derecho en la Universidad de Murcia. Fue encargado entre 1933 y 1936 de la colección de Sociología de la editorial de la Revista de Derecho Privado, dirigida por Adolfo Posada. Durante los años de la Guerra Civil española, entre 1936 y 1939, sirvió como funcionario de la República en tareas diplomáticas en la legación de España en Varsovia. Llegó exiliado a México en 1939. En ese país permaneció hasta 1946, período de tiempo en el que contribuyó a la difusión e institucionalización del pensamiento sociológico desde una cátedra de Sociología en la Facultad de Derecho de la UNAM, desde la Sección de Sociología del Fondo de Cultura Económica y desde el Centro de Estudios Sociales de El Colegio de México, inaugurado en 1943. Entre 1946 y 1952 se desempeñó como catedrático de Sociología en la Facultad de Ciencias Sociales de la Universidad de Puerto Rico. En 1952 es reclutado por el economista argentino y secretario de la CEPAL, Raúl Prébisch, para incorporarse a este organismo internacional localizado en Santiago de Chile. Entre 1957 y 1959 Medina Echavarría dirigió la primera Escuela Latinoamericana de Sociología (ELAS) de la recién creada FLACSO. En 1963 asume la dirección de la División de Planificación Social del ILPES. Allí formó un nutrido grupo de investigación en el que destacaron, entre otros nombres, los de Enzo Faletto y Fernando H. Cardoso. En los últimos años de su vida actuó como consultor externo de la CEPAL. Medina Echavarría, que también fue un destacado editor y traductor, es autor de una importante y extensa obra sociológica caracterizada, de forma sucinta, por recorrer las etapas de maduración e institucionalización del pensamiento sociológico latinoamericano. Así, por ejemplo, su Sociología: teoría y técnica, de 1941, La sociología como ciencia social concreta, de 1946, o sus Presentaciones y planteos, de 1953, abrieron la etapa de la sociología científica en América Latina y ayudaron a sentar las bases teóricas y epistemológicas de la disciplina. Posteriormente, durante sus años santiaguinos, publicó varios libros importantes, de los cuales descuellan Aspectos sociales del desarrollo económico, de 1959; Consideraciones sociológicas sobre el desarrollo económico, de 1964; Filosofía, educación y desarrollo, de 1967; y Discurso sobre política y planeación, de 1972. Son textos que constituyeron un aporte fundamental a la sociología del desarrollo latinoamericano, como lograron, a su vez, insertar la reflexión por la democracia en un complejo contexto histórico y político en la región. 


\section{JUAN FRANCISCO MARSAL (BARCELONA, 1928-1979)}

Llegó a Argentina en 1954 como licenciado en Derecho y Ciencias Políticas por la Universidad de Barcelona. Fue miembro de la primera generación de sociólogos formados por Gino Germani en la Universidad de Buenos Aires, en la que aparecen nombres como los de Torcuato Di Tella, Jorge Graciarena, Miguel Murmis, Ruth Sautu, Inés Izaguirre, Juan Carlos Marín o Eliseo Verón. En 1961 se doctoró en Derecho en la Universidad de Barcelona con la tesis La sociología en la Argentina, dedicada a reflexionar sobre la institucionalización y las escuelas de conocimiento de la sociología argentina. Entre 1962 y 1965 asistió a la Universidad de Princeton y escribió su tesis doctoral de sociología, titulada The Image of a Changing Latin American: a Sociological Criticism of some Current American and Latin American Models. Decidió volver a Argentina tras su paso académico por los Estados Unidos. En aquel país llegaría a ser investigador de carrera, catedrático de Sociología en la Universidad de Salvador de Buenos Aires y, posteriormente, director entre 1966 y 1970 del Centro de Investigaciones Sociales y de la Revista Latinoamericana de Sociología, ambos pertenecientes al Instituto Torcuato di Tella de Buenos Aires. También ejerció como profesor e investigador visitante de la Universidad Nacional Autónoma de México y de El Colegio de México. Regresó a España en 1972. Fue catedrático de Sociología y director del Departamento de Sociología en la Universidad Autónoma de Barcelona. Además fue miembro creador y director de la revista Papers, gran referente de la literatura sociológica española. También fue miembro fundador de la Associació Catalana de Sociología, lo que le convirtió, a la postre, en uno de los máximos impulsores de la sociología en Cataluña. Marsal desarrolló una obra marcada por la reflexión sobre el estado vital de las ciencias sociales latinoamericanas, contenida en libros como Cambio social en América Latina, de 1967; La crisis de la sociología norteamericana, de 1977; y Dependencia e independencia. Las alternativas de la sociología latinoamericana en el siglo XX, de 1979. Además realizó valiosas aportaciones en torno al método biográfico y a la sociología de los intelectuales. En ese sentido, destacan sus libros Hacer la América: autobiografía de un inmigrante español en la Argentina, de 1969; El intelectual latinoamericano. Un simposio sobre sociología de los intelectuales, de 1970; Los intelectuales politicos, de 1971; y La sombra del poder. Intelectuales y política en España, Argentina y México, de 1975. 


\section{IGNACIO SOTELO \\ (MADRID, 1936)}

Estudió Bachillerato en el Liceo Francés de Madrid. Entre 1953 y 1958 estudia Derecho y Filosofía y Letras en la Universidad Central de Madrid. En 1957 es procesado por el régimen franquista por asociación ilegal. En 1959 sale clandestinamente de España, exiliándose primero en Francia y después en la República Federal de Alemania. Entre 1960 y 1965 estudió filosofía y sociología en la Universidad de Colonia con los profesores Ludwig Langrebe y René König. En 1965 obtuvo el doctorado en Sociología por esa universidad alemana con una tesis sobre Jean Paul Sartre. Entre 1966 y 1973 se dedicó a investigar y a enseñar en distintas universidades de Ecuador, México y Perú. Por ejemplo, en 1969 fue profesor visitante en la Facultad de Ciencias Políticas de la UNAM y entre 1970 y 1971 realizó trabajo de campo en distintos países de la región. Aquella experiencia la volcaría en su importante libro Sociología de América Latina: estructuras y problemas, de 1975. Su interés por la región continuaría manifiesto en su obra América Latina: un ensayo de interpretación, de 1980. De hecho, Sotelo había participado en 1970 en la fundación del Instituto de Estudios Latinoamericanos de la Universidad Libre de Berlín, al cual estuvo ligado durante varias décadas. En esa universidad además sería catedrático de Ciencia Política desde 1973 hasta 1998. Desde 1990 compatibilizó esa cátedra con una de Sociología en la Universidad Autónoma de Barcelona, hasta su excedencia en 1996. Respecto a su actividad política y pública, Sotelo es miembro del PSOE, al que se incorporó durante la dictadura franquista. En ese partido llegó a ser, entre 1976 y 1984, secretario de Cultura de la Comisión Ejecutiva Federal. Además es colaborador del diario El País desde su fundación en 1976, en donde ha publicado más de 600 artículos. Asimismo Sotelo es miembro de la Academia Europea de Ciencias y Artes. Sus reflexiones sobre el socialismo democrático, la historia política de España, el despliegue del capitalismo financiero o la crisis del Estado moderno las ha volcado en libros como El socialismo democrático, de 1980; Los socialistas en el poder, de 1986; El desplome de la izquierda: modalidades españolas del fin de una época, de 1994; El Estado social: antecedentes, origen, desarrollo y declive, de 2010; y España a la salida de la crisis: la sociedad dual del capitalismo financiero, de 2014. 


\section{MANUEL LIZCANO PELLÓN (MADRID, 1921-2004)}

Perteneció a la llamada "generación perdida" de la sociología española de la posguerra. Se licenció en Ciencias Políticas con premio extraordinario por la Universidad Complutense de Madrid. Después, en 1956, siguió cursos de Sociología de las Religiones en el CNRS de París, donde trabó amistad con Enri Desroche y Edgar Morin. En esos años publica en revistas internacionales y participa en congresos de Alemania, Francia, Inglaterra y Estados Unidos, abriendo al exterior la incipiente sociología española del interior. Fue Jefe del Departamento de Sociología de la Religión en el Instituto Balmes de Sociología y profesor del Instituto de Estudios Sindicales, Sociales y Cooperativos. Ante la presión de las autoridades franquistas, funda en Madrid el Instituto de Sociología y Desarrollo del Área Ibérica (ISDIBER). Desde este Instituto, de orientación iberoamericanista y comunalista, pudo profundizar en la comprensión de la realidad social y política de América Latina como establecer importantes redes académicas e intelectuales con la región. En 1973 y en 1975 organizó desde el ISDIBER los primeros Foros Iberoamericanos, celebrados en Bogotá y La Rábida respectivamente, y que son los precursores de las actuales Cumbres Iberoamericanas. Después Lizcano se integra a la Universidad Complutense de Madrid como profesor de Sociología. Al mismo tiempo acomete, durante los años ochenta y noventa, otras iniciativas intelectuales e institucionales, como la coordinación del "Seminario de Historia y de Sociología del mundo hispánico" y la dirección de la revista Cuadernos de Estrategia, ambos pertenecientes al Instituto Español de Estudios Estratégicos. También participaría en otros proyectos editoriales como la Revista Iberoamericana de Autogestión y Acción Comunal o el Boletín Informativo del Centro Superior de Estudios de la Defensa Nacional (CESEDEN). Respecto a su ascendente político y público, Lizcano militó en la izquierda obrera católica y se encargó de estudiar el sindicalismo y la autogestión en España y en América Latina. Fue miembro fundador en 1958, junto a otros sociólogos e intelectuales como Jesús Ibáñez o Julio Cerón Ayuso, del Frente de Liberación Popular (FELIPE), una organización política ilegal que actuó en oposición al régimen franquista. Sin embargo, Lizcano abandonó esta organización ante su deriva comunista y se decantó, en cambio, por promover el diálogo entre los sectores más abiertos del anarcosindicalismo, del obrerismo cristiano y del sindicalismo oficial. Dejó escrito varios originales libros, como Estructura y cambio social en los pueblos ibéricos, de 1967; El nuevo proyecto español: quince tesis sobre la sociedad iberoamericana y su identidad cultural, de 1977; o La revolución comunal: hacia una nueva comunidad iberoamericana, de 1979, 
los cuales recogen su pensamiento sociológico humanista y su particular visión integradora respecto a la comunidad iberoamericana.

\section{JUAN MAESTRE ALFONSO (TÁNGER, 1938)}

Inició su andadura profesional como sociólogo rural del Ministerio de Agricultura, trabajando en el gabinete de estudios de la Dirección General de Concentración Parcelaria y Ordenación Rural. Ese puesto de trabajo le permitió recorrer la sociedad rural española y conocer de primera mano las contradicciones sociales y políticas del desarrollo económico de la España franquista. En 1966 viaja por primera vez a Guatemala, país en el que después vivirá y realizará trabajo de campo antropológico y sociológico en numerosas ocasiones. Precisamente se doctoró por la Universidad Complutense de Madrid con una tesis dedicada a los problemas sociales de ese país. Después se especializaría en temas de desarrollo en Bélgica, Francia e Israel, como también colaboraría en las actividades y en los cursos del Instituto de Sociología y Desarrollo del Área Ibérica (ISDIBER) de Madrid. En los años setenta ejerció como corresponsal y enviado especial de medios de comunicación españoles como Informaciones, Madrid, Triunfo, Cambio 16 y Cuadernos para el diálogo en países africanos, asiáticos y latinoamericanos, tales como Etiopía, Marruecos, Bolivia, Brasil o Perú. Además Maestre Alfonso trabajó en numerosos proyectos de cooperación para el desarrollo en países de América Latina y Oriente Medio como funcionario y consultor internacional para organismos como la Organización Mundial de la Salud, la Organización de Estados Americanos, la Fundación Europea de la Ciencia o la Agencia Española de Cooperación. Fue investigador del Consejo Superior de Investigaciones Científicas (CSIC) y en la actualidad es catedrático emérito de Sociología de la Universidad de Sevilla. Además ha sido profesor visitante en diversas universidades mexicanas, entre las que destacan la Universidad Iberoamericana y el Tecnológico de Monterrey. Su experiencia biográfica e intelectual, más su compromiso cultural y político con la realidad latinoamericana, lo ha volcado en diferentes libros que, en síntesis, descuellan por un fructífero diálogo entre diversas disciplinas sociales, como la antropología, la ciencia política, la historia o la sociología. Así sobresalen obras suyas como Guatemala: subdesarrollo y violencia, de 1969; Chile: revolución y contrarrevolución, de 1974; Introducción a la antropología social, de 1974; Bolivia: victoria o muerte, de 1975; Brasil: de situación colonial a Estado gendarme, de 1976; El Che y Latinoamérica, de 1979; La investigación en antropología social, de 1990; Perfiles antropológicos de América Central y el Caribe, de 1991; Cuba: raíces y perspectivas de un proceso revolucionario, de 1998; o 
Guatemala: entre volcanes y poetas, de 2008. Además Maestre Alfonso se hizo cargo en 1991 de una destacada colección de "Pensamiento político, social y económico español sobre América Latina”, patrocinada por Ediciones de Cultura Hispánica, la cual divulgó en el medio hispanoamericano, hasta hace unos años, la tradición del pensamiento español dedicado a la región.

\section{JOSÉ LUIS RUBIO CORDÓN}

(BADAJOZ, 1924-MADRID, 2008)

Fue doctor en Derecho, titulado en Periodismo y profesor titular de la Facultad de Ciencias Políticas y Sociología de la Universidad Complutense de Madrid. En sus años de estudios universitarios fundó los Grupos de Unidad Hispánica, una organización que tuvo por finalidad conocer y difundir el interés por los pueblos de raíz española del otro lado del océano Atlántico. En esos años presidió, a su vez, la Sección Universitaria de la Asociación Cultural Iberoamericana. Esa inquietud por América Latina lo llevaron a realizar numerosos viajes por la región y a encabezar distintas empresas institucionales sobre los estudios latinoamericanos en el difícil clima de la España franquista. Así, por ejemplo, formó parte en 1966 de la fundación de la Asociación de Sociólogos de Lengua Española y Portuguesa (ASLEP), la cual creó y tuteló la Escuela Ibérica de Sociología y Desarrollo. Esta escuela desembocaría en 1969 en el Instituto de Sociología y Desarrollo del Área Ibérica (ISDIBER). Rubio Cordón también participaría en diversas actividades e iniciativas del Instituto de Cultura Hispánica y del Instituto de Estudios Sindicales, Sociales y Cooperativos. Fue miembro fundador y presidente de la Federación Internacional de Estudios sobre América Latina y el Caribe (FIEALC). Asimismo creó el Consejo Español de Estudios Iberoamericanos, el cual agrupa a todas las instituciones españolas dedicadas, especialmente, a estudiar las relaciones contemporáneas entre América Latina y la Península Ibérica. En sus últimos años de docencia en la Facultad de Ciencias Políticas y Sociología de la Universidad Complutense de Madrid se encargó de dirigir una cátedra de Estudios Iberoamericanos. Respecto a su faceta política, Rubio Cordón participó en las primeras elecciones democráticas españolas después de la dictadura franquista dentro de las listas del Partido Sindicalista. Después militó en el Partido de Acción Socialista (PASOC) y, a través de este partido, en Izquierda Unida. Dejó una abundante obra en la que destacó, principalmente, su perspectiva por integrar a España en la dinámica revolucionaria y contestaría de la América Latina de los años sesenta y setenta. Precisamente sus últimas preocupaciones giraron sobre la integración de los pueblos iberoamericanos, pero ya en el marco histórico de finales del siglo 
XX y principios del XXI. Algunos de sus libros más importantes son: La rebelión mestiza, de 1966; Evolución sindical en Iberoamérica, de 1967; Europa como evasión, Iberoamérica como revolución, de 1968; Las internacionales obreras en América, de 1971; Aproximación a la revolución peruana, de 1974; Dependencia y liberación en el sindicalismo iberoamericano, de 1977; Neocolonialismo en Iberoamérica, de 1990; Regímenes políticos del Cono Sur, de 1991; o El mito de la C.E.E. y la alternativa socialista, de 1992.

\section{JOAN GARCÉS}

\section{(LLÍRIA, VALENCIA, 1944)}

Se licenció en Derecho por la Universidad Complutense de Madrid en 1966. Al año siguiente obtuvo un Diploma de Estudios Superiores en Ciencias Políticas por la Fondation Nationale des Sciences Politiques de París. Después ejerció como profesor visitante de las Universidades Autónoma de Madrid, Lovaina, Oxford, Los Andes (Colombia), y la Facultad Latinoamericana de Ciencias Políticas (FLACSO, Chile). En 1970 se doctoró en Ciencias Políticas por Sciences-Po y la Universidad de la Sorbona. Desde julio de ese año y hasta el 11 de septiembre de 1973 se desempeñó como asesor político personal de Salvador Allende. La experiencia en el gobierno de la Unidad Popular y su trágico desenlace marcaron, sin duda, su trayectoria personal, intelectual y política a la hora de poner en valor el ideario democrático de Allende como de encabezar causas legales contra los crímenes de lesa humanidad cometidos por la dictadura civil-militar en Chile. Después del golpe militar, Garcés huyó a Francia. En aquel país trabajó como asesor del director general de la UNESCO y formó parte en 1974 del equipo personal de François Mitterrand en las elecciones a la Presidencia de la República francesa como candidato del Programa Común de las Izquierdas. También se desempeñó en París, hasta el año 1977, como investigador titular de la Fondation Nationale des Sciences Politiques. Volvió a España una vez restaurada la democracia y se convirtió en miembro de la Asociación de Abogados de Madrid en 1981. También participó en la actividad política nacional desde las filas del PSOE. En 1996 lideró el equipo internacional de juristas que, usando el principio de jurisdicción universal, inició el juicio contra el dictador Augusto Pinochet en nombre de más de 3.000 sobrevivientes y familiares de sobrevivientes de asesinatos, desapariciones y tortura cometidos bajo su régimen. Fue galardonado en 1999 con el Premio Nobel Alternativo (Right Livelihood Award) que concede el Parlamento de Suecia. Al año siguiente recibió la Orden de Mérito de Francia por sus contribuciones al derecho internacional. En los últimos años ha sido conferenciante invitado en diferentes universidades europeas, 
latinoamericanas y estadounidenses. Actualmente continúa con su labor de abogado en su estudio de Madrid impugnando, principalmente, las consecuencias nefastas de prolongar la impunidad de los graves crímenes cometidos en dictaduras civil-militares como la impuesta a los españoles entre 1936 y 1975. Algunas de sus publicaciones más destacadas son: Chile, el camino político hacia el socialismo, de 1971; Desarrollo político y desarrollo económico. Los casos de Chile y Colombia, de 1972; Revolución, congreso y constitución. El caso Tohá, de 1972; El Estado en el gobierno de Allende, de 1973; Orlando Letelier. Testimonio y vindicación (en colaboración con Saul Landau), de 1995; Soberanos e intervenidos. Estrategias globales, americanos y españoles, de 1996; y Allende y la experiencia chilena, reeditada en 2013 (versión original de 1976).

\section{MANUEL CASTELLS}

\section{(HELLÍN, ALBACETE, 1942)}

Cursó, entre 1958 y 1962, estudios de Derecho y Ciencias Económicas en la Universidad de Barcelona, interrumpidos por el exilio político a Francia. En ese país se licenció en Derecho por la Facultad de Derecho y Ciencias Económicas de la Universidad de París en 1964. Al año siguiente obtuvo un Diplomado en Ciencias Sociales del Trabajo por el Instituto de Ciencias Sociales del Trabajo de esa misma casa de estudios. En 1966 logró un Master en Sociología por la Escuela Práctica de Altos Estudios de París. En 1967 se doctoró en Sociología por la Universidad de París. Ocupa un cargo de profesor asistente de sociología en el Campus de Nanterre de la Universidad de París. En esos años, además, visita con frecuencia América Latina, especialmente Chile, país en el que trabaja en la Universidad Católica y en la FLACSO, organismo regional en el que coincide con otros sociólogos reconocidos como José Serra, Fernando H. Cardoso y Alain Touraine. Entre 1970 y 1979 es profesor titular de sociología de la École des Hautes Études en Sciences Sociales de París. Entre 1979 y 1998 Castells se desempeñó como Catedrático de Sociología y de Planificación urbana y regional de la Universidad de California en Berkeley. Entre esos años ocupa, asimismo, otros importantes cargos académicos, como una Cátedra de Sociología en la Universidad Autónoma de Madrid (1988-93) o la dirección en 1990 del Instituto Universitario de Sociología de las Nuevas Tecnologías de esa misma universidad española. Entre 1994 y 1998 se encargó de dirigir el Centro de Estudios de Europa Occidental de Universidad de California en Berkeley. Además fue profesor de investigación del Consejo Superior de Investigaciones Científicas en el Instituto de Estudios Sociales Avanzados en Barcelona entre los años 1996 y 1997. Al año siguiente regresa de- 
finitivamente a España para incorporarse a la Universitat Oberta de Catalunya. Castells ha recibido por su obra numerosas distinciones, doctorados honoríficos y premios, entre los que destacan el Premio C. Wright Mills de la Sociedad Americana para el Estudio de los Problemas Sociales en 1983; el Premio Robert y Helen Lynd de la Asociación Americana de Sociología en 1988; la Orden Gabriela Mistral en 2005 del presidente de Chile; o el Premio Nacional de Sociología y Ciencia Política de España en 2008. Es además Académico Numerario de la Real Academia de Ciencias Económicas y Financieras, académico de la Academia Europea, de la Academia Británica, de la Academia Mexicana de Ciencias y de la Academia Americana de Ciencias Políticas y Sociales. Publicó su primer libro en 1972, La cuestión urbana, traducido a diez idiomas, que le acreditó como uno de los fundadores de la nueva sociología urbana. Posteriormente desarrolló una nueva visión de lo urbano relacionado con la aparición de las nuevas tecnologías de la información. Su visión sobre la sociedad en red, como estructura interactiva para la transmisión de la información y el conocimiento, ha alcanzado una significativa difusión mundial a partir de su trilogía La era de la información. Economía, cultura y sociedad, publicada entre 1997 y 1998. Otras obras significativas de Castells son Crisis urbana y cambio social, de 1981; La ciudad y las masas. Sociología de los movimientos sociales urbanos, de 1986; Movimientos sociales urbanos, de 1991; La ciudad informacional, de 1995; La sociedad red, de 2006; Comunicación y poder, de 2009; y Redes de indignación y esperanza. Los movimientos sociales en la era de Internet, de 2012.

\section{XABIER GOROSTIAGA}

\section{(GALICIA, 1937-LOYOLA, GUIPÚZCOA, 2003)}

Nacido en Galicia de padres vascos emigrados por la Guerra Civil española, Gorostiaga pasó, sin embargo, gran parte de su vida pensando y trabajando en América Latina. Llegó a Cuba en 1958 como novicio jesuita. Al año siguiente fue testigo de la Revolución encabezada por Fidel Castro. Esa experiencia tuvo profundas repercusiones en su pensamiento y en su compromiso de luchar por la transformación social y la democracia en toda la región, involucrándose principalmente en Panamá, Nicaragua y en toda la zona centroamericana. Entre 1961 y 1962 estudiaría filosofía en Ecuador y en México. Después sería destinado a Panamá, donde se incorporó a la red jesuita de CIAS (Centros de Investigación y Acción Social en Centroamérica y América Latina). Fue en Panamá donde a través de la Revista Mensaje, de Chile, se vinculó con la experiencia que llevaron a cabo en aquel país el grupo "Cristianos por el Socialismo". Regresó al País Vasco para estudiar Teología, entre 1965 y 1969, en la Universidad de Deusto. 
Después comenzaría a estudiar economía en la Universidad de Cambridge, interesándose por la economía marxista y los estudios sobre la pobreza a través del magisterio de profesores como Joan Robinson, Maurice Dodd o Piero Sraffa. Entre 1971 y 1975 fue asesor del gobierno de Panamá en las negociaciones con Estados Unidos por la devolución del Canal. En 1976 se doctora finalmente en Economía por la Universidad de Cambridge, con una tesis dedicada, precisamente, al Canal de Panamá como plataforma de servicios transnacionales. Posteriormente, entre 1979 y 1981, fue convocado por el Frente Sandinista en Nicaragua para ocupar el cargo de Director de Planificación del gobierno de Daniel Ortega. Su presencia y la de otros curas en el gobierno sandinista provocaron en su momento fuertes reacciones del Vaticano. Comandó, además, diferentes iniciativas académicas para promover el estudio de las ciencias sociales en Centroamérica. Por ejemplo, fundó el Centro de Estudios y Acción Social y la revista Diálogo social en Panamá, fue director del Instituto Nacional de Investigaciones Económicas y Sociales (INIES) en la Universidad Nacional Autónoma de Nicaragua, y fue rector, entre 1991 y 1997, de la Universidad Centroamericana (UCA) en su sede de Managua. También dirigió la Coordinadora Regional de Investigaciones Económicas y Sociales (CRIES), institución que agrupa a centros de investigación de la región centroamericana y del Caribe. Gorostiaga dejó numerosos trabajos sobre Centroamérica, su economía, sus problemas sociales y políticos, su educación y desarrollo, en los que trató de abrir nuevas rutas de pensamiento propio y de acción colectiva. En sus últimos días reflexionó críticamente sobre el tema de la globalización y sus consecuencias en las comunidades y en las personas. Algunos de sus textos más importantes son: Panamá y la Zona del Canal: el impacto estructural de la Zona del Canal en la economía panameña, de 1975; Los centros financieros internacionales en los países subdesarrollados, de 1978; Para entender América Latina: aporte colectivo de los científicos sociales en Puebla, de 1979; Towards an alternative for Central America and the Caribbean, de 1985; y La mediación de las ciencias sociales y los cambios internacionales, de 1993.

\section{IGNACIO ELLACURÍA}

\section{(PORTUGALETE, 1930-SAN SALVADOR, 1989)}

Destacó como filósofo, teólogo de la liberación, científico social e impulsor de la teoría crítica de los derechos humanos. Son cuatro dimensiones intelectuales difíciles de encontrar y de armonizar en una sola persona, pero, en el caso de Ellacuría, convivieron con absoluta lucidez y coherencia. También su pensamiento destacó por un fuerte compromiso con los problemas de la realidad latinoamericana, en 
especial por la defensa y liberación de las mayorías populares frente a las múltiples formas de dominación, opresión o violencia. Su trayectoria en la región comenzó en 1949, cuando fue enviado como noviciado jesuita a El Salvador. Después completó sus estudios de Humanidades y estudió Filosofía en Quito, licenciándose en 1955. Desde ese año y hasta 1958 reside nuevamente en El Salvador. Posteriormente estudió Teología en Innsbruck (Austria) hasta 1961. Entre 1962 y 1965 realizó estudios doctorales de Filosofía en la Universidad Complutense de Madrid bajo la dirección de Xavier Zubiri. En 1967 regresa a El Salvador para incorporarse a la Universidad Centro Americana (UCA). La Conferencia de Medellín de 1968, en la que participó activamente, marcará su inflexión intelectual hacia la teología de la liberación. En 1972 es nombrado Director del Departamento de Filosofía. Al año siguiente publica su libro Teología política. En 1976 es nombrado director de la revista de Estudios Centroamericanos (ECA), en la que publicará muchos de sus artículos filosóficos, teológicos y políticos. Al año siguiente Ellacuría vive su primer destierro de El Salvador. Desde entonces, y sobre todo a partir de la guerra civil iniciada en 1979 - año en el que es nombrado rector de la UCA-, sus viajes a España serían constantes ante la amenaza paramilitar. Ellacuría sobresalió, de hecho, por ser un claro defensor de la solución negociada al conflicto y como voz de las mayorías populares. En el año 1985 funda, junto con Jon Sobrino, la Revista Latinoamericana de Teología. A principios de noviembre de 1989 recibía en Barcelona el Premio de la Fundación Comín, otorgado a la UCA de San Salvador. Días después, justo el 16 de ese mes, es asesinado por soldados salvadoreños del Ejército Nacional, en la residencia de la Universidad, junto con los jesuitas españoles Ignacio Martín Baró, Segundo Montes, Armando López, Juan Ramón Moreno, Joaquín López y López. Fueron también vilmente asesinadas Elba Julia Ramos, persona al servicio de la Residencia, y la hija de esta, Celina, de 15 años. Ignacio Ellacuría dejó una importante obra de pensamiento teológico, político y social que se ha venido editando después de su muerte. En 1990 y 1991 aparecieron dos de sus libros mayores: Conceptos fundamentales de la teología de la liberación, editada por Jon Sobrino y que destaca por ofrecer un análisis completo de esta corriente de pensamiento latinoamericano; y Filosofía de la realidad histórica. Posteriormente la UCA publicó sus Escritos Políticos, 3 vols., en 1991; sus Escritos Filosóficos, 3 vols., 1996, 1999, 2001; sus Escritos Universitarios, 1999; y sus Escritos Teológicos, 4 vols., 2000-2004. 


\section{PEDRO CASALDÁLIGA}

\section{(BALSARENY, BARCELONA, 1928)}

Nacido en una familia de campesinos, su infancia coincidió con la Guerra Civil española. De muy joven ingresa en el seminario de la diócesis de Vic. En 1952 es ordenado sacerdote por la congregación claretiana. En 1958 es destinado a Barcelona, donde ejerce una múltiple actividad pastoral. De Barcelona es enviado al poco tiempo a Guinea para promover los "Cursillos de Cristiandad". Aquella experiencia le marcará en su compromiso social por el Tercer Mundo. En 1965 regresa a España. En Madrid dirige la revista Iris de Paz, la cual se convierte en una publicación teñida de preocupación social. Casaldáliga trabaja entonces en las comunidades cristianas de base al calor de las reformas del Concilio Vaticano II. En 1968 es destinado al Estado brasileño de Matto Grosso y tres años después es consagrado obispo de São Félix do Araguaia, un territorio de 150.000 kilómetros cuadrados y una de las mayores reservas indígenas de ese país. Desde entonces se ha comprometido apoyando y participando en las luchas de los campesinos, las mujeres, los indígenas y los ribereños de esta parte del centro-oeste brasileño. Ha encabezado la fundación de diferentes organismos que aglutinan a estos movimientos sociales como, entre otros, la CNBB (Confederación Nacional de Obispos de Brasil), la CPT (Comisión Pastoral de la Tierra) o el CIMI (Consejo Misionero Indígena). Su activismo social, pastoral y político le llevó a sufrir amenazas de muerte y persecución por parte de la dictadura civil-militar brasileña y de los terratenientes del Matto Grosso, quienes llegaron a matar a su vicario, João Bosco, confundiéndolo con él. Además, siendo uno de los fundadores de la teología de la liberación latinoamericana, irritó con sus denuncias y su opción por los pobres a la jerarquía eclesiástica de Roma. En 1988 realiza por primera vez su visita "ad limina" a la Santa Sede y se entrevista con Juan Pablo II. Su viaje al Vaticano se convierte en noticia internacional al denunciar las preocupaciones, las vidas y las muertes de los más desfavorecidos de América Latina. En 2003, al cumplir los 75 años, es jubilado de su diócesis de São Félix do Araguaia. Desde entonces se ha dedicado a escribir sus memorias, sus reflexiones teológicas más íntimas, como a seguir perfilando su vertiente de ensayista social y de poeta. Además en los últimos años ha recibido varios reconocimientos, como los premios "Honoris Causa" concedidos por las Universidades de Campinas y del Mato Grosso, o el Premio Internacional Catalunya que le otorgó la Generalitat de Catalunya en el 2006. Entre su extensa y vasta literatura, sobresalen obras como: En rebelde fidelidad. Diario 1977-1983, de 1983; El vuelo del Quetzal. Espiritualidad en Centroamérica, de 1988; Al acecho del Reino. Antología de textos 1968-1988, de 1989; Sobre la op- 
ción por los pobres, de 1991; (con José María Vigil), Espiritualidad de la Liberación, de 1992; o el más reciente, Martírio do padre João Bosco Penido Burnier, del año 2006.

\section{JON SOBRINO}

\section{(BARCELONA, 1938)}

Nacido en el seno de una familia de origen vasco, ingresó en la Compañía de Jesús en 1956. Al año siguiente se trasladó a El Salvador. Posteriormente concluiría en 1963 una Licenciatura de Filosofía y Letras en la Universidad de Saint-Louis (Estados Unidos). En 1975 obtuvo un doctorado en Teología por la Universidad Hochschule Sankt Georgen de Frankfurt (Alemania). Ya por aquel entonces residía en El Salvador, país en el que ha desarrollado toda su carrera como filósofo, teólogo y pensador social de las realidades salvadoreña y latinoamericana. Allí ha trabajado como profesor universitario en la Universidad Centroamericana (UCA). Fue estrecho colaborador del arzobispo de San Salvador, Óscar Romero, asesinado en 1980, y de Ignacio Ellacuría, rector de la UCA y también asesinado en 1989. Después de la muerte de Ellacuría, Sobrino asumió la rectoría de esa casa de estudios. Además en la UCA también se encargó de dirigir el Centro Teológico Monseñor Romero y la Revista Latinoamericana de Teología. Muy influenciado por la Segunda Conferencia General del Episcopado de Latinoamericano, realizada en Medellín en 1968, Sobrino se encaminó hacia la reflexión teológica, social y política de los pobres, participando activamente en dar contenido teórico y sustento filosófico a la teología de la liberación latinoamericana. De hecho, es considerado en la actualidad, junto a Leonardo Boff y Pedro Casaldáliga, como uno de los máximos intelectuales y representantes de este movimiento que unió la defensa de los valores cristianos con la lucha por los derechos de los más desfavorecidos, como las clases populares, la población indígena, los campesinos sin tierra y el proletariado. Su obra, caracterizada por sus profundas preocupaciones sociales y orientada hacia un compromiso en la lucha contra la pobreza y la injusticia, cuenta con importantes títulos con los que ayudó a consolidar la teología de la liberación latinoamericana, como Iglesia de los pobres y organizaciones populares, de 1979; Óscar Romero: profeta y mártir de la liberación, de 1981; Jesús en América Latina. Su significado para la fe y la cristología, de 1982; o Liberación con espíritu, de 1985. 


\section{MANUEL ALCÁNTARA \\ (MADRID, 1952)}

Se licenció en Ciencias Políticas y Sociología por la Universidad Complutense de Madrid en 1976. Al año siguiente obtiene un Diploma en Sociología política por el Instituto de Estudios Políticos. En 1984 se doctora en Ciencias Políticas por la Universidad Complutense de Madrid. Desde 1993 es Catedrático de Ciencia Política y de la Administración de la Universidad de Salamanca. En esa casa de estudios impulsó y desarrolló el Instituto de Estudios de Iberoamérica y Portugal, hoy Instituto de Iberoamérica, del que fue director entre 1994 y 2007. También se desempeñó como vicerrector de Relaciones Internacionales y Cooperación de la Universidad de Salamanca entre los años 2007 y 2009. Además fue Secretario General de la Asociación Latinoamericana de Ciencia Política entre 2002 y 2009. Alcántara lleva impartiendo cursos y realizando estancias de investigación en distintas universidades españolas, latinoamericanas y extranjeras desde hace más de 20 años. De hecho, es profesor emérito invitado de FLACSO-Ecuador. Sus principales líneas de investigación giran en torno a la profesionalización de la política, al estudio de las élites parlamentarias, de los partidos políticos y los poderes legislativos en América Latina. Su labor académica e investigadora ha sido reconocida con un Doctor 'honoris causa' concedido en 2008 por la Universidad Nacional de San Martín (Argentina) y con la Orden de Bernardo O’Higgins, otorgada por el gobierno de Chile en 2009. Desde el año 2014 es además director de la sede en España de la FLACSO. Entre su extensa producción académica, destacan sus libros: Proceso y crisis del Grupo Andino. Un esquema de integración regional entre países en vías de desarrollo, de 1985; Gobernabilidad, crisis, y cambio, de 1995; Sistemas políticos de América Latina, de 1999 y 2003; ¿Instituciones o máquinas ideológicas? Origen, programa y organización de los partidos latinoamericanos, de 2004; Políticos y política en América Latina, de 2008; y el más reciente, El oficio del político, del año 2012.

\section{LUDOLFO PARAMIO (MADRID, 1948)}

Se licenció en la Escuela Oficial de Periodismo en 1972 y en 1982 se doctoró en Ciencias Físicas por la Universidad Autónoma de Madrid con una tesis titulada Los límites de la metodología: de la lógica de la ciencia a la sociología de la comunidad científica. Sin embargo, ha destacado por sus análisis políticos y sociológicos sobre el comportamiento político, las reformas estructurales o los modelos económicos de América Latina, Estados Unidos o la Unión Europea. Además ha sido durante años uno de los teóricos de referencia del socialismo es- 
pañol. De hecho, comenzó su militancia en el PSOE en 1982 y fue miembro de la dirección de ese partido entre 1990 y 1997. Posteriormente fungió como director del departamento de Análisis y Estudios del Gabinete de la Presidencia del Gobierno entre 2004 y 2008 durante el primer mandato de José Luis Rodríguez Zapatero. También dirigió la Fundación Pablo Iglesias y su revista de ciencias sociales Zona Abierta ligadas al PSOE. Respecto a su actividad docente, ha sido Profesor de Sociología en las Universidades Autónoma y Complutense de Madrid, y ha impartido además cursos de doctorado en varias universidades e instituciones de educación superior españolas, como el Centro de Estudios Políticos y Constitucionales o el Instituto Universitario de Investigación Ortega y Gasset. Precisamente en este último instituto fue director del programa de América Latina. Además es miembro de la Asociación Latinoamericana de Ciencia Política desde su fundación en julio de 2002 y perteneció a su Comisión Ejecutiva hasta agosto de 2008. En la actualidad es Profesor de Investigación en el Instituto de Políticas y Bienes Públicos del Centro de Ciencias Humanas y Sociales del CSIC. Sus trabajos más recientes se centran en los problemas de la democracia, en especial en América Latina. Entre sus últimos libros destacan los siguientes títulos: La socialdemocracia, de 2009; Clases medias y gobernabilidad en América Latina, de 2010; La socialdemocracia maniatada: de los orígenes y la edad de oro a la trampa de la crisis de la Eurozona, de 2012; Clases medias y procesos electorales en América Latina (2009-2010), de 2012; y Desafección política y gobernabilidad: el reto político, de 2015.

\section{MARISA REVILLA BLANCO (MADRID, 1965)}

Es doctora en Ciencias Políticas y Sociología por la Universidad Complutense de Madrid (1993), grado conseguido con la tesis doctoral titulada "... ¿Y todo lo que nos mueve nos une? Movimiento social, identidad y sentido: experiencias contemporáneas en la R.F.A. y Chile." En 1994 realizó una estancia de investigación post-doctoral en FLACSO, sede Santiago de Chile. En 1998 comenzó su carrera docente en la Facultad de Ciencias Políticas y Sociología de la Universidad Complutense de Madrid. Ese mismo año y hasta el año 2000 fue investigadora postdoctoral en el Instituto de Estudios Sociales Avanzados del Consejo Superior de Investigaciones Científicas (CSIC). Entre el año 2004 y 2008 fue Vocal Asesora del Gabinete de Presidencia de Gobierno, siendo entonces el socialista José Luis Rodríguez Zapatero presidente del gobierno de España. Después, entre 2008 y 2012, ejerció como directora del Centro de Estudios para América Latina y la Cooperación Internacional (CEALCI) de la Fundación Carolina. En 
la actualidad es Directora del Departamento de Sociología I (Cambio Social) de la Facultad de Ciencias Políticas y Sociología de la Universidad Complutense de Madrid. Su área de especialización docente e investigadora es la sociología política, con especial interés en el estudio de los movimientos sociales y en la sociología del género. Entre sus libros destacan Las ONG y la política, del año 2002; Una nueva agenda de reformas en América Latina (junto con Ludolfo Paramio), de 2006; Infancia, juventud y migraciones. Una mirada para la cooperación internacional, de 2011; y Caminos de ida y vuelta. Redes, migración y desarrollo (coordinado junto con Cristina Gómez-Johnson), de 2012.

\section{JUAN CARLOS MONEDERO (MADRID, 1963)}

Es licenciado en Ciencias Políticas y Sociología por la Universidad Complutense de Madrid. Entre 1989 y 1992 realizó estudios de posgrado en la Universidad de Heidelberg (Alemania), bajo la dirección del politólogo Klaus von Beyme. En 1996 se doctoró en la Universidad Complutense de Madrid con la tesis doctoral "Causas de la disolución de la República Democrática Alemana. La ausencia de legitimidad: 1949-1989". Precisamente en la Facultad de Ciencias Políticas y Sociología de esa casa de estudios superiores se desempeña desde el año 1992 como profesor dedicado a investigar e impartir asignaturas relacionadas con las instituciones políticas, la teoría del Estado, América Latina, el sistema político español o el proceso actual de globalización. Igualmente ha sido profesor invitado y visitante en distintas universidades europeas y latinoamericanas como el Instituto de Estudios Políticos de la Universidad Humboldt de Berlín, la Universidad Nacional de Quilmes, la Universidad Nacional de Medellín, la Universidad Iberoamericana de Puebla, la Universidad Nacional de Córdoba o las Universidades Bolivariana y Central de Venezuela. En la actualidad es director del Departamento de Gobierno, Políticas Públicas y Democracia del Instituto Complutense de Estudios Internacionales, ha sido también responsable de Formación del Centro Internacional Miranda de Caracas y ha colaborado en diversos cursos y actividades del Consejo Latinoamericano de Ciencias Sociales (CLACSO). Además de su tarea académica e investigadora, desempeñó funciones de asesoría política, entre 2000 y 2005, de Gaspar Llamazares, coordinador general de Izquierda Unida. Desde ese año y hasta 2010 fue asesor del presidente venezolano Hugo Chávez y del Ministerio de Planificación de ese país. En 2014 participó en la fundación del movimiento Podemos, creado para tratar de aunar a la izquierda española contra el sistema financiero y político europeo. En 2015 dimitió de la junta ejecutiva de este partido. Asimismo Monedero ha trabajado como consultor 
internacional para diferentes organismos, como el Instituto Europeo de Florencia, el Banco Central Europeo o el Programa de Naciones Unidas para el Desarrollo. Ha sido observador internacional en elecciones en Colombia, México y Venezuela. También es colaborador en diferentes medios de comunicación periodísticos y televisivos. Entre sus últimas publicaciones destacan los libros: Claves para un mundo en transición. Crítica y reconstrucción de la política, de 2009; La Transición contada a nuestros padres. Nocturno de la democracia española, de 2011; ¡Que no nos representan! El debate sobre el sistema electoral español, (junto con Pablo Iglesias) de 2011; Dormíamos y despertamos. El 15M y la reinvención de la democracia, de 2012; o Curso urgente de política para gente decente, del año 2013.

\section{ENRIQUE V. IGLESIAS}

\section{(ARANCEDO, ASTURIAS, 1930)}

A los 4 años emigró con sus padres a Uruguay. En 1953 se graduó en Economía y Administración en la Universidad de la República (Montevideo). Después realizó estudios de especialización en los Estados Unidos y en Francia. Entre 1961 y 1969 se encargó de la dirección técnica de la Comisión de Inversiones y Desarrollo Económico (CIDE) de Uruguay, teniendo a su cargo la elaboración del Primer Plan Nacional de Desarrollo Económico y Social de ese país. Durante esos años ocupó además destacados cargos en el gobierno uruguayo, como la presidencia, entre 1967 y 1969, del Banco Central del Uruguay. Entre 1964 y 1967 fue también delegado de Uruguay a las Conferencias de la Asociación Latinoamericana de Libre Comercio (ALALC) y de la Comisión Económica para América Latina (CEPAL), y representante ante el Comité Interamericano de la Alianza para el Progreso (CIAP). Desde 1965 fue miembro de la directiva del Instituto Latinoamericano de Planificación Económica y Sociales (ILPES), siendo su presidente entre 1967 y 1972. Preocupado por el desarrollo económico latinoamericano encabezó en 1968 un grupo de expertos que colaboraron con Raúl Prébisch en la preparación de un estudio de la situación económica de América Latina, a solicitud del entonces presidente del Banco Interamericano de Desarrollo (BID), Felipe Herrera. En el campo académico fue profesor de Desarrollo Económico y Director del Instituto de Economía de la Universidad de la República. Fue miembro del Directorio del Consejo Latinoamericano de Ciencias Sociales (CLACSO), y participó también en diferentes cursos de la CEPAL, el ILPES y de la Asociación Latinoamericana de Integración (ALADI). Entre 1972 y 1985 fue secretario ejecutivo de la CEPAL. Desde ese último año y hasta 1988 fue ministro de Relaciones Exteriores de Uruguay. Desde 1988 hasta 2005 fue presidente del BID. A partir 
de 2005 y hasta 2014 fue Secretario General de la Secretaría General Iberoamericana. Iglesias ha recibido numerosas distinciones y reconocimientos internacionales, entre ellos el Premio Príncipe de Asturias, así como condecoraciones de países latinoamericanos y títulos académicos honorarios de varias de sus universidades. Respecto a su producción académica, ha escritos numerosos artículos y ensayos sobre las diferentes dimensiones - económica, política y social-del desarrollo en América Latina, publicados un gran número de ellos en la Revista de la CEPAL. También se ha ocupado en sus trabajos sobre la integración y el multilateralismo latinoamericano, las relaciones económicas de la región con el mundo, las fluctuaciones de los mercados de capital, el financiamiento externo y la gobernabilidad en la región. Es autor de, entre otros, los siguientes libros: Uruguay: una propuesta de cambio. Introducción al Plan Nacional de Desarrollo Económico y Social, de 1966; La crisis económica internacional y su impacto en la economía latinoamericana, de 1984; Reflexiones sobre el desarrollo económico: hacia un nuevo consenso latinoamericano, de 1992; Cambio y crecimiento en América Latina (1988-1998): ideas y acciones, de 1999; o Lecciones de economía para América Latina, del año 2008.

\section{MARCOS ROITMAN}

\section{(SANTIAGO DE CHILE, 1955)}

Militó en las Juventudes Socialistas chilenas cuando era estudiante de ingeniería metalúrgica en la Universidad Técnica del Estado. Después del golpe militar del 11 de septiembre de 1973 fue llevado como preso político al Estadio Nacional. En 1974 comienza su exilio en España. Estuvo 25 años sin regresar a su país natal. La experiencia del destierro se transforma en Roitman en un compromiso político e intelectual con la lucha por la democracia en España y en América Latina. Se doctoró en Ciencias Políticas y Sociología por la Universidad Complutense de Madrid. En esa casa de estudios ejerce como profesor titular de Estructura Social de América Latina en su Facultad de Ciencias Políticas y Sociología. Como profesor invitado, ha dictado cursos, seminarios y conferencias en diferentes universidades de América Latina, incluyendo países como México, Chile, Ecuador, Venezuela, Argentina, Brasil, Perú, Cuba, Nicaragua, El Salvador, Honduras, Guatemala, Panamá, Costa Rica y Bolivia. También ha sido profesor invitado de la FLACSO en sus sedes de Guatemala, México y Panamá. Además en los últimos años ha sido profesor del Campus Virtual del Consejo Latinoamericano de Ciencias Sociales (CLACSO). Es miembro consultor de consejos editoriales de revistas especializadas de ciencia política y sociología en América Latina. En su faceta periodística colabora habitualmente con La Jornada de México, Clarín de Chile, El Correo del Orinoco de 
Venezuela y Le Monde Diplomatique (edición España). Fue, asimismo, coordinador para España de CLACSO y miembro del consejo científico de ATTAC-España. Es autor de más de un centenar de artículos publicados en revistas especializadas de América Latina y España, así como referente, dentro del mundo académico, en áreas como los procesos sociales y revolucionarios latinoamericanos o la configuración del poder político en la región. Tuvo una destacada participación en la preparación, con la coordinación del abogado Joan Garcés, de la estrategia legal tendiente al juzgamiento de Augusto Pinochet luego de su detención en Londres, a pedido del juez español Baltasar Garzón. Entre sus libros descuellan los siguientes títulos: Pensamiento sociológico y realidad nacional en América Latina, de 2002; Las razones de la democracia en América Latina, de 2005; Pensar América Latina. El desarrollo de la sociología latinoamericana, de 2008; Democracia sin demócratas y otras invenciones, de 2008; El pensamiento sistémico. Los orígenes del social-conformismo, de 2009; Los indignados. El rescate de la política, de 2012; y Tiempos de oscuridad. Historia de los golpes de Estado en América Latina, de 2013. Además junto a Pablo González Casanova escribió La democracia en América Latina, de 1992; Democracia y Estado multiétnico en América Latina, de 1996; y La formación de conceptos en ciencias y humanidades, del año 1999.

\section{JESÚS MARTÍN BARBERO}

\section{(ÁVILA, 1937)}

En 1963 llega a Colombia después de haber estudiado filosofía en España, preocupado entonces por conectar su reflexión filosófica con las ciencias sociales. Aproximándose a la realidad colombiana y latinoamericana comienza su particular indagación teórica en los márgenes de disciplinas como la antropología, la estética, la historia, la literatura y la sociología. Después estudió en el Instituto de Filosofía de la Universidad de Lovaina, doctorándose en 1971 con una tesis titulada "La palabra y la acción: por una dialéctica de la liberación". Posteriormente realizó un posdoctorado en Antropología y Semiótica en la Escuela de Altos Estudios de París. Vuelve a Colombia en 1973 y desde el año siguiente hasta 1995 se encargó de dirigir el Departamento de Comunicación de la Universidad de Cali. Durante esos años Martín Barbero escribió algunas de sus principales obras como Comunicación masiva: discurso y poder, de 1978; Comunicación educativa y didáctica audiovisual, de 1979; o su clásica obra De los medios a las mediaciones, de 1987, con la que contribuyó a generar en América Latina la inflexión teórico-metodológica en los estudios sobre cultura y comunicación proponiendo el énfasis en el mensaje como estructura ideológica de los procesos de consumo. Entre 1995 y 2003 continuó 
su labor docente en el Instituto Tecnológico y de Estudios Superiores en Guadalajara (México). Durante ese período publicó importantes libros como Mapas nocturnos, de 1998, u Oficio de cartógrafo. Travesías latinoamericanas de la comunicación en la cultura, del 2002. Además de su extensa producción académica, ha sido profesor visitante en varias universidades europeas y latinoamericanas. También fue presidente de la ALAIC (Asociación Latinoamericana de Investigadores de la Comunicación) y es miembro del comité consultivo de la FELAFACS (Federación Latinoamericana de Facultades de Comunicación Social). Sus ideas le han llevado a ser reconocido, junto con Néstor García Canclini, Beatriz Sarlo, Carlos Monsiváis, Nelly Richard o Martín Hopenhayn, como uno de los autores que desde América Latina ha aportado más para la comprensión de la cultura en el actual proceso de globalización. Estos reconocimientos le han valido el otorgamiento del Doctorado "Honoris causa" de la Universidad Nacional de Rosario, la Pontificia Universidad Javeriana de Bogotá y la Pontificia Universidad Católica de Lima. 


\section{SOBRE EL ANTOLOGISTA}

\section{JUAN JESÚS MORALES MARTÍN (MADRID, 1980)}

Doctor en Sociología por la Universidad Complutense de Madrid. Amplió estudios gracias a una beca posdoctoral del CONICET en el Instituto de Ciencias Humanas, Sociales y Ambientales (INCIHUSA, Mendoza, Argentina). Actualmente se desempeña como académico e investigador de la Escuela de Sociología de la Universidad Católica Silva Henríquez (Santiago de Chile). Es miembro de la Red sobre Internacionalización y Movilidades Académicas y Científicas (RIMAC, Conacyt-México). Además ha sido colaborador del Programa de Investigaciones sobre Dependencia Académica en América Latina (PIDAAL, Universidad Nacional de Cuyo) y miembro del grupo de investigación "Sociología en lengua castellana: perspectiva histórica" (Universidad Complutense de Madrid). También ha disfrutado de estancias de investigación en el Centro de Investigaciones y Estudios Superiores en Antropología Social (CIESAS, México. DF), en la División de Desarrollo Social de la CEPAL (Santiago de Chile), y en el Departamento de Investigaciones Educativas del CINVESTAV (México DF). Sus intereses de investigación se centran en la historia de la sociología española y de la sociología latinoamericana. También se ocupa de investigar temas relacionados con el exilio español de 1939, las élites intelec- 
tuales latinoamericanas, la movilidad académica o la circulación del conocimiento en el desarrollo del campo científico-universitario en América Latina. Ha editado en la colección de "Pensamiento político, social y económico español sobre América Latina" las antologías dedicadas a Juan Francisco Marsal (Ediciones de Cultura Hispánica, $\mathrm{N}^{\circ}$ XI, AECID, Madrid, 2009) y a Américo Castro (Ediciones de Cultura Hispánica, $\mathrm{N}^{\circ}$ XVII, AECID, Madrid, 2012). Junto con Laura Moya preparó en 2008 la reedición y el estudio introductorio del libro $\mathrm{Pa}$ norama de la sociología contemporánea, de José Medina Echavarría, publicado por El Colegio de México. 




\section{COLECCIÓN ANTOLOGÍAS DEL PENSAMIENTO SOCIAL LATINOAMERICANO Y CARIBEÑO SERIE MIRADAS LEJANAS [ESPAÑA]}

La antología Pensamiento social español sobre América Latina tiene el objetivo principal de acercar al público académico y general la rica y diversa tradición de ideas, autores y escuelas españolas que han pensado América Latina y que, también, han influido en el propio desarrollo de las ciencias sociales latinoamericanas como impactaron, igualmente, en los ámbitos académico, cultural y político de uno y otro lado del Atántico. Pues el desarrollo de las ciencias sociales, tanto en España como en América Latina, ha seguido historias con bastantes entrecruzamientos, algunos elementos comunes y con importantes redes intelectuales de intercambio que han establecido un contrapunto dialéctico. Pues si las circunstancias y la gestación de la propia idea de ciencias sociales y de "sociología latinoamericana" fueron fundadas como tal a mediados del siglo $X X$ como un campo de investigación regional y como un proceso endógeno de producción de ideas, de categońas y de teorías, no solo tiene un valor anecdótico el señalar, entonces, la particular participación de pensadores españoles en ese movimiento. Por tal motivo, ese interés sobresaliente por América Latina lo concebimos en este volumen como un puente tendido entre dos orillas y como un diálogo franco y plural.

De la Introducción de Juan Jesús Morales Martín.

\section{Patrocinado por}

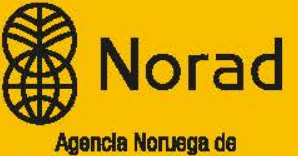

Cooperación para ol Desarrollo

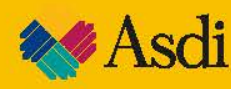

Agencla sueca de Desamollo Internacional 